
THE UNIVERSITY

OF ILLINOIS

\section{LIBRARY \\ 583.53 H 148}

$$
\text { B1OLOGY }
$$


OCI 231955

AUl: 18 low

0072 1 4955ी

OC: बिकीजि1

Juh 0758

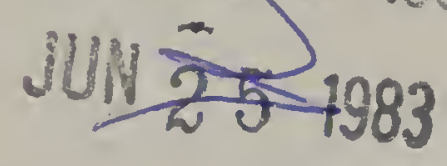

BCT 241988 


Digitized by the Internet Archive in 2019 with funding from

University of Illinois Urbana-Champaign

https://archive.org/details/genushaplopappus00hall 


\section{CARNEGIE INSTITUTION OF WASHINGTON Publication No. 389}

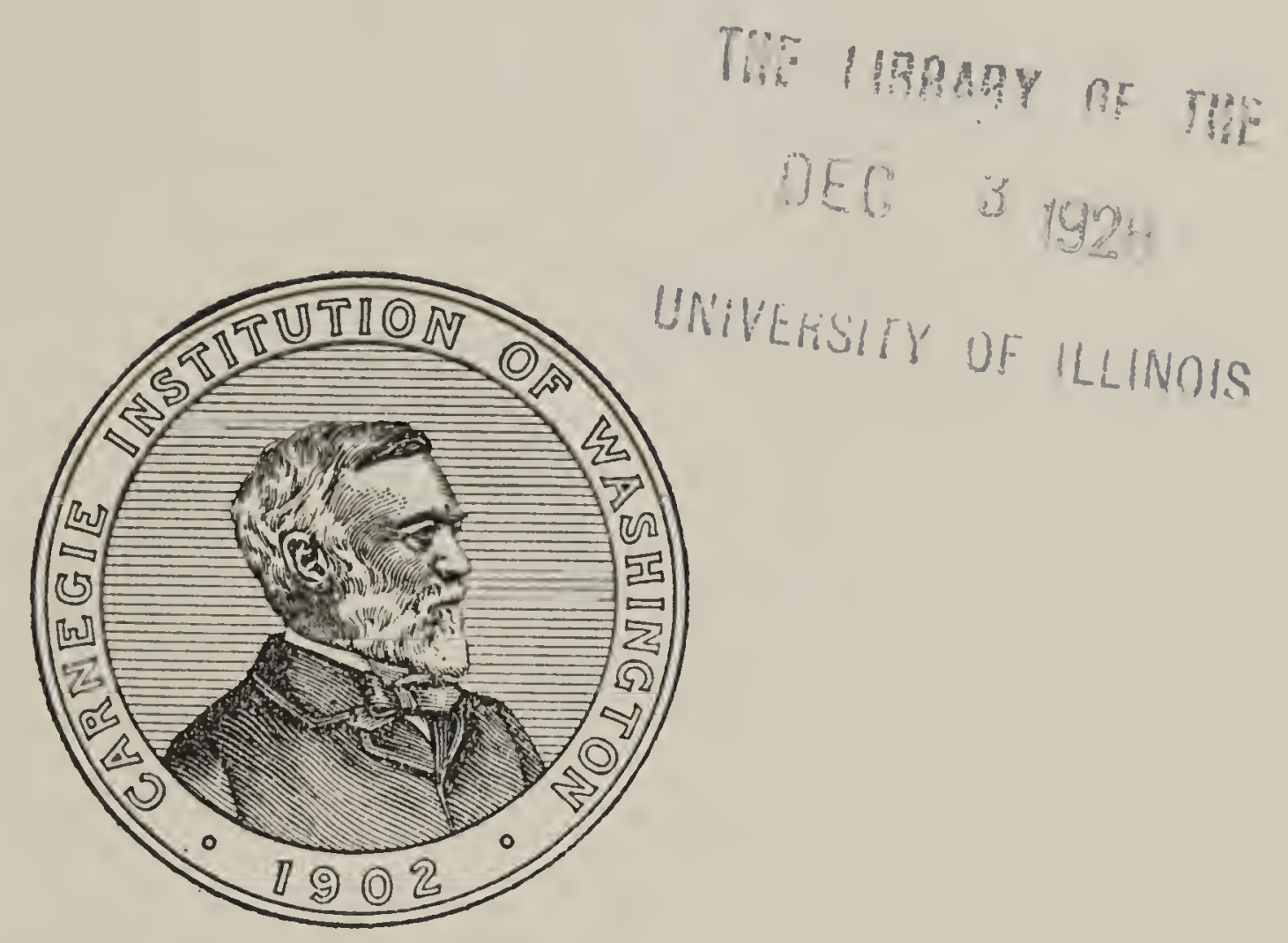


J. B. LIPPINCOTT COMPANY EAST WASHINGTON SQUARE PHILADELPHIA, PENNA.

PRINTED IN THE UNITED STATES OF AMERICA. 


\title{
THE GENUS HAPLOPAPPUS
}

\author{
A PHYLOGENETIC STUDY \\ IN THE COMPOSITAE
}

BY

HARVEY · M. HALL

\section{TwE URRARY Of TIE \\ OED : Y Y \\ UNIVERSIIY OF ILENOIS}

Published by Carnegie Institution of Washington Washington, 1928 
Copies of this publication

were first issued

October 1, 1928 


\section{CONTENTS}

I. Introduction PAGE

Phylogeny the basis of classification..............

The nature of taxonomic units

The evolutionary stream...

Transition stages from smaller to larger units...

Character combinations and parallel variations.......

Subspecies, species, and sections..................

Methods of investigation.....

Field studies............

Expcrimentation..........

Herbarium studies........

Methods of presentation.....

Descriptions and keys.....

Results of statistical studies

Phylogenetic charts.......

Illustrations. . . . . . . . . . .

Citation of authors, herbaria, and specimens....

Criteria for recognition of taxonomic units in Haplopappus................

Achenes..............

Pappus...................

Style-branches..........

Ray-flowers.............

Disk-flowers............

Receptacle..............

Involucre.............

Arrangement of heads.... .

Leaves..................

Pubescence...............

Resins, oils, and rubbers...

Underground parts.......

Habit................

Diagnosis and nomenclature of

- the genus.............

Original description . . ......

Amplified diagnosis.......

Nomenclature...........

Phylogenetic position of the genus.

Relations between the species of North America and those of South America. .

Acknowledgments..........

References.............

II. The North American species of Haplopappus ..........

Diagnoses of the sections.....
II. The North American species of Haplopappus - continued

Phylogeny and status of the sections.

Key to the North American sections and species of Haplopappus......... 40

Section 1. Osbertia........ 48

1. IIaplopappus stoloniferus 48

2. H. brandegei........ 51

Section 2. Blepharodon..... 53

3. II. phyllocephalus..... 55

4. H. gracilis.......... 62

5. H. aureus.......... 64

6. H. stenolobus......... 65

7. H.gymnocephalus..... 66

8. H. nuttalli......... 69

9. H. arenarius......... 71

10. H. spinulosus........ 72

11. H. junceus.......... S1

12. H. brickellioides...... 83

Section 3. Prionopsis....... 84

13. H. ciliatus.......... 84

Section 4. Oonopsis........ 86

14. H. fremonti ........ 86

15. H. multicaulis........ 91

16. H. engelmanni........ 93

Section 5. Pyrrocoma....... 95

17. H. croceus ......... 97

18. H. carthamoides ...... 101

19. H. clementis......... 107

20. H. integrifolius. . . . . . 109

21. H. lanceolatus........ 114

22. H. hirtus.......... 123

23. H. racemosus........ 126

24. H. apargioides........ 144

25. H. uniflorus......... 147

26. H. contractus........ 155

Section 6. Stenotopsis....... 156

27. H. linearifolius....... 156

28. H. parrasanus....... 160

Section 7. Stenotus......... 161

29. II. armerioides. . . . . 162

30. H. acaulis......... 164

31. H. lanuginosus....... 171

32. H. stenophyllus....... 174

33. H. macleani......... 176

Section 8. Tonestus........ 177

34. H. lyalli.......... 177

35. H. eximius.......... 181

36. H. pygmaeus........ 183

37. H. aberrans........ 185

Section 9. Macronema...... 187

38. H. suffruticosus....... 187 
II. The North American species of Haplopappus - continued

39. H. greenei......... 193

40. H. bloomeri......... 196

41. H. macronema....... 204

Section 10. Oreochrysum.... 208

42. H. parryi......... 208

Section 11. Isopappus..... 212

43. H. divaricatus....... 212

44. H. occidentalis....... 214

Section 12. Hesperodoria.... 218

45. H. scopulorum....... 218

46. H. halli.......... 221

Section 13. Isocoma....... 222

47. H. venetus......... 223

48. H. acradenius....... 232

49. H. hartwegi........ 235

50. H. pluriflorus........ 237

51. H. drummondi...... 240

Section 14. Hazardia....... 243

52. H. canus......... 243

53. H. berberidis....... 245

54. H. orcutti......... 248

55. H. squarrosus. ....... 249

56. H. whitneyi........ 255

Section 15. Ericameria...... 258

57. H. eastwoodae....... 258

58. H. pinifolius........ 260

59. H. ericoides........ 262

60. H. palmeri.......... 265

61. H. propinquus....... 269

62. H. sonoriensis....... 271

63. H. laricifolius....... 273

64. H. cooperi........... 275

65. H. parishi......... 280

66. H. arborescens....... 281

67. H. cuneatus......... 284

68. H. vernicosus......... 286

Section 16. Asiris......... 288

69. H. watsoni......... 288

70. H. rydbergi ........ 290

71. H. cervinus......... 292

72. H. nanus.......... 294

73. H. resinosus. . ...... 296

74. H. purpusi. . . . . . . 299

III. The South American species of

Haplopappus .......... 301

Historical summary ........ 301

Diagnoses of the sections.... 302

Phylogeny and status of the sections............ 303

Key to the South American sections and species of Haplopappus........... 304

Section 17. Euhaplopappus.. 311

75. H. pectinatus........ 311

76. H. araucanus....... 312

77. H. chrysanthemifolius . . 312

78. H. hirtellus......... 315

79. H. uncinatus........ 315

80. H. velutinus........ 316
III. The South American species of Haplopappus - continued

81. H. illinitus......... 318

82. H. elatus........... 318

83. H. pulchellus......... 319

84. H. donianus. . . . . . 319

85. H. stolpi............ 320

86. H. poeppigianus...... 320

87. H. canescens........ 321

88. H. bustillosianus...... 322

89. H. patagonicus...... 322

90. H. grindelioides....... 323

91. H. marginalis ....... 323

92. H. decurrens........ 324

93. H. reicheanus....... 324

94. H. philippi......... 325

95. $H$. rigidus . . . . . . 325

96. H. villaneuvae...... 325

97. H. ochagavianus ..... 326

98. H. baylahuen........ 326

99. H. glutinosus........ 327

100. H. rosulatus......... 329

101. H. macrocephalus..... 330

102. H. scaposus......... 331

103. H. arbutoides......... 331

104. H. cuneifolius........ 332

105. H. scrobiculatus...... 333

106. H. diplopappus....... 334

107. $H$. anthylloides........ 335

108. H. paucidentatus...... 336

109. H. prunelloides....... 337

110. H. chrysocephalus..... 337

111. H. ameghinoi........ 338

Section 18. Steriphe....... 338

112. H. pedunculosus...... 338

113. H. rosmarinifolius.... 339

114. H. punctatus........ 339

115. H. breviradiatus..... 340

116. H. integerrimus....... 340

117. H. sericeus.......... 341

118. H. humilis.......... 342

119. H. setiger.......... 342

Section 19. Polyphylla..... 344

120. H. linifolius. ........ 344

121. H. meyeni.......... 344

122. H. foliosus.......... 344

123. H. multifolius....... 345

124. H. phyllophorus...... 345

125. H. kingi.......... 346

126. H. ischnos......... 346

127. H. rengifoanus....... 346

128. H. rotundifolius . . . . . 347

129. H. mucronatus...... 347

130. H. platylepis......... 348

131. H. deserticolus......... 349

132. H. remyanus........ 349

Section 20. Xylolepis...... 350

133. H. bezanillanus....... 350

134. H. saxatilis.......... 351

135. H. pristiphyllus...... 351

136. H. reticulatus....... 352 
III. The South American species of Haplopappus - continued 137. $H$. parifolius....... 352

138. H. angustifolius. . . . . 353

139. H. macraeanus ...... 354

140. H. cerberoanus....... 354

141. H. stelliger.......... 355

Sectron 21. Diplostephioides . 355

142. H. assuensis....... 355

143. H. fuligineus........ 356

144. H. hypoleucus........ 356
III. The South American species of Haplopappus - continued

145. H. rufescens......... 358

146. H. lehmanni........ 358

147. H. caucanus....... 359

148. H. lucidulus . . . . . . . 359

149. H. ledifolius . . . . . . 359

South American species not sufficiently known..... 361

IV. Excluded names. . . . . . . . . . . 364

Index 


\section{PLATES}

Plate 1. Haplopappus occidentalis and $H$. divaricatus.... 367

2. Haplopappus chrysanthemifolius........ 368

3. Haplopappus velutinus, $\mathrm{H}$. illinitus, and H. pulchellus. . . . . . . . . . . . . 369

4. Haplopappus donianus, $\mathrm{H}$. poeppigianus, and $\mathrm{H}$. bustillosianus........ 370

5. Haplopappus grindelioides, $\mathrm{H}$. decurrens, and $\mathrm{H}$. baylahuen.......... 371

6. Haplopappus glutinosus, H. macrocephalus, and H. arbutoides........ 372

7. Haplopappus cuncifolius. . 373

8. Haplopappus diplopappus, H. anthylloides, H. paucidentatus, and H. prunelloides........... 374
PAGE

9. Haplopappus pedunculosus and H. punctatus.... 375

10. Haplopappus integerrimus and H. setiger....... 376

11. Haplopappus foliosus, $\mathrm{H}$. rengifoanus, and $\mathrm{H}$. rotundifolius......... 377

12. Haplopappus mucronatus. 378

13. Haplopappus deserticolus and H. remyanus.... . . 379

14. Haplopappus bezanillanus, H. saxatilis, and $\mathrm{H}$. pristiphyllus........ 380

15. Haplopappus parvifolius, $\mathrm{H}$. angustifolius, and $\mathrm{H}$. macraeanus......... 381

16. Haplopappus cerberoanus and H. stelliger...... . 382 


\title{
THE GENUS HAPLOPAPPUS
}

\section{A PHYLOGENETIC STUDY IN THE COMPOSITAE}

\author{
By Harvey M. Hall
}

With sixteen plates and one hundred and fourteen text-figures 



\title{
I. INTRODUCTION
}

\author{
OBJECTIVES
}

The present monograph illustrates the application of the principles of phylogeny to the classification of a complex and highly specialized group of plants. It is intended also as a contribution regarding the characteristics, relationships, and geographic distribution of the forms treated, and a plan has been worked out whereby the nomenclature may be serviceable to workers holding widely divergent views as to the taxonomic status of the various groups. It is hoped, also, that some additional light has been thrown upon fundamental principles of organic evolution.

When the Haplopappus group of the Compositae was selected some 25 years ago as a subject for special investigation it was undergoing radical treatment by several very active botanists. Especially noteworthy were the activities of Dr. E. L. Greene, who had been reviving old generic segregates and proposing new ones, more especially for the species of western North America, while in western South America the enthusiasm of Dr. R. A. Philippi had led to the description of more than 80 supposedly new species. These, like similar studies of the same period, were essentially analytic in nature. Since they did not extend to all parts of the genus and took no account of many of the intervening forms, a synthetic presentation was at that time impossible, but they were useful in supplying detailed data, in suggesting certain natural assemblages of species, and in calling attention to the complexities of the situation. It soon became evident that this was one of the most highly developed of all plant groups and one in which the processes of evolution were still in active progress. It was chosen, therefore, partly because of the need of a guide to the identification of the genera, sections, species, and other units involved, and partly because of the opportunity offered for the synthetic working out of natural relationships and for the application of phylogenetic principles.

Other objectives have developed during the course of the studies. Among these may be mentioned the need of a flexible nomenclature for the generic segregates. It now develops that practically all of these are better treated as sections of one inclusive genus, the oldest name of which is Haplopappus. But it is not to be expected that all taxonomists will agree with this conclusion. It is therefore desirable to have sectional names so selected as to permit of their use also in the generic category, and this with the least possible displacement of the species names under them. Still more important 
is the proper delimitation and arrangement of these sections and the provision of keys and diagrams to enable one properly to distribute the species among them. The realization of these objectives has been kept constantly in mind in the preparation of the present monograph.

Finally should be mentioned the desire to understand and portray as clearly as possible the steps whereby the smaller units of evolutionary change become separated, shift about in accordance with the laws of geographic distribution, and reunite in those character combinations best suited to each set of environmental conditions. Such investigation requires the aid of detailed ecologic and genetic experiment, but it is believed that the present one, which has been conducted principally in the field and herbarium, together with assistance from transplant experiments, will aid in a better understanding of the processes which lead up to the emergence of subspecies, species, and still larger taxonomic units.

\section{PHYLOGENY THE BASIS OF CLASSIFICATION}

The adoption of phylogeny as the guiding principle in the classification of animals and plants would seem naturally to follow the acceptance of the theory of evolution. It must be admitted, however, that the spirit of phylogeny is not evident in a large proportion of the revisions and monographs of the present day. Most of our classifications appear to be based upon degree of similarity and a vague sense of relationships rather than upon the application of fixed principles. This can perhaps be accounted for in most cases by the large field to be covered, the impatience with slow and laborious methods, and the desire to produce a clear-cut and workable key to the flora or fauna under consideration. The economic demand for an early classification of the natural resources of new or little-known territories is justification for such procedure. In fact, the analysis of a flora and the more or less artificial grouping of its elements naturally precede any attempt at a synthetic presentation based upon phylogeny. The latter should be the ultimate goal of all taxonomy and might well receive more attention from those working upon groups in which the preliminary analysis has already proceeded to an advanced stage. It is possible that from such endeavor may come to light fundamental laws or principles of wide application.

But serious objections have occasionally been made to the use of phylogeny as a basis for classification. These follow from a recognition of the great complexity of life and the grave doubts that may be cast upon the accuracy of any arrangement that aims at being natural. Of the complexity of life there can be no question and it may at once be also admitted that no phylogenetic arrangement thus far proposed is beyond criticism, but to abandon the 
attempt at a natural classification because of these objections would be to forego values arising from use of speculative hypotheses in science. Such hypotheses are based in part upon verified knowledge, they increase in value with the degree of verification, and they should lead ultimately to generally acceptable conclusions.

Difficulties encountered in the formulation of a system which will truthfully portray the complexities of phylogeny are well understood by those who have followed recent developments in genetics and ecology or who have noted the interweaving nature of evolutionary lines connecting the smaller taxonomic units. The portrayal of phenomena, however, is quite secondary in importance to their recognition. If present nomenclatorial methods are inadequate for expression of the facts, the obvious remedy is to improve the methods rather than to mask the facts through the adoption of simplified formulae.

It may here be noted that some exception (Mattfeld, 1925) has been taken to the expression "The Phylogenetic Method in Taxonomy," as used in a title for a preceding publication on this subject (Hall and Clements, 1923), since phylogeny is not a method in the ordinary sense. But phylogeny is the record of descent and the phylogenetic method consists in keeping the evolutionary concept constantly in mind while transcribing the record, $i . e$. , while arranging the products of evolution in a system designed to display their natural relationships. The concepts of phylogeny thus become tools in the same sense as experiments or statistics and are used in much the same manner, except that more dependence is placed upon mental processes and upon the rules of logic. The phylogenetic method consists, therefore, in the application of established principles to the portrayal of processes which can not now be seen. But whether classed as a method or merely as an attitude of mind, it is essential that the phylogenetic spirit furnish the background for every system of classification.

\section{THE NATURE OF TAXONOMIC UNITS THE EVOLUTIONARY STREAM}

The ultimate goal of taxonomy is to discover the sequence in which evolutionary units have been developed and to portray this sequence in a detailed system of classification. As an aid toward this arrangement, systematists have thought it necessary to assemble all plants and animals into named groups of gradually increasing complexity. The smallest of these are composed only of individuals of the same immediate ancestry. Then follow other assemblages of increasingly larger size, each comprising in turn a natural assemblage of smaller ones. These groups of various sizes and representing various degrees of relationship are the units of taxonomy. Their usefulness is beyond question, but it is regrettable that some method has not 
thus far been found which would better portray the changeable nature of the organic world.

It is not necessary to subscribe to any particular theory as to the origin of species, whether by mutation, by hybridization, or by the method of somatic modification and subsequent hereditary fixation, to recognize the constant shifting of characters between many of the smaller units. From recent work in genetics it seems not unlikely that these "character changes" are the expression of recombination of the most minute particles of the hereditary substance. It is even possible that they result from reciprocating influences between these particles, which may themselves be in a fluid or semifluid state. At any rate, the shifting is so marked in some of the more recent groups, such as Rosa, Viola, Oenothera, and many of the Compositae that the situation may be likened to that of a slowly moving current, with numerous shoals, back-waters, and cross-rivulets. The attempt to classify all organisms into fixed and definitely bounded groups is thus seen to be impossible, for what the taxonomist has been attempting to confine within boxes of various shapes and sizes is in reality a shifting stream of minute hereditary units, these constantly appearing in new combinations. Certain groups, to be sure, may be set off as distinct and non-intergrading, especially if past time is not taken into account, just as certain lagoons may become isolated and develop ultimately into lakes or seas. Here are to be classed monotypic genera and those species which have no present connection with any other. Some of these have persisted for long periods of geologic time and some of the changeable groups, such as complex species, have likewise persisted as groups, but with frequent internal transfers between the component parts. But detailed studies, at least of genera and smaller groups, tend in most cases to break down distinctions between taxonomic units. This is especially true when studies are carried into the field, and it is obvious that a nearly continuous current could be demonstrated in all cases if one were to take into acount the forms of all past time.

The complexity of the organic world has been noted by workers in many fields, and especially by Cook (1906), who presents a vivid picture of what he calls the "vital fabric of descent." This figure well illustrates the situation at any given moment and permits the possibility of perfect intermixture and combination where the threads cross and interlace. But the picture is of a static condition, although Cook himself emphasizes the kinetic view of evolution as resulting from heterism and from interbreeding in a specific network of descent.

In the related field of ecology, Clements (1916) has emphasized the successional aspects of vegetation and has proposed a classification based upon this idea of succession in plant and animal 
communities. Cooper (1926) has gone even further in stressing the viewpoint that all life is in a state of change, and shows that progress in the science of ecology has been greatly retarded by the attempt rigidly to classify the units of vegetation. The principle applies equally well in taxonomy, where so much effort has been lost in attempts to set fixed barriers between units which refuse to be circumscribed in so arbitrary a manner.

This continuity from form to form, and less strictly from species to species, is illustrated over and over again in the genus Haplopappus. It is not necessary to present detailed evidence at this place, since it will be given in the discussions of the minor variations and relationships of many of the species. Noteworthy examples may be found under Haplopappus acaulis, H. racemosus, H. uniflorus, $H$. venetus, and others. Although much thought has been given in the present study to the examination of character's which might serve for recognizing the various units, it is hoped that this has not interfered with the presentation of a picture of the genus as a whole and of the interrelations of the numerous parts of which it is composed.

\section{TRANSITION STAGES FROM SMALLER TO LARGER UNITS}

The smaller the taxonomic unit the more direct are the connections with other units. For this reason the investigation of minute differences offers the most attractive field to one interested in the study of relationships. The underlying causes are of interest to the taxonomist, for they enable him better to classify the products, but their investigation falls within the domains of ecology and genetics. A difference due to immediate effect of environment and not transmissible is a "modification," in the sense of Nägeli and as later defined by Johannsen (1913) and by Baur (1914), or a "somatic modification" as this expression is used by Babcock and Clausen (1927). If the difference, be it ever so slight, is the expression of germinal unlikeness and therefore transmissible, it may be classed as genetic. Whether or not a somatic modification may in time affect the germinal constitution, and also the rôle of environment in direct induction of genetic change, are problems of fundamental biologic significance; but they are not primarily taxonomic. On the other hand, the systematist's first duty is to distinguish between easily modifiable and relatively permanent characters. This need not require detailed ecologic and genetic analysis, although these are highly desirable, for experimental methods are now in process of development with a view to supplying the desired information by more direct means (Clements, 1926; Turesson, 1926; Hall, 1928). The next problem of the taxonomist is to discover the processes whereby small units become so grouped as to yield the successively larger ones of his classification. Such discovery must 
await attack by combined analytic and synthetic methods of research on the respective rôles in evolution played by mutation, hybridization, somatic modification, isolation, and natural selection. It is only through an understanding of these evolutionary processes that a dependable natural system can be built up.

Differences in plant structures resulting from temporary modification, when understood as such, seldom receive taxonomic recognition. (Some botanists classify these as formae, but this term is used also for various other categories.) The smallest genetic units likewise are commonly overlooked, although some systematists attempt to catalog them. The principal reason for this neglect is the larger number involved. Geneticists have demonstrated the multitude of true-breeding forms within each of a few species (Oenothera lamarckiana, Zea mays, Antirrhinum majus, Capsella bursa-pastoris, Triticum aestivum, Lathyrus odoratus, Crepis capillaris, Hemizonia congesta, etc.). Even the inadequate studies of field botanists already indicate that these are not exceptional cases, for numerous wild species will yield fully as many segregates.

\section{CHARACTER COMBINATIONS AND PARALLEL VARIATIONS}

Reference is made in the preceding to forms differing by a single character. But plant forms usually differ by several or many characters, and it is the more frequent combinations of these that catch the taxonomist's attention. The unusual combinations are either ignored or thrown into the limbo of "intermediates," or, if the specialist in charge of the group has a penchant for novelties, they may become "new species."

The number of possible character combinations within a variable cross-fertilized Linnean species is, of course, very great. This accounts for parallelism in evolution, a phenomenon first noted by Naudin (1856) but much more clearly described by Duval-Jouve (1865), who presents numerous examples from his studies on the flora of France. Parallel variations have since been discussed in a general way by Darwin and others, but recently it has been proposed that a definite classification of variations be worked out for each species on a mathematical basis, the idea being that as the various combinations are discovered they will fit into this prearranged system. This is the suggestion of Vavilov (1922), who bases his method upon what he calls the Law of Homologous Series in Evolution. The proposal is perhaps too far-reaching, for chance combination of all the units and the dispersal of each combination to an environment suited to its survival are phenomena so dependent upon time and ecologic factors that there is no assurance of their complete realization. But a study of minute parallel variations and the classification of those combinations which have survived are of first importance in showing, (1) the fluidity of the smaller taxonomic units, and, (2) the 
final segregation into subspecies and species. Tabulations have been prepared to exhibit the combinations of characters within each of several species of Haplopappus. These are not here reproduced, since much better results have been obtained by Clausen in his detailed study of Viola tricolor (Clausen, 1922). The tabulations show, however, that even with the small amount of collecting thus far carried out, it is feasible to demonstrate many of the possible combinations of some 20 characters within a single species (Haplopappus racemosus, $H$. venetus, etc.). This gradual advance by steps too minute for ordinary classification demonstrates the almost fluid nature of taxonomic units so far as these species are concerned.

\section{SUBSPECIES, SPECIES, AND SECTIONS}

When character combinations are tabulated in the manner just mentioned it often happens that a considerable number of the possibilities are wanting in nature. Such deficiencies, when they occur in proximity to one another, signify an absence of connecting forms and the consequent production of subspecies. This usually is associated with geographic or physiologic isolation, chiefly because otherwise the intervening combinations would be expected through hybridization, at least in cross-fertilized species. Thus, subspecies come to stand between the category of minor variation on the one hand and that of full species on the other. Minor variations, because of their large number and the complications resulting from interbreeding, often are impossible of classification by standard taxonomic methods. The category of species, on the other hand, is reserved for the more distinct groups between which there is no longer or but rarely an interchange of character-determining factors. (The nomenclatorial status of the subspecies and its value as contrasted with that of the variety has been discussed by Babcock and Hall, 1924, p. 22.)

As one proceeds to the larger taxonomic units the connections naturally become less marked. Thus, in the case of Haplopappus the sections are units of much significance. Nearly all have been accepted at various times as distinct genera, and this is the usual temptation when working over a limited area or when all of the forms need not be taken into account. An assembling of all available data, however, discloses rather close connections even between some of the sections (p. 37). The external connections with other genera have now nearly or quite disappeared, but suggestive remnants of earlier ties have received attention in the discussion of the phylogenetic position of the genus.

There is thus seen to be a gradual transition from those evolutionary units too minute for taxonomic recognition to the larger phyla now separated by impassable barriers. A consistent nomen- 
clature for the various stages is one of the aims of systematic botany. Still more important, for purposes of classification, however, is an understanding of the principles and processes which have led to the formation of these stages.

\section{METHODS OF INVESTIGATION}

The author's views as to the relative value of various methods employed in studies on evolutionary taxonomy have been set forth in an earlier publication (Hall and Clements, 1923), but it is desirable here to indicate the application of these methods to the present investigation.

\section{FIELD STUDIES}

Collections and field notes with a view to a revision of the Haplopappus group were begun in California as early as 1900, and in 1907 a publication on the Compositae of southern California included the results of field studies for that area (Hall, 1907). It was not until 1918, however, that opportunity was offered for more extensive studies, and since that time the work has been carried into all of the Rocky Mountain, Great Basin, and Pacific Coast States, that is, into those parts of North America where the genus is best represented. Here have been studied the influence of environmental factors, the rôle of geographic isolation in the development of species, the extent of variation in each of the species and subspecies, and the presence or absence of intergradations. The result has been a better understanding of relationships and, it is hoped, an increased ability to evaluate the criteria of a classification which had been developed almost entirely in the herbarium.

These field studies permitted also the assembling of living transplant material. Some general conclusions resulting from a combination of field and experimental methods will be mentioned in a succeeding paragraph.

The inability to observe a few of the outlying North American species under natural conditions is unfortunate, but still more regrettable is the absence of field work in South America on the part of the author. But the species of the latter continent constitute a distinct phylogenetic branch of the genus, so that their treatment from herbarium studies alone may serve as a basis for more intensive work later, the results of which probably will not modify the arrangement of the North American groups.

\section{EXPERIMENTATION}

The testing of taxonomic criteria by means of experiment is a tedious and laborious process and requires special facilities. A thorough study of the characters of even a single species becomes too involved to permit of completion within a reasonable period of 
time. This need not deter one, however, from utilizing the experimental method so far as time and facilities are available, for it has been found that a single definite conclusion reached by such means will at once answer the problem in hand and give one a much better understanding of similar phenomena in related species.

Experiments with Haplopappus have consisted chiefly in bringing transplants of diverse forms and from diverse habitats into a uniform environment in order to test the stability of their differentiating characters. The reverse experiment, namely, that of carrying a single form into diverse environments, has received less attention because of the greater difficulties encountered, but a few experiments with plants moved into different types of soil have yielded some definite results. The conclusions thus far drawn have been utilized in the taxonomic treatment of the genus, where they will be mentioned especially in the paragraphs on relationships and on minor variations, but by way of summary the following general results may be here noted:

(1) Plants of Section Pyrrocoma removed from strongly alkaline soils of the interior or from saline soils of the coast do not lose in vigor when moved into approximately neutral soil. On the contrary, most of these exhibit increased vigor, but this may be due to cultivation or to reduction of competition.

(2) Most characters, except those of size, habit, and position, are not modified when the plants are subjected to a changed environment for a period of several years. This constancy is noted particularly in such features as pubescence of herbage, pubescence of achenes, general contour or cut of leaf (but not size), shape of involucre, etc.

(3) Plants with heads racemosely arranged tend to become paniculate, through elongation of the peduncles and branching, when brought under cultural conditions (especially H. racemosus).

(4) Erect plants from interior alkaline districts frequently have prostrate or decumbent radially spreading stems or branches when grown in good soil (section Pyrrocoma). This applies both to transplants grown near sea-level and to those of the same form grown at 1,500 meters altitude.

(5) Seashore plants with thick leaves bear leaves of average thickness when removed from the immediate influence of the sea.

Perhaps the conclusion of widest application that has been thus far drawn from the results of these field and experimental studies is that the "small species" of many workers, while often purely fictitious or only the result of a temporary modification, are, in the main, of evolutionary significance. They may differ from one another by only a single character or by only a different combination of characters, but nevertheless the individual plants sometimes hold tenaciously to this difference in all of the environments to which 
they have been thus far experimentally subjected. Similar results have been noted for other genera and families of plants by Turesson (1922) and by Hall (1928). But equally significant is the enormous number of these slightly different natural "species," as one might expect from the large number of possible combinations of characters and from the great variety of environments available to them. Detailed and exhaustive field studies of any highly variable group like Haplopappus, together with even a few transplant experiments, soon convince one that the recognition of these innumerable character combinations either as species or as subspecies is entirely impractical. A more logical method is to reserve these categories for the larger units and to list the remainder as minor variations. Although the description and ultimate disposal of these is a duty of taxonomy, their exact placement can be made only after a careful genetic and ecologic analysis.

\section{HERBARIUM STUDIES}

The importance of field and garden methods in taxonomic research can not be too strongly emphasized, but the results will attain their highest degree of accuracy and usefulness only by a detailed comparative study of specimens, and these are most conveniently assembled in herbaria. Furthermore, reports of phenomena observed in the field or as the result of experimental manipulation can scarcely be accepted as evidence unless vouched for by authentic specimens or photographs.

The preservation of materials in herbaria permits of subsequent verification and the examination of characters previously overlooked. Pressed specimens, if provided in abundance, are especially serviceable in the assembling of data for statistical studies, since certain characters are more easily and accurately examined in dried specimens than in fresh, and the microscope is much more easily manipulated in the herbarium than in the field. Moreover, herbarium practice furnishes the best known means of correlating the studies of workers operating in diverse places and at diverse times and is conducive to stability in nomenclature.

During the progress of the present investigation, studies were made in all the principal herbaria of North America and in many of Europe. Data of value were thus brought together regarding the geographic distribution, characters, and variability of the species and their subdivisions. Particularly appreciated was the opportunity of thus learning exactly what forms each of the earlier workers had in hand at the time his contribution was made. Practically all of the type specimens were studied, except for a few no longer extant and for some of the later South American species. Most of the latter were described by Dr. R. A. Philippi, who deposited the types at the Chilean National Museum. Perhaps the most regret- 
table feature of the study was the inability to visit this rich collection, but there was some compensation in finding duplicate types in one or another or in several of the European herbaria. Great care is necessary, however, in the use of Philippi's material, since it is frequently misnamed and the data are so meager that what appears to be of the type collection may be something quite different. However, by a comparison between specimens in several herbaria and between these and the original description it has been possible, in most cases, to gain an idea of the form described. Especially helpful in this connection was knowledge gained from a study of the types of species described by Lessing, Hooker, DeCandolle, and Remy, for the Philippi species are often synonymous with these earlier ones or are minor variations of them. There still remain, however, a number of the later South American species which are known to the writer only from descriptions and which will require herbarium and field studies, especially in Chile, for their satisfactory understanding.

Herbarium studies were carried out in greater detail at the University of California than elsewhere. Here were assembled, from other herbaria, photographs of types and other critical specimens, these accompanied in many cases by fragments of the specimen itself, and here are now permanently deposited also the principal collections of the author.

\section{METHODS OF PRESENTATION}

\section{DESCRIPTION AND KEYS}

In preparing the diagnoses of the species an effort has been made to have these consistent as to structures described and as to sequence, thus permitting of direct comparison. This consistency is maintained, however, only within each of the sections. Because of the wide difference in habit between some of the sections, it seems undesirable to repeat for each species certain features common to the entire group. Similarly, the descriptions of the subspecies are consistent in form and sequence only within each species. When a form is described for the first time a more detailed account is given. This necessarily destroys the attempted consistency, as also do the abbreviated descriptions of little-known species, especially those of South America.

All measurements are based upon fresh material or upon herbarium specimens restored by boiling. A reasonable amount of deviation from the figures given is to be expected in most cases, since occasional extreme variations are usually ignored. This applies particularly to size of involucre, for there is often much doubt as to whether the lower bracts are to be considered as a part of the head or as belonging to the peduncle. In cases of this kind an attempt has been made to adopt the same relative position for the 
base of the involucre. The breadth of this structure is the most unsatisfactory measurement of all, especially when measurements can not be made in the field. In many such cases the measurement as given amounts to but little more than an estimate based upon the width of dried heads. For this reason the breadth of head or involucre is sometimes omitted.

Throughout the keys and descriptions, measurements given for length of corolla include the lobes, even where the length of these is also stated.

\section{RESULTS OF STATISTICAL STUDIES}

The importance of statistical methods in botanical taxonomy has been emphasized in a previous publication (Hall and Clements, 1923). The tabulations there presented may still serve to illustrate the usefulness of such methods, and the number of tables is therefore reduced in the present monograph. This has been accomplished in some instances by summarizing in one table the results obtained from several of considerable extent (see, for example, table 8, p. 193); in other cases the measurements, counts, and tabulations have been prepared in detail, but preserved only in manuscript form, the data having been used in determining specific and subspecific limits and in the drawing of descriptions.

\section{PHYLOGENETIC CHARTS}

The value of a diagram lies in the ease and rapidity with which the reader may acquaint himself with an author's views; the danger lies in the definiteness with which the diagram portrays what may be a very indefinite and temporary hypothesis. The phylogenetic chart is intended to represent graphically conclusions reached after examination of all available evidence as to relationships between taxonomic units, but as knowledge advances important changes will be necessary both as regards relative position of these units and the direction of evolutionary movements. All charts employed in this monograph are to be considered, therefore, as expressions of present opinion and suggestions for future investigation and not as statements of demonstrated facts.

In a recent paper on archetypes and symbolism in studies on human anatomy, Streeter has called attention to the strong tendency to state things in a simple way, even when the things themselves are not simple, and to supply sharp contours where the real margins are indistinct or where the margins intimately blend (Streeter, 1927). This unfortunate tendency is marked in connection with phylogenetic charts, where boundaries between actual units are vague more often than sharp, and where all units merge into one another when their historical development is taken into account. But a more truthful presentation would involve the use 
of plastic models in which the units would appear as swellings upon a basic network of more than two dimensions. ${ }^{1}$ Since this obviously is impracticable at the present time, the two-dimensional chart appears to be the best method of expressing phylogenies, particularly if more than the author's intentions is not read into it by those seeking for simplicity, definiteness, and finality.

\section{ILLUSTRATIONS}

Line drawings are used almost exclusively in this book, since their reproduction on text paper is more durable than that of halftones, with their demand for calendered plate paper. An additional advantage lies in the ease with which illustration and text may be compared when the figures are placed near the corresponding descriptive matter, an arrangement which is impractical when plates are used. In the case of many South American species it is considered that the greatest service can be rendered by reproducing photographs of the types. This has necessitated a resort to the half-tone method.

Nearly all of the line drawings were executed by Miss Helen M. Rearwin, to whom the author is much indebted for the patience and care with which she has portrayed the subjects presented to her for delineation. The figures prepared by other artists are numbers 10,20,70,113, and 114, which are the work of Miss Anna Hamilton. In addition, use has been made in some cases of preliminary drawings by Miss Ruth Jeanette Powell (now Mrs. Alexander Brede). These, which have been completed and inked by Miss Rearwin, who drew most of the details, appear as figures 16, $24,25,47,59,61,64,65,66,67,72,74,76,77,78,86,89,94,99$, 103, 104, 108, and 110 .

A majority of the drawings have been prepared from fresh material collected for the purpose. Where this was not available, resort has been had to herbarium specimens, but at least the details of these have been restored to their original condition by boiling. All measurements have been made with great care, the larger ones by the aid of calipers, the smaller ones by the use of micrometer disk inserted into the eyepiece of a binocular dissecting microscope. The scale of reproduction is uniform for each structure throughout the genus (except for a very few cases where the modified scale is clearly indicated) and is as follows:

Habit...................... $\times 1$

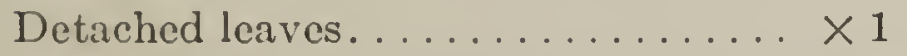

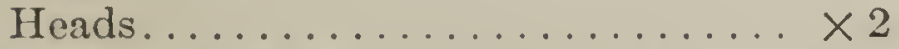

Detached bracts of the involucre.... $\times 4$

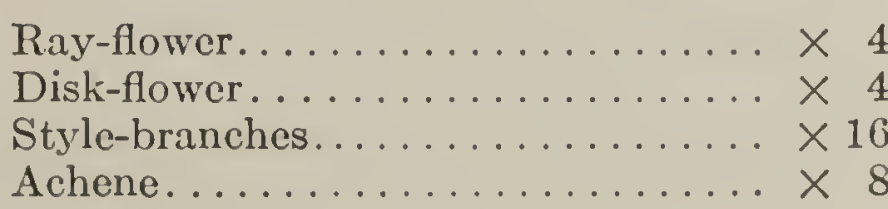

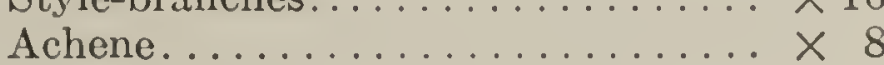

\section{CITATION OF AUTHORS, HERBARIA, AND SPECIMENS}

In the main, the methods of citation follow the principles laid down in the introduction to The Phylogenetic Method. As in that

1 A three-dimensional chart on a single plane has been recently worked out through the use of heavier and lighter lines, by a European botanist (Handel-Mazzetti, 1927). 
work, only a portion of the specimens seen are listed in the citations, since a complete enumeration would lead in many cases to the repetition of practically identical data or to the addition of localities within the known area of distribution. It is obvious that even a citation of all available specimens of common species would still fail to give a complete picture of the geographic distribution and would occupy space better reserved for other purposes.

The names of herbaria in which cited specimens were seen are indicated by abbreviations in parentheses, the adopted abbreviations being as follows:

B, Herbarium of the Botanical Museum and Gardens, Berlin.

BM, Herbarium of the British Museum of Natural History.

Boiss, Boissier Herbarium, University of Geneva.

CI, Unmounted specimens provisionally retained as a part of the working collection of the Carnegie Institution.

DC, DeCandolle Herbarium, Botanical Conservatory, Geneva.

Del, Delessert Herbarium, Botanical Conservatory, Geneva.

DS, Dudley Herbarium of Stanford University.

Field, Herbarium of the Field Museum of Natural History.

Gr, $\quad$ Gray Herbarium of Harvard University.

Greene, Herbarium of E. L. Greene, now at the University of Notre Dame.

K, Herbarium of the Royal Botanic Gardens, Kew.

MW, Herbarium of the Natural History Museum, Vienna.

NY, Herbarium of the New York Botanical Garden, including the herbaria of Columbia University, there on deposit.

P, Herbaria assembled at the Museum of Natural History, Paris.

Phila, Herbarium of the Academy of Natural Sciences of Philadelphia.

Po, Herbarium of Pomona College, Claremont, California, including the C. F. Baker and M. E. Jones herbaria.

R, Rocky Mountain Herbarium of the University of Wyoming, Laramie.

SF, Herbarium of the California Academy of Sciences, San Francisco.

UC, Herbarium of the University of California, Berkeley, including the Brandegee Herbarium.

UG, Herbarium of the University of Geneva.

US, United States National Herbarium, including that of the United States Department of Agriculture.

UW, Herbarium of the University of Vienna.

UZ, Herbarium of the University of Zürich.

Other herbaria are occasionally cited by abbreviations easily understood.

\section{CRITERIA FOR RECOGNITION OF TAXONOMIC UNITS IN HAPLOPAPPUS}

\section{ACHENES}

In some portions of Haplopappus, achenial characters are of the highest value for purposes of classification, in others they are so 
nearly uniform as entirely to pass out of consideration. For example, in all species of section Blepharodon the short, subturbinate achenes are unlike those encountered in any other group, and the character thus possesses sectional value, while throughout most of the genus the subcylindric, faintly four- or five-angled type is so common as to be monotonous. In section Hazardia the long achenes have a marked tendency toward a fusiform shape and to be glabrous and very smooth. The length is sometimes of specific value and in one case furnishes the only sharp distinction between two important subspecies of very unlike distribution (H. venetus typicus and $H . v$. vernonioides).

The disk-achenes are fertile and the ray-achenes sterile in most North American species, but in some, especially of section Pyrrocoma, the ray-achenes also are fertile, although this varies within a single species. Among South American students of the genus, fertility has been assumed for both ray and disk, except in section Steriphe, where the ray is sterile, but sterility of ray-achenes appears not to be confined to this section. One species of Isopappus (North American) rever'ses the usual order by having a sterile disk and fertile ray, while the only other member of the section has achenes all fertile. Sterility is encountered also among the disk-achenes of $H$. ciliatus and $H$. stoloniferus, but here only the central ones are affected.

The presence or absence of pubescence of the achene is a character of value in a few instances, but must be used with great caution. In section Ericameria it follows species lines. Here absence seems to indicate a recent development. In Pyrrocoma, on the other hand, the character is quite unreliable, for gradations appear with discouraging frequency. In $H$. apargioides, of this section, glabrous achenes are universal, but in the closely related $H$. racemosus they are sericeous in most subspecies, glabrous in one (similar to $H$. apargioides) and with varying degrees of pubescence in others (see p. 141). Variation within a single species is particularly noted in $H$. integrifolius. Here some collections have all achenes perfectly glabrous; others have achenes with hairs only near the base; sometimes a single plant will have a few of the achenes glabrous, the remainder with a few hairs; while in still other collections they are either moderately or densely villous over the entire surface. A similar variation is encountered in several South American species. Cases of separation of forms, distinguished by the presence and absence of achenial pubescence but occurring within a single colony, are noted under minor variations 6 and 14 of $H$. acaulis (pp. 167-168). Such phenomena suggest a shuffling of certain hereditary units in so complicated a manner that the results are impossible of application as taxonomic criteria unless accompanied by genetic analysis. 


\section{PAPPUS}

The color, texture, length, and number of pappus-bristles attain sectional importance in this genus, where resort must be had to criteria considered elsewhere as of little moment. These pappus differences furnish key characters for identification of natural groups first recognized through their combinations of other features even less clearly defined. The chief difficulties encountered in the use of pappus criteria are associated with the fact that all differences are relative and therefore almost impossible of expression quantitatively, and that in some species color develops only in age.

\section{STYLE-BRANCHES}

The best development of the style-branches and the sharpest differentiation of their parts are found in the sections most highly developed in other respects. Such sections are Macronema, Pyrro-
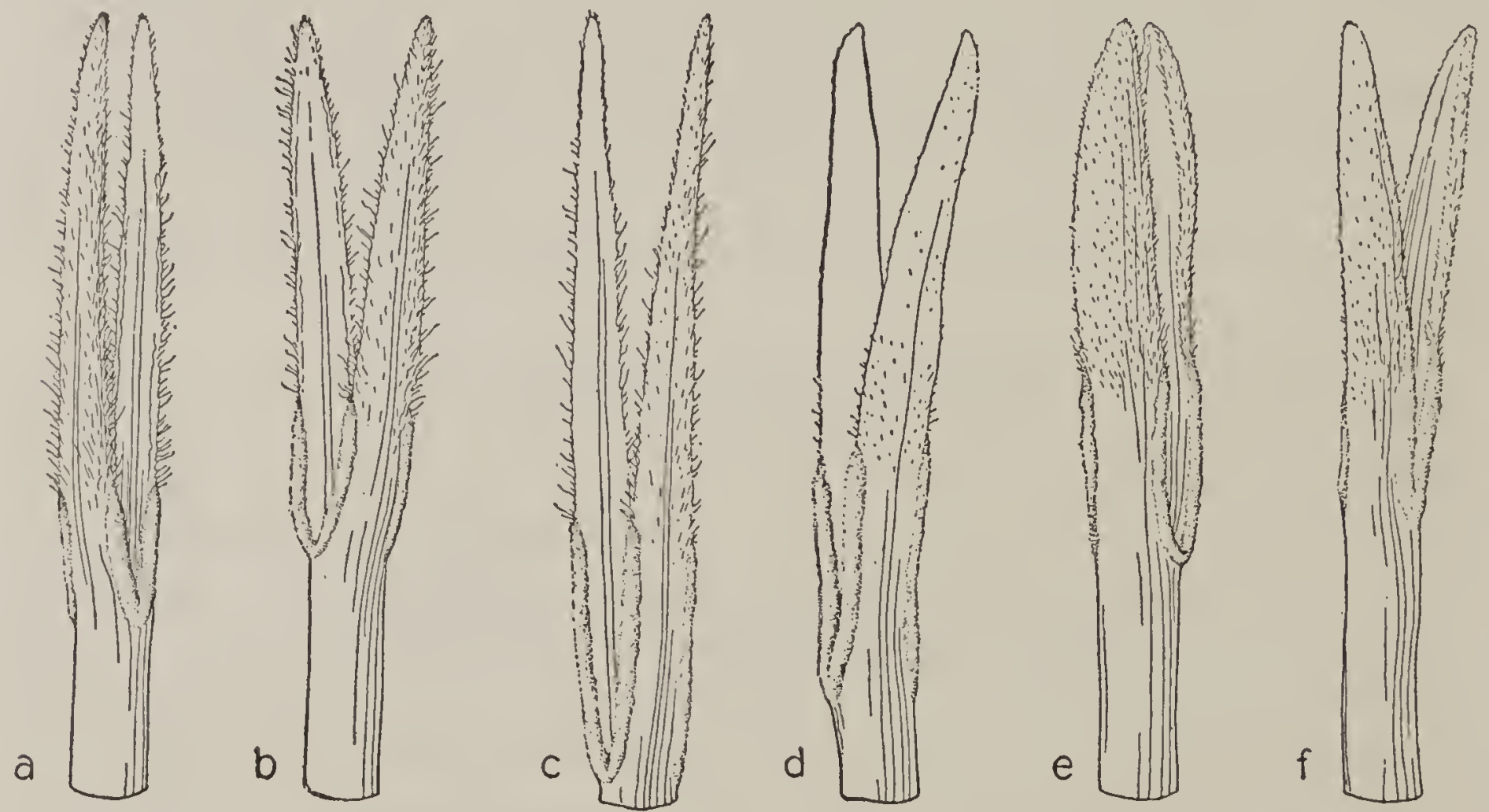

FIG. 1-Variation in characters of the style-branches; $a, b, c$, from Haplopappus greenei typicus (Univ. Calif. Nos. 216869, 216887, 62961, respectively); $d, e, f$, from $H$. acaulis typicus (Univ. Calif. Nos. 222695, 167688, 219412, respectively)

coma, Isopappus, and Asiris. Short style-branches with short and less pointed appendages, the whole structure therefore resembling the styles found in Aster, are characteristic of certain relatively primitive sections, such as Blepharodon, Osbertia, and most of the South American species. When actual measurements are made from a wide selection of material, it is found that the variation is so great within most of the sections and even within many of the species that this criterion can seldom be used with absolute certainty. Evidence of this variation is given in scome of the tabulations (pp. 143, 193) and illustrated in figure 1. General conclusions resulting from extensive series of measurements and tabulations are 
that shape of branch and relative length of appendage are of prime importance as indicating evolutionary trends and for the sharp differentiation of certain sections and species; but that in other parts of the genus they fail to have even subspecific value. Furthermore, the customary descriptions based upon casual examination might well yield to exact statements as to shape and as to ratio between the lengths of appendage and stigmatic portion.

\section{RAY-FLOWERS}

The importance of fertility in ray-flowers has been mentioned under the discussion of achenes. Isocoma is the only North American section in which the ray-flowers are constantly suppressed in all the species. In sections Osbertia, Stenotopsis, Stenotus, and Oreochrysum they are uniformly present. In all of the other sections and in the South American groups ray-flowers are present in some species and absent in others. In a few cases suppression runs parallel with other minor differences and thus serves to set off subspecies, while in $H$. cooperi and in a few others individual plants commonly bear both radiate and discoid heads, the former with a variable number of ray-flowers. Although suppression necessarily follows the presence of ray-flowers and so marks an evolutionary advance, it is to be noted that it does not always run parallel with other criteria of advancement. Apparently it has developed independently at a number of places in the genus, as indicated by partial suppression in different sections. The number of ray-flower's when present is sometimes useful in classification, as is also the width and shape of the ligules. The significance of color of the ligules has been treated elsewhere (p. 26).

\section{DISK-FLOWERS}

The number of flowers, more than anything else, determines the breadth and shape of the head, and is therefore of much diagnostic value. It is possible that statistical studies of this feature would yield high returns, but they would require large amounts of material and the results would be difficult of application when studying herbarium specimens. The shape of the corolla is distinctive for some groups, for example, section I socoma, and the depth to which the limb is cleft is of service for the setting off of a few species. Pubescence of corolla is given in the descriptions as a basis for future studies, but probably is not of taxonomic value.

\section{RECEPTACLE}

The receptacle is always more or less alveolate. Deep alveoli are especially characteristic of the comparatively primitive section Blepharodon. Here the walls often are dentate or even cleft so deeply as to form separate scales resembling bracts of the, receptacle. 
These scales may be as much as $1 \mathrm{~mm}$. in length, thus approximately equaling the achenes, but their irregular disposal indicates that they are not true bracts and hence have little phylogenetic significance. Long scales resulting from the breaking down of the walls of the alveoli are most prominent in $H$. gracitis, where they are always present. In $H$. gymnocephalus and $H$. phyllocephalus they are nearly as noticeable, while in the remaining species of Blepharodon the scales vary down to mere teeth. Similar chaff occurs also in $H$. sonoriensis.

\section{INVOLUCRE}

Shape of involucre has been accepted for the separation of groups of North American sections. The result is a cleavage apparently more natural than could be obtained through the use of any other criterion. This importance doubtless is due to the fact that shape is here largely determined by number of flowers, and this, in turn, by operation of evolutionary factors. Although there is good evidence that not all species with a large number of flowers are primitive, it is a reasonable assumption that heads with few flowers (and therefore narrow at base) are indicative of a derivation from largeheaded types through reduction.

Texture of bracts and distribution of pigments within them are features much used by experienced students of the genus for determining relationships, but are difficult of expression in quantitative terms. The number of bracts and the number of lengths are more definite, while the total length of involucre, that is, distance from base to tip of longest bract, is perhaps still more useful.

\section{ARRANGEMENT OF HEADS}

The inflorescence is, of course, capitulate, but this is so obvious that the various terms used in describing inflorescences often are applied to the arrangement of the heads themselves. Perhaps the most common type is the paniculate. This passes insensibly in some sections to racemose and thence to solitary. The distinction between a paniculate and a racemose arrangement furnishes the most satisfactory clue to the recognition of certain species, especially in section Pyrrocoma, but must be used with caution, for experimental tests prove that the arrangement is easily modified (p. 141). There is a transition from paniculate to cymose arrangement in $H$. laricifolius, which thus connects the two main branches of section Ericameria. The heads are chiefly solitary in sections Osbertia, Stenotus, Macronema, and Toneshus. This is due to reduction, from the paniculate arrangement in some cases, from the cymose in others. In Oonopsis the solitary disposal is the result of reduction from the cymose type within the section. 


\section{LEAVES}

As elsewhere in the Compositae, foliage differences signify no fundamental phylogenetic cleavage. They often serve, however, as aids to recognition of species and subspecies. An alternate insertion of the leaves is almost universal in Haplopappus. A notable exception is found in $H$. racemosus brachycephalus, where an opposite arrangement of the lower leaves is associated with a marshy habitat. The other subspecies of racemosus have uniformly alternate leaves. Size, shape, and texture are all too variable to be of more than specific value, and then only as supplementing other features.

The presence of resin-pockets in the leaves and twigs of some species has led to the use of this character by certain authors for the separation of Ericameria as a distinct genus. These structures have, therefore, been studied in some detail. The result is that nearly one-half of the species referred to Ericameria are found not to possess the pockets, but have been so classified on merely general appearance. In the present treatment Ericameria is accepted as a section, but those species of the group which lack the resin-dots are set aside in the new section Asiris. The result is a segregation of natural units and does away with the attempted application of a character where it does not exist. In Ericameria (as also in Stenotopsis) the pits are definite, sharply outlined depressions in the tissue, often amounting to as much as one-fifth the thickness of the leaf. Resinous material exudes into these pits, often entirely filling them. The resins may even protrude beyond the surface, forming minute warts. In Asiris, on the other hand, the surface is either smooth and more or less resinous-coated, or marked by cellular projections (modified trichomes?) from which the resin exudes. The projections often are enlarged and gland-like at the tip, which, however, retains vestiges of a multicellular structure (H. watsoni). Although the species of Ericameria may be distinguished at a glance from those of Asiris by the use of this feature alone, there is at least one place in the genus where there seems to be a transition from non-pitted to pitted leaves. This is in section Isocoma (particularly in $H$. acradenius, $H$. hartwegi, and the Lower California forms of $H$. venetus).

\section{PUBESCENCE}

Only in rare instances are pubescence character's useful as taxonomic criteria. In section Macronema one species, well set off also by other characters, has stems heavily coated with tomentum. But other Macronemas are so variable in respect to tomentum that its presence is of doubtful value even for the characterization of subspecies. A notable case of two forms of the same habitat and identical as to characters, save for the presence of stipitate glands in the one and their absence in the other, will be described under 
H. lanceolatus subviscosus. Pubescence of achenes and of corollas has been discussed under these headings.

\section{RESINS, OILS, AND RUBBERS}

Resinous substances are abundant in all the shrubby species and in some of the herbaceous ones. They commonly pass freely through the epidermis, giving this a more or less shining coat; often they exude from the tips of short, simple trichomes ( $H$.divaricatus, $H$. racemosus subviscosus, $H$. suffruticosus, etc.) or from the tips of multicellular outgrowths (H. watsoni); or they may be deposited in specially constructed internal "pockets" (especially in the involucral bracts of $H$. acradenius). The chemical and physical nature of these substances, if once understood, might furnish criteria of worth, but a study of the structures set aside for their storage, transfer, and elimination doubtless would yield results of more direct application in taxonomy. Some of the latter have been described in the foregoing account of the leaves. Rubber occurs in the tissues of a few woody species, especially of sections Ericameria and Asiris, the amount running as high as 10 per cent of the dry weight in $H$. nanus (Hall and Goodspeed, 1919). The percentage varies with the species and apparently with the strains within each species, but definite correlations have not been worked out.

\section{UNDERGROUND PARTS}

A fibrous root system branching from a well-defined taproot is characteristic of the shrubby species, as also of the few annual ones. The herbaceous perennials have, for the most part, a deep taproot crowned by a multicipital caudex. This is especially characteristic of sections Pyrrocoma and Oonopsis. Rootstocks are present only in one species of Osbertia, in the single species of Oreochrysum, and in two of the four species of Tonestus, but prostrate stems produce roots from the nodes in several South American species. The presence of rootstocks is not a dependable criterion, since some species in which they usually occur include plants in which they fail to develop.

\section{HABIT}

Those who would dismember Haplopappus into a series of related genera make much of habit differences (Nuttall, 1840; Greene, 1894; Nelson, 1904; Rydberg, 1900 and 1917). This presents a strong appeal to field workers, especially when the field is limited, so that troublesome intermediate forms of outlying geographic areas need not be taken into account. The present author, working at one time under such conditions, found possible the maintenance of several of these segregates (Hall, 1907), but when the scope of the investigation was extended to all of North America so many discrepancies developed in the supposed parallelism between habit and floral char- 
acters that a reassembling into one comprehensive genus became almost imperative. A more recent study of the South American species confirms this conclusion. Here a few groups may be set off fairly well on features of habit (sections Diplostephioides, Steriphe, etc.), but Euhaplopappus, which includes everything from creeping herbs to erect shrubs, can be segregated on basis of habit only by sacrificing the values of a natural system.

The advisable procedure, in a case of this kind, obviously is to utilize habit characters when they lead to natural groupings, and to abandon their use when this would result in artificial assemblages. Such practice is followed in the present monograph. But habit alone is not accepted as of generic value, and seldom does it run consistently parallel with floral characters of generic worth. Its inclusion in the key to the sections, even when not strictly diagnostic, indicates its usefulness in classification. Instances of its failure to mark natural groups are given in the discussion of the phylogeny of the sections, particularly in connection with section Blepharodon.

\section{DIAGNOSIS AND NOMENCLATURE OF THE GENUS}

\section{ORIGINAL DESCRIPTION}

The first description of the genus was by H. Cassini in Dictionnaire des Sciences Naturelles 56:168-169, 1828. Since this publication is not generally accessible, Cassini's diagnosis is here reproduced.

III. Aplopappus, H. Cass. Calathide radiée: disque multiflore, régulariflore, androgyniflore; couronne unisériée, sub-duo-décimiflore, liguliflore, féminiflore. Péricline presque égal aux fleurs du disque, formé de squames inégales, imbriquées, appliquées, linéaires, aiguës au sommet, foliacées. Clinanthe large, plan, nu (probablement fovéolé). Fleurs du disque: Ovaire oblong, tout couvert d'une couche épaisse de longs poils; aigrette simple (point double), plus longue que la corolle, composée de squamellules nombreuses, très inégales, filiformes, amincies vers le sommet, barbellulées. Corolle glabre, à tube court, suffisamment distinct, à limbe très-long, subcylindracé, un peu infundibulé, divisé au sommet en cinq lanières courtes. Etamines à filets ayant l'article anthérifère long; à anthères exsertes, munies d'un appendice apicilaire oblong, obtus au sommet, et privées d'appendices basilaires. Style à deux stigmatophores d'Astérée. Fleurs de la couronne: Ovaire et aigrette comme dans les fleurs du disque. Corolle à tube long, à languette jaune, plus longue que le tube, oblongue, large, à peine tridentée au sommet.

Then follows a description of a single species, namely, A. glutinosus, which thus becomes the type of the genus. (Not to be confused with $A$. glutinosus DC. See p. 328.) Cassini further adds (p. 169):

Nous avons fait cette description, générique et spécifique, sur un échantillon sec, innommé, de l'herbier de M. Mérat, et qui paroît avoir été recueilli dans le Chili par M. d'Urville.

A discussion of the relation to other genera is then entered into. 


\section{AMPLIFIED DIAGNOSIS}

Haplopappus Cassini. Annual and perennial herbs and shrubs, usually resinous or glandular. Roots fibrous, with a taproot, a few species also with rootstocks or stolons. Leaves alternate (lower rarely opposite), entire to variously lobed, rarely dissected. Heads rather small to large, variously disposed, sometimes solitary. Involucre depressed-hemispheric to obconic; bracts numerous, from nearly equal to closely and regularly imbricated in several lengths (never in vertical rows), not keeled, but the midrib sometimes prominent, from entirely herbaceous to chartaceous or coriaceous, but at least the tips usually greenish; receptacle alveolate, not bracteate (walls of the alveoli sometimes broken into bract-like scales). Ray-flowers 1 to about 100, pistillate or neutral or wanting, fertile or sterile; ligules (if present) usually yellow, occasionally purple, turning brown or saffron in a few species. Disk-flowers several to numerous, hermaphrodite, usually fertile (sterile only in $H$. occidentalis and $H$. stoloniferus); corolla funnelform to subcylindric, the throat ventricose in one section (Isocoma), regularly 5-toothed or 5-lobed; anthers oblong, obtuse, entire or barely emarginate at base; style-appendages exserted from the corolla-tube, ovate to subulate, obtuse or acute, either shorter or longer than the stigmatic portion. Achenes subprismatic or subcylindric to turbinate or rarely fusiform, 4- or 5-angled or striate or smooth, densely pubescent to glabrous. Pappus simple, consisting of numerous capillary scabrous bristles in one or more series, unequal in length.

\section{NOMENCLATURE}

There is no doubt as to the plant which Cassini had in mind when drawing up his description. His diagnosis is sufficiently ample and detailed, and there are extant specimens which apparently are duplicates of his type. (No attempt has been made to locate his own specimen in the Mérat herbarium.) The only name that has been proposed as a substitute for Haplopappus is Hoorebekia Cornelissen. This genus was published by Mussche, for Cornelissen, in Hortus Gandavensis, pages 12 to 14, June 1817, as follows (paragraphs of description not retained here):

(P. 12.) Nous avons acquis cette Plante originaire du Chili, par graine, donnée par Mr. Pierre de Grave en 1811; elle a fleuri au mois d'Août 1816, et reçu son nom par une Commission nommée ad hoc dans le sein de la Société royale d'Agriculture et de Botanique, et composée de sept de ses membres: MM. Van Rotterdam, Verbeeck, Van Hoorebeke, Delbecq, P. de Grave, Malpé et Mussche, qui après s'être assurés qu'elle n'avait pas été décrite, l'ont dédiée à Mr. Charles van Hoorebeke, auteur de l'Herbier de la Flandre orientale, déjà cité avec éloge dans la notice qui précéde.

(P. 13.) Cette Plante classée dans la syngénésie superflue de Linnée, et indiquée page 120 de l'Hortus Gandavensis, a été peinte par Mr. Malpé, et gravée par Mr. Massau. Mr. N. Cornelissen l'a décrite dans une notice présentée à la Société de Botanique, de Gand, et à l'Académie royale des sciences et belles-lettres, de Bruxelles, dont il est membre. Nous avons pensé qu'un extrait de cette description pourrait ne pas déplaire, et nous la consignons ici pour l'instruction des amateurs.

\section{Hoorebekia chiloensis}

Radiée. Tournefort: xiv classe 1re section; Jussieu: famille des corymbifères; Linnée: syngénésie superflue. Calice: ventru, imbriqué à écailles 
nombreuses, terminées en pointes allongées et redressées. Corolle: radiée; fleurons des rayons sur deux rangs en languettes bifides ou trifides; rarement entières. Fleurons du disque, très-nombreux, en entonnoir, à cinq divisions égales et peu profondes. Anthères dépourvues d'appendice. Stigmate bifurqué, les pointes rapprochées. Semences, tant du rayon que du centre, à aigrettes soyeuses, comme filacées, décidues (du latin deciduus, qui tombe facilement), communément au nombre de neuf. Réceptacle nu et alvéolé. Tige: sousligneuse, rameuse, rameaux diffus et étalés; pédoncule formé du prolongement des (p. 14) rameaux, très-long, uniflore, à feuilles florales nombreuses, décurrentes et éparses sur toute la longueur. Feuilles linéaires lancéolées, pointues; inégalement dentées vers leur sommet, éparses, rétrécies vers leur base en pétioles ailées et semiamplexicaules. Visqueuse dans toutes ses parties. Fleur jaune.

Elle habite le Chili, au pied des Cordillières, dans l'Amérique méridionale.

Arbuste de serre tempérée.

The foregoing description by Cornelissen is accompanied by an unnumbered plate showing habit and some details. Although the pappus is not clearly shown in this illustration, there is no doubt in the mind of the present author that both description and plate refer to some Chilean species of Grindelia. The general character's, as given, fit certain specimens of undoubted Grindelia much better than they do any form of Haplopappus. Reference is made particularly to a specimen of the former in the Berlin Herbarium (Diamante, Argentina, January 1883, Güssfeldt).

An attempt has been made to locate the type specimen of Hoorebekia chiloensis, but without success. Through the kindness of Professor De Bruyne and M. Burvenich it has been learned that the Mussche Herbarium was sold in 1840 , perhaps to some Belgian collector, but no later trace of it could be found.

Since Hoorebekia now appears to be a synonym of Grindelia, Haplopappus remains as the proper name for the genus typified by $H$. glutinosus Cassini. In any event, no other course is open for those who, like the present author, follow the International Rules, for Haplopappus was included in the list of nomina conservanda by the Berlin Congress.

Cassini, who coined the word, spelled Haplopappus without the initial $H$. He was followed in this by DeCandolle and by perhaps a majority of North American botanists, including Gray. The corrected spelling of Haplopappus has been used by Remy (in Gay's Flora of Chile), Bentham and Hooker, Hoffman (in Engler and Prantl's Pflanzenfamilien), Reiche, and others, as well as in the list of nomina conservanda referred to in a preceding paragraph. Because of this discrepancy in spelling an opinion was sought of Dr. C. B. Bradley, eminent philologist of the University of California, who responded as follows:

' $a \pi \lambda_{0}$ - and ' $a \pi \lambda_{0}$ - are both Greek adjective-stems, exactly alike so far as the letters are concerned, but sharply distinguished, first, by the initial 
"breathings," so-called, namely, and '; and, second, by their meanings, 'a $a \lambda_{o}$ - meaning simple or single, and 'a $a \lambda_{o}$ - meaning unsailed or unnavigable. Our letter $h$ is the exact equivalent of the former "breathing," while the latter has no equivalent in our alphabet, although it is not infrequently heard in our speech. ... The rough breathing which we represent by initial $h$ was certainly not dropped by the Greeks; and it could not have been dropped by the Romans, because they never had the word in their vocabulary. .. . Turning now to the meanings of the two compound words, we find that Haplopappus has a complete and intelligible meaning, namely, single or simple pappus-row; while Aplopappus makes mere nonsense.

Since the dropping of the initial $H$ gives to the word a meaning entirely different from that obviously intended by Cassini, it would seem that Haplopappus should be the preferred spelling by all, except those who follow the original orthography of botanical names regardless of eirors.

\section{PHYLOGENETIC POSITION OF THE GENUS}

Haplopappus is a genus of the Compositae and belongs to the homochromous group of the tribe Astereae. As here delimited it is believed to be a natural assemblage of species which, notwithstanding their high degree of diversity, are connected throughout by evolutionary lines emanating from a common ancestral plexus. At several points there are suggestions of connections with other genera, but these are in the more primitive sections and the evidence is not sufficiently strong to justify the unqualified acceptance of a theory of polyphyletic origin. It is possible, however, that in the early stages of its history the genus came into contact with other's of the same general group and received from them, perhaps through hybridization, certain characteristics not present in its direct ancestral line.

Since it is impossible to derive Haplopappus from any presentday genus, the early contacts just referred to are of prime importance in an attempt to determine its phylogenetic position. Most suggestive in this connection is the frequent occurrence of a purplish pigment in the ray-flowers of a few of the lower species. This sporadic appearance of a feature of the subtribe Heterochromeae suggests that Haplopappus had its beginning at a time when diversity of color was first being "tried out" in the Astereae and that its relationships are to be sought among the heterochromous rather than the homochromous genera. Of the former, the genus Aster seems to make the nearest approach, some of its species of the southwestern United States being scarcely distinguishable from forms of Haplopappus spinulosus except by color of ray-flowers and nervation of achenes. It is in some of the subspecies of $H$. spinulosus and in the closely related $H$. gymnocephalus that purple ligules sometimes occur, while in section Hazardia, another southwestern group, 
the ligules turn saffron in age. An early connection with the heterochromous series is suggested also by the presence of purple pigment in the ligules of several South American species of section Euhaplopappus (H. macrocephalus and allies). These facts point to three conclusions: (1) that the Haplopappus stock was in contact with an aster-like group in its early stages; (2) that the three sections which occasionally exhibit purple ligules are to be rated as among the lower (although not necessarily the lowest) members of the genus; and (3) that the original center of distribution of Haplopappus was in a region then common to these three sections or to their ancestors, probably in Mexico or some similarly warm-temperate district, and that from this center migrations carried the genus both toward the north and to the west coast of South America.

Coming now to a consideration of possible connections within the Homochromeae, it is found that only one can be demonstrated with any degree of probability, and this is not with an ancestral but with a derived type. Reference is here made to the genus Chrysothamnus, which, as will be shown under $H$. sonoriensis, is probably a development from the section Ericameria. Nearly all of the other homochromous genera are distinguished by a more or less paleaceous pappus and are therefore considered as of more primitive origin. These are small genera and have the appearance of being short branches from the general line of advance which culminated in Haplopappus and Chrysothamnus. None, so far as known, ever produce purple pigments in their flowers. In addition is to be noted especially the genus Grindelia, which, because of its much narrowed and deciduous pappus-awns, closely resembles section Prionopsis. This section, however, comprises but a single species and is so doubtfully placed in Haplopappus that a real connection with Grindelia, even if demonstrated, would scarcely aid in bringing the two genera together. A greatly reduced number of pappus-awns and a highly organized involucre suggest that Grindelia may be as highly developed as Haplopappus, although representing the terminus of a divergent evolutionary line. Another genus which simulates Haplopappus and doubtless is of close affinity is Chrysopsis. This is, however, set off by the essentially equal pappus-bristles of the principal series and usually, but not always, by the presence of a very short outer series. No connection has been demonstrated between species of the two genera, since additional differences appear whenever any pair of species is selected for comparison.

A notable deviation from the paleaceous type of pappus is found in Solidago. Here the pappus is as finely divided into bristles as in any Haplopappus and there are numerous other indications of a highly organized genus. It seems impossible, however, to trace any direct phylogenetic connection between the two genera. An approach through the section Oreochrysum has been suggested, but 
this is now believed not to exist (see p. 39). There are still other genera of the Homochromeae in which the pappus consists of numerous bristles, but these differ so radically in other essentials that their possible relationships need not be here considered.

From the foregoing evidence it may be concluded that Haplopappus is one of the most highly developed genera of the homochromous Astereae, a distinction which it shares with Solidago and, to a less degree, with Grindelia; that it is not a derivative of any present-day genus; and that there was formerly a connection with some asterlike member of the Heterochromeae. These conclusions are to be taken merely as the most probable solution of a difficult phylogenetic problem.

\section{RELATIONSHIPS OF THE NORTH AMERICAN SPECIES OF HAPLOPAPPUS TO THOSE OF SOUTH AMERICA}

All of the available evidence suggests the Mexican region as the ancestral home of the genus Haplopappus (pp. 27, 38,60). In past geologic time, however, there came about a separation into two groups, or subgenera, one now confined to North America, the other to western South America, with the tropics forming an impassable barrier between them. These groups exhibit the same generic characters and they possess in common certain potentialities which in some instances have been developed along parallel lines. But such development has in no instance resulted in the production of identical forms or species. Either certain features present in one region are lacking in the plants of the other, or important characters occur in different combinations, in addition to differences in superficial features. It is impossible even to set up a single satisfactory natural section which will include species from both sides of the tropics.

It appears that the more noteworthy development of specialized features has taken place in North America, where, in consequence, is found the larger number of well-marked sections. ${ }^{1}$ This has a direct relation to the larger geographic area there occupied and to the greater diversity of habitats. In this connection one is impressed by the highly specialized style-branches in most of the northern species, as contrasted with the conservatively short branch and appendage of South American forms. Similarly the special resin-holding pits of sections Ericameria and Stenotopsis are not known in any southern species, and the neatly cymose arrangement of the heads, believed to indicate a mark of advance in Ericameria, Asiris, Isocoma, etc., is approximated in South America only in the very distinct section (or genus?) Diplostephioides. In the southern

1 The number of species accepted in the present monograph is approximately the same for the two regions, but this is partly due to the author's tendency to preserve "weak" species of South America, since he is less well acquainted with them. It is probable that further exploration and collection of intermediates will reduce rather than increase the total for the Southern Hemisphere. 
group the tendency has been rather toward a reduction in the number of heads, in most species these being solitary but large and with numerous flowers. Although suppression of ray-flowers has taken place in both groups, this is much more frequent in the north than in the south.

In searching for possible phylogenetic approaches between the North American and South American representatives of the genus, it is found that these occur between what are taken on other evidence as the more primitive sections, especially Blepharodon of the north and Euhaplopappus of the south. In both are noted the predominance of lobed or dentate leaves with bristle-tipped or at least pungent teeth, short stylar appendages, numerous narrow bracts, and broad heads with many flowers. It is also in these sections that purplish ligules occur the most frequently. From this tendency an early connection with Aster has been assumed (p. 26). But a fusion of these sections is prohibited by several notable differences, particularly the short, subturbinate achenes of Blepharodon, as contrasted with the narrow, elongated ones of Euhaplopappus. As to habit, the reduction from shrubs to herbs has taken place in both sections, but the resulting form is never the same.

The suggestion has been made of a connection from the southern section Diplostephioides through the northern genus Chrysothamnus and thence to the northern Haplopappi, but this idea appears to have resulted from an early artificial grouping based upon the presence or absence of ray-flowers, which threw these two groups into the heterogeneous assemblage once called Bigelovia. The absence of a phylogenetic connection is shown by the very different involucre and style-branches as well as by habit, and in any event the connections between Diplostephioides and the other sections of Haplopappus is too weak to give value to the setting up of a hypothetical connection by this route.

Although a direct relationship between the North American and South American species seems impossible of demonstration, a superficial similarity is sometimes almost startling. This applies particularly to comparisons between some species of the northern section Hazardia with some of the southern section Polyphylla, for example, between $H$. berberidis and $H$. mucronatus. The former has involucres distinctly narrower at base until swollen by the fully ripened achenes, as compared with the broader-based involucre of mucronatus at the same stage; and the flowers have a tendency to turn brown or saffron in age in the northern species, a trait not noted in the southern one. If these species grew in the same region they certainly would be included within a single section, but it is believed that their similarities are due chiefly to external form and do not indicate a close relationship. Doubtless other differentiating criteria will in time be found which, added to those of the involucre, 
color of flowers, and considerations of geographic distribution, will justify the sectional separation of such species.

In the absence of any demonstrated connection the conclusion is drawn that the species of North America have become definitely separated from those of farther south and that within each group there has been a development and differentiation which has led to the separation of smaller groups sufficiently distinct to be recognized as sections, 16 of these being in the north, 5 in the south. The nearest approach between sections appears to be between Blepharodon and Euhaplopappus, but even here the separation is based upon good technical grounds. It seems impossible, however, to set up any single character for the separation of all sections of North America from all those of South America, chiefly because of the numerous combinations in which the characters occur. It is for this reason that the primary geographic groups are not formally designated as subgenera.

\section{ACKNOWLEDGMENTS}

So many friends have contributed to the present undertaking that mention can be made of only a few. Professor W. L. Jepson, of the University of California, first called the author's attention to the need of a critical revision of the Haplopappus group and aided in the initiation of the study. Professor W. A. Setchell made possible the carrying out of detailed herbarium studies at the University of California, and the advantage of being in frequent consultation with him has been of much value. In 1919 the writer joined with Dr. F. E. Clements, of the Carnegie Institution of Washington, in the preparation of monographs of several genera of plants, and from that time on has benefited by the opportunity of frequent consultation with this inspiring worker. Field excursions made in connection with him have yielded especially high returns, since in this manner could be discussed on the ground those intricate problems where field knowledge and living demonstrations are essential to a satisfactory solution. Dr. Clements has, moreover, read nearly all of the text and his numerous suggestions have greatly aided in the clarification of phylogenetic questions and in the expression of results.

Thanks are due in no small measure to those in charge of herbaria consulted, not only for permission to study and photograph specimens but also for opinions as to source and authenticity of data, and, more especially, for suggestions and inspiration emanating from them and from their staff members. Among the more helpful in this connection may be mentioned Dr. John Briquet, Director of the Conservatory of Botany, Geneva; Dr. Robert Chodat, Director of the Botanical Institute of the University of Geneva; Dr. H. Lecomte, Director of the Herbarium of the Museum of Natural History of 
Paris, and members of his staff; Dr. Ch. Flahaut, Director of the Botanical Institute of the University of Montpellier; Dr. E. De Wildeman, Director of Botanical Gardens of Brussels; Dr. L. Diels, Director of Botanical Gardens and Museums, Dahlem-Berlin, and Dr. J. Mattfeld, in charge of the Compositae at the same institution; Dr. A. W. Hill, Director of the Royal Botanic Gardens, Kew, and Mr. A. D. Cotton, Mr. J. Hutchinson, and Mr. T. A. Sprague, of the same institution; Dr. A. B. Rendle, Keeper of the Herbarium of the British Museum; Dr. B. L. Robinson, Curator of the Gray Herbarium; Director-in-Chief N. L. Britton and Dr. P. A. Rydberg, of the New York Botanical Garden; Dr. F. W. Pennell, of the Philadelphia Academy of Natural Sciences; Dr. F. V. Coville, Dr. J. N. Rose, Dr. William R. Maxon, and Dr. S. F. Blake, of the United States National Herbarium; Professor Aven Nelson and the late Professor E. B. Payson, of the University of Wyoming; Miss Alice Eastwood, of the California Academy of Sciences; Dr. L. R. Abrams, Leland Stanford Junior University; and Dr. P. A. Munz, Pomona College. Professor E. B. Babcock, of the University of California, has kindly read parts of the manuscript and contributed valuable suggestions, especially from the point of view of genetics. Finally, it is a pleasure to refer to the generous assistance of Dr. R. A. Harper, of Columbia University, who has critically read portions of the introduction and whose counsel has been of much value to the author.

\section{REFERENCES}

BABCOCK, E. B., and R. E. Clausen. 1927. Genetics in relation to agriculture. 2d ed. - and H. M. HALL. 1924. Hemizonia congesta, a genetic, ecologic, and taxonomic study of the hay-field tarweeds. Univ. Calif. Pub. Bot. 13:15.

BAUR, E. 1914. Einführung in die experimentelle Vererbungslehre. 2d ed.

Clauden, J. 1922. Studies on the collective species Viola tricolor L. Bot. Tids. 37:363.

Clements, F. E. 1916. Plant succession. Carnegie Inst. Wash., 242.

- - 1926. Fixation. Year Book Carnegie Inst. Wash. 25:338.

Coor, O. F. 1906. The vital fabric of descent. Proc. Wash. Acad $7: 301$.

Cooper, W. S. 1926. Fundamentals of vegetational change. Ecology $7: 391$.

Duval-Jouve, J. 1865. Variations parallèles des types congénères. Bull. Soc. Bot. de France 12: 196-211.

Greene, E. L. 1894. Observations on the Compositae, IV. Erythea 2:53.

HaLl, H. M. 1907. Compositae of southern California. Univ. Calif. Pub. Bot. 3:1.

- 1928. Taxonomic treatment of units smaller than species. Proc. Inter. Bot. Congress, Ithaca.

__ - and F. E. Clements. 1923. Phylogenetic method in taxonomy. Carnegie Inst. Wash., 326.

—, and T. H. GoonSPEED. 1919. Occurrence of rubber in certain west American shrubs. Univ. Calif. Pub. Bot. 7:265.

Handel-Mazzetti, H. 1927. Beihefte zum Bot. Centralbl. $44^{2}: 167$.

Jorinnsen, W. 1913. Elemente der exakten Erblichkeitslehre. 2d ed.

Mattreld, J. 1925. Review in Engler, Bot. Jahrb. 59 (Lit.): 79.

Naudin, C. 1856. Article in, Ann. d. Sci. Nat. IV, 6:5

Nelson, Aven. 1904. New genera among the Aplopappus segregates. Bot. Gaz. $37: 260$.

Nuttall, Thomas. 1840. Descriptions of new genera and species of plants in the natural order of Compositae. Trans. Am. Phil. Soc. II, $7: 284$. 
Rydberg, P. A. 1900. Studies on the Rocky Mountain flora, III. Bull. Torr. Club $27: 614$.

- 1917. Flora of the Rocky Mountains and adjacent plains.

Streeter, G. L. 1927. Archetypes and symbolism. Science, N. S., 65:405.

Turesson, G. 1922. Genotypical response of the plant species to the habitat. Hereditas $3: 211$.

1926. Die Bedeutung der Rassenökologie für die Systematik und Geographie der Pflanzen, Rep. Spec. Nov. Reg. Veg. Beih. 41:15.

Vavilov, N. I. 1922. Law of homologous series in variation. Jour. Genetics 12:47. 


\title{
II. THE NORTH AMERICAN SPECIES OF HAPLOPAPPUS
}

\author{
DIAGNOSES OF THE SECTIONS
}

Section 1. Osbertia Greene, Erythea $3: 14$, 1895, as genus. Perennial herbs, stoloniferous in one species. Herbage puberulent to densely pilose, glandular. Leaves entire or merely denticulate. Heads solitary, terminal. Involucre medium-sized to large, hemispheric; bracts not imbricated, of nearly equal length, very slender and acute, somewhat scarious, reddish. Ray-flowers present. Disk-corollas either abruptly or gradually dilated upward. Style-appendages ${ }^{1}$ ovate or lanceolate, acute, shorter than stigmatic portion. Achenes subcylindric or somewhat prismatic. Pappus fine and soft, brown to nearly white. Type species: $H$. stoloniferus DC. Inulopsis DC., Prodr. 5:349, 1836, as to first species only, the second being now the type of the genus Inulopsis Hoffm.

Section 2. Blepharodon DC., Prodr. 5:346, 1836, excluding species No. 9. Evergreen subshrubs and annual and biennial herbs. Herbage scabrid or puberulent to tomentulose, often also glandular. Leaves dentate or variously pinnatifid or lobed, each tooth or lobe ending in a bristle or short spine. Heads solitary or few and cymosely arranged. Involucre of medium size, broadly campanulate to broadly hemispheric; bracts regularly imbricated in several lengths, scarious at least on the margins or wholly green. Ray-flowers present or absent. Disk-corollas slightly enlarged above the tube or the throat somewhat prominent. Style-appendages either thick and shorter than stigmatic portion or slender and more elongated (in $H$.gymnocephalus and $H$. nuttalli). Achenes turbinate, short (densely villous or canescent). Pappus rigid or slender, scanty, brownish. Type species: $H$. gymnocephalus was first described by DeCandolle and is now selected as the type. Sideranthus Nutt. in Fraser's Cat. Nos. 80 and 81, 1813, as genus, nomen nudum, but see Britton in Bull. Torr. Club $27: 620$, 1900. Eriocarpum Nutt., Trans. Am. Phil. Soc. II, $7: 320,1840$, as genus. Eriocarpaea Benth. et Hook., Gen. Pl. 2:254, 1873.

Section 3. Prionopsis Gray, Pl. Wright. 1:98, 1852. Annual and biennial very leafy herbs. Herbage glabrous. Leaves dentate, the teeth spiny at tip. Heads in open cyme-like clusters or solitary. Involucre, large, broadly hemispheric; bracts closely imbricated, acuminate, more or less chartaceous. Ray-flowers present. Disk-corollas slightly and gradually ampliate upward. Style-branches linear-lanceolate, the acute appendage shorter than stigmatic portion. Achenes turgid-ellipsoid or narrower, glabrous. Pappus of few rigid bristles, some flattened near base, tardily deciduous (persistent in all other sections except Stenotopsis and Isopappus), reddish in age. Type species: $H$. ciliatus (Nutt.) DC. Leiachenium DC., Prodr. 5:346, 1836, as to first species only. (The section Leiachenium of DeCandolle is a very unnatural assemblage. Both Gay and Reiche have used the name for a section of South American species, including the

I In these diagnoses the style-branches and achenes referred to are those of the disk-flowers, and the arrangement of the heads is sometimes described as though this were an inflorescence, although strictly speaking the head is itself an inflorescence. 
second on DeCandolle's list (H. foliosus DC.), which may, therefore, be accepted as the type of Leiachenium, if this name is used.)

Section 4. Oonopsis Nutt., Trans. Am. Phil. Soc. II, $7: 335$, 1840, as section under Stenotus. Perennial herbs with deep taproot and somewhat woody caudex. Herbage glabrous or sparingly tomentulose. Leaves entire. Heads cymosely disposed or solitary, leafy-bracted. Involucre medium-sized, campanulate to hemispheric; bracts imbricated, abruptly acuminate, herbaceous or the inner ones chartaceous. Ray-flowers present or absent. Disk-corolla funnelform, the tube short. Style-appendages oblong, acute, shorter than stigmatic portion (rarely longer). Achenes subprismatic or slenderly turbinate, strigose to glabrous. Pappus rigid, scanty, brown. Type species: H. multicaulis (Nutt.) Gray.

Section 5. Pyrrocoma Hook., Fl. Bor. Am. 1:307, 1833, as genus. Perennial herbs with deep taproots. Herbage glabrous to tomentose, sometimes glandular. Leaves entire or merely sharp-dentate. Heads variously disposed. Involucre large or medium-sized, hemispheric or broadly campanulate; bracts varying from closely imbricated to nearly equal (in the same species), acute or obtuse, herbaceous or only the base and margins scarious or coriaceous. Ray-flowers present (rarely wanting). Diskcorollas slightly ampliate upward. Style-appendages acuminate to lanceolate, from shorter than to well exceeding stigmatic portion. Achenes tapering slightly from summit to base, often angled, pubescent or glabrous. Pappus rather scanty, fragile, light brown to reddish. Type species (of genus Pyrrocoma): H. carthamoides Hook. Pyrrocoma, section Eupyrrocoma DC., Prodr. 5:350, 1836, as to first species only. Homopappus Nutt., 1. c. 330,1840 , as genus. Arnicella Torr. et Gray, Fl. N. Am. $2: 241,1842$.

Section 6. Stenotopsis Rydb., Bull. Torr. Club 27:617, 1900, as genus. Large shrubs. Herbage glabrous or only scabrid or puberulous, resinous, impressed-punctate. Leaves entire. Heads long-peduncled, terminating cymosely arranged twigs. Involucre large, hemispheric; bracts little imbricated (in 2 or 3 series), acute, scarious or the middle portion herbaceous. Ray-flowers present, large. Disk-corollas gradually enlarged upward. Style-appendages oblong or lanceolate, acute, shorter than stigmatic portion. Achenes somewhat flattened, nearly linear, sericeous. Pappus fine, copious, permanently white, partly deciduous. Type species: H. linearifolius DC.

Section 7. Stenotus (Nutt.) Gray, Proc. Am. Acad. 7:353, 1868. Cespitose subshrubs with numerous short, crowded stems. Herbage glabrous to scabrid or tomentulose. Leaves entire. Heads solitary, terminal, the peduncles nearly naked. Involucre medium-sized, campanulate or hemispheric; bracts slightly imbricated, chartaceous or herbaceous, but at least the margins scarious. Ray-flowers always present. Disk-corollas slightly ampliate upward. Style-appendages acute or obtuse, shorter than or slightly exceeding stigmatic portion. Achenes somewhat compressed, tapering slightly to base, usually striate, densely villous to glabrous. Pappus soft, white. Type species: H. acaulis (Nutt.) Gray. Stenotus Nutt., Trans. Am. Phil. Soc. II, $7: 334,1840$, as genus.

Section 8. Tonestus Nels., Bot. Gaz. $37: 262$, 1904, as genus. Low leafy perennial herbs, some with rhizomes. Herbage puberulent, often glandular. Leaves entire or dentate. Heads solitary, terminal, the pe- 
duncles leafy-bracted. Involucre medium sized, nearly hemispheric; bracts not imbricated, mostly herbaceous. Ray-flowers present. Disk-corollas slender-fumnelform. Style-appendages thick, obtuse (very acute in $H$. aberrans), about equaling stigmatic portion. Achenes subcylindric, somewhat compressed, tapering slightly to base, often ribbed, pubescent. Pappus scanty, soft, sordid or nearly white. Type species: H. lyalli Gray.

Section 9. Macronema (Nutt.) Gray, l. c. 6:542, 1865. Subshrubs, never cespitose. Herbage viscid, glandular-pubescent or tomentose. Leaves entire (sometimes undulate). Heads variously arranged, the peduncles leafy-bracted. Involucre rather large, hemispheric or somewhat campanulate; bracts obscurely or not imbricated, mostly chartaceous, but at least the middle portion herbaceous. Ray-flowers either present or wanting. Disk-corollas funnelform. Style-appendages slender, acuminate, always much longer than stigmatic portion. Achenes compressed-prismatic, elongated, villous to nearly glabrous. Pappus fine, soft, copious, white or only sordid. Type species: H. suffruticosus (Nutt.) Gray. Macronema Nutt., l. c. 322,1840 , as genus.

Section 10. Oreochrysum Rydb., Bull. Torr. Club 33:152, 1906, as genus. Perennial leafy-stemmed herb with rootstocks. Herbage puberulent or glabrous. Leaves entire. Heads cymosely arranged. Involucre rather large, campanulate; bracts loosely or not imbricated, the outer herbaceous, the others chartaceous. Ray-flowers present. Disk-corollas gradually ampliate upward. Style-appendages slender, acute, about equaling stigmatic portion. Achenes subfusiform, angled and striate, chiefly glabrous. Pappus copious, soft, white. Type species: H. parryi Gray.

Section 11. Isopappus (Torr. et Gray) Benth. et Hook., Gen. Pl. 2:254, 1873. Slender annuals. Herbage scabrid and stipitate-glandular. Leaves entire to acutely dentate. Heads paniculately scattered. Involucre small, turbinate; bracts imbricated, linear-attenuate, green, the margins scarious. Ray-flowers present. Disk-corollas either abruptly or gradually enlarged above the tube. Style-appendages linear-acute, exceeding stigmatic portion. Achenes cylindric-turbinate or subprismatic, pubescent or glabrous. Pappus scanty, ferruginous, deciduous in one species. Type species: $H$. divaricatus (Nutt.) Gray. Isopappus Torr. et Gray, Fl. N. Am. 2:239, 1842 , as genus.

Section 12. Hesperodoria Greene, Leaflets $1: 173,1906$, as genus. Leafy-stemmed subshrubs. Herbage glabrous or only scabrid. Leaves entire, somewhat membranous. Heads glomerate, cymose-paniculate, or racemose. Involucre small, cylindric-turbinate; bracts well imbricated, oblong, chartaceous. Ray-flowers present or wanting. Disk-corollas with long tube gradually enlarged to a narrow throat. Style-appendages linear, much exceeding stigmatic portion. Achenes subcylindric, narrowed below, angled, sericeous. Pappus fine and soft, copious, white. Type species: H. scopulorum (Jones) Blake.

Section 13. Isocoma Nutt., Trans. Am. Phil. Soc. II, $7: 320$, 1840, as genus. Shrubs and subshrubs with soft wood. Herbage glabrous to tomentose, heavily resinous. Leaves entire to pinnatifid, thick. Heads glomerate in close cymes, these sometimes paniculately arranged. Involucre small, turbinate or obconic; bracts regularly and closely imbricated, coriaceous, hard, the tips sometimes greenish. Ray-flowers wanting. Disk- 
corollas with slender tube and abruptly dilated short throat. Styleappendages ovate, much shorter than stigmatic portion, scarcely exserted. Achenes subprismatic but tapering to base, densely villous. Pappus copious, coarse, brownish. Type species: $H$. venetus (HBK.) Blake. Haplodiscus DC., Prodr. 5:350, 1836, as section; not Haplodiscus Benth. et Hook., Gen. Pl. 2:254, 1873. DeCandolle's section included two species, the first being the one which includes (as a subspecies) the only form described by Nuttall under his genus I socoma, while the second is now referred to Baccharis. The name Isocoma is here taken up for the present section because, (1) it was the first name consistently applied to the group, (2) it avoids confusion with the later use of Haplodiscus, and (3) it has been universally used for the group when this has been treated as a distinct genus.

SEction 14. Hazardia Greene, Pittonia 1:28, 1887, as genus. Shrubs with soft wood. Herbage glabrous to tomentose, often resinous. Leaves entire or dentate, coriaceous. 'Heads cymose, racemose, paniculate, or solitary. Involucre medium-sized or rather large, turbinate to campanulate (sometimes approaching hemispheric); bracts closely imbricated in several series (loose in Haplopappus whitneyi), chartaceous or the tips herbaceous. Ray-flowers present or wanting, often turning brownish. Diskcorollas nearly cylindric, only slightly enlarged upward. Style-appendages subulate to lanceolate, mostly shorter than but sometimes exceeding stigmatic portion. Achenes subprismatic or fusiform, sometimes compressed, angled, striate, elongated, sericeous to glabrous. Pappus copious, rigid, brown or reddish. Type species: H. canus (Gray) Blake. Hazardia has a subgeneric name in Aplostephium Gray (Proc. Am. Acad. 11:75, 1876), under the genus Diplostephium. Greene later cited Aplostephium as though it were a section, but in speaking of the only species Gray (1. c. 76) said, "a subgeneric distinction may mark its peculiarities." The way is thus left clear for the transferral of the name Hazardia from generic to sectional rank.

Section 15. Ericameria (Nutt.) Gray, Pl. Wright. 2:80, 1853. Evergreen shrubs. Herbage glabrous or only puberulent, conspicuously dotted by resin-pits. Leaves entire (except in the doubtful $H$. vernicosus). Heads cymosely arranged or solitary, or the cymes themselves sometimes irregularly paniculate. Involucre small, narrowly to broadly turbinate (hemispheric only in vernal heads of $H$. pinifolius); bracts imbricated, chartaceous or coriaceous. Ray-flowers present (except sometimes in H. cooperi, $H$. sonoriensis, and $H$. cuneatus). Disk-corollas with throat gradually enlarged upward. Style-appendages filiform to oblong-subulate (oblongovate in E. cooperi), either shorter or longer than stigmatic portion. Achenes slender, subcylindric but tapering to base. Pappus fine and soft, dull white, becoming reddish. Type species (of genus Ericameria): $H$. ericoides (Less.) Hook. et Arn. Ericameria Nutt., Trans. Am. Phil. Soc. II, $7: 318,1840$, as genus. Haplopappus, section Ericameria (excluding last three species) and Bigelovia, section Euthamiopsis Gray, Syn. Fl. $1^{2}: 132$ and 141, 1884.

Section 16. Asiris Hall, Carnegie Inst. Wash. Yearbook 25:342, 1926. Evergreen shrubs of low stature. Herbage glabrous or puberulent or stipitate-glandular, devoid of resin-pits. Leaves entire. Heads cymosely arranged or solitary through reduction. Involucre small, obconic or tur- 
binate; bracts imbricated, chartaceous. Ray-flowers present (except in the doubtfully placed $H$. purpusi). Disk-corollas subcylindric, slender, gradually ampliate upward. Style-appendages subulate, always longer than stigmatic portion. Achenes nearly prismatic or subcylindric, tapering slightly to base. Pappus rather scanty, fragile, brownish. Type species: H. nanus (Nutt.) D. C. Eaton.

\section{PHYLOGENY AND STATUS OF THE SECTIONS}

The North American species of Haplopappus may be grouped into 16 sections of very unequal size (see fig. 2). All of these, except Asiris, have been given generic rank at one time or another, and this treatment is preferred even by some contemporary botanists. This assigns too high a taxonomic value to certain characters, such as habit (see p. 22), which furnishes almost the only basis for separation of some sections. If one adopts a middle course and treats as genera only those sections with several differentiating criteria, the expression of relationship between these units is destroyed and the picture of continuity in evolutionary development is obliterated. In other words, the residue could not be pieced together into a natural genus without reinserting these detached blocks. Possible exceptions are two or three small peripheral sections (Prionopsis, Isopappus) which apparently have made little if any contribution toward the development of the group as a whole.

The primary division into two series, one of ten sections, the other of six, is based upon a sense of relationships acquired through the comparative study of all the species involved, rather than upon a value assigned to the few characters which differentiate the series. Among critical students of the genus there will be little question as to the naturalness of this grouping. There may, however, be much difficulty as to application of the differentiating criteria to certain species. There is no doubt, for example, that Hazardia is a natural section; that it is more closely related to Isocoma than to any other, and that these two are not far removed from Asiris and Ericameria in a natural system; but some species of Hazardia have heads so broad that, without a knowledge of their connections with the others, they might be classed with the large-headed series. Shape of head, or more particularly shape of lower part of involucre, is believed, nevertheless, to furnish a clue to these natural groups. As shown under Criteria (p. 20), a narrowing of involucre is associated with reduction in number of flowers in the head. It is also accompanied by a development of imbrication among the bracts, but since imbrication has been attained also by a few species of the broad-headed series, it is not an infallible criterion. Degree of imbrication is exceedingly useful for determining relationships if taken in connection with other features; it is of only secondary value as a key character.

Section Osbertia is placed first in the linear sequence because of its apparently remote origin. It is directly traceable to no other group. Its generic separation, as proposed by Greene (Erythea 3:14, 1895), therefore would not disturb the phylogenetic arrangement of the sections of Haplopappus, but satisfactory differentiating characters are wanting. The broad heads, numerous flowers, and sometimes reddish ligules suggest 
that the section may be not far removed from the original stock of the genus, which position it seems to share with the next following group.

The chief interest in Blepharodon lies in its position between the other Haplopappi and outside genera. Especially notable is the occasional presence of a red pigment in the ligules, a character which, if applied arbitrarily, would throw such forms into the heterochromous group of the Astereae. It doubtless indicates an early connection with Aster or some similar genus and also with the South American Haplopappi, where reddish or purplish ligules occur in several of the species. This view is strengthened by the rather common phenomenon of reddish ligules in Mexican forms ( $H$. phyllocephalus primitivus, $H$. gymnocephalus), a trait which becomes increasingly rare toward the north. It is not constant for any one species. Other primitive features especially frequent in the section are the large heads with numerous flowers, the preponderance of short, poorly developed stylebranches, and the tendency toward flattened pappus-bristles, the last suggestive of a connection with Grindelia and related genera. There is a notable absence of those features associated with the more highly specialized sections.

Blepharodon is a decided deterrent to the breaking up of Haplopappus into distinct genera. Those who follow this procedure ascribe much importance to matters of habit; but although this section embraces such diverse forms as annual and biennial herbs, herbaceous and suffrutescent perennials, and even shrubs, its homogeneity has never been doubted. When treated as a genus by itself it takes the name Eriocarpum, or, less properly, Sideranthus.

The uncertain position of Prionopsis and its possible connection with Grindelia have been taken up in discussing the phylogeny of the genus.

Oonopsis is very weak, even as a section. Its separation from Pyrrocoma rests on its leafy-bracted heads and abruptly attenuate bracts. These characters will separate it from most Pyrrocomas, but the type species of the latter (carthamoides) often has one or several upper leaves subtending the head and the bracts are frequently so acuminate as closely to simulate those of Oonopsis. This is particularly true of minor variation 5, which might well be an undescribed species of this section but connects with undoubted carthamoides. If the latter can not be kept out of Oonopsis, the two sections should be united under Pyrrocoma, this being the older name. Phylogenetically, Oonopsis branches off from Pyrrocoma near its base, that is, from near carthamoides, as is indicated not only by habit and involucre but also by the short style-appendages.

Pyrrocoma embraces some of the most highly developed species of the genus. It is undoubtedly the end of an important phylogenetic branch. Beginning with species remarkable for their large heads, each with numerous flowers, the section undergoes a decided reduction in size of head and number of flowers before the last species is reached. An erratic but marked development of stylar appendages, which is perhaps always a sign of advance, is also noted as one passes from the lower to the higher species. The latter are decidedly polymorphous and their characters unite in so many combinations that these can not be accounted for by any practicable system of classification. The development of Pyrrocoma, especially its adoption of the habit of a perennial herb, has been associated with its 
LESITY

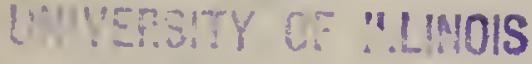




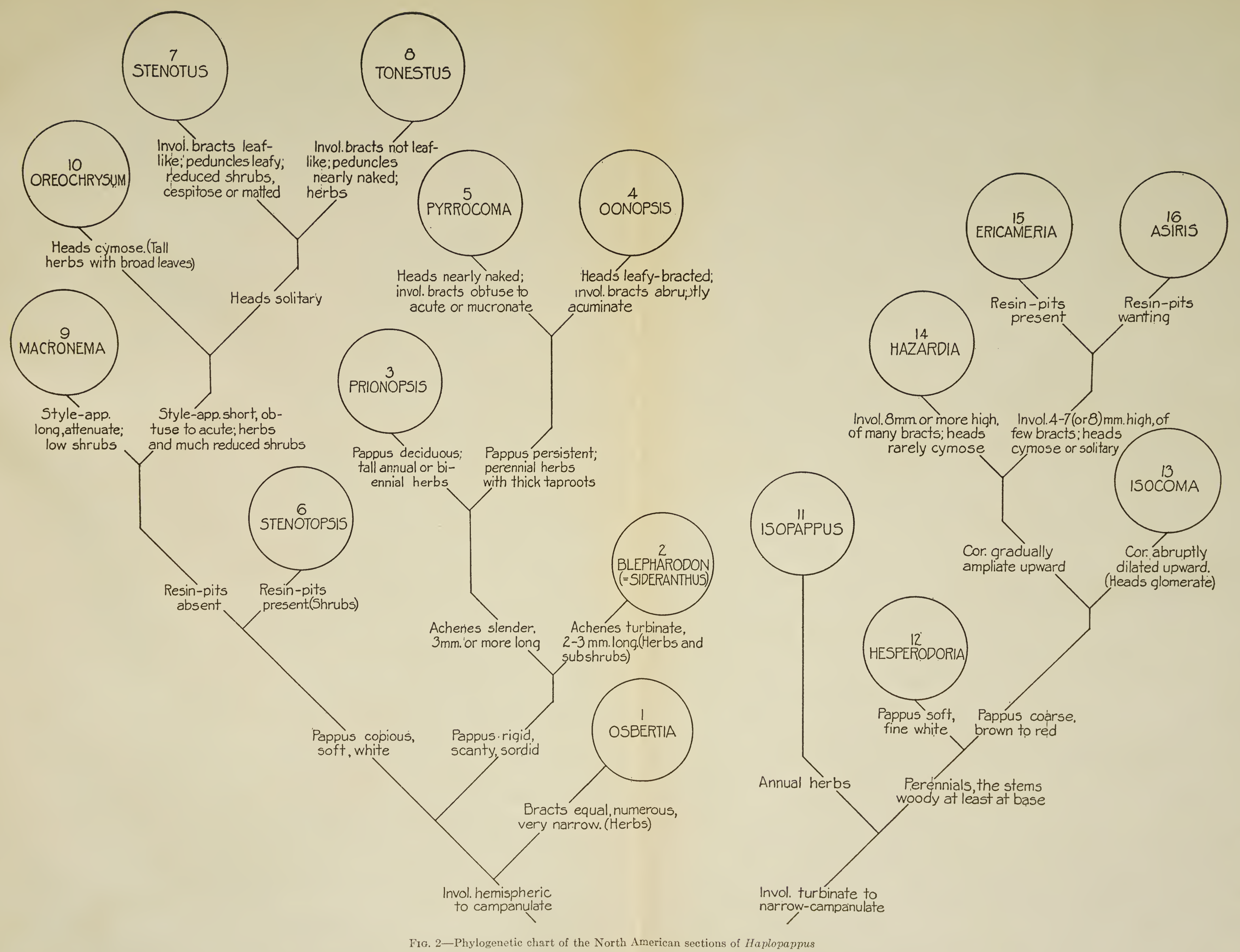


occupancy of moist habitats in northerly or mountainous districts. As contrasted with this, the more primitive Blepharodons, of the south, have retained the xerophytic habit of shrubs and annual herbs.

Notwithstanding its name, Stenotopsis has no direct connection with Stenotus, nor with any other section. The decidedly shrubby habit and pitted leaves suggest a remote relationship with Ericameria, which, however, has proceeded far in reduction of number of flowers and in imbrication of bracts in the narrowed involucres.

The sections Stenotus, Tonestus, and Macronema form an almost continuous series. The first exhibits a marked reduction from the shrubby habit without, however, becoming true herbs. Its species are inhabitants of arid and often alkaline districts, to which they are adapted especially because of the reduced habit and long taproot. A connection with Tonestus is suggested by certain species with more leafy stems and short or even obtuse style-branches ( $H$. lanuginosus, $H$. stenophyllus). This latter section connects, on the other hand, with Macronema, but through development of its own peculiarities, notably an herbaceous habit, it has produced a divergent phylogenetic branch. Possible connections will be specifically referred to in discussing the relationships of $H$. lyalli (p. 179) and $H$. aberrans (p. 186).

In the section Macronema the style-appendages reach their maximum development. Because of this, the section is placed at the apex of its phylum. It is to be noted, however, that other sections have progressed farther in certain features, as, for example, the assumption of an herbaceous habit by Pyrrocoma, and the development of rootstocks in some species of Tonestus and in Oreochrysum. The single species of Oreochrysum differs so markedly in habit from any other member of the genus occurring in its region that its inclusion has sometimes been questioned. It was referred to Solidago by Greene (Erythea 2:57, 1894) and it is true that the leaves sometimes simulate those of certain species of this genus, but the involucre is of an entirely different type, being broad, with oblong, mostly herbaceous bracts, these scarcely imbricated and in but few series. The white pappus, especially noted as similar to that of the golden-rods, is duplicated in many other species of Haplopappus (especially in sections Stenotus, Stenotopsis, and Hesperodoria).

At the beginning of the series with narrow, few-flowered, and mostly imbricated involucres is placed one of those small sections which could drop out of the genus without deranging the phylogenetic plan. This is Isopappus, a section so different from the others that probably its relationships never will be understood. Possibly its former connections were with the other series or with the South American group. Because of these doubts, it is given an independent line from near the base of the chart. Section Hesperodoria is much more closely associated with the other sections, especially with Isocoma, as will be noted in considering the relationships of H. scopulorum (p. 219). But it is easily separable from all Isocomas on the basis of its long and linear style-appendages, the gradually tapering corollas, and the soft, white pappus. Possibly it represents the original stock of Isocoma and for this reason its taxonomic treatment as a distinct genus would be unfortunate. 
The four remaining sections divide naturally into pairs. Isocoma and Hazardia have much in common. Both are soft-woody but not herbaceous perennials and both had their origin in the Mexican region, from which they reached out toward the coast of upper California, changing and adapting their characters in the process. Isocoma has proceeded the farther in reduction of heads, in bringing these into glomerules, and in the production of multitudinous forms adapted to an equally great number of habitats (see especially under $H$. venetus). Hazardia, which should perhaps precede Isocoma, includes some species which closely simulate certain ones of South America, but there is no evidence of a direct connection. As a section it is easily recognized by field students, but an attempt to find constant features for its characterization leads only to exasperation. The heads are large and full but always narrow at base; the bracts of the usually wellimbricated involucre are often outwardly curved at tip or even squarrose; the ray-flowers (when present) commonly turn brown or saffron in age, and the pappus is predominantly reddish. It is the combination of these tendencies which best marks the group, for there are exceptions to all of them.

The significance of the principal character used for the separation of Asiris from Ericameria has been discussed under Criteria (p. 21). Taken together, these sections are recognized by a similarity in their compact, shrubby habit, usually narrow leaves, and copious production of resins, all indicative of a marked adaptation to an arid climate. These shrubs are, in fact, pronounced xerophytes of western deserts, sagebrush plains, and dry, coastal chaparral. A technical character of much importance is the cyme-like disposal of the heads. This reduction from a more copiously and irregularly branched arrangement, a reduction which sometimes leaves the heads solitary, is a mark of advance, as also is the reduction in number of flowers within the heads themselves. Such features, together with the well-developed style-appendages, imbricated involucres, etc., have led to the placing of these two sections at the apex of the second series of North American Haplopappi.

\section{KEY TO THE NORTH AMERICAN SECTIONS OF HAPLOPAPPUS}

a. Involucre campanulate to broadly hemispheric; its bracts mostly without imbrication or loosely imbricated, but regularly imbricated in some species (especially in Blepharodon and Pyrrocoma), mostly herbaceous, at least in the middle, but often scarious, and sometimes coriaceous or chartaceous throughout.

$b$. Bracts of the involucre nearly equal in length and width, very slender and acuminate, numerous. (Perennial herbs.) Sect. 1. Osbertia (p. 42)

$b$. Bracts of the involucre more or less unequal, or if nearly equal then not slender and acuminate, less numerous.

c. Achenes turbinate, 2 to $3 \mathrm{~mm}$. long; leaves dentate to bipinnatifid, the teeth spinulose-tipped or bristle-tipped, 
or leaves sometimes nearly entire.

(Herbs and shrubs).............

c. Achenes nearly prismatic, subcylindric, or fusiform (approaching turbinate in Oonopsis), $3 \mathrm{~mm}$. or more long (occasionally less in Pyrrocoma?); leaves various (but spinulosedentate only in Prionopsis, rarely also in Pyrrocoma).

d. Pappus of comparatively few rigid bristles, sordid or brownish.

e. Pappus deciduous, more or less in a ring; tall annual and biennial herbs with spiny-dentate leaves........... Sect. 3. Prionopsis (p. 43)

e. Pappus persistent; perennial herbs (slightly woody at base in Oonopsis), with thick taproots.

f. Heads subtended by numerous upper leaves, these scarcely reduced in size; involucral bracts abruptly acuminate................. Sect. 4. Oonopsis (p. 43)

$f$. Heads naked or on few-bracted peduncles (subtended by several leafy bracts in forms of carthamoides); involucral bracts obtuse, acute, or mucronate................. Sect. 5. Pyrrocoma (p. 43)

d. Pappus copious, soft, white (sometimes becoming sordid or pale brown, only moderately copious in T'onestus).

g. Herbage dotted with conspicuous resinpits; large or medium-sized shrubs (unless depauperate)........... Sect. 6. Stenotopsis (p. 44)

g. Herbage devoid of resin-pits; low shrubs and herbs.

h. Heads on nearly naked peduncles, solitary, involucre of firm close bracts, these sometimes herbaceous but never leaf-like. (Cespitose or matted low shrubs; style-appendages thick, mostly obtuse.)..... Sect. 7. Stenotus (p. 44)

$h$. Heads on leafy peduncles or in leafybracted inflorescences; involucre of loose bracts, these often leaflike (except Oreochrysum).

$i$. Narrow-leaved herbs and shrubs (leaves less than $15 \mathrm{~mm}$. wide); heads not regularly cymose (irregularly cymose in one shrubby species).

$j$. Herbs with a caudex or with rootstocks; style-branches thick and obtuse (except in aberrans)..... Sect. 8. Tonestus (p. 44)

$j$. Low shrubs; style-branches very slender, acuminate........... Sect. 9. Macronema (p. 45)

$i$. Broad-leaved tall herb (leaves over $15 \mathrm{~mm}$. wide); heads regularly cymose............... Sect. 10. Oreochrysum (p. 45)

a. Involucre turbinate or subcylindric to narrow-campanulate; its bracts imbricated in several lengths, chartaceous or coriaceous, except sometimes the middle portion or tip, which may be herbaceous. 
$k$. Root annual; stems not at all woody. (Slender herbs with narrow radiate heads in loose panicles; style-appendages very long and slender.).... Sect. 11. Isopappus (p. 45)

$k$. Root perennial; stems woody at least at base.

l. Pappus fine and soft, white. (Leaves all entire, none fascicled in the axils; styleappendages slender, much elongated.).................. Sect. 12. HesperodoriA

l. Pappus of coarse brown to reddish bristles.

$m$. Disk-corolla ventricose, $i$. e., with slender tube abruptly dilated to a much broader throat. (Heads discoid; involucre closely imbricated.)... Sect. 13. Isocoma (p. 45)

$m$. Disk-corolla gradually ampliate upward.

$n$. Involucre large, $8 \mathrm{~mm}$. or more high, its numerous bracts closely imbricated in 6 or more lengths (only 4 or 5 lengths but involucre $12 \mathrm{~mm}$. high in whitneyi); heads spicate or paniculate, or solitary through reduction (cymose only in canus, recognized by its tomentum.)... Sect. 14. Hazardia (p. 46)

$n$. Involucre small, 4 to 7 or $8 \mathrm{~mm}$. high, its comparatively few bracts loosely imbricated in 3 to 5 lengths; heads cymose-paniculate, or solitary through reduction.

o. Leaves and twigs with distinct resin-pits. Sect. 15. Ericameria (p. 46)

$o$. Leaves and twigs without pits......... Sect. 16. Asiris (p. 47)

\section{KEY TO THE NORTH AMERICAN SPECIES OF HAPLOPAPPUS}

\section{SeCtion 1. OSBERTIA}

Plants with stolons; involucre 12 to $15 \mathrm{~mm}$. high; ligules of ray-flowers 12 to $15 \mathrm{~mm}$. long. Tropical America.............

Plants without stolons; involucre 6 to $8 \mathrm{~mm}$. high; ligules 1. H. stoloniferus (p. 48) of ray-flowers 6 to $9 \mathrm{~mm}$. long. Northwest America..........

2. H. brandegei. (p. 51)

\section{SECTION 2. BLEPHARODON}

Root annual or at most biennial.

Disk-pappus about equaling the corolla; corolla (including lobes) 4.5 to $7 \mathrm{~mm}$. long (shorter only in dwarfs of gracilis); leaves various.

Plant robust, usually more than $2 \mathrm{dm}$. high (except dwarfs); principal leaves 4 to 12 $\mathrm{mm}$. wide; heads large, the ligules 9 to $14 \mathrm{~mm}$. long, ${ }^{1}$ yellow or reddish....................

Plant slender, rarely $2 \mathrm{dm}$. high; principal leaves 1 to $4 \mathrm{~mm}$. wide; heads small, the ligules 6 to $8 \mathrm{~mm}$. long, yellow:

Bracts of the involucre rigidly acuminate, closely imbricated in 5 or 6 lengths.... 4. H. gracilis (p. 62)

1 Only fresh or boiled flowers are used for this measurement, which extends from the orifice to the tip of the ligule. 
Bracts of the involucre obtuse or acutish, loosely imbricated in 3 or 4 lengths.....

Disk-pappus much shorter than the corolla; corolla 3.5 to $4.5 \mathrm{~mm}$. long; leaves pinnately parted into linear lobes...

Root perennial and stems more or less woody, at least at base.

Style-appendage much longer than the stigmatic portion; ${ }^{1}$ leaves only dentate to serrate, not lobed.

Heads radiate, the ligules roseate. (Mexico-New Mexico)..................

Heads discoid. (New Mexico to Canada.)....... Style-appendage equaling or shorter than the stigmatic portion; leaves dentate serrate or lobed.

Heads radiate, the ligules yellow (very rarely roseate); subshrubs.

Leaves thick, obtusely dentate to nearly entire; bracts of the involucre strongly squarrose................

Leaves thinner, rigid, spinulose-dentate to pin-

5. H. aureus (p. 64)

6. H. stenolobus (p. 65)
7. H. gymnocephalus (p. 66)

8. H. nuttalli (p. 69)

9. H. arenarius (p. 71) natifid; bracts of the involucre erect or more or less spreading (especially in age), rarely squarrose.

Stems leafy, at least up to the peduncles.... 10. H. spinulosus (p. 72)

Stems nearly leafless, the leaves reduced and remote (the upper ones $5 \mathrm{~mm}$. or less long, scale-like).......... 11. H. junceus (p. 81)

Heads discoid; tall shrub................. 12. H. brickellioides (p. 83)

\section{SECTION 3. PRIONOPSIS}

A single species.................... 13. H. ciliatus (p. 84)

\section{SECTION 4. OONOPSIS}

Heads large; involucre broad-campanulate, 12 to $20 \mathrm{~mm}$.

high; leares 4 to $15 \mathrm{~mm}$. wide... 14. $H$. fremonti (p. 86)

Heads small; involucre turbinate-campanulate, 7 to 10 $\mathrm{mm}$. high; leaves 2 to $5 \mathrm{~mm}$. wide.

Heads few and long-peduncled; ray-flowers present; achenes strigose............ 15. H. multicaulis (p. 91)

Heads cymose-glomerate; ray-flowers wanting; achenes glabrous................... 16. H. engelmanni (p. 93)

\section{SECTION 5. PYRROCOMA}

Heads large; involucre 12 to $18 \mathrm{~mm}$. high (10 to $13 \mathrm{~mm}$. in integrifolius liatriformis); diskcorolla 7 to 11 or $13 \mathrm{~mm}$. long; style-appendages mostly shorter than the stigmatic portion (except in carthamoides and one subspecies of integrifolius).

Bracts of the involucre obtuse.

17. H. croceus (p. 97)

Bracts of the involucre acute.

Ligules short, the heads apparently discoid.

18. H. carthamoides (p. 101)

Ligules elongated, much exceeding the disk.

Bracts herbaceous to the base, abruptly acute... 19. H. clementis (p. 107)

Bracts cartilaginous at base, gradually acute... 20. H. integrifolius (p. 109)

' See exception under a dwarf form (minor variation 3 ) of $H$. nuttalli. 
Heads medium-sized; involucre 5 to $10 \mathrm{~mm}$. high (or rarely $12 \mathrm{~mm}$.); disk-corolla 5 to $7 \mathrm{~mm}$. long; style-appendages almost always longer than the stigmatic portion.

Inflorescence ${ }^{1}$ corymbiform, or reduced to a single head in small plants; achenes always pubescent................

Inflorescence ${ }^{1}$ racemose, or the heads mostly solitary in some species; achenes either pubescent or glabrous.

Bracts of the involucre distinctly graduate in 2 or 3 series or subequal and the achenes glabrous (subequal also in forms of racemosus with several heads).

Herbage glandular or viscid, especially the inflorescence..................

21. H. lanceolatus (p. 114)

Herbage not glandular.

Heads several to many, or reduced to one in some plants (these with pubescent achenes or connecting through subsp. prionophyllus with next species) ................

Heads solitary, terminal. (Stems $3 \mathrm{dm}$. or less high; achenes glabrous. High

Sierra Nevada).............24. H. apargioides (p. 144)

Bracts of the involucre subequal and achenes pubescent. (Heads solitary or few.)

Leaves lanceolate; bracts acute or cuspidate... 25. H. uniflorus (p. 147)

Leaves oblanceolate; bracts acuminate.......26. H. contractus (p. 155)

\section{SECTION 6. STENOTOPSIS}

Involucre 8 to $13 \mathrm{~mm}$. high, its bracts white-chartaceous 27 . H. linearifolius (p. 156) Involucre 3.5 to $4.5 \mathrm{~mm}$. high, its bracts green except at margins and base........... 28. H. parrasanus (p. 160)

\section{SECTION 7. STENOTUS}

Involucral bracts in 3 series; style-branches 2.5 to $4 \mathrm{~mm}$. long, nearly acute.

Bracts very obtuse, imbricated, the outer regularly shorter................ 29. H. armerioides (p. 162)

Bracts acute, not imbricated, the outer not regularly shorter................... 30. H. acaulis (p. 164)

Involucral bracts in 2 series; style-branches 2 to $2.7 \mathrm{~mm}$. long, the appendage thick and very obtuse.

Leaves 2 to $6 \mathrm{~mm}$. wide (rarely only $1 \mathrm{~mm}$.), soft... 31. H. lanuginosus (p. 171) Leaves 0.3 to $0.7 \mathrm{~mm}$. wide, rigid.

Leaves pubescent on both faces; disk-corollas 6 to 7 $\mathrm{mm}$. long................... 32. H. stenophyllus (p. 174)

Leaves glabrous except for the ciliate margins; diskcorollas 7 to $8 \mathrm{~mm}$. long....... 33. H. macleani (p. 176)

\section{SECTION 8. TONESTUS}

Ray-flowers present; style-branches obtuse or merely acutish.

1 Throughout this key the term inflorescence is used to indicate the assemblage of heads. Strictly speaking, each head is an inflorescence in itself. 
Plants with well-developed rootstocks; herbage minutely glandular.

Bracts of the involucre lanceolate, acute or acuminate; leaves entire or sparsely denticulate.............. 34. H. lyalli (p. 177)

Bracts of the involucre oblong to obovate, obtuse; leaves coarsely dentate........35. H. eximius (p. 181)

Plants without rootstocks; herbage not glandular... 36. H. pygmaeus (p. 183) Ray-flowers wanting; style-branches very acute. (Leaves dentate) ................ 37. H. aberrans (p. 185)

\section{SECTION 9. MACRONEMA}

Twigs thinly if a tall tomentose; ray-flowers usually present.

Heads large, 20- to 40-flowered; involucre not imbricated...................

Heads smaller, 6- to 23-flowered; involucre more or 38. H. suffruticosus (p. 187) less imbricated.

Involucral bracts (except the inner) mostly green and herbaceous, the outer ones even foliaceous; leaves 3 to $7 \mathrm{~mm}$. wide; heads cymose or shortracemose; involucre 12 to $15 \mathrm{~mm}$. broad................. 39. H. greenei (p. 193)

Involucral bracts chartaceous, only the tips green (a few outer sometimes green to base), the margins thin and eroseciliate, the fine tips usually spreading; leaves 0.5 to $4 \mathrm{~mm}$. wide; heads racemose or cymose; involucre 10 to $12 \mathrm{~mm}$. broad.... 40. H. bloomeri (p. 196)

Twigs closely tomentose; ray-flowers uniformly wanting 41. H. macronema (p. 204)

\section{SECTION 10. OREOCHRYSUM}

A single species.

42. H. parryi (p, 208)

\section{SECTION 11. ISOPAPPUS}

Involucre 5 to $7 \mathrm{~mm}$. high, its bracts reflexed in age; rayachenes subcylindric, $2.5 \mathrm{~mm}$. or less long; pappus-bristles numerous, persistent.............

Involucre 8 to $10 \mathrm{~mm}$. high, its bracts permanently erect; 43. H. divaricatus (p. 212) ray-achenes triangular, 3.5 to 4 $\mathrm{mm}$. long; pappus-bristles few, deciduous.................

44. H. occidentalis (p. 214)

\section{SECTION 12. HESPERODORIA}

Heads discoid 45. H. scopulorum (p. 218)

Heads radiate... 46. H. halli (p. 221)

\section{SECTION 13. ISOCOMA}

Principal leaves with smaller fascicled ones in the axils. Corolla-lobes ovate, 0.5 to $1 \mathrm{~mm}$. long; involucre 5 to $8 \mathrm{~mm}$. high. (California to southern Mexico.)

Involucral bracts with greenish but thin tips; stems pale brown or darker..........47. H. venetus (p. 223)

Involucral bracts with conspicuous thickened subepidermal gland, or resin-pocket, 
near tip (this almost wart-like on drying); stems white and shining.

(Desert species)........... 48. H. acradenius (p. 232)

Corolla-lobes lanceolate or linear-lanceolate, $1 \mathrm{~mm}$. or more long; involucre 4 to 5.5 $\mathrm{mm}$. high.

Leaves lobed or parted, the lobes usually linear; outer bracts with conspicuous dark tips............... 49. H. hartwegi (p. 235)

Leaves entire or only dentate; involucral bracts without conspicuous spot at apex 50. H. pluriflorus (p. 237) Principal leaves without secondary fascicled ones in the axils. (Leaves narrow, mostly entire; involucre 6 to $8 \mathrm{~mm}$. high. From Arizona eastward.)...... 51. H.drummondi (p. 240)

\section{Section 14. HAZARDIA}

Leaves heavily tomentose, at least beneath. (Insular shrub with broad heads.)...... 52. H. canus (p. 243)

Leaves not tomentose.

Shrubs, more or less woody for some distance above the base; involucre closely imbricated, the bracts in 6 to 8 lengths, acute or obtuse.

Ray-flowers present. (Lower California.)

Leaves strongly serrate; involucre turbinatecampanulate 12 to $18 \mathrm{~mm}$. high. 53. H. berberidis (p. 245)

Leaves entire or only the lower with a few teeth; involucre obconic, 7 to $9 \mathrm{~mm}$. high.................. 54. H. orcutti (p. 248)

Ray-flowers wanting. (Leaves serrate)........ 55. H. squarrosus (p. 249) Herb, only the base suffrutescent; involucre loosely imbricated, the bracts in 4 or 5 lengths, very acute. (Sierra Nevada and northern California).. 56. H. whitneyi (p. 255)

\section{SECTION 15. ERICAMERIA}

Inflorescence paniculate or racemose-paniculate, or the heads solitary.

Ray-flowers present.

Heads solitary; disk-flowers 20 to 25 ; corolla-lobes erect..................57. H. eastwoodae (p. 258)

Heads paniculate or subracemose (except the abnormal vernal heads of No. 58); disk-flowers 5 to 20 ; corollalobes spreading.

Achenes glabrous or at most only puberulent near summit; outer involucral bracts acute.

Leaves mostly 1.5 to $3.5 \mathrm{~cm}$. long; ray-flowers 5 to 10 ; disk-flowers 12 to 18 ; achenes puberulent at top..... 58. H. pinifolius (p. 260)

Leaves mostly 0.5 to $1.2 \mathrm{~cm}$. long; ray-flowers 2 to 5 ; disk-flowers 8 to 12 ; achenes perfectly glabrous..... 59. H. ericoides (p. 262)

Achenes densely villous; outer involucral bracts more or less obtuse.........60. H. palmeri (p. 265)

(H. laricifolius, of Arizona to Texas, might be sought here when the heads are irregularly cymose.) 
Ray-flowers wanting.

Heads few, large; receptacle naked; involucre 4 to 6 $\mathrm{mm}$. broad, of 16 to 22 bracts;

flowers about 10 to $12 \ldots \ldots$...61. H. propinquus (p. 269)

Heads numerous, small, receptacle chaffy; involucre 2 to $2.5 \mathrm{~mm}$. broad, of 8 to 12 bracts; flowers about 4 to $6 \ldots 62$. H. sonoriensis (p. 271)

Inflorescence regularly cymose.

Leaves filiform to linear or oblanceolate.

Ray-flowers present in at least a portion of the heads.

Involucral bracts 12 to 20 , firmly imbricated; disk-flowers 9 to 13 ; style-appendages linear-filiform............

Involucral bracts 10 to 12 , rarely to 14 , very loose

63. H. laricifolius (p. 273) in age; disk-flowers 6 to 9 ; styleappendages ovate to linear-lance-

Ray-flowers none. olate..................6.64. H. cooperi (p. 275)

Leaves broadly linear to oblong or oblanceolate; flowers 9 to $12 \ldots \ldots \ldots \ldots$....65. H. parishi (p. 280)

Leaves filiform or narrowly linear, $2 \mathrm{~mm}$. or less wide; flowers 20 to $25 \ldots \ldots$...66. H. arborescens (p. 281)

Leaves obovate or spatulate.

Leaves entire or only undulate, the apex obtuse or retuse..............67. H. cuneatus (p. 284)

Leaves sharply dentate, acute.............6. 68. H. vernicosus (p. 286)

\section{SECTION 16. ASIRIS}

Leaves not spinose; achenes 4 to $5.5 \mathrm{~mm}$. long.

Herbage densely stipitate-glandular, the glands terminating short or long hairs.

Disk-flowers about 20 to 25 ; involucre with a few of the outer bracts elongated and herbaceous...............69. H. watsoni (p. 288)

Disk-flowers about 10 to 15 ; involucre of chartaceous imbricated bracts....... 70. H. rydbergi (p. 290)

Herbage not stipitate-glandular, but of ten roughened by the resinous exudate.

Disk-flowers 4 to 11 (or perhaps 15 in cervinus), the lobes less than $1 \mathrm{~mm}$. long.

Leaves oblanceolate, 2 to $5 \mathrm{~mm}$. wide........71. H. cervinus (p. 292)

Leaves linear or linear-spatulate, 0.5 to $1.5 \mathrm{~mm}$. wide.................. 72. H. namus (p. 294)

Disk-flowers 11 to 16 , the lobes 1 to $2 \mathrm{~mm}$. long... 73. H. resinosus (p. 296) Leaves spinose; achenes about $2.5 \mathrm{~mm}$. long........ 74. H. purpusi (p. 299) 


\section{SECTION 1. OSBERTIA}

\section{PHYLOGENY OF THE SPECIES}

This section includes but two species, both inhabitants of high volcanic peaks, but one is restricted to southern Mexico and Guatemala, the other to northwest America. The similarities in structure are not the result of environment acting upon forms of wide evolutionary divergence, as is indicated by their deep-seated nature. They have to do, for example, with such fundamental features as shape of style-branches, relative lengths of stigma and appendage, and arrangement of the bracts of the involucre. The habit, too, is similar, although the northern species (brandegei) is much reduced in size, more compact, and lacks the stolons of the southern one (stoloniferus). It seems that both are relicts of a group once much more abundant in species and of general distribution in the ancestral home of the genus. In the course of the numerous migrations since those times, and which were associated with climatic changes, one of these relicts became stranded upon the volcanic peaks of tropical America, the other upon extinct volcanoes of the Northwest, where it found somewhat similar conditions.

The broad heads with numerous equal bracts and numerous flowers in both ray and disk, as well as the very short style-branches, suggest that Osbertia represents the original Haplopappus stock and that it is not far removed from Erigeron and Aster. This basal position has been considered in discussing the phylogeny of the sections (p. 37).

\section{Haplopappus stoloniferus DC., Prodr. 5:349, 1836}

A perennial herb, typically 2 to $6 \mathrm{dm}$. high but only 0.5 to $1.5 \mathrm{dm}$. in dwarf forms (minor variations 3,4 , and 9), with slender stolons which bear small leaves and strike root from some of the nodes, thus producing new plants; stems several, mostly erect or ascending but weak and often more or less curved, thick, finely striate, at first green but soon brown or reddish, densely and minutely glandular, also roughish with a short spreading pubescence or sparsely pilose; leaves chiefly basal, these narrowly to broadly elliptic or slightly broader above middle and then obovate or oblanceolate, short-petioled, entire or sparsely low-denticulate, obtuse but often mucronate, the blade 3 to $7 \mathrm{~cm}$. long, 10 to $20 \mathrm{~mm}$. wide (much smaller in dwarf forms), with strong midrib and faint anastomosing veins, short-pilose to densely short-hirsute (as in the types) or scarcely puberulent but minutely glandular (in var. glabratus Coult.); cauline leaves similar but sessile, more or less reduced, lanceolate rather than elliptic, sometimes acute and with a few obscure dentations, more glandular; heads solitary, terminating the long scapelike stems the upper part of which is naked or minutely bracteate; involucre broadly hemispheric, 12 to $15 \mathrm{~mm}$. high, 15 to $25 \mathrm{~mm}$. broad; bracts very numerous, nearly equal, longer than disk, linear-attenuate, the tips very slender and tail-like, scarious and reddish, especially tips, densely white-villous and glandular; ray-flowers 
from about 50 to 120 , the yellow or rarely reddish ligules 12 to $15 \mathrm{~mm}$. long, 2 or $3 \mathrm{~mm}$. wide; disk-flowers numerous; disk-corolla with narrow tube abruptly enlarged to a longer throat, the whole 5 to $6 \mathrm{~mm}$. long, glabrous; lobes lanceolate, acute, about $1 \mathrm{~mm}$. long, glabrous; style-branches well exserted, 1.3 to nearly $2 \mathrm{~mm}$. long, the lanceolate acute appendage shorter than stigmatic portion; achenes subcylindric, tapering to base, short (immature), apparently striate or perhaps 4-angled, densely villous; disk-pappus about as long as the corolla, moderately copious, fine and soft, brown. (Fig. 3.)

At high altitudes in southern Mexico and Guatemala. Type locality, near the summit of Mount San Felipe, Mexico. Mexico: type, Andrieux 322 (DC); Nevada de Toluca, State of Mexico, Pringle 4239 (Field Mus, Gr, P, B, K, UC, US, type collection of Erigeron heleniastrum, minor variation 2 , but also including some plants of $H$. stoloniferus puberus, minor variation 6); Ixtaccihuatl, near timber-line, October 1905, Purpus (UC); Sierra de Pachuca, Hidalgo, Pringle 9847 (Field, B, K, US); Orizaba Peak, Vera Cruz, Galeotti 2168, and Linden 493 (K); near Reyes, Oaxaca, Nelson 1738 (Gr, US); State of Orizaba, Liebmann

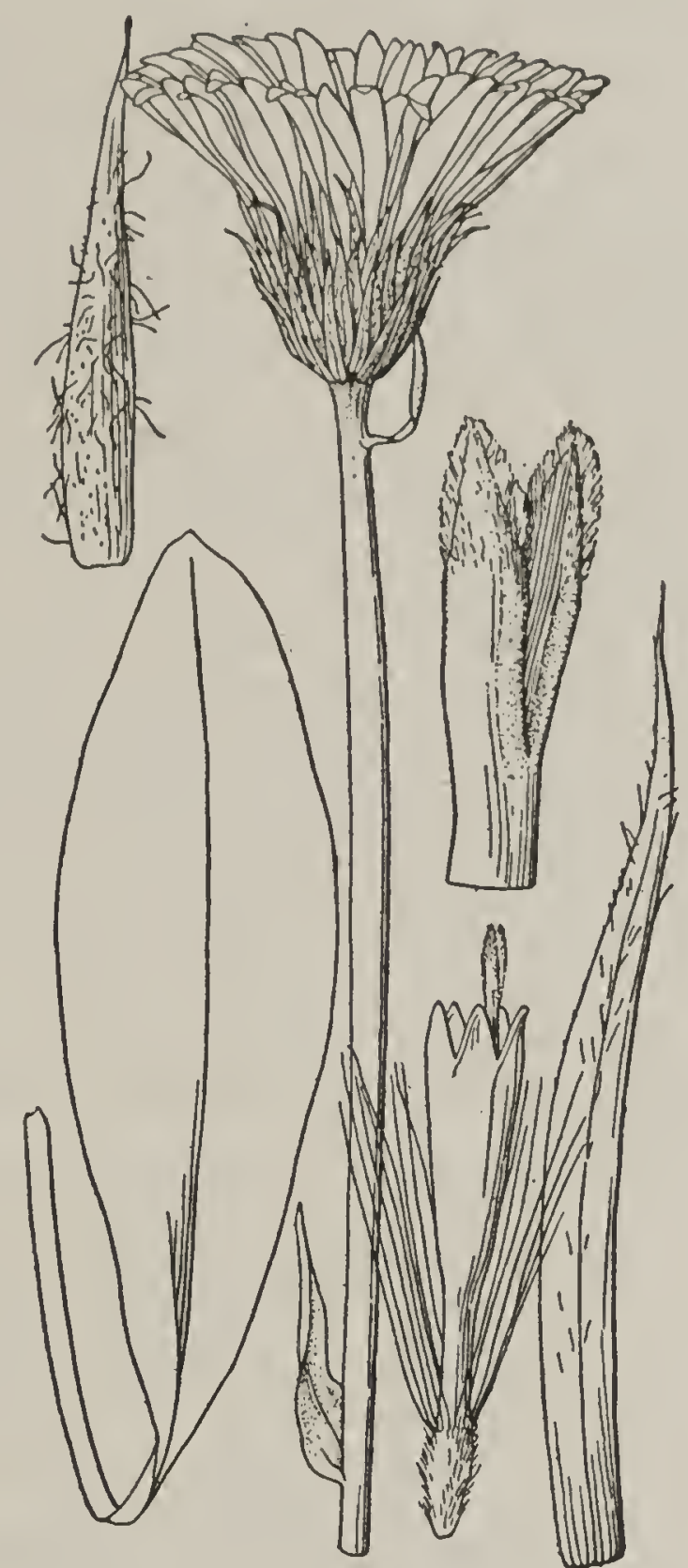

FIG. 3-Haplopappus stoloniferus 493 (P); "De Pápalo á la Cumbre de Cheve," Gonzales and Conzatti 778 (Gr); no definite locality but from Mexico, 1831, Alaman (DC, type of var. puberus, minor variation 6). Guatemala: Volcan de Agua, Smith 2328 (Field, B, K, US, a dwarf, sparsely pubescent form, type of var. glabratus, minor variation 4); same locality, in the crater, Hartweg 591 (P, B, same variation, sometimes erroneously labeled as from Mexico); Volcan de Acatenango, Shannon (Field, same variation); summit of Volcano Atitlan, Kellerman 5348 (Field, similar variation); Volcan de Fuego, 1873-74, Salvin (B, a dwarf but very pubescent form, minor variation 3 ).

\section{MINOR VARIATIONS AND SYNONYMS}

The forms included under the foregoing description of Haplopappus stoloniferus are of such a nature that several natural subspecies seem to be involved. It is probable that a satisfactory phylogenetic classification might be worked out through a correlation of the forms with their geographic distribution, but to undertake this with the material at present available and without opportunity for field studies doubtless would lead only to greater confusion. The most satisfactory accounting of the forms thus far made is that of Blake (Contr. Gray Herb. 52:25, 1917). With the omission of the synonymy and a discussion of the relation of var. heleniastrum to Erigeron, and with the addition of the author's name as the authority for a new combination there made. this revision is here reproduced as follows: 
Var. genuinus. Caulis bracteatus sed vix foliatus.

Var. heleniastrum (Greene) Blake. Caulis foliis 3-9 plus minusve reductis donatus.

Var. glabratus Coult: Folia vix pubescentia sed glandulosa. Caulis abbreviatus bracteatus non foliatus dense glandulosus sparsissime pilosus. Involucrum parce pilosum et glandulosum.

Nearly all of the specimens in herbaria may be satisfactorily placed according to the foregoing synopsis, although intermediate forms are of course to be expected. In addition, there is a dwarf but very pubescent form not accounted for. This comes from Volcan de Fuego, Guatemala (1873-74, Salvin, in Berlin Herb.). Furthermore, there is a tall but only sparsely puberulent form, the var. $\beta$ puberus DC., so that all four of the possible combinations of stature and pubescence are now known. It is doubtful if the separation of the first two varieties on the basis of relative leafiness of the stems will prove of value. The type of heleniastrum is Pringle 4239. At the University of California, where Greene was located at the time his paper was published, the original sheet bearing this number is made up of three plants. One of these has leaves of good size carried well up the stem, but the two others mounted with it bear stem-leaves only 5 to $10 \mathrm{~mm}$. wide and naked peduncles 7 to $14 \mathrm{~cm}$. long. These plants are as little leafy as the Alaman specimens cited by DeCandolle, the types of his var. puberus, to which form they are to be referred, and even the less leafy types of true stoloniferus have leaves $5 \mathrm{~mm}$. wide as far as midway up the stem. In view of such variation within the type collections of stoloniferus and heleniastrum, it would seem that this character, although possibly of sufficient importance to justify the recognition of varieties, such as those of Blake, is not sufficiently constant to indicate the presence of two well-marked subspecies, much less of two distinct species, as was proposed by Greene.

The synonymy of the species and its subdivisions is as follows:

1. Aster stolonifer O. Kuntze, Rev. 318, 1891-H. stoloniferus.

2. Erigeron heleniastrum Greene, Erythea 1:150, 1893-H. stoloniferus var. heleniastrum Blake. (See foregoing synopsis and discussion.)

3. Haplopappus stoloniferus, but much dwarfed. Similar in habit to var. glabratus and to minor variation 9 , but very densely pubescent. Volcan de Fuego 1873-74, Salvin (B).

4. H. stoloniferus var. glabratus Coult., Bot. Gaz. 16:98, 1891. A depressed form with glandular but only minutely pubescent leaves. The type is from 3,700 meters altitude on the crater of Volcan de Agua, Zacatepequez, Guatemala (Smith 2328).

5. H. stoloniferus var. heleniastrum Blake, Contr. Gray Herb. 52:25, 1917. Described in the synopsis immediately preceding this list.

6. H. stoloniferus $\beta$ puberus DC., Prodr. 5:350, 1836. A larger-leaved and more sparsely pubescent form. The type specimens, gathered in Mexico by Alaman, are similar to the types of stoloniferus, except that the lower leaves are oblanceolate (originally described as lanceolate), thinner, much less densely pubescent, and larger, the blades of the largest measuring $7 \mathrm{~cm}$. long by $16 \mathrm{~mm}$. wide. This form seems to be a temporary modification found in less sunny places.

7. Osbertia heleniastrum Greene, Erythea 3:14, 1895. Based upon Erigeron heleniastrum Greene, which see.

8. O. heleniastrum var. glabrata Greene, 1. c.-H. stoloniferus var. glabratus Coult. (See foregoing synopsis.)

9. O. heleniastrum var. ? scabrella Greene, 1. c. A scabrous and hirsutulous dwarf form very close to $H$. stoloniferus var. glabratus Coult.; the bracts of the involucre broader, almost subulate, and only hirsutulous. The type is from Guatemala (J. D. Smith 3697).

10. O. stolonifera Greene, l. c. Based upon H. stoloniferus DC. 


\section{RELATIONSHIPS}

This species is well separated both phylogenetically and geographically from all the other Haplopappi, except the very close Haplopappus brandegei. In technical characters it is much like the species of Euhaplopappus and possibly it comes nearest to representing the original stock from which have been derived the South American species on the one hand and the North American species on the other. These connections have been sufficiently discussed in treating of the phylogeny of the sections (p. 37), and the more obvious relation to the only other species of its section will be taken up under $H$. brandegei.

The habit, together with the large number of very narrow bracts and the numerous ray-flowers, suggests some of the species of Erigeron, especially of the macranthus group, and it was once referred to this genus by Greene. This similarity is increased by the occasional appearance of heads in which the ligules are reddish with perhaps a suggestion of blue. But this connection with Erigeron, if it ever actually existed, is now very remote and, on the other hand, the alignment with Haplopappus is much more satisfactory, especially because of the more highly developed features of the stigmas and their appendages.

\section{ECOLOGY}

In growth-form Haplopappus stoloniferus is a perennial herb reproducing by stolons. These slender "runners" spread horizontally along the surface of the ground and sometimes are 4 or $5 \mathrm{dm}$. long. The absence of stolons on some dwarf plants has been noted by Greene, but this is probably due to the incomplete nature of the specimens. Geographically the species is restricted to high volcanic peaks of southern Mexico and Central America and is a relict persisting from the time when the genus was better represented in this and neighboring regions. It grows by streams and in moist meadows, probably in alluvial soil, at about timberline in southern Mexico, where the plants are of the typical tall-growing form, and on the craters of volcanoes in Guatemala, where only dwarf forms have thus far been collected. Dwarfing is not due to altitude alone, as is indicated by the repeated collection of the tall form at an altitude of 3,660 meters and of the dwarf form at about the same elevation (3,690 meters, according to the labels). The tall plants exhibit much variation in leafiness of stem, which apparently is to be accounted for by differences in the environment.

Apparently there are two seasons of flowering, correlated with the rainy seasons, for plants in full bloom have been collected both in spring and in autumn.

\section{Haplopappus brandegei Gray, Syn. Fl. $1^{2}: 132,1884$}

A perennial herb, 0.5 to $1 \mathrm{dm}$. high, the scape-like erect stems and numerous leaves tufted on the short branches of a caudex, forming small mats; stems very obscurely striate, pale green but sparsely clothed with a cinereous pubescence, this often dense near heads, also minutely glandular; leaves all nearly basal, the middle cauline few and reduced to bracts, the heads naked; principal leaves obovate or spatulate or nearly orbicular, contracted into a slender petiole, erect or spreading, entire, very obtuse, the blade 1 to $2 \mathrm{~cm}$. long (entire leaf 2.5 to $5 \mathrm{~cm}$.), 4 to $8 \mathrm{~mm}$. wide, retic- 
ulate but thick and the veins obscure, cinereous on both faces with a more or less strigose pubescence; heads solitary, terminating the simple stems; involucre broadly hemispheric, 6 to $8 \mathrm{~mm}$. high, 10 to $15 \mathrm{~mm}$. broad; bracts 30 to 50 , inserted in about 3 series, loose and spreading, nearly equal and equaling disk, linear-attenuate, scarious and reddish, especially

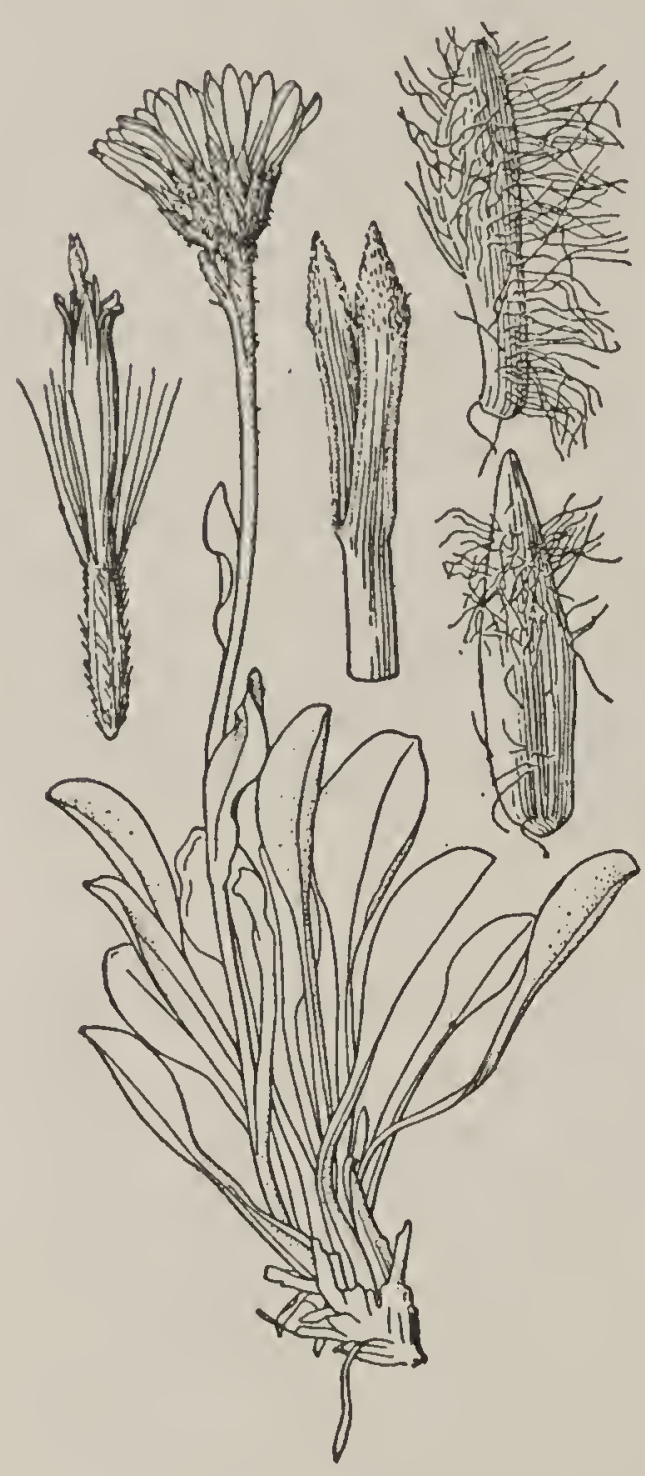

FIG. 4-Haplopappus brandegei the margins and the slender tips, densely to sparsely white-villous and reddish glandular; ray-flowers 50 to 70 , the ligules 6 to $9 \mathrm{~mm}$. long, 1 to $2 \mathrm{~mm}$. wide; disk-flowers numerous; disk-corolla either with short tube abruptly dilated into a longer throat or slender and gradually tapering, 3.5 to 4.5 or nearly $5 \mathrm{~mm}$. long, glabrous; lobes ovate, acute, 0.6 to 0.8 $\mathrm{mm}$. long, glabrous; style-branches short-exserted, 0.8 to $1.2 \mathrm{~mm}$. long, the triangularovate very acute appendage shorter than stigmatic portion; achenes more or less quadrangular with thickened edges, two opposing faces broader than the others, the central achenes sterile and flattened but with a medial ridge on each face, all tapering to base, scarcely $2 \mathrm{~mm}$. long, appressed-villous, somewhat glabrate; disk-pappus about as long as corolla, rather scanty, fragile, nearly white.

High mountains of Washington and western Canada. Type locality, in the Yakima district, Washington. Washington: Càscade Mountains, in the Yakima region, 1882, Brandegee (UC); alpine region near Mount Stewart (Stuart?), July-August, 1883, Brandegee 918 (Gr, UC); Stevens Pass, Sandberg and Leiberg 782 (Gr); Chiquash Mountains, Skamania County, Suksdorf 2379 (Gr, UG, B); Mount Rainier, Allen 94 (Gr, K, UC); above Lake Chelan, 1883, Wilcox (Gr). British Columbia: Beaverfoot Mountains, Petersen 376 (Gr, B); Chilliwack Valley, Macoun 26312 (Gr, K); Bishop's Range, Butters and Holway 460 (Gr); Selkirk Mountains, July 1890, Greene (UC). Alberta: Moraine Lake, Butters and Holway 103 (Gr); near Banff, July 22, 1891, Macoun (K).

\section{SYNONYMS}

1. Aster brandegei O. Kuntze, Rev. 318, 1891.

2. Erigeron aureus Greene, Pittonia 2:169, 1891.

3. Stenotus brandegei Howell, Fl. N. W. Am. 300, 1900.

\section{RELATIONSHIPS}

Notwithstanding its wide geographic separation, this species of northwest America is, with little doubt, closely related to Haplopappus stoloniferus, of the high mountains of southern Mexico and Guatemala. In such very important technical characters as those of the involucre and style-branches it is almost a counterpart of this southern species, except for the smaller size of all the structures. The style-appendages are per- 
haps a little sharper, but the relative length of these and the stigmatic portion is about the same. Even the supposed difference in shape may not be real, for in stoloniferus the long pubescence makes the appendage seem broader than it really is. The true outline is shown in figure 3 by the heavily shaded middle portion.

The relationships of Osbertia to Aster and Erigeron have been already discussed. The similarities of the present species to Erigeron are obvious, but its transfer to this genus, as proposed by Greene, does not improve the situation. To be sure, it has almost the exact habit of such species as $E$. lanatus and $E$. leiomerus, and the character of yellow ray-flowers is not sufficient for generic separation, but the appendages to the stylebranches are slightly different in shape and decidedly more acute. This last feature was first mentioned by Gray and since emphasized by Blake (Contr. Gray Herb. 52:26, 1917). To such evidence is to be added the obvious connection with $H$. stoloniferus and thence to undoubted species of Euhaplopappus.

\section{ECOLOGY}

Haplopappus brandegei is a loose mat-former of moist but well-drained soil above timber-line. On Mount Rainier it grows in volcanic glacial gravel, where it associates with such arctic-alpine species as Cassiope mertensiana, Phyllodoce glandulifera, Lupinus lyalli, and L. volcanicus. The flowering period is from late July through August.

\section{SECTION 2. BLEPHARODON \\ PHYLOGENY OF THE SPECIES}

The North American branch of the genus Haplopappus apparently had its beginning in forms similar to those now included within the section Blepharodon. Although no one of the ten species of this section can be selected as the phylogenetic starting-point, several of them exhibit features of a primitive nature and suggest connections with the other sections and with the South American branch. These external connections have been already considered (Phylogeny of the sections, p. 37), but they are also an aid in working out the relationships within the section. Thus, the marked tendency towards the presence of red pigment in the ligules places phyllocephalus near the beginning of the section. It suggests a persistence in this species of a trait highly developed in the heterochromous Astereae, but almost wanting in Haplopappus. It occurs also in gymnocephalus and in some forms of spinulosus, but it is rarely found in regions to the north.

The species of Blepharodon have evolved in two series, one of annuals, the other of perennials. This differentiation is fundamental, since no intermediate forms appear between the wholly herbaceous species and the woody-based perennial ones. It seems impossible to determine which is the more primitive and it is unlikely that either series has arisen directly from the other. Of the annuals, phyllocephalus is given the basal position because of its southern distribution, many-flowered heads, and strong tendency toward reddish ligules. The remaining three annuals seem to have arisen from phyllocephalus, but each as a distinct evolutionary line. 'Haplopappus gracilis, with its neatly imbricated involucral bracts in many series and its narrowed heads, is perhaps the most highly specialized. It 
is by far the most common and the most northerly in its distribution. The others, aureus and stenolobus, are comparatively local and little known. Each represents specialization in a few characters, as shown on the chart and in the descriptions, and no intimate connections can be found. (Fig. 5.)

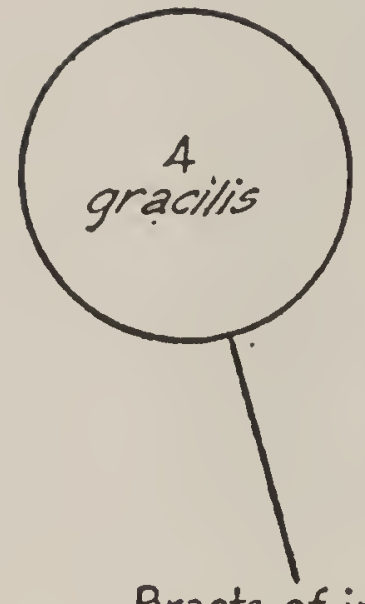

Bracts of invol. many, closely imbricated
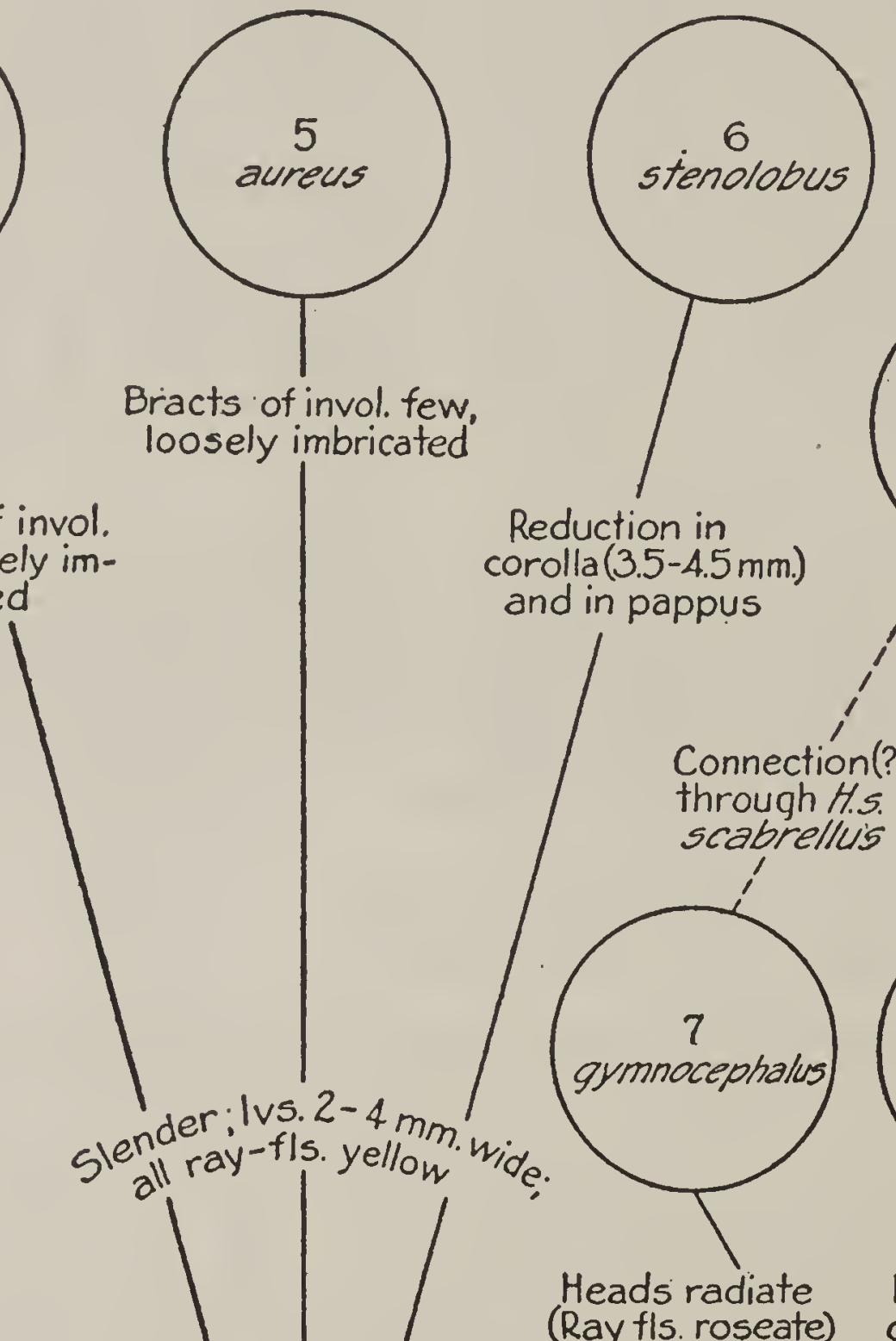

Bracts of invol. few, loosely imbricated
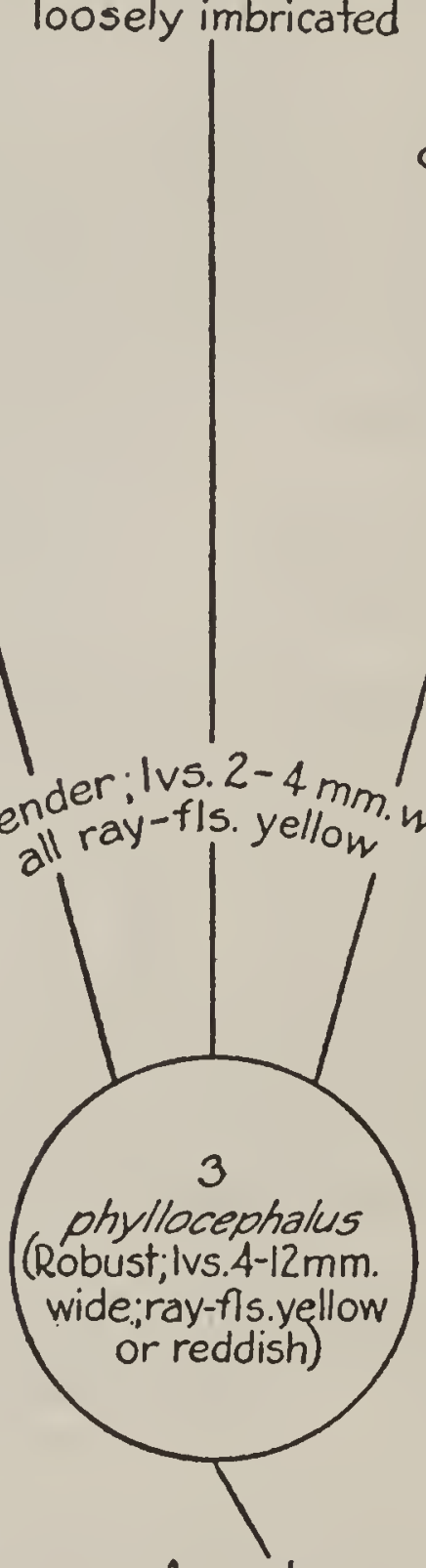

(Ray fls. roseate)

Reduction in corolla (3.5-4.5 mm.) and in pappus

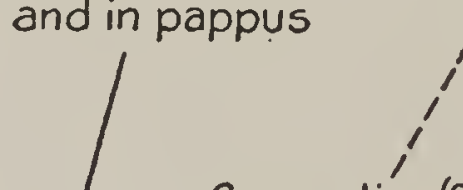

Connection(?) through H.S. scabrellu's
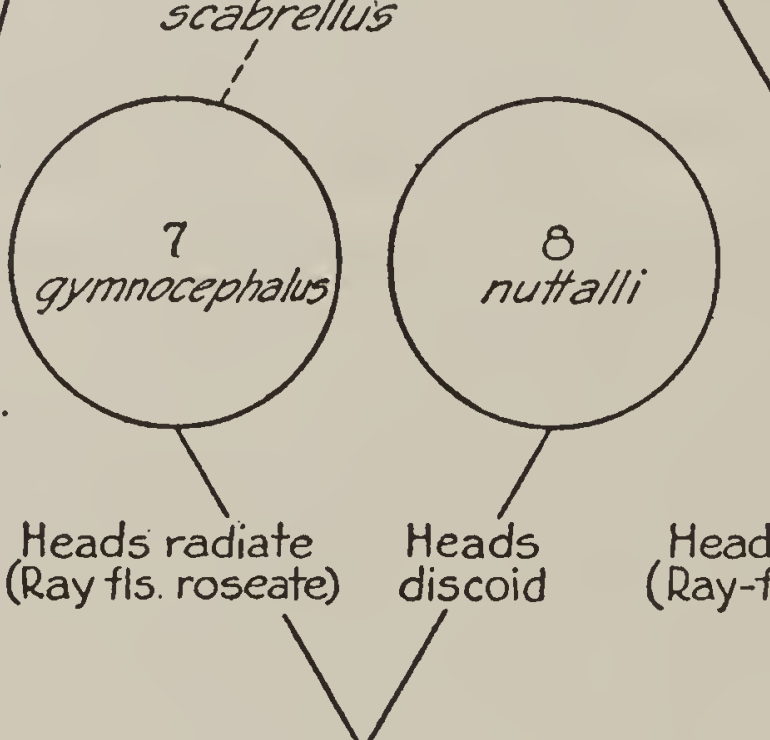

Heads discoid Teeth of lvs. Lvs. not bristly, bristle-tipped; nearly entire; bracts of invol. bracts of invol. mostly erect strongly squarrose much reduced,

mostly scale-like

10
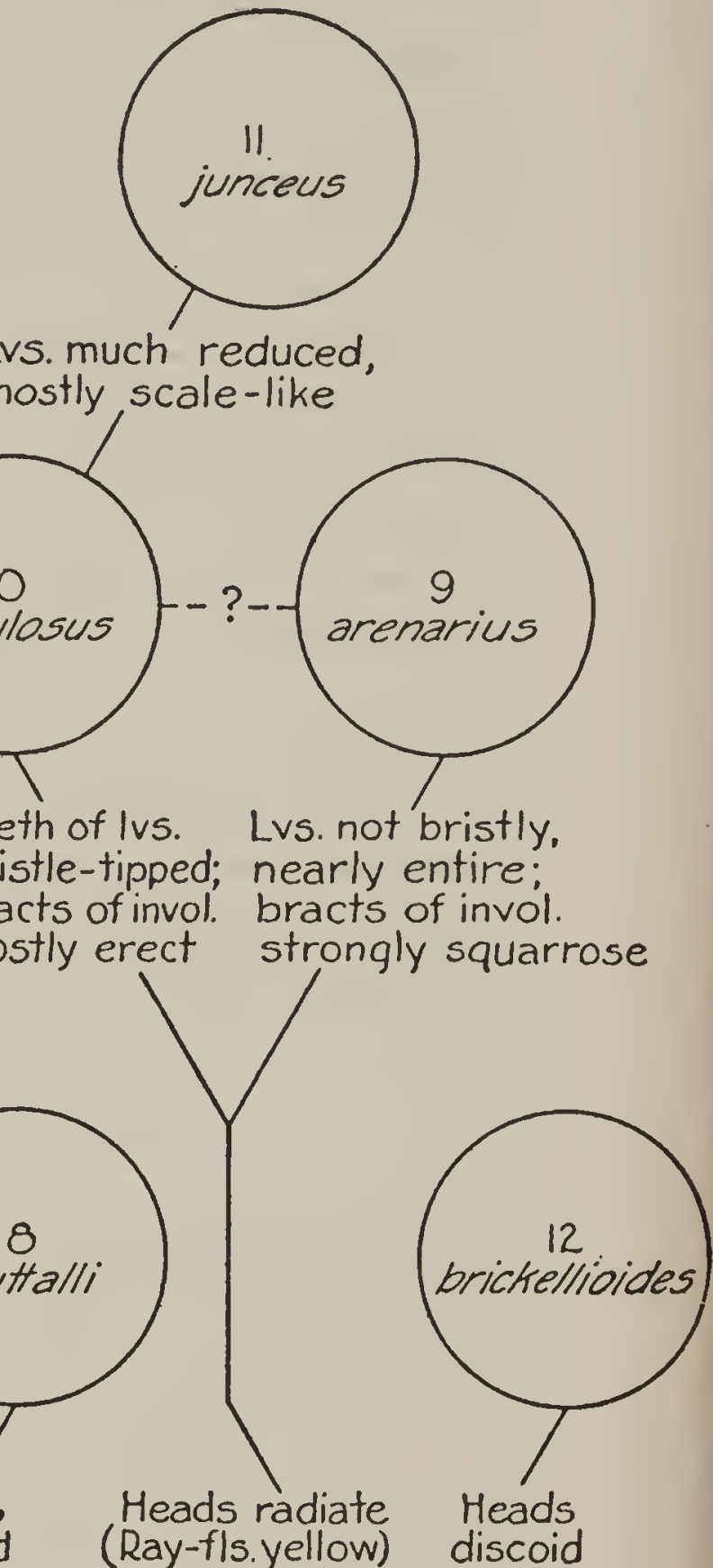

Heads discoid Annuals

(Style-app.shorter than stigma)

Original (Mëxican?)

forms. Aster-like, with roseate liqules and short style-appendages.

Frg. 5-Phylogenetic chart of the species of Haplopappus section Blepharodon. The suggested connection between spinulosus and arenarius would pass through subsp. incisifolius of the former 
Coming to the perennial species, Haplopappus gymnocephahus is placed first notwithstanding its well-developed stylar appendages. This is because of its roseate ray-flowers and southerly distribution. It is not so closely related to nuttalli as its position on the chart would seem to indicate, for the latter has not only suppressed its ray-flowers, but also has taken on a very individual type of involucre and other specialized features. All of the other perennials have short and thick style-appendages, presumably a mark of primitiveness. But although they remain primitive in this respect they are advanced in others. Haplopappus spinulosus is a polymorphous species of wide distribution, especially notable for the range of variation in foliage. It occasionally produces roseate ligules, indicating that this usually latent character is still present. These roseate forms are as frequent in the northeastern part of the range as in the southwest, where subsp. scabrellus is sometimes difficult to distinguish from $\mathrm{H}$. gymnocephalus. It is believed, however, that no present connection exists, there being no intergradation in characters of the style. The involucral bracts of arenarius, a species of the Cape Region of Lower California, are so remarkably squarrose as to suggest this as the beginning of the section Hazardia. Such involucres are not found in spinulosus, but in one of its subspecies the bracts are occasionally so strongly curved as to suggest either a common origin or a confluence of the evolutionary currents. Haplopappus junceus is an obvious offshoot of spinulosus, and the last species, $H$.brickellioides, is far too little known to permit of satisfactory placing.

\section{Haplopappus phyllocephalus DC., Prodr. 5:347, 1836}

An annual (or sometimes biennial?) herb, 3 to $10 \mathrm{dm}$. high, with a short straight taproot, branched above the base or rarely from the ground; branches striate, gray or tinged with red, glandular-scabrid and often with additional villous or tomentulose pubescence; principal leaves oblong or spatulate-oblong, ascending, with few salient teeth or divergent lobes, each tooth or lobe bristle-tipped, obtuse or acute, sessile by a narrowed but half-clasping base, 3 to $5 \mathrm{~cm}$. long, 4 to $12 \mathrm{~mm}$. wide (larger in minor variations), thick, usually only the midvein prominent, glandular-scabrid, rarely somewhat cinereous or tomentulose; upper leaves little or much reduced, less deeply lobed, more strictly sessile; heads either solitary, nearly sessile and terminal among the upper leaves or on more or less elongated peduncles, these often naked, sometimes cymose; involucre hemispheric, 6 to 8 or $14 \mathrm{~mm}$. high, 10 to $15 \mathrm{~mm}$. broad; bracts numerous, imbricated in 2 to 4 lengths, mostly longer than disk, erect to squarrose, lanceolate, attenuate to a slender awn, the base scarious, the middle portion herbaceous or inner bracts scarious throughout, glandular-scabrid; receptacle with alveoli bordered by deeply lacerate walls, the resulting scales often $1 \mathrm{~mm}$. long; ray-flowers about 25 to 40 , the ligules 9 to 14 $\mathrm{mm}$. long, pale yellow or reddish; disk-corolla rather abruptly dilated above middle, 5 to $7 \mathrm{~mm}$. long, glabrous or nearly so; lobes lanceolate, 0.5 to $1.2 \mathrm{~mm}$. long, the thick obtuse appendage only one-half to two-thirds as long as stigmatic portion; achenes turbinate, $2 \mathrm{~mm}$. or less long, $10-$ ribbed but ribs sometimes obscured by the dense villous pubescence; diskpappus of rather copious unequal slender bristles, the longest about equaling corolla, pale brown becoming ferruginous. (Figs. 6 to 9.)

Colorado to southern Mexico and Florida. 


\section{SUBSPECIES}

Key to the sUbSPECies of Haplopappus phyllocephalus

Ligules reddish (rarely yellow?); heads terminating nearly naked peduncles or peduncle-like stems. (Southern Mexico.)..........

Ligules yellow (rarely reddish in typicus, recognized by its leafybracted heads); heads either naked-pedunculate or leafybracted.

Involucre 8 to $9 \mathrm{~mm}$. high, its bracts usually curved or squarrose.

Heads sessile or short-peduncled among the upper leaves, by which they are often overtopped; middle leaves 8 to $12 \mathrm{~mm}$. wide.

Heads terminating nearly naked peduncles or stems; middle leaves 3 to 8 (rarely 12) mm. wide. (Texas to Nebraska.).... (c) annuus

Involucre 10 to $14 \mathrm{~mm}$. high, its bracts flat, straight except at tip. (Texas to Florida.)...........................

(a) primitivus

(d) megacephalus

3a. Haplopappus phyllocephalus primitivus, subsp. nov.-Stems solitary, leafy at base, the leaves diminishing in size up the stem, which is nearly naked toward the heads, annual or at most biennial; herbage densely glandular-scabrid, also slightly villous above; middle leaves oblong or slightly oblanceolate in outline, deeply dentate with 6 to 8 pairs of triangular bristle-tipped teeth, the blade itself also acute and bristle-tipped, sessile by a broad half-clasping base, 1.5 to $2 \mathrm{~cm}$. long, 3 to $4 \mathrm{~mm}$. wide; (crowded basal leaves narrowed to a petiole-like base); heads solitary, terminating the nearly naked peduncle-like branches or sometimes accompanied by an additional undeveloped head; involucre 8 to $9 \mathrm{~mm}$. high, about $12 \mathrm{~mm}$. broad (16 to $18 \mathrm{~mm}$. when pressed); bracts numerous, obscurely imbricated in about three lengths, narrowly linear, attenuate, bristle-tipped, moderately curved to squarrose from above the middle, chartaceous at base, greenish or reddish above or (inner) pale and chartaceous except at the red tips, densely scabrid, most of the hairs glandtipped; ligules narrow, 11 to $14 \mathrm{~mm}$. long, reddish or maroon; stylebranches about $1.5 \mathrm{~mm}$. long, the ovate acute appendage about one-half as long as stigmatic portion; achenes of both ray and disk thick, turbinate, about $2 \mathrm{~mm}$. long, 10-ribbed, silky-villous; pappus of about 40 moderately unequal slender bristles. (Fig. 6.)

Type collection, calcareous bluffs, Flor de Maria, State of Mexico, July 31, 1890, C. G. Pringle 3179 (type Univ. Calif. Herb. 193511). The preceding description was drawn from the type. In order to accommodate collections cited below, which obviously should be included within the subspecies, it is necessary to supplement the description as follows: Stems rarely 2 or 3 from the base (probably as result of previous injury to growing shoot), 1.5 to $4 \mathrm{dm}$. high; lower leaves to $5 \mathrm{~cm}$. long and dentate to pinnately parted into oblong lobes; middle leaves often oblong-spatulate, finely dentate (Purpus 5149) to pinnately parted (Purpus 2458); ligules 9 to $14 \mathrm{~mm}$. long; style-branches 1 to $1.5 \mathrm{~mm}$. long, the appendage from one-half to nearly as long as the stigmatic portion. Agua del Medio, July 1911, Purpus 5149 (UC); Zacatecas, 1903, Purpus (UC, a dwarf only $3 \mathrm{~cm}$. high); in sandy soil and on rocky hills, Esperanza, Tehuacan, Puebla, June 1907, Purpus 2458 (UC); Hucyotlipan, vicinity of Puebla, 2,180 meters, June 15, 1908, Arsène 2151 (Gr, ligules yellow). 


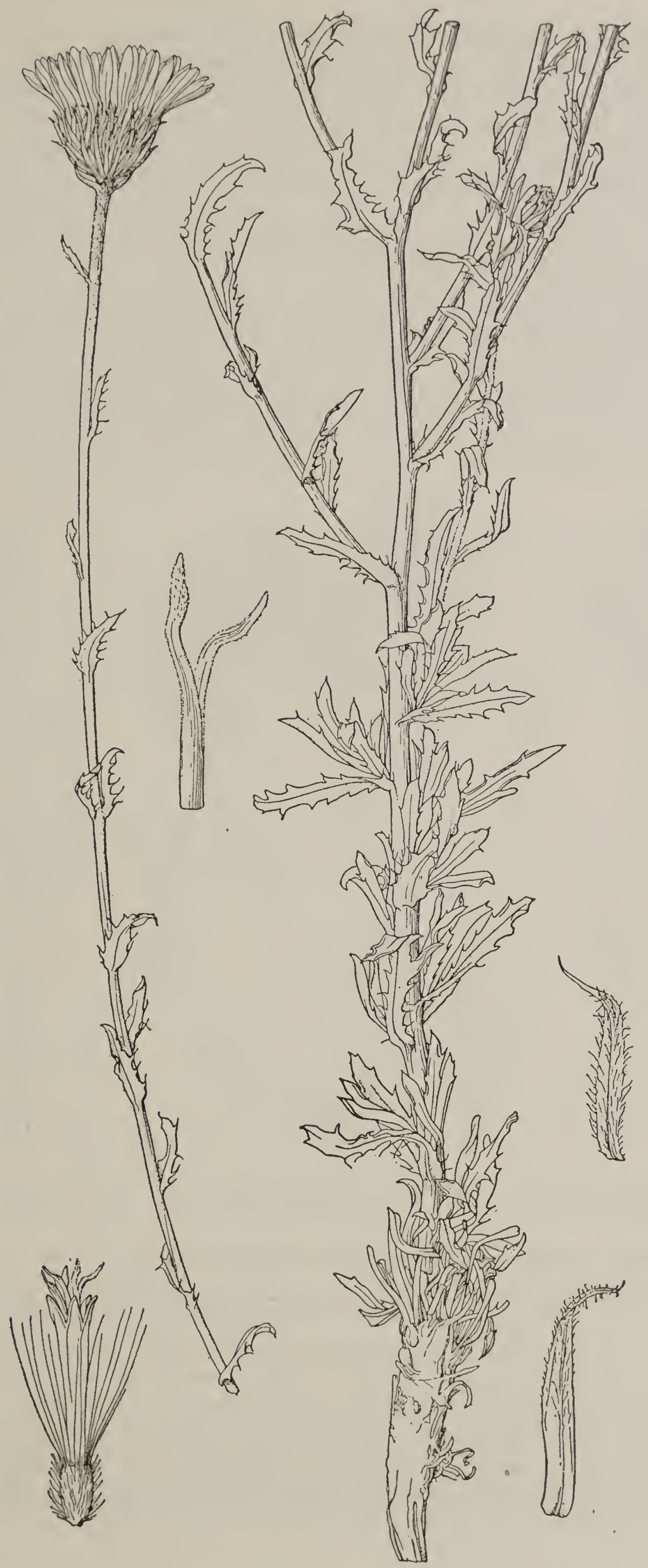

Fra. 6-Haplopappus phyllocephalus primitivus. From the type specimen 
3b. Haplopappus phyllocephalus typicus-Stems leafy throughout, some of the upper leaves overtopping the heads (especially in the type); herbage densely glandular-scabrid, also villous or tomentulose at least on peduncles; middle leaves 8 to $12 \mathrm{~mm}$. wide, including the divergent lobes or teeth $(5$ to $6 \mathrm{~mm}$. wide in minor variation 11); heads 1 to 3 at the end of each stem, sessile among the upper leaves or short-peduncled and the peduncles leafybracted; involucre typically 8 to $10 \mathrm{~mm}$. high, the bracts with upcurved body and variously spreading tips; ligules yellow, rarely reddish. ( $H$. phyllocephalus DC., l. c.). (Fig. 7.)

Gulf slope of northeastern Mexico and Texas. Type locality, in Mexico, between San Fernando and Matamoros (Tamaulipas). Durango: near the city of Durango, 1896, Palmer 310 (UC). Tamaulipas: type collection, 1832, Berlandier 2278 (DC, Del, K). Texas: Galveston, Bush 3935 (Gr); Galveston Island, Tracy 7365 (Gr, US, Del, see minor variation 3). Louisiana: Cameron, Cocks 1726 (Gr, form with several heads).

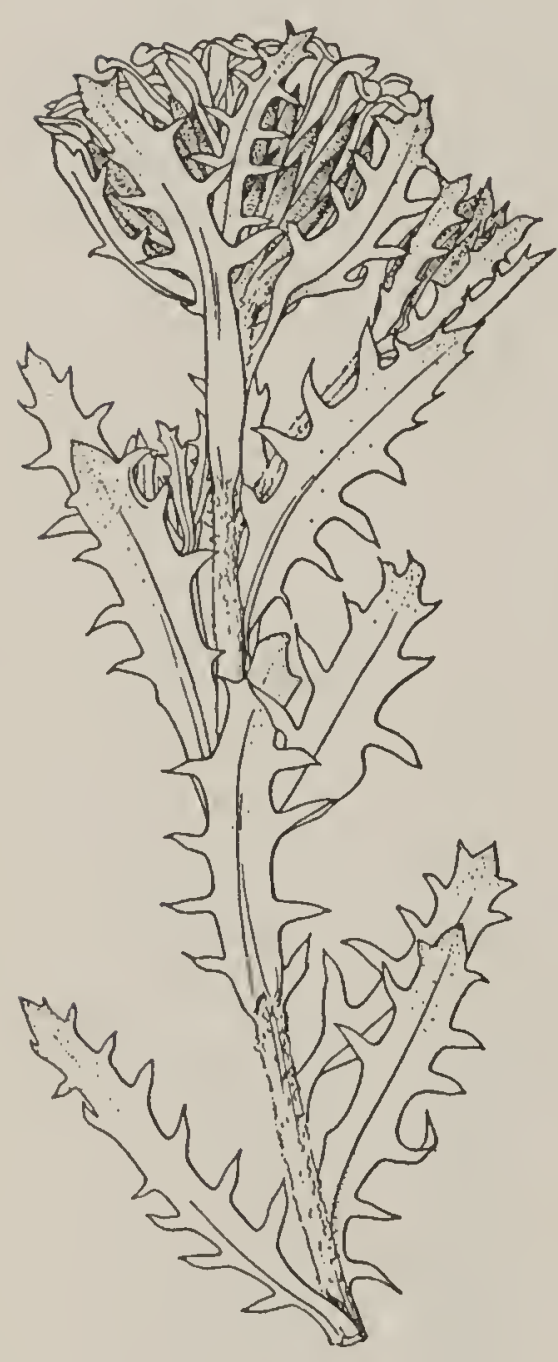

FIG. 7-Haplopappus phyllocephalus typicus

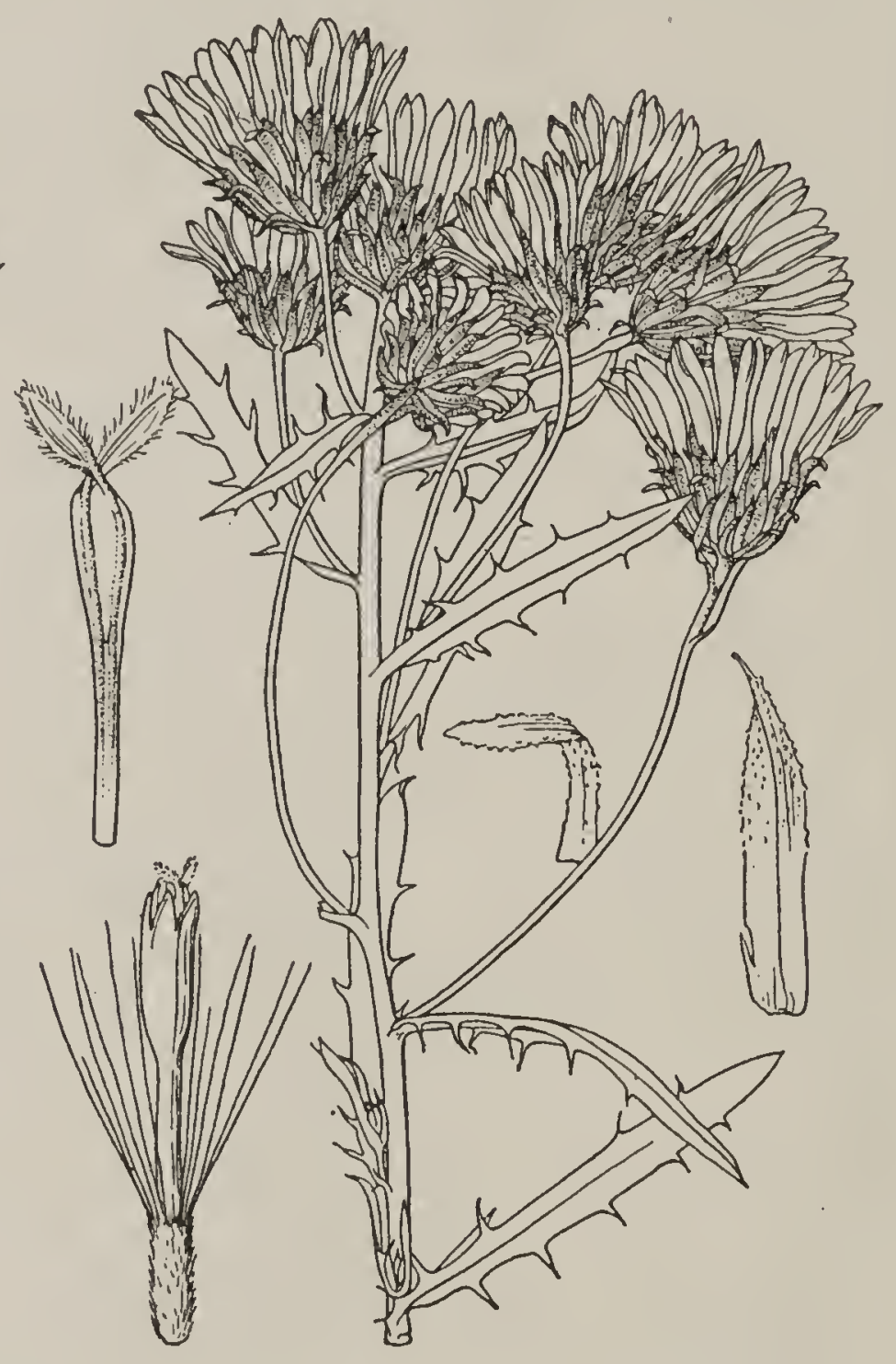

FIG. 8-Haplopappus phyllocephalus annuus

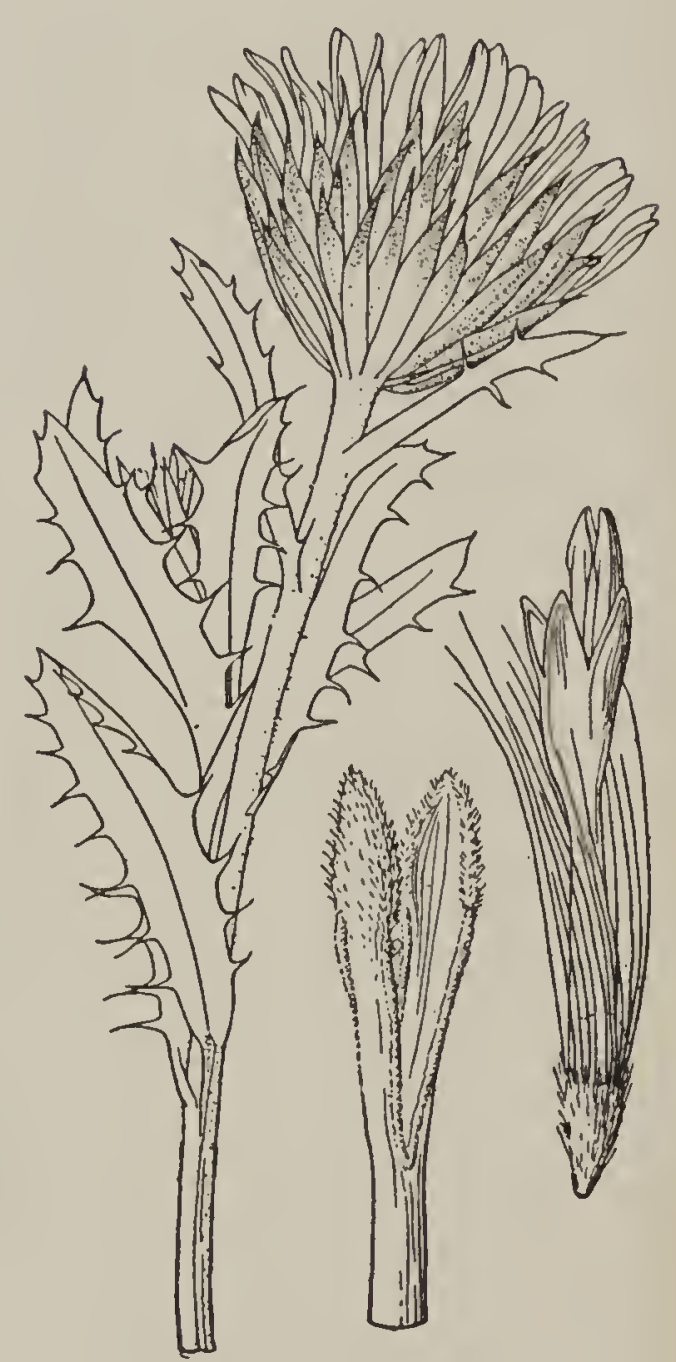

Fig. 9-Haplopappus phyllocephalus megacephalus

3c. Haplopappus phyllocephalus annuus (Rydb.)-Stems leafy to or sometimes through the inflorescence, but the uppermost leaves reduced and rarely if ever surpassing the heads; herbage densely glandular-scabrid and with a mere trace of loose villous pubescence; middle leaves 4 to $S$ or rarely $12 \mathrm{~mm}$. wide, including the teeth or lobes; heads 2 to many at the end of each stem, cymosely or paniculately disposed on peduncles 1 to $5 \mathrm{~cm}$. long, these naked or with very few linear bracts; involucre 6 to $8 \mathrm{~mm}$. high, the bracts usually curved or squarrose from the middle; ligules yellow. (Sideranthus annuus Rydb., Bull. Torr. Club 31:653, 1904.) (Fig. 8.) 
Eastern Colorado to Kansas and southern Texas. Type locality not stated, but the region of the upper Platte River is mentioned. Colorado: North Denver, Eastwood 45 (UC, K, US); New Windsor, Osterhout 2338 (Gr, R, US, Po); Arvada, Jefferson County, Clokey 3887, 3888 (Gr, US, Phila, Po). Kansas: Meade County, Hitchcock 1008 (Gr, US). Texas: Corpus Christi, 1912, Rehn and Hebard (Phila); Nueces Bay, Heller 1440 (K); branch of Palo-duro Cañon, September 10, 1917, Young (Gr).

3d. Haplopappus phyllocephalus megacephalus (Nash) - Stems leafy throughout, some of the upper leaves subtending and often surpassing the heads; herbage glandular-scabrid and also villous or tomentulose, at least on the peduncles; middle leaves 8 to $12 \mathrm{~mm}$. wide, including the divergent lobes or teeth; heads mostly solitary at the end of each stem or branch, sessile among the upper leaves or short-peduncled and the peduncles leafybracted; involucre 10 to $14 \mathrm{~mm}$. high, the lanceolate bracts flat and recurved only at the fine tip; ligules yellow. (Eriocarpum megacephalum Nash, Bull. Torr. Club 23: 107, 1896.) (Fig. 9.)

Gulf coast from Texas to western Florida. Type locality, Sneed's Island, near the mouth of the Manatee River, Florida. Texas: Galveston Island, Tracy 7365 (Gr). Louisiana: Cameron, Cocks 1726 (Gr). FlorIDA: waste ground, Pensacola, Curtiss 6494 (UC, Gr); same locality, Tracy 8515 (Gr, US, Greene, see minor variation 2); type collection, Palmetto, Manatee County, Nash 2482 (Gr, US, Greene, Del, K); Punta Rassa, Lee County, Hitchcock 1\%/ (Gr, leaves only 5 to $10 \mathrm{~mm}$. wide). (Fig. 9.)

\section{MINOR VARIATIONS AND SYNONYMS}

1. Aster phyllocephalus O. Kuntze, Rev. 316, 1891-H. phyllocephalus typicus.

2. Eriocarpum floridanum Gandoger, Bull. Soc. Bot. France 65:41, 1918. "Folia angustius oblonga acuta copiose dentata viridia sessilia, caules recti, phylla involucri breviter acuta." The type is from Pensacola, Florida (Tracy $8515)$.

3. E. glaucum Gandoger, 1. c. "Folia lata obtusa plerumque integra glauca fere amplexicaulia, caules decumbentes, phylla involucri longe cuspidata." The type is from Galveston, Texas (Tracy 7365).

4. E. megacephalum Nash, Bull. Torr. Club 23:107, 1896-H. phyllocephalus megacephalus.

5. E. phyllocephalum Greene, Erythea 3:15, 1895-H. phyllocephalus typicus.

6. E. rubiginosum Britton, Mem. Torr. Club 5:316, 1894. Based upon H. rubiginosus Torr. et Gray, which see in this list.

7. E. rubiginosum phyllocephalum Heller, Contr. Herb. Franklin and Marshall Coll. 1:101, 1895-H. phyllocephalus typicus.

8. E. tracyi Gandoger, 1. c. "Folia anguste oblonga subacuta copiose dentata viridia sessilia, dentibus spinulosis, caules rigidi, phylla involucri cuspidata." The type is from Sneed's Island, Florida (Tracy 6354).

8a. Haplopappus megacephalus Hitchc., Trans. Kans. Acad. 16:131-H. phyllocephalus megacephalus.

9. H. phyllocephalus var. genuinus Blake, Contr. Gray Herb. 52:22, 1917-H. phyllocephalus typicus.

10. H. phyllocephalus var. rubiginosus Blake, 1. c. Based upon H. rubiginosus Torr. et Gray, which see in this list.

11. H. rubiginosus Torr. et Gray, Fl. N. Am. 2:240, 1842. The description includes features which assign this to $H$. phyllocephalus typicus. These are: "cinereous ..... heads solitary or corymbose, terminating the leafy branches, of ten bracteate ..... scales of the involucre .... in about 2 series." The type specimen (Drummond 110) is easily referred to typicus, notwithstanding its narrow leaves, although the base is so thick and branch- 
ing, as the result of injury, that Gray suspected it of being suffruticose. The H. rubiginosus of Gray (Syn. Fl. $1^{2}: 130,1884$ ), although evidently drawn to include what is now taken as subsp. annuus, is followed by the citation of Drummond's plant. (See further on p. 61.)

12. H. rubiginosus var. phyllocephalus Gray, Syn. Fl. $1^{2}: 130,1884-H$. phyllocephalus typicus.

13. Sideranthus annuus Rydb., Bull. Torr. Club 31:653, 1904-H. phyllocephalus annuus.

14. S. megacephalus Small, Fl. S. E. U. S. 1185, 1903. Based upon Eriocarpum megacephalum, which see.

15. S. phyllocephalus Small, l. c. 1186-H. phyllocephalus typicus.

16. S. rubiginosus Britton, in Rydb., Bull. Torr. Club 27:621, 1900. Based upon $H$. rubiginosus Torr. et Gray and hence the same as $H$. phyllocephalus typicus. No description was given, but the distribution indicates that subsp. annuus was the form in mind.

\section{RELATIONSHIPS}

The large, many-flowered heads, the frequent recurrence of red pigment in the ligules, the loosely imbricated involucre, and the short styleappendages all point to this species as one of the most primitive of its section. Its geographic distribution also supports this hypothesis, for the species obviously had its origin in southern Mexico, not far from the center of distribution of others of this primitive group, namely, Haplopappus gymnocephalus and $H$. spinulosus scabrellus. But while these two perennial forms spread out to the west and north, the annual phyllocephalus extended its area toward the northeast, especially around the borders of the Gulf of Mexico, where it is almost the only representative of the genus. It has probably given rise to other species, as will be discussed under $H$. stenolobus and other annuals. But these sprang out of the original Mexican form (subsp. primitivus?) and apparently had no direct connection with the more northern and eastern variations now included under phyllocephalus.

In searching for the most primitive form of this species, one is impressed with a series from central and southern Mexico which have been variously identified as Haplopappus gymnocephalus and as an unknown species of Aster. These are now found to connect very closely with $H$. phyllocephalus typicus and are therefore described as a new subspecies, namely, H. phyllocephalus primitivus. This is considered as lepresenting the original stock of the species, not only because of its southern distribution, but also because of the almost constant presence of a reddish pigment in the ligules and its apparent approach to other species of the section. The connection with subsp. typicus is indicated by a collection of the latter from an intermediate station (Durango, Palmer 310). In this, some of the heads are overtopped by upper leaves as in typicus, but others are distinctly pedunculate as in primitivus, although the peduncles are not so leafy-bracted. At least some of the heads have the reddish ligules of the southern form. In the matter of leaf reduction and inflorescence the new subspecies is more like subsp. annuus, but the geographic connection is decidedly interrupted and the latter connects more directly with typicus, from which it in turn has doubtless arisen as a northern offshoot. In many respects primitivus is suggestive of $H$. gymnocephalus. which has a similar geographic distribution and with which it has been confused. This confusion, however, certainly has come about through a failure to appreciate certain characters of gymnocephalus. The type of this and all specimens properly 
referred to it are decidedly woody at base, although herbarium specimens sometimes consist only of herbaceous branches which one might assume to have come from an annual root. Haplopappus phyllocephalus primitivus is usually an annual, although some plants are thick at base and may be of biennial duration. The plants show no evidence of becoming suffruticose. It differs from gymnocephalus also in the absence of chaff from the receptacle, in the short stylar appendages, these always exceeded by the stigmatic portion, and in minor features of heads and flowers.

Although the subspecies typicus can not be accepted as basal from the phylogenetic point of view, it is central as regards geographic distribution. It is a form of northern Mexico and adjacent portions of the United States and is characterized especially by the very leafy stems and peduncles. Toward the north it passes insensibly into subsp. annuus, which differ's in its smaller and more numerous heads on peduncles nearly devoid of foliage. In their extreme forms the two are so unlike that there would seem to be some justification for their recognition as distinct species. As indicative of a close connection, however, may be mentioned a form of typicus from Louisiana with 2 to 8 heads on each branch (Cameron, Cocks $1726, \mathrm{Gr}$ ), and, on the other hand, as representative of annuus in most of its features, especially the small heads, but as leafy as typicus and the heads reduced to 1 to 5 is a collection from near the Texas-Mexico line (Berlandier 858, Gr). Also intermediate is Palmer 310 (of 1896) with pubescence and involucre of typicus, but many of the heads on nearly naked peduncles. Difficulties encountered in an attempt to recognize distinct units are illustrated by Gray's treatment of a plant from Texas (Drummond 110). This was taken by Torrey and Gray as the type of their H. rubiginosus and was later cited by Gray (Syn. Fl. $1^{2}: 130,1884$ ) in connection with a description intended to include only forms with usually naked-pedunculate heads. This collection, however (at least at Kew), has leafy-bractate heads and plainly goes with typical phyllocephalus.

Some confusion has been introduced through the attempt to use method of branching as a criterion. It is doubtful if any of the forms normally branch from the base. The Drummond specimen just referred to is sometimes taken as perennial and described as branched from below, but it is a malformation. The growth of the several stems from the base, which is unnaturally thickened, almost certainly followed destruction of the central axis. Because of confusion introduced into the nomenclature by Gray's unfortunate attempt to establish an appropriate name for the collective species (Syn. Fl., l. c.) and errors in descriptions, rubiginosus is now discarded and the name annuus, first proposed by Rydberg, is taken up as the subspecific name for the northern form.

A second derivative of typicus is a robust, large-headed variant of the Gulf coast from Texas or Louisiana eastward. This form, first described by Nash as Eriocarpum megacephalum, is here treated as a subspecies, although further exploration may demonstrate that it is only a climatic or edaphic modification. In its extreme form, the heads are not only much larger than those of any other subspecies, but the comparatively broad bracts are very straight, appressed, and of nearly equal length. The ray-flowers are always yellow, and the plants appear to be quite different from subspecies primitivus, which represents the other end of the phylogenetic line. 


\section{ECOLOGY}

But little is known of the ecology of this species as it occurs in southern Mexico. The forms of northern Mexico and of the United States are halophilous tall herbs of sea-beaches, flood-plains, and alkaline flats. The subspecies typicus, in its many forms, inhabits especially the northern shores of the Gulf of Mexico and sandy flats of adjacent lagoons and lakes; subsp. annuus is of more northerly distribution and grows in alkaline soil of the interior. The plants are weedy in appearance and sometimes occupy

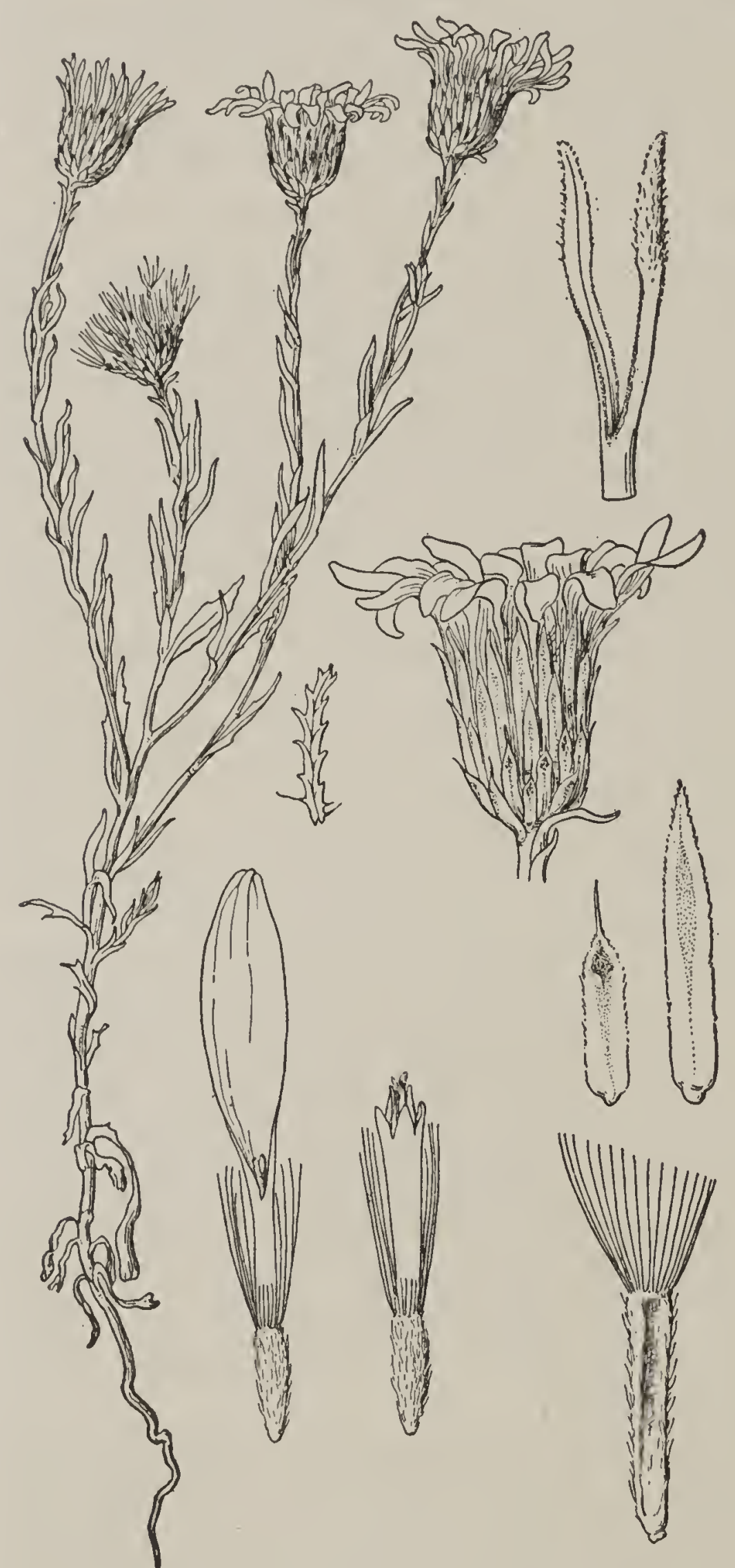

FIg. 10-Haplopappus gracilis waste places, so that their introduction into other warm districts is to be expected. The growing period extends over the warm months of the year and the flowers appear from July to October.

\section{Haplopappus gracilis (Nutt.)} Gray, Mem. Am. Acad. II, $4: 76,1849$

An erect annual herb with a straight taproot, 0.5 to 2 or rarely $3 \mathrm{dm}$. high, branched from near the base and usually throughout (for depressed form see under Ecology); branches with few striae, strigose; principal leaves linear or the lower lanceolate - spatulate, ascending, dentate to pinnately divided or the lower sometimes twice divided, each tooth or lobe ending in a long white bristle, the leaf itself bristletipped from an obtuse summit, sessile (the lower sometimes petioled), 1 to 2 or $3 \mathrm{~cm}$. long, 1 to $3 \mathrm{~mm}$. wide, only the midrib evident, white-strigose; upper leaves much reduced, appressed, linear, mostly entire but margined with bristles; heads solitary or terminating short peduncle-like branches and then cymosely arranged; involucre nearly hemispheric, slightly narrowed at base, 6 to

$7 \mathrm{~mm}$. high, 8 to $10 \mathrm{~mm}$. broad; bracts numerous, closely and regularly imbricated in 5 or 6 lengths, the longest about equaling disk, all linearlanceolate, acuminate to a white awn, the middle portion herbaceous, the tip dark green, the edges white-scarious, cinereous or strigose, not glandular; 
receptacle with numerous linear scales about $1 \mathrm{~mm}$. long (these resulting from breaking down of the walls of alveoli); ray-flowers 18 to 28 , the ligules 7 or $8 \mathrm{~mm}$. long; disk-corolla rather abruptly enlarged above the tube, 4.5 to $5.5 \mathrm{~mm}$. long, usually glabrous; lobes ovate or triangular, 0.5 to $0.8 \mathrm{~mm}$. long, glabrous; style-branches short-exserted, 1 to $1.5 \mathrm{~mm}$. long, the appendage shorter than stigmatic portion; achenes narrowly turbinate, about $2.5 \mathrm{~mm}$. long, canescent; disk-pappus of moderately unequal bristles, the longest about equaling corolla and slightly dilated below, varying from reddish brown to nearly white. (Dieteria gracilis Nutt., Jour. Acad. Phila. II, 1:177, 1848.) (Fig. 10.)

Dry plains from southern Colorado and Utah south to Durango, west to the eastern borders of California. Type locality, "Near Santa Fe (New Mexico)." Colorado: Piedra, September 15, 1924, Schmoll (UC); San Juan Valley, Hall 11121 (UC); Durango, Baker, Earle, and Tracy 537 (Gr, Del, B, K, UC, R). Utah: St. George, 1875, Palmer (Gr); near Kanab, Jones 6047c (US). New Mexico: near Dulce, Standley 8110 (US); near Santa Fe, Gambel (Gr, K, type collection); near Albuquerque, Rose and Fitch 17802 (US); Tierra Blanca Creek, Sierra County, Metcalfe 1390 (US, Del, B); Organ Mountains, Wooton 414 (Gr, Del, P, B, K, UC, R). Arizona: near Flagstaff, Leiberg 5860 (US); Ash Fork, W. W. Jones 163 (Gr); Kingman, August 13, 1911, Wooton (US); Prescott, August 20, 1894, Toumey (UC); Paradise, Chiricahua Mountains, Blumer 1703 (Gr, US, B, K); Bisbee, Mearns 1062 (US); Tucson, August 28, 1901, Thornber (UC). California: Vanderbilt, New York Mountains, Parish 10324 (Gr, UC); Providence Mountains, June 6, 1902, Brandegee (UC); Rialto, Wilder 1105 (UC, introduced). Chinuahua: near Sierra en Media, Nelson 6466 (Gr); Sierra Madre, August 25, 1899, Nelson (Gr); near Chihuahua, Pringle 684 (Gr, Del, P, B). Coahuila: Saltillo, Arsène 10623 (Gr.) Durango: near Santiago, Papasquiara, Palmer 427 (Gr, B, UC).

\section{SYNONYMY}

1. Aster dieteria O. Kuntze, Rev. 315, 1891.

2. Dieteria gracilis Nutt., Jour. Acad. Phila. II 1:177, 1848.

3. Sideranthus gracilis Nels., Bot. Gaz. 37:266, 1904.

4. Eriocarpum gracile Greene, Erythea 2:109, 1894.

\section{RELATIONSHIPS}

There can be no doubt that this is the most highly developed of the annual species of Blepharodon. As indications of this may be mentioned the slender bracts of the involucre, these closely imbricated in numerous series, the sharp differentiation from other species, and the adaptation to semi-desert conditions. In all of these features it differs markedly from the more southerly Haplopappus phyllocephalus, which is the only existing form from which it possibly could have arisen, unless there was formerly a connection with the at present very distinct $H$. spinulosus. Another feature which assists in the identification of gracilis is the definite green tip to each bract, giving to the involucre a spotted appearance not found in other species. The involucre itself is slightly more narrowed at base than is usual in this section. A still further character, not known elsewhere among the annual species, is the remarkable development of socalled chaff on the receptacle. This consists of slender, sometimes dentate awns, about as long as the achenes. There are usually several to 
each flower and obviously result from rupturing of the walls of the alveoli. They are not, therefore, comparable to receptacular bracts.

\section{ECOLOGY}

This is a species of arid plains of the southern Rocky Mountain region. It grows at moderate altitudes and belongs to the Lower and Upper Sonoran zones. Here it appears in abundance after the summer rains. Under such conditions the plants are tall, freely branched, and with numerous showy heads of yellow flowers. But in Arizona and adjacent California, at least, there is also a spring form, blossoming from April to June. This is a much smaller plant, sometimes only $1 \mathrm{~cm}$. high, but varying to $12 \mathrm{~cm}$., the stems simple or with few branches, and the heads correspondingly reduced in number. This is probably a climatic and hence a seasonal variation, but thus far the two forms have not been found in exactly the same locality.

\section{Haplopappus aureus Gray, Mem. Am. Acad. II, 4:76, 1849}

A slender annual about 1.5 to $2 \mathrm{dm}$. high, with slender taproot, branched throughout (in the few collections thus far made), the branches sometimes

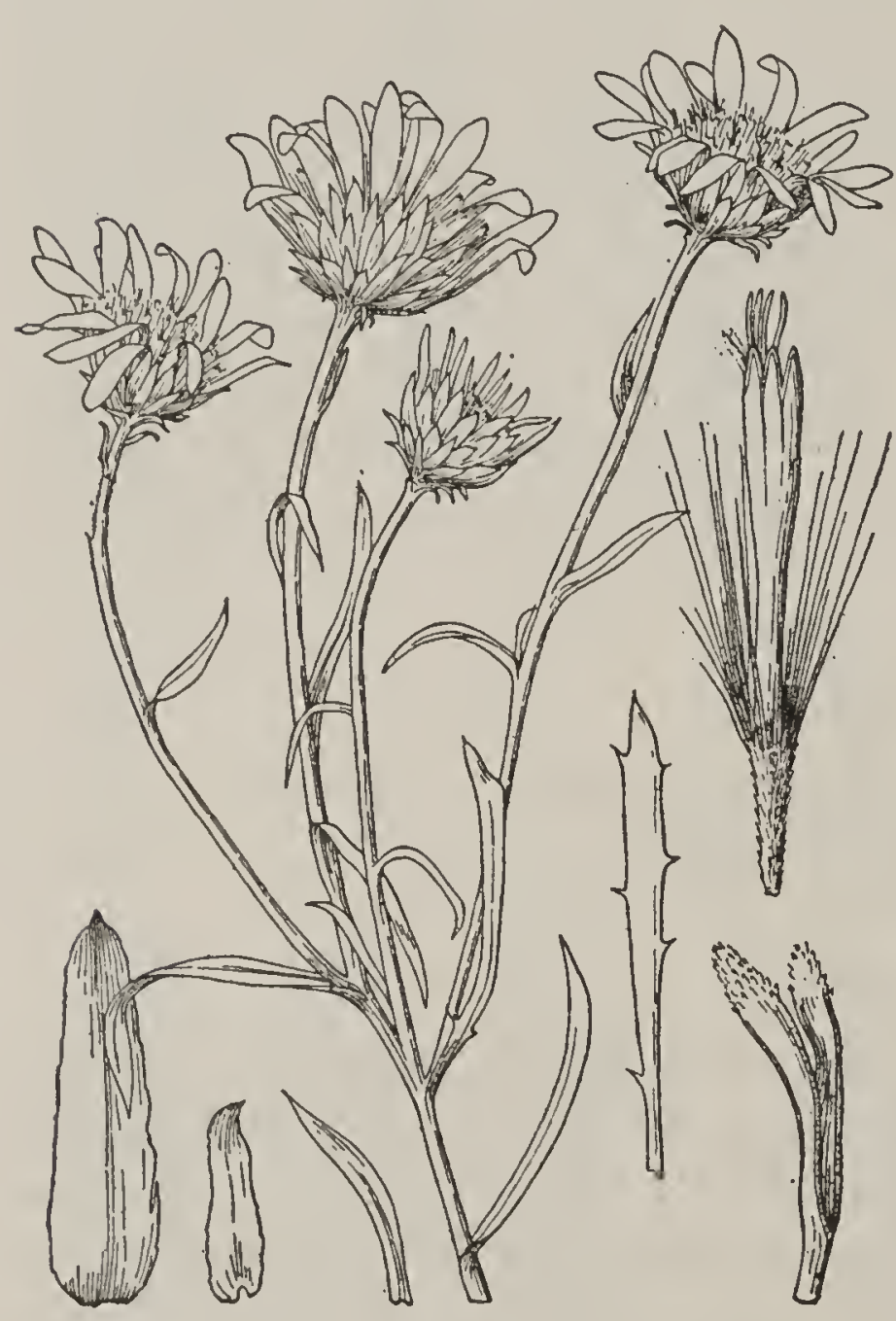

FIG. 11-Haplopappus aureus decumbent; branches faintly striate, minutely viscid-glandular, or at first slightly tomentulose; principal leaves narrowly linear, widely spreading, sparsely dentate or with a few short lobes each ending in a bristle, acute, sessile, about $2 \mathrm{~cm}$. long, 1 or $2 \mathrm{~mm}$. wide, faintly one-nerved, minutely glandular like the stems; upper leaves but little reduced, nearly entire, otherwise like the lower; heads terminating leafy-bracted branches of an open cyme; involucre hemispheric, about $6 \mathrm{~mm}$. high, 10 to $12 \mathrm{~mm}$. broad; bracts few, loosely imbricated in three or four lengths, appressed, none equaling disk, linear, obtusish, the outer mucronate, herbaceous except near the base (inner ones scarious), minutely viscid-glandular; ray-flowers about 25, the ligules 6 to $8 \mathrm{~mm}$. long; disk-corolla nearly cylindric, gradually and slightly enlarged above the middle, 5 to $6 \mathrm{~mm}$. long; lobes lanceolate, 0.7 to $1 \mathrm{~mm}$. long; style-branches scarcely exserted, 1 to $1.5 \mathrm{~mm}$. long, the thick appendage much shorter than stigmatic portion; achenes turbinate, less than $2 \mathrm{~mm}$. long, densely white-villous; pappus of 30 to 40 ; slender bristles, the longest about equaling corolla and slightly dilated below, the others of various lengths, all reddish brown. (Fig. 11.)

A rare species known from but few collections, these from southern Texas. Low prairies, near Houston, September-October, Wright (Gr, type specimen); Houston, Fisher 199 (Gr, US); $6.4 \mathrm{~km}$. north of Cypress, October 10, 1897, Thurow (UC, US, Gr); Harris County, Thurow $31(\mathrm{Gr})$. 


\section{SYNONYMS}

1. Aster aureus O. Kuntze, Rev. 317, 1891.

2. Sideranthus aureus Small, Fl. S. E. U. S. 1186, 1903.

\section{RELATIONSHIPS}

When first described this species was thought to be a perennial, but a later collection (by Thurow) demonstrates that the root is of only annual duration. This confirms the position near Haplopappus phyllocephalus and $H$. stenolobus, which two species it resembles also in the few-seried bracts of the involucre and in the short and thick stylar appendages. Its origin probably has been through the most southern form of phyllocephalus, that is, subsp. primitivus or some similar type perhaps now extinct. If this is correct, it has progressed through a reduction in the size of heads and flowers, through the development of a much more slender habit, and, in common with most other species, through a loss of red pigment from the ray-flowers. It is an easterly development suited to a warm and moist habitat.

\section{Haplopappus stenolobus (Greene)}

An erect annual, 2 to $5 \mathrm{dm}$. high, with straight taproot and ascending branches from above the base; branches striate, gray or reddish brown, coarsely glandular-scabrid; principal leaves oblong or lanceolate in outline, spreading, pinnately once or twice divided into linear divergent lobes, each lobe ending in a short mucro, the entire leaf 2 to $5 \mathrm{~cm}$. long, 10 to $30 \mathrm{~mm}$. wide, rather thin, without prominent veins except sometimes the midvein, glandularscabrid; upper leaves reduced in size and number, less parted, some of them simply lobed; heads solitary, terminating peduncle-like branches 3 to $15 \mathrm{~cm}$. long; involucre depressedhemispheric, the base upturned, 7 or $8 \mathrm{~mm}$. high, 10 to $15 \mathrm{~mm}$. broad; bracts numerous, loosely imbricated in about 3 lengths, more or less squarrose, the longest equaling the disk, linear-acuminate, ending in a short cusp, herbaceous throughout or the inner scarious at least toward the base, glandular-scabrid; recep-

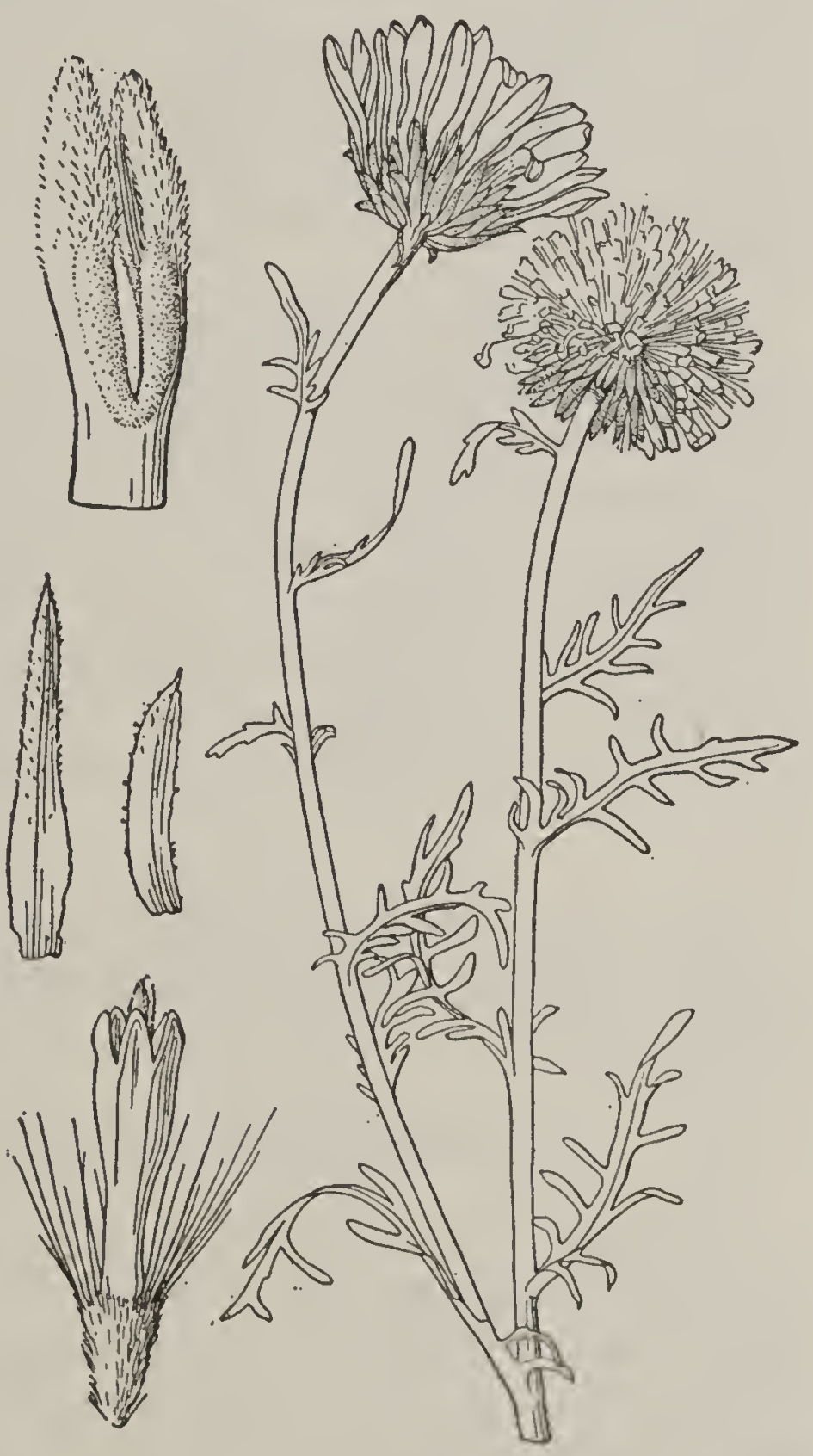

Fig. 12-Haplopappus stenolobus

tacle alveolate; ray-flowers about 20 to 30 , the ligules 9 to $12 \mathrm{~mm}$. long, yellow; disk-corolla gradually enlarged upward, 3.5 to $4.5 \mathrm{~mm}$. long, glabrous; lobes lanceolate, 0.6 to $1 \mathrm{~mm}$. long, glabrous or puberulent; style-branches scarcely exserted, about $1.5 \mathrm{~mm}$. long, the thick obtuse 
appendage about as long as stigmatic portion; achenes turbinate, 5-angled, 1-nerved between the angles, $2 \mathrm{~mm}$. long, densely silvery villous; diskpappus of rather few unequal bristles, the larger ones distinctly flattened toward base, all much shorter than corolla. (Eriocarpum stenolobum Greene, Erythea 2:109, 1894.) (Fig. 12.)

Known only from the State of Chihuahua, Mexico. Type locality, not specifically stated, but reference is made to Pringle's Mexican collections. The first of the following is best taken as the type: sandy flats, Arroyo Ancho, Sierra Madre, Chihuahua, October 16, 1887, Pringle 1303 (Greene, K, Gr); Sierra Madre, Pringle 1646 (UC, Del, B); southwestern Chihuahua, Palmer 408 (Gr).

\section{SYNONYMS}

1. Eriocarpum stenolobum Greene, Erythea 2:109, 1894.

2. Haplopappus tenuilobus Gray in Greene, 1. c. Published only in synonymy, since it appeared only on labels until mentioned by Greene.

\section{RELATIONSHIPS}

The specific name suggests the most striking feature of this species. The foliage is so variable in neighboring species, however, that the long, slender lobes of this one will not suffice always to distinguish it. The most dependable characters are found in the very short disk-corollas and pappus. The latter is so abbreviated that even the longest bristles never approximate the corolla in length, and often they are only about one-half as long.

Haplopappus stenolobus is most closely related to $H$. phyllocephalus, the connection apparently being through subspecies primitivus of the latter. The present species and primitivus have a similar habit, practically identical involucres, these with recurving bracts, and closely similar stylebranches and pubescence. The changes which produced stenolobus involved a reduction in the size of corollas and pappus, the complete loss, as far as known, of the red pigment in the ligules, and at the same time a lobing of the foliage carried beyond anything known in primitivus. It is a northwestern derivative apparently of limited distribution.

\section{ECOLOGY}

The only ecologic information at hand concerning this rare species is that it inhabits sandy flats and alluviums of cañons in the Sierra Madre of Chihuahua, and that it grows only after summer rains.

\section{Haplopappus gymnocephalus DC., Prodr. 5 :346, 1836}

A suffruticose perennial, 2 to $4 \mathrm{dm}$. high or perhaps more, the stems ascending; bark pale gray, becoming dark in age; branches with prominent striae leading to the leaf-bases, densely and finely scabrid and also more or less glandular; principal leaves oblong, ascending, serrate with bristle-tipped teeth, rounded to the obtuse apex, slightly narrowed to a half-clasping base, 1.5 to $3 \mathrm{~cm}$. long, 4 to $6 \mathrm{~mm}$. wide, with prominent midrib and sometimes two additional parallel nerves, the cross-veinlets obscure, scabrid and glandular like the stems; upper leaves similar, moderately reduced in size; heads solitary and terminal or two on short leafybracted peduncles; involucre depressed-hemispheric, 7 to $8 \mathrm{~mm}$. high, about 
$15 \mathrm{~mm}$. broad; bracts numerous, imbricated in 5 or 6 lengths, the longest equaling disk, appressed or variously curved, linear-lanceolate, acuminate to a usually curved awn, rigid, finely scabrous and glandular (especially in the type); receptacle alveolate, the walls splitting into scales 0.5 to $1 \mathrm{~mm}$. long; ray-flowers 40 or more, the ligules 10 to $15 \mathrm{~mm}$. long, rose-pink (said to be sometimes yellow); disk-corolla gradually enlarged upward from near middle, 5 to $5.5 \mathrm{~mm}$. long, usually puberulent; lobes ovate, 0.6 to $0.8 \mathrm{~mm}$. long, puberulent or glabrous; stylebranches well exserted, about 1 to 2 $\mathrm{mm}$. long, the appendage much longer than stigmatic portion (usually 2 or 3 times as long), very slender; achenes short-turbinate, about $2.5 \mathrm{~mm}$. long, shaggy with long villous hairs; diskpappus of rather few unequal rigid bristles, the longest about equaling corolla, brown. (Fig. 13.)

In the mountains from western Texas and New Mexico to the vicinity of Mexico City. Type locality, near the city of Mexico. Texas: Guadalupe Mountains, Havard 87 (Gr). New Mexico: White Mountains, Lincoln County, 2,072 meters altitude, Wooton 251 (UC, Del, B, K, R, type collection of Eriocarpum serratum, minor variation 4); Cloudcroft, Schulz 317 (Gr, US); along Tularosa Creek, Otero County, August 18, 1899, Wooton (Gr, US); Lincoln Forest, Chapline 416 (Gr); Gray, Lincoln County, Skehan 72 (Gr, US, Del, R, UC). Coahuila: Sierra de la Paila, Purpus 4796 (UC). Mexico: "Environs de Mexico," Berlandier 588 (DC, one of the types). Puebla: Hueyotlipan, June 15, 1908, Nicolas (Del, US); Rancho Posada, 2,194 meters altitude, Nicolas 115 (Montp). (Other collections, almost

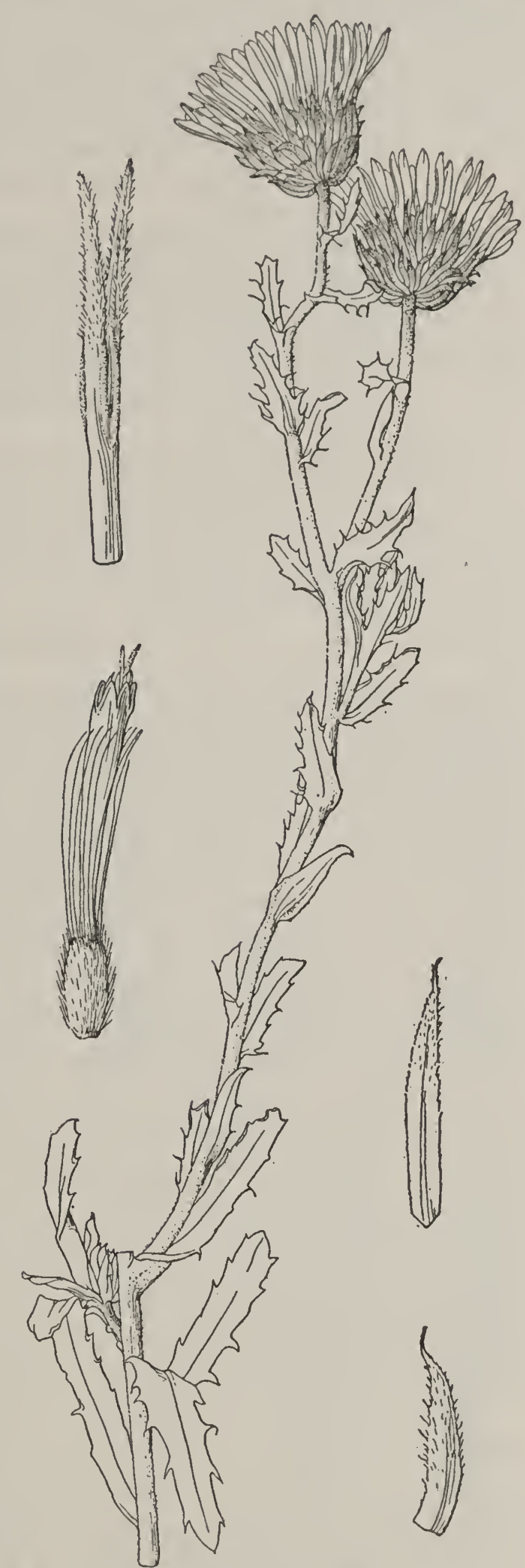

FIG. 13- IIaplopappus gymnocephalus certainly of this species, but not at the moment available for verification, are from Lomas and Santa Fé, State of Mexico; San Luis Potosi; and Acatzinco, Puebla.)

\section{MINOR VARIATIONS AND SYNONYMS}

1. Aster gymnocephalus Gray, Proc. Am. Acad. 15:32, 1879-H. gymnocephalus. Transferred to Aster by Gray, with the statement that "the rays are bright violet-purple." The reference to Botanical Magazine, pl. 6549, probably is erroneous. This plate appears to represent some other plant. 
2. Eriocarpum blephariphyllum Greene, Erythea 3:14, 1895. Based upon H. blephariphyllus, which see.

3. E. gymnocephalum Greene, 1. c. 2:109, 1894-H. gymnocephalus.

4. E. serratum Greene, Bull. Torr. Club 25:119, pl. 331, figs. 3, 4, 1898. Specimens of the type collection from White Mountains, New Mexico (Wooton 251), have been compared with the types of gymnocephalus (Berlandier 588) and no differences could be found, except that the northern plants taken as serratum are less densely scabrid and less glandular. Greene's statement that the pappus is little longer than the achene is misleading, for it is several times as long.

5. Haplopappus blephariphyllus Gray, Pl. Wright. 1:97, 1852. This has been reduced to gymnocephalus by Gray (under Aster, Syn. Fl. $1^{2}: 205,1884$ ). After examining the type collection, Greene maintained that the two are most unlike each other, blephariphyllus having more the foliage, habit, and inflorescence of Grindelia inuloides (Greene, Erythea 3:14, 1895); but the present writer, who has studied both types, is unable to recognize any significant difference.

6. Machaeranthera setigera and $\beta$ latifolia Nees, Linnaea $19: 722$, 1847. From the brief descriptions these seem to be leaf-forms of $H$. gymnocephalus.

7. Sideranthus serratus Standl., Contr. U. S. Nat. Herb. 13:222, 1910; Wooton and Standl., Contr. U. S. Nat. Herb. 19:664, 1915. Based upon Eriocarpum serratum, which see.

\section{RELATIONSHIPS}

Perhaps no species of Haplopappus has given so much difficulty as to its generic placement as has H. gymnocephalus. By all criteria, however, except that of color, the plant is plainly a member of the section Blepharodon. It is, in fact, so closely connected with $H$. spinulosus scabrellus that the two are sometimes distinguished only with great difficulty. Because of the roseate ligules, Gray has transferred the species to Aster. This would render easy the identification of the two genera, but convenience can not be permitted to outweigh the advantages of a natural grouping. When Gray made the transfer, the value of color was rated higher than at present. Since that time it has been found that pink or reddish ligules may be expected occasionally also in several other species of undoubted Haplopappus, particularly in $H$. phyllocephalus and $H$. spinulosus of this same section, and in H. macrocephalus and other species of South America. It is thus seen that even as a matter of convenience the color character can not be universally used. In transferring the present species to Aster, Gray placed it in the section Machaeranthera, but this has not the short pappus of unequal awn-like bristles found in the present species, nor has it the densely silky achenes (Greene, Erythea 2:110, 1894).

The conclusion, therefore, is that the relationships of this species are with $H$. spinulosus through its subspecies scabrellus and with $H$. phyllocephalus, and that there has been a previous connection, long since broken, with South American species of the macrocephalus group.

Due to lack of knowledge of the type specimens, error has crept into the description of this species. As a result, entirely distinct forms have sometimes been included and this in turn has led to the redescription of gymnocephalus itself as new. The type collections at the DeCandolle Herbarium comprise several minor forms, but all have a peculiar stamp, which holds them within a single species. They are woody-based plants with strict leafy stems, the leaves oblong and bristly serrate, the heads broad and round. Some have involucral bracts rather broadly lanceolate; others have more numerous and narrower bracts, more inclined to spread or 
curve irregularly. Since all of these came from the vicinity of the City of Mexico, it is assumed that the variations just mentioned are fluctuating and not of specific value. These southern plants are more densely glandular than those from farther north, but much too little is known as to forms in the intervening territory to justify a segregation into taxonomic units.

\section{ECOLOGY}

This is a shrubby-based perennial of arid districts. In New Mexico it belongs to the Transition Zone and it is probable that throughout its range it is restricted to this zone or its borders. The altitudinal distribution, as far as known, is 1,800 to 2,500 meters. All flowering specimens at hand were collected between July and October.

\section{Haplopappus nuttalli Torr. et Gray, Fl. N. Am. $2: 242,1842$}

A perennial herb or subshrub from a strong woody caudex, 1 to $3 \mathrm{dm}$. high, sometimes depressed and then densely cespitose (minor variation 3); bark gray to nearly white, darkening only on woody basal portions; branches obscurely striate, tomentulose or strigose to nearly glabrous; principal leaves oblong-spatulate, erect or ascending, low-dentate to serrate with bristle-tipped teeth, obtuse, sessile, half-clasping, 2 to $3.5 \mathrm{~cm}$. long, 4 to $10 \mathrm{~mm}$. wide, with prominent midrib often paralleled by two fainter nerves, the cross-veinlets evident only in glabrate forms, strigose to glandular-scabrid, sometimes glabrate; upper leaves similar, little or not at all reduced; heads solitary and terminal or several and cymosely arranged at ends of branches, the peduncles then 0.5 to $5 \mathrm{~cm}$. long and nearly naked to foliose-bracted, these bracts sometimes overtopping the heads (as in a part of the type collection); involucre campanulate, 7 to $10 \mathrm{~mm}$. high, 8 to $10 \mathrm{~mm}$. broad; bracts few, imbricated in about three lengths, about equaling disk, lanceolate (outer) to linear-oblong, pungently acute, appressed or only slightly spreading, mostly green, especially toward tip, glandular-scabrid; receptacle alveolate, the walls breaking into short teeth; rayflowers none, disk-corolla moderately enlarged above the middle, 6.5 to 7 or rarely $8 \mathrm{~mm}$. long, glabrous except lobes; lobes

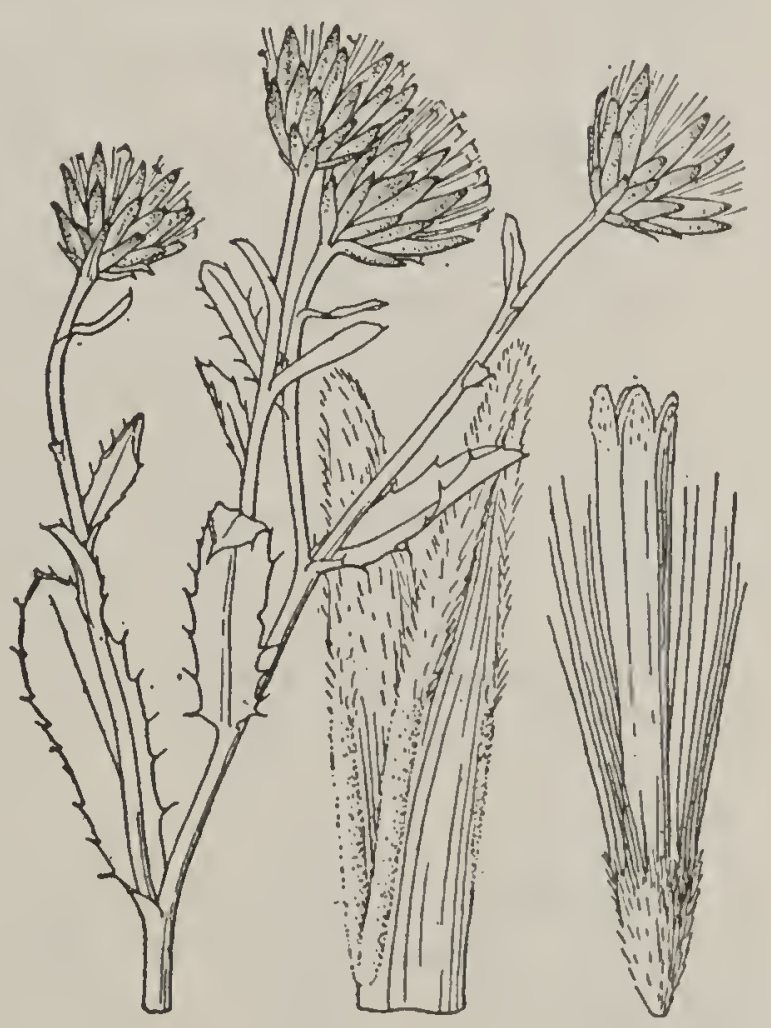

Frg. 14-Haplopappus nuttalli lanceolate, nearly $1 \mathrm{~mm}$. long, puberulent; style-branches slightly exserted, 2 to $3 \mathrm{~mm}$. long, the acuminate appendage equaling or longer than stigmatic portion (except minor variation 3); achenes prismatic-turbinate, 2.5 to $3 \mathrm{~mm}$. long, densely sericeous-canescent; disk-pappus of unequal bristles, some slightly flattened, the longest about equaling corolla, reddish brown. (Eriocarpum grindelioides Nutt., Trans. Am. Phil. Soc. II, $7: 321,1840$.) (Fig. 14.) 
Rocky hills and mesas from Saskatchewan and Assiniboia south and west to New Mexico and southeastern Nevada. Type locality, "Shelving rocks in the Rocky Mountain range, Oregon," but the types (BM, Phila) labeled merely as "R. Mts.," and the species does not occur so far west as the present State of Oregon. SASKATCHEWAN: without locality, Bourgeau (Gr, K). Assiniboia: Cypress Hills, Macoun 5033 (Gr) and 10874 (K). Montana: Great.Falls, Williams 69 (US); Bull Mountains, August 11, 1882, Canby (Gr); north of Billings, August 16, 1882, Canby (Field); Park County, 1889, Tweedy (US). South Dakota: Cave Hills, Harding County, Over 11397 (US); Hot Spring, Black Hills, Rydberg 760 (US). Nebraska: Kimball County, Rydberg 143 (US). Wyoming: Wind River, Parry 163 (Gr, P); Natrona County, Goodding 222 (R, Gr, Del); Fort Bridger, July, 1873, Porter (Gr, Phila); Evanston, August 5, 1883, Sanford (UC); Laramie, Nelson 7630 (Gr, R, B, K). Colorado: Grand Junction, Crandall 292 (Gr); Paonia, Delta County, Eggleston 14962 (Gr); Paradox, Montrose County, Walker 149 (R, Gr, B); Naturita, Payson 484 (R, Gr); Mancos, July, 1890, Eastwood (US); Huerfano, Parry 98 (Gr). UтAн: Weber Valley, July 1869, Watson 581 (US); Price, June 20, 1898, Stokes (UC); near Orangeville, Jones $5464 b$ (US, UC); near Wilson Mesa, Grand County, Rydberg and Garrett 8406 (US); Cannonville, Jones 5310 (US, UC); Deep Creek, June 6, 1891, Jones (UC). NevadA: Highland Range, Purpus 6322a (UC); Mount Irish, Purpus 6322 (US, P, K, UC); Morey Range, 1898, Purpus (UC). New Mexico: Aztec, Jones (Po); near Farmington, Standley 7111 (US). ARIzona: Navaho Reservation, Vorhies 39 (Gr); Flagstaff, August 13, 1884, Jones (US).

\section{MINOR VARIATIONS AND SYNONYMS}

1. Aster nuttalli O. Kuntze, Rev. 318, 1891-H. nuttalli.

2. Eriocarpum grindelioides Nutt., Trans. Am. Phil. Soc. II, $7: 321,1840$. (Not Haplopappus grindelioides DC., 1836.)-H. nuttalli.

3. H. nuttalli, as in the typical form, but closely cespitose and with leaves all crowded at the base. The best example of this is from Deep Creek, Utah (June 6, 1891, Jones, UC). In this the very compact plants grow in rounded, leafy tufts only 2 or $3 \mathrm{~cm}$. high, from which the nearly naked peduncles protrude for a distance of about $2 \mathrm{~cm}$. In the cited collection the appendage is decidedly shorter than the stigmatic portion of the style-branch (appendage 0.8 , stigma 1.2), which would seem to indicate a definite specific segregation.

4. Sideranthus grindelioides Britton in Rydb., Bull. Torr. Club 27:620, 1900-H. nuttalli.

\section{RELATIONSHIPS}

In habit, foliage, development of leaf-bristles, and style-branches, this is very representative of the section Blepharodon, of which it is, indeed, the taxonomic type. It is, however, the most distinct species of its section. It most closely approaches Haplopappus spinulosus, but has an involucre of much firmer and relatively broader bracts and the heads are more narrowed at base, in some cases approaching the turbinate shape. The uniform suppression of ray-flowers is unknown elsewhere in Blepharodon, except in the very different $H$. brickellioides. Because of these marked differences the origin of nuttalli is difficult to trace and it is therefore indicated in the phylogenetic scheme as having descended from some southern form now extinct. Its northerly distribution is further indication that the species is not of recent origin. 


\section{ECOLOGY}

This is a rather common species in the more arid portions of the Upper Sonoran and Transition zones of western mountains. In the south it ascends to as high as 2,200 meters on warm slopes, while in the north it descends to 1,000 meters or less. It inhabits rocky slopes and poor soils, especially alkaline clays, and is common in the bad lands. Among its adaptations to such habitats is noted especially the deep and well-developed root system and the heavily cutinized, canescent foliage. At high altitudes the plants are much dwarfed. In some cases this dwarfing is associated with other features suggestive of an hereditary segregation (see under minor variation 3). The flowering period extends from May to August.

\section{Haplopappus arenarius Benth., Bot. Sulph. 24, 1844}

A compact subshrub, with soft wood, 1.5 to $10 \mathrm{dm}$. high, the stems much branched and spreading to form rounded bushy plants; bark changing from gray to dark brown; branches and twigs with striae leading to leaf-bases, coarsely and densely glandularpubescent; principal leaves obovate-spatulate to oblanceolate-spatulate, ascending or spreading, from nearly entire to obtusely dentate, obtuse, subclasping, 1.5 to $3.5 \mathrm{~cm}$. long, 3 to $12 \mathrm{~mm}$. wide, with prominent midnerve, the lateral nerves hidden, densely and coarsely glandularpubescent; upper leaves similar but narrower; heads mostly solitary, terminating divergent leafy branches (these 2 to $10 \mathrm{~cm}$. long); involucre broad-hemispheric, 6 to $8 \mathrm{~mm}$. high, 12 to $18 \mathrm{~mm}$. broad; bracts numerous, imbricated in 5 or 6 series, all much shorter than disk, linear, acute or acuminate, strongly squarrose above the middle, thick and herbaceous except margins, densely and finely stipitate-glandular; ray-flowers 30 to 50 , the ligules 6 to $10 \mathrm{~mm}$. long; disk-corolla abruptly expanded above the middle, the whole 5 to $6.5 \mathrm{~mm}$. long, glabrous; lobes lanceolate, 0.5 to $0.8 \mathrm{~mm}$. long, glabrous or slightly ciliate; style-branches short-exserted, 1.2 to $1.6 \mathrm{~mm}$. long, the blunt appendage much shorter than stigmatic portion (usually one-half as long); achenes cylindric-turbinate, 2 to $2.3 \mathrm{~mm}$. long, multistriate beneath the dense ascending pubescence; disk-pappus unequal, the longest

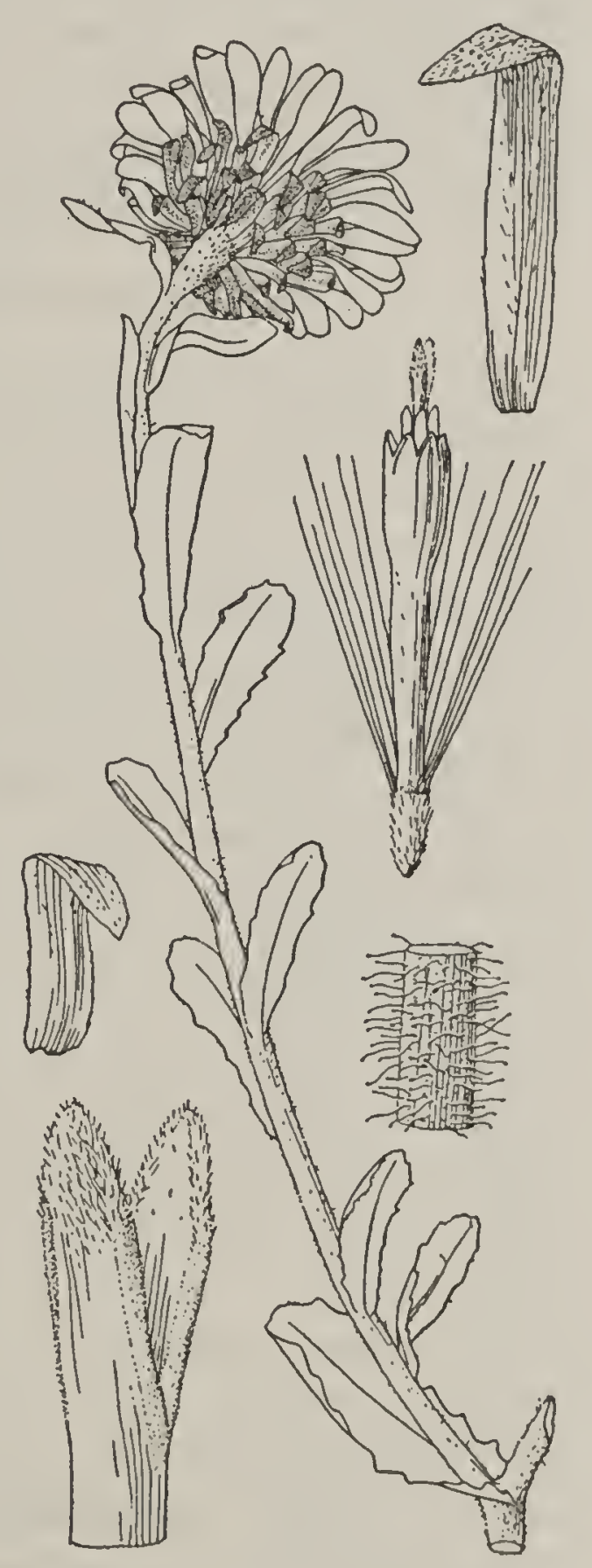

Fig. 15-Haplopappus . arenarius bristles about equaling corolla, fragile, scanty, brown. (Fig. 15.)

Cape region of Lower California. Type locality, Cape San Lucas. San Jose del Cabo, October 6, 1890, Brandegee (Gr, UC); same locality, May 1899, Grabendörfer (UC); type specimen (K); west coast, Cape Region, November 1902, Brandegee (UC); west coast, south of Pescadero, on rocks, November 1902, Brandegee (UC). 


\section{MINOR VARIATIONS AND SYNONYMS}

No synonyms appear under this species and no variations have been described. Two varieties formerly referred to $H$. arenarius (incisifolius and rossi) will now be found under $H$. spinulosus.

\section{RELATIONSHIPS}

The half-woody habit and large, many-flowered heads suggest that this species may be one of the most primitive of its section. It is even possible that it represents the early stock from which the section Hazardia has sprung, the strongly squarrose bracts being especially noteworthy in this connection. In other features, however, it connects too closely with Haplopappus spinulosus, as will be noted under subspecies incisifolius of the latter.

\section{ECOLOGY}

Haplopappus arenarius is a characteristic psammophyte of warm coasts. It here grows so near the water that it is to be classed also as a halophyte. The spreading habit and the thick, heavy foliage, almost covered by shortstalked glands, are associated with this habitat. Plants from rocky places have reduced leaves and heads, the former with deep dentations. Flowering apparently follows the rainy seasons.

\section{Haplopappus spinulosus (Pursh) DC., Prodr. 5:347, 1836}

A perennial herb with a woody caudex, the branches often also woody toward the base, 2 to $6 \mathrm{dm}$. high, the stems commonly erect or ascending, sometimes divergent at base (especially in subsp. incisifolius); bark light green or gray, gray or brown on woody parts; branches striate, from nearly glabrous to scabrid or tomentose, usually also glandular; principal leaves oblong-spatulate or linear-spatulate in outline (broad when much parted), ascending, from nearly entire to twice pinnately parted, sometimes all dentate or serrate, sometimes the lower parted and the upper nearly entire, or all may be parted into narrow lobes, acute or somewhat obtuse, usually bristle-tipped, as also the teeth or lobes when present, sessile by a narrow but subclasping base, 1.5 to $6 \mathrm{~cm}$. long, 2 to $10 \mathrm{~mm}$. wide, the midnerve prominent, the lateral nerves either prominent or obscure, pubescent like the stems; upper leaves slightly to strongly reduced, often more nearly entire; heads solitary, terminating leafy or naked branches, these pedunculiform when short; involucre hemispheric, 5 to $8 \mathrm{~mm}$. high, 8 to $12 \mathrm{~mm}$. broad; bracts numerous, imbricated in 4 to 6 series, all shorter than disk, linear, acute or attenuate usually to a bristle, mostly erect and appressed when young, spreading and reflexed in age (but almost never squarrose from the middle), thin, chartaceous, but with a green medial portion, from minutely glandular to glandular-scabrid or tomentulose; receptacle alveolate, not chaffy; ray-flowers 15 to 50 , the ligules 8.5 to $10 \mathrm{~mm}$. long; diskcorolla abruptly or somewhat gradually expanded above the middle, the whole 4.5 to $6 \mathrm{~mm}$. long, glabrous or occasionally pubescent; lobes ovate, 0.6 to $0.8 \mathrm{~mm}$. long, usually glabrous; style-branches short-exserted, 1 to $1.5 \mathrm{~mm}$. long, the blunt appendage much shorter than stigmatic portion (rarely more than one-half as long); achenes narrow-turbinate, 2 to 2.5 $\mathrm{mm}$. long, striate, but striae hidden by the dense appressed pubescence; disk-pappus unequal, the longest bristles about as long as corolla, the 

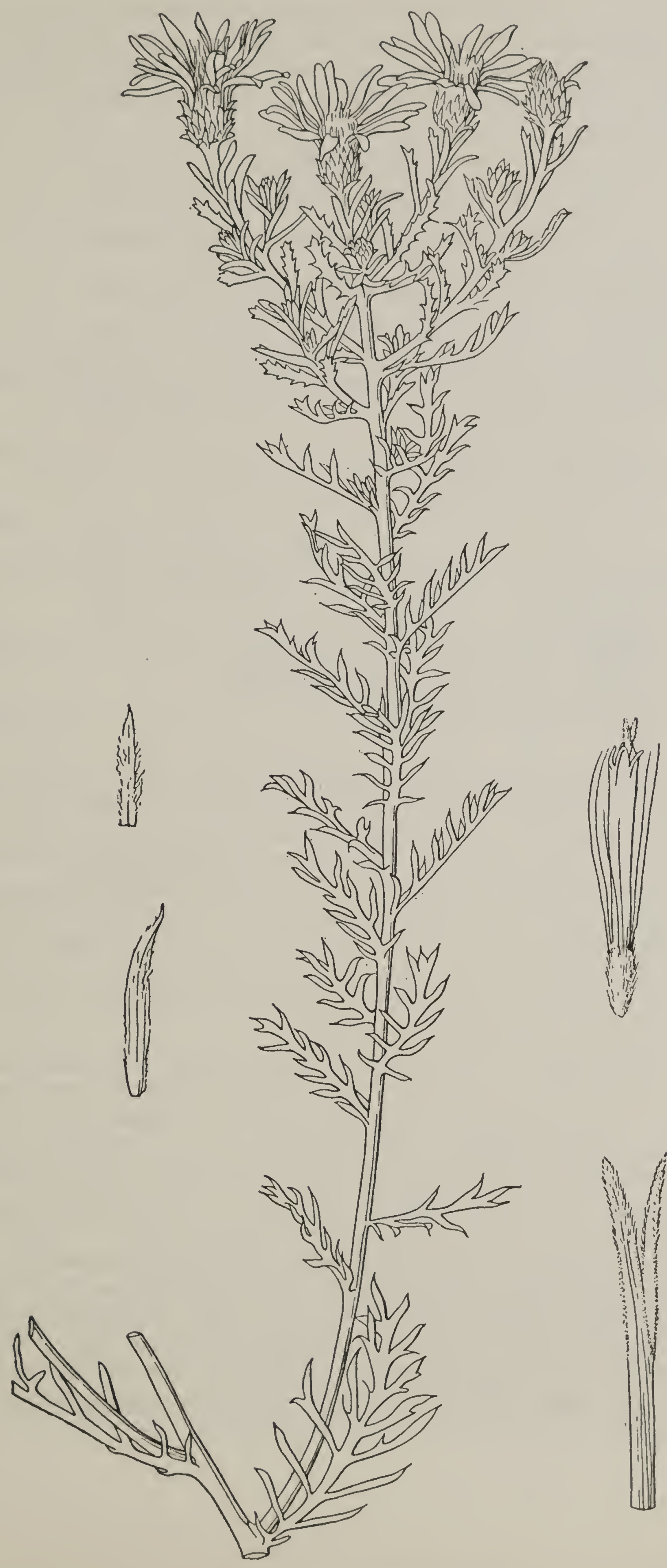

Fra. 16-Haplopappus spinulosus typicus

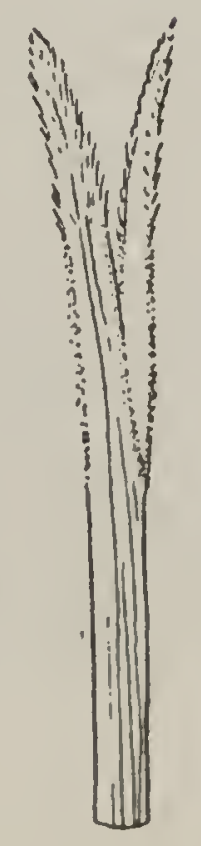


others varying to one-half as long, all fragile, rather scanty, brown. (Amellus spinulosus Pursh, Fl. Am. Sept. 2:564, 1814.) (Figs. 16 to 19.)

Western North America, at middle and lower altitudes; Alberta, Saskatchewan, and Minnesota to Oklahoma, Coahuila, Lower California, Idaho, and Montana.

\section{SUBSPECIES}

Key to the Subspecies of Haplopappus spinulosus

Herbage densely scabrid or stipitate-glandular to cinereous or tomentose.

Peduncles obvious, naked or with much reduced leaves. (No tomentum.)

Heads medium; involucre 10 to 12 or $15 \mathrm{~mm}$. broad when pressed; leaves linear-oblong, mostly with short broad teeth or lobes; herbage scabrous or cinereous and glandular............(a) scabrellus

Heads large; involucre 12 to $20 \mathrm{~mm}$. broad when pressed; leaves or their lobes narrowly linear, elongated; herbage glandular, scarcely scabrous or cinereous.................... (b) gooddingi

Peduncles short, leafy or bracted up to the heads or nearly.

Stems decidedly woody, rigidly branched. (Glandular. Lower California.) . . . . . . . . . . . . . . . . . . .

Stems herbaceous above the woody caudex, not rigidly branched.

Herbage more or less tomentose, at least near the heads.......

Herbage scabrid or cinereous but scarcely tomentose, sometimes also glandular.

Puberulence of straight or spreading hairs, obscurely glandular. (e) australis Puberulence mostly of stiff gland-tipped hairs.......... $(f)$ cotula

Herbage glabrous or very sparingly glandular-puberulent.

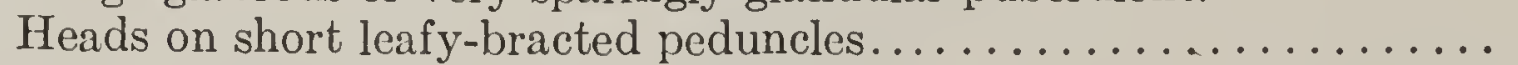

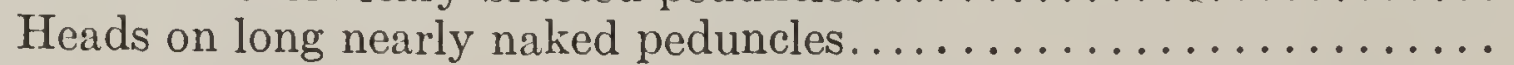

(g) glaberrimus

(h) laevis

10a. Haplopappus spinulosus scabrellus (Greene)-Stems many, typically spreading and woody at base, but more erect and herbaceous above a short woody caudex in some forms, leafy except toward the ends; herbage gray-scabrid, some of the hairs gland-tipped, especially those of the inflorescence, not tomentose; leaves mostly oblong and merely dentate or with short bristle-tipped lobes (bristles wanting in minor variation 32 ), the lower ones pinnatifid or rarely bipinnatifid; heads terminating long peduncles, these with small and remote bracts on the upper part; involucre 6 to 7 or $8 \mathrm{~mm}$. high, glandular-scabrid, not tomentose. (Eriocarpum scabrellum Greene, Erythea 2:108, 1894.)

Plains and mesas from southern Colorado south through Texas, New Mexico, and Arizona as far as Hidalgo, Mexico, north and west to Lower California. Type locality, Los Angeles Bay, Lower California. Colorado: Deer Run, Baker 79 (UC, Gr, US); Montrose, Payson 662 (Gr); Naturita, Payson 496 (Gr, form approaching subsp. australis). Texas: foothills of Davis Mountains, Tracy and Earle 35a (Gr, US). New Mexico: Mesilla, Dona Ana County, Wooton 32 (UC); near Hope, August 3, 1905, Wooton (US, type of Sideranthus viscidus, minor variation 32); near Silver City, Greene 115 (Gr); Burro Mountains, Grant County, Wooton 83 (Gr, UC); Kingston, Sierra County, Metcalfe 1375 (Gr, US). Arizona: mesas near Tucson, May 5, 1884, Pringle (Del); Douglas, Goodding 2261 (UC); Chalcedony Park, near Adamana, Hall 11158 (UC). Nuevo Leon: without exact locality, 1880, Palmer 474 (Gr). Coahuila: Parras, Purpus 1015 
(UC). San Luis Potosi: Guascama, Purpus 5125 (UC). Guanajuato: without exact locality, 1904, Duges 9 (Gr). Hrdalgo: Ixmiquilpan, Purpus 1346 (UC). Zacatecas: near Conception del Oro, Palmer 373 (US, identification doubtful). Durango: vicinity of Durango, 1896, Palmer 278 (UC, Gr); Durango, Nelson 4627 (US). Chinuanua: Santa Eulalia Plains, July 15, 1885, Wilkinson (UC); plains and mesas near Chihuahua, Pringle $15 \% 2$ (UC). Lower California: Todos Santos, Cape Region, Brandegee 287 (UC); Sierra de la Trinidad, Cape Region, November, 1902, Brandegee (U); El Taste, November, 1902, Brandegee (US, UC); La Paz, Palmer 17 (Gr, K, US, UC); La Paz, November 9, 1899, Brandegee (UC, Gr); Santa Cruz, Rose 16851 (US); San Gregorio, February 1, 1889, Brandegee (US, UC); Agua Verde, Rose 16608 (US); San Bartolome Bay, Rose 16197 (US); San Bartolome Bay, April 13, 1897, Brandegee (UC); San Sebastian, April 28, 1889, Brandegee (UC); foothills Los Angeles Bay, Gulf of California, December 1887, Palmer 539 (UC, Gr, K, US, type collection).

10b. Haplopappus spinulosus gooddingi (Nels.)-Stems more or less crowded, erect or ascending, slender, herbaceous above the woody caudex, or lower portion of stems themselves also woody (commonly 2 to $4 \mathrm{dm}$. high), the upper leaves much reduced; herbage bright green, sparsely to densely stipitate-glandular, rarely cinereous; leaves typically linear and with few teeth or short linear lobes, varying to pectinately pinnatifid with slender divergent lobes (minor variation 17), all leaves and their divisions bristle-tipped; heads terminating elongated branches with remote reduced leaves; involucre 6 or $7 \mathrm{~mm}$. high, densely stipitate-glandular or almost scabrid. (Sideranthus gooddingi Nels., Bot. Gaz. $37: 266$, 1904.) (Fig. 17.)

Southern Nevada, northern Arizona, and southeastern California. Type locality, "The Pockets," southern Nevada. Nevada: type collection, Gooddingi 667 (US, R) ; rocky slopes, Las Vegas Mountains, Gooddingi 2376 (UC, Del, Gr, R); Muddy Valley, Lincoln County, Kennedy and Gooddingi 73(UC, R); Logan, Clark County, Kennedy 1837 (UC, US, Del, K, Gr); St. Thomas

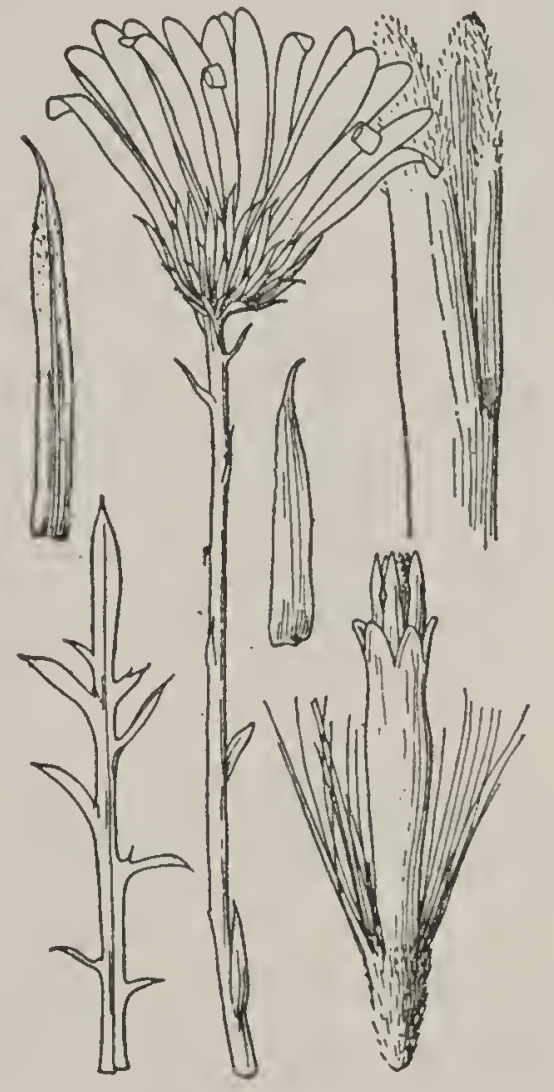

Frg. 17-Haplopappus spinulosus gooddingi

Cañon, Jones 5069; Mesquite Well, Goodding 2251 (R). Arizona: Diamond Creek Cañon, April 1893, Wilson (Greene, minor variation 17). California: $18 \mathrm{~km}$. west of Needles, 200 meters altitude, Munz and Harwood 3603 (UC, Po); near The Needles, Jones 3857 (US, Del, Po).

10c. Haplopappus spinulosus incisifolius (Johnston)-Stems spreading, rigidly much branched to form rounded bushes, decidedly woody well above the base, leafy nearly to the heads; herbage green, minutely stipitateglandular, rarely with traces of tomentum (in the type collection); leaves incisely serrate to bipinnatifid, the teeth and lobes mostly bristle-tipped; heads terminating short divergent pedunculiform branches, these with leaves reduced above to linear bracts; involucre 6 or $7 \mathrm{~mm}$. high, minutely 
stipitate-glandular, neither tomentose nor scabrid, the bracts mostly erect or outwardly curved in age but squarrose in most heads of the type, (H. arenarius var. incisifolius Johnston, Proc. Calif. Acad. Sci. IV, 12:1190. 1924.) (Figs. 18 and 19.)

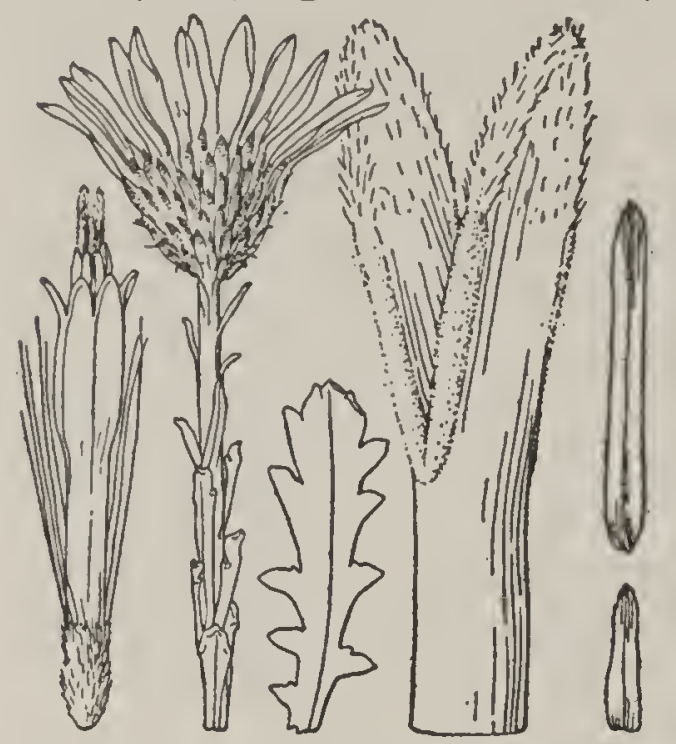

FIG. 18-Haplopappus spinulosus incisifolius

Islands in the Gulf of California. Type locality, South San Lorenzo Island. Type collection, Johnston 3529 (SF, UC); San Diego Island, on slopes near the sea, Johnston 3930 (SF, UC); Santa Cruz Island, Johnston 4096 (SF, UC); Coronados Island, Johnston 3754 (SF, UC, a low spreading form with small leaves less deeply serrate).

10d. Haplopappus spinulosus typicusStems many, erect or curved-ascending, herbaceous above the short woody caudex, leafy throughout; herbage more or less white-tomentulose, at least toward the heads; leaves mostly pinnatifid into linear bristle-tipped lobes, the lower ones commonly bi- or tri-pinnatifid; heads terminating leafy branches or short bracted peduncles; involucre 5 to $6 \mathrm{~mm}$. high, somewhat tomentose, scarcely if at all glandular. (Amellus spinulosus Pursh, Fl. Am. Sept. 2:564, 1814.) (Fig. 17.)
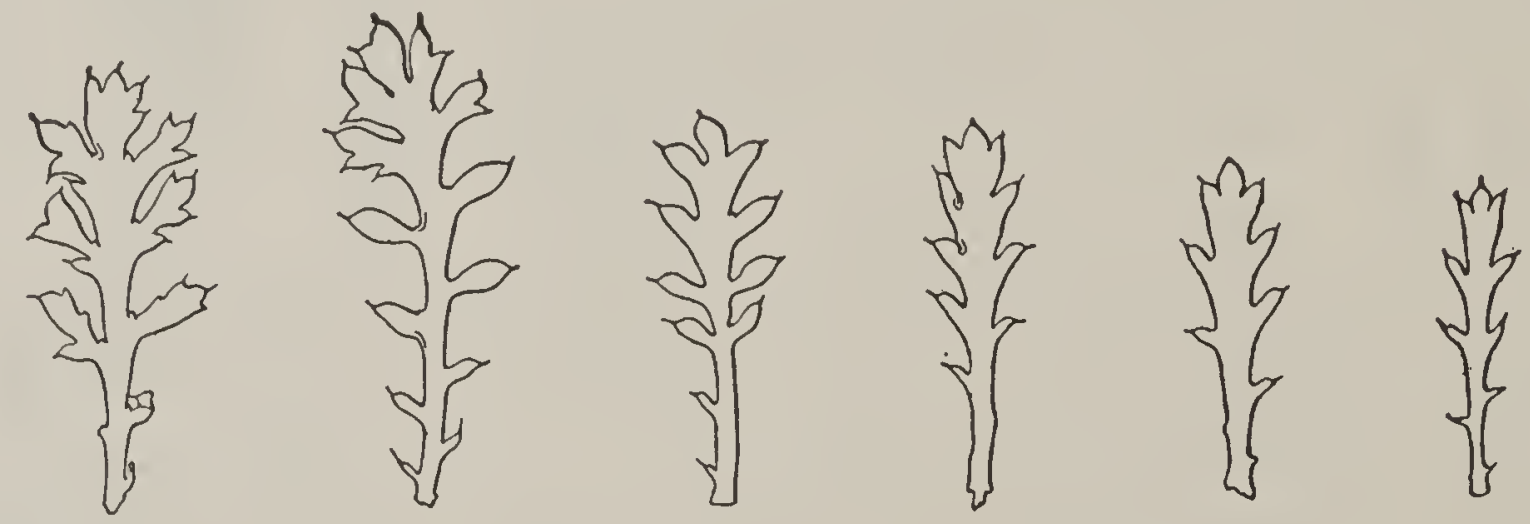

Fig. 19-Haplopappus spinulosus incisifolius. Variation in leaves, all from one plant (on Univ. Calif. sheet 251748)

Saskatchewan and Minnesota to Texas, Coahuila, Colorado, and Alberta. Type locality, in open prairies on the Missouri. "Prairies, Sept. 15, 1804," Lewis (Phila, type specimen). SaskatchewaN: without exact locality, 1857-58, Bourgeau (Gr, P, B, K). North Dakota: Gooly's Slough, Hawkinson, Metcalfe 175 (Gr); Leeds, August 2, 1900, Lunnell (Gr). South Dakota: Iroquois, August 7, 1894, Thornber (Gr, UC); Black Hills, 1887, Forwood (K). Minnesota: Brown's Valley, Traverse County, September 1893, Sheldon (Gr, B, UC). Iowa: Missouri Valley, Pammel 302 (Gr); Sioux City, Pammel 41 (Gr, B). Kansas: Selkirk, Wichita County, August 8, 1892, Reed (UC). Texas: Dalhart, W. W. Jones 350 (Gr). Colorado: Mitchell County, June 9, 1900, Eggert (UC); Taylor County, Reverchon 1358 (Gr, UC). Coahuila: hills near Diaz, Pringle 8315 (Gr). New Mexico: Santa Fe, Fendler $546(\mathrm{Gr})$; near Pecos, San Miguel County, Standley 4912 (Gr); Vermejo Park, August 31, 1913, Wooton (Gr); White Mountains, Lincoln County, Wooton 518 (Greene, US, type collection of Eriocarpum wootoni, minor variation 8); Albuquerque, September 9, 1894, 
Herrich (US, same variation); near Farmington, Standley 7104 (US, same variation). Colorado: Arboles, Baker 680 (UC, Gr); Cañon City, Fremont County, Brandegee 505 (UC); Denver, Eastwood 67 (UC); north of Fort Collins, September 9, 1919, Hall (UC). Wroming: Laramie, Nelson Sors (Gr, K); Cold Spring, Nelson 456 (Gr.). Montana: Bear Tooth, August 21, 1898, Brandegee (UC); Colgate, Dawson County, Sandberg, MacDongal, and Heller 1000 (Gr, B); Glendive, September 1892, Sandberg (Gr). Alberta: Thomas Lake, Macoun and Herriot 72810 (Gr); vicinity of Rosedale, Moodie 1176 (Gr); Fort McLeod, Macoun 10872 (K, Greene).

10e. Haplopappus spinulosus australis (Greene)-Stems several or numerous, mostly crect, herbaceous above the short woody caudex, leafy to summit; herbage pale, rough with a short spreading puberulence, also minutely glandular, scarcely if at all tomentose; leaves pinnately toothed to pinnatifid, the teeth or lobes mostly bristle-tipped, the lower leaves with lobes again dentate or parted; heads terminating leafy pedunculiform branches; involucre about $6 \mathrm{~mm}$. high, puberulent and minutely glandular. (Eriocarpum australe Greene, Erythea 2:108, 1894.)

Southeastern Idaho (?) to southern Colorado, Oklahoma, and southern Texas and New Mexico; reported by Greene also from Arizona and adjacent Mexico. Type locality, not stated. Idaho: Pocatello, August 25, 1892, Mulford (NY, type of Sideranthus turbinellus, minor variation 31). Colorado: Del Norte, Rio Grande County, September 18, 1920, Hall (UC); Salida, Clarke 174 (NY, type of Sideranthus puberulus, minor variation 28); San Miguel County, Walker 446 (Gr, B). Oklahoma: near Waynoka, Stevens 583 and 587 (Gr.) Texas: near Kerrville, Kerr County, Heller 1858 (UC, Gr, slightly tomentose and thus connecting with typicus); El Paso, 1881, Dunn (Greene); foothills of Davis Mountains, Tracy and Earle $35 a$ (Greenc). New Mexico: near Silver City, June 2, 1880, Greene (Greene).

10f. Haplopappus spinulosus cotula (Small)-Stems numcrous, erect or curved-ascending, slender, herbaceous above the short woody caudex, leafy to summit; herbage dull green, densely stipitate-glandular, nearly devoid of other pubescence; leaves all twice pinnately parted into very slender lobes, bristlc-tipped; heads terminating branches leafy almost to the summit; involucre 5 or $6 \mathrm{~mm}$. high, rather densely puberulent with short straight gland-tipped hairs. (Sideranthus cotula Small, Fl. S. E. U. S. 1186 , 1903.)

Known only from type collection, made in Indian Territory in 1868, probably in that portion now included in Oklahoma (Palmer $442 \mathrm{~A}, \mathrm{NY}$ ). 1913.)

10g. Haplopappus spinulosus glaberrimus (Rydb.)-Stems several, nearly erect, herbaceous above the short woody caudex, leafy up to the heads; herbage very pale, glabrous or very sparingly glandular-puberulent; leaves pinnatifid into linear bristle-tipped lobes, the lower sometimes with lobes toothed or again parted; heads terminating short leafy branches; involucre about $5 \mathrm{~mm}$. high, glabrous or minutely glandular. (Sideranthus glaberrimus Rydb., Bull. Torr. Club $27: 621,1900$.) 
Dry plains from South Dakota and Iowa to Texas and New Mexico. Type locality, Nebraska. North Dakota: Maza, Kildahl 54 (R). Wroming: Buffalo, Tweedy 3046 (R). Nebraska: on Middle Loop near Thedford, Thomas County, Rydberg 1403 (Gr); Midden, June 1893, Milligan (US); Niobrara, Clements 2718 (Gr); Longpine, July 2, 1899, Bates (Gr). Iowa: Pammel 302 (US). Colorado: Manitou, Clements 61 (R). Kansas: hills near Osborne City, Shear 116 (Gr, NY); Long Island, August 3, 1884, Hatcher (UC); near Keeney, July 8, 1892, Reed (UC). Oкцанома: near Alva, Ward 68 (US); near Huntsville, May 30, 1896, Blankinship (Gr). Texas: prairie between Victoria and Gonzalia, Trécul 343 (P); Brazos River, Schott 508a (NY, type of Sideranthus machaeranthera, minor variation 26).

10h. Haplopappus spinulosus laevis (Wooton et Standl.)-Stems erect, slender, much branched, the branches ascending, bright green, probably herbaceous above the caudex, sparsely leafy, nearly naked toward the summit; herbage green, smooth, nearly glabrous but with a few stipitate glands near the heads; leaves linear or linear-oblong, entire or sparingly serrate, the teeth inconspicuous or reduced to bristles, apex of leaf ending in a slender bristle; heads naked-pedunculate; involucre scarcely $5 \mathrm{~mm}$. high, very minutely stipitate-glandular and with a few short nonglandular hairs. (Sideranthus laevis Wooton et Standl., Contr. U.S. Nat. Herb.16: 180, 1913.)

Known only from the type specimens, collected on Gypsum Hills near Lakewood, Eddy County, New Mexico, at an altitude of about 1,000 meters, August 6, 1909, Wooton (US).

\section{MINOR VARIATIONS AND SYNONYMS}

1. Amellus ? spinulosus Pursh, Fl. Am. Sept. 2:564, 1814-H. spinulosus typicus.

2. Aster pinnatifidus O. Kuntze, Rev. 316, 1891-H. spinulosus typicus.

3. Dieteria spinulosa Nutt., Trans. Am. Phil. Soc. II, $7: 301,1840-H$. spinulosus typicus, since $H$. spinulosus is cited as a synonym.

4. Diplopappus 'pinnatifidus Hook., Fl. Bor. Am. 2:22, 1834. Generally accepted as synonymous with $H$. spinulosus. From the description and type locality (Jasper Lake, Rocky Mountains) it falls with little doubt into subsp. typicus.

5. Eriocarpum australe Greene, Erythea 2:108, 1894-H. spinulosus australisa.

6. E. scabrellum Greene, Erythea 2:108, 1894-H. spinulosus scabrellus.

7. E. spinulosum Greene, Erythea 2:108, 1894-H. spinulosus typicus.

8. E. wootoni Greene, Bull. Torr. Club 25:120, 1898. A spreading southern form of $H$. spinulosus typicus, with the leaf-lobes perhaps more divaricately spreading than in the average. The heads are more distinctly pedunculate than usual. Type locality, White Mountains, New Mexico, at 1,980 meters altitude.

9. Haplopappus arenarius var. incisifolius Johnston, Proc. Calif. Acad. IV, 12: 1190, 1924-H. spinulosus incisifolius.

10. H. arenarius var. rossi Johnston, 1. c. 1191, 1924. Probably a form of $H$. spinulosus incisifolius, but the plants slender, erect, 5 to $10 \mathrm{dm}$. high. According to Johnston, it suggests $H$. junceus in general contour and habit. The type has markedly reduced foliage. The leaves are only 1 to $4 \mathrm{~mm}$. long, but green, appressed, minutely toothed to incised. The involucral bracts are erect and appressed. San Marcos Island, Johnston 3637 (SF).

11. H. coulteri Harvey et Gray, Pl. Fendl. 76: 1849. A nomen nudum said by Gray to be the same as $H$. spinulosus canescens. The Coulter plants referred to did not come from California, but probably from Texas.

12. H. gooddingi Munz et Johnston, Bull. Torr. Club 49:44, 1922-H. spinulosus gooddingi. 
13. H. spinulosus var. canescens Gray, Pl. Fendl. 75, 1849. A nomen subnudum. (See Blake, Contr. Gray Herb., $52: 23,1917$.

14. H. spinulosus var. genuinus Blake, l. c. 22, 1917-H. spinulosus typicus.

15. H. spinulosus var. glaber Gray, 1. c. 1849, and Pl. Wright. 1:97, 1852. A nomen subnudum. (See Blake, 1. c. 23, 1917.)

16. H. spinulosus var. glaberrimus Blake, l. c., 24, 1917-H. spinulosus subsp. glaberrimus.

16a. H. spinulosus gooddingi Blake, Contr. U. S. Nat. Herb., 25:543, 1925 (without designation of rank) - H. spinulosus subsp. gooddingi.

17. H. spinulosus gooddingi, but with nearly all the leaves pectinately parted into slender divisions. This has received an herbarium name by Greene to indicate the pectinate nature of the foliage (Diamond Creek Cañon, April 1893, Wilson). Apparently the form is a geographic one, since all collections at hand from northern Arizona have leaves of this type, whereas typical gooddingi has not thus far been collected in Arizona, unless near the western border. Most specimens from other States have some leaves as slenderly lobed as those on the Arizona plants, but such foliage is confined for the most part to the lower half of the stems. As intermediate may be cited specimens from Las Vegas Mountains, Nevada (Goodding 2376).

18. H. spinulosus var. scabrellus Blake, Contr. Gray Herb. 52:22, 1917-H. spinulosus subsp. scabrellus.

19. H. spinulosus scabrellus, but stems covered by a white pubescence. The trichomes are very long and appressed to the stem, giving the appearance of a tomentum, but they are straight, not interwoven or cobwebby. The heads terminate mostly straight simple stems from near the base, the plant thus having a very strict habit. The only collections are from San Sebastian (April 29, 1889, Brandegee, UC), and San Enrique, both in Lower California.

20. H. spinulosus var. turbinellus Blake, 1. c. 23, 1917. An extension of Sideranthus turbinellus (which see).

21. Sideranthus australis Rydb., Bull. Torr. Club 27:621, 1900-H. spinulosus australis.

22. S. cotula Small, Fl. S. E. U. S. 1186 and 1339, 1903-H. spinulosus cotula.

23. S. glaberrimus Rydb., Bull. Torr. Club 27:621, 1900-H. spinulosus glaberrimus.

24. S. gooddingi Nels., Bot. Gaz. $37: 266,1904-H$. spinulosus gooddingi.

25. S. laevis Wooton et Standl., Contr. U. S. Nat. Herb. 16:180, 1913-H. spinulosus laevis.

26. S. machaeranthera Small, Fl. S. E. U. S. 1186 and 1339, 1903. A rather stout form of $H$. spinulosus glaberrimus, the largest leaves $4 \mathrm{~cm}$. long and with spreading dentate lobes nearly $10 \mathrm{~mm}$. long. The herbage seems to be more coarsely stipitate-glandular than in glaberrimus, the form in this respect approaching subsp. cotula, but this is a much more slender plant, with short and fine leaf-lobes. The type of machaeranthera is from the Brazos River, Texas.

27. S. pinnatifidus Nutt. in Fras. Cat. n. 81, 1813. A nomen nudum, but referring to H. spinulosus.

28. S. puberulus Rydb., Bull. Torr. Club 27:622, 1900. Here included under $H$. spinulosus australis. The type, from Salida, Colorado, is a densely puberulent plant with the heads on short leafy branches and therefore corymbosely arranged. The herbage is finely puberulent and only slightly glandular.

29. S. spinulosus Sweet, Hort. Brit. 227, 1826. A nomen nudum, but referring to H. spinulosus.

30. S. spinulosus var. glaberrimus Nels., in Coult. et Nels., Man. Rocky Mt. 499, 1909-H. spinulosus glaberrimus.

31. S. turbinellus Rydb., Bull. Torr. Club 27:622, 1900. A very doubtful form, only once collected (near Pocatello, Idaho, Mulford). In habit the plant is most like $H$. spinulosus typicus, of the same area, but it lacks the tomentum of typicus and is therefore placed provisionally with subsp. australis. The type specimen differs from both of these in the narrower, subturbinate involucre, which would constitute almost a specific character if found to be 
constant. In reducing turbinellus to a variety under $H$. spinulosus, Blake greatly extends its taxonomic boundaries to include specimens with broad involucres (here mostly referred to australis) and cites some with tomentose herbage (here referred to typicus).

32. S. viscidus Wooton et Standl., Contr. U. S. Nat. Herb. 16:180, 1913 . A form of $H$. spinulosus scabrellus best marked by the large and numerous stalked glands and by a remarkable reduction in the bristles which usually tip the leaves and their lobes. In some cases the lobe ends in a very short mucro, scarcely exceeding the gland-tipped hairs; in others the bristle seems to be entirely suppressed. The principal leaves are oblong, obtuse, and coarsely serrate. Type locality, near Hope, New Mexico.

33. S. wootoni Standl., Contr. U. S. Nat. Herb. 13:222, 1910; Wooton et Standl., Contr. U. S. Nat. Herb. 19:664, 1915. Based upon Eriocarpum wootoni, which see.

34. Starkea ? pinnata Nutt., Genera 2:169, 1818. Based upon Amellus spinulosus; therefore H. spinulosus typicus.

\section{RELATIONSHIPS}

The origin of this species scarcely can be even conjectured at this time. It is doubtless to be sought somewhere in that Mexican plexus which was the starting-point of both the North American and the South American sections of the genus. This is suggested by present distribution and by retention of characters assumed to be primitive. Among these latter may be mentioned the perennial habit, broad involucre with an abundance of flowers in both disk and ray, and short style-appendages. Particularly suggestive is also the occasional appearance of purple color in the ligules, as is noted also in $H$. phyllocephalus and $H$. gymnocephalus, of the same section, and in certain South American species. Purple or roseate rays have been noted as occasional in the subspecies scabrellus and australis of H. spimulosus.

Within the species it seems nearly futile to attempt a phylogenetic arrangement in advance of experimental evidence. The facts thus far established suggest an early divergence in several directions, followed by an interweaving of evolutionary lines. The simplest forms now found are perhaps those included in subsp. scabrellus, which also is the most southerly in its distribution, although it extends north at least to Colorado. In comparing the other subspecies with this it is found that gooddingi lies nearest. This is a local development of the southwestern desert area, marked especially by its long, peduncle-like branches and large heads. It in turn is breaking up into two geographic races, one with a nearly entire type of leaf, the other with pectinately pinnatifid foliage (minor variation 17). Subspecies incisifolius also lies close to scabrellus, especially to the taxonomically typical form, and like it has its type locality in Lower California. In this district the two may too frequently overlap in their characters to render a separation possible, but the twigs of incisifolius are so short and rigidly divergent that it has a markedly peculiar aspect. With incisifolius, as originally described, are now included plants with only serrate leaves. The extent of variation is shown in Figures 18 and 19 . It seems likely that leaf-form may here be determined by competition with neighboring leaves of the same branch. But the most disturbing feature of incisifolius is the tendency towards a squarrose recurving of the involucral bracts, suggesting a connection with arenarius, which, however, differs markedly in its herbaceous stems, large, broad, obtuse, and 
thick leaves, and in other features. In most specimens of incisifolius, as now extended, the bracts are erect or only spreading in age. In the type collection some involucres have erect bracts, others have bracts strongly squarrose.

Unfortunately, the name spinulosus was first applied to a form which almost certainly is not the evolutionary type. Thus subsp. typicus represents only the taxonomic, not the phylogenetic type. It connects with scabrellus, both in characters and in distribution, near the southern borders of the United States, whence it ranges farther north than any other. But it is absent both from the plains of the east and from the Arizona-Sonora districts of the west. Its notable development of tomentum is almost unique in the species. The subspecies australis is a collection of forms of the plains and slopes around the southern Rocky Mountains. It has proceeded far in the division of its foliage, which persists well up among the heads. Although no specimens were cited with the original description, this is sufficiently clear to permit the use of the name for plants with these characters.

The three remaining subspecies are more local in their distribution and less well understood. Subspecies cotula, much like australis but with still more divided foliage and only glandular pubescence, is from the Mississippi Valley. Here, however, the common subspecies is glaberrimus, in which even the gland-tipped hairs are mostly lacking. The most outstanding of all the subspecies is laevis, but this is known only from a single collection made in New Mexico. It is not closely related to the smooth types just mentioned, for it has long-peduncled heads, nearly entire leaves, and other features which suggest $H$. junceus. Further collections may demonstrate its entire independence from spinulosus, but no satisfactory key characters have as yet been found.

\section{ECOLOGY AND USES}

This is a low, bushy plant, chiefly of the grasslands of plains and foothills in western North America. It sometimes ascends to an altitude of 1,800 meters, but only on warm southerly or open slopes. In western Mexico it descends to sea-level, where it grows on gravel beaches. This wide range of altitude, extending from the Lower Sonoran to the Transition Life-zone, is doubtless made possible through the large number of subspecies and biotypes of which it is composed. The root system has been studied by Weaver in the mixed prairies of the Mississippi Valley. This authority cites the species as illustrative of a moderately branched, rather wide-spreading, and fairly deep-seated root system (Weaver, Carnegie Inst. Wash. Pub. 292:49, fig. 19, 1920).

Medicinal value is attributed to Haplopappus spinulosus by the people of northern Mexico. Here it is said to be used, under the name of "yerba de vibora" for stomach and uterine disorders. According to Palmer, it is sold in the markets of Coahuila as a blood purifier. Apparently there has been no critical study of its properties.

11. Haplopappus junceus Greene, Bull. Calif. Acad. 4:190, 1885

A perennial herb with deep taproot and woody caudex, the branches sometimes also somewhat woody, 3 to $10 \mathrm{dm}$. high, the slender wiry stems 
erect to widely spreading; bark bright yellowish green, becoming gray only near base; branches striate, nearly glabrous, but slightly glandular or scabrid, especially in the inflorescence, often cinereous or subtomentose on young shoots; principal leaves few, linear, pinnatifid, and the lobes

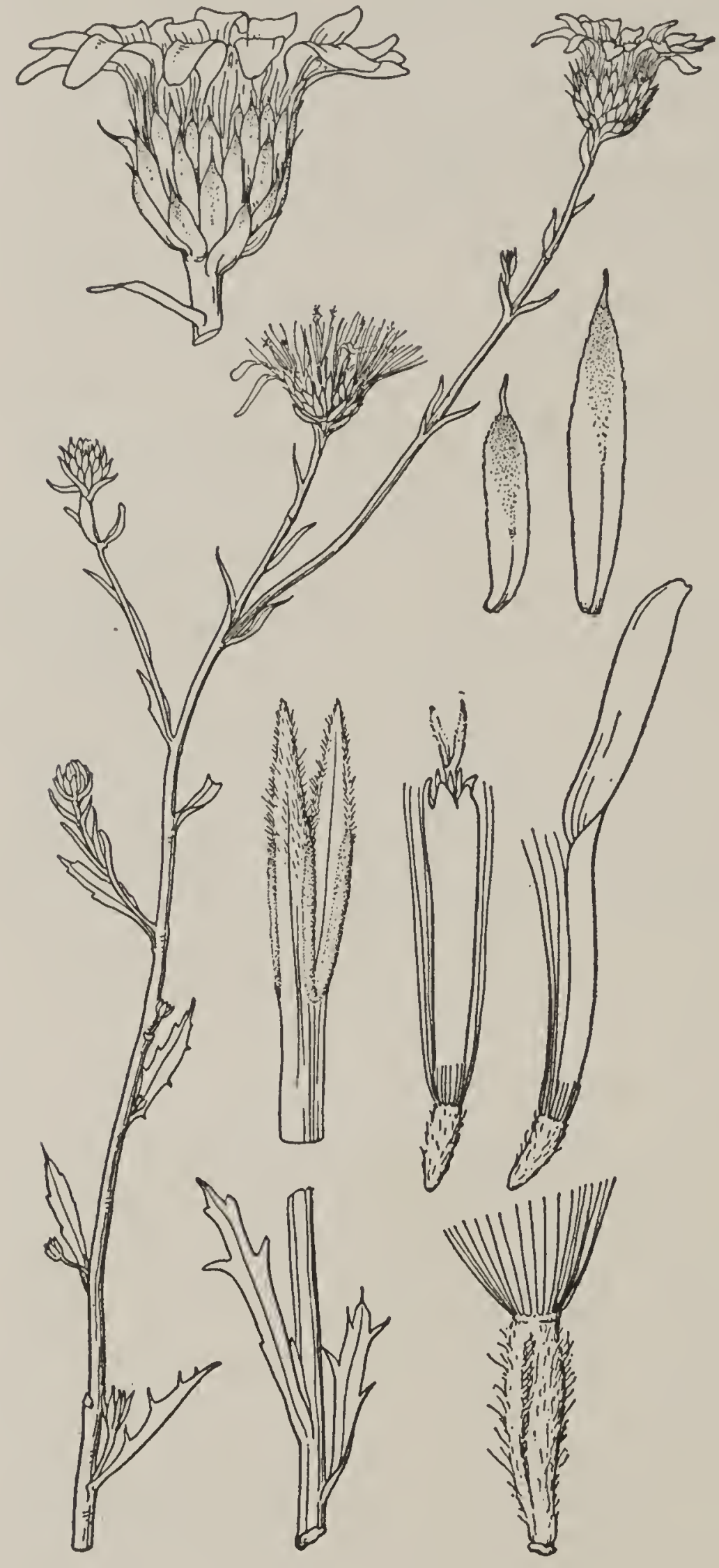

Frg. 20-Haplopappus junceus spiny-toothed, or entire, tipped by a white mucro, about $2 \mathrm{~cm}$. long by $4 \mathrm{~mm}$. wide, or often smaller, only the midnerve prominent, glabrous or cinereous and glabrate; upper leaves reduced to mostly entire bristle-tipped scales, $5 \mathrm{~mm}$. or less long; heads terminating long divergent scalybracted branches of an open cyme; involucre nearly hemispheric but narrowed at base, 5 to $8 \mathrm{~mm}$. (usually 6 to $7 \mathrm{~mm}$.) high, 10 to $12 \mathrm{~mm}$. broad; bracts numerous, closely imbricated in 5 or 6 lengths, all shorter than disk, linear, acute, bristle-tipped, appressed, white-chartaceous at base, the upper third and midrib green, minutely glandular; rayflowers 15 to 25 , the ligules 5 to $6 \mathrm{~mm}$. long (9 or $10 \mathrm{~mm}$. in minor variation 3); disk-corolla with narrow tube and abruptly expanded throat, 5 to $6.3 \mathrm{~mm}$. long, puberulent; lobes ovate, 0.5 to $0.8 \mathrm{~mm}$. long, usually glabrous; style-branches very shortly exserted, 1.2 to $2 \mathrm{~mm}$. long, the appendage shorter than stigmatic portion; achenes narrowly turbinate, about 2.5 to $3 \mathrm{~mm}$. long, villous; disk-pappus equaling or slightly exceeding corolla, consisting of several lengths of pale-brown bristles. (Fig. 20.)

Southern borders of California, northern Lower California, and northwestern Sonora; perhaps also in Arizona. Type locality, San Diego County, California (and citations made as far south as Santo Tomas, Lower California). CALifornia: near Valley Center, Chandler 5397 (UC); Descanso, Brandegee (UC); Granite, vicinity of San Diego, Spencer 167 (UC); Mount Tecate, Parish 8712 (UC); San Diego Falls, July 7, 1896, Brandegee (UC); Cottonwood Grade, September 11, 1884, Cleveland (UC). Sonora: Pinacate Mountain, November 21, 1907, MacDougal (US, type of Sideranthus viridis, minor variation 3). 


\section{MINOR VARIATIONS AND SYNONYMS}

1. Eriocarpum junceum Greene, Erythea $2: 108,1894-H$. junceus.

2. Sideranthus junceus Davidson et Moxley, Fl. So. Calif. 377, 1923-H. junceus.

3. S. viridis Rose et Standl., Contr. U. S. Nat. Herb. 16:19, plate 15, 1912 . A form from Sonora with leaves only moderately reduced, fewer bracts to the involucre, and the pale ligules 9 or $10 \mathrm{~mm}$. long. The pappus is perhaps a little paler than in typical junceus. Type, Pinacate Mountains, MacDongal (US).

\section{RELATIONSHIPS}

The connections of this species obviously are with Haplopappus spinulosus, with which it may ultimately be united. It is a development particularly suited to the arid districts of northwestern Mexico and adjacent United States, having long, slender, nearly leafless stems. The connection with spinulosus is best seen in a form once described as Sideranthus viridis (see minor variation 3), in which the foliage is less reduced, although the stems retain the bright light-green color characteristic of junceus.

\section{ECOLOGY}

As just noted, this is a species of very arid habitats. It is especially common in the Lower Sonoran Zone near the borders of California and Lower California. It here grows intermingled with low chaparral, blossoming throughout the late summer and autumn. The occasional leafy shoots, more or less white-villous, as often seen in herbaria, are produced toward the close of favorable rainy seasons.

12. Haplopappus brickellioides Blake, Proc. Biol. Soc. Wash. 35:173, 1922

A rigidly branched shrub with hard wood, the size and habit not known; bark white, becoming smooth and papery; twigs at first striate, densely scabrid, many of the hairs thick and tipped with yellow glands, glabrate in age; principal leaves broadly elliptic, with a tendency to obovate or oblanceolate, ascending, sharply dentate, with 2 to 6 pairs of lanceolate or triangular spine-tipped teeth, acute, sessile by a narrow base, 1 to $2 \mathrm{~cm}$. long, 5 to $12 \mathrm{~mm}$. wide, 3-nerved from near the base, the middle nerve much the strongest, reticulate between the nerves, light green, pubescent like the stem; heads sessile, solitary or in twos at tips of branches (these 4 to $8 \mathrm{~cm}$. long); involucre campanulate, 6 to $7 \mathrm{~mm}$. high, about $6 \mathrm{~mm}$. broad, nearly equaling the disk; bracts few, loosely imbricated in 4 or 5 series, lanceolate to (inner) linear-lanceolate, acuminate, or the outer merely acute, with thick white rib at base and short spreading herbaceous
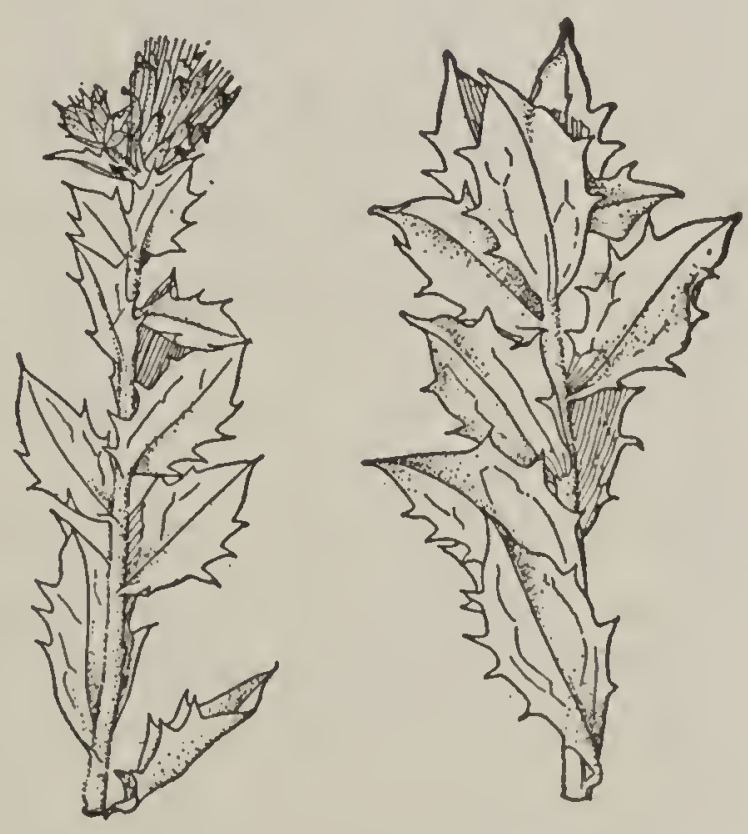

FIg. 21-Haplopappus brickellioides tip or the tips of inner bracts erect, the exposed surface with sessile and short-stipitate glands and hispidulous; ray-flowers none; diskflowers about 12 , the tube gradually expanding to the throat, $6 \mathrm{~mm}$. long, glandular-pubescent; lobes triangular-ovate, rather obtuse, about $0.8 \mathrm{~mm}$. long, hispidulous; style-branches short-exserted, about $1.7 \mathrm{~mm}$. long, the 
somewhat obtuse appendage shorter than stigmatic portion (young); achenes not known; pappus exceeding the young corollas, consisting of a few subequal rigid bristles. (Fig. 21.)

Known only from the type collection, "Rocks, Ash Meadows, Sheep Mountain, Nevada," altitude 900 to 1,200 meters (US, UC). Ash Meadows are on the California-Nevada line southeast of Death Valley, and have an altitude of 1,160 meters. The Sheep Mountains lie about $100 \mathrm{~km}$. northeast of Ash Meadows.

\section{RELATIONSHIPS}

The character of involucre and flowers leave no doubt that this is a Haplopappus of the section Blepharodon, but one can scarcely go farther in determining its relationships. It is much more decidedly shrubby than any other and its foliage also is unique. Its scarcity and wide morphologic divergence indicate that it may be a relict from some otherwise extinct branch of the section.

\section{SECTION 3. PRIONOPSIS}

13. Haplopappus ciliatus (Nutt.) DC., Prodr. 5:346, 1836

An annual or biennial erect herb, 5 to $15 \mathrm{dm}$. high, with few ascending branches; stems very leafy to top, smooth, glabrous; leaves oval ovate or oblong (or the lower obovate), sessile, ascending, saliently and evenly dentate with spine-tipped teeth, very obtuse, 3 to $8 \mathrm{~cm}$. long, 15 to 40 $\mathrm{mm}$. wide, with prominent midrib and lateral veins, perfectly glabrous; heads few, open-cymose or rarely solitary on short leafy-bracted peduncles or nearly sessile; involucre broadly hemispheric, 12 to $18 \mathrm{~mm}$. high, 20 to $25 \mathrm{~mm}$. broad; bracts in several series, well imbricated, the outer ones shorter than the inner and more or less spreading or squarrose, all linearlanceolate and rigidly acuminate, firm and more or less chartaceous, green on exposed portions, faintly several-nerved, glabrous; ray-flowers numerous, the ligules elliptic and 12 to $18 \mathrm{~mm}$. long; disk-flowers numerous; diskcorolla almost filiform, the tube passing gradually into a throat of scarcely greater breadth, about $4 \mathrm{~mm}$. long, glabrous; lobes very short, ovate, acute, nearly glabrous; style-branches linear-lanceolate, short (about 1.5 to $2.5 \mathrm{~mm}$. long), the acute appendage shorter than stigmatic portion; achenes of ray-flowers turgid-ellipsoid, about 3 to $4 \mathrm{~mm}$. long, those of the disk narrower and oblong, the central ones sterile, all of the achenes glabrous and with longitudinal ridges; disk-pappus exceeding corolla, of few very rigid and unequal bristles, the innermost ones somewhat flattened toward base and their margins scabrous-ciliolate, the outermost very slender and short, all bristles reddish in age and tardily deciduous, often in groups. (Donia ciliata Nutt., Jour. Acad. Phila. 2:118, 1821.) (Fig. 22.)

Western Missouri to Texas, New Mexico, and probably Colorado. Type locality, Arkansas, but described from garden plants. Mrssourr: Kansas City (introduced?), Mackenzie 370 (B, K); Stone County, August 29, 1882, Eggert (Gr). Kansas: on ravines and hillsides at Ellis, 1875, Watson (Gr). OKLahoma: northwestern Oklahoma, near Liberal, Kansas, Rose and Fitch 17144 (US); near Shattuck, Ellis County, Stevens 2918 (Del); 
Sapulta, Bush 1417 (B, K); Verdigris River, August 21, 1895, Blankinship (Gr); Tulsa, Stevens 29921/2 (Gr). Texas: Tarrant County, Ruth 272 (Gr); Houston, Fisher 118 (US); Prairies of the Pecos, Wright 295 (Gr). New Mexico: Carlsbad, Eddy County, Standley 40375 (Gr).

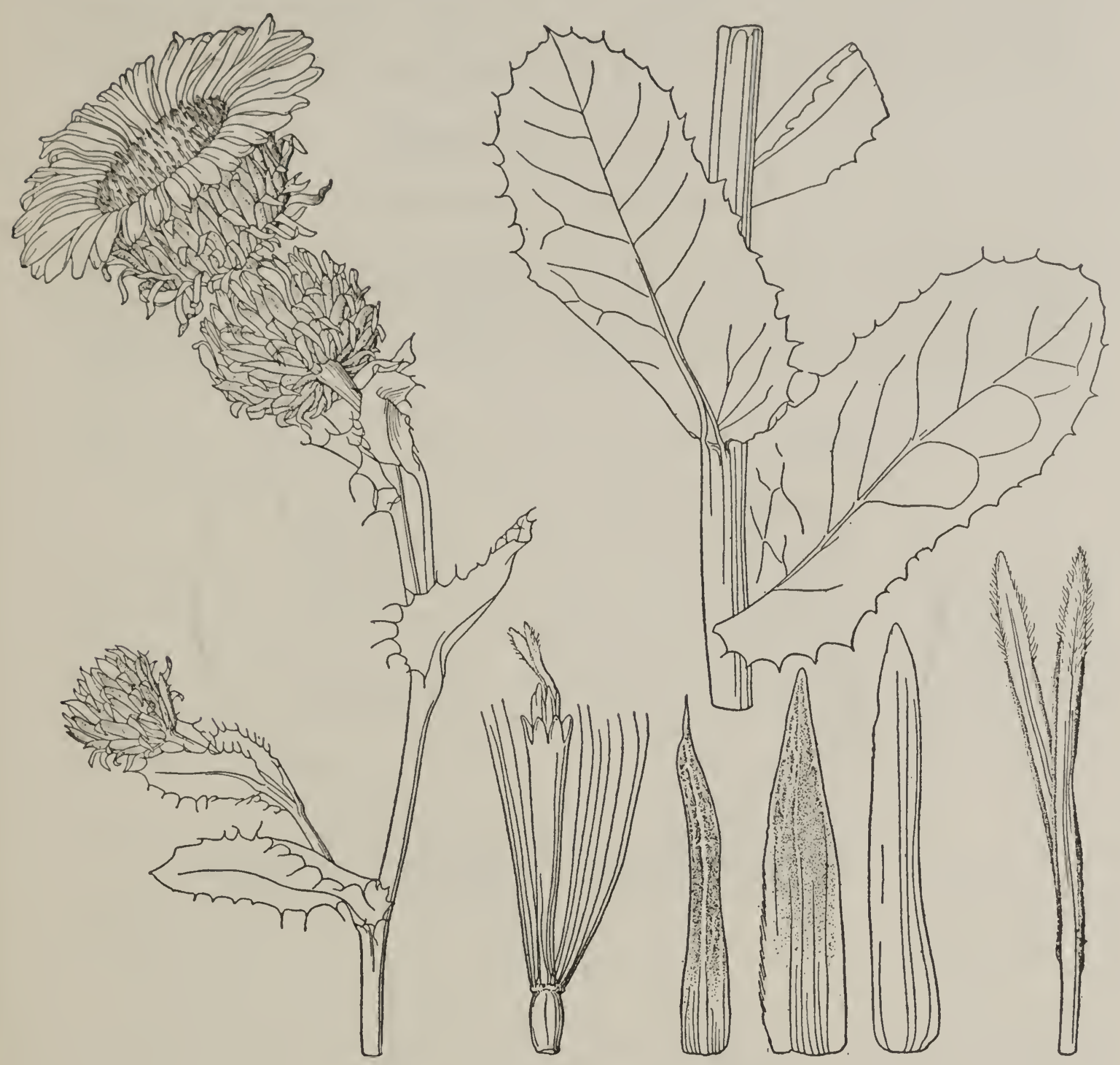

FIG. 22-Haplopappus ciliatus

\section{SYNONYMS}

1. Aster ciliatus O. Kuntze, Rev. $317,1891$.

2. Donia ciliata Nutt., Jour. Acad. Phila. $2: 118,1821$.

3. Prionopsis ciliata Nutt., Trans. Am. Phil. Soc. II, $7: 329,1840$.

\section{RELATIONSHIPS}

Since this is the only species of Prionopsis, its relationships have been sufficiently discussed in connection with the phylogeny of the genus (p. 27). There is little variation among the plants except such as the matter of size and extent of branching, features doubtless modified with ease by changes in environment. No segregate species or subspecies ever has been proposed. 


\section{ECOLOGY}

Little is known of the ecology of Haplopappus ciliatus other than its habit of growing on river banks and other disturbed areas, sometimes along roadsides or waste places, where it acts like a ruderal. According to Gray (Pl. Fendl. 77, 1849), it is a very showy plant in cultivation and flowers the first autumn from spring-sown seed. The flowering specimens in herbaria have been gathered in late summer and autumn.

\section{SECTION 4. OONOPSIS}

\section{PHYLOGENY OF THE SPECIES}

This section comprises but three species, well set off from one another morphologically, although all are in geographic contact. It seems impossible, therefore, to trace any phylogenetic connections between them. The more significant differentiating characters are given in the key (p. 43).

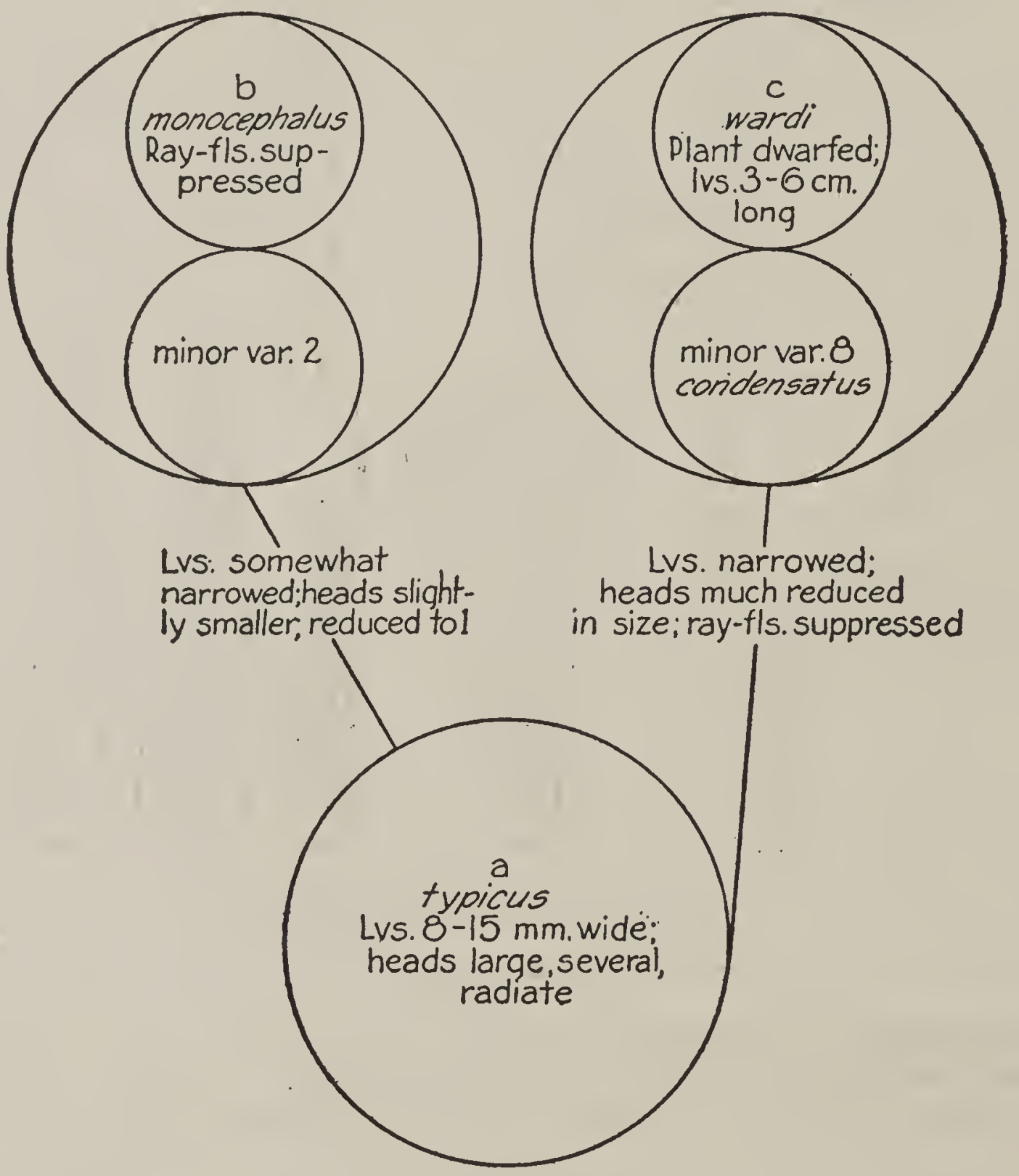

FIG. 23-Phylogenetic chart of the subspecies and minor variations of Haplopappus fremonti

14. Haplopappus fremonti Gray, Proc. Acad. Phila. for 1863:65, 1864

An herbaceous perennial, 1.5 to $2.5 \mathrm{dm}$. high, with many very leafy erect stems from a woody caudex or crown; bark white or at least pale, very smooth, striate at first, eventually splitting transversely; twigs firm, not brittle (?), glabrous or slightly tomentulose near the heads; leaves 
linear-lanceolate to oblong-lanceolate, rigidly erect or ascending, entire, very acute, 5 to $10 \mathrm{~cm}$. long, 4 to $15 \mathrm{~mm}$. wide, with 2 or 4 faint nerves in addition to the strong midrib, glabrous and smooth; heads few to many in a leafy flat-topped cyme or solitary and leafy-bracted; involucre campanulate to hemispheric, 12 to $20 \mathrm{~mm}$. high, 15 to $30 \mathrm{~mm}$. broad; bracts imbricated, nearly equal, broadly lanceolate, conspicuously acuminate or cuspidate, firm, the outer commonly herbaceous and the inner with a green area below the acumination, glabrous; ray-flowers about 15 to 25 or wanting in some subspecies, the ligules when present 10 to $15 \mathrm{~mm}$. long; disk-flowers 25 to 40 or numerous (perhaps as high as 100 in large heads); disk-corolla rather broadly funnelform above the shorter tubular portion, 7 to $9 \mathrm{~mm}$. long, glabrous throughout; lobes about $1 \mathrm{~mm}$. long, ovate, erect; style-branches included or scarcely exserted, the oblong-acute appendage shorter than or equaling stigmatic portion or rarely a little exceeding it; achenes narrowly turbinate, 5 to $7 \mathrm{~mm}$. long at maturity, glabrous or obscurely puberulent at summit, striate; disk-pappus usually shorter than corolla, scanty, rigid and fragile, brown. (Pyrrocoma foliosa Gray, Jour. Boston Soc. Nat. Hist. 5:108, 1845.) (Fig. 24.)

On the plains of Kansas, Colorado, and Wyoming.

\section{SUBSPECIES}

In the southeastern part of its range this species has broad leaves and large, radiate heads; in the northwestern part the leaves are narrower and the much smaller heads discoid. There is no sharp break anywhere except in the matter of the presence or absence of rays and this feature is not considered as of specific value. The forms are therefore assembled into three subspecies.

Key to the SUbspecies of Haplopappus fremonti

Ray-flowers present, the ligules well developed; heads large to me-

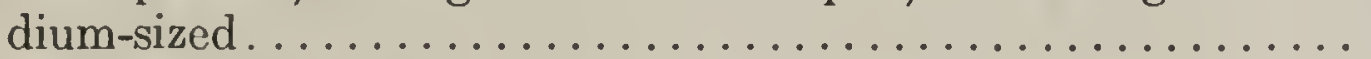
Ray-flowers wanting; heads medium-sized to small.

Heads solitary; involucre about $18 \mathrm{~mm}$. high

(a) typicus

Heads cymose; involucre 12 to $16 \mathrm{~mm}$. high.

(b) monocephalus

(c) wardi

14a. Haplopappus fremonti typicus-Leaves ample, 5 to $15 \mathrm{~mm}$. wide; heads several and cymose or solitary (minor variation 2), radiate; involucre approximately hemispheric, 15 to $22 \mathrm{~mm}$. high, 20 to $30 \mathrm{~mm}$. broad; diskflowers numerous; achenes with a few short deciduous hairs near summit or apparently glabrous. (Pyrrocoma foliosa Gray, l. c.) (Fig. 24.)

Kansas and southeastern Colorado. Type locality, not stated. Kansas: without exact locality, 1876, Popinos (US). Colorado: Rocky Ford, Arkansas Valley, Crandall 290 (Gr); Cañon City, Brandegee 492 (UC); La Junta, July 17, 1889, Greene (UC, Greene); dry hills north of Pueblo, Bethel, Willey, and Clokey 4932 (DS, US); plains east of Colorado Springs, July 20, 1920, Johnston (UC, a form with mostly solitary heads, minor variation 2); dry soil north of Florence, Fremont County, Clokey 3894 (DS, US, Gr, same variation); Huerfano, Parry 97 (B, same variation).

14b. Haplopappus fremonti monocephalus (Nels.)-Leaves of about medium size, about $10 \mathrm{~mm}$. wide; heads solitary and terminal on the stems, discoid; involucre nearly hemispheric, about $18 \mathrm{~mm}$. high, 18 to 


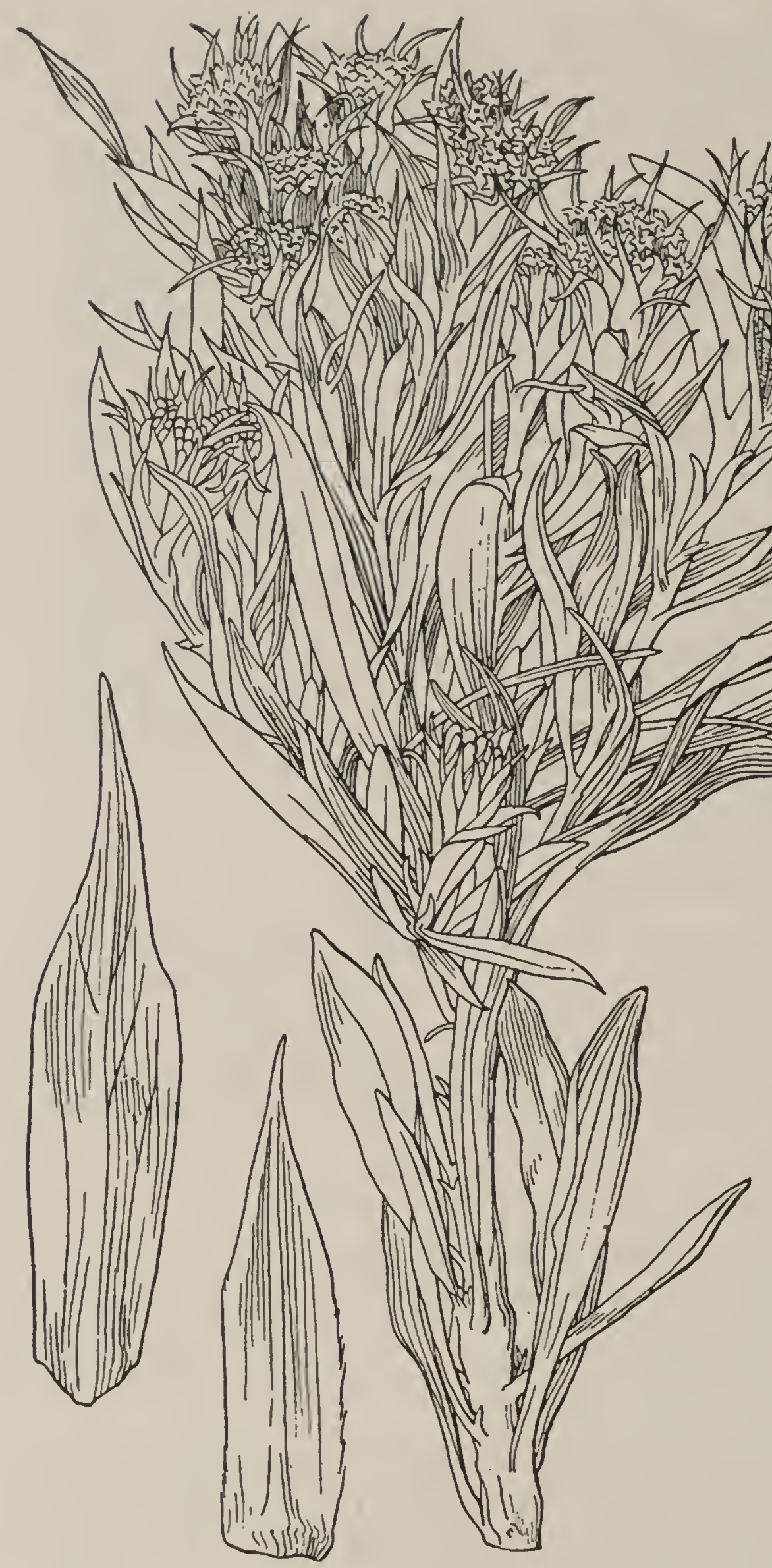

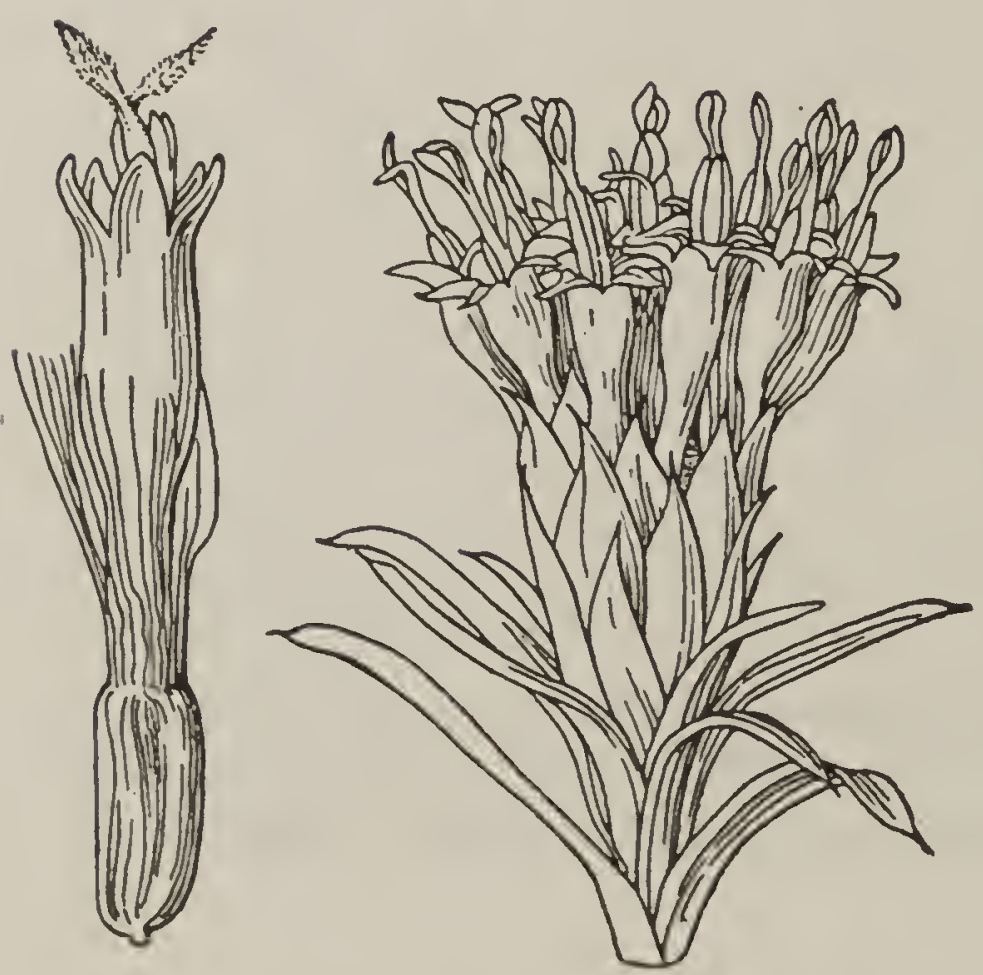

FIG. 24-Haplopappus fremonti wardi

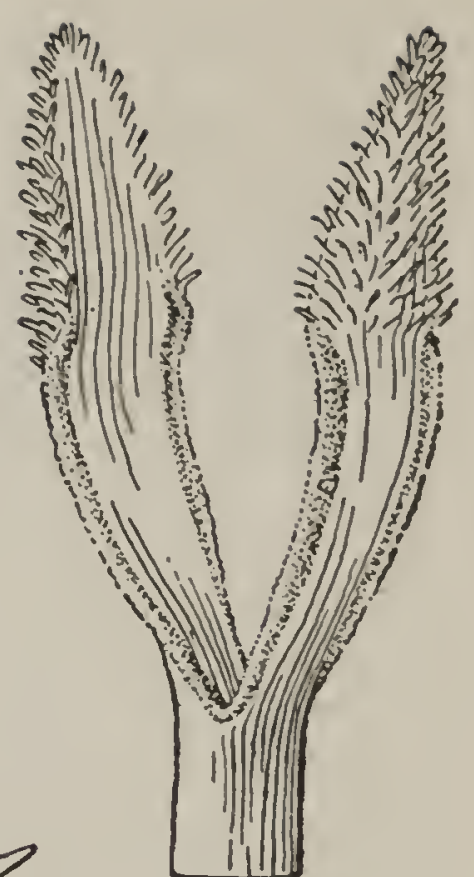

$20 \mathrm{~mm}$. broad; disk-flowers numerous; achenes obscurely and sparsely puberulent at summit. (Oonopsis monocephala Nels., Bot. Gaz. $31: 399$, 1901.)

Known only from the type collection, Berwind, southern middle Colorado, 1900, Jennie M. Archibald (R).

14c. Haplopappus frem on ti wardi (Gray) - Leaves comparatively narrow, 4 to $7 \mathrm{~mm}$. wide; heads 3 to 12 in each terminal leafy cyme, discoid; involucre campanulate, 12 to $16 \mathrm{~mm}$. high, 10 to $15 \mathrm{~mm}$. broad; disk-flowers 25 to 40 ; achenes ap parently always glabrous at maturity. ( $H$. fremonti var. wardi Gray, Syn. Fl. N. Am. 12:128, 1884.)

Wyoming. Type locality, probably in the southwestern part of Wyoming. Collections, all from Wyoming: type collection, 1881, L. F. Ward (Gr); Rock Creek, July 7, 1896, Greene (UC); 8 km. east of Powder River, Payson 3119(UC); Laramie Plains, Nelson 3459 ( $\mathrm{R}$, type of Oonopsis wardi condensata, minor variation 8 , to which form also all of the following belong); same locality, Nelson 1553, 8930 (R, UC, US, Gr) ; Medicine Bow, Nelson 9172 (Gr, R, UC); Seven Mile Lakes, Goodding 590 (R, UC, US). 


\section{MINOR VARIATIONS AND SYNONYMS}

1. Aster wardi O. K̈untze, Rev. 317, 1891-H. fremonti "incl. var. warli."

2. Haplopappus fremonti typicus, but with mostly solitary heads. This has been collected from the slopes of a shallow swale east of Colorado Springs by Johnston (July 20, 1920, UC). Of the 20 stems in this collection all are monocephalous but one, and this has but two heads. The heads are somewhat smaller than in the typical form and bear about 20 ray-flowers and 45 to 65 disk-flower's each. 'This variation is of chief interest as an intermediate between typical fremonti and monocephalus, as will be further indicated in the discussion of relationships.

3. H. fremonti val. wardi Gray, Syn. Fl. N. Am. 12:128, 1884-H. fremonti subsp. wardi.

4. Oonopsis condensata Nels. in Coult. et Nels., Man. Rocky Mt. 501, 1909. Reference is made by Nelson to the original publication of $O$. wardi condensata, here listed as minor variation 8 .

5. O. foliosa Greene, Pittonia 3:46, 1896. Based upon Pyrrocoma foliosa, which see.

6. O. monocephala Nels., Bot. Gaz. 31:399, 1901-H. fremonti monocephalus.

7. O. wardi Greene, 1. c.-H. fremonti wardi.

8. O. wardi condensata Nels., Bull. Torr. Club 25:376, 1898. This differs from typical $H$. fremonti wardi only in the slightly taller habit and in the longer leaves, these described as 6 to $12 \mathrm{~cm}$. long as against 3 to $6 \mathrm{~cm}$. for wardi. It is thus far known only from southeastern Wyoming, where it appears to be the only form, whereas the short-leaved type is represented by but three collections, one from north central Wyoming and perhaps both of the others from the southwestern part of the same State. O. condensata is looked upon as the normal growth-form of wardi, the taxonomic type of which may then be considered as a geographic or ecologic variation due to unfavorable local conditions. Much more intensive field studies across southern Wyoming will be necessary before the geographic isolation of the forms can be demonstrated, if, indeed, this is possible. The collections already at hand indicate that the differences are perhaps not so sharp as the early descriptions lead one to believe. For example, the type specimen of wardi has leaves from 4.5 to $5 \mathrm{~cm}$. long; in Greene's specimen cited above and also in Payson's the leaves are 4 to $6 \mathrm{~cm}$; in Goodding's 590, accepted as condensata, the length is 4.5 to $7 \mathrm{~cm}$; and in other collections the leaves run from 5.5 to 10 and $12 \mathrm{~cm}$. in length. These measurements are taken from sheets in the University of California Herbarium. Doubtless some deviation will be found in duplicates at other institutions. Another consideration in favor of the view that this form is of ecologic origin is that short leaves are associated with low stature. The type of wardi is a plant only $10 \mathrm{~cm}$. high (measured from the soil-line); Greene's plant is $14 \mathrm{~cm}$. high, but with a separate branch taken from a plant at least $15 \mathrm{~cm}$. high; Goodding 590 is 18 to $20 \mathrm{~cm}$; other condensata plants are 18 to $28 \mathrm{~cm}$. high. The number of flowers was given in the original description of condensata as 15 to 25 . One head from the type sheet has been examined and found to contain 31 flowers. Counts from other collections gave 25, 40, and 42 flower's respectively.

9. Pyrrocoma foliosa Gray, Jour. Boston Soc. Nat. Hist. 5:108, 1845 . The name under which $H$. fremonti was first published. The specific name was changed by Gray when making the transfer to Haplopappus because of the carlier H. foliosus DC., a Chilean species.

\section{RELATIONSHIPS}

This is the most primitive of the three species of the section Oonopsis. In the typical form, inhabiting eastern Colorado and adjacent Kansas, the plants are robust and each of the stems is terminated by a cyme of several large, radiate heads with very numerous disk-flowers. In an unnamed deviation from this, found at Colorado Springs and perhaps elsewhere within the range of typicus, the heads are nearly always solitary 
and somewhat smaller, with a corresponding reduction in the number of disk-flowers (minor variation 2). This decrease in size of individual heads occurs concomitantly with a decrease in their number and is the reverse of what is usually found in the Compositae, for in general a reduction in number is accompanied by an increase in size and in the number of florets.

From southern Colorado, near the borders of the area of the species, comes a form which almost duplicates the minor variation just mentioned, except that the ray-flowers are suppressed. This subspecies (monocephalus) may be taken, therefore, as the next stage in the evolution of the group. It is in most respects intermediate between the foregoing and the more northwestern subspecies wardi, but this last, while also discoid and with the smallest heads of all, has a cymose inflorescence, as in typicus, and therefore can scarcely be considered a derivative from monocephalus. The low stature of wardi appears to be an ecologic response, since there is an intermediate (minor variation 8) with the size of typicus but with other characters as in wardi. It should here be noted also that the leaves are the widest in typicus and the narrowest in wardi. From these facts it seems that typicus is the phylogenetic as well as the nomenclatural type, that monocephalus has been derived from this, with minor variation 2 as an intermediate stage, and that wardi represents an early and independent departure from typicus. These conclusions are based upon the generally accepted hypothesis that discoid heads, simple inflorescences, and a reduced number of florets are all marks of advance. This view of the origins of the forms under consideration strengthens the position of those who would accept wardi as a distinct species, but it renders impossible the use of the easily determined criterion of the absence of ray-flowers as a distinguishing feature. However, the obviously close relationship of all of the forms here discussed points to their assemblage into one species with several subdivisions as at once the most logical and the most useful treatment.

Table 1 indicates something of the degree to which these forms approach one another in their characters, or, in some cases, the actual overlapping of the forms. It is based upon all of the collections available, which, however, are so few that a much higher degree of intergradation may be expected as these plants become better known. The phylogenetic chart is intended to bring out the relationships as set forth. (Fig. 23, p. 86.)

TABLE 1-Variations in Haplopappus fremonti

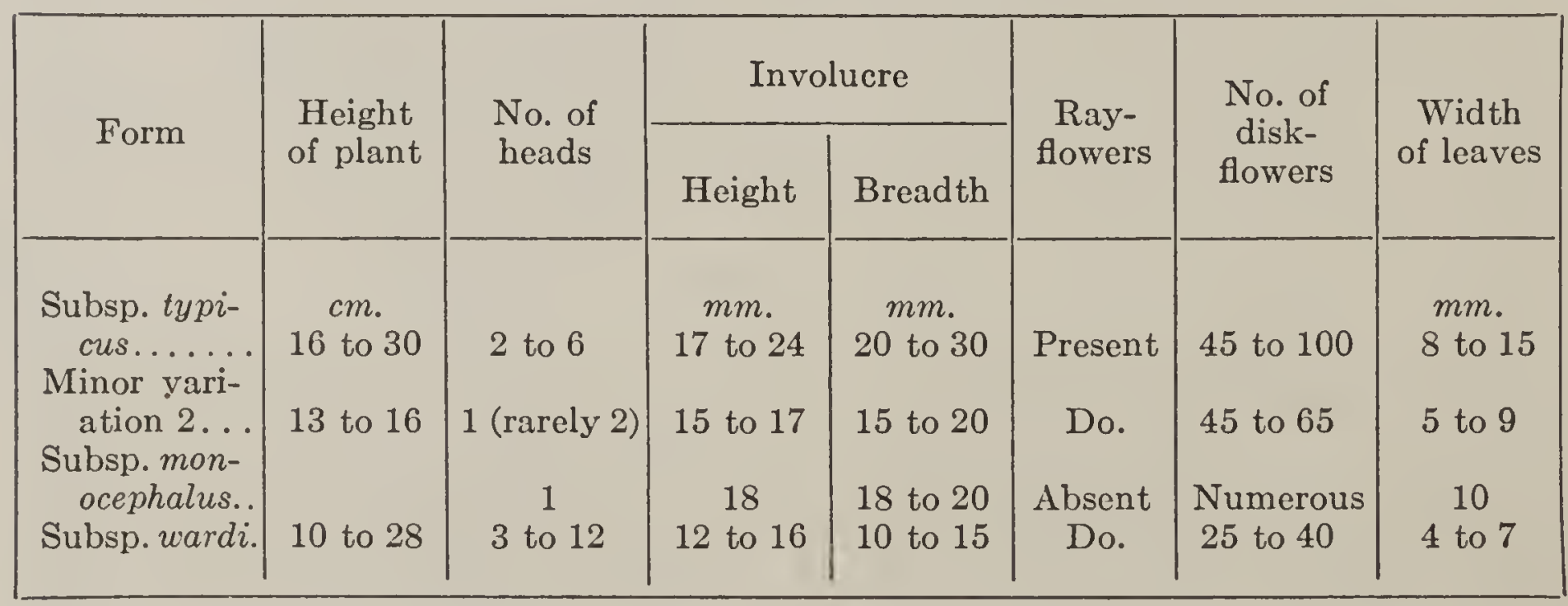




\section{ECOLOGY}

Together with other low-growing perennials this forms associes of varying composition on the high plains. It is commonly and perhaps always restricted to more or less alkaline clay soils and is especially partial to shallow depressions. Apparently this is because of the stronger competition with grasses, etc., on the less alkaline areas and because of the more favorable moisture conditions in the swales. In southern Wyoming it is sometimes a roadside plant, growing in shallow basins left after grading. Although flooded in such situations during the rainy season, and sometimes partly inundated with alkaline mud which later hardens about the lower portions of the stems, the plants continue to yrow and show no obvious injury.

The underground parts of the plant are but little known. Nelson (Bull. Torr. Club $25: 376,1898$ ) has described one form as having horizontal rootstocks. It is not improbable that all of the forms have deep-seated rootstocks connecting what appear to be vertical roots but which are in reality underground stem structures. The development of this habit is to be ex-

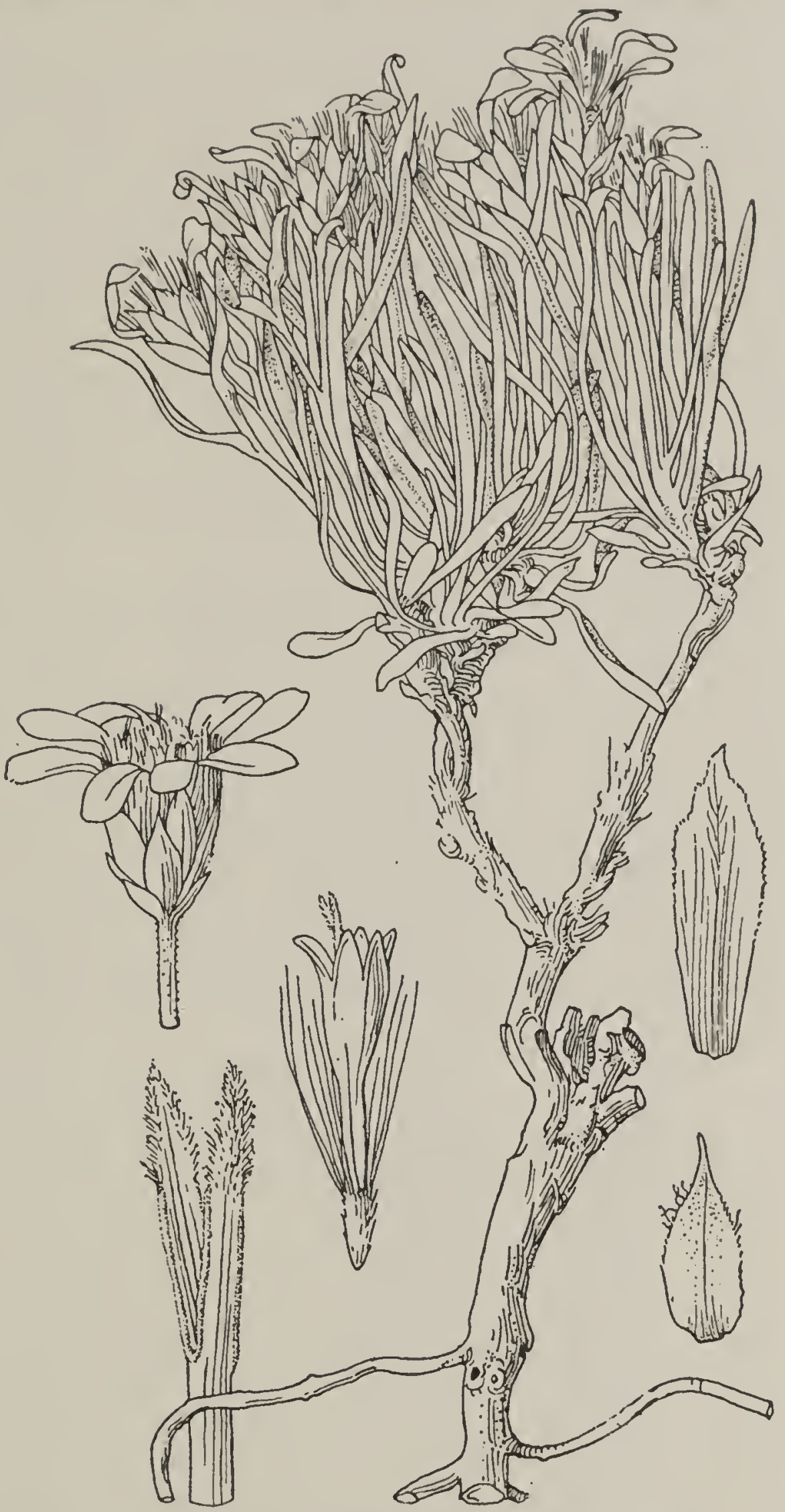

Fig. 25-Haplopappus multicaulis

pected from the conditions under which the plants grow, and especially from the frequent muddy inundations. The flowers appear from late June to late September.

\section{Haplopappus multicaulis (Nutt.) Gray, Am. Nat. 8:213, 1874}

A dwarf subcespitose herbaceous perennial, 0.5 to $1 \mathrm{dm}$. high, with slender erect leafy stems tufted on the branches of a subterranean caudex; stems pale, striate, tomentulose but soon glabrate and smooth; leaves 
linear or linear-spatulate, at first erect but some inclined to spread or droop, entire, pungently acute, except the lower very obtuse ones, 2 to $8 \mathrm{~cm}$. long, 1 to $5 \mathrm{~mm}$. wide, 1-nerved, sparingly tomentulose, glabrate; heads solitary or few and long-pedunculate, leafy-bracted; involucre campanulate, 7 to $10 \mathrm{~mm}$. high, 7 to $10 \mathrm{~mm}$. broad; bracts imbricated, appressed, from ovate to lanceolate-oblong, cuspidate-acuminate, firm, chartaceous, marked with a green spot below the slender cusp or some of the outer mostly herbaceous and often with a foliaceous tip, more or less tomentulose where exposed; ray-flowers about 6 to 12 , the ligules 5 to 8 $\mathrm{mm}$. long; disk-flowers about 20; disk-corolla rather abruptly funnelform from a slightly shorter tube, 5 to $6 \mathrm{~mm}$. long, glabrous; lobes 1 to 1.4 $\mathrm{mm}$. long, ovate, erect; style-branches only slightly if at all exserted, the ovate-triangular appendage one-half as long to as long as stigmatic part or slightly longer; achenes narrowly turbinate or those of the ray broader, all narrowed to base and slightly rounded to summit, multistriate, strigose; disk-pappus about equaling corolla, scanty, rigid, fulvous. (Stenotus multicaulis Nutt., Trans. Am. Phil. Soc. II, 7:335, 1840). (Fig. 25.)

Known only from Wyoming and South Dakota. Type locality, on rocks, on the western declivity of the Rocky Mountains. Collections all from Wyoming except the last and possibly the type; type collection, from Rocky Mountains "and Columbia hills," Nuttall (Phila); Wind River, Parry 164 (Gr, P, K); Bate's Hole, E. Nelson 4867 (Gr, R, UC, type collection of Oonopsis argillacea Nels., minor variation 2); Seventeen Mile Well, on Salt Creek Road, Natrona County, Goodding 213 (UC, US, same variation); Powder River, Nelson 9374 (R, Gr, US, B); Bear Lodge Mountains, June 20, 1912, Cary (US); 8 miles north of Bellefourche, Butte County, South Dakota, Eggleston 12522 (US).

\section{MINOR VARIATIONS AND SYNONYMS}

1. Aster multicaulis O. Kuntze, Rev. 318, 1891-H. multicaulis.

2. Oonopsis argillacea Nels., Bull. Torr. Club 26:481, 1899. This is included in the above description of multicaulis, but according to Nelson it differs from the typical form in the "less ligneous base, much longer leaves which overtop the stems, more numerous heads and rays, longer and more abundant pappus, and different style-appendages." These last are described as lanceolate and as long as or longer than the stigmatic portion. Measurements from type material of argillacea bear out this statement, although the appendage is never more than a trifle longer than the stigmatic part and varies from this down to scarcely more than one-half as long. Such variations may be due to differences in maturity, which may also account for the very short appendages reported for multicaulis by Gray and others. However this may be, the criterion needs further study before it can be finally accepted, but satisfactory material for this purpose is not now available. The stems in argillacea are 3 to $8 \mathrm{~cm}$. long above the soil-line and the leaves are 4 to $8 \mathrm{~cm}$. long, some overtopping the heads. It seems, therefore, that this is a more robust and perhaps the normal form of multicaulis, the type of which grew in rocky places and is much reduced in size.

3. O. multicaulis Greene, Pittonia 3:45, 1896. Based upon Stenotus multicaulis, which see.

4. Stenotus multicaulis Nutt., Trans. Am. Phil. Soc. II, $7: 335,1840$. The name under which $H$. multicaulis was first described. 


\section{RELATIONSHIPS}

The multistriate, round-topped achenes, the features of the involucre and style-branches, and the entire leaves all give evidence of the alliance of this species with Haplopappus fremonti. Even the habit is similar, although too much stress should not be given to this point, since the similarity may be the outcome of a response to a corresponding habitat. But of its specific distinctness there can be no doubt. The conspicuously strigose achenes, the smaller heads, and the tomentum serve for the ready recognition of multicaulis as compared with fremonti. When taken to include its minor variation described as Oonopsis argitlacea, it becomes one of the bestdefined species of the genus.

\section{ECOLOGY}

But little is known of the ecology of this plant. According to Nuttall, the types grew on rocks, but perhaps between rocks or in rocky places was meant, while Nelson states that the argillacea form occurs on naked clay slopes and flats. The only available data as to period of flowering indicate this as late June and July.

\section{Haplopappus engelmanni}

\section{(Gray)}

An herbaceous perennial, 1 to $3 \mathrm{dm}$. high, with many very leafy erect stems in tufts from a suffrutescent subterranean branching caudex or rootstock; bark pale, smooth, striate, turning brown only near the soil; stems probably brittle, glabrous; leaves narrowly linear, rigidly erect, entire, pungently acuminate, 3 to 7 $\mathrm{cm}$. long, 1 to 2 or perhaps $3 \mathrm{~mm}$. wide, 1-nerved, the margins inclined to be involute and thus form a groove on each side of the midrib, glabrous and smooth or

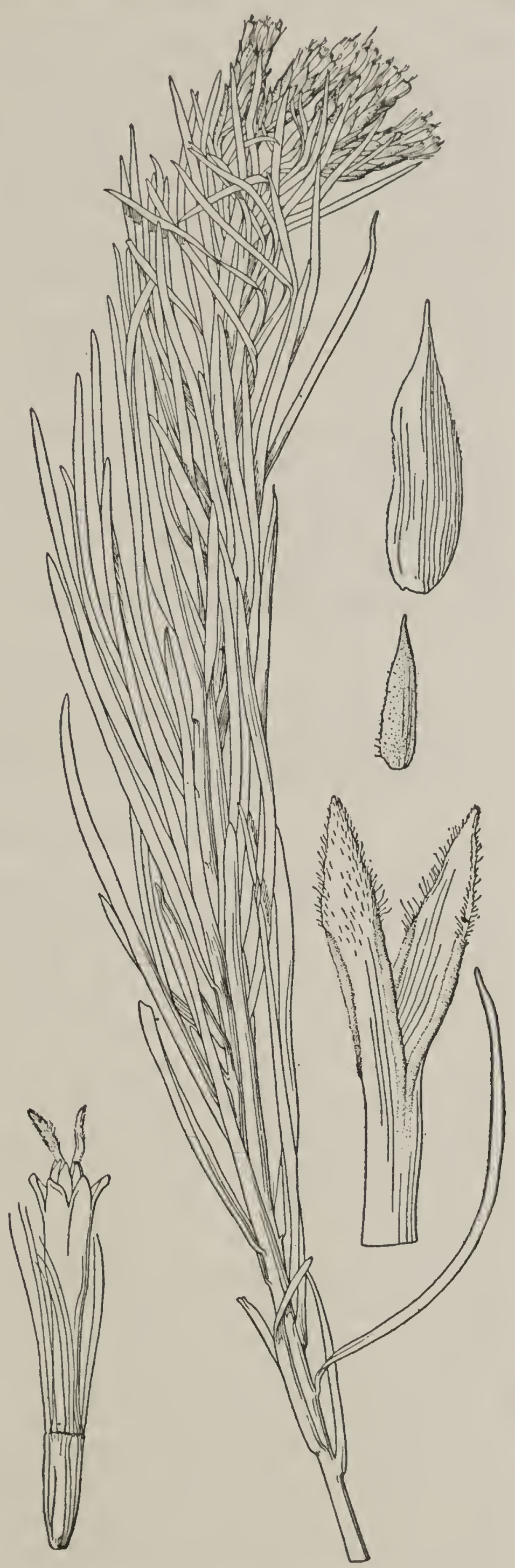

Frg. 26-Haplopappus engelmanni 
the uppermost obscurely scabro-ciliolate near base; heads few or rather numerous, terminally cymose-glomerate, much exceeding the short bracts of the peduncles; involucre turbinate, 8 to $10 \mathrm{~mm}$. high, about 6 to $8 \mathrm{~mm}$. broad; bracts imbricated, very unequal, none exceeding disk, mostly oblong, but the outermost and the innermost lanceolate, all abruptly narrowed to a short cusp, firm, mostly chartaceous but greenish below the tip, glabrous except for the erose or short-ciliate margins; ray-flowers wanting; disk-flowers 15 to 20 ; disk-corolla with short tube and longer broadly funnelform throat, 6.5 to $8 \mathrm{~mm}$. long, apparently always glabrous; lobes about $1.2 \mathrm{~mm}$. long, ovate-lanceolate, erect; style-branches exserted from the throat but not exceeding lobes, the short-oblong acute appendage scarcely more than one-half as long as stigmatic part; achenes nearly prismatic, narrowed below, glabrous, obscurely or not striate; disk-pappus shorter than mature corollas, scanty, rigid, brown. (Bigelovia engelmanni Gray, Proc. Am. Acad. 11:75, 1876.) (Fig. 26.)

High plains of eastern Colorado and western Kansas. Type locality, Hugo Station, Lincoln County, Colorado. Colorado: type collection, 1874, Parry (Gr, Phila); same locality, August 17, 1875, Patterson (UC); East Denver, Bethel and Bates, August 17, 1919 (UC); dry prairie, Denver, Duthie and Clokey 3893 (DS, US, Gr); Purgatoire River, Osterhout 4090 (R). Kansas: Coolidge, western border of Kansas, Kellerman 35 (Phila)

\section{SYNONYMS}

1. Aster angelandri O. Kuntze, Rev. 315, 1891.

2. Bigelovia engelmanni Gray, Proc. Am. Acad. 11:75, 1876.

3. Oonopsis engelmanni Greene, Pittonia 3:45, 1896.

\section{RELATIONSHIPS}

This species was assigned by Gray to Bigelovia, section Chrysothamnopsis, that is, to the genus Chrysothamnus of recent authors. It is probable that the determining factor in this decision was the absence of ray-flowers, which was the principal criterion then used for the separation of Bigelovia from Haplopappus. But Gray himself later admitted a few discoid forms to the latter and the attempt to use this as a mark of generic segregation has since been abandoned by practically all workers on the group. The situation has recently been summarized by Hall and Clements (Carnegie Inst. Wash. Pub. 326:158, 1923). The best mark of Chrysothamnus is the tendency toward a vertical arrangement of the involucral bracts and the keeled midrib of these. In engelmanni there is not the slightest suggestion of a vertical arrangement and the bracts are not obviously keeled, although with a strong midrib. From the section to which Gray referred it and which it resembles in the abruptly attenuate or cuspidate involucral bracts, it differs in the absence of all tomentum, in the glabrous achenes, and in the very short style-appendages.

In removing engelmanni from Bigelovia, Greene referred it to his new genus Oonopsis, now taken as a section of Haplopappus. This was done with the comment that "though rayless, the involucre, the corolla, styletips, pappus, and even the entire leaves are those of the genus here to be 
proposed." This is perhaps the best disposal of the species. The glomerate heads, narrow, well-imbricated involucres, and broad-topped achenes might lead to a classification with the section Isocoma, but there is no evidence of a phylogenetic connection.

\section{ECOLOGY}

Little is known of this exceedingly rare species. Thus far it has been found at only a few stations, all of these on the high plains of eastern Colorado and western Kansas. In east-central Colorado it is a member of autumnal societies of the mixed prairie where Artemisia frigida, Gutierrezia sarothrae, and Haplopappus spinulosus are prominent elements. The exact ecologic relation to these, however, is not understood.

\section{SECTION 5. PYRROCOMA PHYLOGENY OF THE SPECIES}

The forces of evolution seem to be more actively at work in Pyrrocoma than in any other section of the genus. The result is a commingling of the phylogenetic streams in so complicated a manner that only the major currents can be determined. After these have been arbitrarily designated as species and subspecies, in accordance with taxonomic practice, there still remain innumerable connecting forms - the cross-rivulets of our figure -which render futile any attempt to prepare a system for their classification. In not a few cases two forms will appear to be almost identical, and yet they may be of very different origin. Such cases of parallel variation can not be provided for in the usual "key" or phylogenetic chart and their true origins can be determined only by tracing out the connecting forms in the field, or, still better, by controlled experiments.

The section as a whole divides into two rather well marked divisions. By taking the large-headed, many-flowered species as the more primitive, it is found that four species qualify for the basal group. Here there is less development of special features, such as elongated stylar appendages, than in the remaining forms. $H$. croceus seems to come nearest to representing the ancestral type. $H$. clementis is plainly a high-mountain derivative, now well set off by its unique involucral bracts. The bracts of carthamoides are also modified, but in a more usual fashion. The most notable feature of this species is the elongated style-appendage of the smallerheaded division. $H$. integrifolius is placed as basal to the second division because of its smaller heads and apparent connections with lanceolatus and racemosus.

In the group with smaller heads and flowers it is entirely impossible to draw satisfactory specific lines. The inflorescence of lanceolatus is sufficiently distinctive in typical forms, but the frequent reduction to a single head leads to confusion with all of the other species except hirtus. Although hirtus is easily recognized when once understood, its key character of glandular herbage occurs also in one subspecies of lanceolatus, and even its usually raccmose inflorescence approaches the corymbiform when the lower peduncles are elongated. The central species, from a phylogenetic point of view, appears to be racemosus. This may have arisen from an integrifolius-like ancestor, but there are also suggestions of a connection with lanceolatus. 


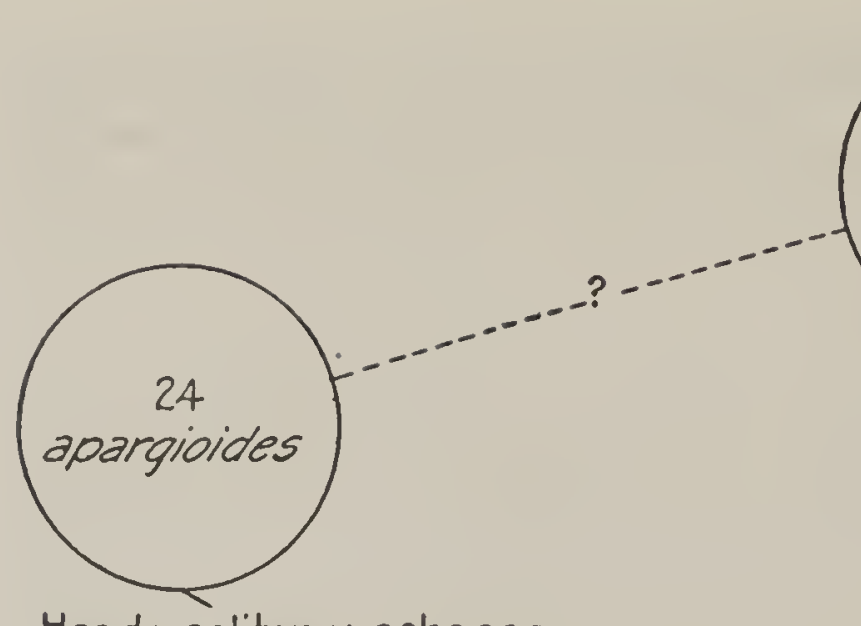

Heads solitary: achenes glabrous; bracts equal or graduate (High Sierran)

Connection through

H.racemosus prionophyllus

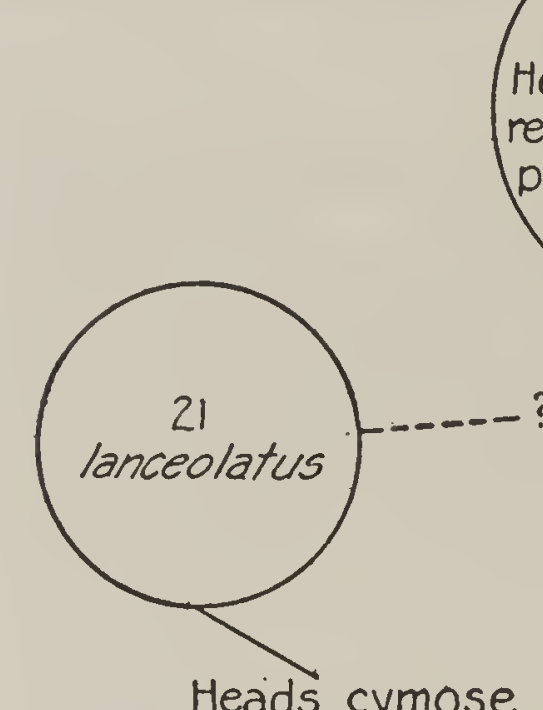

rarely reduced to 1 head; achenes always pubescent; bracts imbricated

\section{3} racemosus Heads racemose or reduced tol;achenes

pubesrent or glab-

rous; bracts rare-

iy subequal

25

uniflorus

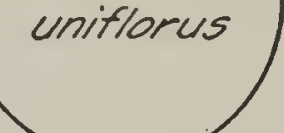

unifloris

Lvs. lanceolate

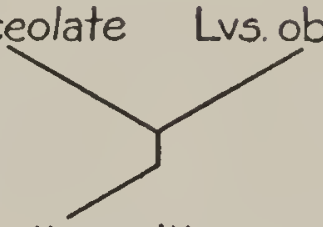

Meads usually solitary; achenes pubescent; bracts subequal
26

contractus

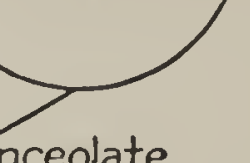

lanceolate

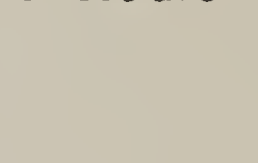

22

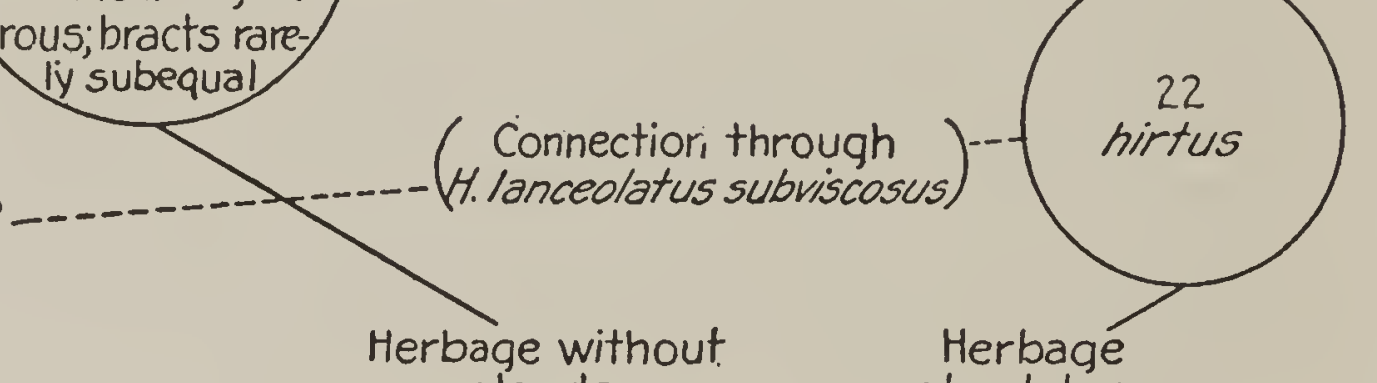
Herbage
glands
glandular

\section{Herbage with
glands}

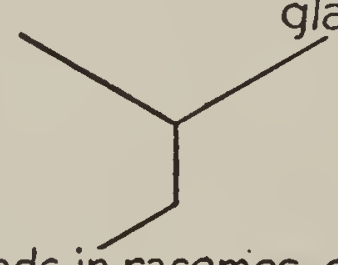

Heads in racemies or reduced
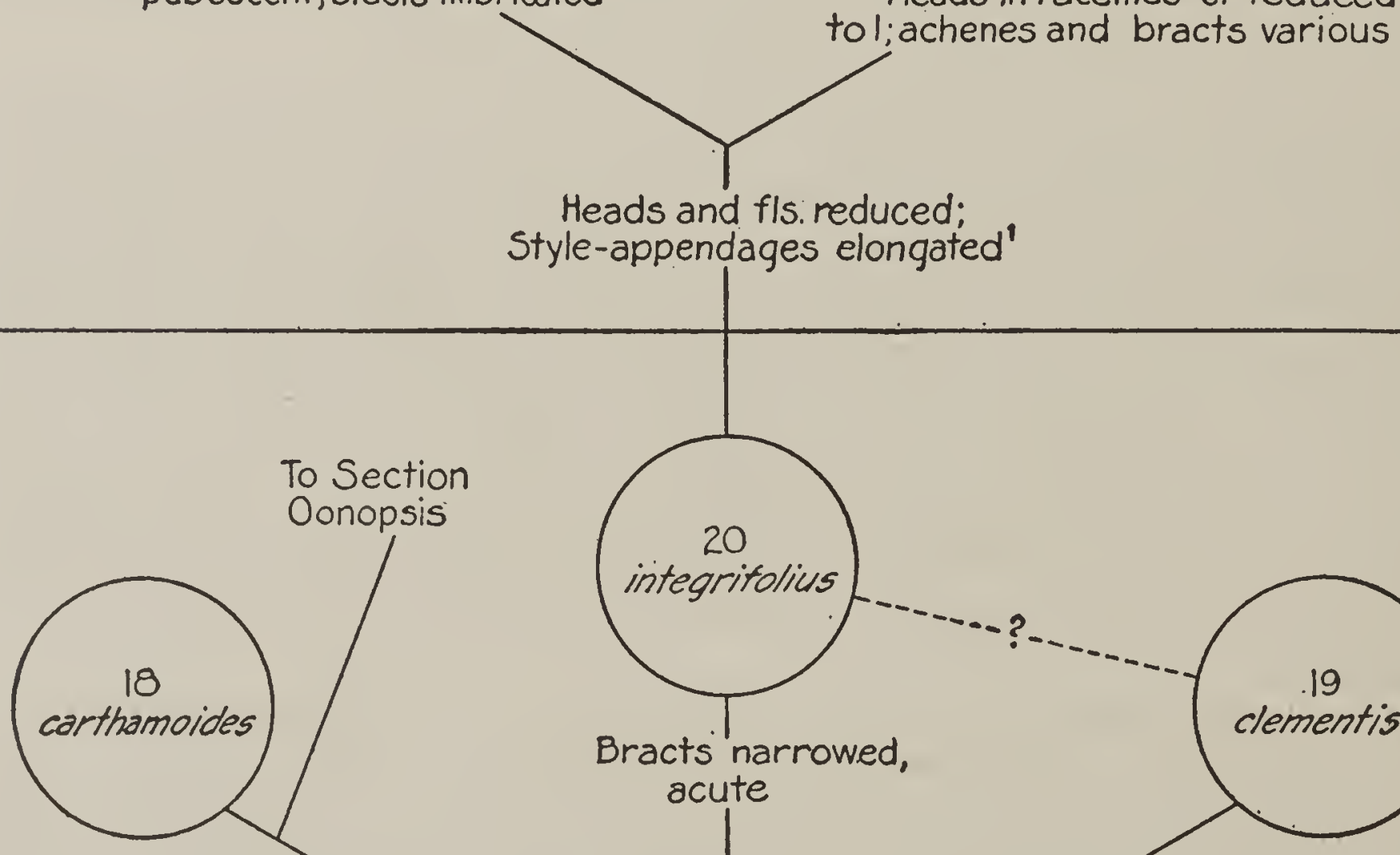

Heads and fls. reduced;

Style-appendages elongated'

Ligules much reduced;style-app. exceeds stigma

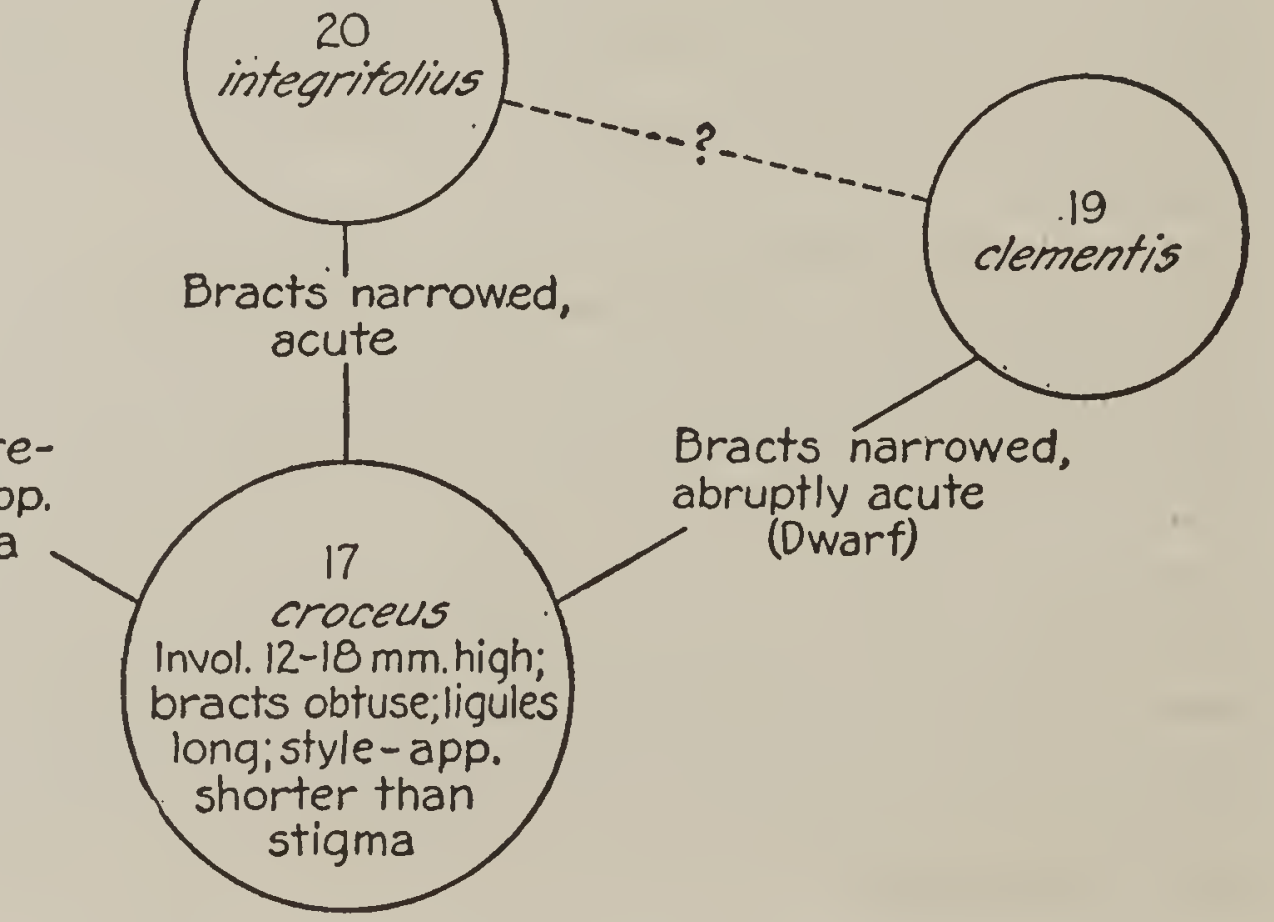

Bracts narrowed, 20

FIG. 27-Phylogenetic chart of the species of Haplopappus section Pyrrocoma. In the four species below the horizontal line the involucre is 12 to $18 \mathrm{~mm}$. high (10 to $13 \mathrm{~mm}$. in $H$. integrifolius liatriformis), the disk-corolla 7 to $13 \mathrm{~mm}$. long, the appendage either longer or shorter than the stigma. In the 6 species above the line the involucre is 5 to $10 \mathrm{~mm}$. high (or to $12 \mathrm{~mm}$. in hirtus), the disk-corolla 5 to $7 \mathrm{~mm}$. long, the appendage mostly longer than stigma 
There is considerable distributional as well as morphologic evidence that apargioides has arisen through racemosus (subsp. prionophyllus) and that uniflorus has had a similar history. The occasional racemose inflorescence of the latter is especially suggestive in this connection. But similarities between apargioides and uniflorus are sometimes so marked that a direct connection between the two is strongly suspected. Perhaps here, as elsewhere, two divergent evolutionary streams contribute each to the other through occasional cross-rivulets.

\section{Haplopappus croceus Gray, Proc. Acad. Phila. for 1863:65, 1864}

A perennial herb, 1 to $6 \mathrm{dm}$. high, with several or numerous erect or curved-ascending stems from a thick and deep taproot, the closely branching crown surrounded by fibrous remnants of a few leaves; stems pale but more or less tinged with red, glabrous or early glabrate below, from nearly glabrous to densely tomentulose toward heads; leaves in basal tufts and scattered along the stems, the lower ones lanceolate to broadly elliptic or slightly oblanceolate, always broadest near middle, tapering to a petiole, erect or spreading, entire or merely undulate, obtuse or acutish, the blade 10 to $25 \mathrm{~cm}$. long, 8 to $40 \mathrm{~mm}$. wide, thick and subsucculent, drying leathery, with thick midrib and less prominent secondary and cross-veins, glabrous even on petioles or rarely puberulent; middle and upper leaves gradually reduced, sessile, somewhat clasping, lanceolate; heads usually solitary and terminating the stems, sometimes several and long-pedunculate (minor variation 3); involucre broadly hemispheric, or somewhat narrower when number of flowers is reduced (subsp. genuflexus), 12 to $18 \mathrm{~mm}$. high, 20 to $30 \mathrm{~mm}$. broad; bracts in several series, the outer ones nearly as long as inner or rarely imbricate (minor variation 3), none overtopping disk, ovate to spatulate-oblong, very obtuse but often minutely mucronate, all herbaceous except for a whitish cartilaginous base and a narrow pale border, glabrous; ray-flowers about 25 to 70 , the ligules 9 to 25 or $30 \mathrm{~mm}$. long (commonly saffron-color); disk-flowers numerous; disk-corollas tubularfunnelform, 7 to $11 \mathrm{~mm}$. long, often microscopically puberulent when young; lobes lanceolate, 1.0 to $1.5 \mathrm{~mm}$. long, usually glabrous; stylebranches either moderately or conspicuously exserted, 2.0 to $2.5 \mathrm{~mm}$. long, the obtuse appendage shorter than stigmatic portion; achenes 4-angled, striate between angles, narrowed to each end, about $6 \mathrm{~mm}$. long, glabrous as far as known; pappus about equaling corolla, light brown, rather scanty. (Fig. 28.)

In the middle and southern parts of the Rocky Mountains, from Wyoming to New Mexico, Arizona, and eastern Utah.

\section{SUBSPECIES}

Key to the Subspecies of Haplopappus croceus

Involucre 15 to $18 \mathrm{~mm}$. high; ligules $13 \mathrm{~mm}$. or more long; tall robust

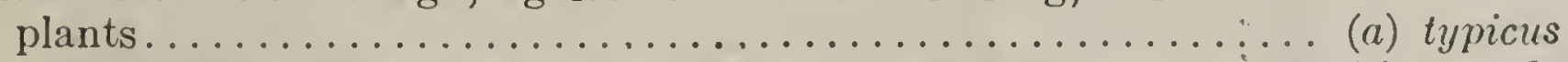

Involucre 12 to $15 \mathrm{~mm}$. high; ligules 9 to $12 \mathrm{~mm}$. long; low slender plants. (b) gemuflexus

17a. Haplopappus croceus subsp. typicus -Stems robust, erect or with only a short curved base, usually 3 to $6 \mathrm{dm}$. high; leaves ample, the blades 


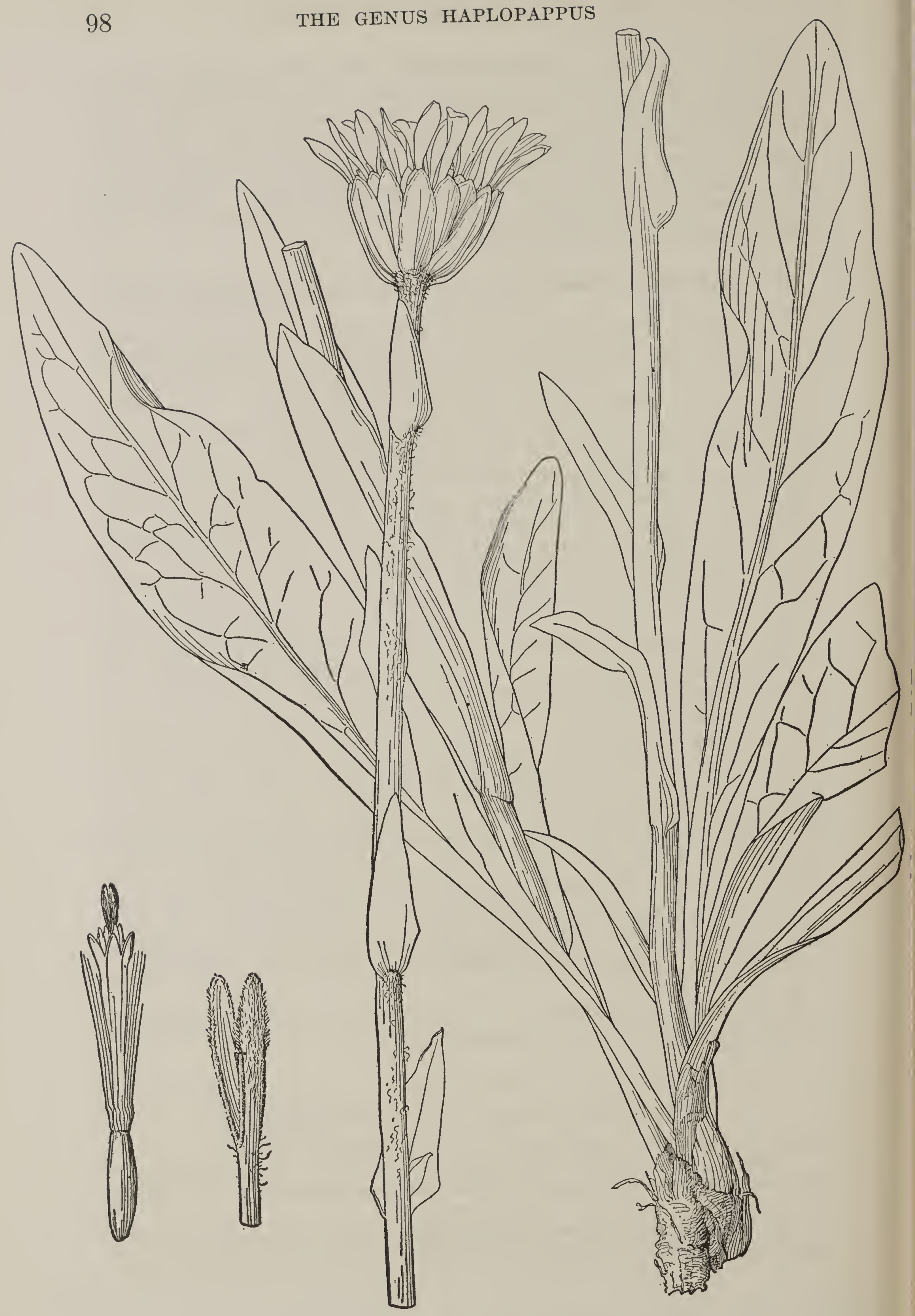

FIG. 28-Haplopappus croceus typicus 
of the lower ones 10 to $25 \mathrm{~cm}$. long by 20 to $40 \mathrm{~mm}$. wide; involucre 15 to $18 \mathrm{~mm}$. high, 20 to $30 \mathrm{~mm}$. broad (as pressed); bracts broadly oblong or subspatulate, very obtuse but commonly tipped with a small mucro, 4 to $6 \mathrm{~mm}$. wide; ligules 13 to 25 or even $30 \mathrm{~mm}$. long; disk-corolla 8 to $11 \mathrm{~mm}$. long; style-branches only moderately exserted. (H. croceus Gray, Proc. Acad. Phila. for 1868:65, 1864.) (Fig. 28.)

In the Rocky Mountains from Wyoming to New Mexico, northern Arizona, and eastern Utah; especially common in Colorado. Type locality, Colorado. Wroming: Coppertown, Carbon County, August 1, 1901, Tweedy (NY, US). Colorado: type collections, 1862, Parry, and 1862, Hall and Harbour (Gr); Willow Creck, Routt County, Goodding 1684 (UC, Gr, R); North Park, Crandall 289 (Gr); Middle Park, Ramaley and Robbins 3542 (UC, R); Cerro Summit, August 30, 1896, Greene (UC), also Baker 691 (Gr, K); Iron Spring Mesa, San Miguel County, Walker 524 (Gr, B, R); Doyle's, west central Colorado, Baker 645 (UC, R); Elk Mountains, 1881, Brandegee (UC, minor variation 2); Tabeguache Basin, southwestern Colorado, Payson 554 (Gr, R); Parrott City, southwestern Colorado, September, 1875, Brandegee (UC); La Plata Cañon, Baker, Earle, and Tracy 559 (Gr, B, K). New Mexico: vicinity of Chama, Rio Arriba County, Standley 6833 (US); near El Rito, Wooton 2600 (US). ArIzonA: San Francisco Mountains, October, 1884, Lemmon (UC, with spreading base of $H . c . g e n u f l e x u s)$. Utaн: La Sal Mountains, eastern Utah, Purpus 7006 (UC, Po).

17b. Haplopappus croceus subsp. genuflexus (Greene)-Stems comparatively weak and slender, outwardly curved at base, then erect, 1 to 2 $\mathrm{dm}$. high; leaves narrow, the blades of the lower ones $15 \mathrm{~cm}$. or less long, $10 \mathrm{~mm}$. or less wide; involucre 12 to $15 \mathrm{~mm}$. high, 20 to $25 \mathrm{~mm}$. broad; bracts oblong, obtuse, minutely mucronate, about $3 \mathrm{~mm}$. wide; ligules about $10 \mathrm{~mm}$. long; disk-corolla 7 to $8 \mathrm{~mm}$. long; style-branches long-exserted. (Pyrrocoma genuflexa Greene, Pittonia $3: 348,1898$.

Known only from the type collection, Flagstaff, Arizona, September 5, 1894, Toumey (Greene, UC) and from a few gatherings in the same district of forms approaching H. integrifolius (Leiberg 5829, Rusby 645, Jones 4005 , etc.).

\section{MINOR VARIATIONS AND SYNONYMS}

1. Aster croceus O. Kuntze, Rev. 317, 1891-H. croceus typicus.

2. H. croceus typicus, but with an openly branched inflorescence of 4 or 5 heads (Elk Mountains, Colorado, 1881, Brandegee, UC.). The peduncles are 10 to $20 \mathrm{~cm}$. long and racemosely arranged, giving the plant a very different appearance from the typical form, but the broad leaves and the large, broad heads with long ligules are entirely typical. The only observed approach to this is in an occasional plant with two long-peduncled heads to each stem.

3. Pyrrocoma adsurgens Greene, Leaflets $2: 22,1909$. A form of $H$. croceus genuflexus with leafy stems and strongly imbricated bracts. The distribution is given by Greene as "Mountains of northern Arizona, especially those near Flagstaff." An extreme form has been collected about Walnut Cañon, Arizona (July 28, 1898, MacDougal 356, UC). This has heads intermediate in size between those of typicus and those of genuflexus; the bracts regularly imbricated in three or four series, the outer ones successively shorter, all very broad and obtuse and the green upper half sharply set off from the hard and pale basal portion. The imbricate feature is approached in other collections (Purpus 252, UC), but these are otherwise very different. Fur- 
ther field studies may demonstrate the presence in Arizona of several taxonomically separable units, but the evidence at hand does not justify such separation at present.

4. P. crocea Greene, Erythea 2:69, 1894-H. croceus typicus.

5. P. genuflexa Greene, Pittonia 3:348, 1898-H. croceus genuflexus.

\section{RELATIONSHIPS}

The large heads, numerous flowers, and long ligules indicate an absence in this species of those reductions so commonly encountered in other parts of the genus. Together with the lack of long style-appendages and other highly developed features, this suggests Haplopappus croceus as the most primitive of the Pyrrocomas. It is not closely connected with any species outside its section and was undoubtedly separated from the other sections at a comparatively early date. The geographic restriction to the Rocky Mountain region and the almost complete absence of subspecies may be brought forward as testimony against its acceptance as a primitive type. But if the assumption is correct that the other Pyrrocomas have been derived from this one (or from a scarcely different common ancestor), through reductions and other changes, then the group of which it is the center is of wide distribution, as well as rich in taxonomic and ecologic forms.

Variation within the species as now delimited is not great. The uniformity of subspecies typicus is shown in table 2. A few doubtful forms are discussed under Minor Variations and in addition to these there is only the subspecies genuflexus. This has every appearance of a derivation through reduction in practically all of its parts, but especially in the size and number of flowers. It seems to be connected with subsp. typicus by a collection made somewhere near its type locality (San Francisco Mountains, Arizona, October 1884, Lemmon, UC), but this specimen, although apparently intermediate, also resembles $H$. integrifolius. Detailed field studies and collections from this region will be necessary before the status of subsp. genuflexus can be satisfactorily determined.

TABLE 2-Variation in Haplopappus croceus typicus

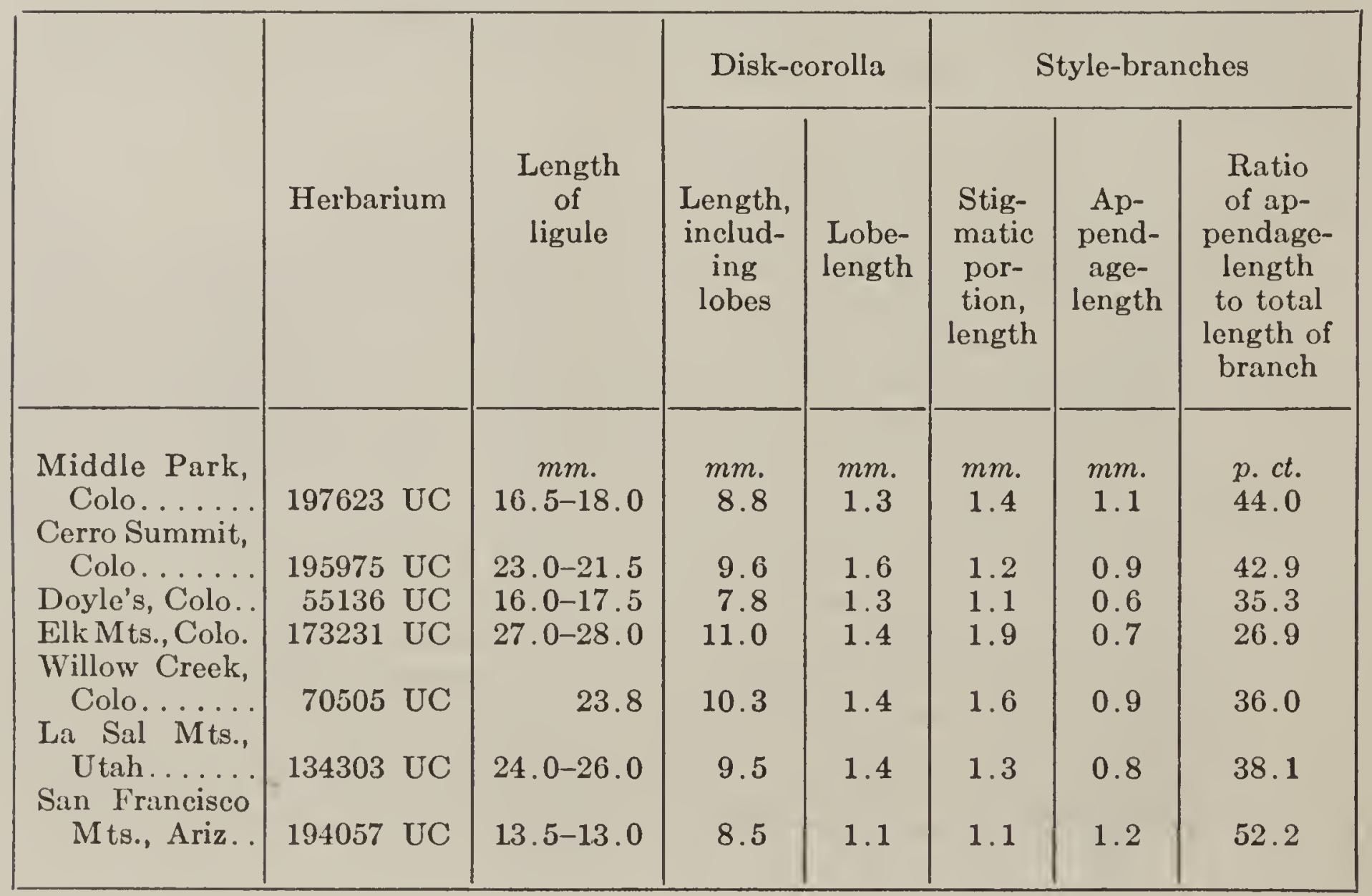




\section{ECOLOGY}

"Moist soil" and "clay hillsides" are notes given on herbarium labels and scarcely anything more is known concerning the habitat requirements of this species. It grows in the mountains, usually at altitudes of 2,000 to 3,000 meters, but does not approach timber-line, being confined chiefly or perhaps entirely to the Transition and Canadian zones. Collections in flower have been made from late July to October.

18. Haplopappus carthamoides (Hook.) Gray, Proc. Acad. Phila. for 1863: 65,1864

A perennial herb, usually 1.0 to $6.0 \mathrm{dm}$. high, with a thick taproot and several leafy erect or curved-ascending stems from a branched crown, this surrounded at base by a continuation of the dark root-bark and above

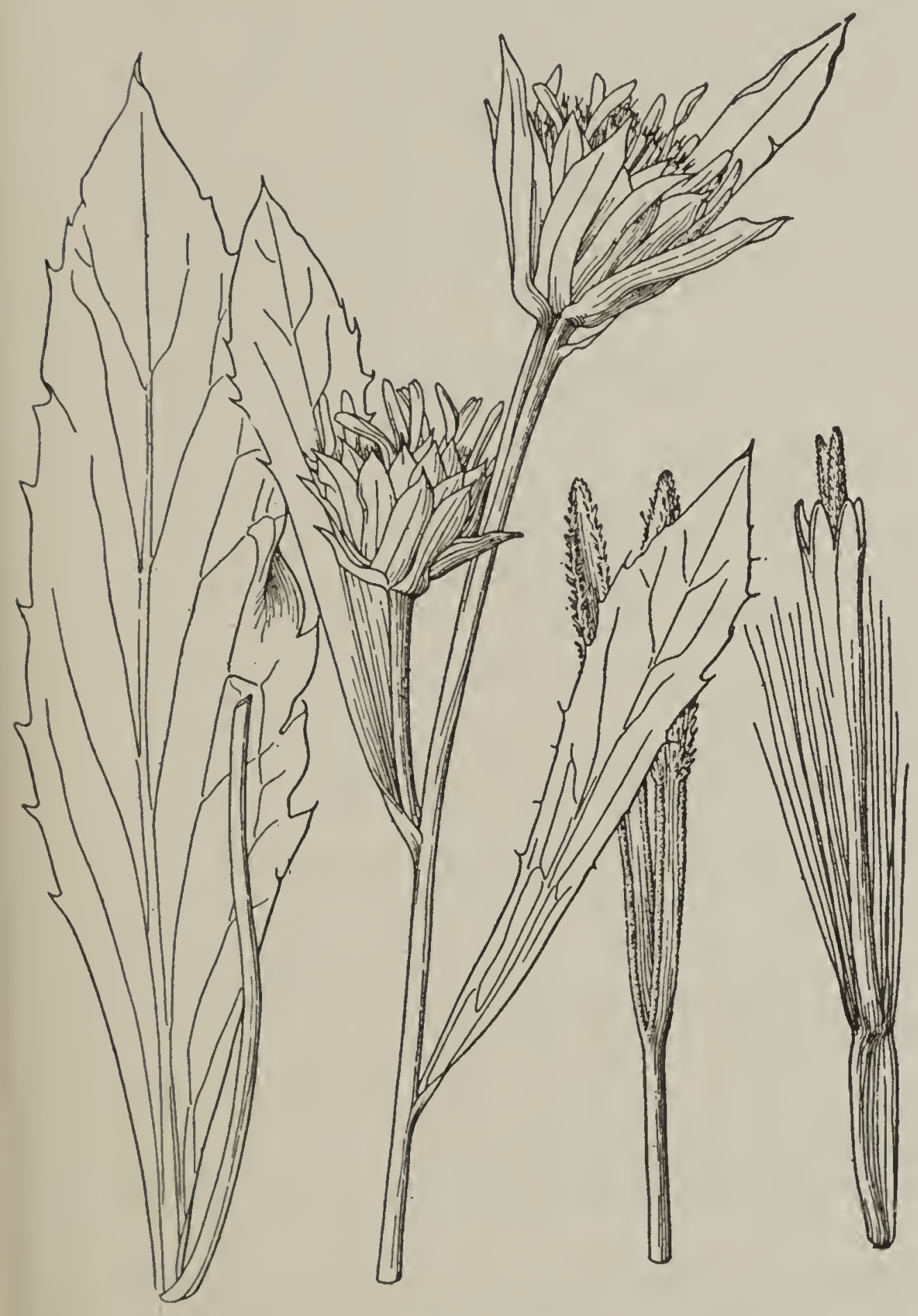

FJG. 29-Haplopapmus carthamoides typicus

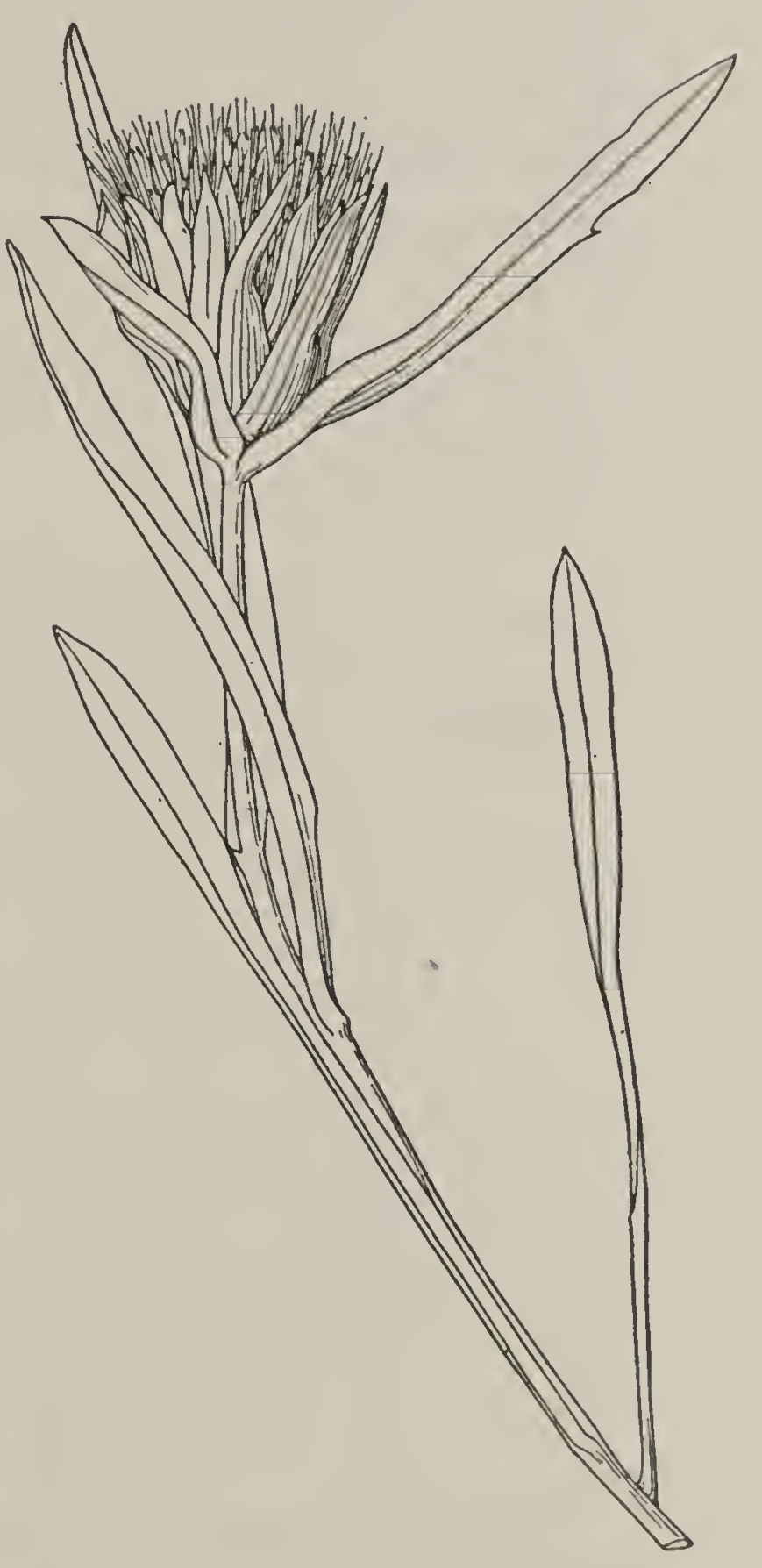

FIG. 30-Haplopappus carthamoides cusicki

by a few membranous leaf-bases; stems pallid throughout or more commonly tinged with red, either finely scabrous, especially toward the heads, or glabrous; leaves equally distributed up the stem, the lower ones oblanceolate or spatulate, tapering to an obvious petiole, entire or undulate to sparsely spinulose-toothed, pungently acute (obtuse and mucronate in ap- 
parently abnormal foliage), the blade 3 to $12 \mathrm{~cm}$. long by 10 to $60 \mathrm{~mm}$. wide, with strong midrib and prominent anastomosing lateral nerves, scabro-puberulent; cauline leaves similar but moderately smaller and sessile by a narrowed base; heads usually solitary and terminal on the stems, sometimes 2 or 3 in a terminal cluster, short-peduncled or sessile among upper leaves; involucre campanulate or hemispheric, 12 to $20 \mathrm{~mm}$. high, 15 to $30 \mathrm{~mm}$. broad; bracts loose, few, scarcely imbricated, shorter than mature disk (this sometimes overtopped by upper subtending leaves), oblong to lanceolate or the innermost linear, mostly mucronate or pungently acute, herbaceous like the leaves, only the margins and sometimes the base scarious, entire or spinulose-denticulate, puberulent to glabrate; ray-flowers entirely wanting to some plants, sometimes 30 or more, the ligules when present 1 to $7 \mathrm{~mm}$. long; disk-flowers numerous; disk-corolla tubular-funnelform, 10 to $13 \mathrm{~mm}$. long, glabrous as to tube; lobes ovate, erect, 1.0 to $1.5 \mathrm{~mm}$. long, either glabrous or minutely puberulent; stylebranches exserted, the acute to attenuate appendage longer than stigmatic portion, sometimes twice as long; achenes subcylindric or flattish, 4-costate, the costae sometimes prominent and the achene then almost prismatic, the intervals either smooth or finely striate, 6 to $8 \mathrm{~mm}$. long, glabrous; pappus exceeding corolla (or rarely shorter), light brown to reddish. (Pyrrocoma carthamoides Hooker, Fl. Bor. Am. 1:307, 1833.) (Figs. 29 and 30.)

Montana and western Wyoming to northern California and British Columbia.

\section{SUBSPECIES}

Key to the Subspecies of Haplopappus carthamoides

Heads medium to large; involucre 15 to $20 \mathrm{~mm}$. high, 15 to $30 \mathrm{~mm}$. broad, or larger, the outer bracts usually foliaceous.

Bracts not recurved-mucronate.

Involucre about 20 to $30 \mathrm{~mm}$. high, 30 to $40 \mathrm{~mm}$. broad. Robust plants with ample leaves...................... (a) maximus

Involucre mostly 15 to $20 \mathrm{~mm}$. high, 15 to 20 or $25 \mathrm{~mm}$. broad.

Bracts oblong, narrowed only near the summit; heads hemi- spheric.

Leaves mostly dentate; bracts inconspicuously margined. .

Leaves mostly entire; bracts with conspicuously scarious margins..............................

Bracts lanceolate; heads campanulate.................

Bracts (except the outermost foliaceous ones) abruptly mucronate from the broad summit, the mucro inclined to be re-

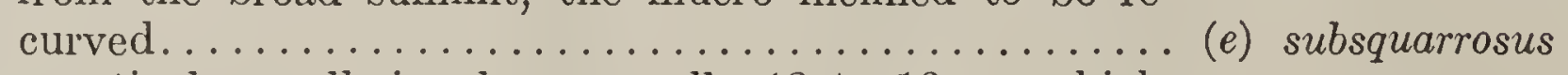

Heads comparatively small; involucre usually 12 to $16 \mathrm{~mm}$. high, 15 to $18 \mathrm{~mm}$. broad, the outer bracts not foliaceous but the heads sometimes closely subtended by upper leaves.

(b) typicus

(c) rigidus

(d) cusicki

(f) erythropappus

18a. Haplopappus carthamoides maximus (Gray) -Stems robust, leafy, 3 to $6 \mathrm{dm}$. high; leaves rigid, pale, entire or undulate to slightly denticulate, the lower oblong or narrowly obovate and 10 to $20 \mathrm{~cm}$. long by 4 to $7 \mathrm{~cm}$. wide, the upper reduced ones lanceolate with a narrow but subclasping base; heads broadly hemispheric, mostly solitary and terminal (openly to closely subcorymbose in original collections); involucre 20 to $30 \mathrm{~mm}$. high, 30 to $40 \mathrm{~mm}$. broad; bracts rather closely imbricated, oblong, narrowed to a straight mucro, the margins commonly spinulose-dentate; 
disk-corolla about $11 \mathrm{~mm}$. long; pappus sordid. (Pyrrocoma radiata Nutt., Trans. Am. Phil. Soc. II, 7:333, 1840. Haplopappus carthamoides var. maximus Gray, Syn. Fl. $1^{2}: 126,1884$.)

Eastern Washington, eastern Oregon, and probably adjacent Idaho. Type locality, "Plains of Oregon, near Walla Walla." Washington: Klickitat Prairie, July 1880, Howell (Gr, Boiss). Oregon: "Wahlamet," Nuttall (Gr, K, probably of the type collection, the exact locality not known); Snake River, Baker County, September 1882, Cusick (Gr); Hood River, Howell 1538 (UC).

18b. Haplopappus carthamoides typicus-Stems moderately robust, leafy, about 3 or $4 \mathrm{dm}$. high; leaves only moderately firm, pale green, mostly sharp-denticulate but varying to entire, the lower oblong to broadly spatulate and 10 to $20 \mathrm{~cm}$. long by 2 to $5 \mathrm{~cm}$. wide, the upper ones smaller and narrower, mostly oblong to oblanceolate with a subclasping base; heads hemispheric, solitary and terminal or with a few also peduncled in the upper axils; involucre 15 to $20 \mathrm{~mm}$. high, about as broad; bracts loosely imbricated, the outer ones foliaceous and often exceeding disk, the others oblong to above the middle and narrowed to an erect pungent tip, mostly sharp-denticulate (as in the type) but some only undulate; disk-corolla 10 or $11 \mathrm{~mm}$. long; pappus sordid. (Pyrrocoma carthamoides Hook., Fl. Bor. Am. 1:307, pl. 107, 1833.) (Fig. 29.)

Eastern Washington and Oregon (also Alberta, British Columbia, and Montana, according to Rydberg). Type locality, northwest coast of America. Type collection, without specific locality, Douglas (Kew). Washington: dry hillsides, Columbia River, Klickitat County, August 22, 1881, Suksdorf (US, combines narrow heads of subspecies cusicki with bract-shape of typicus). OREGON: upper Burnt River, Cusick 1399 (Gr, UC); Hood River, in dried meadow, July 16, 1896, Henderson (R); dry run between Prineville and Button Springs, Crook County, Leiberg 397 (US).

18c. Haplopappus carthamoides rigidus (Rydb.) - Stems moderately robust, 2 to $5 \mathrm{dm}$. high; leaves firm, pale bluish-green, typically entire, the lower broadly oblanceolate and 8 to 15 or $20 \mathrm{~cm}$. long by 1.5 to $4 \mathrm{~cm}$. wide, the upper ones smaller and narrower; heads hemispheric, solitary or with one or two additional heads nearly sessile in the upper axils; involucre 15 to $20 \mathrm{~mm}$. high and fully as broad; bracts imbricated, broadly oblong but contracted above (or the inner rounded) to an erect mucro, entire or the inner only erose, mostly with conspicuous cartilaginous margins; disk-corolla about $12 \mathrm{~mm}$. long; pappus light brownish or sordid. (Pyrrocoma rigida Rydb., Bull. Torr. Club 27:64, 1900; not Phil., 1856.)

Western Montana to eastern Washington and Oregon. Type locality, Granite Station, Kootenai County, Idaho. Montana: Columbia Falls, August-September, 1894, Williams (Gr, NY, R, US); Wild Horse Island, Flathead Lake, Jones 8513 (BM); near Glacier Park Station, Standley 17652 (US, inner bracts with somewhat spreading mucro, as in subsp. subsquarrosus). IDaHo: type collection, Sandberg, MacDougal, and Heller 785 (NY, B, K). Washington: Loomiston, on southeast slope Mount Chapaca, Elmer 603 (NY, R, US, Del, B, K, a peculiar form with many foliaceous bracts recurved from the middle); Spokane County, September 
21, 1912, Turesson (R); between Ellensburg and Swank Creek, Whited 795 (US, Gr); arid barren plains of the Columbia near the Great Falls, 1825, Douglas (K). Oregon: Hood River Valley, Hall 12002 (UC, with very long peduncles).

18d. Haplopappus carthamoides cusicki (Gray)-Stems comparatively slender, occasionally spreading at base, leafy, 0.5 to 2 or rarely $3 \mathrm{dm}$. high; leaves firm, pale gray, mostly entire or only undulate, mostly spatulate-lanceolate, the lower ones 5 to $15 \mathrm{~cm}$. long, 1 to $2 \mathrm{~cm}$. wide; heads broadly campanulate to nearly hemispheric, usually solitary and terminal, sometimes one or two additional ones in the upper axils; involucre 15 to $18 \mathrm{~mm}$. high, nearly as broad across the summit; bracts loosely imbricated, the outer ones foliaceous, some at least equaling disk, the others mostly lanceolate and gradually tapering to an erect mucro, occasional bracts oblong and abruptly narrowed to the mucro, usually all entire; diskcorolla 11 to $13 \mathrm{~mm}$. long; pappus sordid (reddish in minor variation 3). (H. carthamoides var. cusicki Gray, Syn. Fl. $1^{2}: 126,1884$.) (Fig. 30.)

Southeastern Washington and southern Idaho to northeastern California. Type locality, Union County, Oregon (dry ridges at 3,000 to 4,000 feet, according to label at Univ. Calif. Herb.). Washington: Yakima region, Brandegee 841 (UC, intermediate in bracts to typicus); Falcon Valley, July 17, 1886, Suksdorf (Gr). Oregon: Wallowa Mountains, Cusick 2077 (Gr, UC, US, Del, P, K); type collection, Cusick 445 (Gr, UC); stony hillsides, Maurey's Mountains, Cusick 2702 (UC, R, US, Gr, Del, P, B, K); stony flats of the desert, Harney County, Cusick 2604 (UC, R, US, Gr, Del, P, B); Warner Range, Lake County, Coville and Leiberg 43 (US). Idaho: about Forest, Nez Perces County, Heller 3452 (UC, Del, $\mathrm{P}$, other specimens distributed under this number seem to be subsp. erythropappus); Snake River near Ballard's Landing, Cusick 2344 (UC, Gr, Del, B, K); Cedar Creek, Latah County, Henderson 4870 (Gr); Boise County, Macbride 1635 (Gr, R, intermediate to subsp. rigidus as to bracts). California: Big Valley, near Lookout, Modoc County, June 29, Baker; foot of Mount Eddy, August 18, 1900, Congdon (UC); Castle Lake trail, Shasta region, August 18, 1900, Congdon (UC); near Eagle Lake, Lassen County, July 21, 1894, Baker and Nutting (UC, with reddish pappus and dentate leaves, minor variation 3); Willow Creek Valley, A ustin 93 (Greene). Nevada: near Holborn, Elko County, July 15, 1896, Greene (Greene); vicinity of Gold Creek, Elko County, Hitchcock 1075, 1188 (US).

18e. Haplopappus carthamoides subsquarrosus (Greene)-Stems probably rather slender, leafy, 1 to $2.5 \mathrm{dm}$. high, spreading at base; leaves firm, pale, at first tomentulose, spinulose-serrate, lanceolate or narrowly spatulate, the lower ones 8 to $12 \mathrm{~cm}$. long and 1 to $1.8 \mathrm{~cm}$. wide; heads campanulate, solitary and terminal or 2 to 4 and racemosely disposed; involucre about $17 \mathrm{~mm}$. high, 20 to $25 \mathrm{~mm}$. broad at summit; bracts loosely imbricated, tomentulose on the exposed parts, the outer foliaceous ones narrowly lanceolate and spinose-serrate, the inner ones oblong and cuspidate from a broad truncate apex, the mucro more or less recurved; disk-corolla about $10 \mathrm{~mm}$. long; pappus reddish, as far as known. (Pyrrocoma subsquarrosa Greene, Erythea 3:22, 1895.)

Known only from the type collection, Sunlight Basin, northwestern Wyoming, September 5, 1893, Rose 334 (US, UC). 
18f. Haplopappus carthamoides erythropappus (Rydb.) - Stems robust, rigid, leafy, 1.5 to $3.5 \mathrm{dm}$. high; leaves rigid, pale bluish-green, entire or with only a remote denticulation or undulate, the lower ones oblanceolate and about $15 \mathrm{~cm}$. long by $2 \mathrm{~cm}$. wide, the upper ones sessile by a halfclasping base and reduced to about 3 to $6 \mathrm{~cm}$. long by 1 to $1.5 \mathrm{~cm}$. wide; heads narrowly hemispheric, nearly sessile in the axils of the upper leaves; involucre 12 to $16 \mathrm{~mm}$. high, 15 to 18 or $20 \mathrm{~mm}$. broad across the summit; bracts closely imbricated, oblong, narrowed to a straight mucro, the margins thin and entire; disk-corolla about $10 \mathrm{~mm}$. long; pappus decidedly reddish. (Pyrrocoma erythropappa Rydb., Bull. Torr. Club $27: 624,1900$. .)

Southern Idaho, southeastern Washington, and perhaps eastern Oregon. Type locality, Clear Water, Oregon, according to the label on the type specimen, but probably the locality is in Idaho, as given by Rydberg. IDAно: type collection, Spalding (NY); Sweet, Boise County, in lava at 1,060 meters altitude, Macbride 1635 (R, UC, US, Del). Washington: Spokane County, Suksdorf 396 (Gr). Oregon (?): "Spokane County," Geyer 588 (Gr, Boiss, K).

\section{MINOR VARIATIONS AND SYNONYMS}

1. Aster carthamoides O. Kuntze, Rev. 317, 1891-H. carthamoides typicus.

2. Haplopappus carthamoides var. cusicki Gray, Syn. Fl. 12: 126, 1884-H. carthamoides subsp. cusicki.

3. H. carthamoides cusicki, but the finely spinulose-dentate leaves only $1 \mathrm{~cm}$. and less wide, the bracts rather abruptly attenuate, and the pappus reddish. The single plant seen (near Eagle Lake, Lassen County, California, July 21, 1894, Baker and Nutting, UC) is only $1.2 \mathrm{dm}$. high. The pappus color is exactly that of the type of subsp. erythropappus, but the two plants are otherwise very unlike. The bract-shape is such as to almost completely obliterate the distinctions between the sections Pyrrocoma and Oonopsis.

4. H. carthamoides var. maximus Gray, 1. c.-Based upon Pyrrocoma radiata Nutt., here treated as $H$. carthamoides subsp. maximus.

5. H. carthamoides rigidus, but a low stout form with narrow entire leaves and a soft puberulence. This appears to be very distinct from any of the described forms of $H$. carthamoides, but the available material is too old to permit of exact diagnosis. It is from Spokane, Washington (Hall 11626, UC). A similar form, but with some leaves denticulate, comes from dry south slopes on the north side of the Columbia River, $8 \mathrm{~km}$. east of Bingen (Hall 11999, UC).

6. H. rigidus Blank., Mont. Agr. Col. Sci. Stud. Bot. 1:100, 1905. Based upon Pyrrocoma rigida Rydberg, which see.

7. Hoorebekia carthamoides Piper, Contr. U. S. Nat. Herb. 11:559, 1906-Haplopappus carthamoides.

8. Hoorebekia carthamoides cusicki Piper, 1. c. 560-Haplopappus carthamoides cusicki.

9. Pyrrocoma carthamoides Hook., Fl. Bor. Am. 1:307, 1833-H. carthamoides typicus.

10. P. cusicki Greene, Erythea, 2:59, 1894-H. carthamoides cusicki.

11. P. erythropappa Rydb., Bull. Torr. Club 27:624, 1900-H. carthamoides erythropappus.

12. P. radiata Nutt., Trans. $\Lambda$ m. Phil. Soc. II, 7:333, 1840-H. carthamoides maximus.

13. P. rigida Rydb., Bull. Torr. Club 27:624, 1900, not Philippi-H. carthamoudes rigidus.

14. P. subsquarrosa Greene, Erythea 3:22, 1895-H. carthamoides subsquarrosus.

\section{RELATIONSHIPS}

This species is remarkable in its tendency to become discoid, a trait not otherwise known in Pyrrocoma. Perhaps this signifies'an approach 
to the homogamous species of the neighboring section, Oonopsis, which it sometimes approaches also in other features, especially the shape of the involucral bracts (minor variation 3). In other characters Haplopappus carthamoides is most like croceus and integrifolius, and these three doubtless had a common origin, the present species representing the most highly developed line, as indicated by reduction in the ray and greater development of style-appendages.

Within the species there have occurred several well-marked developments, resulting in forms some of which might well be considered as distinct species, were it not for a perplexing variation in their characters and for the unique feature of the ray-flowers which is exhibited by all of the forms and thus binds them into a natural assemblage. If any were treated as distinct species, the expression of this relationship would be lost, while it is clearly expressed in the trinomials. The subspecies maximus is given basal position because of the large size of its heads, the supposition being that the others have been derived through reduction in the number of flowers. There is no certainty, however, that it is not merely a robust form of typicus, adapted to especially favorable soil and climatic conditions; in the absence of experimental evidence its status as anything more than a mere modification is difficult to demonstrate. Along with the feature mentioned go certain others, particularly of the involucral bracts, which make its treatment as a subspecies at least provisionally desirable. Typical carthamoides, with its saliently dentate leaves, mediumsized heads, and oblong involucral bracts, holds an intermediate position and displays no specialized features. It should, perhaps, include subsp. rigidus, although this is quite striking in its entire, pale leaves, and in the original form it lacks the long, dentate, outer involucral bracts, so prominent in the type specimens of typicus. Perhaps the best character of rigidus is the broad cartilaginous margin of the bracts. Subspecies cusicki is the most abundant of all and one of the best marked. Its distinguishing characters are the narrow heads and the lanceolate, acute bracts; but some specimens combine the features of narrow heads and broad, oblong bracts (Suksdorf's collection of August 22, 1881, cited under typicus). The recurved mucro of the bracts might seem to justify the treatment of subsp. squarrosus as a species, but the character is too slight for this purpose, as shown by plants of rigidus in which the inner bracts are provided with a somewhat spreading mucro (Standley 17652). Further collections from the outlying station whence came the types may throw much light upon the constancy of this character. In erythropappus is found the most distinct subspecies of all, as is indicated by the arrangement of the key. However, it must stand upon the differences shown by habit and by the heads, especially the involucre, rather than upon the feature that gave it its name. Throughout the whole species there is much variation in the color of the pappus, which appears to run parallel with no other feature. In many plants necessarily placed in other subspecies the color is as red as in the types of this and, on the other hand, some collections which must be classed as erythropappus have only a brown or tawny pappus.

\section{ECOLOGY}

This is a species of fairly good volcanic soil at moderate altitudes in the more arid portions of the Transition Zone, where it occupies small 
openings in the lava fields. The present center of distribution is that northwest arm of the Great Basin which reaches into Washington. Here are found the typical form and the more abundant subsp. cusicki, but toward the borders of the area of distribution are found only other forms, some of which are sufficiently differentiated to be regarded as subspecies. June to August are the seasons of most abundant bloom, with some plants holding over into September.

19. Haplopappus clementis (Rydb.) Blake, Contr. U. S. Nat. Herb. 25: 543,1925

A perennial herb, 1 to $4 \mathrm{dm}$. high, with several decumbent or ascending stems from a small taproot; stems pale, more or less tinged with red, somewhat villous; leaves chiefly basal, these oblong, lanceolate or oblanceolate (minor variation 1), tapering to a petiole, erect, entire or often saliently dentate (especially in the typical form), acute, the blades 5 to 15 $\mathrm{cm}$. long, mostly about $10 \mathrm{~mm}$. wide with prominent midrib and obscure lateral veins, rather thick and somewhat fleshy, glabrous or sparsely and lightly puberulent, the margins often scabrid, the reduced upper leaves ovate or lanceolate, sessile by a subamplexicaul base; heads solitary and terminating the stems or few and cymosely disposed; involucre broadly hemispheric, about $12 \mathrm{~mm}$. high, 20 to $25 \mathrm{~mm}$. broad; bracts in several series, but the outer sometimes as long as the inner, although usually much shorter, the longest about equaling disk, oblong or narrowly oblanceolate, abruptly acute, green and herbaceous except for a narrow hyaline border, usually villous; ray-flowers 40 to 60 , the ligules 10 to $14 \mathrm{~mm}$. long; diskflowers numerous; disk-corollas tubular, with slightly flaring throat, about $7 \mathrm{~mm}$. long, glabrous or lightly puberulent; lobes ovate, about $1 \mathrm{~mm}$. long,glabrous as far as known; stylebranches well exserted, 1.8 to $2.5 \mathrm{~mm}$. long, the lanceolate appendage shorter than or equaling stigmatic

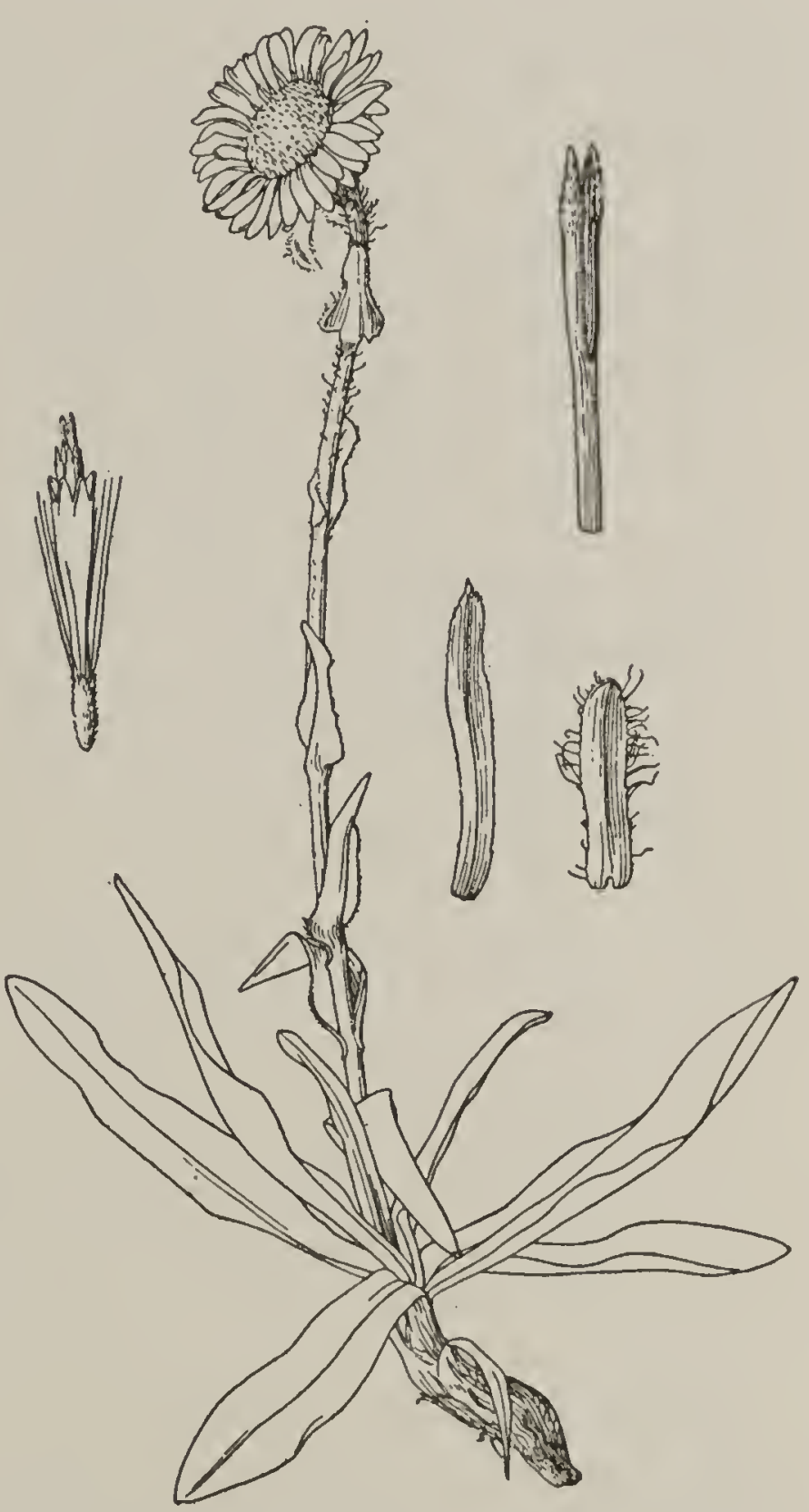

FIG. 31-Haplopappus clementis portion; achenes 4-angled, nearly prismatic but tapering to each end, with longitudinal nerves between the angles, about $6 \mathrm{~mm}$. long, lightly to densely villous; pappus slightly exceeding corolla, light brown, not copious. (Pyrrocoma clementis Rydb., Bull. Torr. Club 27:625, 1900.) (Fig. 31.) 
At high altitudes in the Rocky Mountains from northern Wyoming and Colorado to southwestern Utah. Type locality, Mount Harvard, Colorado. Wyoming: Big Horn Mountains, Sheridan County, Tweedy 2063 (NY, type of Pyrrocoma villosa, minor variation 4); headwaters of Clear Creek and Crazy Woman River, Big Horn Mountains, Tweedy 3042 ( $R$, unites minor variations 3 and 4 ); head of Middle Fork of Powder River, Big Horn County, Goodding 307 (Gr, NY, R). Colorado: Union Creek Pass, Wolf 579, 472 (US, type of P. calendulacea, minor variation 1); type collection, Clements 44 (NY); Turquoise Lake, near Tennessee Pass, Hall 11059 (UC); near Breckenridge, Summit County, Mackenzie 249 (R). Utah: Panguitch Lake, Jones 6005 (US, UC, Po, R, NY, the first being the type of $P$. subcaesia, minor variation 3); Dyer Mine, Uintah Mountains, Goodding 1305 (R, NY, US); Delano Peak, Rydberg and Carlton 7232 (Gr, NY); Aquarius Plateau, Rydberg and Carlton 7978 (Gr, NY, US).

\section{MINOR VARIATIONS AND SYNONYMS}

A number of species have been proposed from the aggregate known as Haplopappus clementis, but none has been based upon more than a single collection. Even to-day there is a great dearth of material, so that the evaluation of these proposals is almost impossible. It therefore seems better to leave them temporarily among the minor variations than to attempt an organization into subspecies. Moreover, it is quite unlikely that any one represents a marked evolutionary divergence, such as subspecies should exhibit, unless it is Pyrrocoma villosa. It is possible that field studies of this form may lead to its acceptance as a full species, in which case its provisional reduction to subspecific rank would only cause confusion.

1. Pyrrocoma calendulacea Greene, Leaflets $2: 9,1909$. A low form with oblanceolate and obtuse lower leaves which equal in length the $10 \mathrm{~cm}$. high stems. The linear-acute bracts and the villous achenes are nearly as in the type of H. clementis. Type locality, Union Creek Pass, Colorado.

2. P. clementis Rydb., Bull. Torr. Club 27:625, 1900-H. clementis.

3. P. subcaesia Greene, 1. c. $2: 12,1909$. A low but stout form, the stems with 1 to 3 heads, these rather large; involucre about $14 \mathrm{~mm}$. high, about $30 \mathrm{~mm}$. broad, the bracts $3 \mathrm{~mm}$. wide. The leaves are entire and the achenes sparsely villous. Type locality, Panguitch Lake, Utah.

4. P. villosa Rydb., Bull. Torr. Club 1. c. A form (or species?) best marked by its entire leaves, glabrous achenes, and narrow involucral bracts which have a tendency to become lanceolate. The hairiness of the achenes in $\mathrm{H}$. clementis is never dense, while in the related $H$. integrifolius this character is well known to be variable. The shape of the bracts is perhaps a better character, although this also is untrustworthy. The shape is so close to the oblong or linear that a slight dislocation of the zone of greatest width will cause a variation from narrowly lanceolate to narrowly oblanceolate. This fluctuation is seen in the collection from Turquoise Lake, Colorado (cited under H. clementis). Type locality, Willow Creek, Big Horn Mountains, Wyoming.

\section{RELATIONSHIPS}

There can be no question that this species stands close to Haplopappus croceus and to $H$. integrifolius. It differs from both in the small size of all parts and especially in the wholly herbaceous bracts of the involucre. These bracts are intermediate in shape, which may be considered as having been developed either through a narrowing of the apex of the croceus bract or through a broadening of the bract found in integrifolius. The former derivation is favored, since integrifolius is itself a derived form, as indicated by other characters, and, moreover, the present species is connected geographically only with croceus. $H$. clementis grows only at very high 
altitudes in the mountains, with croceus just below, but as far as known the two do not come into actual contact. The former may, therefore, have arisen from the latter through reduction in size of vegetative and floral parts and in number of flowers as well as in a softening and narrowing of the involucral bracts, but an origin from integrifolius or from a common extinct form is not impossible.

\section{ECOLOGY}

This is a species of the subalpine zones of the Rocky Mountains. Here it grows in moist soil, especially in meadows and where small openings in the forest of Pinus contorta and Populus tremuloides admit a sufficient amount of light. The basal leaves sometimes lie flat on the ground, with only the ends ascending, and the stems also are always depressed at base. Plants in flower have been collected from late July to September.

20. Haplopappus integrifolius Gray, Proc. Am. Acad. 16:79, 1880 (nom. nud.); Syn. Fl. $1^{2}: 128,1884$

A perennial herb, 2 to $6 \mathrm{dm}$. high, with several erect or curved-ascending stems from a compact branched caudex and thick short taproot, the basal parts of the old leaves persisting as a brown fibrous sheath; stems light brown or reddish, usually glabrous but puberulent to tomentulose near the heads; leaves chiefly basal and scattered along the stems, the lower ones oblanceolate or spatulate-oblong, rarely broadest below middle (especially in minor variation 9), tapering to the petiole, erect or slightly spreading, usually entire, sometimes serrate, obtuse or barely acute, the blade 7 to $14 \mathrm{~cm}$. long, 10 to $30 \mathrm{~mm}$. wide, only moderately thick, with prominent pale midrib and faint secondary nerves and cross veinlets, either perfectly glabrous or scabrid over the entire surface; middle and upper leaves much reduced, especially in width, sessile, subclasping, lanceolate or narrowly ovate; heads commonly several and long-peduncled in an open raceme, sometimes solitary; involucre hemispheric, 12 to $14 \mathrm{~mm}$. high, 10 to $20 \mathrm{~mm}$. broad (somewhat campanulate and smaller in subsp. liatriformis); bracts in several series, the outer from one-half to fully as long as inner, the longest usually equaling or slightly exceeding disk (this sometimes overtopped by bracts of the peduncle), acute, pale and cartilaginous at base and with pale edges, otherwise green and herbaccous, scabrid on the margins or ciliate, otherwise glabrous except in subsp. liatriformis; ray-flowers 20 to 40, the ligules 12 to $18 \mathrm{~mm}$. long; disk-flowers numerous; disk-corollas tubular-funnelform, 7 to $9.5 \mathrm{~mm}$. long, glabrous or minutely puberulent; lobes lanceolate, 1.0 to $1.5 \mathrm{~mm}$. long, usually glabrous; style-branches moderately exserted, 2 to $3 \mathrm{~mm}$. long, the appendage shorter than or moderately exceeding stigmatic portion except in one subspecies (insecticruris, where much longer); achenes longitudinally striate, becoming 4angled, nearly prismatic but narrowed to each end, 6 or $7 \mathrm{~mm}$. long, glabrous or variously pubescent (see under Criteria, p. 17); pappus equaling or slightly exceeding corollas, brown, the bristles coarse and rather few. (Fig. 32).

Chiefly in the northern part of the Rocky Mountains, but extending from Wyoming and Washington to Utah. Probably also in Saskatchewan. 


\section{SUBSPECIES}

Key to the Subspecies of Haplopappus integrifolius

Herbage glabrous, or tomentulose only toward the heads; involucre broad, hemispheric.

Appendage of the style-branch scarcely exceeding stigmatic portion. (a) typicus

Appendage of the style-branch much exceeding stigmatic portion. (b) insecticruris Herbage tomentulose, especially lower leaves and involucres; involucre

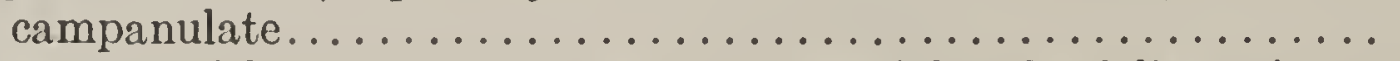
Herbage gray with a scabrid pubescence, especially the foliage; invo(c) liatriformis lucre hemispheric

(d) scaberulus

20a. Haplopappus integrifolius typicus.- Stems erect from the crown or at first spreading and then erect or ascending, essentially glabrous but usually with a sparse tomentum on peduncles; leaves either ample or narrowed, entire or undulate or some of the upper with a few sharp teeth, smooth and glabrous or those near heads slightly tomentulose-ciliate;

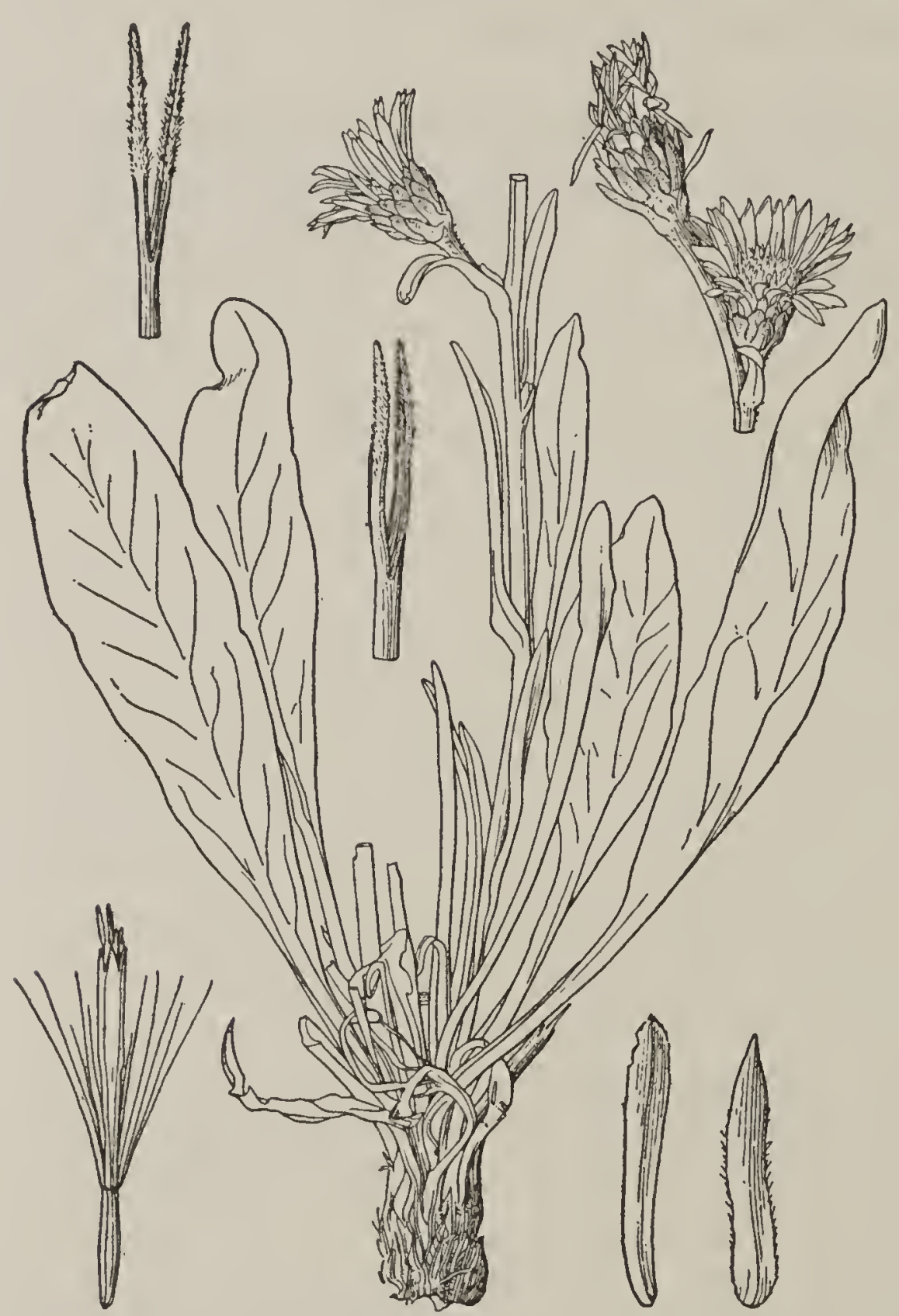

FIG. 32-Haplopappus integrifolius typicus inflorescence racemose, the peduncles often long or the heads solitary and terminal; involucre broad-hemispheric, 12 to $15 \mathrm{~mm}$. high, 15 to $20 \mathrm{~mm}$. broad, the bracts glabrous except on margins; stigmatic portion of style-branch 1.0 to 1.6 $\mathrm{mm}$. long, the appendage of equal length or slightly shorter. (H. integrifolius Gray, Syn. Fl. 12: 128, 1884.) (Fig. 32.)

Western Montana and Wyoming to Utah and Idaho. Type locality, Henry Fork, Idaho, and Rocky Mountains (according to labels with the type specimens, which, however, erroneously assign Henry Fork to Wyoming). MoNTANA: near Judith Gap, August 21, 1882, Canby (Gr, Phila.); Boulder Divide, August 4, 1898, Brandegee (UC); near Helena August, 1888, Kelsey (UC); Sedan, Gallatin County, August 10, 1902, W. W. Jones (UC); Armstead, Beaverhead County, Hall 11500 (UC); Centennial Valley, Beaverhead County, July 26, 1905, Setchell (UC). Wyomrng: near Mammoth Hot Springs, Yellowstone, August 24, 1894, Burglehaus (Phila.). UтAн: without exact locality, Ward 596 (US, type of Pyrrocoma lapathifolia 
Greene, minor variation 9). New Mexico: Mogollon Mountains, Socorro County, Metcalf 540 (US, minor variation 5, type of Pyrrocoma amplectens); Harvey's upper ranch, Pecos River National Forest, Standley 4641 (GR, US, same variation); Colfax County, St. John 43 (Gr). InAнo: Henry Fork of Snake River, eastern Idaho, 1872, Coulter (Gr, a portion of one of the type collections, the other being labeled "Rocky Mountains, Burke"); Henry's Lake, Fremont County, Nelson 6797 (Gr, US).

20b. Haplopappus integrifolius insecticruris (Hend.)-Stems erect, perfectly glabrous except near heads, there sparsely tomentulose; leaves ample, the lower ones 15 to $30 \mathrm{~mm}$. wide, denticulate to saliently serrate or some entire, smooth and glabrous; inflorescence typically a raceme of long-peduncled heads; involucre hemispheric, about $12 \mathrm{~mm}$. high, 15 to $20 \mathrm{~mm}$. broad, the bracts glabrous except on margins; stigmatic portion of style-branch 0.8 to $1.2 \mathrm{~mm}$. long, the appendage 1.5 to $1.7 \mathrm{~mm}$. long. (H. insecticruris Henderson, Bull. Torr. Club $27: 346,1900$.

Known only from southwestern Idaho. Type locality, dry, stony ground, west end of Big Camas Prairic, Blaine County. Type collection, July 14, 1895, Henderson 3013 (US, Gr); Corral, Camas Prairie, Macbride and Payson 3829 (Gr, R, UC).

20c. Haplopappus integrifolius liatriformis (Greene)-Stems erect, tomentulose at first, soon glabrate and shining in middle portions; leaves rather narrow (30 mm. or less wide), entire or undulate, sparsely shorttomentose, glabrate except on petioles; inflorescence an elongated open raceme; involucre broadly campanulate, 10 to $13 \mathrm{~mm}$. high, 10 to $12 \mathrm{~mm}$. broad, white-tomentulose; disk-corolla 8 to $10 \mathrm{~mm}$. long; stigmatic portion of style-branch 1 to $1.6 \mathrm{~mm}$. long, the appendage 0.9 to $1.2 \mathrm{~mm}$. long. (Pyrrocoma liatriformis Greene, Leaflets 2:17, 1909.)

Southeastern Washington. Type locality, Pullman. Type collection, August 29, 1903, Piper (US); same locality, Babcock and Collins 66 (UC); prairies of Spokane County, Suksdorf 923 (US, Del, type collection of minor variation 13, Pyrrocoma suksdorfi).

20d. Haplopappus integrifolius scaberulus (Greene)-Stems erect, rather stiffly pubescent with short but conspicuous spreading hairs, this type of pubescence persisting toward heads, but here more sparse; leaves moderately ample, the basal ones 15 to $25 \mathrm{~mm}$. wide, entire, scabrid on both faces with a gray puberulence; inflorescence a spike or raceme of few heads; involucre nearly hemispheric, 13 to $15 \mathrm{~mm}$. high, about $15 \mathrm{~mm}$. broad, the bracts glabrous except on margins; stigmatic portion of style-branch about $1.5 \mathrm{~mm}$. long, the appendage of about equal length. (Pyrrocoma scaberula Greene, Leaflets $2: 19,1909$.

Known only from the type collection, this from near Forest, Nez Perces County, Idaho, at about 1,050 meters altitude, July 29, 1896, Heller 3469 (US, UC).

\section{MINOR VARIATIONS AND SYNONYMS}

In addition to the following, note should be made of the large variation in inflorescence. The originals of subsp. typicus have heads solitary or 2 or 3 in axils, but this subspecies varies to robust forms with 12 or more long-peduncled heads in an open raceme. 
1. Aster canbyi O. Kuntze, Rev. 315, 1891-H. integrifolius typicus.

2. Haplopappus insecticruris Hend., Bull. Torr. Club 27:346, 1900-H. integrifolius insecticruris.

3. H. integrifolius pumilus Blank., Mont. Agr. Col. Sci. Stud. Bot. 1:100, 1905. Based upon Pyrrocoma integrifolia pumila Rydberg, which see.

4. Hoorebekia integrifolia Jones, Bull. Univ. Mont. Biol. 15:49, 1910-Haplopappus integrifolius typicus.

5. Pyrrocoma amplectens Greene, Leaflets 2:10, 1909. A narrow-leaved form with rather obtuse bracts and therefore difficult to place. Appears to come between $H$. integrifolius typicus and $H$. croceus. The type is from Mogollon Mountains, New Mexico, at 2,740 meters altitude (August 17, 1903, Metcalf, US).

6. P. insecticruris Heller, Muhl. 1:7, 1900. Based upon H. insecticruris.

7. P. integrifolia Greene, Erythea 2:69, 1894-H. integrifolius typicus.

8. P. integrifolia var. pumila Rydb., Bull. Torr. Club 27:626, 1900. This is a monocephalous form with stems $1 \mathrm{dm}$. or less long and with shorter and less acute involucral bracts than in $H$. integrifolius typicus, of which it is doubtless a local modification. The type is from Butte, Montana. Similar plants and intermediate forms are not uncommon.

9. P. lapathifolia Greene, Leaflets $2: 13,1909$. Probably to be accepted as $H$. integrifolius typicus, but there is only one specimen upon which to base a judgment. This is from Utah, without definite locality (Ward 596, US). The plant is about $3 \mathrm{dm}$. high, very leafy, the leaves broad and more or less dentate, suggesting subspecies insecticruris, but the stylar appendages are not of this form. The most striking feature is the shape of leaves. Although some of these are of the usual oblanceolate type, most of them are broadest just below the middle and are therefore narrowly to broadly lanceolate. Some taper to the petiole, but others are abruptly contracted at base, resembling those of Rumex salicifolius. This form is of interest as standing between the subspecies typicus and insecticruris, but it may be an abnormality, and in any event the determination of its taxonomic status may await further field studies.

10. P. liatriformis Greene, l. c. 17, 1909-H. integrifolius liatriformis.

11. P. pratensis Greene, l. c. 19, 1909. The same as H. integrifolius insecticruris, for the type specimen of each is the same sheet in the United States National Herbarium.

12. P. scaberula Greene, 1. c.-H. integrifolius scaberulus.

13. P. suksdorfi Greene, l. c. 18, 1909. A form of $H$. integrifolius liatriformis with smaller leaves, the largest of these $8 \mathrm{~cm}$. long by $14 \mathrm{~mm}$. wide in the type specimen (prairies of Spokane County, Washington, Suksdorf 923, US). The inflorescence is less openly branched, the smaller heads (involucre 10 to 12 $\mathrm{mm}$. high) more strictly racemose, the peduncles only $2 \mathrm{~cm}$. or less long. These characters suggest that it is a form of drier places.

\section{RELATIONSHIPS}

In all of its essential characters this species stands between Haplopappus croceus and $H$. lanceolatus. The reduction in number of flowers and in the size of heads is not so great as in the latter, but the approach in these features is very marked. In habit and in number and arrangement of heads there is enough variation completely to bridge the gap between the two. The style-branches usually are as in croceus, that is, with short appendages, but in one subspecies the appendages are as long in proportion to the stigmatic portion as they are in lanceolatus. The evidence, therefore, all points to the evolution of the latter from the former through integrifolius, although a slightly roundabout route with the present species on a side-line and the intermediate stages now wanting is also a possibility. There is also a suggestion of a direct connection with racemosus through subsp. liatriformis, but differences in size of heads and flowers are considerable. 
Notwithstanding the rather obvious relationships expressed in the foregoing, there can be no thought of taxonomically uniting this with any of the neighboring species, for specimens which approach these in one set of characters are very different in others. It is quite unlikely that there is any present genetic connection between the species as here accepted, since no specimens have been found that have the appearance of being hybrids.

Variation within the species has been sufficiently strong to produce several marked forms. Some of these are entirely habital, and since there is no evidence from their distribution that they are other than modifications resulting from differences in the local environment, they are here discussed only under Minor Variations.

Of seemingly greater significance is subsp. insecticruris, which, in addition to its robust, leafy habit, has remarkably long stylar appendages, as is brought out in the table of variations (table 3). Since this subspecies does not connect through its other characters with those related species in which the appendages are elongated, it seems that we here have a case of parallel variation in two closely related groups. Whether or not the character is sufficiently fixed in insecticruris to indicate the beginning of a new phylogenetic line is a point that can be determined only after much field study and experimentation. Some authorities have attempted to separate it specifically on the basis of the bracts of the involucre, which are nearly equal in length; but this character is exceedingly variable and any such procedure would throw into insecticruris numerous collections which are otherwise of the subspecies typicus (for example, Scdan, Jones; Centennial Valley, Setchell; and Georgetown Lake, Hall 11583, in part;

TABLE 3-Variation in the subspecies of Haplopappus integrifolius

\begin{tabular}{|c|c|c|c|c|c|c|c|}
\hline & \multirow[b]{2}{*}{ Herbariun } & \multirow[b]{2}{*}{$\begin{array}{l}\text { Length } \\
\text { of } \\
\text { ligule }\end{array}$} & \multicolumn{2}{|c|}{ Disk-corolla } & \multicolumn{3}{|c|}{ Style-branches } \\
\hline & & & $\begin{array}{l}\text { Length, } \\
\text { includ- } \\
\text { ing } \\
\text { lobes }\end{array}$ & $\begin{array}{l}\text { Lobe- } \\
\text { length }\end{array}$ & $\begin{array}{l}\text { Stig- } \\
\text { matic } \\
\text { por- } \\
\text { tion, } \\
\text { length }\end{array}$ & $\begin{array}{l}\text { Append- } \\
\text { age- } \\
\text { length }\end{array}$ & $\begin{array}{l}\text { Ratio } \\
\text { of ap- } \\
\text { pendage- } \\
\text { length } \\
\text { to total } \\
\text { length of } \\
\text { branch }\end{array}$ \\
\hline \multicolumn{8}{|l|}{ Subsp. typicus: } \\
\hline $\begin{array}{c}\text { Georgetown } \\
\text { Lake, Mont... }\end{array}$ & 216862 UC & $\mathrm{mm}$ & $m m$. & $m m$. & $m m$. & $\mathrm{mm}$. & p. ct. \\
\hline $\begin{array}{l}\text { Centennial Val- } \\
\text { ley, Mont.... } \\
\text { Boulder Divide, }\end{array}$ & $69849 \mathrm{UC}$ & $17-17$ & 9.6 & 1.4 & 1.6 & 1.0 & 38.5 \\
\hline Mont......... & $86680 \mathrm{UC}$ & 16 & 9.4 & 1.2 & 1.1 & 1.0 & 47.6 \\
\hline Helena, Mont... & $29556 \mathrm{UC}$ & 12 & 8.4 & 1.1 & 1.1 & 1.1 & 50.0 \\
\hline Do.......... & $196771 \mathrm{UC}$ & $15-18$ & $8.6-7.4$ & $1.3-0.9$ & $1.7-1.4$ & $1.1-0.7$ & 31.3 \\
\hline Utah........... & $216633 \mathrm{UC}$ & & 6.0 & 1.0 & 1.2 & 0.9 & 42.9 \\
\hline Sedan, Mont.... & $166244 \mathrm{UC}$ & $13-15$ & 9.3 & 0.9 & 1.4 & 1.2 & 46.2 \\
\hline Armstead, Mont. & $216892 \mathrm{UC}$ & $18-17$ & 9.3 & 1.0 & $0.9-1.2$ & $1.4-1.2$ & 55.5 \\
\hline Do........ & $216891 \mathrm{UC}$ & $15-14$ & 7.9 & 0.9 & $1.2-1.0$ & $1.0-0.9$ & 46.5 \\
\hline $\begin{array}{l}\text { Subsp.insecticruris: } \\
\text { Big Camas Prai- } \\
\text { ri e, I daho } \\
\text { (type)........ } \\
\text { Camas Prairie. }\end{array}$ & 231844 US & $12-10$ & $7.5-7.5$ & $1.1-1.1$ & $1.0-1.1$ & $1.5-1.7$ & 60.4 \\
\hline $\begin{array}{r}\text { Idaho...... } \\
\text { Subsp. liutriformis: }\end{array}$ & $254498 \mathrm{UC}$ & $11-11$ & $9.0-9.5$ & $1.2-1.1$ & $0.8-1.0$ & $1.4-1.5$ & 61.8 \\
\hline $\begin{array}{l}\text { Pullman, Wash. } \\
\text { (type)............ }\end{array}$ & 444984 US & $10-11$ & $10.0-9.5$ & $1.0-1.1$ & $1.4-1.3$ & $1.2-0.9$ & 43.0 \\
\hline
\end{tabular}


all from Montana). Haplopappus insecticruris was first described by Henderson, who compared it with $H$. hirtus. In addition to the differences which he then pointed out, attention should be called also to the entire absence of the glandular pubescence so characteristic of this species. The subspecies scaberulus is characterized by a type of pubescence entirely different from that found elsewhere in this group, but no concomitant characters can be found to serve as a basis for its retention in specific rank. Apparently it is a rare form of very restricted distribution.

\section{ECOLOGY}

This is a meadow plant of plains and mountain valleys, especially in the Transition Zone at altitudes of 1,000 to 2,000 meters. Sometimes it inhabits only slightly alkaline or perhaps neutral soil and even runs up with scattered grasses into the borders of forests of Pinus contorta when the shade is not dense. It is more frequent, however, in alkaline soil, where the associes includes also such herbs as Sporobolus airoides, Juncus balticus, and Iva axillaris, and where there are scattered shrubs of Chrysothamnus nauseosus consimilis, Sarcobatus vermiculatus, and Suaeda depressa erecta. The last two, however, indicate a soil too strongly alkaline for an abundant growth of the Haplopappus. The roots commonly branch a short distance down and occupy the moist soil just below the sod formed from the roots of the grasses and grass-like plants, but when near streams they sometimes penetrate through the soft soil to a depth of 1 to 5 meters, thus reaching the water-table. The flowering period is from the middle of July to the end of September.

\section{Haplopappus lanceolatus (Hook.) Torr. et Gray, Fl. N. Am. 2:241, 1842}

A perennial herb, 1 to $5 \mathrm{dm}$. high, with several erect ascending or spreading and upwardly curved stems from a stout and deep taproot and a very short sometimes branched caudex, this surrounded by a fibrous coat consisting of remains of old leaves; stems stramineous or reddish, often lightly tomentulose; leaves chiefly basal, these lower ones narrowly to broadly lanceolate, long-petioled to subsessile, erect or spreading, rigidly and acutely dentate or some entire, acute or usually attenuate, the blades 5 to $15 \mathrm{~cm}$. long, 5 to $35 \mathrm{~mm}$. wide, smaller in dwarfs, with strong midrib and much fainter lateral nerves, glabrous or tomentulose and glabrate, usually some tomentum persisting, at least on bases of petioles; middle and upper leaves reduced, lanceolate from a sessilc and amplexicaul base; heads terminally paniculate or cymosely disposed or sometimes subracemose because of the short (2 to $4 \mathrm{~cm}$.) lower peduncles (solitary and terminal in minor variation 9); involucre broad-hemispheric at maturity, 5 to $9 \mathrm{~mm}$. high, 10 to $18 \mathrm{~mm}$. broad; bracts rather closely imbricated in 3 or 4 unequal series, the outer successively shorter or occasionally some of these longer, the inner ones shorter than or only equaling disk, all with lanceolate green tips and whitish coriaceous base, acutish to abruptly acuminate, glabrous to lightly tomentulose; ray-flowers 15 to 45 , the ligules 5 to $9 \mathrm{~mm}$. long; disk-flowers numerous; disk-corollas tubular-funnelform, 5 to $7 \mathrm{~mm}$. long, glabrous or only papillate on tube; lobes lanceolate, about $1 \mathrm{~mm}$. long, glabrous or minutely scaberulous; style-branches ex- 
serted at maturity, 1.5 to $2 \mathrm{~mm}$. long, the acuminate appendage equaling or moderately exceeding stigmatic portion; achenes subcylindric, tapering at insertion and shortly rounded at summit, 3 to $4 \mathrm{~mm}$. long, densely sericeous; pappus about as long as corollas, sordid, rather soft and fine for the group. (Donia lanceolata Hook., Fl. Bor. Am., $2: 25,1834$.$) (Figs.$ 33 and 34.)

Saskatchewan to western Nebraska, thence west to northeastern California and north probably as far as British Columbia.

\section{SUBSPECIES}

The subspecies of Haplopappus lanceolatus are not sharply set off from one another. It is therefore impossible to prepare a natural key that will enable one to place with certainty every specimen that is found. In making identifications the geographic position should be taken into account and particular attention given to local environment, injury, etc., as possibly modifying such features as size, habit, number and arrangement of heads, etc.

Key to the Subspecies of Haplopappus lanceolatus

Heads comparatively large, the involucre 7 to $9 \mathrm{~mm}$. high and the disk (as pressed) 12 to $18 \mathrm{~mm}$. broad.

Inflorescence of 4 to many heads in a corymb-like or subpaniculate cluster, rarely more reduced.

Herbage glabrous or tomentulose, never glandular............ (a) typicus

Herbage copiously stipitate-glandular.................... (b) subviscosus

Inflorescence of 1 to 5 heads in a very narrow raceme-like cluster, the lower peduncles being short...................... (c) vaseyi

Heads smaller, the involucre 5 to 6 or rarely $7 \mathrm{~mm}$. high and the disk (as pressed) 10 to 12 or $15 \mathrm{~mm}$. broad.

Heads 7 to 20 or more on each stem; principal leaves 8 to $30 \mathrm{~mm}$.

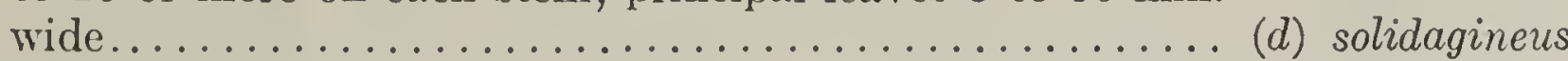

Heads mostly only 1 to 7 or 10 on each stem; principal leaves 4 to $10 \mathrm{~mm}$. wide (occasionally much wider)............. (e) tenuicaulis

21a. Haplopappus lanceolatus typicus-Stems straight and erect or with a short curved base, comparatively stout, usually 3 to $5 \mathrm{dm}$. high, branched above into a more or less rounded corymbiform inflorescence of usually 4 to many heads, the inflorescence either open or, in case of few heads, sometimes rather compact; herbage mostly glabrous but petioles tomentulose, as often also leaf-blades (especially in minor variation 11); basal leaves lanceolate, acuminate at apex, tapering at base into a long petiole, the whole commonly 10 to $18 \mathrm{~cm}$. long, 10 to $20 \mathrm{~mm}$. wide but up to $28 \mathrm{~cm}$. long and $32 \mathrm{~mm}$. wide in the types and some other forms; involucre 7 to 9 or rarely $10 \mathrm{~mm}$. high; disk (as pressed) 12 to $18 \mathrm{~mm}$. broad; ligules 6 to $10 \mathrm{~mm}$. long. (Donia lanceolata Hook. Fl. Bor. Am. $2: 25$ 1834.) (Fig. 33.)

Saskatchewan to western Nebraska, Colorado, northern Nevada (and British Columbia?). Type locality, between Carlton House and Edmonton House, Saskatchewan. Saskatchewan: type, Drummond (K, leaves 18 to $32 \mathrm{~mm}$. wide, heads 3 to 5); Saskatchewan Plains, Macoun 931 (Gr); Whiteshore Lake, Macoun 72808 (Gr). Montana: Montana Valley, Nelson 6844 (R, a peculiar form); Alaska Basin, Madison County, Nelson 6818 (Greene, US, Gr, Del, B, K). Wyomng: Centennial, Nelson 8692 (Po); Laramie, July 29, 1889, Greene (Greene); Spring Creek, Nelson 98 


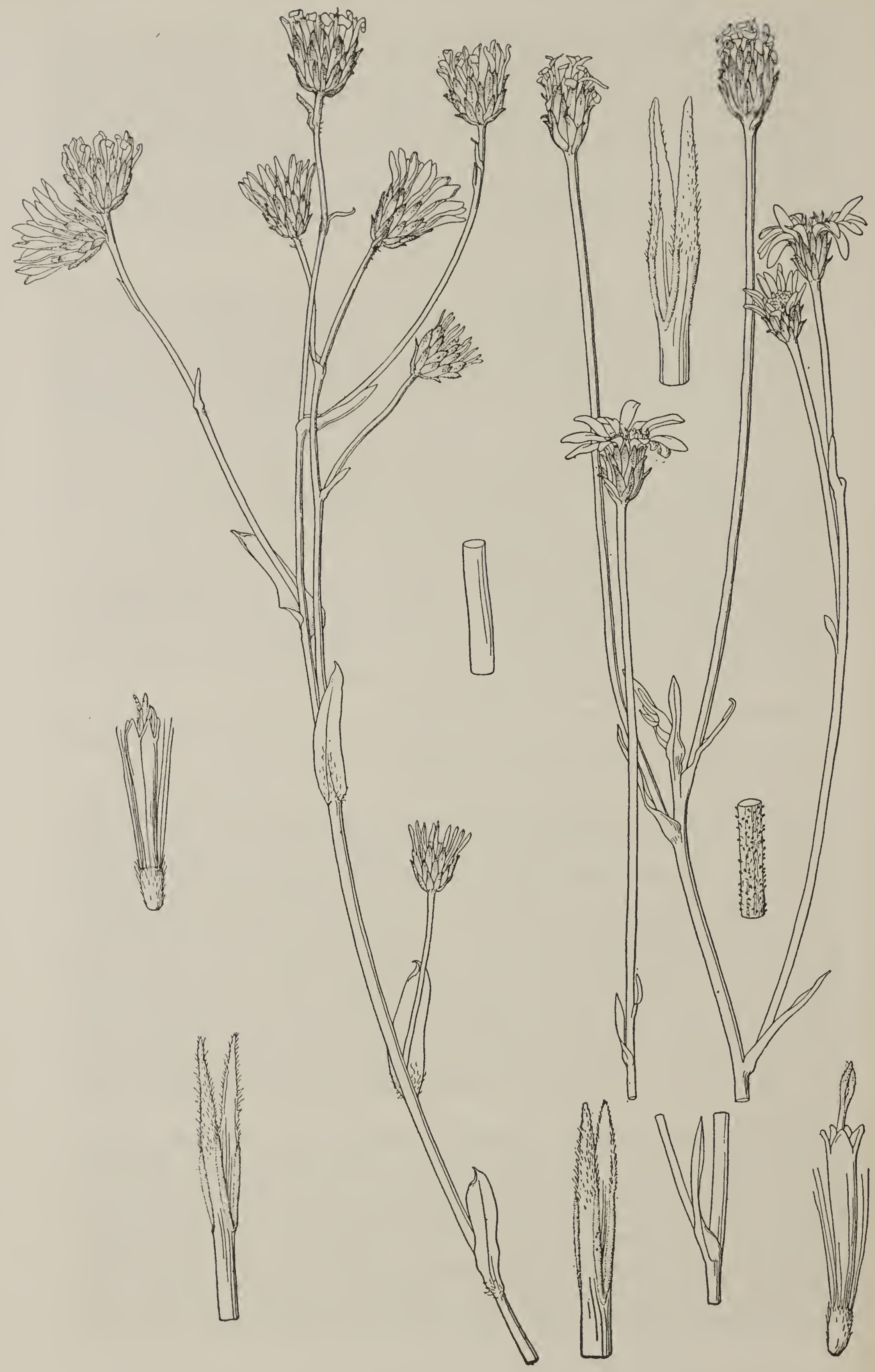


(US). Nebraska: without specific locality, Hayden (NY). Colorado: Saguache and San Luis Valley, Wolf 474 and 485 (Gr, US). UtAr: Kingston, Jones 5983e (US); Trenton, Cache County, Smith 2051 (DS); Rabbit Valley, Ward 616 (US, Gr). NEVADA: near Austin, Hall 12152 (UC); near Deeth, Elko County, Heller 9056 (UC, US); west of Eureka, Hall 12159 (UC); Tuscarora Flats, Elko County, Kennedy 615 (R, UC, DS, a reduced form with pale, tomentulose herbage, similar to minor variation 11); Maggie Creek, Elko County, Kennedy 630 (R, UC, type collection of Pyrrocoma kennedyi, minor variation 11); Elko, Kennedy 4467 (UC, same variation). Oregon: near Fort Klamath, Leiberg 662 (UC, US, Gr, B); Shirk, Leiberg 2580 (UC); between North Powder and Baker, Babcock and Collins 83 (UC, perhaps better as subsp. solidagineus). IDAro: Leadore, Lemhi County, Hall 11504 (UC); Montpelier, July 30, 1889, Greene (Greene). AlberTa: Hand Hills, Macoun 15 (Gr); McLeod, Macoun 20741 (B). Assiniboia: Milk River, Macoun 10873 (Greene).

21b. Haplopappus lanceolatus subviscosus (Greene)-Stems upwardly curved from a more or less spreading base or erect, rather stout, 2 to $4 \mathrm{dm}$. high, branched above to form an open elongated inflorescence of 3 to 7 long-peduncled heads, or the heads solitary and terminal in reduced forms; herbage stipitate-glandular throughout but especially on peduncles, the glands minute but obvious and copious, the petioles often with traces of tomentum; basal leaves lanceolate, acute, tapering below to a petiole, the whole 8 to $20 \mathrm{~cm}$. long, 8 to $30 \mathrm{~mm}$. wide; involucre 7 to $9 \mathrm{~mm}$. high; disk (as pressed) 10 to $15 \mathrm{~mm}$. broad; ligules 6 to $8 \mathrm{~mm}$. long. (Pyrrocoma subviscosa Greene, Proc. Acad. Phila. for 1895:549, 1896.) (Fig. 34.)

Northern Nevada and northeastern California, usually growing with subsp. typicus. Type locality, Humboldt Wells, Nevada. Nevada: type, July 25, 1893, Greene (Greene, see note under minor variation 15); same locality, Hall 12170, 12173 (UC); Cave Creek, southeastern Elko County, Hall 12165 (UC). California: $30 \mathrm{~km}$. south of Alturas, Hall 12212 (UC).

21c. Haplopappus lanceolatus vaseyi (Parry)-Stems mostly curvedascending, stout, 1.5 to $3 \mathrm{dm}$. high, not corymbosely branched but the 2 to 6 heads somewhat racemosely arranged, or the whole sometimes reduced to a single terminal head; herbage pale green and glabrous to obscurely tomentulose; basal leaves lanceolate to oblong-lanceolate, acute to acuminate at apex, tapering at base to a short petiole, the whole 6 to 12 $\mathrm{cm}$. long, 5 to $15 \mathrm{~mm}$. wide; involucre 7 to 9 or rarely $10 \mathrm{~mm}$. high, the bracts commonly abruptly acute; disk (as pressed) 12 to $20 \mathrm{~mm}$. broad; ligules 6 to $9 \mathrm{~mm}$. long. (H. lanceolatus var. vaseyi Parry in D. C. Eaton, Bot. King's Expl. 160, 1871.)

Saskatchewan to Colorado, Idaho, and Alberta. Type locality, Colorądo. Saskatchewan: 1858, Bourgeau (Gr). Wyoming: Muskat Creek, Fremont County, Goodding 518 (Gr, R, UC, US, Po); Laramie, Merrill 473 (US); Poison Spider Creek, Nelson 624 (US); Fort Bridger, July 1873, Porter (US); Ham's Fork and La Barge, July 1900, Curtis (NY, type of Pyrrocoma lagopus, minor variation 12); Centennial Valley, Albany County, Nelson 7957 (US, NY, B, placed here chiefly because of the low, curved stems, but some of the inflorescences as open and corymbiform as in typicus). 
Colorado: Middle Park, Vasey 273 (Gr, type collection); North Fork, Larimer County, Goodding 1927 (Gr. NY, R, UC, DS, US, Del); San Luis Valley, at the lakes, Brandegee 1156 (UC). Montana: near Red Lodge, Rose 682 (US). Idaho: Emmett, Canyon County, MacBride 897 (UC). Alberta: low ground, July 29, 1922, Brinkman 815 (Gr).

21d. Haplopappus lanceolatus solidagineus (Greene)-Stems mostly curved at base but erect for most of their length, rather slender, 2 to $5 \mathrm{dm}$. high, openly branched above or often from near base into a corymbiform or paniculate inflorescence of 7 to 30 or even as many as 75 heads; herbage green and glabrous or lightly tomentulose and glabrate; basal leaves lanceolate, often broadly so, acute at apex, narrowed below into a short or long petiole, the whole 10 to $20 \mathrm{~cm}$. long, 8 to $30 \mathrm{~mm}$. wide, thin; involucre 5 to $6 \mathrm{~mm}$. high; disk (as pressed) 10 to $12 \mathrm{~mm}$. broad; ligules 5 to 6 or rarely $7 \mathrm{~mm}$. long. (Pyrrocoma solidaginea Greene, Proc. Acad. Phila. for 1895: $549,1896$.

Alkaline valleys of northern Nevada and adjacent California. Type locality, along the Humboldt River at Palisade, Nevada. Nevada: type collection, July 24, 1893, Greene (Greene); Pine Valley, Eureka County, July 25, 1893, Greene (Gr, Greene, UC); Camp Halleck, Palmer 202 (UC); $6 \mathrm{~km}$. west of Wells, Hall 11028 (UC, woolly form, discussed under Relationships). California: hills near Alturas, Modoc County, Austin 137 (UC).

21e. Haplopappus lanceolatus tenuicaulis (D. C. Eaton)-Stems upwardly curved from a decumbent base, very slender, 1 to $3.5 \mathrm{dm}$. high, each stem openly branched above into a corymbiform inflorescence of 2 to 7 heads, or these sometimes as many as 10 or reduced to 1 ; herbage green and glabrous or gray-tomentulose and glabrate; basal leaves rather narrowly lanceolate, acute at apex, tapering at base to a short petiole or subsessile, the whole 4 to $12 \mathrm{~cm}$. long, 4 to 10 or rarely $20 \mathrm{~mm}$. wide; involucre 5 to 6 or rarely $7 \mathrm{~mm}$. high; disk (as pressed) 10 to 12 or $15 \mathrm{~mm}$. broad; ligules 5 to $7 \mathrm{~mm}$. long. (Haplopappus tenuicaulis D. C. Eaton, Bot. King's Expl. 160, 1871.)

From Western Utah across northern Nevada to eastern Oregon; perhaps also in adjacent California and Idaho. Type locality, alkaline meadow in Ruby Valley, Nevada. Uтан: Rabbit Valley, Ward 634 (Gr); San Pete River west of Ephraim, Tidestrom 534 (US, see under minor variation 9). Nevada: type collection, Watson $576(\mathrm{Gr}) ; 25 \mathrm{~km}$. north of Simonsen, White Pine County, Hall 12163 (UC); Wells, Elko County, Jones 2196 (Gr, Boiss, B); Ledlie, Lander County, Kennedy 4575 (UC, Del); Fish Creek (near Eureka), August, Brandegee (Gr). Oregon: alkaline meadow, Goose Lake Valley, Cusick 2769 (Del); Crooked and Malheur Rivers, Cycan Marsh, and Alvord Valley, Cusick 2706, 1943, 2741 , and 2015, respectively (UC, US, Gr, Del, P, K, 2741 being the type collection of Pyrrocoma cuspidata, minor variation 10); upper Burnt River, Cusick 1400 (Gr); Shirk, Leiberg 2563 (UC, US, Gr, B, minor variation 2); near Silver Lake, Leiberg 763 (UC, US, Gr, B); Harney Valley, Howell 429 (Gr); Klamath Falls, Peck 3543 (US, type collection of Hoorebekia curvata, minor variation 7 ). 


\section{MINOR VARIATIONS AND SYNONYMS}

1. Aster lanceolatus O. Kuntze, Rev. 313, 1891-H. lanceolatus typicus. On the same page Kuntze describes $A$. lanccolatus var. monocephalus, said to be a reduced form with 1-headed stems like uniflorus, but distinguished from this by the shorter pappus and short, stiff, involucral bracts. The type locality of the variety is Yellowstone Park.

1a. Donia lanceolata Hook., Fl. Bor. Am. 2:25, 1834-H. lanceolatus typicus.

2. Haplopappus lanceolatus tenuicaulis, but with the strong caudex sometimes divided into 2 to 4 branches, each clothed with fibrous vestiges and crowned with a tuft of leaves, from the center of which grow the short $(10 \mathrm{~cm}$. long), slender curved stems. The leaves are only 4 to $6 \mathrm{~cm}$. long, including the short petiole, pale and more or less tomentose, especially near the base. The 4 or 5 heads are corymbosely arranged. Dry, alkaline pools, at 1,520 meters altitude, Shirk, eastern Oregon, Leiberg 2563 (UC, Gr, B). Possibly an aberrant form of $H$. racemosus halophilus.

3. H. lanceolatus var. tenuicaulis Gray, Syn. Fl. 12:129, 1884. Based upon $H$. tenuicaulis, D. C. Eaton, which see.

4. H. lanceolatus var. vaseyi Parry, in D. C. Eaton, Bot. King's Expl. 160, 1871 - H. lanceolatus subsp. vaseyi.

4a. H. subviscosus Blake, Contr. U. S. Nat. Herb. 25:543, 1925-H. lanceolatus subviscosus.

5. H. tenuicaulis D. C. Eaton, 1. c.- H. lanceolatus tenuicaulis.

6. Homopappus multiflorus Nutt., Trans. Am. Phil. Soc. II, 7:333, 1840. Nuttall's suggestion that this may be the same as Donia lanceolata Hook. was confirmed by Gray, who referred both to Haplopappus lanceolatus. From the description and type (Phila) it is seen that this is the form discussed under No. 12 of this list.

7. Hoorebekia curvata Piper, Proc. Biol. Soc. Wash. 31:77, 1918. Here referred to Haplopappus lanceolatus tenuicaulis, with which it closely agrees in all essential features. It has the same slender stems, upwardly curved from the base, but these are a little more tomentulose and the leaves are entire, both of which are common variations. The stems are $4.5 \mathrm{dm}$. long and branched above into 7 to 12 long peduncles bearing the usual small heads, the involucres 5 to $7 \mathrm{~mm}$. high. Type locality, Klamath Falls, southeastern Oregon.

8. H. lanceolata Jones, Bull. Univ. Mont. Biol. 15:49, 1910. Based upon Donia lanceolata, which see.

9. Pyrrocoma cheiranthifolia Greene, Leaflets $2: 47$, 1910. Provisionally referred to $H$. lanceolatus tenuicaulis because of habit, although the heads are nearly as large as in typicus. Perhaps better taken as a distinct species, as done by Greene. Some authors have reduced it to the group of $H$. integrifolius, but it differs from this in the smaller heads, the involucre only $12 \mathrm{~mm}$. high, and especially in the style-branches, the appendages of which are much longer than the stigmatic portion. The heads are mostly solitary. Type locality, San Pete River, west of Ephraim, Utah (Tidestrom 534). Apparently the same also from Nevada (Newark Valley, White Pine County, Hall 12160, UC).

10. P. cuspidata Greene, Leaflets $2: 17,1910$. A nearly glabrous variation of $H$. lanceolatus tenuicaulis, the involucral bracts only ciliate, and the heads rather large. The heads are described as $12 \mathrm{~mm}$. high, but with the type were collected specimens with heads only 9 to $10 \mathrm{~mm}$. high. In the type of tenuicaulis they are $8 \mathrm{~mm}$. high. Greene's description was based upon a portion of Howell's 2741 from the margin of Cycan Marsh, Oregon.

11. P. kennedyi Nels., Bot. Gaz. $37: 265,1904$. An especially luxuriant and tomentose form of $H$. lanceolatus typicus. Stems 2 to $4 \mathrm{dm}$. high, paniculately and profusely branched, so that each bears 10 to 30 or more heads; principal leaves 5 to $10 \mathrm{~cm}$. long, 10 to $18 \mathrm{~mm}$. wide, thus agreeing closely with leaves of the type specimen of lanceolatus, which they also resemble in dentation. The lanate pubescence is especially mentioned by Nelson. The type at the University of Wyoming is notably lanate, but in specimens of the same collection as represented at the University of California the 
tomentum is very sparse and inconspicuous on some of the leaves. In genuine typicus it is common to find more or less tomentum present. It is remarkable that the large size of the heads is maintained notwithstanding their large number, the form differing in this respect from solidagineus, in which high numbers are correlated with a reduction in size, as is to be expected. All of these features should be subjected to experiment to test their constancy under different ecologic factors. The type is from Maggie Creek, Elko Countỹ, Nevada (Kennedy 630, R). Eight collections have now been assembled from the Maggie Creek basin and the area immediately to the north. All exhibit the kennedyi features, indicating that this form is at least a well-marked ecotype and perhaps a geographic subspecies. Kennedy's 615, reluctantly included in kennedyi by Nelson, has some of the characters of subsp. tenuicaulis, notably the small size of plants, leaves, and heads, and the small number of these last.

12. P. lagopus Rydb., Bull. Torr. Club $32: 130,1905$. A segregate from H. lanceolatus vaseyi, differing in its villous stem and involucre. The value of this criterion will be discussed under Relationships (p. 122). The form has an earlier name in Homopappus multiflorus Nutt., No. 6 of this list. Type locality, between Ham's Fork and La Barge, Wyoming.

13. P. lanceolata Greene, Ery thea $2: 69,1894$. Based upon Donia lanceolata, which see.

14. P. solidaginea Greene, Proc. Acad. Phila. for 1895:549, 1896-H. lanceolatus solidagineus.

15. P. subviscosa Greene, 1. c.-H. lanceolatus subviscosus. The types represent a vigorous form with nearly erect stems $4 \mathrm{dm}$. high, each bearing 4 or 5 heads, the peduncles 3.5 to $9 \mathrm{~cm}$. long. There are 4 specimens on the two type sheets, one with heads corymbosely disposed, perhaps as the result of injury, the others with the heads more racemosely arranged. In the former the lower leaves are 20 to $25 \mathrm{~mm}$. wide and about as deeply toothed as in the type of lanceolatus; in the remainder the lower leaves are 10 to $15 \mathrm{~mm}$. wide and the dentations are more prominent, the largest ones $3 \mathrm{~mm}$. long.

16. P. tenuicaulis Greene, Erythea, 2:69, 1894. Based upon H. tenuicaulis, which see.

17. P. vaseyi Rydb., Bull. Torr. Club 27:626, 1900. Based upon H. lanceolatus var. vaseyi, which see.

\section{RELATIONSHIPS}

The probable origin of this species from Haplopappus croceus through integrifolius has been considered under the latter. The principal changes undergone in this process involved a reduction in the number of flowers in each head with a consequent reduction in the size of the head itself, especially the involucre, and an elongation of the sterile tips to the stylebranches. From this newer species there have arisen others with the number of heads again reduced, as shown in the chart of relationships. Each of these has other specialized features that mark it as advanced, so that the position of lanceolatus near the beginning of this group seems fairly well established. Its wide geographic distribution has perhaps permitted the initiation of divergent phylogenetic lines at a number of points. One of these, $H$. racemosus, is simulated by some forms of $H$. lanceolatus vaseyi. There are, for example, specimens from Wyoming (Nelson 62/4) which are truly racemose and which, notwithstanding slight differences in the foliage and habit, might pass for an outlying form of racemosus if their origin were not known. It is believed, however, that such cases are due merely to convergence in vegetative features and that the two species are not now in direct genetic contact.

Within the species there is a tendency toward segregation into distinct genetic stocks. The constancy of some of these has been verified by trans- 
plant experiments. There are also a considerable number of modifications of peculiar aspect but due entirely to the environment. 'This has resulted in the proposal by various botanists of 10 species from among the forms here included under lanceolatus. But with a fair collection of specimens before one, and by taking into account the features of geographic distribution as well as those of morphologic differentiation, it is very difficult to characterize satisfactory segregates even of subspecific rank. Starting with the taxonomic type, which came from the extreme northeastern portion of the range of the species, and which is marked by its robust habit and large but few heads in terminal corymb-like clusters, it is found that this form recurs with but minor modifications as far south as Colorado and west nearly to California. Toward the west there is associated with it, often with the roots almost touching, the most distinct of all the subspecies. This is subviscosus, recognized at a glance by the minute but abundant stipitate glands. There appear to be no intermediate stages, except for variation in abundance of glands, and the two forms retain their characters when transplanted to the Pacific Coast and grown in a uniform environment. But no other difference can be found and this one alone would scarcely justify the retention of subviscosus in specific rank.

Within the easterly portion of the area occupied by typicus, occurs at intervals a form of reduced stature and with a racemiform inflorescence, that is, the lower peduncles are scarcely longer than the upper and unbranched, so that the cluster is elongated. This is here accepted as subsp. vaseyi, although distribution and habit suggest that it may be only a modified form of especially alkaline or otherwise unfavorable habitats. Sometimes it has been separated also on the abruptly acute nature of the involucral bracts. But although this character can be correlated with that of the inflorescence in the case of some Rocky Mountain collections, it breaks down entirely in others and especially in districts farther west, where plants with corymbosely disposed heads and abruptly acute bracts are common (Deeth, Nevada, Heller 9132, UC). The bract character may, therefore, be looked upon as a case of parallel variation in two very closely related stocks.

In passing west from the Rocky Mountain region, there is noted, in addition to subsp. typicus, the development of others marked by a reduction in size of heads, which is of course correlated with number of flowers. There is also a strong tendency toward slenderness of habit, as a result of which the rather weak stems curve outward at base, although the inflorescence is nearly always erect. This is subsp. tenuicaulis, first described from northern Nevada, but better developed and more common in the alkaline soils of southeastern Oregon. In transplant experiments it tenaciously holds the slender habit even when grown in the same beds as the robust typicus. It can not well be correlated with geographic distribution because of the occasional appearance of robust, large-headed typicus in the same area. Moreover, there is still another variation in northern Nevada, namely subsp. solidagineus, in which are combined the features of slender habit and very numerous small heads somewhat paniculately disposed, the whole plant thus resembling Solidago, as the name indicates. In the valley of the Humboldt and its tributaries are found all possible combinations of the characters thus far mentioned and it is 
quite likely that here are to be found the origins of races more fully segregated and developed in neighboring districts. In a collection made from an area of only a few square meters are plants that would pass as typicus, other's that would be classed as tenuicaulis, and still others that fall into solidagineus, in case the several individuals were identified according to the keys (near Wells, Hall 11028). From another source come plants with a copiously branched inflorescence, as in solidagineus, but with the robust stems and large heads of typicus (minor variation 11, from Maggie Creek, Kennedy 630). In both of the collections just mentioned the herbage is more or less tomentulose, the plants from Wells being almost woolly, even on the leaves. This character was used as specific in the attempt to separate Pyrrocoma lagopus from vaseyi, but aside from the fact that the pubescence is perhaps always deciduous, it is much too

TABLE 4-Variation in the subspecies of Haplopappus lanceolatus

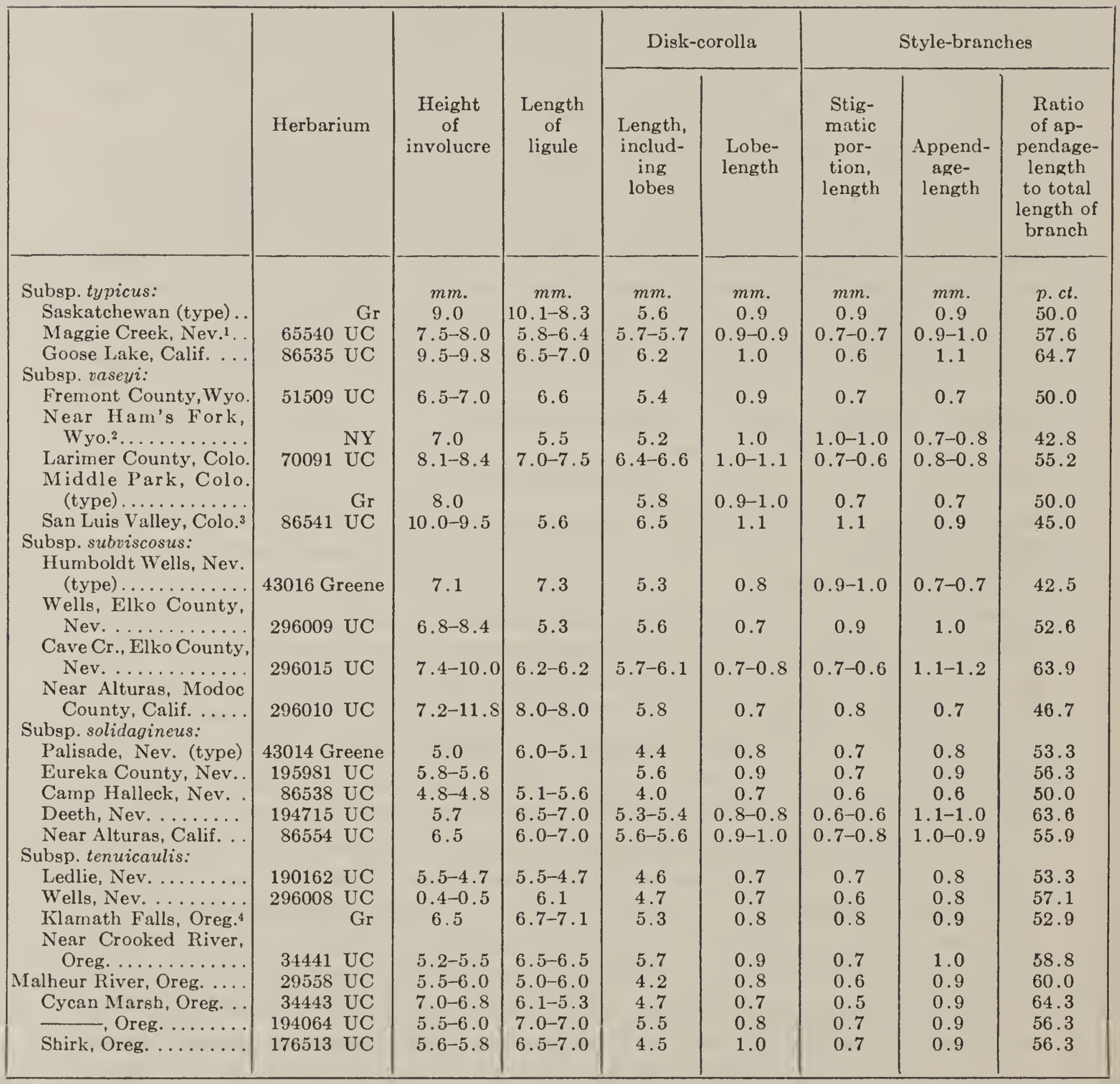

1 Type collection of Pyrrocoma kennedyi, minor variation 11. ' Type of Pyrrocoma lagopus, minor variation 12.
3 Same variation.

4 Type collection of Hoorebekia curvata, minor variation 7 . 
variable as to quantity and distribution on the plant to be of service. Moreover, every subspecies here described has both a green and a tomentulose form, except perhaps subviscosus, so that if this feature is brought forward as of taxonomic value, it will necessitate the erection of three new species or subspecies. It seems more practicable to treat these as parallel minor variations.

\section{ECOLOGY}

Throughout most of its range this species inhabits alkaline mountain valleys and plateaus at 1,500 to 2,100 meters altitude. In Canada it grows in similar places, but probably at much lower altitudes. In the Great Basin it inhabits moist places surrounded by the arid atmosphere of the Artemisia tridentata association. The zonal position is Canadian and Transition. It never becomes dominant, but grows with other perennial herbs, especially grasses, in alkaline clays of depressions in moist meadows, along lake shores, and sometimes on alkaline gravel bars in creeks. Associates noted in Nevada include Distichlis, Elymus condensatus, Iva axillaris, Carduus drummondi, Crepis glauca, and Chrysothamnus nauseosus consimilis. The flowering period is from the middle of June to September.

\section{Haplopappus hirtus Gray, Syn. Fl. $1^{2}: 127,1884$}

A perennial herb, usually 1.5 to $4 \mathrm{dm}$. high, with several erect or curvedascending stems from a deep and stout taproot, this sometimes divided at summit into several short erect caudices, the vestiges of old leaves scarcely noticeable; stems brownish or reddish, especially toward heads, sparsely villous or toward base sometimes slightly woolly, viscid and more or less glandular in inflorescence; leaves forming basal tufts and also well distributed up the stems, the lower ones oblanceolate to broadly elliptic, tapering to a long petiole, mostly erect, closely dentate with salient subulate teeth or pectinately serrate, sometimes bidentate, very acute, the blade 4 to $15 \mathrm{~cm}$. long, 5 to $40 \mathrm{~mm}$. wide, with strong midrib and faint divergent anastomosing veins, thin-membranaceous, sparsely short-villous to tomentulose; upper leaves similar but sessile, moderately reduced in size; heads few, in an open raceme, this corymbiform when lower peduncles are much elongated, the whole sometimes reduced to a single terminal head; involucre broad-hemispheric or subturbinate, 8 to $12 \mathrm{~mm}$. high, 12 to $24 \mathrm{~mm}$. broad; bracts scarcely or at the most loosely imbricated, varying from all equal (or the outer even a little the longest) to moderately unequal, the outer then successively shorter, the longest about equaling disk, herbaceous throughout or with green tips and pale base, acuminate or acute, short-villous and notably viscid or minutely glandular; rayflowers about 20 to 30 , the ligules 8 to $12 \mathrm{~mm}$. long; disk-flowers numerous; disk-corollas tubular-funnelform, about $7 \mathrm{~mm}$. long, glabrous or the tube puberulent; lobes lanceolate, 1 to $1.5 \mathrm{~mm}$. long, glabrous; style-branches well exserted, 1.5 to $2.5 \mathrm{~mm}$. long, the slender appendage nearly always longer than stigmatic portion, sometimes twice as long; achenes densely sericeous (not known in mature condition); pappus about as long as corollas, pale brown, rather soft. (Figs. 35 and 36. )

Southeastern Washington and southern Idaho to northern Nevada. northeastern California, and eastern Oregon. 


\section{SUBSPECIES}

Key to the Subspecies of Haplopappus hirtus

Involucral bracts nearly equal, herbaceous nearly to the base; leaves usually greenish or dark, scarcely tomentulose.

Leaves of medium size, 6 to $20 \mathrm{~mm}$. wide; involucre 10 to $11 \mathrm{~mm}$.

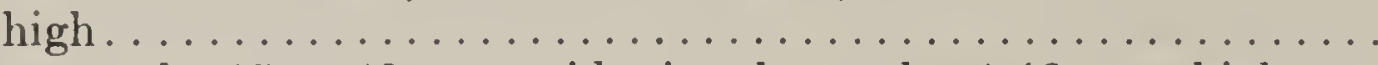

(a) typicus

Leaves ample, 15 to $40 \mathrm{~mm}$. wide; involucre about $12 \mathrm{~mm}$. high.... (b) sonchifolius Involucral bracts unequal, the outer successively shorter, herbaceous only toward the tips; leaves gray-tomentulose, 6 to $20 \mathrm{~mm}$. wide.

(c) lanulosus

22a. Haplopappus hirtus typicus-Stems 1.5 to $4 \mathrm{dm}$. high; leaves moderately ample to very narrow, firm, the blade 5 to $10 \mathrm{~cm}$. long, 6 to $20 \mathrm{~mm}$. wide, varying from dark green and only sparsely short-villous to gray and short-tomentose; heads usually several on each stem except in depauperate plants; involucre hemispheric to subturbinate, 10 to 11 or nearly $12 \mathrm{~mm}$. high, the linear-attenuate bracts all nearly alike and greenish almost throughout. (H. hirtus Gray, l. c.) (Fig. 35.)

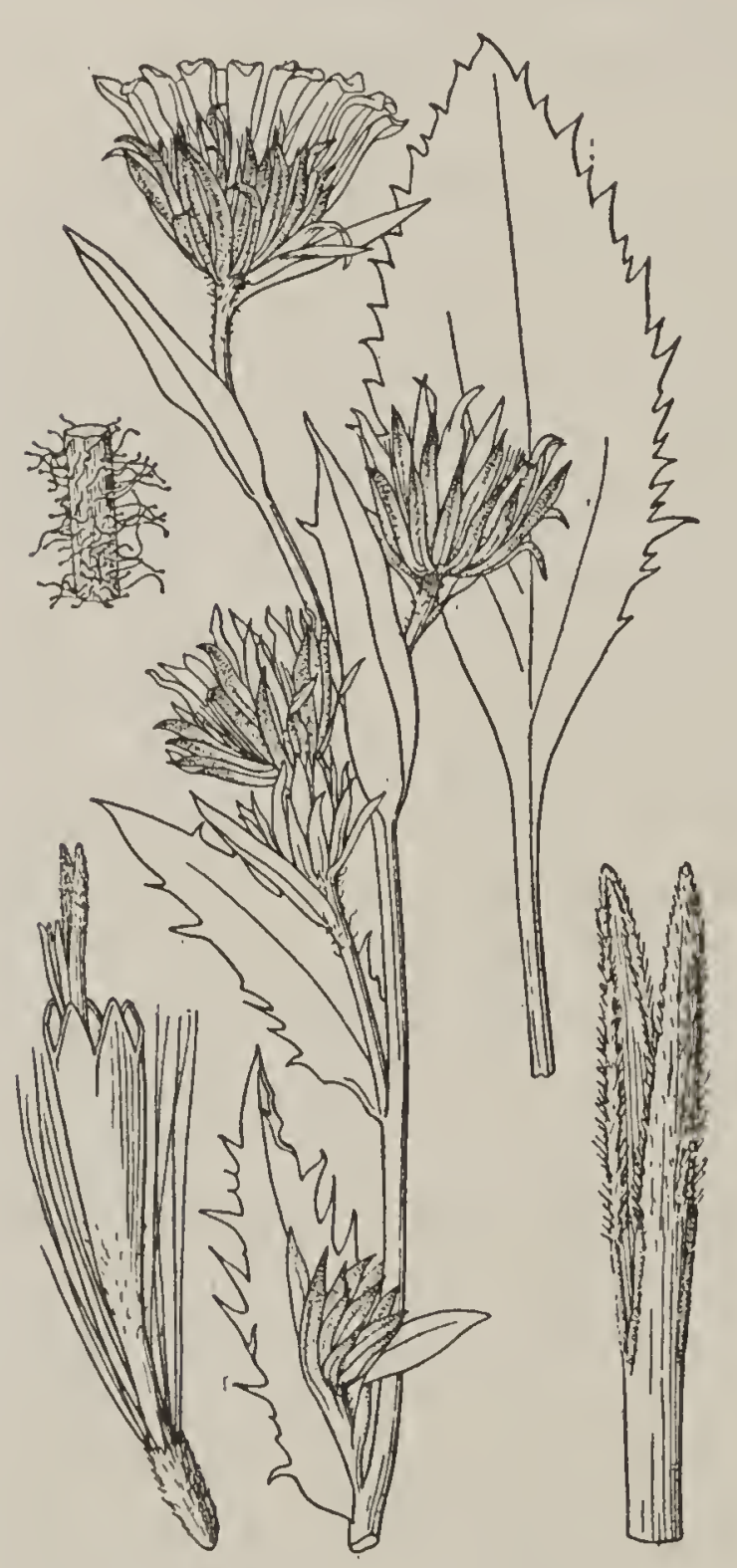

FIG. 35-Haplopappus hirtus typicus

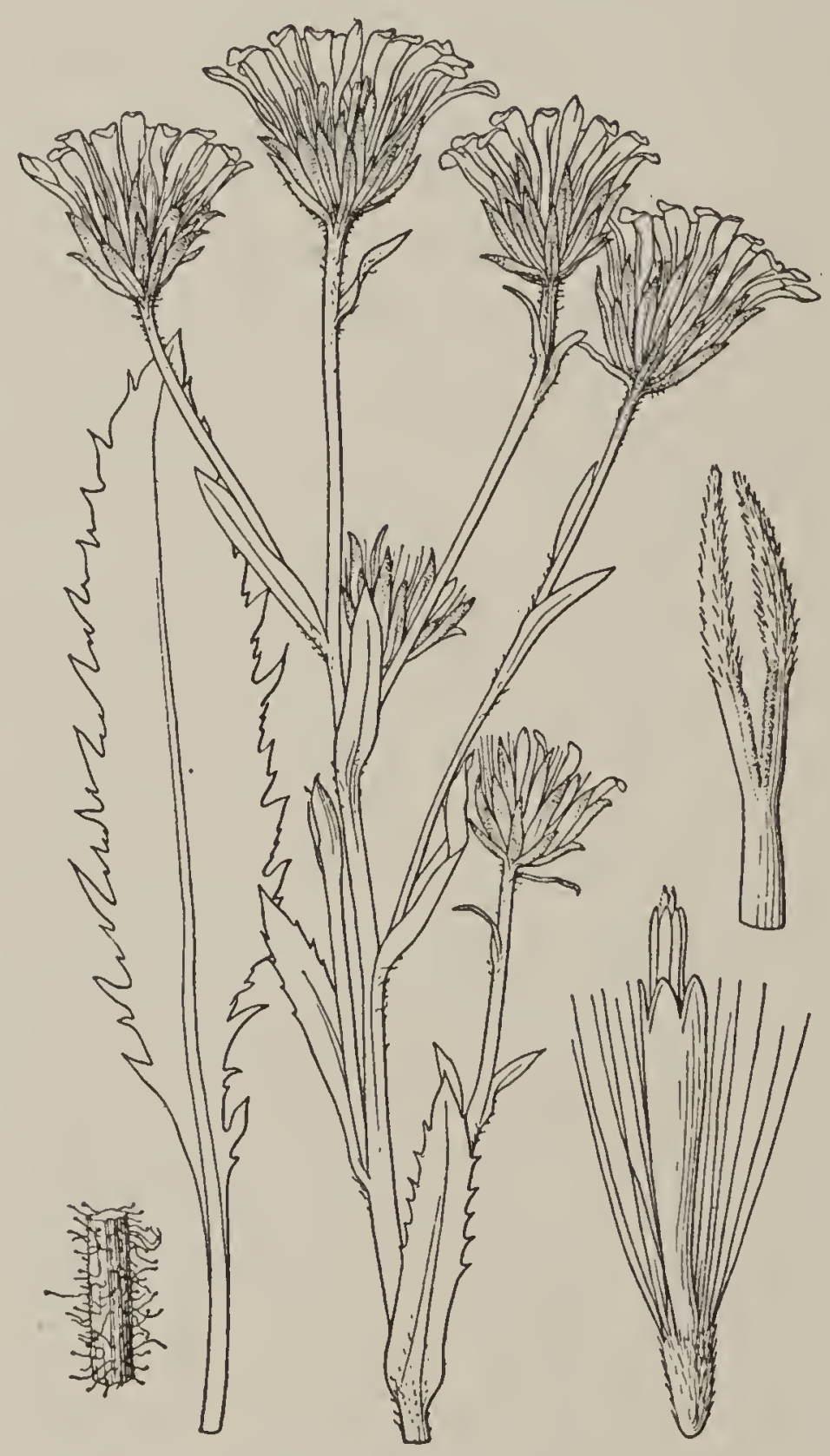

FIG. 36-Haplopappus hirtus lanulosus

Eastern Oregon (and adjacent Idaho?), Nevada, and California. Type locality, Baker County, Oregon; later stated by the collector to be on upper Burnt River, in the Blue Mountains of Baker County. Oregon: Waloupi Cañon, Wallowa County, Sheldon 8275 (US, B); type collection, July, 1886, Cusick 951 (Gr, US, Boiss); type locality, Cusick 2056 (UC, 
US, Del, P, K). Nevada: Gold Creek, Elko County, Nelson and MacBride 2145 (Gi', R). California : Pine Creek, Lassen County, July 12, 1894, Baker and Nutting (UC, DS); Eagle Lake, Lassen County, July 21, 1894, Baker and Nutting (UC, R); near Emigrant Spring, in the lava-beds of Modoc County, Austin 259 (UC).

22b. Haplopappus hirtus sonchifolius (Greene)--Stem 3 to $4.5 \mathrm{dm}$. high in the original collections, but reduced to $1 \mathrm{dm}$. in others; leaves ample, thin, the blade 5 to $15 \mathrm{~cm}$. long, 15 to $40 \mathrm{~mm}$. wide, dark green, sparsely short-villous as well as glandular; heads few or solitary on each stem; involucre broad-hemispheric, 12 to $13 \mathrm{~mm}$. high, the linear-attenuate bracts nearly alike or the outer ones the longer, greenish almost throughout. (Pyrrocoma sonchifolia Greene, Leaflets $2: 18,1909$.

Southeastern Washington and adjacent Idaho and Oregon. 'Type locality, Yakima region, Washington. Washington: type collection, 1882, Brandegee (US, UC); same region, 1883, Brandegee 840 (Gr, UC). IDAнo: near Forest, Nez Perces County, Heller 3434 (UC, DS, the latter intermediate to typicus); Collins, in wet gravelly meadows, Piper 2891 (Gr). Oregon: Meacham, Umatilla County, Peck 2693 (Gr).

22c. Haplopappus hirtus lanulosus (Greene)-Stems 1.5 to $3 \mathrm{dm}$. high; leaves narrow, thick and firm, the blade 4 to 10 or rarely $15 \mathrm{~cm}$. long, 6 to 20 or $25 \mathrm{~mm}$. wide, gray or whitish with a soft villous pubescence, the hairs more or less intertangled, giving the effect of woolliness; heads several on each stem; involucre narrowly hemispheric or almost turbinate, 8 to $10 \mathrm{~mm}$. high, the outer bracts successively shorter, all with rather distinct green tips and pale chartaceous base. (Pyrrocoma lanulosa Greene, Leaflets $2: 16,1909$.) (Fig. 36.)

Eastern Oregon and adjacent California. Type locality, eastern Oregon. Oregon: type collection, Bear Flat, 1,650 meters altitude, Leiberg 748 (UC, US, P, B); in dry soil of Cycan Valley, Cusick 2744 (Gr, UC, R, US, Del, B, K, type collection of Pyrrocoma turbinella Greene minor variation 7); Yanix Reservation, Austin 1730 (US); Warner Range, Lake County, Coville and Leiberg 42 (US). California: sagebrush plain at Grizzly Flat, Leiberg 5195 (US).

\section{MINOR VARIATIONS AND SYNONYMS}

1. Aster grayanus O. Kuntze, Rev. 316, 1891- H. hirtus.

2. Hoorebekia hirta Piper, Contr. U. S. Nat. Herb. 11:560, 1906. Based upon Haplopappus hirtus. The only specimen cited by Piper is here referred to subsp. sonchifolius.

3. Pyrrocoma foliosa Greene, Leaflets 2:18, 1909; not Gray, 1844. A form with deeply toothed leaves up to $30 \mathrm{~mm}$. wide, as in subspecies sonchifolius; but the heads no larger than in typicus, the involucre 9 to $11 \mathrm{~mm}$. high, some of them with outer bracts longer. The type is from Washington (Vasey $505, \mathrm{US})$.

4. P. hirta Greene, Erythea $2: 69,1894$. Based upon $H$. hirtus.

5. P. lanulosa Greene, Leaflets $2: 16,1909-H$. hirtus lanulosus.

6. P. sonchifolia Greene, 1. c. 18-H. hirtus sonchifolius.

7. P. turbinella Greene, 1. c. 17 . This appears to be exactly the same as $H$. hirtus lanulosus. The two were described simultaneously, with no mention of differentiating features, and differences can now be found only in trivial characters. In the type of lanulosus the heads are racemosely arranged 
on short erect peduncles. On the type sheet of turbinella (at US) the heads are somewhat corymbosely arranged, the lower peduncles spreading and 4 or $5 \mathrm{~cm}$. long, but in other plants of this same collection (Cycan Valley, Oregon, Cusick 2744, as at Gr) the heads are racemosely arranged, the peduncles 0.5 to $2 \mathrm{~cm}$. long, or some heads practically sessile. All of these specimens are minutely stipitate-glandular, at least on the involucres.

\section{RELATIONSHIPS}

In many respects this species is much like some forms of Haplopappus lanceolatus, from which it usually may be distinguished by the more racemose arrangement of the heads, and, in its typical form, by the more loosely imbricated involucre. The contact, if it actually exists, probably is through the subspecies subviscosus of Haplopappus lanceolatus, since this also has the glandular pubescence well developed. The direction of evolution is here in much doubt. The glandular feature may be a modern development, perhaps of a reversional nature, or a trait that has come uninterruptedly from a remote ancestor. In any case it seems better to derive hirtus from below lanceolatus, rather than either of these from the other, for the two are now divergent in their tendencies.

In the northwestern part of its range, hirtus has taken on the imbricated form of involucre, resulting in subspecies lanulosus. Possibly this should be given specific rank, but involucral characters in this group are much less significant than in other sections, as witness the high degree of variability in involucres of $H$. apargioides and H. racemosus. Moreover, intermediate stages between typicus and lanulosus are represented in herbaria (Eagle Lake and Pine Creek, Lassen County, California, Baker and Nutting, UC), and even in a portion of the type collection of lanulosus the involucral bracts are nearly equal (Leiberg 748, as at Berlin). The latter subspecies is also notable for its gray-tomentulose foliage, but it should be pointed out that some plants with decidedly lanulosus foliage have also just as decidedly typicus involucres (lava-beds of Modoc County, California, A ustin 259, UC).

Of less significance is subspecies sonchifolius, a form with exceptionally broad leaves and large heads, but overlapping typicus in all its characters. It has the appearance of an adaptation, probably to moister or otherwise favorable habitats, or at the most of being a geographic variation.

All three of the subspecies above described are alike in the feature of the glandular pubescence, although this was not mentioned in any of the original descriptions. All of the types have been examined by the writer in this connection.

\section{ECOLOGY}

Haplopappus hirtus inhabits mountain valleys in the northwestern part of the Great Basin area, mostly at altitudes of 1,050 to 2,200 meters. It grows in heavy soils, probably of an alkaline nature. The remarkable differences between the extreme narrow-leaved forms of subsp. lanulosus and the broad-leaved subsp. sonchifolius doubtless enable the species as a whole to occupy a wide variety of habitats. The flowers appear in July and August. 


\section{Haplopappus racemosus (Nutt.) Torr., in Sitgreaves, Rep. 162, 1854}

A perennial herb, 2 to $6 \mathrm{dm}$. high, with several erect or curved-ascending stems from a deep slenderly fusiform taproot, surrounded at base by stramineous and often fibrous vestiges of old leaves; stems pale brown or nearly white, varying to reddish-brown, smooth or very rarely tomentulose; leaves chiefly basal, these lower ones lanceolate to oblong or oblanceolate, sometimes approaching spatulate but always broadest near middle, tapering into a petiole, mostly erect, entire to denticulate, rarely with salient rigid teeth, acute or acuminate or somewhat obtuse (especially in subsp. longifolius), the blade 5 to $10 \mathrm{~cm}$. long (up to $30 \mathrm{~cm}$. in robust forms), 5 to 25 or even $35 \mathrm{~mm}$. wide, with strong midrib, either thick and firm and the lateral nerves then obscure or thinnish and with evident lateral anastomosing nerves, glabrous or rarely puberulent or petioles villous, the margins usually scabrous or ciliate; upper leaves reduced, sessile, amplexicaule; heads in racemes or spikes, sometimes in narrow panicles, but branches then short or appressed so that the inflorescence is raceme-like in outline, or head solitary and terminal through suppression of lateral peduncles; involucre hemispheric, sometimes with turbinate base, 5 to $12 \mathrm{~mm}$. high, 6 to $18 \mathrm{~mm}$. broad; bracts regularly imbricated in 3 or 4 lengths, rarely subequal, all shorter than mature disk, with conspicuous green tips which tend to spread and pale coriaceous base, abruptly acute or cuspidate at the broad summit, glabrous to lightly tomentulose; ray-flowers 10 to 25 or 30 , the ligules 5 or 6 to 8 or rarely $9 \mathrm{~mm}$. long; disk-flowers mostly 25 to 70 ; disk-corollas tubular-funnelform, 5 to $7 \mathrm{~mm}$. long, glabrous or only the tube puberulent; lobes lanceolate, 0.5 to $1 \mathrm{~mm}$. long, glabrous; stylebranches well exserted at maturity, 1.5 to $2 \mathrm{~mm}$. long, the slender acuminate appendage equaling to considerably exceeding stigmatic portion; achenes nearly prismatic but narrowed at base, 4-angled, with several longitudinal nerves or striae between each pair of angles, 3 to $4 \mathrm{~mm}$. long, usually sericeous but varying to glabrous, often pubescent only near ends; pappus longer than corollas or slightly shorter, dull white to reddish, rather rigid. (Homopappus racemosus Nutt., Trans. Am. Phil. Soc. II, $7: 332,1840$. ) (Figs. 37 to 44. )

Northeastern Oregon to southern Nevada and the Mohave Desert of California, thence northerly to San Francisco Bay and western Oregon.

\section{SUBSPECIES}

\section{Key to the Subspecies of Haplopappus racemosus}

Leaves not thick, the lateral veins visible (least so in typicus, known by its large heads). Plants of non-alkaline soil.

Leaves firm but not chartaceous, not spiny-dentate; achenes pubescent (as far as known). West of the Cascade Mountains.

Stems strictly erect; involucre 10 to $12 \mathrm{~mm}$. high.......... (a) typicus

Stems inclined to spread at base; involucre 7 to $11 \mathrm{~mm}$. high.. (b) congestus

Leaves very stiff, chartaceous, the teeth spiny-tipped; achenes glabrous or pubescent. East of Cascade Mountains.. (c) duriusculus

Leaves thick, drying leathery, the lateral veins obscure. Plants of saline or alkaline soil.

Involucre 9 to $11 \mathrm{~mm}$. high, broad, the bracts with broad green tips, very smooth and glabrous; leaves rather obtuse. (Achenes villous.) Western California.............(d) longifolius 
Involucre 5 to $8 \mathrm{~mm}$. high ( 8 to $12 \mathrm{~mm}$. in prionophyllus, with glabrous achenes); the bracts with narrower tips and at least scabrid on margins; leaves usually acute.

Bracts of the involucre glabrous save for the sometimes ciliate margins; leaves glabrous except on petioles and margins.

Heads mostly scattered; involucre 8 to $12 \mathrm{~mm}$. or more broad. Mature involucre large, 8 to $12 \mathrm{~mm}$. high, 12 to $18 \mathrm{~mm}$. broad (smaller in paniculate forms); achenes glabrous.

Mature involucre smaller, 6 to $8 \mathrm{~mm}$. high, 8 to $12 \mathrm{~mm}$. broad; achenes various.

Leaves all alternate; lower petioles slender.

(e) prionophyllus

Leaves partly opposite; some petioles sheath-like........

Heads sessile in spicate glomerules; involucre 5 to $7 \mathrm{~mm}$. broad.

Bracts of the involucre lanuginous on the back; leaves lightly tomentulose on both faces...................

(f) glomeratus

(g) brachycephalus

(h) sessiliflorus

(i) halophilus

23a. Haplopappus racemosus typicus-Stems stout, erect or nearly so, 4 to $7 \mathrm{dm}$. high; lower leaves all alternate, oblong-lanceolate or slightly oblanceolate, acute, usually 10 to $25 \mathrm{~cm}$. long, 12 to $25 \mathrm{~mm}$. wide, entire to denticulate or rarely with salient rigid teeth, moderately thick, scarcely succulent, drying leathery, pale, the lateral nerves obvious but not prominent, glabrous or the petioles sometimes ciliate; inflorescence strictly racemose; involucre broad-hemispheric, 10 to $12 \mathrm{~mm}$. high, 12 to $18 \mathrm{~mm}$. broad; bracts imbricated, usually smooth and glabrous or only short-ciliate, but occasionally puberulent (as in type); achenes densely villous. (Homopappus racemosus Nutt., Trans. Am. Phil. Soc. II, $7: 332,1840$. ) (Fig. 37.)

Non-alkaline (or only slightly alkaline?) soil, Oregon west of the Cascade Mountains. Type locality, "Plains of the Wahlamet." Type collection, Nuttall (Gr, BM); Corvallis, in bushy, low places, E. Hall 256 (Field); Spencer Butte, near Eugene, Bradshaw 1923 (DS); north side of Spencer Butte, H. M. Hall 11995 (UC).

23b. Haplopappus racemosus congestus (Greene)-Stems slender, outwardly curved at base, or the central ones erect, 2 to $6 \mathrm{dm}$. high (tomentose in minor variation 8); lower leaves lanceolate to broadly elliptic, acute, 10 to $20 \mathrm{~cm}$. long, including the slender petiole, 8 to $30 \mathrm{~mm}$. wide, entire or sparsely denticulate, thin, not succulent, somewhat membranous when dry, green, the lateral nerves and cross-veinlets visible, nearly glabrous but with traces of a sparse villous pubescence at least on the petioles; inflorescence typically glomerate-spicate, the sessile heads 1 to 4 in the axil of each of the upper reduced leaves, but varying to simply spicate or racemose or even reduced to a solitary terminal head; involucre hemispheric or campanulate, 7 to $11 \mathrm{~mm}$. high (varying with the development of the foliaceous tips of the bracts), 12 to $16 \mathrm{~mm}$. broad; bracts usually well imbricated (sometimes few loose and nearly equal in length even in the same colony), scantily short-villous at least on margins or near the base, bright yellowish green on the tips or throughout, 1-nerved (originally described as 3-nerved, but this erroneous); achenes sericeous. (Pyrrocoma congesta Greene, Pittonia $3: 23,1896$. .) (Fig. 38.)

Southern Oregon and northern California, in non-alkaline soil of open forests and meadow borders. Type locality, western base of Coast Mountains, near Waldo, Oregon. Oregon: Dead Indian Valley, near the summit of the Cascade Mountains, Cusick 2947 (US, Gr, NY, UC, DS, Field, Oreg, Del, P, B, type collection of Pyrrocoma balsamitae, minor variation 19); 
$7 \mathrm{~km}$. east of Dead Indian Valley, Hall 11967 (UC); type collection, September 1892, Howell 1498 (Greene, NY); near Waldo, Eastwood 2115 (UC, form with loose involucre, see minor variation 19); Siskiyou Mountains, on Waldo-Crescent City Road, Cusick 2939 (UC, Gr, NY,US, Del, P, B, same variation); $13 \mathrm{~km}$. southwest of Waldo, Hall 11981,12057 (UC, nearly glabrous); $15 \mathrm{~km}$. southwest of Waldo, Hall 12062W (UC, tomentulose, minor variation 8); Oregon Mountain, Hall 12063 (UC). California: Gasquet, French Hill, Del Norte County, Eastwood2192 (UC); $7 \mathrm{~km}$. above Gasquet, Hall 12078 (UC).

23c. Haplopappus racemosus duriusculus (Greene)-Stems stiffly erect, 3 to $6 \mathrm{dm}$. high; lower leaves alternate or rarely opposite, broadly lanceolate to narrowly oblanceolate, rigidly acuminate, 15 to $25 \mathrm{~cm}$. long, 10 to $30 \mathrm{~mm}$. wide, entire to remotely spinose-denticulate, rather thin, chartaceous, the lateral nerves obvious, glabrous, but the margins scaberulous, inflorescence glomerate-spicate or simply spicate, leafy-bracted; involucre campanulate, rather narrow at base, $S$ to $11 \mathrm{~mm}$. high, 7 to $12 \mathrm{~mm}$. broad; bracts few, loosely imbricated, of 2 or 3 lengths or the outer sometimes nearly as long as the inner, glabrous or the margins minutely scabrous, chartaceous, mostly greenish; achenes glabrous or pubescent. (Pyrrocoma duriuscula Greene, Leaflets $2: 16,1909$.)

Eastern Oregon and northeastern California. Type collection, eastern Oregon, in heavy stony soil 1,065 meters altitude, without specific locality, August

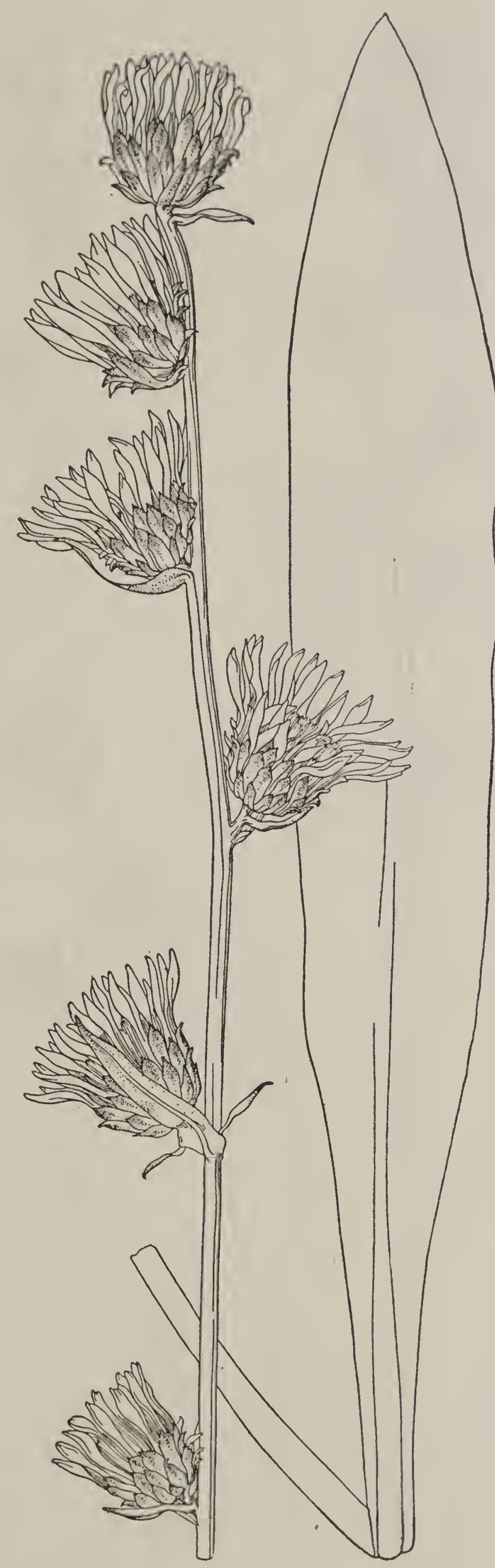

FIG. 37-Haplopappus racemosus typicus 


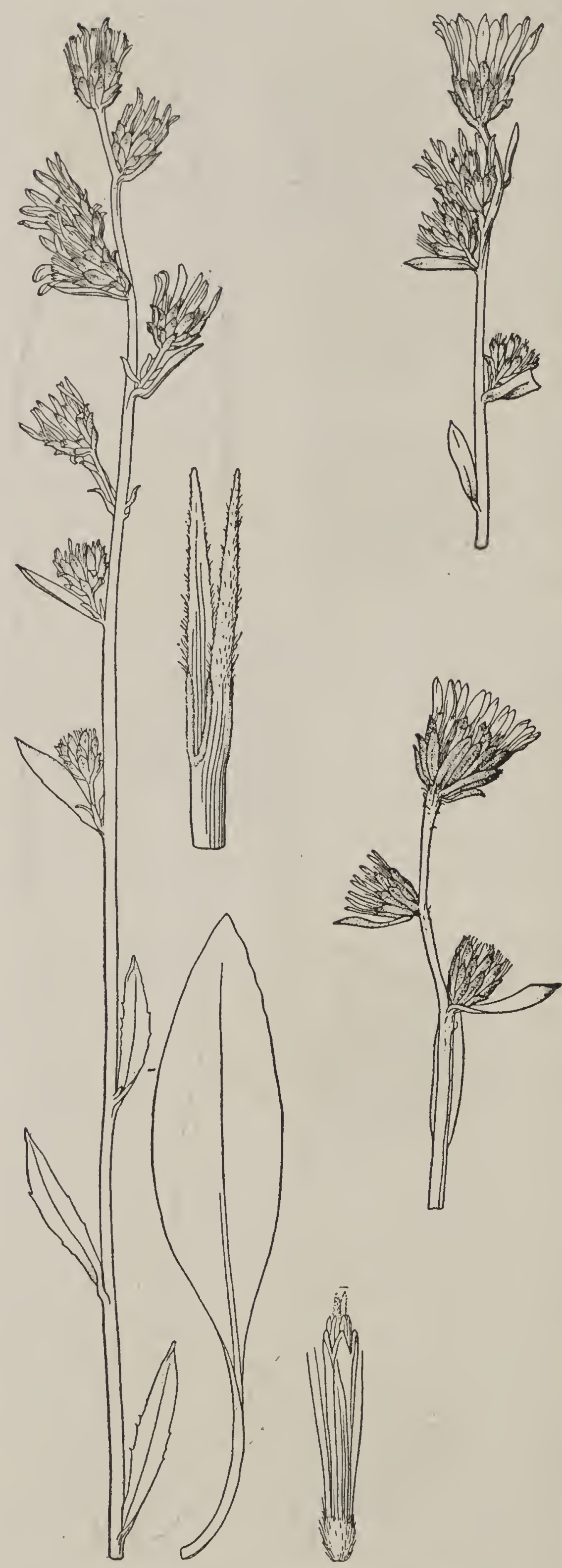

FIG. 38-Haplopappus racemosus congestus
1897, Cusick 1755 (US, UC, the former the type, bracts ending in a rigid cusp and achenes glabrous); alkaline soil on the Malheur River, Oregon, Cusick 1943 (UC, same form); Portola, Plumas County, California, 1913, Brandegee (UC, bracts narrow and attenuate, achenes pubescent).

23d.Haplopappus racemosus longifolius (Greene)Stems very robust, erect, 2 to $7 \mathrm{dm}$. high; lower leaves alternate, spatulate-oblong or oblanceolate, obtuse or only slightly narrowed at tip (the petioles broadly margined), often 20 to 35 $\mathrm{cm}$. long by 15 to $35 \mathrm{~mm}$. wide, but much smaller (10 to $15 \mathrm{~cm}$. by 10 to $15 \mathrm{~mm}$.) in dry soil, entire or callousdenticulate, thick, drying leathery, the lateral nerves scarcely visible, glabrous throughout; inflorescence spicate or racemose or reduced to a solitary terminal head; involucre hemispheric, 9 to $11 \mathrm{~mm}$. high, 10 to $15 \mathrm{~mm}$. broad; bracts regularly imbricated (the outer ones larger than the inner and the heads narrow only in the type and in other pathologic forms), very smooth and glabrous; achenes densely pubescent. (Pyrrocoma longifolia Greene, Pittonia 3:183, 1897.) (Fig. 39.)

Saline borders of marshes,San Francisco Bay to Los Angeles County, California. Type locality, Mount Eden, Alameda County. Type collection, May 1891, Brandegee (UC, 
a fragment with solitary, narrow head, the outer bracts abnormally enlarged, see under minor variation 28) ; same locality, 1907, Brandegee (UC, similarly diseased); same locality, November 17, 1923, Hall 11953 (UC, heads normal, 1 to 8 on each stem, depending on conditions); Alviso, Baker 1703 (Gr, Del, Kew); Jarvis Landing, Hall 11955 (UC); San Jose, July 1887, Rattan (Greene, cited as one of the originals of Pyrrocoma elata, see minor variation 24); Cooley's Landing, San Mateo County, September 29, 1906, Abrams (UC, DS); between Gilroy and Hollister, Abrams 6687 (DS); Los Angeles County, .1880, Bush (US).

23e. Haplopappus racemosus prionophyllus (Greene)Stems moderately stout, usually erect and 3 to $6 \mathrm{dm}$. high, curved at base and shorter in poor situations; lower leaves all alternate, narrowly oblonglanceolate or oblanceolate scarcely petioled or the petiole wing-margined, acute or acuminate, 10 to $25 \mathrm{~cm}$. long, 8 to $20 \mathrm{~mm}$. wide, coarsely and evenly serrate-toothed (in the typical form) to entire, thick, succulent, drying leathery, the lateral nerves obscure, glabrous except for the finely scabrous margin and sometimes ciliate petiole; inflorescence exceedingly variable, narrowly racemose in the type, racemosepaniculate in syntypes, sometimes much reduced, even to solitary heads; involucre hemispheric, 8 to $12 \mathrm{~mm}$. high, 12 to $18 \mathrm{~mm}$. broad at maturity; bracts smooth and glabrous (the broad green tips more conspicuous than in related subspecies); achenes always glabrous. (Pyrrocoma prionophylla Greene, Leaflets 2:12, 1909.) (Fig. 40.)

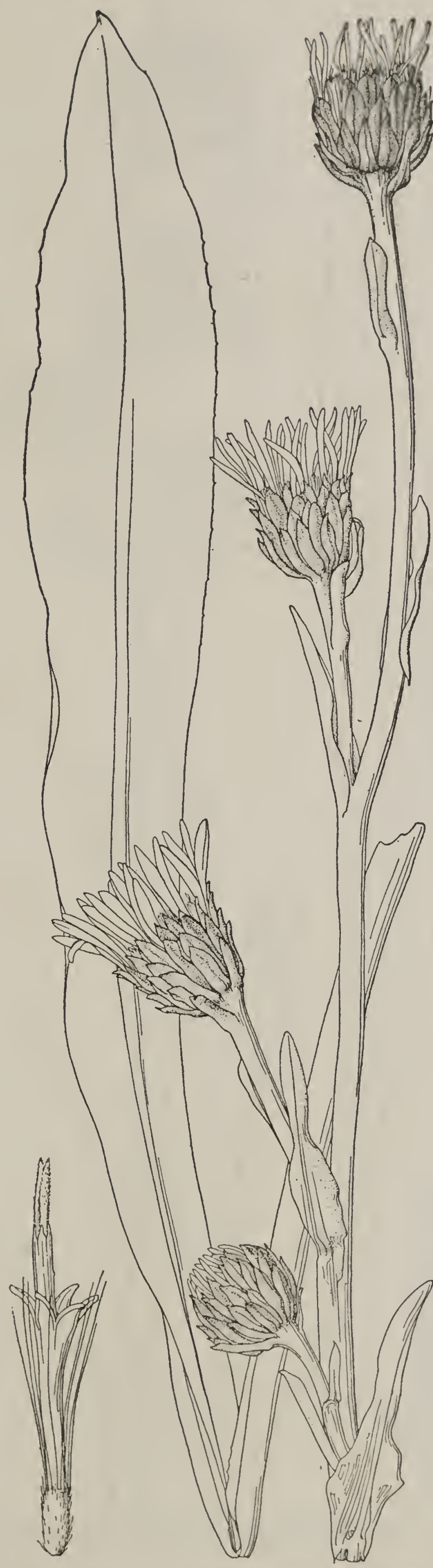

Fra. 39-Haplopappus racemosus longifolius 


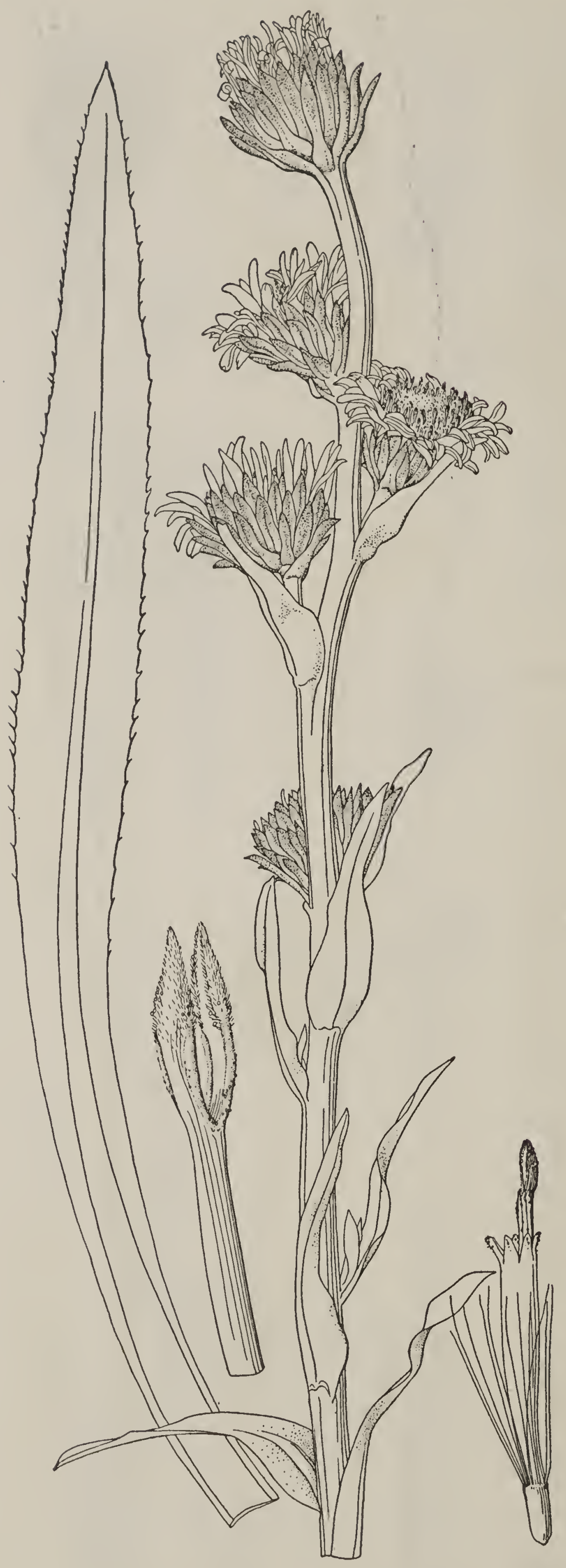

Fig. 40-Haplopappus racemosus prionophyllus
Western Nevada and adjacent California. Type locality, Eagle Valley, Ormsby County, Nevada. Nevada: type collection, at 1,446 meters altitude, August 11, 1902, Baker 1450 (US, UC, NY, Gr, R, SF, Del, B); King's Cañon, Ormsby County, Hall 12220 (UC, dwarf form); Franktown, Washoe County, Kennedy 1936 (UC); Hunter Creek Cañon, Washoe County, July 1907, Kennedy (UC, form with solitary heads); Bowers, Washoe County, Hall 12145 (UC, heads 1 to 4 on each stem); west of Washoe Lake, Hall 12143 (UC); Carson City, Hall 12218 (UC). CaliForNIA: Sardine Valley, Sierra County, Sonne 7 (UC); West Fork Walker River, at 2,280 meter's altitude, Hall 12140 (UC, heads solitary); $5 \mathrm{~km}$. west from Bridgeport, Hall 12224 (UC).

23f. H a p 1 opappus racemosus glomeratus (Nutt.)-Stems slender but stiff and erect (very slender and curved in minor variation 6 ), 2 to 7 $\mathrm{dm}$. high; lower leaves alternate, elliptic-lanceolate, acute or obtuse, 5 to $15 \mathrm{~cm}$. long (or more through elongation of the petiole in grassy places), 5 to $15 \mathrm{~mm}$. wide, entire or denticulate, thick, succulent but drying rigid, pale without obvious lateral nerves, glabrous except for the more or less ciliate petioles; inflorescence typically glomerate-racemose and the 


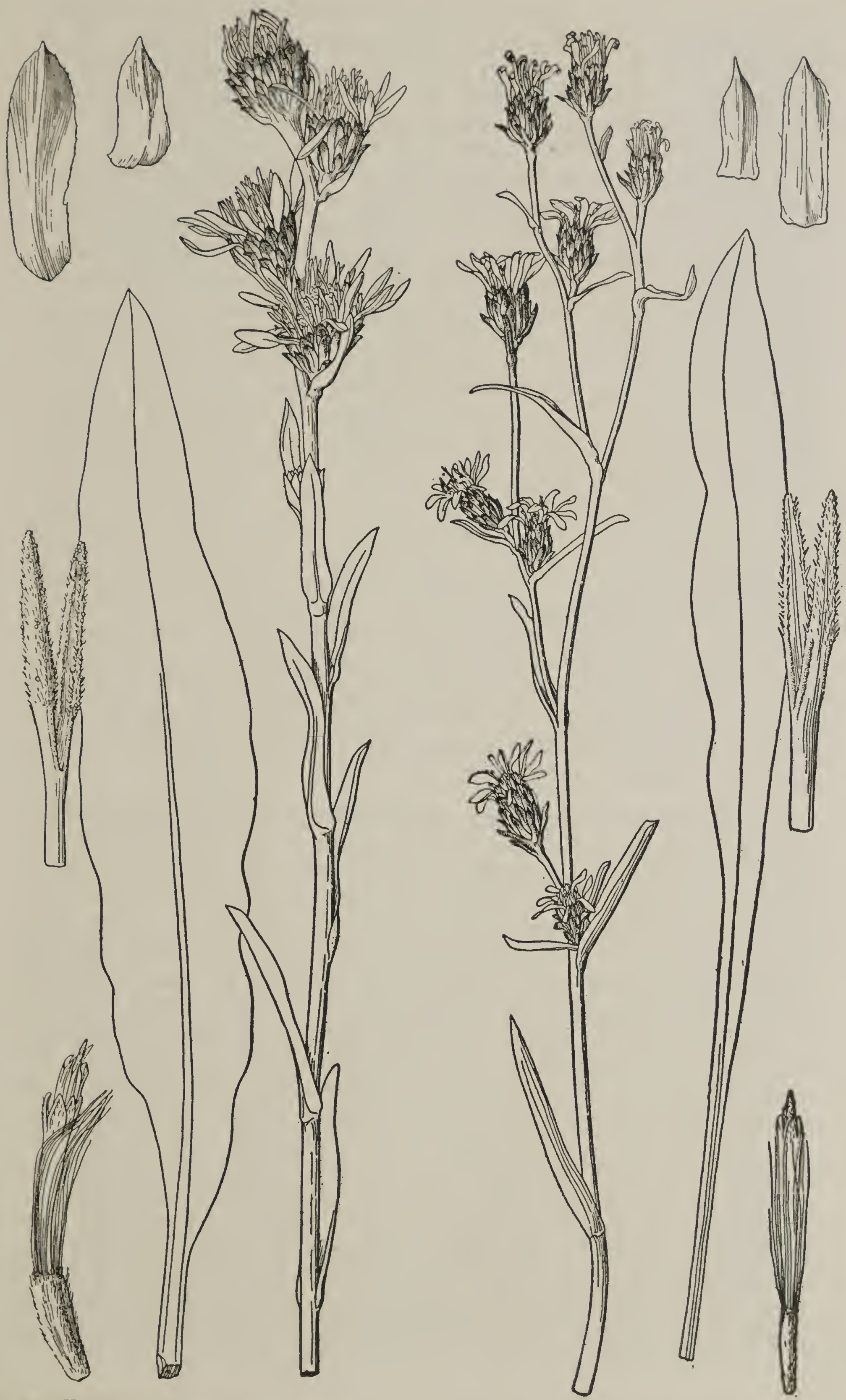

Fı. 41-Haplopappus racemosus glomeralus from Calistoga, California

FIG. 42-Haplopappus racemosus glumeralus from Benton, California 
peduncles short but varying to simply racemose and simply spicate, peduncles longer and spreading in depauperate forms; involucre 6 to 8 $\mathrm{mm}$. high, 8 to $12 \mathrm{~mm}$. broad; bracts glabrous, the margins smooth or ciliate; achenes typically glabrous but varying to densely sericeous in California and Nevada. (Homopappus glomeratus Nutt., Trans. Am. Phil. Soc. II, $7: 331,1840$.) (Figs. 41 and 42.)

Alkaline plains from northeastern Oregon through western Nevada and in California south to the San Joaquin and Antelope Valleys. Type locality, Plains of the Columbia, not far from Walla Walla (probably in the Grande Ronde Valley, Oregon). Oregon: type collection, Nuttall (Phila, Gr, BM); Grande Ronde Prairie, Nuttall (BM, type of Homopappus paniculatus, minor variation 15; Gr, type collection of minor variation 13, Homopappus argutus; Union County, Cusick 530 (Gr). Nevada: Steamboat Springs, Washoe County, Kennedy 1485 (UC, DS), also Heller 10368 (UC, DS); $16 \mathrm{~km}$. south of Reno, Hall 11686 (UC); Soda Spring, Esmeralda County, Shockley 541 (Greene, type of minor variation 25, Pyrrocoma eriopoda). CALIfornta: Shasta Valley, south of Gazelle, Heller 12980 (UC, Gr, SF, DS, US); damp meadows, Shasta Valley, Butler 1821, 1843 (UC, R); in or near Sierra County, 1874, Lemmon (type of minor variation 6, H. paniculatus stenocephalus); Snow Mountain, Lake County, August 25, 1892, Brandegee (UC, minor variation 9); Calistoga, Napa County, October, 1891, Parry (Greene, one of the types of minor variation 24, Pyrrocoma elata); plains near Bakersfield, October 4, 1894, Eastwood (Gr, SF, type collection of Pyrrocoma ciliolata, minor variation 21); Hernandez, San Benito County, September 20, 1902, Lathrop (DS); east of Bridgeport, Mono County, Bolander 6168 (Gr, US, Boiss, K, type collection of minor variation 7, H. paniculatus virgatus); near Mono Lake, August 17, 1898, Congdon (UC); Benton Hot Springs, Mono County, Hall 11697 (UC); Dry Lake; Antelope Valley, Davy 2942 (UC).

23g. Haplopappus racemosus brachycephalus (Nels.)-Stems stout, erect, 4 to $7.5 \mathrm{dm}$. tall; lower leaves commonly in pairs, the petiole enlarged and more or less sheathing at base, oblanceolate, acute, 15 to $25 \mathrm{~cm}$. long including petiole, 15 to $25 \mathrm{~mm}$. wide, entire or denticulate, rather thick, somewhat succulent, green, with obscurely divergent more or less anastomosing lateral nerves, glabrous save for a sparse and deciduous hairiness on the petiole; middle cauline leaves much narrower but only moderately shorter, either alternate or some strictly opposite; inflorescence, à narrow elongated raceme-like panicle, the lower branches sometimes longer than the internodes and bearing 1 to several close heads toward the end, the upper branches crowded, each bearing a glomerule of several heads or the whole inflorescence reduced to a nearly simple raceme (as in one of the types); involucre 6 to $7 \mathrm{~mm}$. high, 8 to $10 \mathrm{~mm}$. broad; bracts smooth and glabrous or only ciliate, regularly imbricated; achenes densely sericeous. (Pyrrocoma brachycephala Nels., Bot. Gaz. 37:265, 1904.) (Fig. 43.)

Alkaline soil, in grassy places, southern Oregon and northern California. Type locality, Abert Valley, southeastern Oregon. Oregon: type collection, in "dry alkaline soil," Cusick 2778 (Gr, R, UC, US, Del, P, B, K); same valley, along moist grassy borders at north end of Abert Lake, Hall 12206 (UC); Warner Valley, Hall 12205 (UC); Alvord Ranch, Harney 

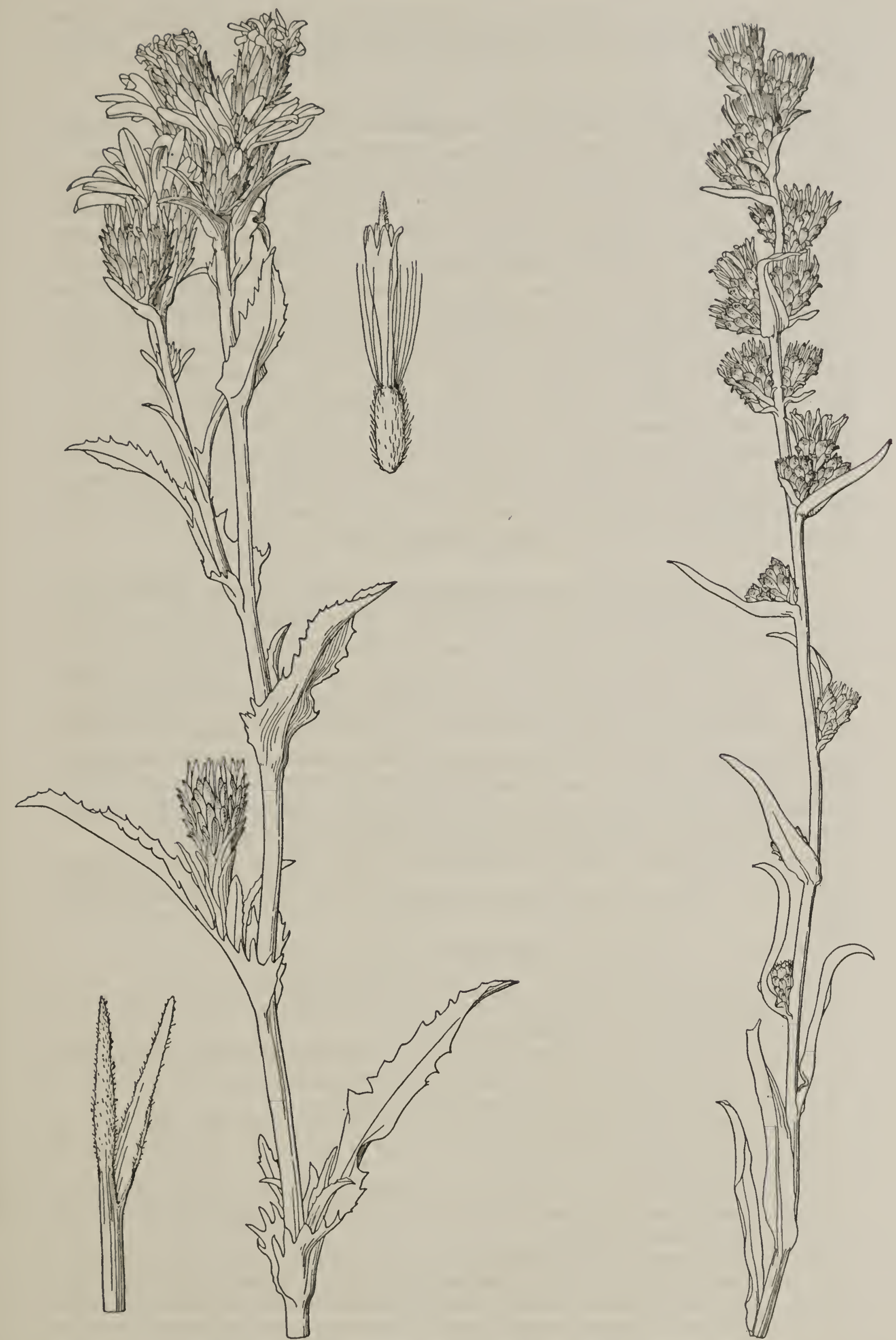
County, Hall 12196 (UC); wet meadow, $20 \mathrm{~km}$. south of Paisley, Lake County, Hall 12207 (UC). California: meadows on Shasta River, Greene $975(\mathrm{Gr})$.

23h. Haplopappus racemosus sessiliflorus (Greene)-Stems slender, curved-ascending to nearly erect, 2 to $5 \mathrm{dm}$. long; lower leaves alternate, linear-oblanceolate, acute, 5 to $10 \mathrm{~cm}$. long, 5 to $10 \mathrm{~mm}$. wide, entire or remotely and obscurely denticulate, thick, succulent, drying leathery, pale, the lateral nerves obscured, glabrous except for the ciliate petioles; inflorescence narrow, spicate or glomerate-spicate, the heads mostly in close, leafy-bracted glomerules, these nearly sessile along the central axis, or some of the heads solitary, rarely all solitary; involucre 5 to $7 \mathrm{~mm}$. high, 5 to $7 \mathrm{~mm}$. broad; bracts glabrous or only ciliate, more inclined to be squarrose than in other forms; achenes densely pubescent or sometimes nearly glabrous. (Pyrrocoma sessiliflora Greene, Leaflets 2:11, 1909.) (Fig. 44.)

Arid alkaline plains, southern Nevada and eastern borders of California. Type locality, Twin Springs, Nevada. Nevada: type collection, from the southern part of the State, Purpus 6340 (UC, US); "Gap," Esmeralda County, Shockley 534 (Gr). California: Inyo County, Austin 296 (UC); plains near Olancha, Inyo County, Purpus 1961 (P).

23i. Haplopappus racemosus halophilus (Greene)-Stems slender, erect or curved-ascending; $2 \mathrm{dm}$. or less high; lower leaves alternate, linearoblanceolate, pungently acute, $10 \mathrm{~cm}$. or less long in the single collection thus far made, $6 \mathrm{~mm}$. or less wide, denticulate to entire, moderately thick, pale, without obvious lateral nerves, lightly tomentulose on both faces, but the tomentum probably deciduous; upper leaves similar but smaller and many with bristly-ciliate margins; inflorescence racemose or spicate; involucre campanulate, about $7 \mathrm{~mm}$. high, 10 to $12 \mathrm{~mm}$. broad; bracts graytomentulose, especially on the margins, probably glabrate; achenes sericeous. (Pyrrocoma halophila Greene, Leaflets 2:16, 1909.)

Known only from the type collection, made in an alkaline meadow, Goose Lake Valley, eastern Oregon, August 19, 1901, Cusick 2769 (NY, UC, US).

\section{MINOR VARIATIONS AND SYNONYMS}

1. Aster pyrrocoma O. Kuntze, Rev. 317, 1891-H. racemosus.

2. Haplopappus eriopodus Blake, Contr. U. S. Nat. Herb. 25:544, 1925. Based upon Pyrrocoma eriopoda, which see.

2a. H. lanceolatus var. brachycephalus Piper in Nelson, Bot. Gaz. 37:265, 1904. A name published only in synonymy and taken from a label accompanying a specimen of $H$. racemosus brachycephalus.

3. H. lanceolatus var. strictus Gray, Proc. Am. Acad. 8:389, 1872. A form with villous achenes, later reduced by Gray to typical H. racemosus (Syn. Fl. $\left.1^{2}: 127,1884\right)$.

4. H. longifolius Jepson, Man. Fl. Pl. Calif. 1027, 1925-H. racemosus longifolius.

5. H. paniculatus Gray, Proc. Am. Acad. 7:354, 1868. Based upon Homopappus paniculatus, which see.

6. H. paniculatus var. stenocephalus Gray, Bot. Calif. 1:312, 1876. Described from a slender specimen collected by Lemmon in "Sierra Co.\&c., California" in 1874, in which the heads are exceptionally narrow and some of the stems produce divergent branches near the summit, the inflorescence therefore paniculate. This branching is now believed to be an abnormality, for it has 
been reproduced in the garden by injuring the young tips of plants which normally bear only spicate or racemose inflorescences. Moreover, in the type specimen at the Gray Herbarium some of the inflorescences are simply racemose and in a duplicate at Kew the nodes are swollen and twisted where the lateral branches arise. The heads are high, but only 10 to $12 \mathrm{~mm}$. broad. The leaves are somewhat veiny, as in congestus. Until such time as its possible union with one of these subspecies can be determined, it is perhaps well to retain the form in the list of minor variations.

7. H. paniculatus var. virgatus Gray, Proc. Am. Acad. 7:354, 1868-H. racemosus virgatus.

8. H. racemosus congestus, but stems and leaves sparsely tomentose. Growing on banks in southwestern Oregon, not far from the typical form (Hall $12062 \mathrm{~W})$.

9. H. racemosus glomeratus, but with very short and practically sessile lower lenves. The material of this variation consists of a single sheet from Snow Mountain, Lake County, California (August 25, 1892, Brandegee). The stems are 2 to $3 \mathrm{dm}$. high or in one specimen only $0.8 \mathrm{dm}$. The larger ones are widely branched above, the heads on peduncles 2 to $10 \mathrm{~cm}$. long. This, however, is believed to be a response to local conditions, since in $H$. racemosus the strict inflorescence is easily changed to the widely branched type by experimental means. The lower leaves are broadly oblong, about $4 \mathrm{~cm}$. long by $12 \mathrm{~mm}$. wide, narrowed below to a short broad petiole, the margins denticulate. The well-imbricated involucre is 9 or $10 \mathrm{~mm}$. high and the achenes pubescent. A similar form as to inflorescence but with elongated leaves comes from northeastern California (shores of Goose Lake, August 1886, Austin, UC).

10. H. racemosus var. glomerellus Gray, Syn. Fl. $1^{2}: 127,1884$. Based upon Homopappus glomeratus, here reduced to Haplopappus racemosus glomeratus, but Gray's description so drawn as to include also forms now referred to subspecies sessiliflorus.

11. H. racemosus var. stenocephalus Gray, l. c. Based upon H. paniculatus.

12. H. racemosus var. virgatus Gray, l. c. Based upon $H$. paniculatus virgatus, which see.

13. Homopappus argutus Nutt., Trans. Am. Phil. Soc. II, 7:331, 1840. A form of Haplopappus r. glomeratus in which the leaves are sharply serrate. But such leaves occur also on plants with entire leaves. In the specimen of argutus at the Gray Herbarium (a part of Nuttall's type) the heads are glomerate in the axils of long leaves, but the upper part of the inflorescence is wanting.

14. H. glomeratus Nutt., l. c.-Haplopappus racemosus glomeratus.

15. H. paniculatus Nutt., l. c.-Haplopappus racemosus glomeratus. It so happens that paniculatus was published on the page preceding that where racemosus first appears. It is therefore taken as the inclusive name by those who follow the rule of priority of position. According to the International Rules, however, the name is Haplopappus racemosus, since this combination was made before that of Haplopappus paniculatus. An additional reason for adopting the name racemosus is that it more accurately describes the normal inflorescence and aids in distinguishing the species from the very similar $H$. lanceolatus, in which the inflorescence is truly paniculate. The most tangible differences used by Nuttall in distinguishing between paniculatus and racemosus are the "obconic" involucre, 8 to 10 ray-flowers, and nearly glabrous achenes of the former as contrasted with the "hemispherical" involucre, 15 to 20 ray-flowers, and subsericcous achenes of the latter. Loss of pubescence from achenes is now known to be a common feature, especially for forms in alkaline soil, but number of ray-flowers is correlated with size (and consequently with shape) of head and this offers the most useful criterion for recognition of subspecies. The Nuttallian types have been examined at the British Museum and elsewhere and measurements from them taken as a basis for the present treatment. The type locality of paniculatus is the Grande Ronde Valley, northeastern Oregon.

16. H. racemosus Nutt., l. c. 332-Haplopappus racemosus typicus. 
17. Hoorebekia racemosa Piper, Contr. U. S. Nat. Herb. 11:560, 1906. Based upon Homopappus racemosus, therefore the same as Haplopappus racemosus typicus. See further under Homopappus paniculatus regarding a choice of specific names.

18. Pyrrocoma arguta Torr. et Gray, Fl. N. Am. 2:244, 1842. Based upon Homopappus argutus, which see.

19. P. balsamitae Greene, Leaflets $2: 15,1909-H$. racemosus congestus. The type specimens, from Dead Indian Valley, in the Cascade Mountains of Jackson County, Oregon (Cusick 2947, US), can not be distinguished from the types of congestus on any character of value. The foliage and inflorescence of the type sheets are almost identical and the involucres are too variable, especially in the type of balsamitae, to yield useful criteria. Greene describes the bracts of balsamitae as "elegantly imbricated" and this is true of one of the specimens; but the neighboring specimen of the type sheet has involucres with loosely imbricated bracts of nearly equal length. Syntypes at the University of Oregon have, on the same plant, some well-imbricated involucres and others in which the outer bracts are loose and as long as the inner. This feature recently has been studied in the field at the type locality and the same variation found, but with most of the heads showing an obvious imbrication. Possibly the others are the result of hypertrophy. Collections from near the type locality of congestus exhibit a similar variation.

20. P. brachycephala Nels., Bot. Gaz. 37: 265, 1904-H. racemosus brachycephalus.

21. P. ciliolata Greene, Pittonia $3: 184,1897$. Described from plants of $H$. racemosus glomeratus, collected on dry plants at Bakersfield, California, after most of the lower leaves had dried up or been eaten off (October 4, 1894, Eastwood). No distinctive characters are mentioned in the description, but the name refers to the leaf margins, which are "closely and rigidly ciliolate from base to apex." In the type specimen preserved at the California Academy of Sciences, these ciliolations are so short as to be scarcely visible to the unaided eye. In this subspecies the leaf margins usually vary from obscurely scabrid to ciliolate, especially in eastern California and western Nevada. In the type mentioned above the involucre is 6 to $7 \mathrm{~mm}$. high and the heads strictly racemose; in other specimens from the same locality the lower leaves are 4 to $6 \mathrm{~mm}$. wide. These features refer the form to glomeratus. It may have reached the Bakersfield station either from east of the Sierra Nevada, the low passes in this region not constituting much of a barrier, or direct from the north-central part of the State.

22. P. congesta Greene, Pittonia 3:23, 1896-H. racemosus congestus.

23. P. duriuscula Greene, Leaflets $2: 16,1909-H$. racemosus duriusculus.

24. P. elata Greene, Man. Bay Reg. Bot. 173, 1894. A tall form of H. racemosus glomeratus, described from specimens collected in subsaline soils at Calistoga and near San Jose, California. No distinguishing characters were pointed out, but the name emphasizes the height, which is given as 1 to 3 feet ( 3 to $9 \mathrm{dm}$.). The radical leaves are described as 6 to 8 inches (15 to $20 \mathrm{~cm}$.) long. A sheet in the Greene Herbarium from Calistoga (October 1881, Parry) is taken as the type, since this is the locality first mentioned. It agrees with the description, the stems being about $5 \mathrm{dm}$. and the leaf $20 \mathrm{~cm}$. long. The other sheet labeled as elata by Greene (San Jose, July 1887, Rattan) is the normal form of subspecies longifolius (stems 4.6 to $7 \mathrm{dm}$.; no lower leaves). Detailed studies have been made of elata at Calistoga. It here grows in abundance in saline flats near the springs, where the stems in 1923 were only 1.5 to $4 \mathrm{dm}$. high. At a less saline flat, $2 \mathrm{~km}$. west, the plants are more robust, the taller ones $5 \mathrm{dm}$. high and their leaves up to $15 \mathrm{~cm}$. long. These features vary with soil conditions, and with the amount of trampling and browsing, which reduces vitality, and quite probably from season to season. Experiments show that plants only $3 \mathrm{dm}$. tall attain more than double this height when moved from their original alkaline habitat to better soil and that the leaves increase in size by a similar ratio. The elata form has a spicate or subracemose inflorescence and rather large 
heads, " $1 / 2$ inch high and as broad." Specimens gathered at the type locality in 1923 ( Hall 11949) are duplicated in these and in fact in all other observable characters by specimens from the center of distribution of subsp. glomeratus (for example, near Reno, Nevada, Hall 11686). All of these facts seem to indicate that clata is scarcely even an ecologic form, the name applying merely to exceptionally tall and robust plants of glomeratus.

25. P. eriopoda Greene, Proc. Acad. Phila. for 1895:549, 1896. A form of H. racemosus glomeratus in which there is a dense persistent tomentum in the axils of the broad basal leaves. This seems to indicate that the entire herbage is tomentulose when young, but if so the tomentum is deciduous from the mature leaf-blades and stems. In all other features eriopoda is matched by specimens of glomeratus from western Nevada and even in this it is approached by some in which there is a scant loose pubescence on the petioles. Basal tufts of tomentum are also present in subsp. halophilus, which, however, is otherwise very different. The type locality of eriopoda is Soda Springs, Esmeralda County, southwestern Nevada.

26. P. glomerata Torr. et Gray, Fl. N. Am. 2:244, 1842 . Based upon the same collection as Homopappus glomeratus, which see.

27. P. halophila Greene, Leaflets $2: 16,1909-H$. racemosus halophilus.

28. P. longifolia Greene, Pittonia 3:183, 1897-H. racemosus longifolius. Unfortunately the types were malformed specimens from an especially moist habitat, so that the original description is somewhat misleading. The plants were gathered by Mrs. Brandegee on saline grassy flats along the railroad at Mount Eden Station, on the shore of San Francisco Bay, May 1891. Additional collections were made at the exact type locality by Mrs. Brandegee in 1907 and by the writer on subsequent dates. Studies have also been made at Jarvis Landing and other localities along the bay shore as well as of garden cultures, so that the form is now fairly well understood. The basal leaves in the type were described as about $30 \mathrm{~cm}$. long, but this exceptional size is due to an ecologic response. At the same locality, but in an unfavorable season, these leaves varied from $20 \mathrm{~cm}$. down to $5 \mathrm{~cm}$., the size depending upon the amount of moisture received by the plant. The involucral bracts are described by Greene as "spatulate and oblanceolate, all with green-herbaceous tips and subequal, the outer quite as long as the inner." This unusual development probably is due to a pathologic condition. At least some of the peduncles in the type collection show evidence of injury, and in the only other collection with such bracts (1907, Brandegee) the involucre and especially the upper foliage leaves are pierced with circular openings made by insects. Later collections from the type locality exhibit perfectly normal involucres in which the bracts are evenly imbricated, the outer ones successively shorter. Plants were collected in moist depressions at Jarvis Landing in 1923 in which the feature of large leaves, even up to $35 \mathrm{~cm}$. in length, is combined with that of a closely imbricated involucre. No other distinguishing characters were pointed out, but longifolius is given subspecific rank because of its obtuse leaves and comparatively broad, green, and glabrous bracts.

29. P. microdonta Greene, Leaflets $2: 11,1909$. A form of $H$. racemosus glomeratus, with the peduncles of the racemose inflorescence up to $4 \mathrm{~cm}$. long. The type is Coville and Funston 269, Resting Springs Valley, Inyo County, California (US).

30. P. paniculata Torr. et Gray, Fl. N. Am. 2:244, 1842. Based upon Homopappus paniculatus, which see.

31. P. paniculata virgata Davidson and Moxley, Fl. So. Calif. 377, 1923. Doubtless intended as a transferral from $H$. racemosus virgatus, here referred to $H . r$. glomeratus.

31a. P. prionophylla Greene, Leaflets 2:12, 1909-H. racemosus prionophyllus.

32. P. racemosa Torr. et Gray, 1. c.-Haplopappus racemosus typicus.

33. P. sessilifiora Greene, 1. c. 11.-H. racemosus sessiliflorus. 


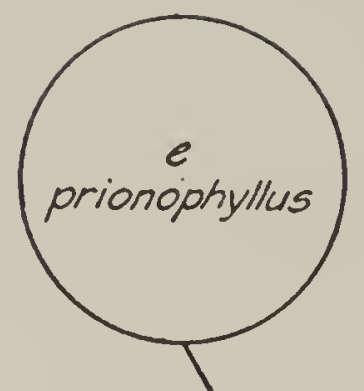

Heads large; mature invol. 8-12 mm. high. achenes glabrous

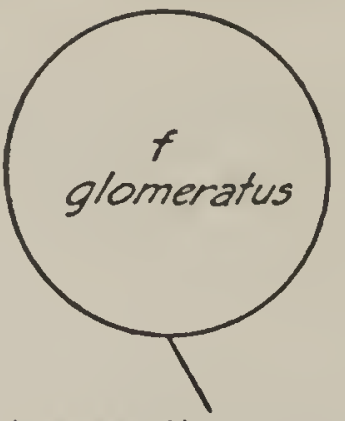

Lvs. all alternate

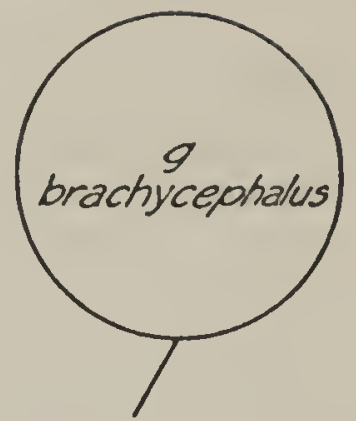

Lvs. partly opposite

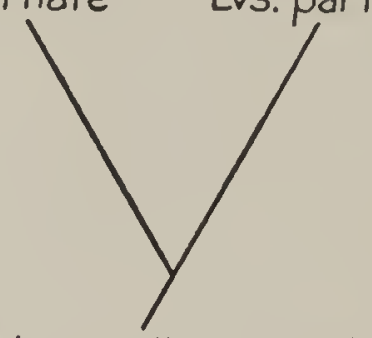

Heads smaller ; invol. 6-8 mm. high; achenes glabrous (in N) or pubescent (in S)

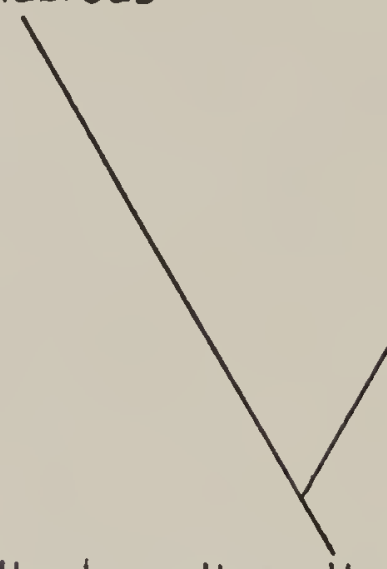

Heads mostly scattered or

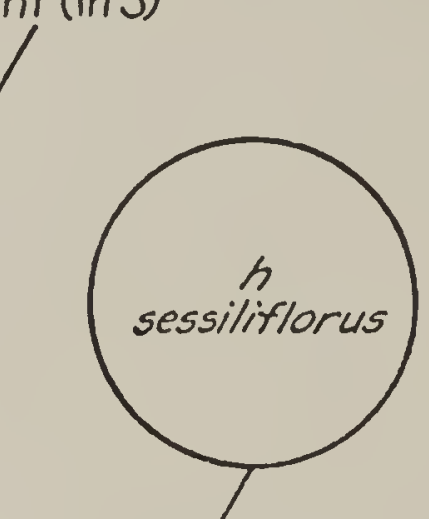
simply spicate; invol.8-16 mm.broad erules; invol. $5-7 \mathrm{~mm}$.broad

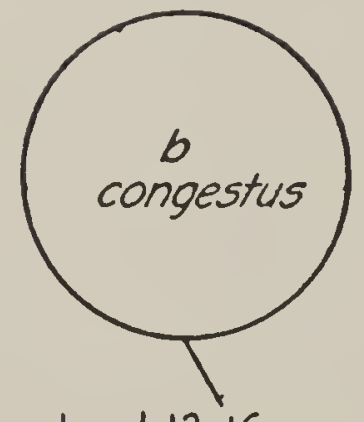

Invol. $12-16 \mathrm{~mm}$. broad; achenes pubescent

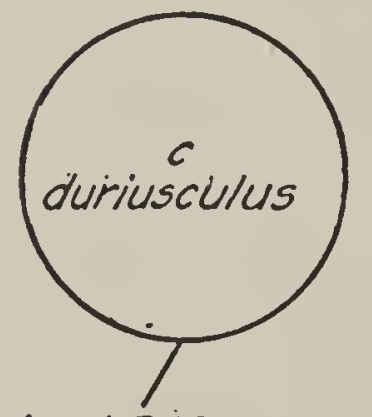

Invol. 7-10 mm. broad; achenes various

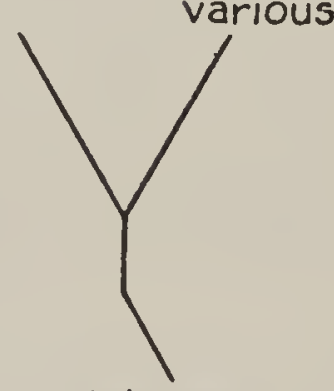

Lvs, thin veiny broad: invol. 8-11 mm. high
Note. Measurements of involucre diameters are for living plants and therefore smaller than for pressed specimens

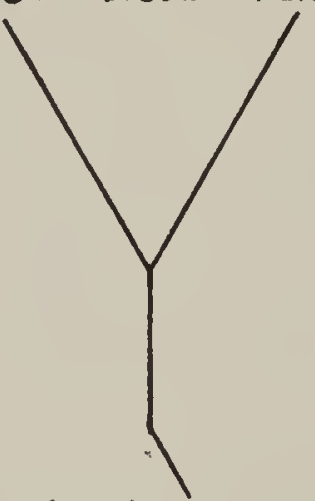

Invol. nearly glabrous; tendency to glabrous achenes

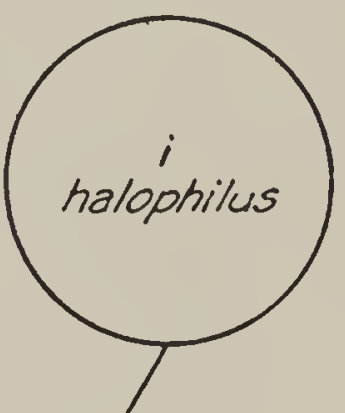

Invol tomentulose: achenes pubescent

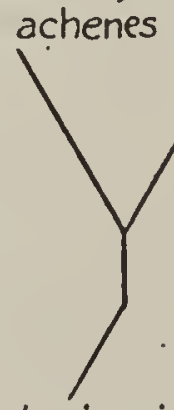

Lvs. thick not veiny; invol. $5-8 \mathrm{~mm}$. high (more in $e$ )

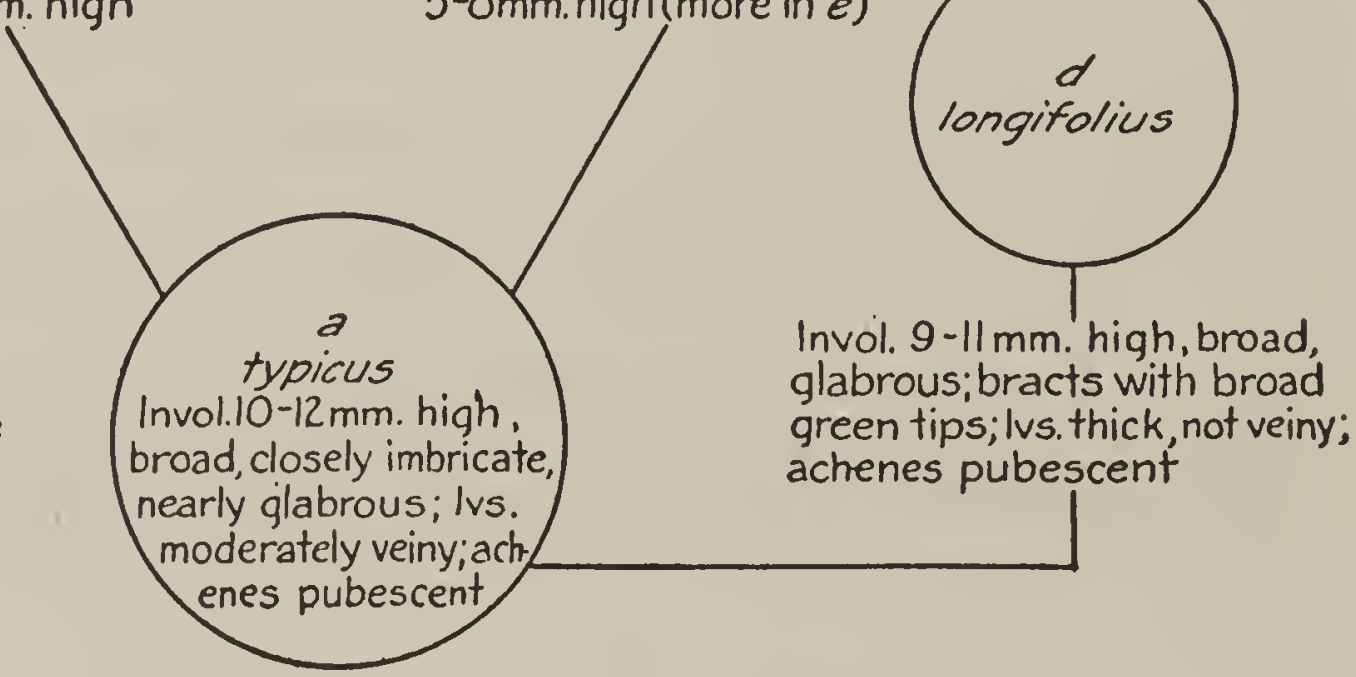

FIg. 45-Phylogenetic chart of the subspecies of Haplopappus racemosus 


\section{RELATIONSHIPS}

There is abundant evidence that this species and Haplopappus lanceolatus are of the same general stock. The connection between certain outlying forms of each is so close that they can be positively placed only after their origin has been determined through the examination of a series or variations. It is probable that lanceolatus is the more primitive and that racemosus has been derived through shortening of the lower branches of the inflorescence. Thus the inflorescence has come to be raceme-like or spike-like, and even when it is compound the lateral branches are so short or appressed that the entire assemblage of heads is very narrow and elongated. Difficulties are encountered when a stem bears only one or two heads, but in such cases more floriferous plants are usually found in the same colony and these serve for the identification of all. Although sometimes difficult to identify, these few-headed forms are not to be looked upon as intermediates but as reductions from the normal form of one or the other species.

The past development of subspecific stocks from what is here included in $H$. racemosus is very obvious. But the taxonomic segregations made by earlier students of the group do not follow these evolutionary lines. This is because trivial and fluctuating characters were used for their characterization, as is suggested, although not proven, by the frequent occurrence of two or more "species" or "varieties" in the same district. The group was first treated by Nuttall, who described 4 species, all under the generic name Homopappus (paniculatus, glomeratus, argutus, racemosus). This early botanist, who worked with only a few collections, attached too much importance to number of ray-flowers and to pubescence of achenes. These features vary to a considerable extent and not in unison. It is not unlikely that a genetic segregation based upon them could be brought about through controlled experiment, but the wild plants exhibit too many intergradations as well as combinations between these and other characters to render practicable the use of such criteria. The achenes in a single head sometimes range from evenly sericeous over the entire surface, through glabrous or glabrate except at either or both ends, to perfectly glabrous. The number of ray-flowers will range at least from 11 to 20 in a single colony (Hall 11687, 11697); from 18 to 34 in another (Hall 12140); and even from 45 to 60 and in two rows in a colony of subsp. prionophyllus (Hall 12145).

The arrangement of the heads, whether borne singly along the axis or in glomerules, was used by Nuttall, by Gray, and by Greene. This is suggestive for the separation of subspecies, but is influenced by environment, and sometimes both types of inflorescence occur on the same plant (in subsp. sessiliflorus, Purpus 6340, UC 86555). Relative stoutness of stems and openness of inflorescence, also ecologic features, were used by Gray in diagnosing varieties, although these could not be correlated with geographic distribution. In garden cultures plants that normally produce a virgate inflorescence sometimes put up a few stems with openly branched inflorescences similar to the more floriferous forms of $H$.lanceolatus. This is particularly true when the plants are grown rapidly or in partial shade and a subdecumbent habit produced. The peduncles may thus be elongated to 5 to $10 \mathrm{dm}$. When such forms are encountered in nature (as described under minor variation 9), they might easily be mistaken for new species. 
The subspecies described in the present work are believed to be natural evolutionary groups. The direction in which development has proceeded is, as always, a difficult question, but the only existing form from which the others could have arisen seems to be subsp. typicus. This is a robust, largeheaded plant of non-alkaline soils in southern Oregon. Along the California border and on west into California nearly to the coast there occurs the subspecies congestus, a form with tendencies to a more spreading habit, a reduction in number and size of heads, and with thinner, more nervose leaves. The only other subspecies with strongly veined leaves is duriusculus, of eastern Oregon and California. This has very rigid stems as well as foliage and in the Oregon form the achenes have lost their pubescence. It is too little known to be placed phylogenetically with any degree of satisfaction. The subsp. longifolius is well isolated geographically and is perhaps confined to saline soil near the sea. The thick, smooth leaves are very different from those of the subspecies just discussed, while its broad, smooth, and very green involucral bracts readily distinguish it from the forms which most closely approach it in distribution. (A misconception as to characters is explained under minor variation 28.)

The remaining subspecies are all thick-leaved inhabitants of interior alkaline areas. They exhibit a strong tendency toward reduction in the number of flowers, with a consequent narrowing of the involucre, and also toward a loss of achene pubescence. The central form is subsp. glomeratus. This has a distribution from eastern Oregon southward across the western part of the Great Basin, but it has also sent a branch, by way of the alkaline plains of northern California, to the San Joaquin Valley, south of which there is perhaps a tenuous connection with the more easterly branch. This wide dispersal has given rise to a number of more or less recognizable forms. Each is a collection of biotypes (an ecotype, according to Turesson's concept), for at least some retain their individual characteristics when transplanted into a uniform environment. Traits thus found to be constant are habit, robustness, tendencies toward a certain shape of leaf, leaf-insertion, dentation of leaf, branching of inflorescence (but not length of the branches), size of heads, and pubescence of achenes. Many attempts have been made to break up glomeratus into species or subspecies, but the criss-crossings of phylogenetic lines, with the resulting combinations of minor features, are too numerous to make this practicable. Some indication of the difficulties is given by the preceding list of minor variations, where are discussed also the characters heretofore utilized for recognition of "species."

Of more significance than the variations just mentioned are the few forms here designated as subspecies. Of these, prionophyllus is the most important, since it apparently leads to Haplopappus apargioides, a distinct species of the neighboring high mountains. Subspecies prionophyllus is itself a confusing mixture of variants, but with rare exceptions any member of the complex can easily be distinguished from other subspecies of the same region. Its best marks include a peculiar outline of leaf with white midrib and short, wing-margined petiole, a tendency toward reduction in the inflorescence of large heads, and glabrous achenes. The subspecies sessiliflorus is an outlying southeastern type with small, glomerate heads of a peculiar shape and with a decided drop in the number of flowers. It is 
easily recognized, but both pubescent and glabrous achenes occur on plants otherwise indistinguishable. Subspecies halophilus is a tomentose form of eastern Oregon, of doubtful affinities. The unique feature of opposite leaves is presented by subsp. brachycephalus, of southeastern Oregon. This grows among tall grasses and rushes on the borders of alkaline lakes, which may account for the peculiar leaf arrangement and for the more or less sheath-like petiole. There are never more than two pairs of opposite leaves, and plants with only alternate leaves often grow in the same colony. But the tendency toward an opposite arrangement, together with short and broad involucres, may at least temporarily keep brachycephalus out of the category of "minor variations."

TABLE 5-Variation in the subspecies of Haplopappus racemosus

\begin{tabular}{|c|c|c|c|c|c|c|c|c|}
\hline & \multirow[b]{2}{*}{ Herbarium } & \multirow[b]{2}{*}{$\begin{array}{c}\text { Height } \\
\text { of } \\
\text { involucre }\end{array}$} & \multirow[b]{2}{*}{$\begin{array}{l}\text { Length } \\
\text { of } \\
\text { ligule }\end{array}$} & \multicolumn{2}{|c|}{ Disk-corolla } & \multicolumn{3}{|c|}{ Style-branches } \\
\hline & & & & $\begin{array}{l}\text { Length, } \\
\text { includ- } \\
\text { ing } \\
\text { lobes }\end{array}$ & $\begin{array}{l}\text { Lobe- } \\
\text { length }\end{array}$ & $\begin{array}{l}\text { Stig- } \\
\text { matic } \\
\text { por- } \\
\text { tion, } \\
\text { length }\end{array}$ & $\begin{array}{l}\text { Append- } \\
\text { age- } \\
\text { length }\end{array}$ & $\begin{array}{l}\text { Ratio } \\
\text { of ap- } \\
\text { pendage- } \\
\text { length } \\
\text { to total } \\
\text { length of } \\
\text { branch }\end{array}$ \\
\hline \multicolumn{9}{|l|}{ Subsp. congestus: } \\
\hline $\begin{array}{r}\text { Del Norte County, } \\
\text { Calif. . . . . . }\end{array}$ & $221416 \mathrm{UC}$ & $\begin{array}{l}m m \\
7.5-8.0\end{array}$ & $\begin{array}{l}m m . \\
\ldots \ldots\end{array}$ & $\begin{array}{l}m m . \\
4.6\end{array}$ & $\begin{array}{l}m m . \\
0.9\end{array}$ & $\begin{array}{l}m m \\
0.6\end{array}$ & $m m$. & p.ct. \\
\hline Do............. & $2192 \mathrm{SF}$ & $8.5-9.0$ & $\ddot{7} .8-7.4$ & $\begin{array}{l}4.0 \\
6.7\end{array}$ & 0.8 & 0.9 & 0.9 & 50.0 \\
\hline Do............... & $2192 a \mathrm{SF}$ & $8.0-9.0$ & $5.9-7.5$ & 5.6 & 0.9 & 0.7 & 1.0 & 58.8 \\
\hline $\begin{array}{r}\text { Dead Indian Valley, } \\
\text { Oreg. . . . . . }\end{array}$ & $53821 \mathrm{SF}$ & $9.0-11.0$ & $7.0-9.1$ & 5.6 & 0.8 & 0.7 & 0.9 & 56.2 \\
\hline $\begin{array}{l}\text { Subsp. longifolius: } \\
\text { San Francisco Bay, }\end{array}$ & & & & & & & & \\
\hline Calif. .............. & $149267 \mathrm{UC}$ & $9.0-11.0$ & $10.5-11.0$ & 6.6 & 1.0 & 0.7 & 1.5 & 68.2 \\
\hline Niles, Calif. . . . . . . & $159281 \mathrm{UC}$ & $10.0-12.5$ & $8.5-10.0$ & $6.8-8.1$ & $1.0-1.2$ & $1.0-0.8$ & $1.5-1.5$ & 62.6 \\
\hline \multicolumn{9}{|l|}{ Subsp. prionophyllus: } \\
\hline $\begin{array}{l}\text { Eagle Valley, Nev. } \\
\text { Near Washoe Lake, }\end{array}$ & $75140 \mathrm{UC}$ & $8.0-10.0$ & $4.7-5.0$ & 5.4 & 0.6 & 0.7 & 0.7 & 50.0 \\
\hline Nev............ & $296043 \mathrm{UC}$ & $8.8-10.9$ & $5.7-6.7$ & $6.5-6.3$ & $0.9-0.9$ & $0.9-0.8$ & $0.9-1.0$ & 52.8 \\
\hline Franktown, Nev... & $194751 \mathrm{UC}$ & $8.0-9.5$ & $6.4-6.7$ & 6.8 & 1.0 & 0.9 & 0.9 & 50.0 \\
\hline $\begin{array}{l}\text { Bowers, Nev....... } \\
\text { Near Bridgeport. }\end{array}$ & $296030 \mathrm{UC}$ & $9.0-11.0$ & 7.0 & 6.1 & 0.9 & 0.8 & 0.8 & 50.0 \\
\hline Calif. .............. & $296027 \mathrm{UC}$ & $9.0-11.0$ & 0.4 & 6.6 & 0.9 & $0.6-0.8$ & $0.8-0.9$ & 55.0 \\
\hline Mono County, Calif. & $296029 \mathrm{UC}$ & $7.0-10.0$ & 7.5 & 6.5 & 0.9 & 0.8 & 0.9 & 53.0 \\
\hline \multicolumn{9}{|l|}{ Subsp. glomeratus: } \\
\hline Shasta Valley, Calif. & $202447 \mathrm{UC}$ & $8.0-8.5$ & $8.0-8.3$ & 6.4 & 1.1 & 0.7 & 1.1 & 61.1 \\
\hline 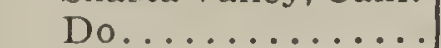 & $166601 \mathrm{UC}$ & $7.0-8.0$ & $6.4-6.8$ & 5.6 & 0.9 & 0.3 & 1.5 & 83.3 \\
\hline Do............. & $166599 \mathrm{UC}$ & $8.0-8.5$ & 9.7 & 5.6 & 0.9 & 0.9 & 1.2 & 57.1 \\
\hline Sierra County, Calif. & 86534 UC & $6.0-6.0$ & 5.8 & 5.6 & 0.9 & 0.9 & 1.0 & 52.6 \\
\hline Bakersfield, Calif. ${ }^{2}$. & $216925 \mathrm{UC}$ & $8.0-8.5$ & $6.7-6.8$ & 6.1 & 0.9 & 0.5 & 1.4 & 73.7 \\
\hline $\begin{array}{l}\text { Near Mono Lake, } \\
\text { Calif. }\end{array}$ & & & & & & & & \\
\hline Benton, Calif. ...... & 86532 UC & $\begin{array}{l}6.0-7.0 \\
6.0-7.0\end{array}$ & $\begin{array}{l}4.9-5.6 \\
6.5-7.0\end{array}$ & $\begin{array}{c}5.6 \\
5.0-5.3\end{array}$ & $\begin{array}{c}0.8 \\
0.7-0.8\end{array}$ & $\begin{array}{c}0.6 \\
0.4-0.4\end{array}$ & $\begin{array}{c}1.0 \\
1.5-1.3\end{array}$ & $\begin{array}{l}62.5 \\
77.7\end{array}$ \\
\hline Near Reno, Nev.... & $216866 \mathrm{UC}$ & $8.0-8.0$ & 7.5 & 6.0 & 0.8 & 0.9 & 1.5 & 62.5 \\
\hline Steamboat Springs, & & & & & & & & \\
\hline Nev. ........... & 196042 UC & $8.0-9.5$ & $6.6-7.5$ & $5.4-5.8$ & $0.9-0.9$ & $0.5-0.6$ & $0.8-0.9$ & 60.8 \\
\hline $\begin{array}{l}\text { Near Carson, Nev. } \\
\text { Subso brachucephalus. }\end{array}$ & $216890 \mathrm{UC}$ & $7.0-8.0$ & $7.7-7.7$ & 6.3 & 0.9 & 0.9 & 0.9 & 50.0 \\
\hline Abert Valley, Oreg. & 34320 UC & $6.0-7.0$ & $0.0-7.0$ & $5.2-4.7$ & $0.9-0.8$ & $0.5-0.4$ & $0.9-0.9$ & 60.8 \\
\hline Abert Lake, Oreg. .. & $296016 \mathrm{UC}$ & $0.0-7.0$ & 5.6 & 4.7 & 0.6 & 0.8 & 0.9 & 53.0 \\
\hline \multicolumn{9}{|l|}{ Subsp. sessiliflorus: } \\
\hline Twin Springs, Nev. & 86555 UC & $5.5-6.0$ & $|6.6-5.8-6.7|$ & $5.3-5.4$ & $0.7-0.7$ & $0.7-0.7$ & $1.0-1.0$ & 58.8 \\
\hline Inyo County, Calif. & 35840 UC & $6.0-7.0$ & $5.4-6.1$ & $5.3-6.1$ & $0.6-0.6$ & $0.4-0.5$ & $1.4-1.4$ & 75.7 \\
\hline
\end{tabular}

1 Only the larger and fully mature involucres are selected for this measurement. The length is the vertical distance from the base of the lowest to the tip of the highest bract.

A form intermediate to subspecies typicus; from the type locality of Pyrrocoma ciliolata, minor variation 21. 


\section{ECOLOGY}

With the exception of typicus and congestus, all of the subspecies of Haplopappus racemosus are indicators of an alkaline or saline soil. Several of the subspecies are especially common in moist alkaline meadows along the western edge of the Great Basin area, where they associate with such halophiles as Distichlis spicata, Juncus balticus, Sporobolus airoides, Chrysothamnus nauseosus consimilis, and Atriplex truncata. The plants sometimes mix with Sarcobatus and Suaeda, but are unable to grow in the more alkaline soils where these are dominant. Along the shores of San Francisco Bay subsp. longifolius sometimes associates with Distichlis, Frankenia, Hemizonia pungens, and Tissa. Here the plants vary much in size, depending upon the amount of moisture. The most robust specimens are from clay soil, moist at all seasons, but rather well drained and only moderately saline, as indicated by the mixture of such halophytic and non-halophytic species as Frankenia grandiflora, Atriplex patula, Lolium perenne, and Rumex conglomeratus. The altitudinal distribution of the species varies from about sea-level to approximately 1,500 meters, but it occurs outside the Upper Sonoran Zone only in subspp. typicus and congestus. These inhabit non-alkaline soils of the Transition Zone, especially along meadow borders and in open forests. The period of normal blossoming extends from early August to the end of October, but belated heads often flower much later and precocious spring blossoming sometimes occurs.

\section{Haplopappus apargioides Gray, Proc. Am. Acad. 7:354, 1868}

A perennial herb, usually 1.0 to $1.5 \mathrm{dm}$. high but varying from dwarfs of the alpine region to $3 \mathrm{dm}$., with a deep taproot and several few-leaved or scapiform erect or curved-ascending stems from a thick caudex, this surmounted by remnants of old leaves; stems more or less deeply tinged with red, lightly villous, somewhat glabrate; leaves chiefly basal, these lanceolate or narrowly oblanceolate, narrowed to a nearly sessile base, denticulate to rigidly subpinnatifid, rarely entire, very acute, the blades 4 to $10 \mathrm{~cm}$. long by 3 to $8 \mathrm{~mm}$. wide, with strong midrib and obscure lateral veins, the cauline leaves narrower, more reduced and sessile, all green or pale on the surfaces, the margins scabrous or ciliate but with no traces of villous or tomentose pubescence except near base; heads mostly solitary and terminal, long-peduncled; involucre somewhat hemispheric (truly so when pressed), 8 to $10 \mathrm{~mm}$. high, 10 to $14 \mathrm{~mm}$. broad; bracts imbricated in few rather loose ranks, the outer sometimes equaling the inner, lanceolate to narrowly oblong, mostly acute, often pungently so, with green middle portion and white or purplish hyaline margins and base, glabrous and smooth or the edges scabrid; ray-flowers 20 to 40 , the ligules 8 to $15 \mathrm{~mm}$. long; disk-flowers about 40 to 100 or more; disk-corolla tubular-funnelform, 6.0 to $7.5 \mathrm{~mm}$. long, glabrous or slightly hirtellous on tube; lobes lanceolate, erect, 0.6 to $1 \mathrm{~mm}$. long, glabrous or scaberulous; style-branches exserted at maturity, the appendage equaling or slightly longer than stigmatic portion; achenes slightly fusiform, 3 to 3.5 or $4.5 \mathrm{~mm}$. long, glabrous shining, with about 5 longitudinal ribs and some faint intervening striae; pappus about equaling corolla, rather scanty, moderately rigid, tawny. 


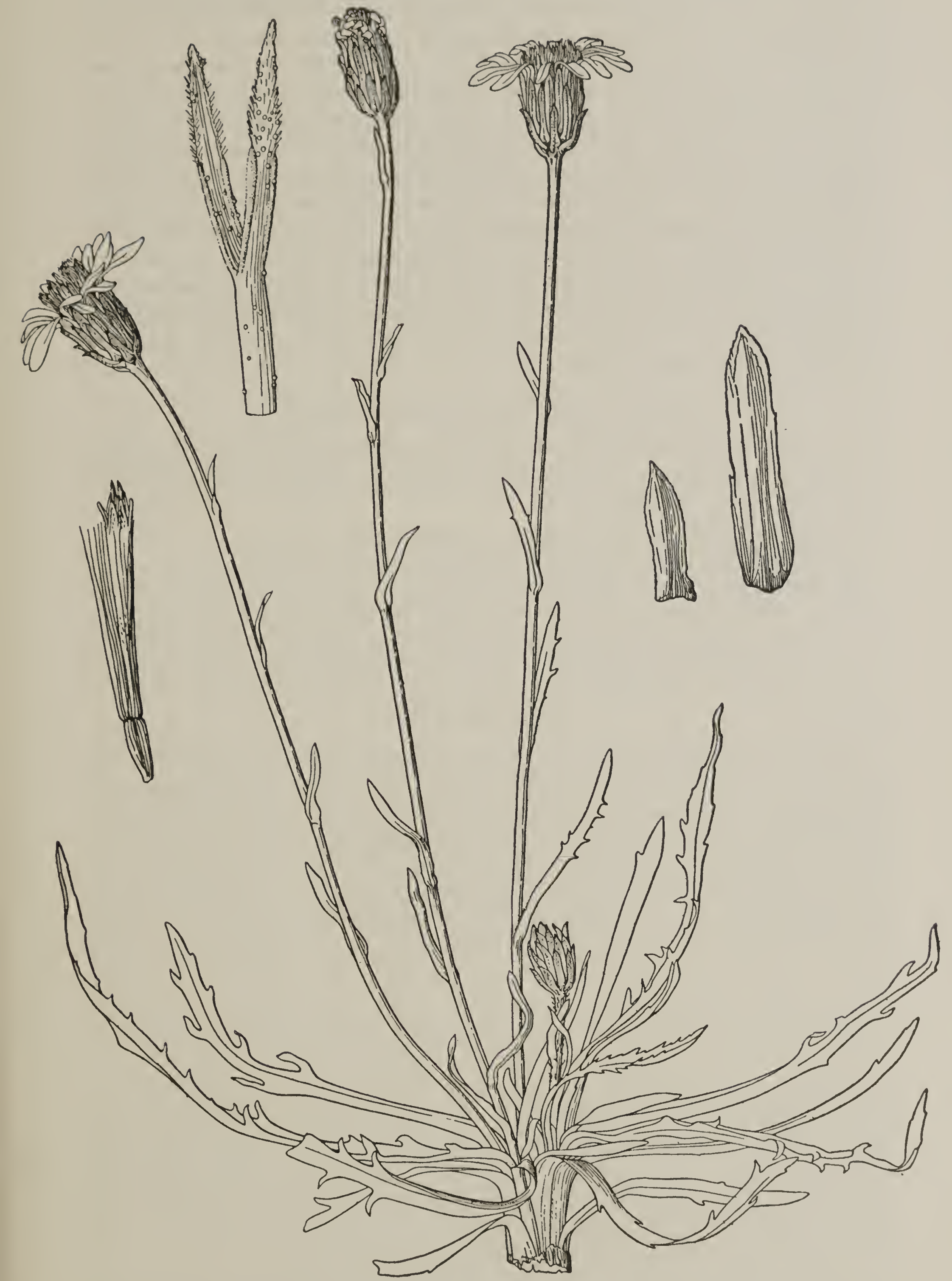

Fig. 46-Haplopappus aparoioides 
Sierra Nevada and Inyo ranges of California. Type locality, Soda Springs, on the Tuolumne River. (Altitude originally given as 9,700 feet, but modified in the Botany of California to 7,000 to 9,000 feet. The actual altitude of Soda Springs is 8,594 feet, or 2,620 meters. It is probable that the type specimens were collected at several localities of different altitudes.) California: Beckwith, Plumas County, September 2, 1920, Clemens (SF, an extreme form, the heads varying from solitary to 4 and racemose); Loyalton, Sierra County, Eastwood 7836 (SF); Mount Stanford, Nevada County, Sonne 199 (Greene, type of Pyrrocoma demissa, minor variation 3); Sardine Valley, Sierra County, Sonne 7 (UC); type collection, Bolander 5050 (Gr, UC, US, Boiss); Andrews Camp, Bishop Creek, Inyo County, Davidson 2558 (UC); Whitney Meadows, Tulare County, Coville and Funston 1608 (US, Gr, Kew); Crabtree Meadows, eastern Tulare County, Hall 8450 (UC); Monache Meadows, Tulare County, Hall and Babcock 5295 (UC); White Mountains, Shockley 478 (Gr).

\section{MINOR VARIATIONS AND SYNONYMS}

The many notable variations in the size of plant, leaf, and heads are believed to be the result of environmental factors, and are therefore discussed under the heading of Ecology. The only one of these ever to have been proposed as a taxonomic unit is variation 3 of the following list.

1. Aster apargioides O. Kuntze, Rev. 317, 1891-H. apargioides.

2. Pyrrocoma apargioides Greene, Erythea 2:70, 1894- H. apargioides.

3. P. demissa Greene, Leaflets 2:10, 1909. An alpine or subalpine dwarf with notably depressed, almost decumbent stems and short leaves. The type was collected in August 1888, on Mount Stanford, by Sonne (139, US). The achenes in the type are nerveless, but specimens of the same form and from the same locality have striate achenes (July 19, 1885, Sonne 173, UC).

\section{RELATIONSHIPS}

Recent field exploration in western Nevada and eastern California has established, with but little doubt, a connection between this species and Haplopappus racemosus. The contact is through $H$. racemosus subsp. prionophyllus, a plant of alkaline meadows along the easterly base of the Sierra Nevada. In its robust, large-leaved, many-headed form this subspecies does not closely resemble apargioides, but it has glabrous achenes and a similar involucre, while in reduced forms it approaches very closely even in habit. Such plants come from West Fork Walker River, California, and King's Cañon, Nevada (Hall 12140 and 12220, UC). They are classed with prionophyllus only because of their geographic position and their obvious connection through less reduced forms. The Walker River plant has solitary heads. The other has solitary terminal heads and 3to 7 -headed racemes from the same root. As far as known, there is a zonal gap between the localities whence these plants came and the high area of apargioides, but a commingling in comparatively recent times is not difficult to imagine. The tentative conclusion, therefore, is that apargioides has arisen from prionophyllus through the almost complete fixation of the monocephalous habit, through complete loss of achenial pubescence, and through minor changes in habit, color of involucre, etc.

In the matter of habit, the present species is most like uniflorus, but this is looked upon as merely a case of parallel development in derivatives 
of the same primitive stock, each derivative developing in the moantims certain unique features, especially of involucre and achenes.

\section{ECOLOGY}

The area occupied by this species is comparatively small. It grows only in the boreal zones of the Sierra Nevada and Inyo ranges; but throughout its range Haplopappus apargioides is by no means rare, for it occurs in nearly all of the drier upland meadows from about 2,100 meters to timber-line. Often, as in Tuolumne Meadows, it thickly dots these with its yellow blossoms, the rays of which expand only under the influence of warm sunshine, closing early on cloudy days and remaining closed in the morning if the day is cold and wet. Unlike related species, this plant avoids saline soils and does not grow in swales where the water stands for any length of time. Among its common associates in the higher parts of short-grass meadows are scattered bunch-grasses, especially Stipa kingi and Trisetum canescens, and such perennial herbs as Horkelia fusca, Pentstemon confertus caeruleo-purpureus, Antennaria rosea, and Solidago multiradiata scopulorum. It is thus seen to grow only where the original meadow grasses have been disturbed, as by excessive grazing, by burrowing rodents, or by erosion.

The varying ecologic conditions are almost certainly responsible for some of the striking variations in habit. For example, at and near timber-line, where the plants sometimes occupy small areas in the rocky outcrops, the whole above-ground portion is much reduced. Here heights of only 4 to $8 \mathrm{~cm}$. are common. Extreme dwarfs of this nature come from 3,400 to 3,600 meters altitude on slopes above Whitney Meadows (Purpus $1634, \mathrm{UC})$. Intergrades to the usual form are plentiful. The type specimens are described by Gray as about $22 \mathrm{~cm}$. high, but others of the type number are only $5 \mathrm{~cm}$. high, from which it seems that this collection was gathered at various altitudes or from different types of soil.

A second variation is one in which the leaves are exceptionally thick and cartilaginous, the faces smooth and very pale. The stems are densely villous or almost tomentulose. This form grows scatteringly in the drier parts of open meadows toward the southerly part of the range of the species. Further field study may show that it is a geographic race. It is best represented by collections from Monache Meadows, Tulare County, California (Hall 5292, UC).

\section{Haplopappus uniflorus (Hook.) Torr. et Gray, Fl. N. Am. 2:241,} 1842

A perennial herb, 1 to 3 or rarely $4 \mathrm{dm}$. high, with stout and deep taproot and several to many erect or curved-ascending stems from a leafy and sometimes branched caudex, this with a coarse fibrous coat made up of vestiges of old petioles; stems at first green but soon more or less tinged with red, varying to gray or white when clothed with a loose tomentum; leaves chiefly basal, these lower ones linear-lanceolate to broadly lanceolate, on erect or upward-curving petioles, entire to laciniate-dentate, very acute, the blade 3 to $10 \mathrm{~cm}$. long by 3 to $15 \mathrm{~mm}$. wide, with strong midrib and much fainter lateral nerves, or these quite obscure; cauline leaves 
similar but sessile, much reduced, and often with enlarged basal portion; heads solitary, terminal, long peduncled or occasionally 1 to 4 heads from lateral peduncles in luxuriant plants; involucre nearly hemispheric, 6 to 10 $\mathrm{mm}$. high, 13 to $20 \mathrm{~mm}$. broad; bracts scarcely imbricated, all about as long as the disk, linear, acute to cuspidate, mostly green and herbaceous but with scarious margins, especially below, glabrous to densely tomentose; ray-flowers 25 to 45 , the ligules 7 to $9 \mathrm{~mm}$. long; disk-flowers numerous; disk-corolla tubular-funnelform, 5.5 to $6.5 \mathrm{~mm}$. long, glabrous or puberulent on tube; lobes lanceolate, erect, 0.6 to $1 \mathrm{~mm}$. long, glabrous; stylebranches well exserted at maturity, the subulate appendage very much exceeding to slightly shorter than stigmatic portion; achenes subcylindric, tapering, about $2 \mathrm{~mm}$. long, densely sericeous; pappus about equaling corolla, somewhat sordid and scanty but paler and softer than in related species. (Donia uniflora Hook., Fl. Bor. Am. 2:25, pl. 124, 1834.) (Fig. 47.)

In somewhat alkaline soil at moderate altitudes in mountainous districts from Saskatchewan to Colorado, southern California, eastern Oregon, and Montana.

\section{SUBSPECIES}

\section{Key to the Subspecies of Haplopappus uniflorus}

Involucre 6 to $8 \mathrm{~mm}$. high; bracts close, similar, none exceeding the disk at maturity.

Leaves lanceolate, acute, 4 to $18 \mathrm{~mm}$. wide except in dwarfs........ (a) typicus

Leaves linear or linear-lanceolate, attenuate, 3 to $5 \mathrm{~mm}$. wide...... (b) howelli

Involucre 8 to $10 \mathrm{~mm}$. high; bracts loose, dissimilar, some overtopping the disk. Southern California...................... (c) gossypinus

25a. Haplopappus uniflorus typicus-Stems 1 to $4 \mathrm{dm}$. high, more or less tinged with red except when covered with tomentum; basal leaves narrowly to broadly lanceolate, acute or subacuminate, exceedingly variable as to size, but blades commonly 5 to $10 \mathrm{~cm}$. long by 5 to $15 \mathrm{~mm}$. wide, smaller in dwarf plants, usually low-dentate, the teeth remote and rigidly acute, the margins rarely laciniate or entire; heads solitary and terminal on peduncles 3 to $10 \mathrm{~cm}$. long (up to $15 \mathrm{~cm}$. in minor variation 5 ), or rarely 1 or 2 additional lateral peduncled heads; involucre 6 to $8 \mathrm{~mm}$. high, 13 to $18 \mathrm{~mm}$. broad; bracts about 30 to 45 , linear, appressed, scarcely equaling disk, either all similar or a few of the outer ones slightly shorter; achenes 2 to $3 \mathrm{~mm}$. long. (Donia uniflora Hook., Fl. Bor. Am. 2:25, pl. 124, 1834.) (Fig. 47.)

Saskatchewan to Wyoming, western Colorado, Idaho, and eastern middle California. Especially common around geysers and in other saline places in the Yellowstone National Park. Type locality, plains of Saskatchewan and prairies of the Rocky Mountains. Saskatchewan: type collection, Saskatchewan, Drummond (K, fragment in Gr). Montana, Midvale, Umbach 641 (US); Browning, Jones; Anaconda, Blankinship 710 (US); Grasshopper Valley, southwestern Montana, Watson 184 (US, Phila). ${ }^{1}$ WY-

${ }^{1}$ In this and following descriptions the length of the peduncle is arbitrarily taken to be that upper portion of the stem, which is naked except for much reduced bracts, none of these over $15 \mathrm{~mm}$. long. 


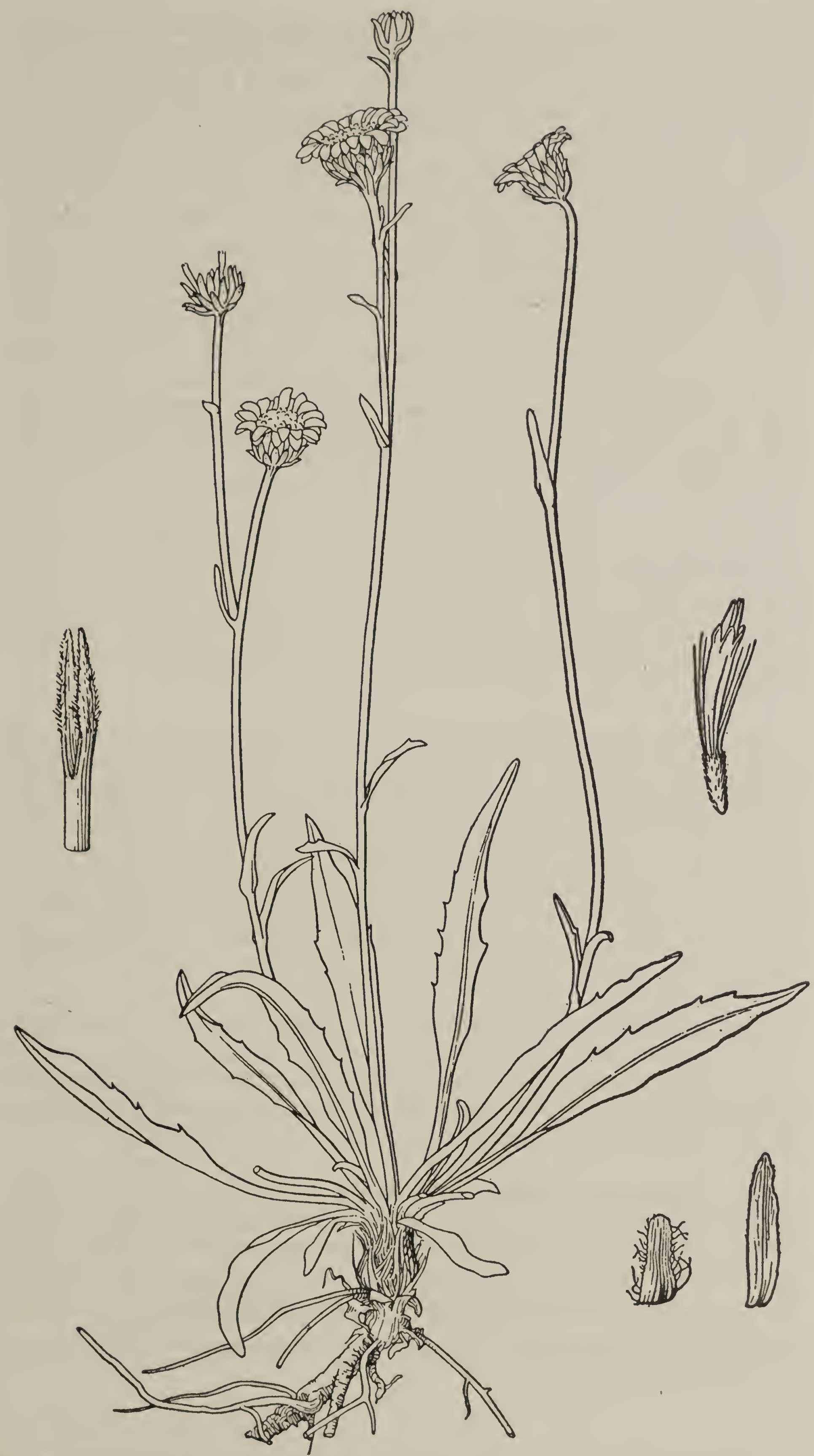

Fia. 47-Haplopappus uniflorus typicus (A form with peduncles more branched and involucre more imbricated than usual.) 
oming: Bacon Creek, Nelson 911 (Gr, US) ${ }^{1}, 3561$ (R); Lone Star Geyser Basin, Yellowstone National Park, Rydberg and Bessey 5051 (NY, US, type collection of Pyrrocoma plantaginea, minor variation 14); Yellowstone National Park, Mearns 3188 (US, type of P. hololeuca, minor variation 12); Gros Ventre and Wind River, 1887, Forwood (Gr); Spring Creek, Big Horn County, Goodding 355 (Gr, US, Del) ${ }^{1}$; La Barge, Uinta County, Stevenson 196 (US); Centennial, Nelson 8692 (US, Del) ${ }^{1}$; Evanston, July |10, 1897, Williams (US); Leckie, Merrill and Wilcox $55^{7}$ (Gr, R); Buffalo River, Merrill and Wilcox 1137 (US, type of $P$. crepidinea, minor variation 9 ); hills $44 \mathrm{~km}$. west of Big Piney, Sublette County, Payson 2639 (UC, R); Green River, Nelson 1035 (UC). Utaн: Marysvale, Jones 5965d (US) ${ }^{1}$; Gilbert's Meadow, Uinta Mountains, July 28, 1873, Porter (Phila); Aquarius Plateau and Thousand Island Mountain, Ward 506, 381 (US)1 ; Echo Mountain, Watson $57 \%$ (Gr, US); south end of Fish Lake, Rydberg and Carlton 7535 (R, W, see under minor variation 6); Burrville, Jones 5640 (US, UC); Rabbit Valley, Ward 595 (Phila). Idaнo: Soda Springs, Bannock County, Payson 1711 (UC, SF, discussed under minor variation 6); Arco, Palmer 197 (US, type of Pyrrocoma sericea, minor variation 15); Killgore, Rust 890 (US); Clyde, Blaine County, MacBride and Payson 3179 (UC). Nevada: Kingston Cañon, Lander County, Kennedy 4132 (UC, DS, minor variation 5); Italian Ranch, Reese River Valley, Lander County, Kennedy 4425 (UC, Del, same variation). CALIfornia: Mammoth, Mono County, 1913, Brandegee (UC). "Rocky Mountains" (the State not determinable), Nuttall (Phila, BM, types of Homopappus inuloides, minor variation 6 ).

25b. Haplopappus uniflorus howelli (Gray) -Stems 0.5 to $1.5 \mathrm{dm}$. high, reddish after the fall of the light tomentum; basal leaves linear or linearlanceolate, acuminate, often very slightly so, grass-like, the blades scarcely distinguishable from the petioles, the whole leaf 4 to $12 \mathrm{~cm}$. long by 3 to $5 \mathrm{~mm}$. wide, entire or only rarely a denticulation, sericeous-tomentose, glabrate in age; heads terminal and solitary as far as known, on peduncles 4 to $8 \mathrm{~cm}$. long; involucre 7 to $8 \mathrm{~mm}$. high, 13 to $18 \mathrm{~mm}$. broad; bracts about 30 to 40 , linear, appressed, a little shorter than disk, nearly equal and similar; achenes 2 to $4.2 \mathrm{~mm}$. long, this feature apparently variable. (H. howelli Gray; Syn. Fl. $1^{2}: 446,1886$.)

Known only from eastern Oregon, but doubtless grows also in adjoining States. Type locality, Stein's Mountain. Oregon: type collection, June 6, 1885, Howell (Gr, Del, UG); vernal stream banks of lower Stein's Mountain, Cusick 1245 (Gr, US, UG); lower Stein's Mountain in swales, Cusick 1962 (UC, US, Del, P, K); South Malheur River, Howell 836 (UC).

25c. Haplopappus uniflorus gossypinus (Greene)-Stems 1 to $3 \mathrm{dm}$. high, at first floccose-tomentose, becoming nearly smooth and then reddish; basal leaves lanceolate to oblong-lanceolate, only acute or even somewhat obtuse, the blade 2 to $8 \mathrm{~cm}$. long by 10 to $20 \mathrm{~mm}$. wide, entire to rigidly dentate; heads solitary and terminal on peduncles 2 to $7 \mathrm{~cm}$. long,

1 Intermediate to minor variation 6, Homopappus inuloides, being more or less woolly with deciduous tomentum. 
or commonly racemose, there then being 1 to 4 small heads on short lateral peduncles in addition to the large terminal one; involucre 8 to $10 \mathrm{~mm}$. high, 18 to $20 \mathrm{~mm}$. broad; bracts about 25, linear-oblong or lanceolate, rather loose, many overtopping disk, but of unequal lengths; achenes about $2 \mathrm{~mm}$. long (immature?), densely villous. (Pyrrocoma gossypina Greene, Pittonia $3: 23,1896$.

Known only from the vicinity of the type locality, namely, Bear Valley in the San Bernardino Mountains of southern California, where the following collections have been made: August 1882, Parish 1558 (Gr, UC, DS, Greene, US, type collection according to Parish); Abrams 2917 (Gr, UC, DS, US, Del, K); Abrams 2130 (Greene); September 1, 1924, Johnston (Po, from Arrastre Flats).

\section{MINOR VARIATIONS AND SYNONYMS}

1. Donia uniflora Hook., Fl. Bor. Am. 2:25, 1834-H. uniflorus typicus.

2. Haplopappus gossypinus Hall, Univ. Calif. Pub. Bot. 3:49, 1907. Based upon Pyrrocoma gossypina, here transferred to $H$. uniflorus gossypinus.

3. H. howelli Gray, Syn. Fl. 12:446, 1886-H. uniflorus howelli.

4. H. inuloides Torr. et Gray, Fl. N. Am. 2:241, 1842. Based upon Homopappus inuloides Nutt., which see.

5. H. uniflorus typicus, but the peduncles more elongated and the leaves mostly laciniate-dentate. This is best represented by plants from Kingston Cañon, Lander County, Nevada (Kennedy 4132, UC, DS). In these the flowering stems are $3 \mathrm{dm}$. high and naked for most of their length except for a few scattered and much reduced bracts. Such plants are strikingly different from the general run of uniflorus, but intermediate forms occur in which the peduncles are of varying lengths and the leaves laciniate-dentate to nearly entire (for example, Reese River Valley, Lander County, Nevada, Kennedy 4425, UC).

6. Homopappus inuloides Nutt., Trans. Am. Phil. Soc. II, 7:333, 1840. This is the form or state of Haplopappus uniflorus typicus in which the herbage is softly lanuginous. This feature is much too variable to be of taxonomic value. It is not unlikely that there are certain strains in which the tomentum is more dense and more persistent than in others, but the intermediates and specimens in which both glabrate and tomentose leaves occur on the same stem are too numerous to make the distinction practical. In fact, in the type specimen of inuloides, as noted by Nuttall, and in nearly all others thus far examined, the heavily tomentose plants have at least a few leaves which were either glabrous from the beginning or from which the tomentum has fallen so that the surface is smooth (see, for additional examples, Palmer 197 and Payson 1711, both from Idaho, the former the type of Pyrrocoma sericea, No. 15 of this list, and Rydberg and Carlton 7535, from Utah). The type locality was given as moist, open, grassy plains of the Rocky Mountains toward the sources of the Platte. The type specimen is labeled "R. Mts. (U. Calif.), Nuttall" (Phila).

7. H. uniflorus Nutt., l. c. Based upon Donia uniflora, the type form of the species.

8. Hoorebekia uniflora Jones, Bull. Univ. Mont. Biol. ser. 15:49, 1910. Also based upon Donia uniflora and therefore the same as Haplopappus uniflorus typicus.

9. Pyrrocoma crepidinea Greene, Leaflets $2: 12,1910 .-H$. uniflorus typicus but with herbage whitened with a soft, silky woolliness as in other minor variations of this list. The type is a rather small plant with stems depressed at base and short leaves. The broad, subcordate-clasping base of the cauline leaves is a common feature in this species. The rays are many and rather short, but the specimens are not fully mature. The type locality is near Alkali Spring, Buffalo River, central Wyoming. The description of this and the closely similar $P$. sericea of the same paper can be accounted for only on the theory of the proponent that there are good species in nature which 
can not be distinguished by any visible feature. This has since been demonstrated by geneticists as holding in some forms of plants, but it is not practicable to employ such criteria for species. The type number of crepidinia was doubtfully referred to Pyrrocoma kennedyi by Nelson (Bot. Gaz. 37.265, 1904), a form here included under $H$. lanceolatus. The subimbricate involucre and the tendency toward a corymbiform inflorescence suggest that crepidinia may really belong to this species, as a much reduced form. Further field studies at the type locality are much needed.

10. P. cusicki Greene, Erythea 2:59, 1894. Based upon H. cusicki, here reduced to a subspecies of $H$. uniflorus.

11. P. gossypina Greene, Pittonia $3: 23,1896-H$. uniflorus gossypinus.

12. P. hololeuca Greene, Leaflets $2: 10,1909$. The same as Homopappus inuloides Nutt., here referred to Haplopappus uniflorus typicus. This form has "all the parts, even to the involucres, more or less whitened with a loose, cottony or flocculent indument." The ephemeral nature of this character has been demonstrated under No. 6 of this list. The bracts are somewhat more imbricated and unequal than in typical uniflorus, but not so much so as in $H$. lanceolatus, to which the present variation is an approach. However, the variation of the latter which most closely approaches hololeuca in pubescence (that is, lagopus) is the most unlike it in the well-imbricated and abruptly acute bracts. Type locality, Yellowstone National Park.

13. P. inuloides Greene, Erythea 2:60, 1894. Based upon Homopappus inuloides, which see.

14. P. plantaginea Greene, Leaflets 2:13, 1909-H. uniflorus typicus. No distinguishing characters were given in the original description and the type specimen shows no deviation of consequence. These specimens represent a common low and nearly glabrous red-stemmed form, the stems somewhat inclined to branch and thus produce two or three heads, although mostly monocephalus. The leaves are mostly entire, but there are also dentate leaves on some duplicates of the type collection, as, for example, those at the herbarium of the New York Botanical Garden. The type specimens came from Lone Star Geyser Basin, Yellowstone National Park, Rydberg and Bessey 5051.

15. P. sericea Greene, l. c. 19. This is almost exactly the same as Homopappus inuloides Nutt., shown in this enumeration to be only the tomentose form of H. uniflorus typicus. One leaf in Greene's type is devoid of tomentum and on another leaf this has partially disappeared. The ray-flowers are described as orange. The type locality is given as somewhere in Idaho and the type specimen (Palmer 197) at the U. S. National Herbarium is labeled "Arco," which is a town in Blaine County, southern Idaho. Payson's 1711 (UC) from Soda Spring, Bannock County, Idaho, is a good match in all respects except that the involucral bracts are too dark.

16. P. uniflora Greene, Erythea 2:60, 1894. Based upon Donia uniflora, the type form of the species.

\section{RELATIONSHIPS}

All evidence points to the origin of Haplopappus uniflorus from some stock with a spicate or racemose arrangement of heads. This is perhaps best represented by $H$. racemosus, from which species the present one may have been derived through reduction in the number of heads and an equalization of the involucral bracts. Exact intergradation does not occur, but it is suggested by a frequent tendency on the part of uniflorus to produce several heads along the stem, although these are seldom so well formed as the terminal head. There is also a considerable variation in the relative length of bracts, this leading sometimes to a subimbricate condition. The evolution from uniflorus of a still more highly modified type will be taken up under contractus. 
The subspecies here described are remarkable in the manner of their distribution. Typicus occupies by far the largest area and is the only one in the Rocky Mountains; howelli is limited to eastern Oregon along the northwestern borders of the area covered by the species; while gossypinus is found only in southern California, far removed to the southwest from the other two. The high Sierra Nevada, although situated between the areas of howelli and gossypinus, has no representative, although typicus was once collected on the eastern slope. But this mountain range is occupied by the specifically distinct $H$. apargioides. Such distribution suggests a radial dispersal from an eastern center both to the northwest and to the southwest.

When howelli was first described by Gray it was given specific rank and special attention called to the long and slender stylar appendages and to the length of the achenes. But the several collections since made show that the average style-branch is no more slender than in the other subspecies and that even mature achenes are sometimes short. This latter character merits careful study, for in some specimens achenes measure as much as $4.2 \mathrm{~mm}$. in length as contrasted with 2 to $3 \mathrm{~mm}$. in typicus. Until such time as this feature can be carefully worked out, it seems better to treat the form as a subspecies and to fall back upon the narrow foliage as its chief distinguishing characteristic. The acceptance of the achenial character alone would break up this northwestern variant of peculiar aspect into apparently unnatural units. Greene (Erythea 2:70, 1894) considers howelli distinct from all other Pyrrocomas because of its branching caudex, which is said to be like that of many western species of Erigeron, and he adds that uniflorus has a taproot and no caudex. However, none of the available collections of subsp. howelli, including the type itself, gives any indication that the caudex is branched or otherwise different from that of subsp. typicus. Moreover, if this branching occurs, as it doubtless did in some specimens examined by Greene, it can not be taken as of importance, since branched caudices are occasionally found in true uniforus (Payson 2792). While the unbranched caudex is always very short, it is sufficiently long to permit the attachment of the stems and basal leaves.

The subspecies gossypinus can be separated from the tomentose form of uniflorus only on differences in the involucre, but these are sharp and constant as far as is shown by the few collections thus far made. In proposing this as a species, Greene noted especially the nature of the pubescence. He described the stems and petioles of the radical leaves as densely clothed with a fine white mass of cottony-wool, and added that no other Pyrrocoma except eriopoda has an actually cottony pubescence. However, Nuttall described his type of inuloides as having all but the primary leaves "softly lanuginous with a long, white, loose, woolly pubescence," and 15 years after the publication of gossypinus Greene characterized the stems and cauline leaves of his P. sericea as loosely white-woolly, adding that the basal leaves are "white on both faces, with a long soft and almost silky wool." These distinctions, if really intended as such, are not clear. Moreover, specimens from the type locality of gossypinus are exactly matched in pubescence by plants from Idaho (for example, Payson 1711), the center of distribution of the tomentose form of typicus. It seems that 
because of its isolation, gossypinus has been able to develop certain tendencies to a much greater extent than the other subspecies. There is, for example, the production of several short-peduncled heads along the upper portion of the stem. These are sometimes as many as four, but they seem not to develop fully, and even when the flowers are well formed the heads are not so large as the terminal one. Other collections from the type locality have only monocephalous stems or at most one poorly formed head in addition. In the type, as in all later collections, the achenes are densely silky-villous.

The relationships of the three subspecies one to another are difficult to make out, but it seems that typicus is the most primitive. This is assumed because it is the most common and covers much the largest area, and because all of the others may be derived from it without running counter to the laws of evolution. Possibly gossypinus is more primitive, as indicated by a tendency toward the racemose type of branching, but the peculiarly developed involucre and the restricted distribution militate against the acceptance of this assumption.

TABLE 6-Variation in the subspecies of Haplopappus uniflorus

\begin{tabular}{|c|c|c|c|c|c|c|c|}
\hline & \multirow[b]{2}{*}{ Herbarium } & \multirow[b]{2}{*}{$\begin{array}{l}\text { Length } \\
\text { of } \\
\text { ligule }\end{array}$} & \multicolumn{2}{|c|}{ Disk-corolla } & \multicolumn{3}{|c|}{ Style-branches } \\
\hline & & & $\begin{array}{l}\text { Length, } \\
\text { includ- } \\
\text { ing } \\
\text { lobes }\end{array}$ & $\begin{array}{l}\text { Lobe- } \\
\text { length }\end{array}$ & $\begin{array}{c}\text { Stig- } \\
\text { matic } \\
\text { por- } \\
\text { tion, } \\
\text { length }\end{array}$ & $\begin{array}{l}\text { Append- } \\
\text { age- } \\
\text { length }\end{array}$ & $\begin{array}{l}\text { Ratio } \\
\text { of ap- } \\
\text { pendage- } \\
\text { length } \\
\text { to total } \\
\text { length of } \\
\text { branch }\end{array}$ \\
\hline Subsp. typicus: & & $m m$. & $m m$. & $m m$ & $m m$. & $m m$. & p. ct. \\
\hline $\begin{array}{l}\text { Merna, Wyo. ..... } \\
\text { Shirking Water, }\end{array}$ & 219414 UC & 7.9 & 6.3 & $|1.2-0.9-1.0|$ & 1.0 & 0.9 & 47.4 \\
\hline $\begin{array}{r}\text { Oreg. ............ } \\
\text { Reese River Vallev }\end{array}$ & $175953 \mathrm{UC}$ & 7.5 & 7.0 & 1.0 & 1.0 & 0.8 & 44.4 \\
\hline $\begin{array}{c}\text { Nev.............. } \\
\text { Toivabie Range }\end{array}$ & $190163 \mathrm{UC}$ & 6.6 & 5.4 & 0.7 & 0.6 & 0.9 & 60.0 \\
\hline Nev. ............. & $175456 \mathrm{UC}$ & 6.1 & $5.6-6.1$ & $0.8-0.7$ & $1.0-1.0$ & $0.5-0.7$ & 37.3 \\
\hline $\begin{array}{l}\text { Yellowstone Lake, } \\
\text { Wyo............ }\end{array}$ & $219405 \mathrm{UC}$ & 8.0 & 4.1 & 0.6 & 0.7 & 0.5 & 41.7 \\
\hline $\begin{array}{r}\text { Bannock County, } \\
\text { Idaho.......... }\end{array}$ & $219359 \mathrm{UC}$ & 7.0 & $5.3-5.6$ & 0.9 & 0.6 & 1.0 & 62.5 \\
\hline Big Pine, Wyo. & 219404 UC & 9.5 & 5.7 & 0.9 & 1.0 & 0.8 & 44.4 \\
\hline Teton Forest, Wyo. & 86540 UC & $9.0-9.0$ & 5.6 & 0.6 & 0.7 & 0.9 & 56.3 \\
\hline Wyo............ & 216884 UC & 6.7 & 6.3 & 0.6 & 0.6 & 0.9 & 60.0 \\
\hline Leadore, Idaho.... & $216900 \mathrm{UC}$ & $6.6-6.5$ & 5.0 & 0.6 & 0.7 & 0.7 & 50.0 \\
\hline Green River, Wyo. & $86559 \mathrm{UC}$ & 6.1 & 5.1 & 0.6 & 0.5 & 0.5 & 50.0 \\
\hline Kendal, Wyo. .... & 219413 UC & 5.1 & 5.4 & $0.4-0.5$ & 0.7 & 0.4 & 36.4 \\
\hline $\begin{array}{l}\text { Subsp. howelli: } \\
\text { L ow er Stein's }\end{array}$ & & & & & & & \\
\hline Mountains, Oreg. & 86645 UC & 9.6 & $5.8-6.2$ & $0.8-0.8$ & 0.5 & 0.9 & 64.3 \\
\hline Do........ & $2955 \mathrm{UC}$ & 8.0 & 5.6 & 1.0 & 0.8 & 1.2 & 60.0 \\
\hline $\begin{array}{r}\text { Stein's Mountains, } \\
\text { Oreg............. }\end{array}$ & $216586 \mathrm{UC}$ & 9.6 & 6.6 & 0.9 & 0.9 & 1.0 & 52.6 \\
\hline Subsp. gossypinus: & & & & & & & \\
\hline Bear Valley, Calif. & $134223 \mathrm{UC}$ & 7.5 & 5.9 & $0.9-0.8$ & $0.7-0.5$ & $1.1-1.3$ & 86.6 \\
\hline Do....... & 195692 UC & 6.4 & $6.2-6.3$ & $0.9-0.9$ & $0.4-0.5$ & $1.7-1.8$ & 79.6 \\
\hline
\end{tabular}




\section{ECOLOGY}

Although doubtless descending to the lower plains in the northern part of its range, this is a species of middle altitudes on plateaus and in the mountains, as far as its distribution in the western part of the United States is concerned. Here it is found especially in the Transition Zone. On the plains, it occupies saline or alkaline and often stony flats or swales, but it grows also in meadows that are dry at some seasons. Its tolerance to alkali is not so great as that of such marked halophiles as Sarcobatus and Salicornia. Its associates include Suaeda, Triglochin, and Linum lewisi. The flowering period is from June to August.

\section{Haplopappus contractus nom. nov.}

A perennial herb, about 1 to $1.5 \mathrm{dm}$. high, with many erect stems from a woody root; stems gray-villous; leaves somewhat equitably distributed, linear-oblanceolate, narrow at base but scarcely petioled, erect, entire, acute, 2 to $4 \mathrm{~cm}$. long, 2 to $4 \mathrm{~mm}$. wide, strongly 1-nerved, finely villoustomentulose on both faces, perhaps sometimes glabrate; heads solitary and terminal, the naked peduncles 3 or $4 \mathrm{~cm}$. long; involucre broadly hemispheric, 9 or $10 \mathrm{~mm}$. high, 12 to $16 \mathrm{~mm}$. broad; bracts not imbricated although slightly unequal, the outer ones lanceolate, the inner linear-lanceolate, all gradually contracted into slender tips, some of which exceed disk while others recurve, the outer ones green but with narrow scarious margins and villous-tomentulose; ray-flowers rather few, the ligules 10 to $12 \mathrm{~mm}$. long; disk-flowers numerous; disk-corolla tubular-funnelform, about $6 \mathrm{~mm}$. long, glabrous as far as known; lobes lanceolate, erect, about $1.3 \mathrm{~mm}$. long, glabrous; style-branches (in the only flower examined) included, the rather thick appendage about as long as stigmatic portion; achenes subcylindric, about $2.5 \mathrm{~mm}$. long, densely villous;

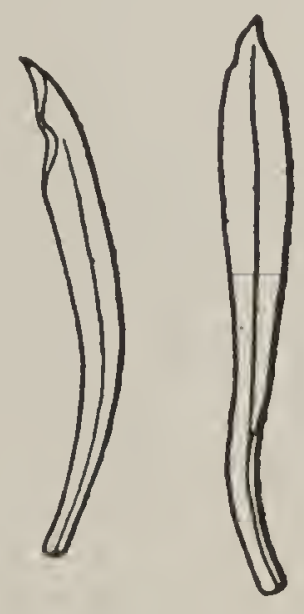

Frg. 48-

Leaves of Haplopappus contractus pappus a little longer than corolla, tawny. (Pyrrocoma acuminata Rydb., Bull. Torr. Club $27: 626,1900$. Not H. acuminatus DC.) (Fig. 48.)

Known only from the type specimen, this from Fort Bridger, Wyoming, 1873, J. Van A. Carter (NY).

\section{RELATIONSHIPS}

This species undoubtedly belongs in the uniflorus group, but it seems impossible to place it more closely in any phylogenetic arrangement. This is because of its scarcity in collections and the absence of all field knowledge. While perhaps more closely related to Haplopappus uniflorus than to any other species, it is very distinct and the differentiating characters are such that intermediate forms are not to be expected. The leaves are exactly the reverse in shape from those of uniflorus, that is, instead of lanceolate they are oblanceolate, and they clothe the stems nearly to the heads with scarcely any reduction in size. The acuminate bracts of the involucre, which gave to the species its name, are strikingly different from 
anything in uniflorus, but in some forms of the latter the bracts are drawn out into tips which, although always rigid and short by comparison, are suggestive of intergradation.

\section{SECTION 6. STENOTOPSIS}

\section{PHYLOGENY OF THE SPECIES}

There being but two species in this section, it is unnecessary to discuss their phylogeny further than as mentioned under the heading of Relationships.

27. Haplopappus linearifolius DC., Prodr. 5:347, 1836

A much branched bushy shrub, of rounded outline when well developed, 4 to $15 \mathrm{dm}$. high (sometimes depauperate), the branches hard and brittle and 4 or $5 \mathrm{~cm}$. thick in old plants; bark at first green but soon becoming dark brown or nearly black, irregularly breaking and becoming shreddy; twigs fastigiate, rather soft, densely leafy, striate, resinous, usually puberulent near heads; leaves nearly linear but narrowed toward base, straight, entire, acute, 1 to $4 \mathrm{~cm}$. long, 1 to $2.5 \mathrm{~mm}$. wide, 1 -nerved, thick and sometimes subterete, glabrous, the margins often sparsely scaberulous, resinous and conspicuously impressed-punctate; heads numerous, solitary on nearly naked peduncles, these cymosely arranged and 2 to $7 \mathrm{~cm}$. long beyond the leafy twigs; involucre broadly hemispheric, 8 to $13 \mathrm{~mm}$. high, 10 to $18 \mathrm{~mm}$. broad; bracts in two irregular series, none longer than disk, the outer ones moderately shorter than the inner, all broad-lanceolate to linear, acute or acuminate, thin, scarious-margined, even the middle portion scarcely herbaceous, minutely granular-glanduliferous or smooth, sometimes also slightly puberulous; ray-flowers 12 to 18 , the ligules 9 to 15 or $20 \mathrm{~mm}$. long, 4 to $5 \mathrm{~mm}$. wide; disk-flowers numerous; disk-corolla passing gradually from the tube to a slightly enlarged throat, 6.5 to $10 \mathrm{~mm}$. long, glabrous; lobes ovate or oblong, acute, erect, 1.2 to $2 \mathrm{~mm}$. long, glabrous; stylebranches well exserted, about 2 to $2.5 \mathrm{~mm}$. long, the lanceolate-acute appendage shorter than stigmatic portion; achenes compressed, nearly linear but narrowed toward base and rounded to summit, 4 to $5 \mathrm{~mm}$. long, 2-ribbed on each face but ribs often masked by the dense silvery-silky pubescence; pappus exceeding disk-corollas, fine and soft, copious, white, somewhat deciduous. (Fig. 49.)

In arid districts from southwestern Colorado to the inner Coast Ranges of California and Lower California.

\section{SUBSPECIES}

\section{Key to the SUbspecies of Haplopappus linearifolids}

Leaves mostly 2 to $4 \mathrm{~cm}$. long; involucre 10 to $13 \mathrm{~mm}$. high; achenes about

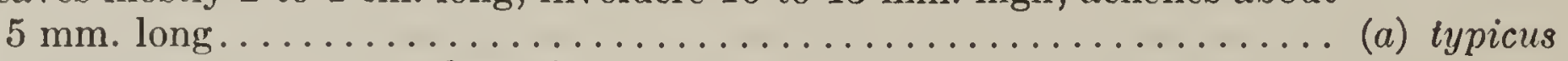
Leaves mostly 1 to $2 \mathrm{~cm}$. long; involucre 8 to $10 \mathrm{~mm}$. high; achenes about

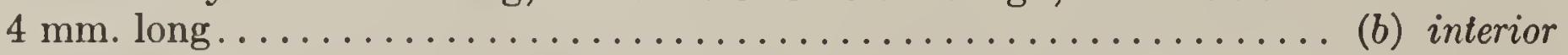

27a. Haplopappus linearifolius typicus-Leaves commonly 2 to $4 \mathrm{~cm}$. long; heads large, the involucre 10 to $13 \mathrm{~mm}$. high, its bracts broadly lanceolate-acuminate; ligules 12 to $15 \mathrm{~mm}$. or more long; achenes 4.5 to $5 \mathrm{~mm}$. long. (H. linearifolius DC., l. c.). 
Coastal districts of California and Lower California, extending to interior valleys and desert borders in favorable situations. Type locality, California.

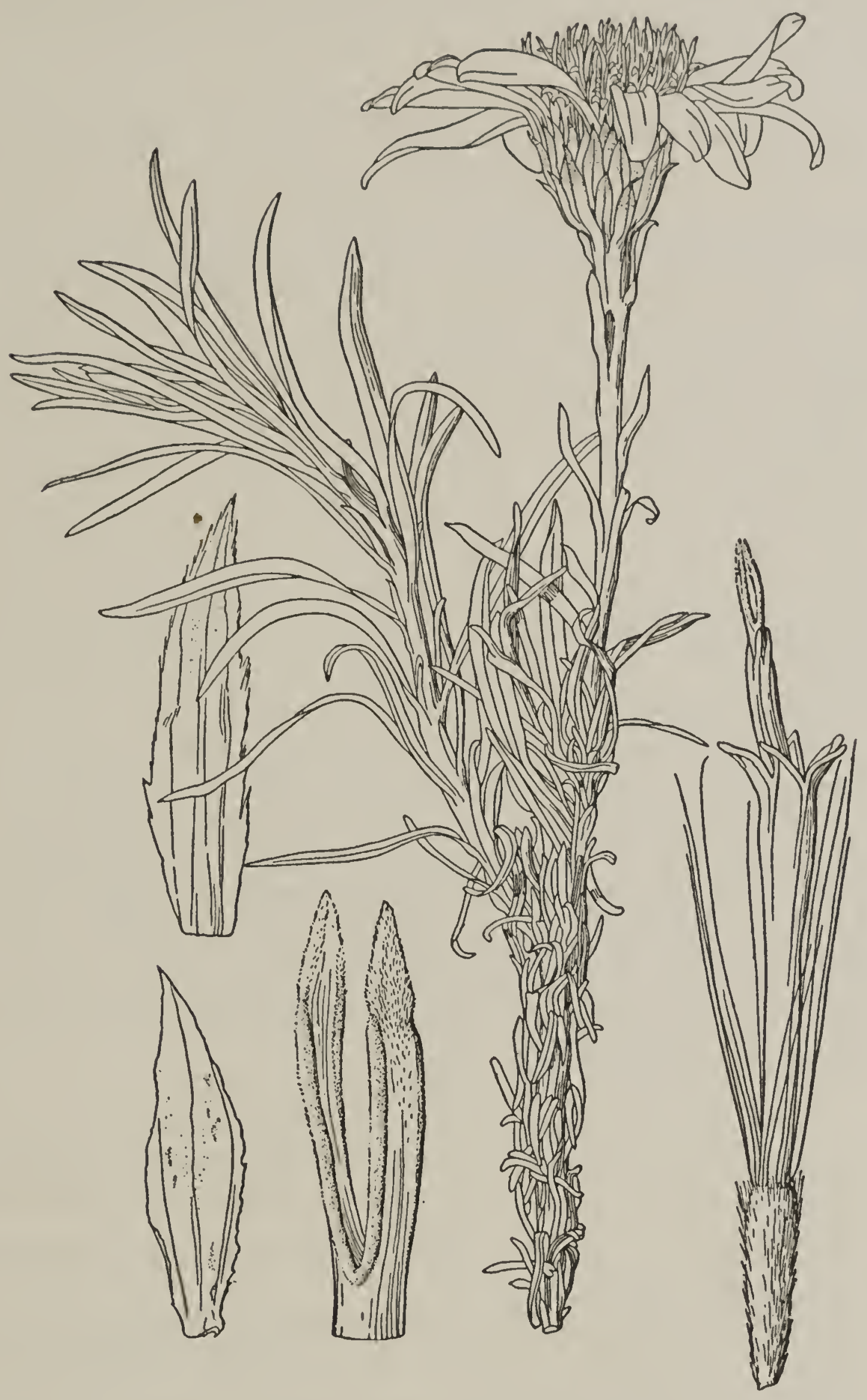

Fra. 49-Haplopappus linearifolius typicus

The following are all from California, except the last: East Marysville Butte, Heller and Brown 5558 (R, Phila); Mount Diablo, Brewer 1054 (UC); type specimens, 1833, Douglas (DC); Corral Hollow, Alameda County, Brewer (UC); Tres Pinos River, San Benito County, Abrams and Borthwick 7840 (DS); Alcalde, western Fresno County, April 1, 1891, Brandegee (UC); near Port Hartford, San Luis Obispo County, December 28, 1893, Dudley (DS); Mono Creek, Santa Barbara County, Hall 7806 (UC); McKittrick and Keene, Kern County, Heller $7 \% 90$ and 7813 (UC); near Mohave, June 1884, Brandegee (UC); 
foothills of the San Bernardino Mountains, Parish 234 (UC); Coahuila Hills, south of San Jacinto, Hall 2902 (UC); near Potrero, San Diego County, Abrams 3549 (UC, minor variation 4, under which other specimens are cited); Zapato Chino, Lower California, April 27, 1893, Brandegee (UC).

27b. Haplopappus linearifolius interior (Coville)-Leaves commonly 1 to $2 \mathrm{~cm}$. long, but sometimes up to $3 \mathrm{~cm}$.; heads smaller, the involucre 8 to $10 \mathrm{~mm}$. high, its bracts lanceolate-linear and either acuminate or only acute; ligules 8 to $12 \mathrm{~mm}$. long or rarely up to $15 \mathrm{~mm}$.; achenes 4.0 to 4.5 mm. long. (H. interior Coville, Proc. Biol. Soc. Wash. 7:65, 1892.).

Interior districts from the California deserts and Lower California to southwestern Colorado. Type locality, about $6.5 \mathrm{~km}$. southeast from Mill Cañon Divide, at the northern end of Darwin Mesa, Inyo County, California. California: eastern slope of Greenhorn Range, Kern County, Hall and Babcock 5088 (UC); San Emigdio Cañon, Kern County, Davy 2014 (UC); Seymour Creek, Mount Pinos, Ventura County, Hall 6498 (UC); type collection, Coville and Funston 794 (DS); Hunter's Ranch Mountains and Panamint Mountains, Inyo County, Hall and Chandler 7134 and 6987 (UC); east slope, Providence Mountains, Munz, Johnston, and Harwood 4055 (UC); Kramer, Mohave Desert, Parish 9740 (UC); Coyote Cañon, western borders Colorado Desert, Hall 2862 (UC); San Felipe, San Diego County, April 30, 1894, Brandegee (UC). Nevada: Mormon Mountains, Lincoln County, Kennedy and Goodding 95 (UC, Phila, DS); Searchlight, Clark County, April 1906, Stirling (UC); Mica Spring, Jones 5060 (UC). Utrat: Santa Clara River, southwestern Utah, Parry 97 (UC). Arizona: Peach Springs, May 4, 1893, Wilson (UC); near Prescott, Palmer 200 (UC); Hackberry, Jones 4508 (R, Del). ColoRado: Surface Creek, Grand Mesa, June 1892, Payson (UZ). Lower California: San Pedro Martir, May 4, 1893, Brandegee (UC); Placitis Creek, April 22, 1893, Brandegee (UC).

\section{MINOR VARIATIONS AND SYNONYMS}

1. Aster linearifolius O. Kuntze, Rev. 318, 1891-H. linearifolius typicus.

2. Haplopappus interior Coville, Proc. Biol. Soc. Wash. 7:65, 1892-H. linearifolius interior.

3. H. linearifolius var. interior Jones, Proc. Calif. Acad. II, 5:697, 1895-H. linearifolius subsp. interior.

4. H. linearifolius typicus, but the leaves, although elongated, only 0.5 to $1.5 \mathrm{~mm}$. wide, the involucral bracts as narrow as in subspecies interior but as acuminate as in typicus.

The best expression of this form is found on the coastal slopes of the low mountains of San Diego County, California, where no other occurs, as far as known, and intermediate forms are common to the north along the coastal slopes of the foothills of the San Jacinto and San Bernardino Mountains. The characters are suggestive of those which separate $H$. bloomeri angustatus from $H$. b. typicus, but they are not so well marked and intergradation is much more abundant. Specimens, all from San Diego County, California, representative of minor variation 4 are: Ramona, April 3, 1894, Brandegee (UC); Granite, in the chaparral, Spencer 34 (UC); dry hills near Potrero, Abrams 3549 (UC); Witch Creek, 1893, Alderson (UC). Specimens intermediate to genuine typicus are: Mill Creek Cañon, San Bernardino Mountains, Reed 3894 (UC); foothills of San Bernardino Mountains, Parish 234 (UC). 
5. Stenotopsis interior Rydb., Bull. Torr. Club 27:617, 1900-H. linearifolius interior.

6. S. linearifolia Rydb., l. c.-H. lincarifolius typicus.

7. S. linearifolia var. interior Macbr., Contr. Gray Herb. 49:59, 1917.-H. linearifolius interior.

8. Stenotus interior Greene, Erythea 2:72, 1894-H. linearifolius interior.

9. S. linearifolius Torr. et Gray, Fl. N. Am. 2:238, 1842-H. linearifolius typicus.

10. S. linearifolius interior Hall, Univ. Calif. Pub. Bot. 3:48, 1907-H. lincarifolius interior.

\section{RELATIONSHIPS}

Since this is the principal member of the section Stenotopsis, the relation to other species has been sufficiently indicated in connection with the discussion of the sections (p. 39).

Within the species there is an evident tendency toward the natural segregation of two forms. These are sufficiently unlike to be here treated as geographic subspecies and by some authors as distinct species. Difficulties encountered in an attempt to follow the latter course are the occasional appearance of the one form in areas inhabited chiefly by the other; also the presence of intermediate forms where the ranges meet; and, finally, the lack of concomitance in the characters used for their recognition. Illustrations of these phenomena, seen in specimens preserved at the herbarium of the University of California, may be cited as follows: Some plants of subsp. typicus at Mount Diablo, California, which is near the type locality, have only the short leaves of subsp. interior (Chandler 971). The small heads and achenes of interior are found on plants from Corral Hollow, in the same district (Brewer 1221). The large heads and long ligules of typicus occur on plants with the short leaves of the interior subspecies on the Mohave Desert (May 1895, Davidson). The narrow involucral bracts of interior may be seen on plants from the area of typicus (Corral Hollow, Brewer 1221), and intermediates as to this feature are common where the ranges overlap (Keene, Kern County, Heller 7813; Coahuila Hills, Hall 2902; San Felipe, Brandegee). Moderately broad and very acuminate bracts occur on plants well within the area of interior (Prescott, Arizona, Palmer 200) and decidedly acuminate bracts are so common throughout the whole area of the species that this feature is perhaps of no taxonomic value.

Evidence such as that just cited may seem to indicate that the two forms are mere modifications brought about by an adjustment to climatic conditions. That this can not be the case, unless it is admitted that these modifications have become partially fixed, is proven by the fact that transplants of the interior form hold their characters without appreciable change for at least five years when grown in the coastal district alongside of typicus. This experiment has been carried out at Mills College, California, by McMinn with plants from the Mohave Desert. The conclusion is that we are here dealing with two slightly different genetic types, each adapted to a slightly different environment, that these types mingle and intergrade where their ranges meet, that certain features of the one may at times appear within the area of the other, and that the differences are best expressed in the least variable characters, namely, those of leaf-length, size of achene, and width of involucral bracts.

A third geographic form, which possibly is of genetic significance, has been described as minor variation 4 . 


\section{ECOLOGY}

In growth form Haplopappus linearifolius is a shrub, sometimes almost arboreous, but at other times, especially in the desert areas, reduced to a subshrub. In its taxonomically typical form it belongs to the AdenostomaCeanothus association of the coastal chaparral, where it is sometimes subdominant, as, for example, on Mount Diablo, where it covers large areas at altitudes of about 1,000 meters in the belt of Quercus douglasi. More commonly, however, it occurs only as scattered plants on disturbed areas, more especially in dry, stony streamways and on crumbling banks. It avoids the immediate proximity of the ocean and belongs rather to the hot and arid inner coast ranges.

The subspecies interior is of wide distribution around the borders of the interior deserts and on desert ranges. In California it extends as far west as eastern Ventura County, but only where the vegetation has a decidedly xerophytic stamp, due to the proximity of the desert and the direction of desert winds. This form belongs chiefly to the piñon-juniper woodland, but grows only in nearly open places. It attains to altitudes of 2,500 meters on west slopes of the Panamint Mountains, but is common only much below this, and on the lower slopes it mixes with desert scrub, especially in the Larrea belt. The zonal position of typicus is chiefly Upper Sonoran, that of interior usually Lower Sonoran.

Both of the subspecies are strictly aestival as to time of flowering, the heads opening from March to April. Rubber in small amounts forms in the stems of this shrub, which, however, is believed to have no commercial possibilities.

28. Haplopappus parrasanus Blake, Contr. U. S. Nat. Herb. 23:1490, 1926

A shrub, with apparently open branches; bark gray, firm, not known as to older parts; twigs slender, not crowded, at first leafy but soon nearly naked, sparsely and faintly striate, resinous when young, glabrous; leaves linear, straight or upwardly curved, entire, mucronulate, 0.5 to $1 \mathrm{~cm}$. long, $1 \mathrm{~mm}$. or less wide, thick, 1-nerved, concave on upper surface, impressed-punctate and scabrous, resinous (occasionally with smaller ones fascicled in the axils); heads terminating leafy branches, these 0.5 to $3 \mathrm{~cm}$. long and cymosely arranged; involucre hemispheric, 3.5 to $4.5 \mathrm{~mm}$. high, 6 to $8 \mathrm{~mm}$. broad; bracts 16 to 20 , in three series, shorter than disk, very loosely imbricated, the outer ones only slightly shorter than the inner, all narrowly oblong or oblong-lanceolate, acute, mostly thick and herbaceous but base indurated and coriaceous, the margins irregular and white-scarious, glandular-viscid, subglabrous; ray-flowers about 10, the ligules 5 to $6 \mathrm{~mm}$. long, about $3 \mathrm{~mm}$. wide; disk-flowers about 25; disk-corolla gradually enlarged from the tube to the funnelform throat, 4.2 to $5 \mathrm{~mm}$. long, glabrous; lobes broadly lanceolate, acute, recurved, about $1.5 \mathrm{~mm}$. long, glabrous; style-branches well exserted, 3.5 to $4 \mathrm{~mm}$. long, the oblong acute appendage slightly shorter than stigmatic portion; achenes slightly compressed, subturbinate, $2 \mathrm{~mm}$. long (immature), slightly angled, very densely sericeous-pilose; disk-pappus equaling corolla (exclusive of the recurved lobes), rather stiff, copious, white. (Ericameria parrasana Blake, Contr. Gray Herb. 52:26, 1917.) (Fig. 50.)

Known only from the type collection, namely, rocky slopes, Sierra de Parras, Coahuila, March, 1905, Purpus 1005 (Gr, UC). 


\section{RELATIONSHIPS}

The relationships of a species so little known as Haplopappus parrasanus must necessarily be in doubt, but the technical characters and even the habit strongly suggest that this is an ally of $H$. linearifolius. The most notable agreements are as follows: impressed-punctate foliage; subcymose arrangement of heads; broad involucres of only two or three series of weakly imbricated bracts; comparatively broad and thick style-appendages, these shorter than the stigmas; subturbinate achenes; and white pappus. The only significant differences are found in the much smaller size of the heads (in parrasanus) and the much greener and more herbaceous bracts of the involucre. At the present time there is no morphologic or geographic connection, although $H$. linearifolius interior, which is the form most like parrasanus, extends to the general area of the latter. If the two are of the same stock, the former has evolved especially in the development of a chartaceous involucre, while the present species has reduced the size of its foliage and capitula.

A connection with the section Ericameria has been suggested. Possibly the plant is only a seasonal or hypertrophic form, corresponding to the vernal form of $H$. pinifolius and the "nelsoni" form of $H$. laricifolius. It differs in so many characters, however, from all known Ericamerias, that this is scarcely a possibility.

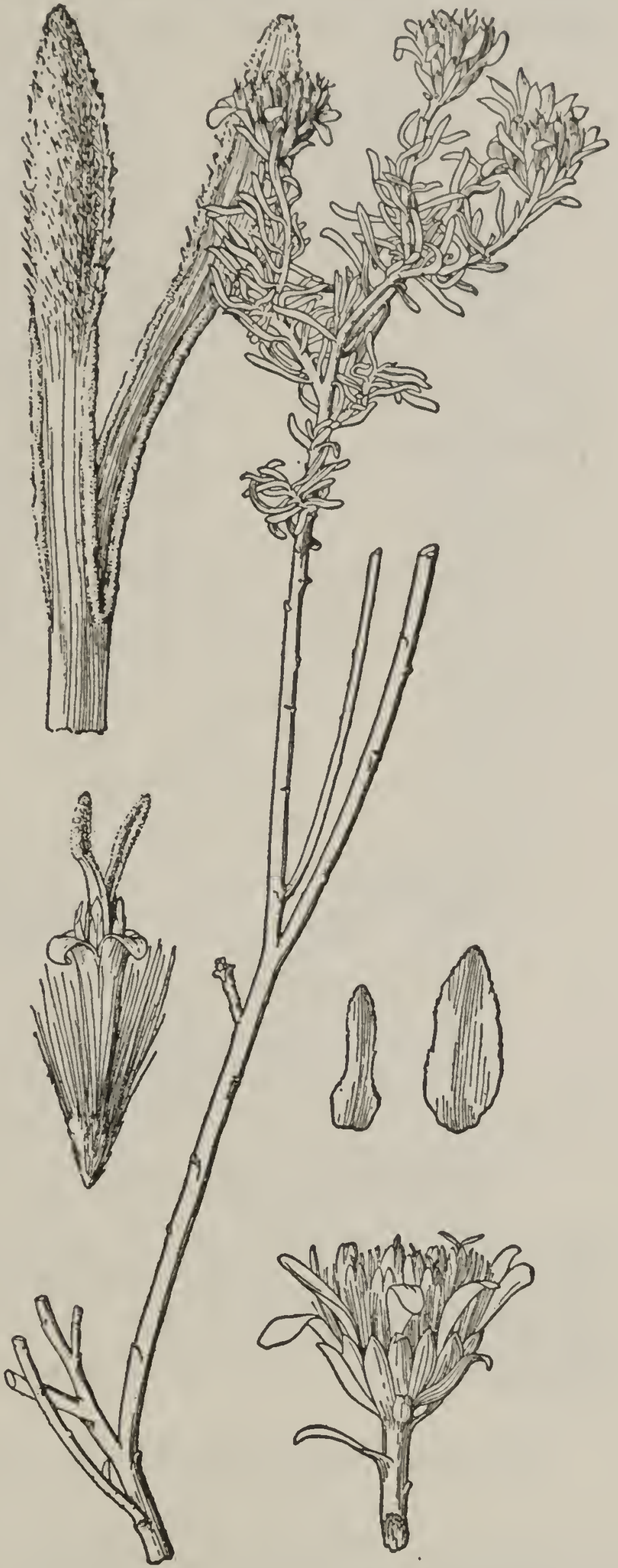

Fig. 50-Haplopappus parrasanus

\section{SECTION 7. STENOTUS}

\section{PHYLOGENY OF THE SPECIES}

The evolution of the species of this section has been strongly influenced by edaphic and climatic conditions. All are inhabitants of arid districts and several are adapted to alkaline soils as well. The first two of the present arrangement probably are no more primitive than the others, for although they are large-headed plants which do not occur far north, their style- 
branches are slender and acute. Haplopappus lanuginosus differs in the reduction of the bracts to two whorls (or this may be the original condition) and in a strong tendency toward the development of tomentum. The two remaining species are much alike in habit and in their remarkable re-

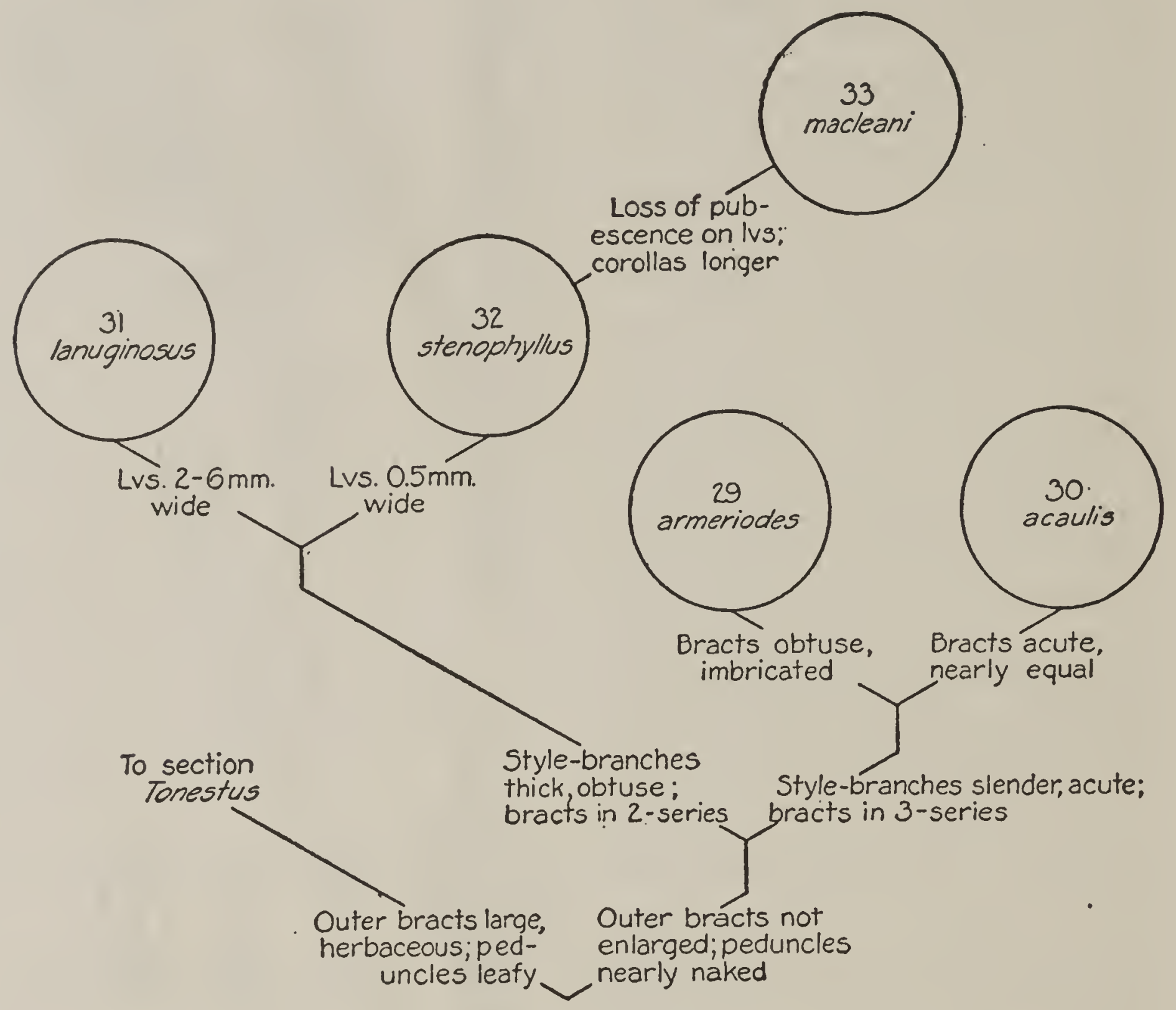

FIG. 51-Phylogenetic chart of the species of Haplopappus section Stenotus

duction in width of leaves. H. stenophyllus is the more southerly of these, occupying very dry situations within the northerly part of the area of the three preceding species, while $H$. macleani, obviously a derivative of this, has the most northerly distribution of any member of the genus. (Fig. 51.)

\section{Haplopappus armerioides (Nutt.) Gray, Syn. Fl. $1^{2}: 132,1884$}

A perennial cespitose subshrub, 1 to nearly $2 \mathrm{dm}$. high, the sparsely leafy flowering stems and short leafy sterile shoots densely clustered on the branches of a stout woody caudex, this with a fibrous bark and crowded remnants of old leaves; stems pale, changing to reddish brown toward summit, obscurely resinous but smooth and glabrous or sometimes tomentose near heads; leaves chiefly basal but usually 1 or 2 medium-sized ones also on the lower half of the flowering stem and a bract or two on the peduncle proper; basal leaves elongated spatulate-linear, tapering to base, mostly erect, entire, pungently acute, 4 to $8 \mathrm{~cm}$. long including the narrow base, 3 to $7 \mathrm{~mm}$. wide, rigid, 3-nerved, the cross-veinlets obvious at least beneath, glabrous but margins faintly scabriusculous, sometimes resinous; 
heads solitary, terminating scape-like peduncles; involucre broadly campanulate, 10 to $11 \mathrm{~mm}$. high, 10 to $12 \mathrm{~mm}$. broad; bracts in 3 or 4 series, the outer decidedly shorter than the inner, well imbricated, all exceeded by disk at maturity, the inner broadly oblong, the outer broadly oval, all obtuse and often muticous, pale and coriaceous, all but innermost conspicuously greenish near apex, glabrous, slightly glutinous; ray-flowers 8 to 12 (or 15?), the ligules 10 to $12 \mathrm{~mm}$. long, about $4 \mathrm{~mm}$. wide; disk-flowers 15 to 30 ; disk-corolla without sharp distinction between tube and throat, 7 to $9 \mathrm{~mm}$. long, glabrous; lobes ovate or ovatelanceolate, about $1 \mathrm{~mm}$. long, glabrous; stylebranches long-exserted, 2.5 or usually 3 to nearly $4 \mathrm{~mm}$. long (originally described as lanceolate and unusually thick, but more slender at least in most cases), the appendage equaling or exceeding stigmatic portion, acutish; achenes compressed, very slightly tapering to base, about $4.5 \mathrm{~mm}$. long, densely silky-villous; pappus about equaling corollas, soft, white, rather copious. (Stenotus armerioi-

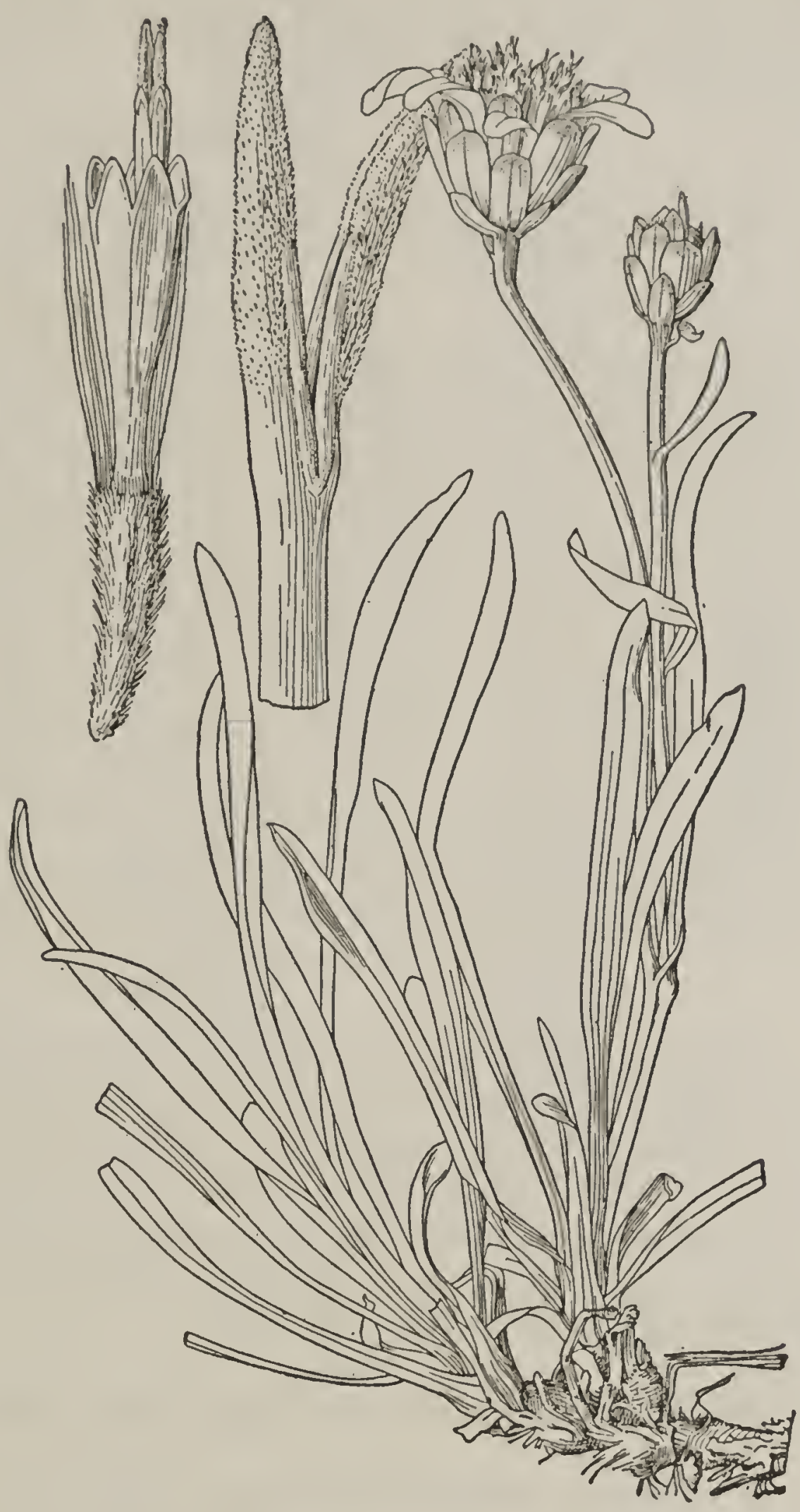

FIG. 52-Haplopappus armerioides des Nutt., Trans. Am. Phil. Soc. II, $7: 335,1840$.) (Fig. 52.)

In the Rocky Mountains, from southern Montana to New Mexico and Arizona, also casual easterly to Nebraska. Type locality, toward the sources of the Platte River. Montana: Custer (Gr, ex-hb. Blankinship, collector not known). Wyoming: Steamboat Mountain, Nelson 7066 (Gr, B, K, R); Wind River, Forwood 32 (B); Cooper Lake, Albany County, Goodding 20 (Gr, Del, UC, R, DS, Po); Laramie Hills, Nelson 9269 (UC, a form with small heads and flowers); Point of Rocks, Nelson 4751 (R); Green River, June 23, 1896, Jones (Po). Colorado: Cimarron, Baker 37 (Gr, Del, B, K, UC, R); Kremmling, Grand County, Osterhout 3475 (R, DS); Naturita, Payson 302 (Gr, R); Kyse Creek, Mesa Grande, Purpus 
88 (P, B); Mancos, June, 1892, Eastwood (UC); Rio La Plata, Brandegee 1100 (UC). Nebraska: near Freeport, Banner County, Rydberg 142 (NY). New Mexico: Oraybe, May 13, Newberry (Gr, P, NY); hills 16 $\mathrm{km}$. north of Santa Fe, Heller 3663 (NY). Arizona: $80 \mathrm{~km}$. south of Lee's Ferry, June 12, 1890, Jones (Po). Utah: cañon above Tropic, Jones 5304 (UC).

\section{SYNONYMS}

1. Aster armerioides O. Kuntze, Rev. 317, 1891.

2. Stenotus armerioides Nutt., Trans. Am. Phil. Soc. II, 7:335, 1840.

\section{RELATIONSHIPS}

Haplopappus armerioides is well set off from other members of the section Stenotus. Intergrading forms are not found and almost never has a specimen been erroneously determined. In habit it is most like $H$. acaulis, but the more obviously imbricated involucre and the green-tipped bracts readily distinguish it. The slender style-branches and the three series of involucral bracts suggest that the similarity between these two species is more than superficial, but the occasional appearance of a definitely tomentose pubescence on the peduncles of the present one suggests also that of the two it is the most nearly related to lanuginosus and therefore to the other members of the section. The appearance of this latent character, however, is so rare that no certain phylogenetic connection can be deduced from it, and all of the species are best considered as end products of lines the interconnections of which have long since disappeared.

\section{ECOLOGY}

This is a species of dry hills and plains in the Upper Sonoran and Transition Zones of the Rocky Mountains. It grows usually, or perhaps always, on disturbed areas, especially in badlands and where the rock surface, as of broken shale, is shifting. Here it is able to persist better than most other plants because of the long, tough roots and strong caudex. In habit it is a mat-former with scattered heads on scapiform peduncles. The flowers appear from May to July.

\section{Haplopappus acaulis (Nutt.) Gray, Proc. Am. Acad. $7: 353,1868$}

A cespitose perennial subshrub, 0.5 to $1.5 \mathrm{dm}$. high, with many scapelike or sparsely leafy stems from tufts of basal leaves densely crowded on the branches of a stout caudex, the whole mat sometimes several decimeters across; stems greenish or very rarely with a tinge of reddish brown, either smooth or scabriusculous; leaves most abundant near base but usually continuing to near midway of the stem and often 1 or 2 reduced leaves above this level, but heads entirely naked; principal leaves narrowly to broadly oblanceolate, tapering to base, mostly erect, entire, acute to acuminate, terminating in a rigid mucro, 1 to $5 \mathrm{~cm}$. long including the narrow base, 2 to $7 \mathrm{~mm}$. wide, rigid, with 1 or 3 prominent ribs from base, the cross-veinlets more or less evident at least beneath, typically scabriusculous on both faces but passing through all stages to perfectly glabrous except on margins; heads solitary, terminating the scape-like peduncles or rarely an accessory head on a short lateral peduncle; involucre 
hemispheric, or somewhat campanulate, 7 to $9 \mathrm{~mm}$. high, 8 to $12 \mathrm{~mm}$. broad; bracts in 3 series, the outer a little shorter than the inner but not closely imbricated, all shorter than mature disk, ovate to ovate-lanceolate, mucronately acute or acuminate or some nearly obtuse, pale and chartaceous or the middle portion greenish, destitute of green tips, glabrous or more or less seabrid; ray-flowers about 6 to 15 , the ligules 8 to $12 \mathrm{~mm}$. long, 2 to $4 \mathrm{~mm}$. wide; disk-flowers 30 to 45 ; disk-corolla with short tube and long funnelform throat, 6 to $7.5 \mathrm{~mm}$. long, glabrous; lobes oblong, about 1 $\mathrm{mm}$. long, glabrous; stylebranches long-exserted, 2.5 to $3.5 \mathrm{~mm}$. long, the appendage equaling or exceeding stigmatic portion, moderately slender and acutish; achenes more or less compressed, each face sometimes with a prominent medial rib and the achene then 4-angled, slightly tapering to base, about $4 \mathrm{~mm}$. long, usually silky-villous but varying to glabrous (minor variations 6 and 14); pappus about equaling corollas, soft and

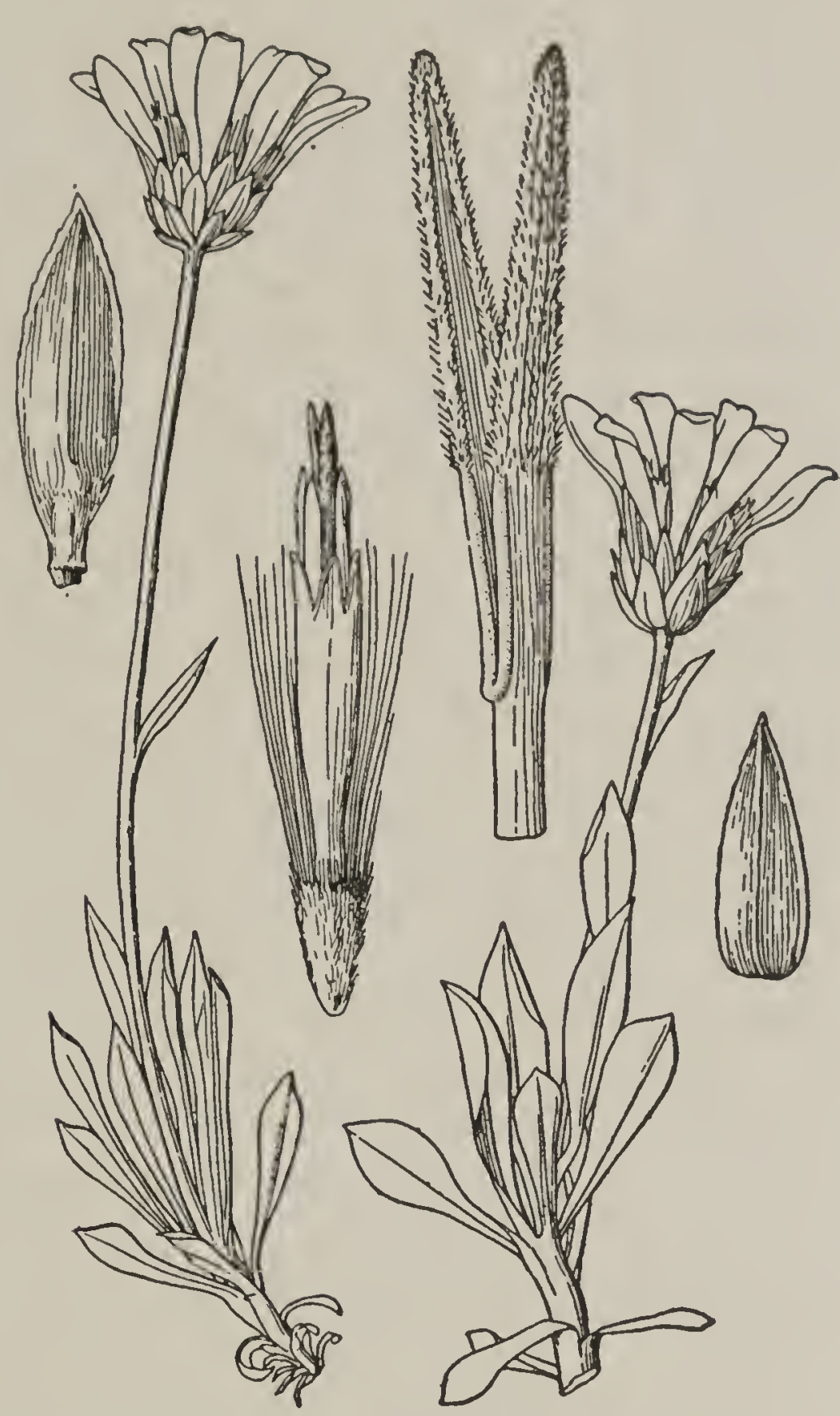

FIG. 53-Haplopappus acaulis typicus white or pale brown. (Chrysopsis acaulis Nuttall, Jour. Acad. Phila. 7:33, 1834.) (Fig. 53.)

Mountains of western North America, from Montana to Colorado, southern Utah, eastern California, and Idaho.

\section{SUBSPECIES}

Key to the Subspecies of Haplopappus acaulis

Herbage scabriusculous throughout, or the upper surface of the leaves rarely glabrous; plant densely cespitose, stout.............. (a) typicus

Herbage glabrous except for the scabrous leaf-margins; plant loosely cespitose, more slender.

(b) glabratus

30a. Haplopappus acaulis typicus-Leafy branches of the caudex much crowded, forming mats; flowering stems rather rigid, usually 4 to $10 \mathrm{~cm}$. high, more or less scabrid; leaves densely crowded near base, 1 to $3 \mathrm{~cm}$. long (originally described as lanceolate, but even in the type specimens they are oblanceolate and only $1.6 \mathrm{~cm}$. long by $2 \mathrm{~mm}$. wide), usually scabrid on both sides, rarely smooth above (types "almost hoary," accord- 
ing to Nuttall). (Chrysopsis acaulis Nuttall, Jour. Acad. Phila. 7:33, pl. 3, fig. 1, 1834.) (Fig. 53.)

Abundant throughout the range of the species. Type locality, in dry soil, Little Goddin River, toward the sources of the Columbia River. Type collection, Wyeth (Gr, labeled by Nuttall as Chrysopsis acaulis). Montana: near Helena, Brandegee (UC). Wroming: Leucite Hills, Merrill and Wilcox 506 (Gr, NY); Bush Ranch, Sweetwater County, Nelson 7096 (K, R, Gr, NY); Ferry Peak, Snake River Mountains, Payson and Armstrong 3455 (UC, R, see under minor variation 16); Piney Mountain, Payson 2683 (UC, R, minor variation 7); near Hemingway, Natrona County, Nelson 9213 (R, minor variation 18, type of Stenotus rudis); Laramie Plains, Nelson 1250 (R, Gr); Red Mountain, east of Smoot, Payson and Armstrong 3655 (UC, Gr); Evanston, Nelson 4510 (R, Gr, NY). Colorado: Hayden, Routt County, Osterhout 5229 (R). Utah: Detroit, May 25, 1891, Jones (UC); Mammoth, May 8, 1910, Jones (Po). NevadA: Pine Mountain, Elko County, Kennedy 4444 (UC, minor variation 7); Austin, Jones 3894 (R); near Pioche, Lincoln County, Minthorn 114 (UC); Miller Mountain, Esmeralda County, Shockley 112 (UC, DS); Peavine Mountain, Washoe County, Heizer 327 (UC, minor variation 6); King's Cañon, Ormsby County, Baker 987 (Gr, Del, B, UC, R, type collection of minor variation 19, Stenotus scaber). California: Benton Range, Mono County, August 29, 1923, Hall (CI); Pyramid Peak, Eldorado County, Hall and Chandler 4734 (Gr, B, UC, DS, some plants with glabrous achenes, minor variation 6); same locality, Smiley 127a (Gr, same variation in the achenes); near Lake Lucile, Tahoe district, July 19, 1904, Baker (UC); Mount Tallac, Tahoe district, Hall and Chandler 4612 (UC, all achenes pubescent on some plants, sparsely or densely pubescent on others); Deer Park, Tahoe district, Geis 54 (UC, minor variation 6); mountains near Truckee River, Tahoe district, July 18, 1886, Sonne (UC, minor variation 6); Tinker's Knob, Tahoe district, July 18, 1897, Sonne (UC, some plants with glabrous achenes, minor variation 6); Mount Stanford, Tahoe district, Hooker and Gray (K); Castle Peak, Nevada County, Heller 7104 (B, UC, minor variation 6 , but other plants of this distribution probably have pubescent achenes); near Susanville, July 2, 1892, Brandegee (UC, minor variation 6); Mount Bidwell, Manning 357 (UC). Oregon: Warner Mountains, Bruce 2135 (UC, minor variation 6); Stein's Mountain, Cusick 1966 (Gr, Del, P, UC, minor variation 6 and intermediate to subspecies glabratus as regards pubescence of foliage). IDAно: Silver City, Owyhee County, Macbride 922 (UC, minor variation 6, that is, with glabrous achenes; DS, with pubescent achenes) ; Montpelier, Bear Lake County, Macbride 23 (UC, DS); Mackay, Custer County, August 1, 1911, Nelson and Macbride $(\mathrm{R})$.

30b. Haplopappus acaulis glabratus (D. C. Eaton)-Leafy branches of the caudex only moderately crowded, forming loose mats; flowering stems erect but comparatively slender, usually 8 to $15 \mathrm{~cm}$. high but sometimes much dwarfed (although with all leaves glabrous on both faces), smooth; leaves mostly near base but disposed to continue up the stem, mostly 2 to $5 \mathrm{~cm}$. long, shorter in depressed plants, longer in luxuriant ones, either glabrous on both faces or minutely scabrid below, the edges scabriusculous. ( $H$. acaulis var. glabratus D. C. Eaton, Bot. King's Expl. 161, 1871.) 
Saskatchewan to Wyoming, Utah, eastern California, and Idaho. Type locality, toward the sources of the Missouri and the Platte Rivers. Heads of the Missouri, Nuttall from Wyeth (Phila, type of Chrysopsis caespitosa, Nutt., see minor variation 3); Rocky Mountains, Nuttall (Gr, labeled by Nuttall as Stenotus caespitosus, see minor variation 15). Saskatchewan: White Horse Lake, Macoun and Herriot 72805 (Gr, B, NY, minor variation 16). Assiniboia: Cypress Hills, June 25, 1894, Macoun (Gr). Montana: Bridger Mountains, Rydberg and Bessey 5049 (Del, B, K, UC); Madison County, Nelson 5/59 (Gr, R, NY); Spanish Creek, Gallatin County, July 1, 1901, Vogel (Gr); Deer Lodge Valley, Blankinship 707 (B); Belt Mountains, Anderson 262 (UC); Helena, July 1887, Kelsey (UC); West Yellowstone, Payson 2063 (UC). Wroming: Cooper Hill, Albany County, Nelson 8940 (Gr, B, UC, DS); Bitter Creek, Nelson 4768 (P); Mammoth Hot Springs, Mearns 1593 (NY, minor variation 16). UтAн: Provo, Wasatch Mountains, Goodding 1111 (R, Gr, Del, UC, type collection of minor variation 17, Stenotus latifolius Nels.); Mammoth, May 27, 1911, Jones (UC, DS, intermediate to typicus); Red Creek, southern Utah, Palmer 202 (US type collection of minor variation 16, Stenotus falcatus Rydb.); Milford, June 22, 1880, Jones (NY, Po, same variation). NevadA: Ruby Mountains, Heller 1112 (Gr, Del, B, UC, DS); Alleghany Creek, Nelson and Macbride $2173(\mathrm{Gr}, \mathrm{B})$. CALIfornia: hills above Red Clover Valley, Plumas County, Heller and Kennedy 8696 (Gr, P, B, UC, DS, some plants with glabrous achenes, type collection of Stenotus acaulis kennedyi, see minor variation 14). IDaнo: Rattlesnake Spring, Owyhee County, Nelson and Macbride 1914 (B); Mount Chauvet, Rydberg and Bessey 5048 (K).

\section{MINOR VARIATIONS AND SYNONYMS}

Some of the variations here listed are discussed under the heading of Relationships, where will be found also a chart illustrating their connections and which may serve more or less as a key.

1. Aster caespitosus O. Kuntze, Rev. 315, 1891. Based upon Chrysopsis caespitosus and therefore the same as $H$. acaulis glabratus.

2. Chrysopsis acaulis Nutt., Jour. Acad. Phila. $7: 33,1834-H$. acaulis typicus.

3. C. caespitosa Nutt., l. c.-H. acaulis glabratus. Although caespitosa might be the name for this unit, glabratus is much more distinctive and was the first one used under $H$. acaulis, although not in the subspecific category. It happens also that caespitosa and acaulis were first published simultaneously, with the former appearing first on the page. Caespitosa is not here taken up for the inclusive specific name because, (1) the description of acaulis was accompanied by a figure, (2) there is another although later $H$. caespitosus, and, (3) acaulis has been universally used.

4. Haplopappus acaulis var. glabratus D. C. Eaton, Bot. King's Expl. 161, 1871. Based upon Stenotus caespitosus Nutt. and therefore the same as $H$. acaulis subsp. glabratus.

5. H. acaulis glabratus, but much depressed and closely cespitose. The stems are only 4 or $5 \mathrm{~cm}$. high and the broadly oblanceolate leaves are about $2 \mathrm{~cm}$. long by $5 \mathrm{~mm}$. wide. The best example is from Bridger Mountains, Montana (August 29, 1902, W. W. Jones, UC).

6. H. acaulis typicus, but the achenes perfectly glabrous. This is a rather common phenomenon, as noted in connection with the citation of specimens under typicus. Apparently it is restricted to the western portion of the area occupied by the species. Here, in a single colony, may be found some plants with all of the achenes glabrous and others in which they are all densely villous. True intergradation has not been found, but in some cases the achenes are perfectly glabrous save for a few scattered hairs near 
the summit. This feature is paralleled in subsp. glabratus, as is noted under minor variation 14 .

7. H. acaulis typicus, but a form with extremely slender leaves and therefore bearing the same relation to the original typicus that minor variation 16 bears to the broad-leaved forms of subsp. glabratus. The plants at hand are also densely cespitose. The leaves are only 1 or $2 \mathrm{~mm}$. wide, although 2 to $4 \mathrm{~cm}$. long and the peduncles also are exceptionally slender, so that some of the heads are slightly nodding. The best representatives of this form are: Piney Mountain, Sublette County, Wyoming, Payson 2683 (R, UC), and Pine Mountain, Elko County, Nevada, Kennedy 4444 (UC).

8. H. falcatus Blake, Contr. U. S. Nat. Herb. 25:545, 1925 . Based upon Chrysopsis caespitosa (which see), but because of the earlier $H$. caespitosus Nutt. a later specific name was transferred from Stenotus falcatus Rydb., which is nearly the same form.

9. H. nelsoni Blake, Contr. U. S. Nat. Herb. 25:545, 1925. Based upon Stenotus latifolius Nels., which see.

10. H. nevadensis Kellogg, Proc. Calif. Acad. 3:9, 1863. The original description and accompanying figure leave no doubt that this is $H$. acaulis typicus. The figure shows a plant with leaves of medium width mostly clustered at the base and a nearly naked peduncle. The plant is described as scabrous throughout, 7 to $10 \mathrm{~mm}$. high, the leaves oblanceolate, the lanceolatesubulate appendages of the style much exserted and exceeding the stigmatic portion. The figure shows style-branches much more acute than is known in this species, but the remaining characters preclude reference to any other. The type was from Nevada. It was lost either in or prior to the San Francisco fire.

11. Hoorebekia acaulis Jones, Bull. Univ. Mont. Biol. 15:49, 1910-Haplopappus acaulis typicus.

12. H. acaulis var. caespitosa Jones, l. c. Based upon Chrysopsis caespitosa Nutt. and therefore the same as Haplopappus acaulis glabratus.

13. Stenotus acaulis Nutt., Trans. Am. Phil. Soc. II, 7:334, 1840. Based upon Chrysopsis acaulis Nutt. and therefore the same as H. acaulis typicus.

14. S. acaulis var. kennedyi Jepson, Man. Fl. Pl. Calif. 1028, 1925. This is the form of $H$. acaulis glabratus in which the achenes are glabrous. In the type, the leaves have the usual scabrous margins and at least some plants of the same collection are minutely scabrous also on the back. The type locality is in Plumas County, California (Heller and Kennedy 8696), and the form thus seems to connect both geographically and morphologically with typicus. Although most plants of this collection have glabrous achenes, some of them (as at DS) have pubescent achenes. A similar combination of glabrous and pubescent achenes in a single colony of plants occurs also in subsp. typicus, as reported by Hall (Zoe 5:266, 1908) and further discussed under minor variation 6 . In the type of kennedyi the leaves are narrowly oblanceolate and elongate, as in the original glabratus and in minor variation 16 , but other collections with glabrous achenes have the broad leaves of minor variation 6 (Deer Park, California, Geis 54, also Stein's Mountain, Oregon, Cusick 1966, both UC). These last, moreover, have a slight scabrid pubescence and are therefore intermediate to typicus, under which they have been cited. The criss-crossing of these characters in so many directions seems to indicate that we are here dealing with an assemblage of interbreeding forms, or at least that segregation is not yet complete.

15. S. caespitosus Nutt., 1. c. 335 . Based upon Chrysopsis caespitosa and therefore the same as $H$. acaulis glabratus.

16. S. falcatus Rydberg, Bull. Torr. Club 27:616, 1900. A form of H. typicus glabratus in which the leaves are narrower than usual, those of the stem being 4 to $7 \mathrm{~cm}$. long by only 2 or $3 \mathrm{~mm}$. wide and more or less falcate. The leaves of the type specimen, which came from southern Utah (or northern Arizona?) are remarkably smooth, even the margins, but similar slenderleaved forms are known of the scabrid subspecies typicus (see under minor variation 7). Intermediate as to scabridity is Payson and Armstrong 3455, from Lincoln County, Wyoming; some specimens of this number (as at UC) 
are scabrid on leaf-face and leaf-margins; others (as at $\mathrm{R}$ ) are smooth except on leaf-margins. Intermediates as to width of leaf are of course not rare, so that the acceptance of segregates here would call also for the division of typicus. The opposite extreme, with broad leaves, is the next following.

17. S. latifolius Nels., Bot. Gaz. $37: 266,1904$. A form of $H$. acaulis glabratus with broad oblanceolate leaves, those of the stems measuring 2 to $4 \mathrm{~cm}$. long by 4 to $7 \mathrm{~mm}$. wide. In the type specimens of glabratus (Chrysopsis caespitosa at Philadelphia) the leaves are only 2 to $4 \mathrm{~mm}$. wide, but intermediates as to shape and size of course are not rare (for example, Nelson 9269 and 8940 from Wyoming). Additional characters assigned to latifolius include the foliose stems, but the types of glabratus also have long leaves occurring well up toward the heads. The comparatively naked stem-bases and the more herbaceous, strongly 3-nerved leaves are more important characters also pointed out by Nelson. The strong nervation, especially noticeable when dry, doubtless is due to the herbaceous texture, and this, together with the absence of crowded leaves on the more slender caudices of the type, is apparently the result of growing in loose, stony soil or in crevices of rock. Crumbling soil always induces copious branching and interferes with the formation or at least the persistence of leaves on the lower parts of the stems. The type came from granite ledges in the Wasatch Mountains and a good representative of the form is labeled as from a crumbling rocky summit ( Nelson and Macbride 2173).

18. S. rudis Nels., Univ. Wyo. Pub. Bot. 1:67, 1924. The original description yields as a basis for the separation of this form from $H$. acaulis typicus only the character of broadly oblanceolate leaves. But in the specimens of acaulis the leaves are oblanceolate (not lanceolate as originally described), 1.6 $\mathrm{mm}$. long by $2 \mathrm{~mm}$. wide. The type of rudis has leaves about $2 \mathrm{~cm}$. long by 4 to $6 \mathrm{~mm}$. wide, and represents a much depressed form. It is from stony hilltops near Hemingway, Natrona County, Wyoming.

19. S. scaber Nels., 1. c. 68. This is the usual form of H. acaulis typicus in which the leaves are somewhat broader than in the Nuttallian types. But there is much variation even among specimens of the type collection of scaber (King's Cañon, Nevada, Baker 987). The University of California sheet of this has some plants with leaves mostly 4 to $8 \mathrm{~mm}$. wide, whereas on other plants the leaves are only 3 to $5 \mathrm{~mm}$. wide. The foliage on all plants is finely and densely scabrid.

\section{RELATIONSHIPS}

The relationship of this species to Haplopappus armerioides has been mentioned in discussing the latter. Taken together, these two form a small group that is more highly developed than the most primitive of the remaining species, that is, $H$. lanuginosus, but is perhaps of lower order than the most highly specialized species of the lanuginosus line, such as macleani and stenophyllus. The differentiating characters upon which these conclusions are based are indicated in the chart to the species (p. 162).

Haplopappus acaulis is given to much variation. The result of this is the production of a large number of forms difficult of organization into satisfactory subspecies. These difficulties arise chiefly from the fact that the distinguishing characters unite in almost all possible combinations. There is a tendency, however, toward a natural grouping of the divergent strains into the two assemblages here taken as subspecies. Of these, typicus is the more pubescent, more densely cespitose, and with shorter and stouter stems which commonly are densely clothed at base with remnants of old leaves. Any one of these features taken alone, as has been done as a basis for specific segregation, leads to confusion. For example, by careful selection of specimens all degrees of pubescence may be found as follows: (a) whole plant densely scabrous; (b) leaves scabrous but stems 
smooth; $(c)$ only upper surface and edges of leaves scabrous; $(d)$ entire absence of scabridity except on the leaf margins. The scabrous pubescence itself varies from strongly marked to low and scarcely detectable.

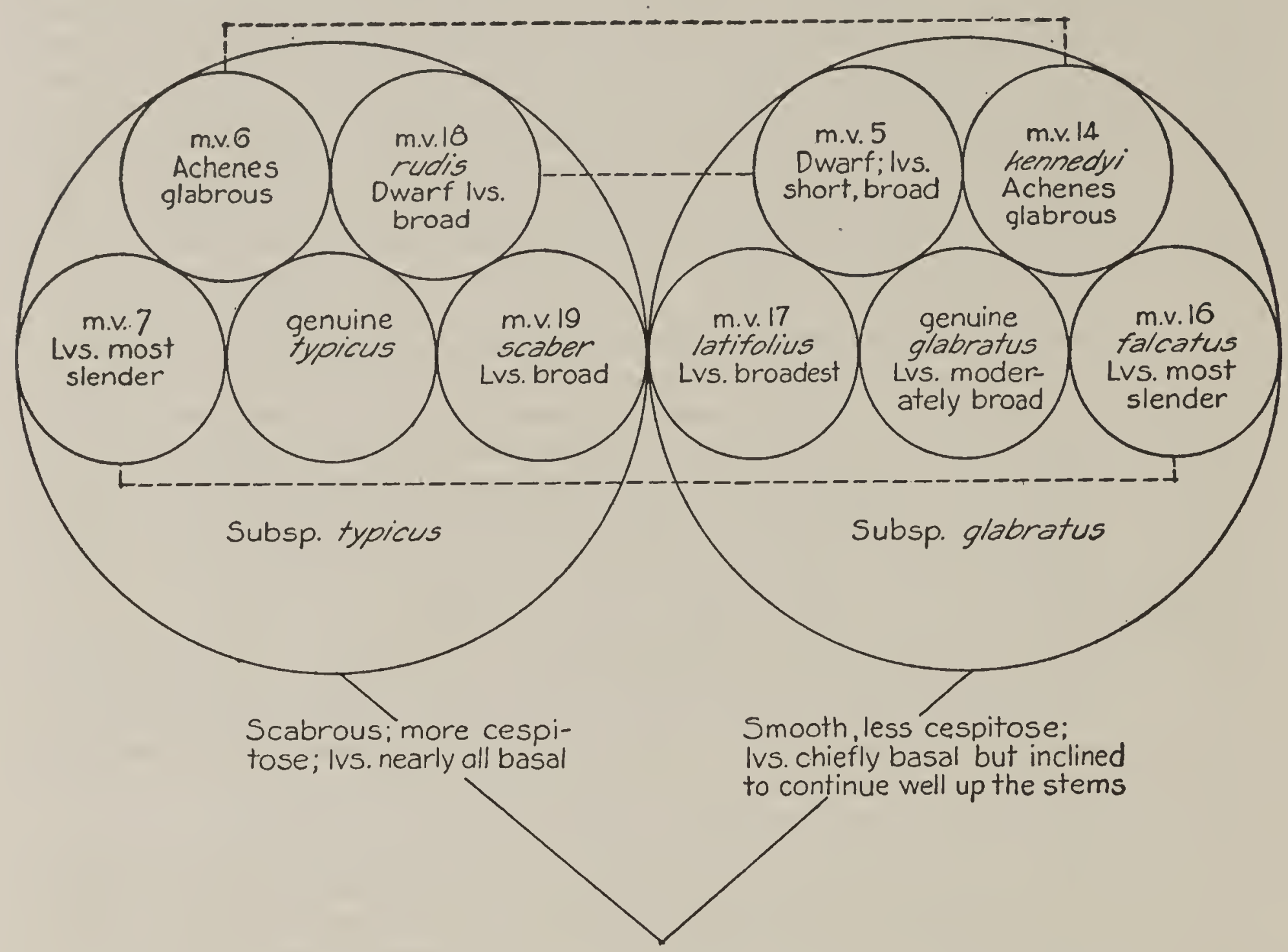

FIG. 54-Chart of parallel variations in Haplopappus acaulis

Notwithstanding the variation just mentioned, the pubescence character supplies the best basis for subspecific segregation, since a separation on this basis results in two groups, the members of which are mostly recognizable also on other features. It is therefore taken to represent the first steps in a phylogenetic cleavage that is incomplete because of occasional recombination of characters, probably through hybridization and back-crossing. The presence or absence of pubescence on the achenes, discussed under minor variations 6 and 14, supplies a character which also is doubtless heritable. It is very questionable, however, if such matters as habit, leafiness, and length and breadth of leaf, although used by some as of specific value in this group, are more than modifications for which the environment is directly responsible. The resulting forms are therefore best left as unclassified minor variations until such time as their status can be finally determined by experiment. The accompanying chart (Fig. 54), which includes fluctuating variations as well as genetic segregates, will indicate something of the complexity of the situation and may serve as a basis for experimental studies.

\section{ECOLOGY}

The habit of the original taxonomic form of Haplopappus acaulis is well described in the specific name, the leaves and peduncles being all crowded upon the cespitose crown of a closely branching caudex. This typical 
growth-form is characteristic of high, wind-swept ridges close to timberline, but at lower altitudes and where protected by rocks the caudex is more openly branched, the leafy tufts form looser mats, and the flowering stems are more leafy. This habit has been especially noted by Nelson in describing his Stenotus latifolius (minor variation 17). The perennial caudices are decidedly woody and the cespitose habit probably is the result of reduction from a shrubby growth-form, although the plants often simulate perennial herbs. The altitude usually is between 1,800 and 3,000 meters and the zonal position is Canadian and Hudsonian, but both subspecies grow also at lower altitudes and in the arid Transition Zone. In California this species is found sparingly at 1,400 meters in the piñonjuniper association of Mono County and more abundantly at high altitudes on mountains of the Lake Tahoe district and northward. Here it grows in well-drained soil of decomposed granite and on slopes with scattered dwarf trees of Pinus albicaulis and P. contorta. Associated timberline plants are Eriogonum incanum, E. ovalifolium, Gilia pungens hookeri, Haplopappus macronema, etc. The presence of Artemisia tridentata indicates a Great Basin influence and farther to the east this shrub, dominant only in lower zones, is not infrequently associated with the present species. The flowering period is from late May to the middle of August.

\section{Haplopappus lanuginosus Gray in Torr., Wilkes Expl. Exped.} $17: 347,1874$

A cespitose perennial herb or subshrub, 0.8 to 1.5 or rarely $2 \mathrm{dm}$. high, with numerous erect leaves and scape-like stems densely tufted on the branches of a short caudex; stems gray with a floccose tomentum, or this nearly wanting, the stems then green and striate; leaves crowded at base and continuing to more than midway up the stems, the uppermost reduced to almost filiform narrow bracts which usually stop short of the head; principal leaves linear-spatulate, tapering to the petiole-like base, erect, entire, nearly obtuse to decidedly acute, 4 to $8 \mathrm{~cm}$. long, 2 to $6 \mathrm{~mm}$. wide toward apex, soft, not at all rigid, with 1 medial and 2 much fainter nerves, the latter often almost masked by the dense floccose tomentum of some forms; heads solitary, terminating the simple stems, the peduncles erect or slightly curved; involucre hemispheric, 9 to $12 \mathrm{~mm}$. high, 10 to $15 \mathrm{~mm}$. broad; bracts in two series, subequal and about equaling disk, oblonglanceolate or linear-lanceolate, acute or short-acuminate, the middle portion greenish, the margins white-scarious or pink, indistinctly 3-nerved, tomentulose; ray-flowers 15 to 20 , the ligules 10 to $12 \mathrm{~mm}$. long by 3 or $4 \mathrm{~mm}$. wide; disk-flowers numerous; disk-corollas gradually tapering from summit to base, 7 to $8.5 \mathrm{~mm}$. long, puberulent at least toward base; lobes lanceolate to ovate, 0.5 to nearly $1.5 \mathrm{~mm}$. long, glabrous; style-branches exserted, 2 to $2.5 \mathrm{~mm}$. long, the appendage only slightly longer than stigmatic portion or shorter, oblong-lanceolate, very obtuse; achenes somewhat compressed, longitudinally striate-ribbed, tapering from summit to base, 4.0 to $4.5 \mathrm{~mm}$. long, densely short-villous; pappus exceeding diskcorolla, soft and white, copious. (Fig. 55.)

Mountains of northwestern United States, from Montana to Oregon and eastern Washington. 


\section{SUBSPECIES}

Key to the Subspecies of Haplopappus lanuginosus

Bracts of the involucre mostly scarious, 2 to $3 \mathrm{~mm}$. wide........... (a) typicus

Bracts of the involucre green except for a narrow scarious margin, 1.5 to

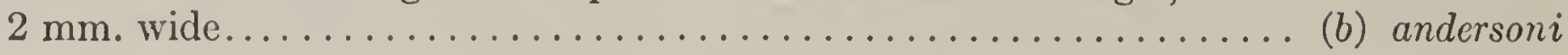

31a. Haplopappus lanuginosus typicus-Herbage usually tomentose; lower leaves rather broadly spatulate, 2 to 4 or $6 \mathrm{~mm}$. wide; bracts of the

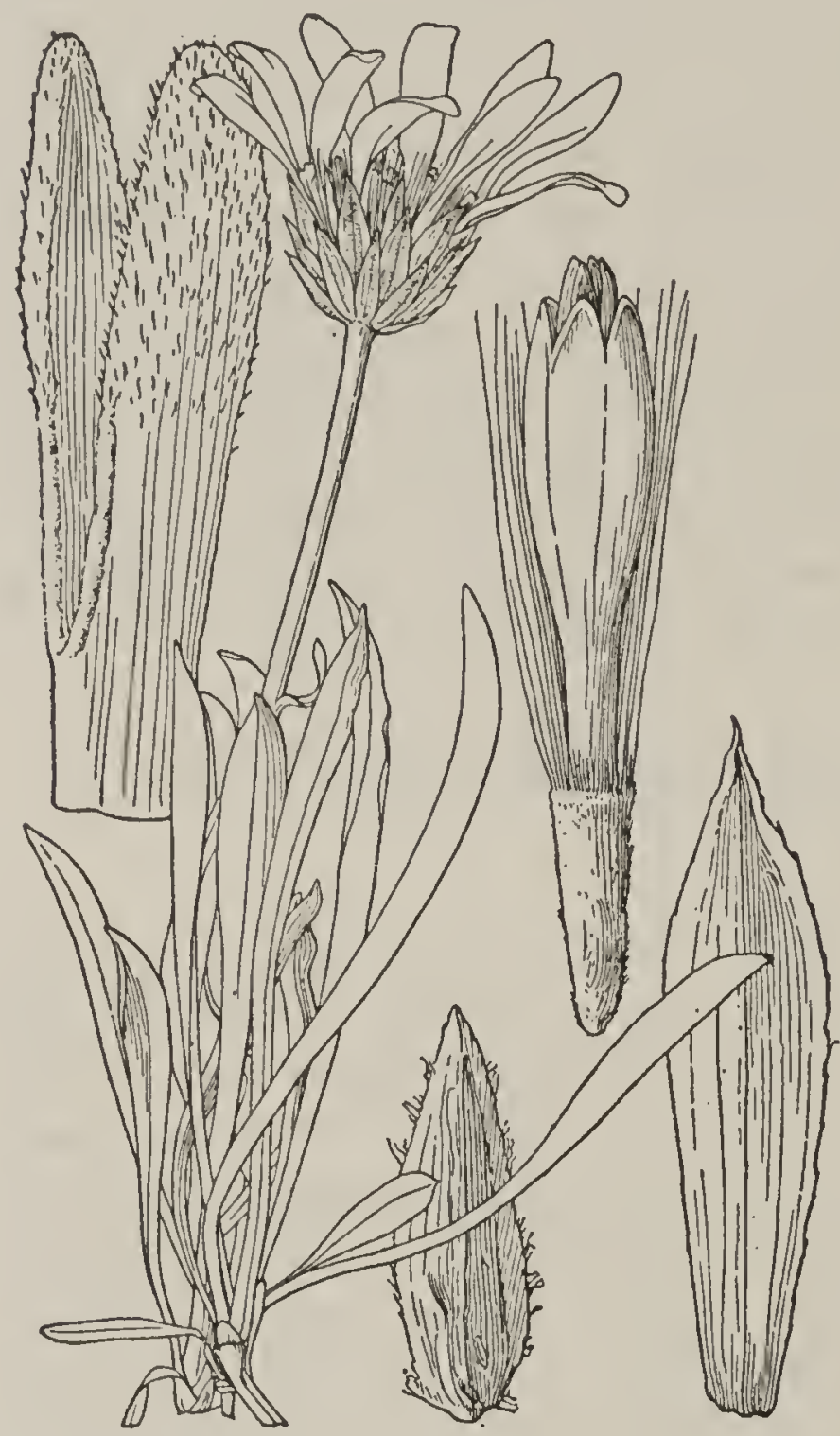

Fig. 55-Haplopappus lanuginosus typicus involucre oblong-lanceolate, 2 to 3 $\mathrm{mm}$. wide, the outer ones greenish under the tomentum but with broad white or pink scarious margins and tips. (H. lanuginosus Gray, l. c.) (Fig. 55.)

Range of the species, at 1,000 to 2,400 meters altitude. Type locality, upper part of North Fork of Columbia River, in open places. Type collection, Wilkes Expedition 1050 (US.) Montana : Trail Creek Prairie, western Montana, Watson 182(Gr); Ellerton, June 2, 1890, Kelsey (Po). Idario: ridge between Sawtooth and Alturas Lake, Evermann 548 (DS); Soldier Mountains, Henderson 3014 (US, type collection of $H$. laceratus, minor variation 3). OREGON: between the heads of Cottonwood and Kinney creeks, Leiberg 2139 (US, Gr, B, UC, narrow-leaved); deserts of eastern Oregon, Cusick 1611 (US, UC); Wallowa Mountains, Cusick 2317 (US. Gr, Del, P, B, K, a dwarf form of high altitudes); summit of Wallowa Mountains, Cusick 3282 (Gr, US, UC, R, DS, leaves broad and heads large); Blue Mountains, Howell 428 (Gr), also May 21, 1885 (US, Del); Burns, Peck 2694 (Gr); Quartz Valley, July 1893, Austin (UC). Washington: west Simcoe Mountains, Howell 285 (Gr); near Wenatchee, June 3, 1900, and June 7, 1896, Whited (US); Blue Mountains, Walla Walla County, July 18, 1896, Piper (UC, Po); Ellensburg, Whited 352 (US); Yakima region, Brandegee 344 (Gr, UC).

31b. Haplopappus lanuginosus andersoni (Rydb.) - Herbage usually green, somewhat viscid-puberulent, or sometimes moderately tomentose; lower leaves linear-spatulate, 2 to 3 or $4 \mathrm{~mm}$. wide; bracts of the involucre linear-lanceolate, 1.5 to $2 \mathrm{~mm}$. wide, mostly green and with green tips, only a narrow margin white-scarious. (Stenotus andersoni Rydb., Bull. Torr. Club $27: 615,1900$.)

Mountains of Montana and Idaho at 2,000 to 3,000 meters altitude. Type locality, Belt Mountains, Montana. Montana: type collection, Anderson 3561 (NY). IDAнo: Payette National Forest, 1912, Mains (R 
type of Tonestus linearis, minor variation 9); Josephine Lakes, Custer County, Macbride and Payson 3559 (R, Gr, UC, NY, same variation); Smoky Mountains, Blaine County, Macbride and Payson 3781 (R, Gr, UC, NY, same variation); Ketchum, Broadhead (Po).

\section{MINOR VARIATIONS AND SYNONYMS}

Aside from the two well-marked subspecies here described, there is but little variation within this species. The only published taxonomic segregates are Nos. 3 and 9 of the following list. In the high mountains there is a dwarf form of subspecies typicus only 4 or $5 \mathrm{~cm}$. high, the leaves $3 \mathrm{~cm}$. and less long by 3 or $4 \mathrm{~mm}$. wide (Joseph-Cornucopia trail, Wallowa Mountains, Oregon, Cusick 2317). Much variation in leaf-width may be noted. In some collections the leaves are mostly 3 to $5 \mathrm{~mm}$. wide; in others only 1 or $2 \mathrm{~mm}$. Such extremes have been indicated in connection with the citation of specimens, but all intermediate forms appear. It is believed that none of the variations just mentioned are more than temporary modincations, with the possible exception of No. 9 .

1. Aster pickeringi O. Kuntze, Rev. 316, 1891-H. lanuginosus typicus.

2. Haplopappus andersoni Blank., Mont. Agr. Col. Sci. Stud. Bot. 1:100, 1905. Based upon Stenotus andersoni, which see.

3. H. laceratus Hend., Bull. Torr. Club $27: 347,1900$. This is a form combining the characters of the two subspecies here described. The type collection came from an elevation of over 3,000 meters on Soldier Mountain, Idaho (Henderson 3014) and is now represented, as far as known, only in the United States National Herbarium. The sheet here on file has some heads with involucres almost indistinguishable from those of the type collection of $H$. lanuginosus. The bracts are 1.5 to $2 \mathrm{~mm}$. wide, acute, and broadly scarious-margined on some involucres; only $1 \mathrm{~mm}$. wide and entirely green except for a very narrow border on others. The herbage is greener and more glandular than in typicus, but this feature is variable in both of the subspecies. The erose or sublacerate edges of the bracts, a character emphasized by Henderson in his choice of a specific name, is a character common to all the forms of $H$. lanuginosus. It was used to differentiate $H$. laceratus from $H$. lyalli and $H$. pygmaeus, but this was not necessary, since it has neither the habit nor the involucre of these species.

4. Hoorebekia lanuginosa Piper, Contr. U. S. Nat. Herb. 11:560, 1906-Haplopappus lanuginosus typicus.

5. Stenotus andersoni Rydb., Bull. Torr. Club $27: 615,1900-H$. lanuginosus andersoni.

6. S. laceratus Heller, Muhlenbergia 1:7, 1900. Based upon H. laceratus, which see.

7. S. lanuginosus Greene, Erythea 2:72, 1894-H. lanuginosus typicus.

8. Tonestus laceratus Nels., Bot. Gaz. 37:262, 1904. Based upon H. laceratus, which see.

9. T. linearis Nels. et Macbr., Bot. Gaz. 56:478, 1913. The original specimens of this are almost identical with those of $H$. lanuginosus andersoni. In later collections (Macbride and Payson 3781) some plants are greenish and only sparsely tomentulose, while others are gray-tomentose. In these the styleappendages are slightly longer than the stigmas, and the narrow bracts, entirely green except for a very narrow border, are mostly 1-nerved. The reference to section Tonestus, as proposed by Nelson and Macbride,would carry all of lanuginosus with it, a course which features of the involucre alone would prevent. It is true, however, that Stenotus and Tonestus find their nearest approach to each other through this species, as will be further discussed under Relationships.

\section{RELATIONSHIPS}

Haplopappus lanuginosus is well set off from all other spccies of Stenotus by its less woody caudex, non-rigid foliage, and tomentose pubescence, as well as by leaf-shape and other minor features. It exhibits closer affinities with Tonestus than do any of the other species, having somewhat the 
habit of this section and comparatively short appendages to the stylebranches. But these appendages are never obtuse and the involucre is that of Stenotus. In characters of the capitulum and flowers it is very much like $H$. linearifolius, and although lacking the shrubby habit and punctate foliage of this species, is therefore suggestive of a connection between Stenotus and Stenotopsis. These resemblances to species of neighboring sections perhaps indicate that it is the most primitive of its group and therefore of ancient lineage. If this is correct, the species is to be looked upon as more or less of a relict, its distribution being limited to poor soils of a small geographic area. This theory receives some support from the fact that it is not given to much variation, there being but two subspecies and no other deviations of note except the few mentioned under Minor Variations.

The reduction of Haplopappus andersoni to the rank of subspecies has been made with much reluctance. In its extreme form it is well set off, especially on the basis of involucral characters, and although its distributional area is almost entirely surrounded by that of typical lanuginosus, it inhabits only the very high mountains. On the other hand, it is plainly of the same immediate stock, with no other species intervening in the phylogenetic sequence, and occasional collections seem entirely to bridge the gap. One of these was described as $H$. laceratus, the intermediate characters of which are noted under minor variation 3. This was described and named shortly before $H$. (Stenotus) andersoni, so that if the latter is accorded specific rank it should perhaps take the name of the doubtful $H$. laceratus. Another intermediate is a collection from Quartz Valley, Oregon (July 1893, Austin, UC) in which some bracts are linear, some broadly lanceolate, and all of these, whether linear or lanceolate, with broad scarious margins. Finally, the greener and more glandular herbage of subsp. andersoni are features which do not always parallel those of the involucre. Thus, some collections of andersoni have a quite tomentose herbage (Macbride and Payson 3781), while others referable to subsp. typicus on the basis of the involucre are green and obscurely if at all tomentulose (Cusick 730). It appears, therefore, that the relationships of these forms can best be expressed through the inclusion of all within one species with two subspecies.

\section{ECOLOGY}

This is a narrow-leaved xerophytic mat-former of poor stony or gravelly soil at middle and upper altitudes in the mountains. It inhabits exposed slopes and flats and has been collected in dry, stony streamways. The zonal position of the typical form is arid Transition, but the species ranges into higher zones, where it may be represented either by what appears to be a dwarfed modification or by the greener subsp. andersoni. This latter occurs even within the Arctic-Alpine Life-zone. The altitudinal distribution is from 1,200 to 2,900 meters and the flowers appear from May to August.

32. Haplopappus stenophyllus Gray, Wilkes Expl. Exped. $17: 347,1874$

A slightly suffrutescent perennial, 0.5 to $1 \mathrm{dm}$. high, with numerous scape-like stems arising from dense leafy mats formed on short branches 
of the caudex; stems pale, hirtellous-scabrous; leaves crowded on lower third of shoots of the season, usually 1 or 2 also on each erect peduncle; principal leaves linear-spatulate or nearly filiform, not distinctly petioled, erect, often slightly curved, entire, obtuse or short-acute, 1.0 to $1.5 \mathrm{~cm}$. long, about $0.5 \mathrm{~mm}$. wide, rigid, 1-nerved, glandular-scabrid over entire surface; heads solitary and erect, terminal; involucre hemispheric to broadly campanulate, 6 to 8 or rarely 9 $\mathrm{mm}$. high, 8 to $10 \mathrm{~mm}$. broad; bracts in two series, loose, nearly equal, shorter than the disk and nearly equaled by the fully mature achenes, linear, pungently acute or acuminate, mostly green and herbaceous but with narrow scarious margins, densely scabriusculous, the projections minutely gland-tipped; ray-flowers 8 to 12 , the ligules 7 to $10 \mathrm{~mm}$. long, 2 or 3 mm. wide; disk-flowers numerous; diskcorollas tubular-funnelform, 6 to $7 \mathrm{~mm}$. long, puberulent on tube; lobes oblonglanceolate, obtuse, 1.3 to $1.8 \mathrm{~mm}$. long, glabrous; style-branches moderately exserted, 1.7 to $2.7 \mathrm{~mm}$. long, the appendage equaling or shorter than stigmatic portion, very thick and obtuse; achenes com-

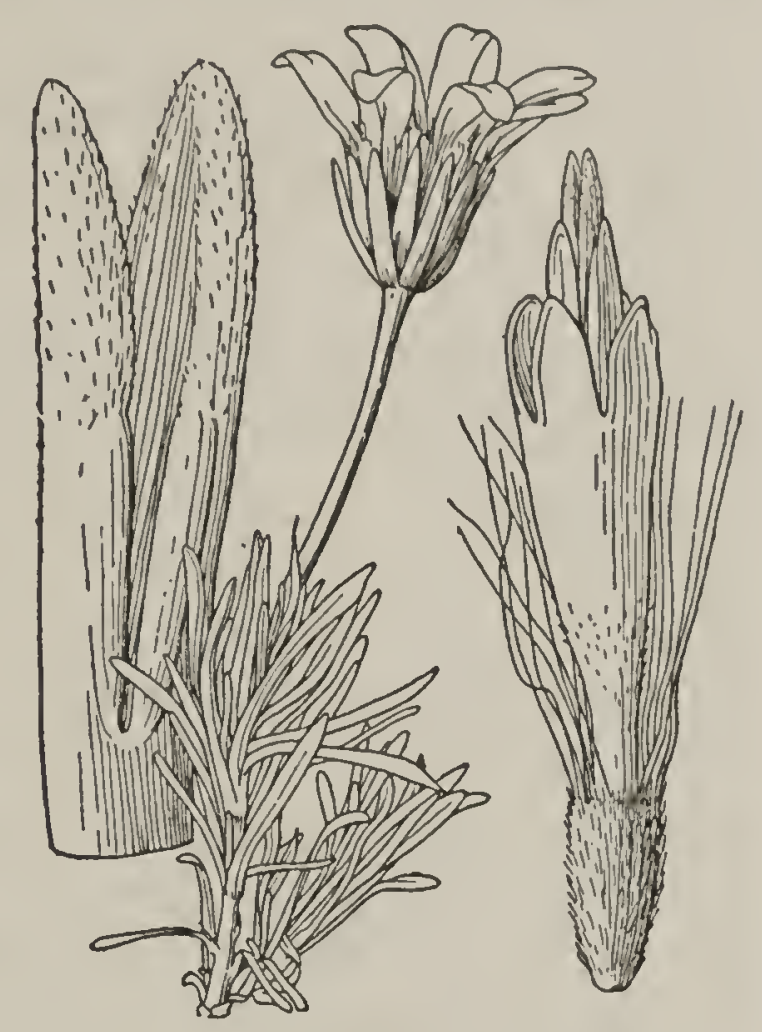

Fig. 56-Haplopappus stenophyllus pressed, shortly rounded at summit, tapering toward the base, more or less striate with about 10 nerves, 6 to $7 \mathrm{~mm}$. long, densely appressedvillous; pappus about as long as corolla, nearly white, soft and copious. (Fig. 56.)

Plains and foothill slopes from northeastern Washington and Idaho to northeastern California and Nevada. Type locality, between Spipen (Naches) River and the North Fork of the Columbia, Washington. WAsHInGton: type, Wilkes Expedition, Pickering and Breckenridge (Gr); Ellensburg, Piper 2685 (Gr); Rattlesnake Mountains, Yakima region, Cotton 346 (Gr, B, R); near Cleveland, Klickitat County, Suksdorf 335 (Gr); Bickelton, Klickitat County, April 27, 1882, Howell (Del, P). IDAHo: Sawtooth National Forest, Woods 52a (R). OREGoN: head of Dry Creek, Leiberg 2142 (Gr, UC); dry, sterile soil at Burns, Peck 2698 (Gr); stony hills of eastern Oregon, Cusick 2193 (Gr, P, B, K, UC); Pine Creek, Lake County, Austin (UC). California: Goose Lake Valley, May 1894, Austin (UC); northeastern Modoc County, Manning 472 (UC). NevadA: Tuscarora, Hall 12190 (CI); Pine Mountain, Elko County, Kennedy 4483 (UC, DS); White Mountains, near Sunland, Mineral County, Heller 10510 (Del).

\section{SYNONYMS}

1. Aster stenophyllus O. Kuntze, Rev. 318, 1891.

2. Hoorebekia stenophylla Piper, U. S. Nat. Herb. 11:561, 1906.

3. Stenotus stenophyllus Greene, Erythea 2:72, 1894.

\section{RELATIONSHIPS}

Haplopappus stenophyllus is a species of limited distribution and, aside from $H$. macleani, which plainly is a derived form, it has no close phylo- 
genetic connections. It resembles $H$. lanuginosus in being thus isolated, and like this species possesses some characters suggestive of the neighboring section, Tonestus. The very obtuse style-branches are especially noteworthy in this connection, but the few, narrow, equal bracts of the involucre are not at all Tonestus-like and the habit is much too woody for this group. It seems, therefore, that stenophyllus is another of the relicts of poor soils of arid districts in northwestern United States, and that it is plainly of the section Stenotus, although all connections with its relatives long since have been obliterated. In the field it is at once recognized by its very dense and scabrid thyme-like foliage.

\section{ECOLOGY}

In growth-form this species is like others of its section in that it makes small and compact mats, but it differs from all of them in being more suffrutescent. It inhabits poor, stony or gravelly soil of table-lands and ridges in the arid districts lying to the northwest of the Great Basin, where the summer temperatures are high. Its zonal position is Upper Sonoran and arid Transition. At the lower altitudes it grows on open stony ridges in the Artemisia consociation, especially where this is dominated by the scrubby $A$. tridentata arbuscula. Above this, it occurs in the belt of Juniperus, here also confined to open places, and at still higher altitudes it invades the lower part of the open Pinus ponderosa woodland. The flowering season is from early May to late July.

\section{Haplopappus macleani Brandegee, Bot. Gaz. $27: 448,1899$}

A cespitose perennial slightly woody at base, only a few centimeters high, the very short flowering stems arising from densely leafy mats formed

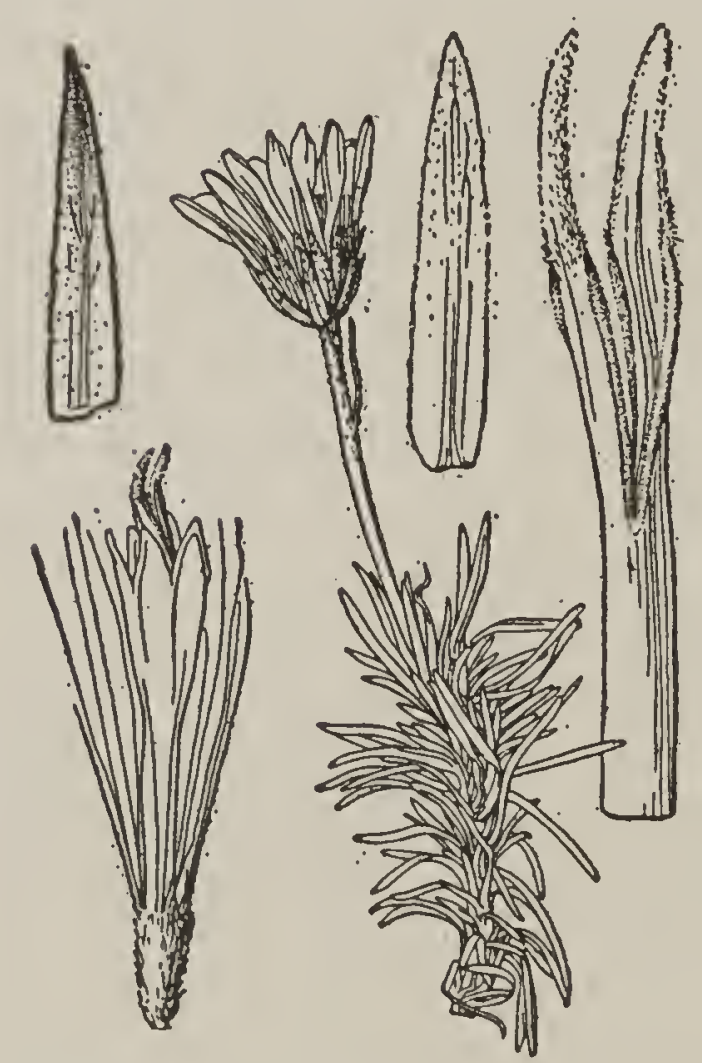

FIG. 57-Haplopappus macleani from short branches of the multicipital caudex; stems pale, densely scabro-puberulent and glandular; principal leaves narrowly linear, entire, almost filiform, 1.0 to $2 \mathrm{~cm}$. long, 0.3 to $0.7 \mathrm{~mm}$. wide, either obtuse or abruptly narrowed to a short mucro, rigid, traversed by a strong midrib, glabrous on both faces, hispidciliate on the margin; heads solitary and erect, terminal; involucre broad-campanulate, about $7 \mathrm{~mm}$. high and 8 or $9 \mathrm{~mm}$. broad; bracts in 2 series, loose, nearly equal, shorter than the disk, linear, acuminate, with green middle portion and a rather broad scarious margin, sometimes reddish, minutely puberulent and somewhat glandular (thinner than in $H$. stenophyllus); ray-flowers (number not known) with ligules about 10 to 20 (?) $\mathrm{mm}$. long and 3 to $4 \mathrm{~mm}$. wide; disk-flowers 20 to 25; disk-corollas narrowly funnelform, 7 to $8 \mathrm{~mm}$. long, puberulent on tube; lobes oblong-lanceolate, acute when dry, about $1.2 \mathrm{~mm}$. long, glabrous; style-branches exserted, about $2 \mathrm{~mm}$. long, the appendage about 
equaling stigmatic portion; achenes (immature) compressed, narrowed toward the base, densely appressed-villous; pappus as long as the corolla or longer, tawny, copious. (Fig. 57.)

Yukon district, northwestern Canada. Type locality, near Dawson. Type, collected in 1S9S, MacLean (UC); foot of Lake Lebarge, June 23, 1S99, Tarleton 51 (US, NY); Ranch Creek, Yukon Valley, Gorman 1002 (Greene, NY).

\section{MINOR VARIATIONS AND SYNONYMS}

1. Stenotopsis macleani Nels., Bot. Gaz. 37:261, 1904-H. macleani.

2. Stenotus borealis Rydb., Bull. N. Y. Bot. Gard. 2:184, 1901.-The type specimens of this (Tarleton 51) have been compared with those of $H$. macleani and found to be almost identical. Dr. Rydberg, on comparing the types, states that borealis would not have been described had he known of the slightly earlier publication by Brandegee.

3. S. macleani Heller, Muhlenb. 1:7, 1900-H. macleani.

\section{RELATIONSHIPS}

This is the far-northern representative of Haplopappus stenophyllus, as is obvious from the similarity in characters. Collections from intermediate stations eventually may demonstrate the presence of connecting forms, in which case a reduction to the subspecific category might be advisable, stenophyllus then consisting of two subspecies paralleling those of the related $H$. acaulis. However, the decided difference in leaf pubescence, smaller corollas, thinner bracts, and especially the geographic hiatus of over $1,500 \mathrm{~km}$., are considerations that make it seem better to retain macleani in specific rank, at least for the present.

\section{ECOLOGY}

Haplopappus macleani grows much farther north than any other species of the genus. In habit it is a mat-former, more compact than its relatives and with shorter leaves and stems. The two collections thus far made were in flower in June. The plants from Ranch Creek (cited under Gorman 1002) grew on dry, rocky slopes and, according to the label, are known to the Indians as Tsuk-ye-jög-hkä.

\section{Section 8. TONESTUS}

The four species of this section are similar in appearance, all being low, leafy, perennial herbs. The group is fairly consistent also in characters of inflorescence, involucre, and flowers, but there is a tendency in two of the species toward more slender and acute style-branches. These are very broad and obtuse in the typical species. According to the best evidence, Haplopappus lyalli appears to be the species from which the others have arisen, each developing in a different direction. As shown in the chart, however, it is possible that development began with $H$. pygmaeus, the line proceeding thence through or close to $H$. lyalli, as will be explained in more detail when the latter species is reached.

34. Haplopappus lyalli Gray, Proc. Acad. Phila. for 1863:64, 1864

A perennial herb, 0.3 to $1.5 \mathrm{dm}$. high, with several erect stems from a subterranean branched caudex, sometimes spreading by deep-seated rhi- 


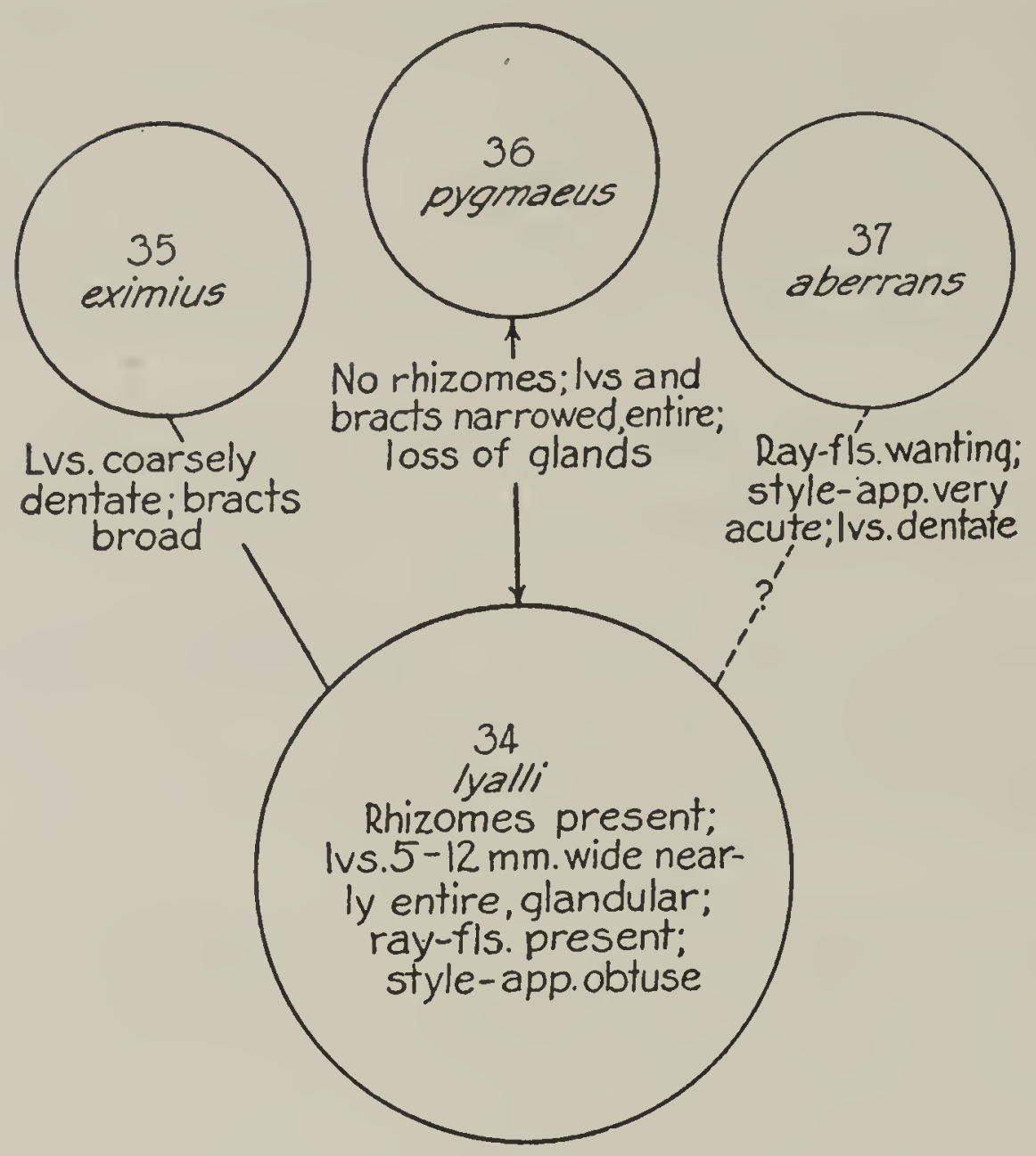

Fig. 58-Phylogenetic chart of the species of Haplopappus section Tonestus

zomes and then forming loose mats; stems greenish, puberulent with short straight spreading hairs, these mostly gland-tipped, often with a few leaves of the preceding season at base; leaves spatulate-oblong, erect, entire, or rarely with a few short teeth at summit, obtuse, mucronate, 2 to $7 \mathrm{~cm}$. long, 5 to $12 \mathrm{~mm}$. wide, 1-nerved from base and with several widely anastomosing additional veins, minutely glandular-puberulent on both faces; heads solitary, terminal, mostly naked at base; involucre broadly campanulate, 9 to $10 \mathrm{~mm}$. high, 8 to $12 \mathrm{~mm}$. broad; bracts not imbricated, nearly equal, slightly shorter than disk, lanceolate or the inner linearlanceolate, acute, green or pinkish, herbaceous to chartaceous, minutely glandular-puberulent, especially the outer ones; ray-flowers 20 to 25 , the ligules 7 to $8 \mathrm{~mm}$. long; disk-flowers 80 to 100 ; disk-corolla narrow-funnelform, 6.5 to $7.5 \mathrm{~mm}$. long, the slender throat longer than tube, glabrous or nearly so; lobes lanceolate, erect, about $1 \mathrm{~mm}$. long, glabrous; stylebranches short-exserted (about $2 \mathrm{~mm}$. long), the thickish obtuse appendage about equaling stigmatic portion; achenes more or less compressed, slightly tapering from summit to base, 3 to $4 \mathrm{~mm}$. long, ribbed, sparsely puberulent; pappus about equaling corolla, soft, whitish, rather scanty. (Fig. 59.)

At high altitudes from Montana and Colorado to Oregon, British Columbia, and Alberta. Type locality, eastern side of the Cascade Mountains at 2,280 meters altitude. Type collection, near the British ColumbiaWashington line, 1860, Lyall (Gr). Montana: McDonald Peak, July 19, 1883, Canby (Gr); Lambert Valley, Mission Mountains, August 17, 1909, Jones (Po). Wyoming: Union Pass, Nelson 1012 (R, UC); Saltlick Mountain, Sublette County, Payson 2962 (UC). Colorado: high mountains, Gray's Peak and vicinity, rare, August 1885, Patterson (UW); Ethel Peak, August 14, 1903, Goodding (R); timber-line west of Chambers Lake, Larimer County, Osterhout 3899 (DS). Nevada: near Lee Postoffice, Elko 
County, Heller 9558 (Gr). Id Aно: Coeur D'Alene Mountains, Leiberg 1952 (Gr); above Meadow Lake, Lemhi Range, Hall 11535 (UC); Smoky Mountains, Macbride and Payson 3782 (Gr). Oregon: summits of the Wallowa Mountains, Cusick 2093 (Gr, UC, Del, P, K) ; Eagle Cap, Imnaha Forest, Sampson and Pearson 195 (US). Washingron: Mount Adams, July 25, 1884, Suksdorf (UC, P, B); Olympic Mountains, Flett 802 (according to Piper); Mount Angeles, Flett 3309 (US); Mount Stuart, Kittitas County, Elmer 1229 (B). British Columbia: Chilliwack Valley, Macoun 26310 (Greene, K) ; Mount Copperstain, Petersen 376 (Del, in part); mountains at Kicking Horse Lake, August 18, 1890, Macoun (Gr, US, P) ; Mount MacDonald, Rogers Pass, Butters 800 (Gr). Alberta : Lake Louise, Brown 725 (Phila); near Banff, 1891, Macoun (Gr, K).

\section{MINOR VARIATIONS AND SYNONYMS}

1. Aster jamesi O. Kuntze, Rev. 1:316, 1891- H. lyalli.

2. Haplopappus lyalli forma $\lambda$ (lyalli) Gray, Proc. Acad. Phila. for 1863:64, 1864. This is the type form and the description is merely a supplement to the original one for purposes of comparison with the next following. Gray's statement in full is as follows: "Involucri squamis omnibus lanceolatis sensim acuminatis, exterioribus paullo brevioribus; foliis parvulis, caulinis superioribus gradatim minoribus (6-3 lin. longis) acutioribus." A little further on Gray states that the ovaries in Lyall's plants are glabrous. But at least some of the achenes, taken from the type specimens at the Gray Herbarium, are lightly puberulent near the summit.

3. H. lyalli $\beta$ halli Gray, l. c. 65 . Based upon a plant collected by Hall and Harbour in Colorado in 1862. The description in full is as follows: "Involucri squamis plerisque latioribus, extimis oblongo-linearibus discum adaequantibus; foliis etiam caulinis magis spathulatis, summis pollicaribus capitulum adaequantibus, radicalibus bipollicaribus." To this, Gray adds that the ovaries are sparsely beset with a few slender hairs. This form with broader bracts and larger leaves, the uppermost of which subtend the heads, grades insensibly into typical lyalli, as shown by more recent collections. Gray doubtless understood this when writing the account for the Synoptical Flora, for in this work he makes no mention of these earlier-described forms.

4. Hoorebekia lyalli Piper, Contr. U. S. Nat. Herb. 11:560, 1906. A transfer of Haplopappus lyalli. The untenability of Hoorebekia as a genus is discussed on page 24.

5. Pyrrocoma lyalli Rydb., Mem. N. Y. Bot. Gard. 1:382, 1900-Haplopappus lyalli.

6. Stenotus lyalli Howell, Fl. N. W. Am. 300, 1900-H. lyalli.

7. Tonestus lyalli Nels., Bot. Gaz. $37: 262,1904-H$. lyalli.

\section{RELATIONSHIPS}

The origin of Haplopappus lyalli apparently is to be sought outside of the section Tonestus, of which it seems to be the most primitive member. In many respects it resembles species of the section Macronema, especially H. suffruticosus. The dwarf and essentially herbaceous habit is perhaps a reduction from the shrubby type, such as that of Macronema, in response to an alpine habitat. The reduced inflorescence, likewise, may have been developed in this connection, but the short style-branches indicate a lower origin than Macronema, and the involucre is more like that of a Stenotus. Moreover, there are present certain features resembling those of Oreochrysum (H. parryi), so it is better for the present to accept this species as the beginning of an independent line which arose before these sections were fully differentiated. 
All of the species of Tonestus are of limited distribution and none of them are anywhere abundant; but the present one is the most widely distributed and the least rare. Furthermore, it occupies a central geographic position,

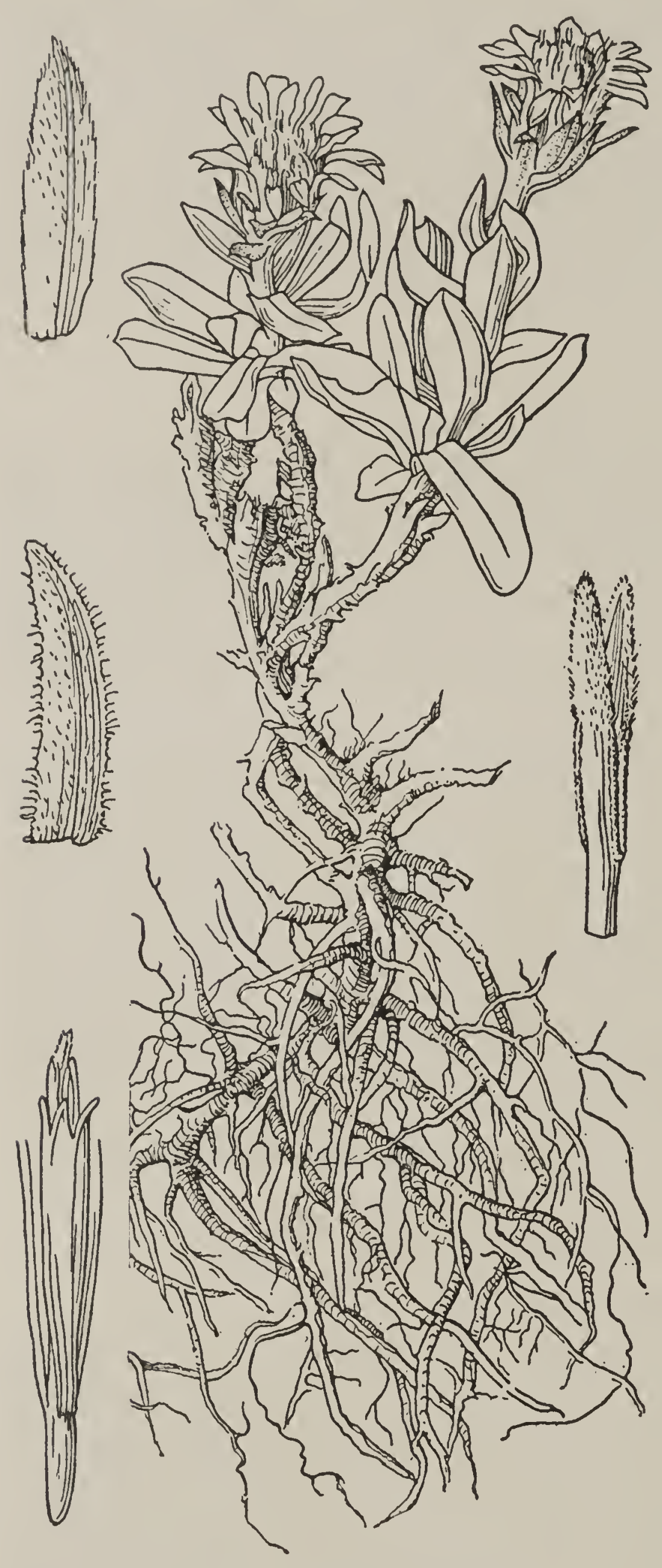

FIG. 59-Haplopappus lyalli

all of which features suggest it as the species from which the others of its section have sprung. The morphologic characters support this hypothesis, except that the almost universal absence of rootstocks in Haplopappus pygmaeus indicates that this species may be equally primitive. It seems that the rootstock habit has been developed in connection with the intermittent covering of the stems by soil, as will be more fully explained under H. eximius, and is therefore a sign of advance. But, on the other hand, pygmaeus exhibits a specialized involucre and narrowed leaves, while the absence of a glandular pubescence is looked upon as the loss of a character. It is therefore impossible to say whether lyalli is the more primitive, the other arising through the loss of the rhizome habit and the development of certain features of its own, or whether the separation took place before the present types were established.

Aside from Haplopappus aberrans, the sectional position of which is in doubt, the only additional member of Tonestus is H. eximius. This is plainly a derivative of $l y$ alli, from which, however, it is well isolated both morpho-

logically and geographically. The most striking feature of eximius is the salient dentation of the leaves. But even this development is foreshadowed in a few specimens of lyalli in which a few of the leaves exhibit one or two teeth, and these of exactly the same peculiar shape as those found in eximius (Saltlick Mountain, Wyoming, Payson 2962, UC). 
In addition to the slight variation just mentioned and others plainly accounted for by differences in the habitat, $H$. lyalli is a remarkably constant species. It seems that after having given rise to two or three specific branches, as discussed above, it became wholly stable and is not now in a variable condition.

\section{ECOLOGY}

This is a constituent of the alpine sedgeland climax from the northern Rocky Mountains to the Olympics of western Washington. It commonly grows in fell-fields, where it is more or less protected by large rocks and where the soil is fairly moist. This perhaps accounts for the fact that the leaves are broader and thinner and the stems taller than in the related H. pygmaeus. Its most frequent associates are several species of Carex, Oxyria digyna, Sibbaldia procumbens, and Antennaria alpina. The rootstocks are probably formed somewhat after the manner described for $H$. eximius, but they are more slender and the plants seldom make such large or dense mats as are found in that species. The plants are in bloom from the middle of July to September and perhaps later.

35. Haplopappus eximius Hall, Univ. Calif. Pub. Bot. 6:170, 1915

A perennial herb, 0.3 to $1.5 \mathrm{dm}$. high, with numerous erect or ascending stems crowded on the summit of a slightly woody underground caudex and also from deepseated rhizomes, inclined to form loose mats of considerable extent; stems green, glandularpuberulent, clothed at base with remains of the previous year's foliage; leaves narrowly to broadly spatulate, erect, saliently dentate above middle, obtuse, mucronate, 2 to $5 \mathrm{~cm}$. long (including the petiole-like base), 3 to $15 \mathrm{~mm}$. or rarely up to $20 \mathrm{~mm}$. wide, with 1 strong and 2 fainter nerves from base, these branching in the blade to form large areoles, both faces with short gland-tipped hairs; heads solitary, terminal, usually subtended by 1 or 2 reduced leaves; involucre hemispheric, 8 to 10 or rarely $15 \mathrm{~mm}$. high, 8 to $16 \mathrm{~mm}$. broad; bracts not imbricated, all much shorter than disk, very unlike, the outer broadly oblong or nearly obovate to oblanceolate, obtuse, mucronate, green and glan-

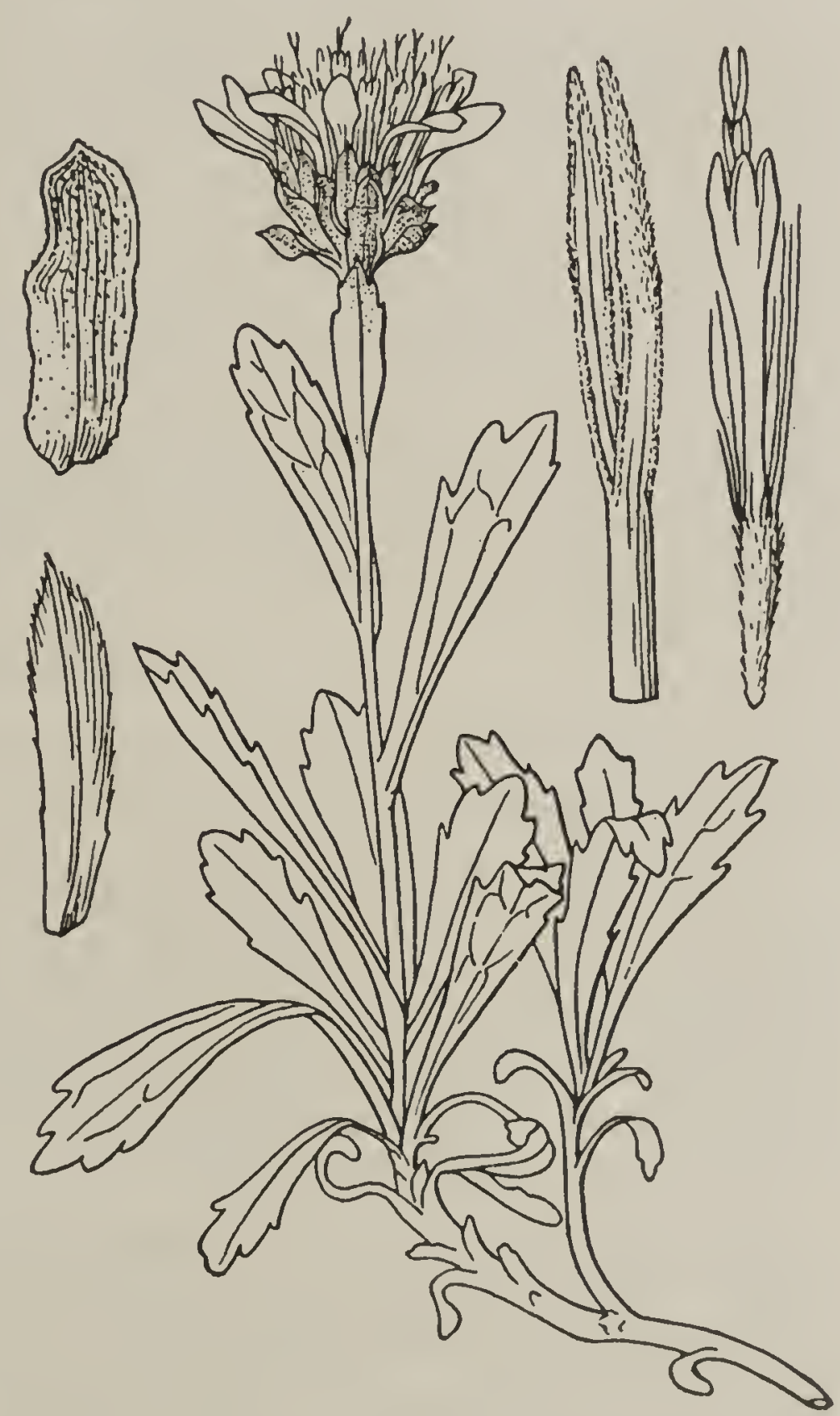

FIG. 60-Haplopappus eximius 
dular-puberulent, the inner lanceolate, attenuate, minutely fimbriate on margin or smooth, scarious, reddish or pale, mostly glabrous; ray-flowers 15 to 20 , the ligules about $8 \mathrm{~mm}$. long; disk-flowers 40 to 80 ; disk-corolla very slenderly funnelform, 6 to 7 or $9 \mathrm{~mm}$. long, the throat longer than tube, glabrous; lobes narrow, erect, about $1 \mathrm{~mm}$. long, glabrous; stylebranches short-exserted (about $2 \mathrm{~mm}$. long), the thickish obtuse appendage about equaling stigmatic portion; achenes subcylindric, slightly compressed, about $4 \mathrm{~mm}$. long, faintly ribbed, densely pubescent; pappus equaling corolla, soft, sordid, rather scanty. (Fig. 60.)

Known only from high peaks in eastern middle California and western Nevada, especially in the vicinity of Lake Tahoe. Type locality, an unnamed peak $1 \mathrm{~km}$. south-southwest of Angora Peak, El Dorado County, California, at 2,680 meters altitude. California: type collection, July, 1910, Geo. R. Hall (Gr, UC, US); Ralston Peak, July 30, 1910, Gen. R. Hall (UC); same locality, June-July 1912, Geis (UC); north side of Ralston Peak, Smiley 417 (Gr); Star Lake, July 24, 1918, Evans (UC); North Fork Bishop Creek, at 3,050 meters altitude, Peirson 2517 (UC); Tabosse Pass, Inyo County, 3,280 meters altitude, August 18, 1921, Peirson (UC); Sawmill Pass, Inyo County, Peirson 1404 (UC). Nevada: Broncho Creek, Washoe County, Kennedy 1363 (R).

\section{MINOR VARIATIONS AND SYNONYMS}

The only synonym of the name here used is Tonestus eximius Nels. and Macbr. (Bot. Gaz. 65:70, 1918). No variations have been described, but two forms divergent from the type are worthy of note. One of these is represented by the Star Lake collection of the foregoing enumeration. In this the leaves are narrowly oblanceolate, 2.3 to $3 \mathrm{~cm}$. long by only 3 to $6 \mathrm{~mm}$. wide, and the teeth are correspondingly slender and lobe-like. The leafy and flowering stems are compacted into close rounded cushions, but there is also evidence of rootstocks that arise from well below the soil-line. The other variation comes from far to the south, and is represented by all of the Peirson collections just cited. This is a large, coarse form, more notably glandular-pubescent and with broad leaves and large heads. The involucres are $15 \mathrm{~mm}$. high, whereas those of the other collections are all under $11 \mathrm{~mm}$., and the outer oblanceolate bracts are wanting. The flowers, too, are larger than usual, the disk-corollas measuring $9 \mathrm{~mm}$. long. It is probable that intermediates will be found when intervening districts are more fully explored.

\section{RELATIONSHIPS}

The relationships of Haplopappus eximius were discussed in connection with the original description as follows:

"The affinities of this species are undoubtedly with $H$. pygmaeus (Torr. et Gray) Gray and H. lyalli Gray, from both of which it differs in its deeply toothed leaves, more foliaceous involucral bracts, and other characters. In habit and pubescence it closely simulates Macronema aberrans Nels., but differs in the outer foliaceous bracts of the involucre (not to be confused with the uppermost leaves of $M$. aberrans), in the radiate heads, and in the broader style-branches."

The probable origin has been further discussed under Haplopappus lyalli. The type specimens were described as having the inner bracts of the involucre minutely fimbriate. In some later collections these fimbriae are very inconspicuous or quite wanting, but their occasional development suggests some of the forms of $H$. lanuginosus, one of which has been described as $H$. lacerus. 


\section{ECOLOGY}

This plant is a dwarf, mesophytic chasmophyte. As far as known, it is restricted to small openings between summit rocks near the upper limit of tree-growth. Here it occurs in rather moist but well-drained soil of decomposed granite mixed with scant remains of decaying vegetation. As the plants become buried in the accumulating soil, the underground stems continue to elongate. Thus there is built up an extensive network of subterranean stems, or rhizomes, each of which, on reaching the surface, produces first a tuft of leaves and then a dense cluster of erect or ascending leafy and flowering shoots. This extensive underground system, from which the roots diverge, enables the plant to draw upon the soil moisture at considerable depths, while at the same time the loose gravel and vegetable matter on the surface act as a mulch which effectively checks surface evaporation. The spreading of the underground parts provides also for the extension of the mats. These sometimes work their way between blocks of rubble until the plant is several decimeters across and an extent of a meter would not be surprising.

Associates of Haplopappus eximius include such characteristic herbaceous perennials as Trisetum spicatum, Juncus parryi, Heuchera rubescens, Oxyria digyna, Erigeron compositus, and Aquilegia truncata. The shrubby Haplopappus suffruticosus often grows near and the neighboring forests are of Pinus albicaulis and Tsuga mertensiana. The altitudinal limits, as far as known, are 2,650 to 2,800 meters in the Tahoe district and to 3,280 meters in Inyo County, opposite the warm Owens Valley. The plants blossom from the middle of July to the last of August and probably later. The herbage is strongly scented.

\section{Haplopappus pygmaeus (Torr. et Gray) Gray, Am. Jour. Sci. II,} $33: 239,1862$

A perennial herb, 0.2 to $0.6 \mathrm{dm}$. high, with many erect stems from a taproot and an underground crown, forming a dense leafy tuft or cushion broader than high; stems greenish, crisp-puberulent or sometimes subtomentose, not viscid or glandular, clothed at base with remnants of old leaves; leaves linear-spatulate to spatulate-oblong, erect, entire, obtuse, 2 to $5 \mathrm{~cm}$. long, or shorter in depauperate forms, 1.5 to $5 \mathrm{~mm}$. wide, 3 -nerved from base, soft-pubescent on margins and often with a sparse puberulence on the faces; heads solitary, terminal, leafy-bracted; involucre broadly campanulate to hemispheric, 9 or $10 \mathrm{~mm}$. high, 8 to $14 \mathrm{~mm}$. broad; bracts not imbricated, the outer ones about equaling disk, broadly oblong, obtuse, green, herbaceous, crisp-puberulent at least on margins, the other's usually a little shorter, linear-oblong, acute, chartaceous, the exposed tips reddish or greenish; ray-flowers about 15 to 30 or more, the ligules 6 to $8 \mathrm{~mm}$. long; disk-flowers numerous (more than 50); disk-corolla funnelform, 6 to $7 \mathrm{~mm}$. long, the ampliate throat longer than tube, nearly glabrous; lobes linearlanceolate, erect, about $1 \mathrm{~mm}$. long, glabrous; style-branches short-exserted ( $2 \mathrm{~mm}$. long), the thickish obtuse appendage moderately exceeding stigmatic portion; achenes subcylindric but compressed, 3 to $4 \mathrm{~mm}$. long, strongly ribbed, sparsely villous; pappus from nearly equaling to slightly exceeding corolla, soft, whitish, rather scanty. (Stenotus pygmaeus Torr. et Gray, Fl. N. Am. $2: 237,1842$.) (Fig. 61.) 

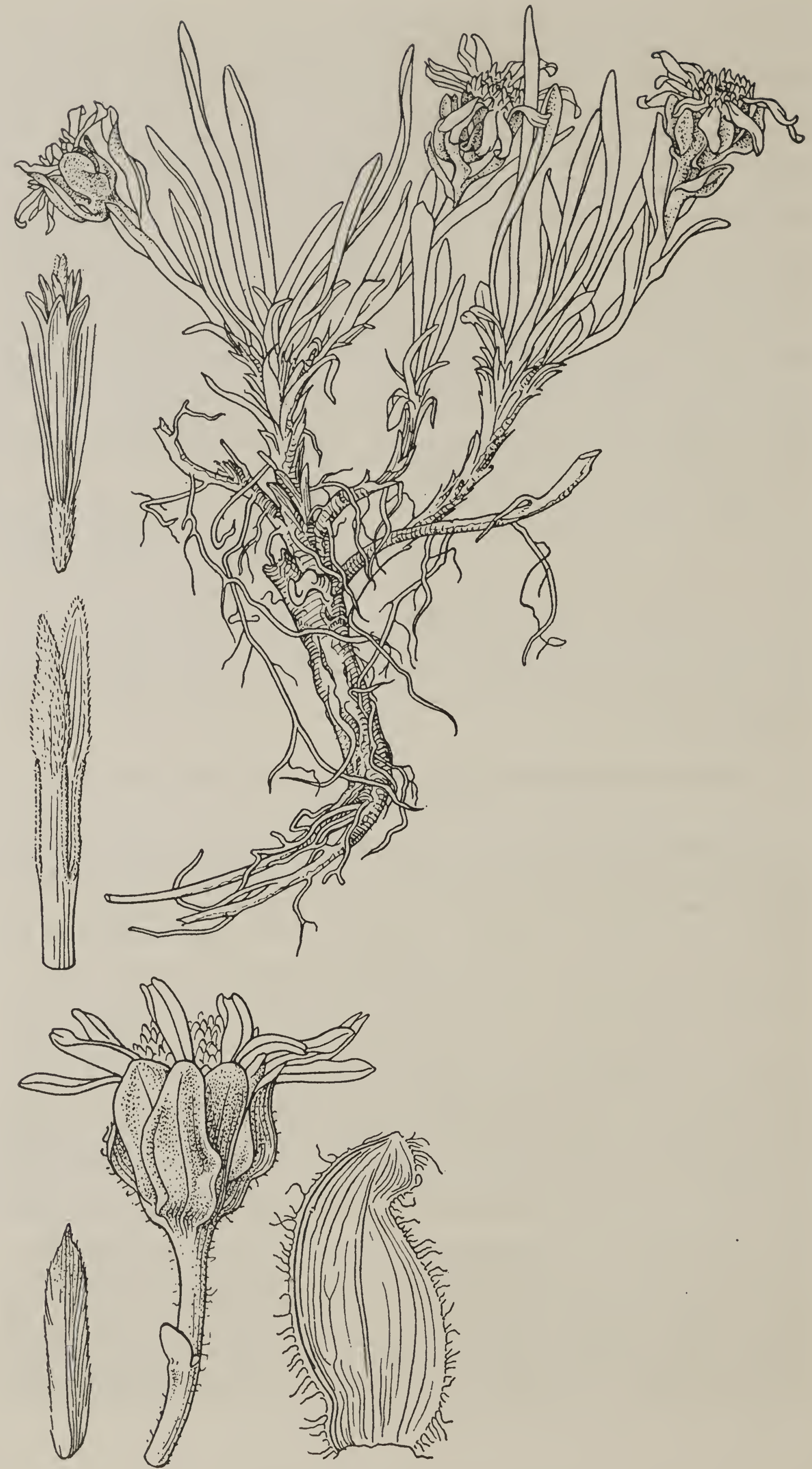

FIG. 61-Haplopappus pyomaeus 
High peaks in the Rocky Mountains from Wyoming to northern New Mexico. Type locality, Rocky Mountains, probably in about latitude $41^{\circ}$. Wroming: La Plata Mines, Nelson 1875 (Gr); Medicine Bow Mountains, Nelson 7856 (Po). Colorado: Rawlin's Pass, Boulder County, Hall 10460 (UC); Long's Peak, Cooper 213 (R); Pike's Peak, in the alpine, August 27, 1895, Canby (UC); Bald Mountain, near Pike's Peak, Johnston 2702 (UC); Gray's Peak and vicinity, Patterson 44 (Gr, UC, B, Del, K); Mount Massive, Eggleston 11892 (US); Sierra Sangre de Cristo, August 1873, Brandegee (UC); near Pagosa Peak, Baker 724 (R, Gr, B, Del, K, Po); Blackface Mountain, near Trout Lake, San Miguel County, Payson 4193 (R). New Mexico: Baldy Peak, Colfax County, about 3,600 meters altitude, Standley 14939 (US); Raton Ranch, in northeastern part of the State, Berg 3233 (NY).

\section{MINOR VARIATIONS AND SYNONYMS}

No varieties or other subdivisions of the species have been proposed, and, in fact, it is so remarkably constant in its characters that there is no temptation to make taxonomic segregates. The following appear in the synonymy, however, all based upon Stenotus pygmaeus, the name under which the species was first published.

1. Aster stenotus O. Kuntze, Rev. 317, 1891.

2. Macronema pygmaeum Greene, Erythea 2:73, 1894.

3. Stenotus pygmaeus Torr. et Gray, Fl. N. Am. 2:237, 1842.

4. Tonestus pygmaeus Nels., Bot. Gaz. $37: 262,1904$.

\section{RELATIONSHIPS}

The probable origin of this species has been discussed under Haplopappus lyalli. The features by which it is most easily distinguished are the narrow leaves, together with the exceptionally broad and foliaceous outer bracts of the involucre. It differs from all other species of its section also in the crisp and non-glandular nature of the pubescence.

\section{ECOLOGY}

Haplopappus pygmaeus is a dwarf perennial of the alpine meadows in the Rocky Mountains, where it is associated in the sedgeland climax with such species as Salix reticulata, Polygonum viviparum, Silene acaulis, Trifolium nanum, Dryas octopetala, Sieversia turbinata, Antennaria alpina, Erigeron uniflorus, Artemisia pattersoni, and Solidago humilis nana. The root is thick, long, and perennial, while the above-ground parts are very compact, the heads scarcely arising above the tufts of narrow and thick basal leaves. These characters are doubtless the result of the short growingseason and of the low temperatures, the latter acting both to retard growth and to reduce the available supply of moisture. The flowering period begins about the middle of July.

\section{Haplopappus aberrans (Nels.)}

A perennial herb, woody only at very base, 0.5 to $1 \mathrm{dm}$. high, with slender erect stems from a branched crown; twigs herbaceous, grooved or angular, glandular-scabrid; leaves obovate to oblanceolate, ascending, remotely but prominently cuspidate-toothed or the upper entire, obtuse or subacute, all but the uppermost tapering to a petiole-like base, the blades 1 to $3 \mathrm{~cm}$. long, 8 to $12 \mathrm{~mm}$. wide, 1-nerved (the nerve branching), sparsely glandular- 
scabrid, green; heads solitary and terminating leafy twigs or few and leafy-racemose; involucre campanulate, 7 or $8 \mathrm{~mm}$. high, nearly as broad (in the scanty matcrial available); bracts imbricated, of 3 or 4 lengths,

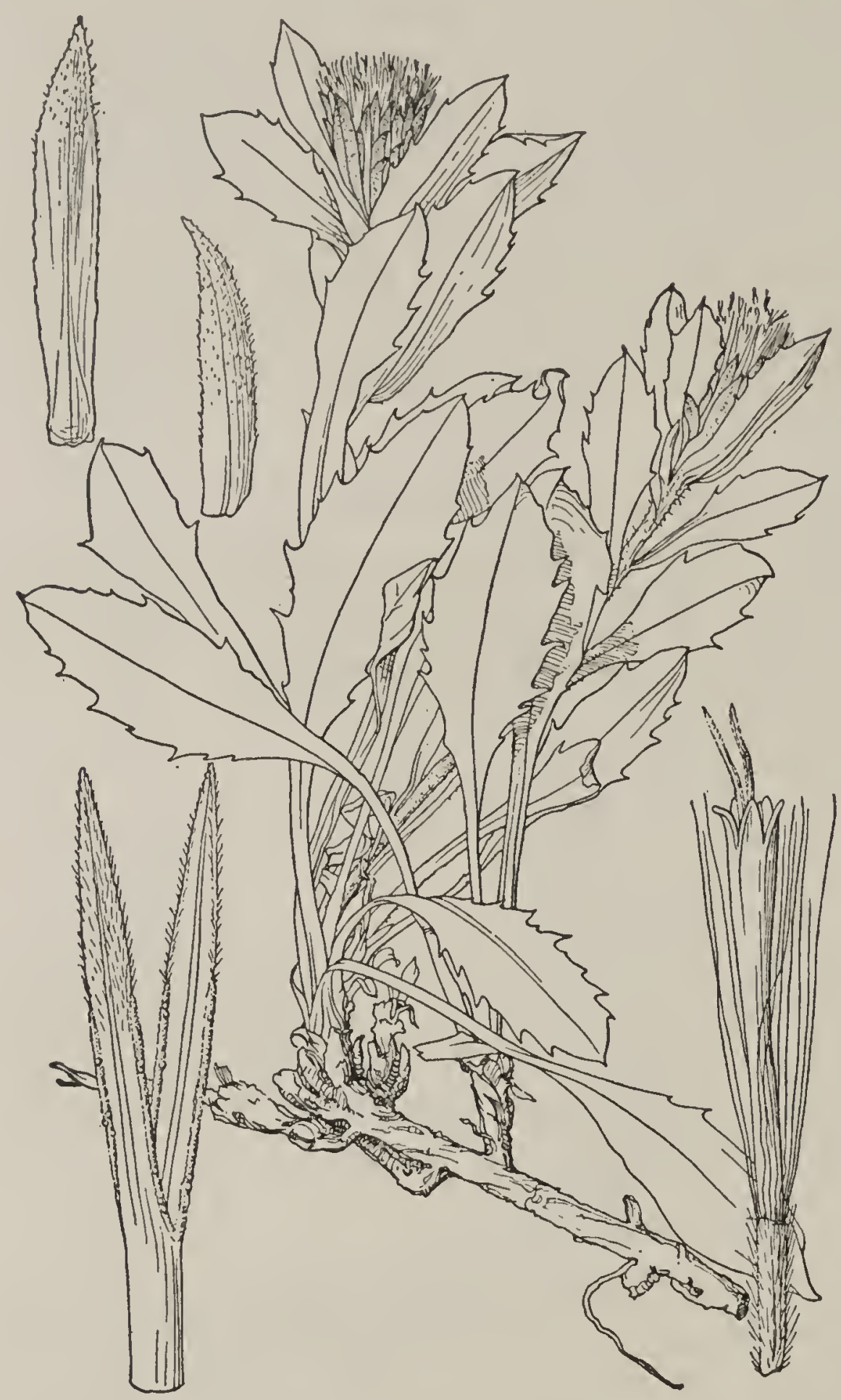

FIg. 62-Haplopappus aberrans outer very short, lanceolate, acute, the others broadly linear and acute or cuspidate, all green and minutely granular on exposed parts (heads closely subtended by broad green upper leaves); ray-flowers wanting; diskflowers about 30 to 40 ; disk-corolla slenderly cylindric, 6.5 to $7 \mathrm{~mm}$. long, throat longer than tube but scarcely wider, tube and throat glabrous; lobes lanceolate, erect, about $0.8 \mathrm{~mm}$. long, minutely and sparsely puberulent; style-branches 2 to $3 \mathrm{~mm}$. long, moderately exserted, the very acute appendage about equaling stigmatic portion; achenes cylindricfusiform, about10-ribbed, sparsely villous; pappus about equaling corolla, soft, sordid, ratherscanty. (Macronema aberrans Nels., Bot. Gaz. $53: 226$, 1912. (Fig. 62.)

Known only from southwestern Idaho. Type locality, Trinity Lake region, Elmore County, Idaho. Type collection, August 27, 1910, MacBride 641 (R, US, Gr, Del). SYNONYMS

1. Macronema aberrans Nels., l. c.

2. Sideranthus aberrans Rydb., Fl. Rocky Mts. 860, 1917.

\section{RELATIONSHIPS}

On the basis of habit and foliage this species belongs in the section Tonestus, but in style-branches it more closely approaches the species of Macronema, to which it was referred by Nelson. This assignment to Macronema unfortunately destroys the homogeneity of a section otherwise quite satisfactorily distinguished from its allies by both habital and floral characters. It seems wise, therefore, to make some other disposal if possible. With the recent discovery that the elongated style-appendages formerly figured (Hall, Univ. Calif. Pub. Bot. $6: 172,1915$ ) are unusual, it now ap- 
pears possible to include it in the present section. Although these appendages are too acute for a T'onestus, they usually are only about equal in length to the stigmatic portion and are much less slender than in Macronema. The species of undoubted Tonestus nearest to aberrans is eximius. This has rather narrow style-appendages, but these are by no means so acute as those of Haplopappus aberrans, which differs also in outline and dentation of leaf, in the very acute bracts of the involucre, in the absence of rays, and in other features.

Thus Haplopappus aberrans is seen to be one of those connecting links so detrimental to the exact pigeon-holing of species but often of high value in determining lines of evolution. Before much use can be made of it in this connection, however, it will be necessary to have much fuller information based upon field and experimental studies.

\section{ECOLOGY}

The roots of this species are slender and creep along crevices in rocks, according to Nelson, but whether or not this indicates the presence of rootstocks is not known. The single collection came from southwestern Idaho, at an altitude of 2,440 meters. This would place the habitat as near and probably above timber-line.

\section{SECTION 9. MACRONEMA}

\section{PHYLOGENY OF THE SPECIES}

Haplopappus suffruticosus is selected as the most primitive member of this section, principally because of its wide geographic distribution and large, many-flowered heads. In the other species there is noted a reduction in number of flowers, and with this has come a narrowing of the involucre and a more definite arrangement of the bracts. It seems that the greenei-bloomeri group may have arisen through some such process. The line from suffruticosus to the others is too nearly continuous for really satisfactory species, and this notwithstanding the fact that some authorities go so far as to assign bloomeri to a distinct genus! This failure to recognize the close connection is due to examination of an insufficient number of specimens and to absence of field studies. Some of the intermediate stages are indicated in the citation of specimens and in tables 7 and 8 . The most remarkable feature of H. macronema is the development of a close tomentum, the significance of which will be discussed further on.

38. Haplopappus suffruticosus (Nutt.) Gray, Proc. Am. Acad. 6:542, 1865

A subshrub, 1.5 to $4 \mathrm{dm}$. high, with many branches that spread to form low bushes commonly broader than high; bark at first green, soon changing to brown, smooth, exfoliating in small sheets from the oldest parts; twigs brittle, glandular-puberulent, especially near heads; leaves narrowly linear to oblanceolate or spatulate-oblong, ascending, entire or with crisp or undulate margins, shortly acute, 1.5 to $3 \mathrm{~cm}$. long, 2 to $5 \mathrm{~mm}$. wide (narrower in subsp. tenuis) 1 -nerved, firm but not rigid, scabrid with minute gland-tipped hairs or the glands sessile and the surface then smoothish; heads solitary, or few in close terminal leafy racemes; involucre 
broadly campanulate, 9 to $13 \mathrm{~mm}$. high, 10 to $15 \mathrm{~mm}$. broad; bracts not imbricated; outer bracts as long as or longer than inner, spatulate-oblong or linear, green and herbaceous throughout, glandular; inner bracts lanceolate, acuminate, green on upper portion, herbaceous or rarely reddish,

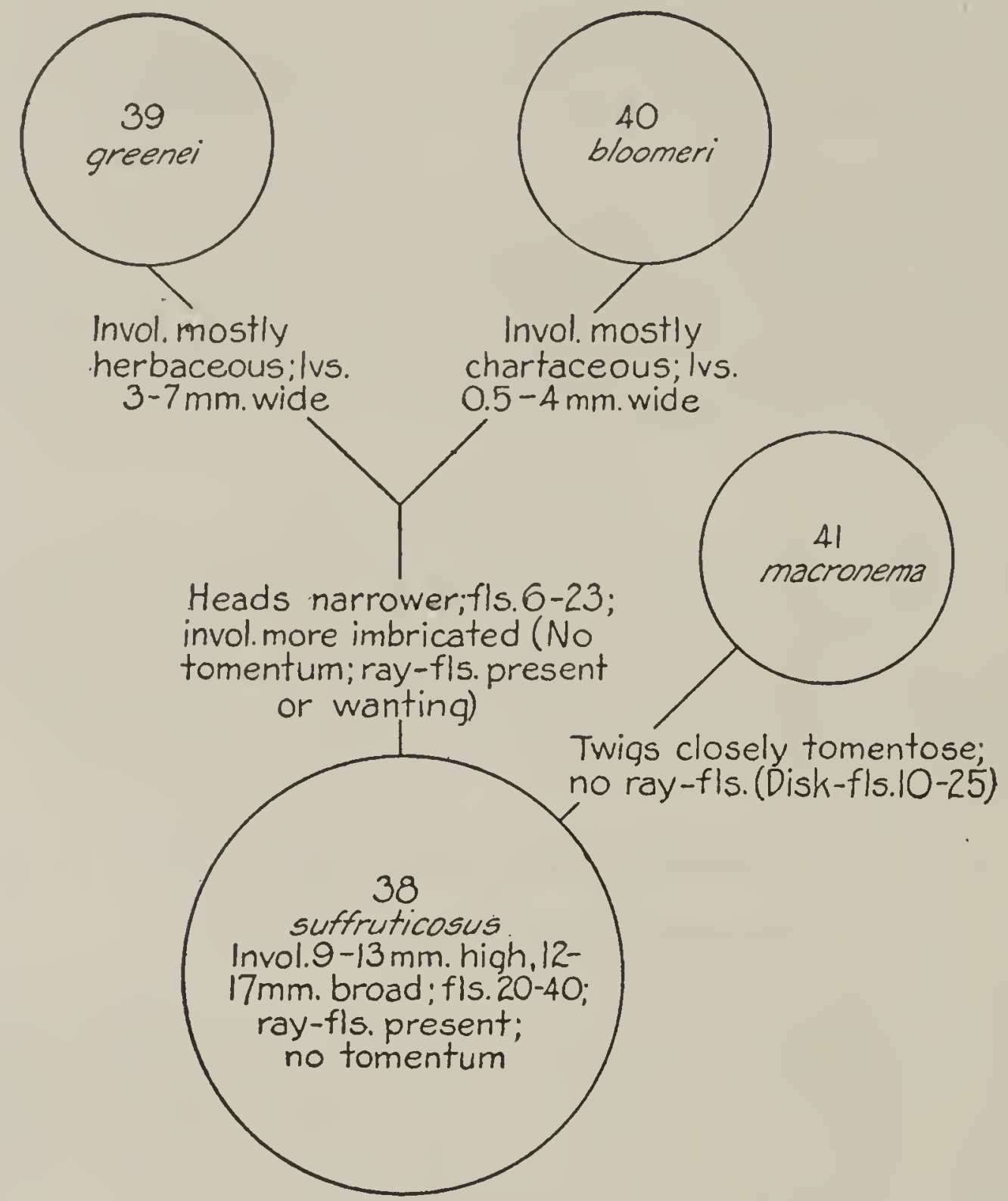

FIG. 63-Phylogenetic chart of the species of Haplopappus section Macronema

the exposed parts glandular; ray-flowers usually present but ligules not always conspicuous, the corolla being sometimes only enlarged or slightly irregular at summit, the ligules when developed 1 to 6 in number, 8 to $12 \mathrm{~mm}$. long; disk-flowers 20 to 40; disk-corolla tubular-funnelform, passing gradually from the tube to a throat of greater length, 8.5 to $10.5 \mathrm{~mm}$. long, glabrous or puberulent on tube; lobes 1.2 to $1.8 \mathrm{~mm}$. long, ovate, erect, glabrous; style-branches long-exserted, the attenuate appendage longer than stigmatic portion; achenes slenderly prismatic, about $6 \mathrm{~mm}$. long, silky-villous; disk-pappus slightly shorter than corolla, fine and soft, white. (Macronema suffruticosum Nuttall, Trans. Am. Phil. Soc. II, $7: 322,1840$.) (Fig. 64.)

In the mountains from Montana and western Wyoming to Arizona (according to Rydberg), the Sierra Nevada of California, eastern Oregon, and Idaho.

\section{SUBSPECIES}

Key to the Subspecies of Haplopappus suffruticosus

Leaves oblong or oblanceolate, 2 to $5 \mathrm{~mm}$. wide; heads large, the involucre

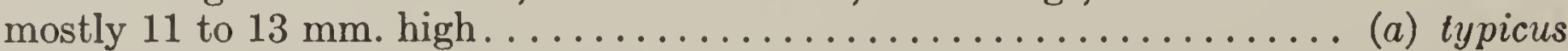

Leaves filiform-linear, 0.5 to $3 \mathrm{~mm}$. wide; heads smaller, the involucre 8 to

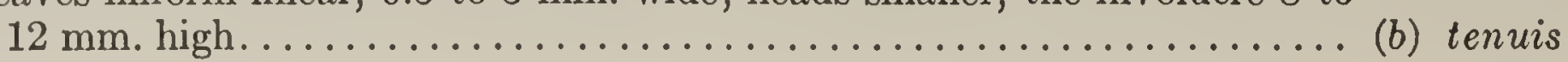



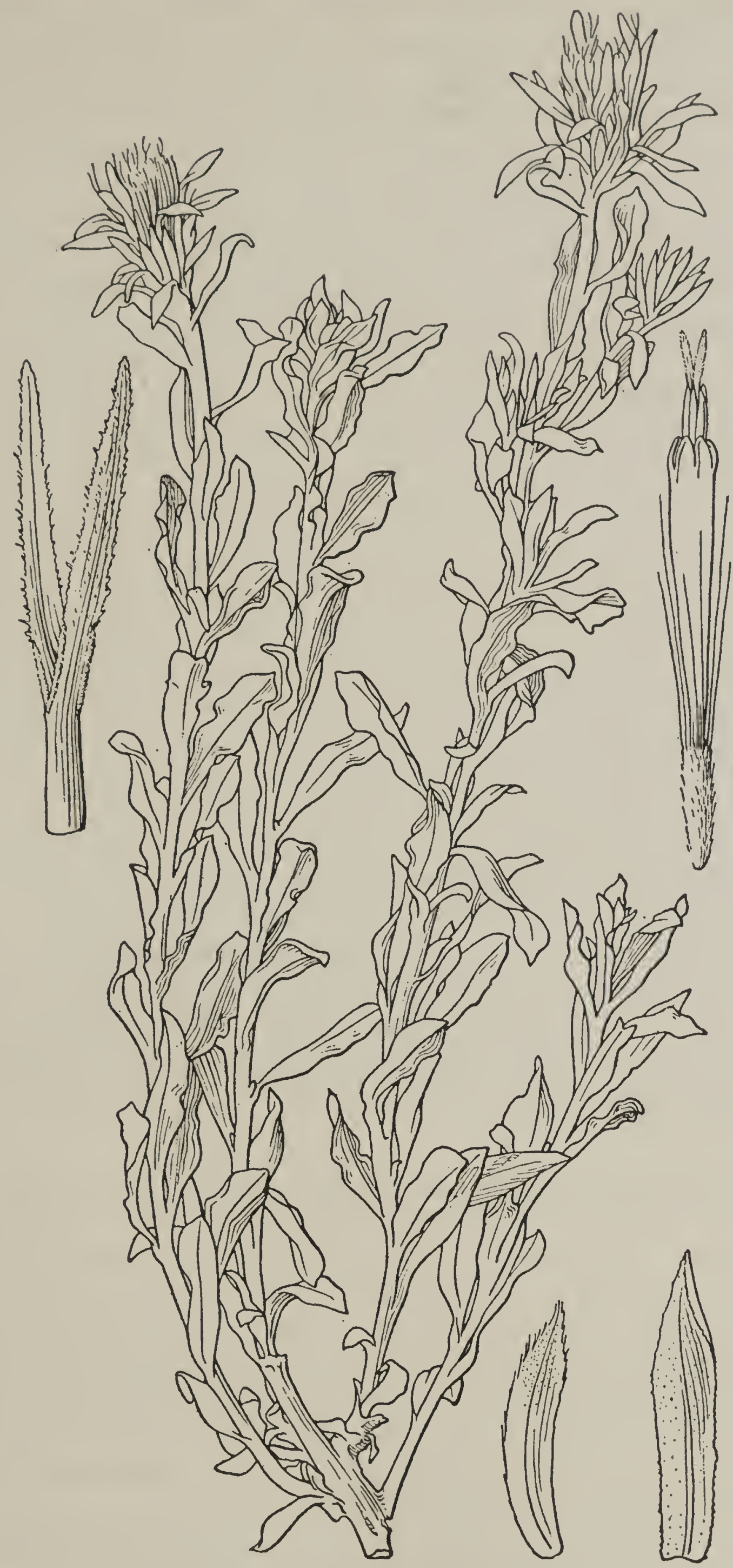

FIG. 64-Haplopappus suffruticosus typicus 
38a. Haplopappus suffruticosus typicus-A compact or spreading subshrub; leaves oblanceolate or somewhat spatulate, 1.5 to $3 \mathrm{~cm}$. long, 2 to 5 (rarely to 8 ) $\mathrm{mm}$. wide; involucre campanulate with a broad base, 11 to $13 \mathrm{~mm}$. high; outer bracts spatulate oblong or linear, acute, herbaceous, glandular; inner bracts lanceolate, acute, rarely acuminate, mostly pale but tips sometimes tinged with red, more or less pubescent; disk-corolla 9 to $10.5 \mathrm{~mm}$. long; style-branches (and other characters) as given in specific description. (Macronema suffruticosum Nutt., l. c.) (Fig. 64.)

Range of the species. Type locality, banks of the Malade, a tributary of the Columbia River, near the Blue Mountains. Type collection, "streams of Columbia, on gravel," Nuttall (Phila). Montana: Bridger Mountains, August 29, 1902, W. W. Jones (UC); Lone Mountain, near Bozeman, Blankinship 557 (Phila). Wroming: Electric Peak, Yellowstone National Park, at 2,400 meters altitude, Rydberg and Bessey 5045 (NY, form-Macronema grindelifolium Rydb., minor variation 2); Taylor Peak, Teton Range, at 2,600 meters, Hall 11453 (UC, same variation); Red Mountain east of Smoot, Payson and Armstrong 363 (UC, same variation); Gros Ventre Mountains, Payson 3052 (UC, Po). Nevada: Fremont's Pass, northern Nevada, Watson 57\% (Gr); Bunker Hill, Toiyabe Range, Kennedy 4008 (UC); near Ely, Hitchcock 1415 (US); Mount Rose, Washoe County, Kennedy 1143 (UC, a form intermediate to subsp. tenuis); Lamoille Cañon, Elko County, Heller 9397 (US). California: White Mountains, Mono County, Shockley 593 (B); near Farewell Gap, southern Sierra Nevada, Hopping 142 (UC); Pyramid Peak, Brewer 2141 (UC, US, K); ridge south of Donner Pass, Heller 7182 (UC, US, R, Del, B, type collection of Macronema imbricatum, minor variation 4). OREGON: Union County, Cusick 837 (Gr). IDAHo: Mount Chauvet, Rydberg and Bessey 5046 (Gr, Del, B, a form named Macronema grindelifolium, minor variation 2); Bear Cañon, near Mackay, Custer County, Nelson and Macbride 1451 (UC, Gr, R, DS, Del); Lemhi Range, eastern Idaho, at 2,600 to 2,900 meters. Hall 11512, 11521, 11545 (UC); Caribou Mountain, Bingham County, Payson and Armstrong 3574 (UC, minor variation 2, Macronema grindelifolium).

38b. Haplopappus suffruticosus tenuis subsp. nov.-A low, compact bushy shrub; leaves crowded, filiform-linear, 1.5 to $2 \mathrm{~cm}$. long, 0.5 to $1.0 \mathrm{~mm}$. wide, glandular-scabrid; heads solitary, terminating the short leafy branches; involucre subcampanulate but with a broadly obconic base, 9 to $10 \mathrm{~mm}$. high, 10 to $12 \mathrm{~mm}$. broad; outer bracts equaling the inner, linear, acuminate, herbaceous, glandular; inner bracts linear-lanceolate, attenuate, chartaceous, pale or reddish, nearly glabrous; ray-flowers wanting or several, the ligules 8 to $10 \mathrm{~mm}$. long; disk-flowers about 25; diskcorolla about $8.5 \mathrm{~mm}$. long; style-branches with long-exserted and attenuate appendage longer than the stigmatic portion.

Dry, rocky hillside near Big Creek, in the Black Mountain district of Fresno County, California, at 3,050 meters altitude, July 1900, Hall and Chandler 586 (UC, type). The foregoing description was drawn entirely from the type sheet, but the inclusion of three other collections now to be cited necessitates the following modifications: Leaves up to $2.5 \mathrm{~cm}$. long by $3 \mathrm{~mm}$. wide; involucre 8 to $12 \mathrm{~mm}$. high; disk-flowers perhaps 
20 to 30 , their corollas 8.5 to $10 \mathrm{~mm}$. long. California: Mount Guyot, eastern Tulare County, at 3,650 meter's altitude, Hall 8425 (UC); borders of meadows near Black Mountain, Fresno County, at 3,050 meters altitude, Hall and Chandler 617 (UC); Mount Hoffmann, Yosemite National Park, at about 3,000 meters altitude, Hall 11 7\%1 (UC).

\section{MINOR VARIATIONS AND SYNONYMS}

1. Aster suffruticosus O. Kuntze, Rev. 318, 1891-H. suffruticosus typicus.

2. Macronema grindelifolium Rydb., Mem. N. Y. Bot. Gard. 1:384, 1900. This is a common variation in which the leaves are shorter and proportionally broader than in typicus. The leaves are 1 to $2 \mathrm{~cm}$. long, as described by Rydberg, who gives as additional characters the more showy rays, these with ligules often $1 \mathrm{~cm}$. long, and a shorter pubescence than in suffruticosus. The two forms have the same general distribution, the shortleaved one being as common in the Sierra Nevada as in the Rocky Mountain region, from whence came the types of grindelifolium. This wide distribution of both forms and their frequent approach both geographically and morphologically indicate that they probably represent a response to different ecologic conditions, the short-leaved one perhaps occurring at higher altitudes. Size of the ligules and length of pubescence do not vary in unison with each other or with size and shape of leaf. For example, plants collected by Macbride (No. 681 UC) in the Trinity Lake Region of Idaho exhibit the extreme form as to size of ligules, which are 1.0 to $1.3 \mathrm{~cm}$. long, and the pubescence, too, is as in grindelifolium, but the leaves are narrowly oblanceolate and 3 to $3.5 \mathrm{~cm}$. long, that is, longer than in the common form of suffruticosus. On the other hand, plants with mostly discoid heads, the ligules short when present, but the leaves short and broad, have been collected by Sonne in Nevada and Placer Counties, California. The enumerated characters are so variable and so impossible of correlation with one another and with geographic distribution that grindelifolium is not believed to possess evolutionary significance. This conclusion was earlier arrived at by Smiley (Univ. Calif. Pub. Bot. 9:360, 1921). The type locality is in the Yellowstone National Park.

3. M. grindelioides Rydb., Bull. Torr. Club 27:619, 1900. Evidently a misprint for $M$. grindelifolium.

4. M. imbricatum Nels. et Macbr., Bot. Gaz. $62: 150,1916$. One of the many forms connecting $M$. grindelifolium, here treated as minor variation 2, with typical $H$. suffruticosus. The leaves are 1.5 to $3 \mathrm{~cm}$. long by 4 or $5 \mathrm{~mm}$. wide; the ray-flowers few and their ligules about $1 \mathrm{~cm}$. long. The type is from a ridge south of Donner Pass, at about 2,600 meters altitude, in the Sierra Nevada of California.

5. M. suffruticosum Nutt., Trans. Am. Phil. Soc. II, 7:322, 1840. H. suffruticosus typicus.

\section{RELATIONSHIPS}

The basal position of this species in its section has been pointed out in the account of the phylogeny of the group (p. 187). It is easily distinguished from all other Macronemas by the large, many-flowered heads and loose involucre, the bracts of which are scarcely imbricated.

Evolution within the species is progressing somewhat as in its close relatives, macronema, bloomeri, and greenei, that is, there is a tendency toward segregation into forms differing in characters of foliage and involucres. One of these forms has leaves so narrow and heads so small that it is here set off as subspecies tenuis. Its marked departure from typicus is shown in table 7, where also is indicated the occurrence of intermediate forms. The distribution is within the general area of typicus, but only at high altitudes and over a restricted area in the Sierra Nevada of Cali- 
fornia. It appears to be a form resulting from a combination of hereditary units and particularly adapted to alpine conditions. Its absence in the Rocky Mountains suggests that this particular combination has never been formed in that district. The second Black Mountain collection cited in the table shows much variation in the texture and color of the bracts as well as in the size of involucre. The Mount Guyot plants are extreme as to color and reduction of heads, but the leaves are not so narrow as in the first collection cited. They are from timber-line, at 3,650 meters altitude, but the form here ranges up to 3,750 meters.

TABLE 7-Characters of Haplopappus suffruticosus typicus and H. s. tenuis

\begin{tabular}{|c|c|c|c|}
\hline Collections, all at University of California & $\begin{array}{l}\text { Height of } \\
\text { involucre }\end{array}$ & $\begin{array}{l}\text { Length of } \\
\text { corolla }\end{array}$ & $\begin{array}{l}\text { Width of } \\
\text { leaf }\end{array}$ \\
\hline 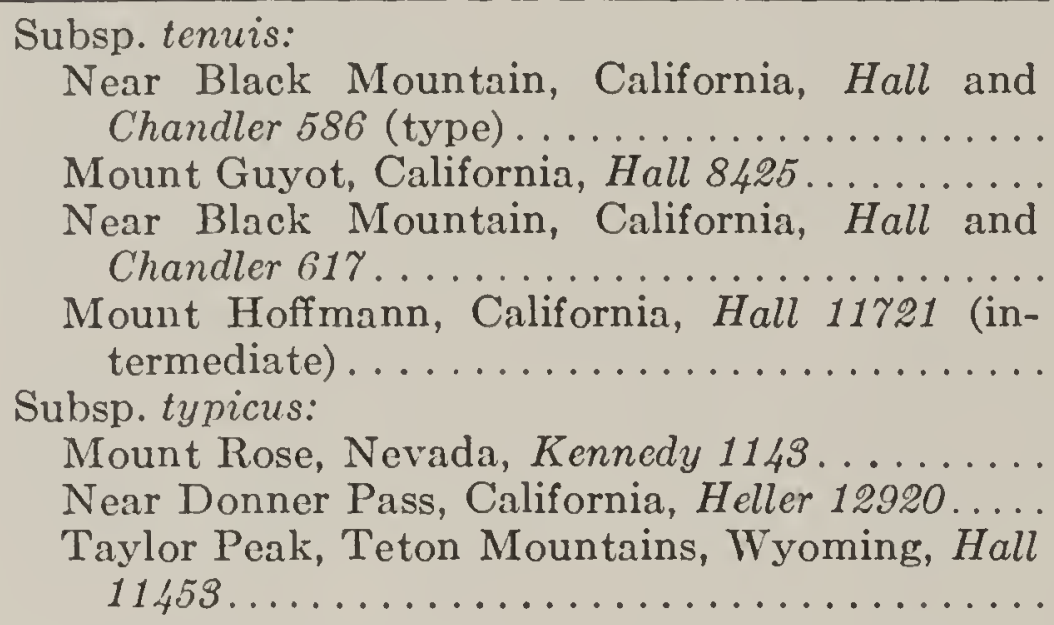 & $\begin{array}{l}m m . \\
9 \text { to } 10 \\
8 \text { to } 9 \\
10 \text { to } 12 \\
9 \text { to } 10 \\
10 \text { to } 11 \\
12 \text { to } 13 \\
12 \text { to } 16^{\circ}\end{array}$ & $\begin{array}{c}m m . \\
8.5 \\
8.5 \text { to } 10 \\
9.2 \text { to } 9.6 \\
9.0 \text { to } 9.5 \\
9.0 \text { to } 9.5 \\
10.0 \text { to } 10.5 \\
9.2 \text { to } 11.0\end{array}$ & $\begin{array}{l}\text { mm. } \\
0.5 \text { to } 1.0 \\
1.0 \text { to } 2.0 \\
1.0 \text { to } 3.0 \\
2.0 \text { to } 3.0 \\
1.5 \text { to } 3.5 \\
2.0 \text { to } 4.0 \\
3.0 \text { to } 6.0\end{array}$ \\
\hline
\end{tabular}

\section{ECOLOGY}

This low shrub grows in the subalpine forest of the northern Rocky Mountains and of the Sierra Nevada. It occurs, however, only in open places and disappears as the forest reaches the closed or climax stage. At and near timber-line it often grows from beneath rocks of the fell-fields, apparently favored by the shelter and moisture found in such situations, but it also invades the alpine and subalpine grasslands to a limited extent. Two ecologic forms result from this exposure to alpine or subalpine conditions. When the plant is sheltered and at the same time provided with sufficient moisture, the result is a low, spreading shrub with shortened leaves and an abundance of large heads, each with several showy rayflowers. Such plants are highly ornamental and it is suggested that the species be brought under cultivation for rockeries and alpine gardens. On the other hand, unfavorable conditions, especially association with strong-rooted grasses, sedges, and other perennials of high altitudes, call forth the inelegant xerophytic subspecies tenuis, notable for its narrow leaves and small heads with few and inconspicuous rays. Along the lower limits of its area of distribution, $H$. suffruticosus sometimes deserts its timber-line associates and invades openings in the Douglas fir forest. Here the herbage is more noticeably fragrant, perhaps because of the effect of the higher temperature upon the resins and essential oils, but the morphologic characters remain unchanged. The known altitudinal limits are 2,400 meters in the Lake Tahoe district and 3,750 meters on Mount Guyot in the southern Sierra Nevada. In the Rocky Mountains the 
range is from 2,400 to 3,050 meters. The zonal position is essentially Hudsonian. The flowering period extends from late July to early October.

TABLE 8-Summary of statistics used in drawing descriptions of Haplopappus suffruticosus, $H$. greenei, and $H$. bloomeri

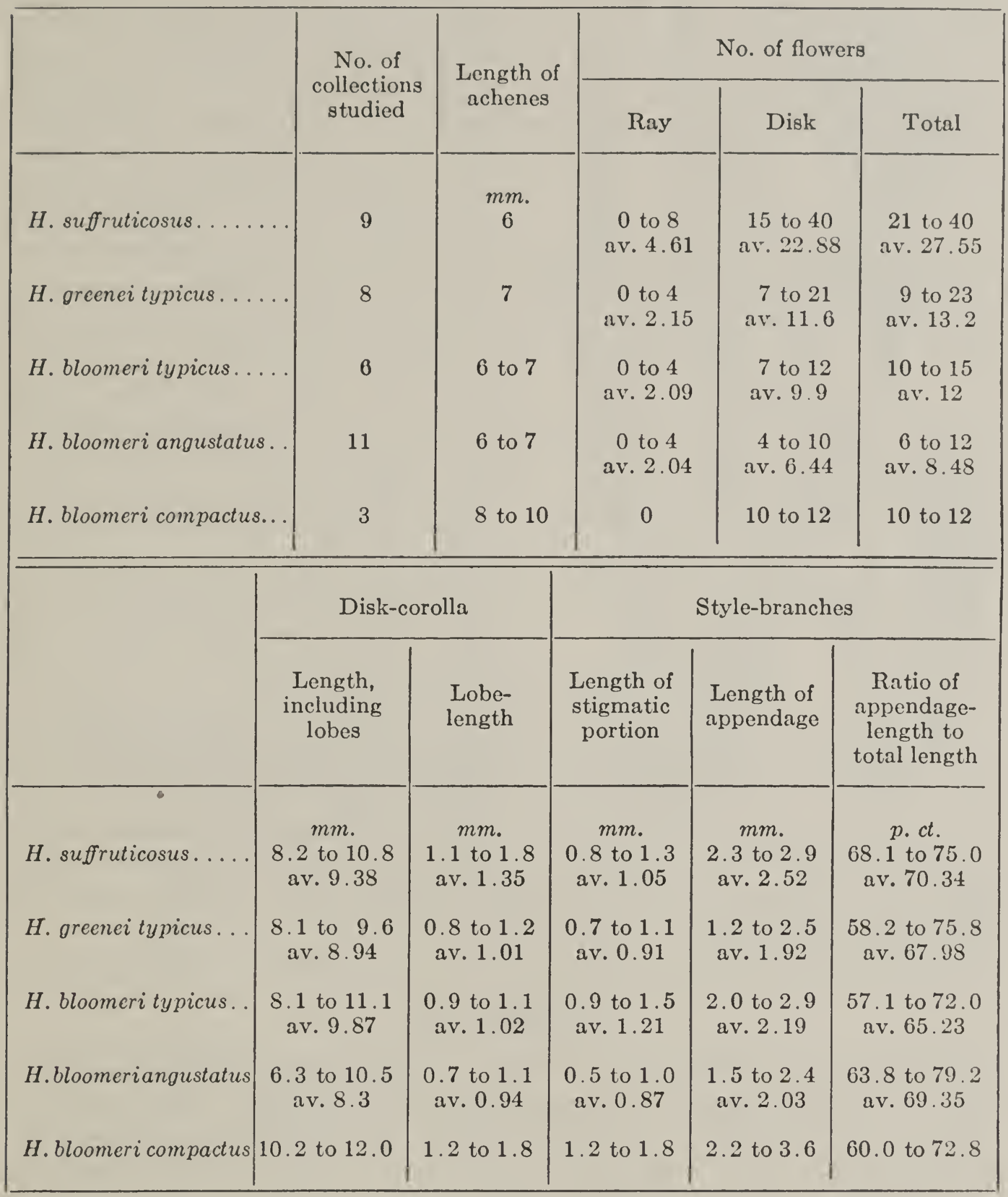

39. Haplopappus greenei Gray, Proc. Am. Acad. 16:80, 1880

A subshrub, about $2 \mathrm{dm}$. high, usually with decumbent woody branches from which arise the erect leafy flowering twigs, the whole plant compact and broader than high; bark green only on young shoots, decidedly reddish even on lower parts of the leafy twigs, becoming gray or brownish on old stems and finally exfoliating in narrow strips; twigs brittle, very leafy, pruinose-glandular when young, the glands minutely stalked in rare cases; leaves broadly spatulate or nearly oblong but always broadest above 
middle, nearly erect, entire, obtuse and mucronate or shortly acute, 1.5 to $3 \mathrm{~cm}$. long by 3 to $7 \mathrm{~mm}$. wide, with prominent midnerve and sometimes 2 additional but fainter nerves from base, more or less glandular or at least

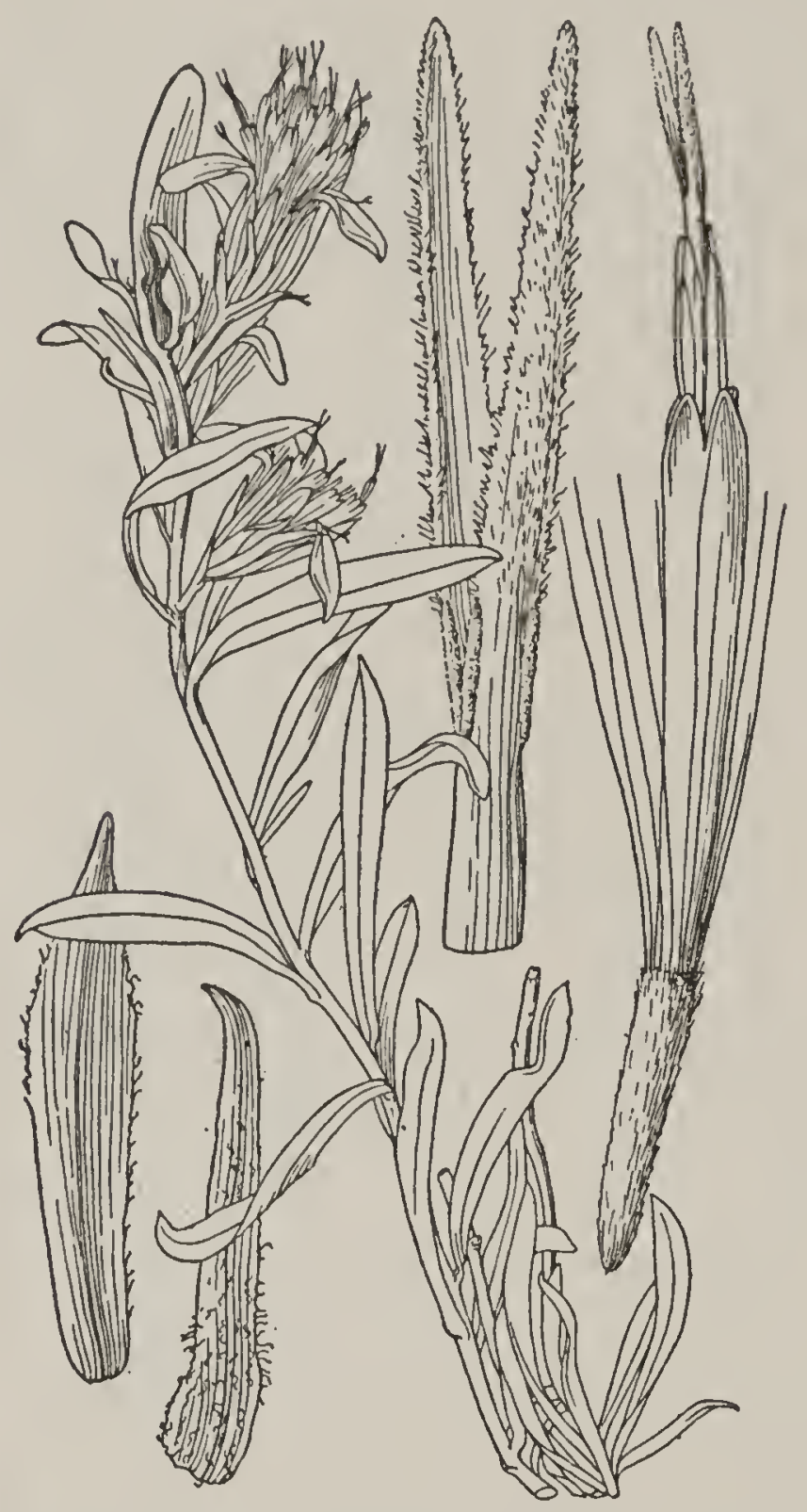

FIG. 65-Haplopappus greenei typicus viscid, otherwise glabrous (except in subsp. mollis); heads in leafy terminal cymes or subsolitary; involucre rather broadly campanulate, 8 to 10 or $12 \mathrm{~mm}$. high, 12 to $15 \mathrm{~mm}$. broad; bracts very obscurely imbricated, the outer sometimes longer than inner and with spatulate green tips, sometimes shorter, narrower, and with tips only greenish, the inner bracts lanceolate, with acute or acuminate greenish tips, all exposed parts of the involucre viscid or glandular and occasionally tomentulose; rayflowers 1 to 7 or rarely wanting in some heads, the ligules 8 to $10 \mathrm{~mm}$. long; disk-flowers 7 to 20 ; diskcorolla tubular-funnelform, the tube passing gradually into a throat of greater length, 9 to $9.5 \mathrm{~mm}$. long, rarely only $8 \mathrm{~mm}$., either glabrous or $\mathrm{mi}$ nutely pubescent; lobes 1 to $1.5 \mathrm{~mm}$. long, lanceolate-ovate, erect, glabrous; style-branches long-exserted, the slender appendage always longer than stigmatic part; achenes compressed, narrowly oblong, about $7 \mathrm{~mm}$. long, densely appressed-villous to nearly glabrate; disk-pappus about as long as corolla, fine and soft, white or light-brown. (Fig. 65.)

In the mountains from northern California to southeastern Washington.

\section{SUBSPECIES}

Nearly all of the collected specimens of this species as well as the plants seen in the field belong to typical Haplopappus greenei. One departure, however, is represented in herbaria, and since it indicates a breaking up of the original stock it becomes necessary to recognize two subspecies, which may be keyed as follows:

\section{Key to the Subspecies of Haplopappus greenei}

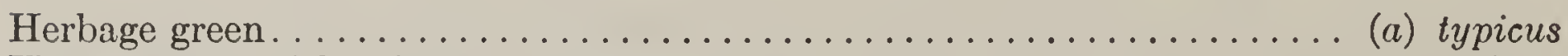
Herbage gray with a fine tomentum, at least in the inflorescence....... (b) mollis

39a. Haplopappus greenei typicus-Foliage and inflorescence green, minutely glandular or viscid; leaves 1.5 to $3 \mathrm{~cm}$. long, 4 to $7 \mathrm{~mm}$. wide; heads solitary or cymose or the cymes sometimes a little elongated and raceme-like; involucre 9 to $12 \mathrm{~mm}$. high; disk-flowers 13 to 18 . ( $H$. greenei Gray, l. c.) (Fig. 65.) 
Mountains from northern California to southern Washington. Type locality, Scott Mountains, Siskiyou County, California. California: type collection, from 2,130 meters altitude, August 22, 1876, Greene (Gr); Mount Eddy, Siskiyou County, Heller 11727 (Gr, UC, Del, heads narrow and outer bracts less foliaceous, but otherwise nearly typical); Modoc County, Gilman 517 (UC). Oregon: rim of Crater Lake, Hall 11649, 11652 (UC); near Cloudcap Inn, Mount Hood, Walpole 98 (US, type of Macronema pulvisculiferum, minor variation 9); Powder River (Eagle Creek) Mountains, eastern Oregon, Cusick 1791 (UC, DS, K). WasfiINGTON: Green River trail, Yakima Region, August 1882, Tweedy (DS); Clealum Lake, Cotton 860 (Gr).

39b. Haplopappus greenei mollis (Gray)-Foliage and inflorescence gray with a close fine tomentum, slightly if at all viscid or glandular; leaves 2 to $3 \mathrm{~cm}$. long, 2 to $5 \mathrm{~mm}$. wide; heads solitary or terminally cymose; involucre 8 to $11 \mathrm{~mm}$. high; disk-flowers many. (H. mollis Gray, l. c.)

Washington to California, said by Gray to grow with typical greenei. Type locality, high mountains of Union County, Oregon. WAshington: Yakima region, Brandegee 839, 842 (Gr, UC); Kittitas County, Sharples 244 (Gr). Oregon: type collection, 1877-88, Cusick (Gr); east of Pine Creek, Peck 2692 (Gr). CALifornia: mountains about the headwaters of the Sacramento River, August 31, 1882, Pringle (Boiss, Kew, some inflorescences approaching racemose).

\section{MINOR VARIATIONS AND SYNONYMS}

1. Aster greenei O. Kuntze, Rev. 318, 1891-H. greenei.

2. Haplopappus greenei, but a form with essentially glabrous achenes. Best represented by a specimen collected by Copeland at 1,800 meters altitude on Mount Eddy, Siskiyou County, California (No. 3868 of the C. F. Baker distribution, UC). The achenes are smooth, shining, and perfectly glabrous except for a few scattered hairs near summit. In the type specimens of greenei the achenes are pubescent over the entire surface, although not densely so. As intermediate may be cited plants from Mount Eddy ( Heller $11727, \mathrm{UC})$, in which the achenes are glabrous only below the middle.

3. H. greenei var. mollis Gray, Syn. Fl. $1^{2}: 135,1884$. Based upon H. mollis Gray, and therefore the same as $H$. greenei subsp. mollis, of the foregoing treatment.

4. H. mollis Gray, Proc. Am. Acad. 16:80, 1880-H. greenei mollis.

5. Hoorebekia greenei mollis Piper, Contr. U. S. Nat. Herb. 11:561, 1906. Based upon Haplopappus mollis.

6. Macronema greenei Greene, Erythea 2:73, 1894-H. greenei typicus.

7. M. greenei var. molle Jepson, Man. Fl. Pl. Calif. 1030, 1925-H. greenei subsp. mollis.

8. M. molle Greene, l. c.-H. greenei mollis.

9. M. pulvisculiferum Nels. et Macbr., Bot. Gaz. 62:150, 1916-In every respect this is like typical $H$. greenei. The resinous or gland-like particles and the cuspidate leaves are as in the type specimen of the latter. Type locality, near Cloudcap Inn, Mount Hood, Oregon.

\section{RELATIONSHIPS}

In its characters this species stands midway between Haplopappus suffruticosus and $H$. bloomeri. From the former it differs in the usually broader and flatter leaves, which are more constantly obtuse, and in the narrower involucre, the bracts of which are more unequal and therefore slightly imbricated. The narrowness of the heads is associated with a 
reduction in the number of flowers, and this furnishes the most satisfactory method for distinguishing the two. The features which serve to distinguish the present species from $H$. bloomeri are given under the latter.

Little is known as to evolutionary tendencies within the species except that the occasional appearance of a tomentose variation, sharply set off from the typical form, suggests a breaking into two subspecies.

\section{ECOLOGY AND USES}

In Oregon, this species has thus far been found only in rocky openings in the subalpine forest and in the fell-fields at and just above timber-line. In California, however, it seems to range farther down into the forest, for it grows at 1,800 meters elevation on Mount Eddy. At Crater Lake and on Mount Hood the low shrubs sometimes form nearly pure stands over limited areas where the soil is volcanic and the exposure good. Such groups, with their close covering of yellow heads, are very attractive and suggest that this species might be added to the list of ornamentals for rock and alpine gardens. The flowering period is from the middle of August to early October, or perhaps later.

\section{Haplopappus bloomeri Gray, Proc. Am. Acad. 6:540, 1865}

A shrub or subshrub, commonly 3 to $6 \mathrm{dm}$. high but becoming $9 \mathrm{dm}$. in shade, with several or many ascending stems that freely branch to form rounded leafy-twigged bushes; bark rich reddish brown, becoming dull and shreddy on old stems (pale or gray in subsp. compactus); twigs brittle, densely leafy, more or less viscid or glandular near heads, sometimes also loosely tomentulose (especially in subsp. sonnei); leaves linear but varying from nearly filiform to oblong-linear, straight falcate or rarely tortuous, entire, acute or acuminate, 2 to $6 \mathrm{~cm}$. long (less in minor variation 6), 0.5 to $4 \mathrm{~mm}$. wide, 1-nerved, the nerve very prominent in wide leaves, rather rigid, the lower ones glabrous, the upper ones viscid or glandular and sometimes slightly tomentulose, all closely tomentulose in one form (subsp. sonnei), none impressed-punctate; heads in leafy racemes or narrow thyrsoid panicles terminating the twigs, the inflorescence rarely reduced to a terminal glomerule or single head; involucre campanulate, 8 to $11 \mathrm{~mm}$. high, 10 to $12 \mathrm{~mm}$. broad at summit; bracts loosely imbricated; outer bracts linear-lanceolate, bearing a slender herbạceous usually spreading tip, viscid, or glandular, also tomentulose at least on margins; middle and inner bracts oblong-lanceolate, acute, chartaceous or only the apex a little green, the exposed parts and especially margins erose-ciliate to arachnoid; rayflowers 1 to 5 or wanting, the ligules 8 to $12 \mathrm{~mm}$. long; disk-flowers 4 to 12 ; disk-corolla tubular-funnelform, passing gradually from the tube to a narrow throat of slightly greater length, 7 to $11 \mathrm{~mm}$. long, glabrous or minutely hairy on tube; lobes ovate, erect, about $1 \mathrm{~mm}$. long (0.7 to 1.8), glabrous; style-branches moderately exserted, the slender and acute appendage mostly two to four times as long as stigmatic portion; achenes slenderly prismatic, compressed, 5-nerved, 6 to $10 \mathrm{~mm}$. long, densely villous to glabrate (usually pubescent at least around the summit); diskpappus about as long as corolla, fine and soft, white or becoming sordid. (Figs. 66 to 68. ) 
In the mountains, especially in sparse, coniferous forest, from western Nevada and the southern Sierra Nevada of California to southeastern Washington.
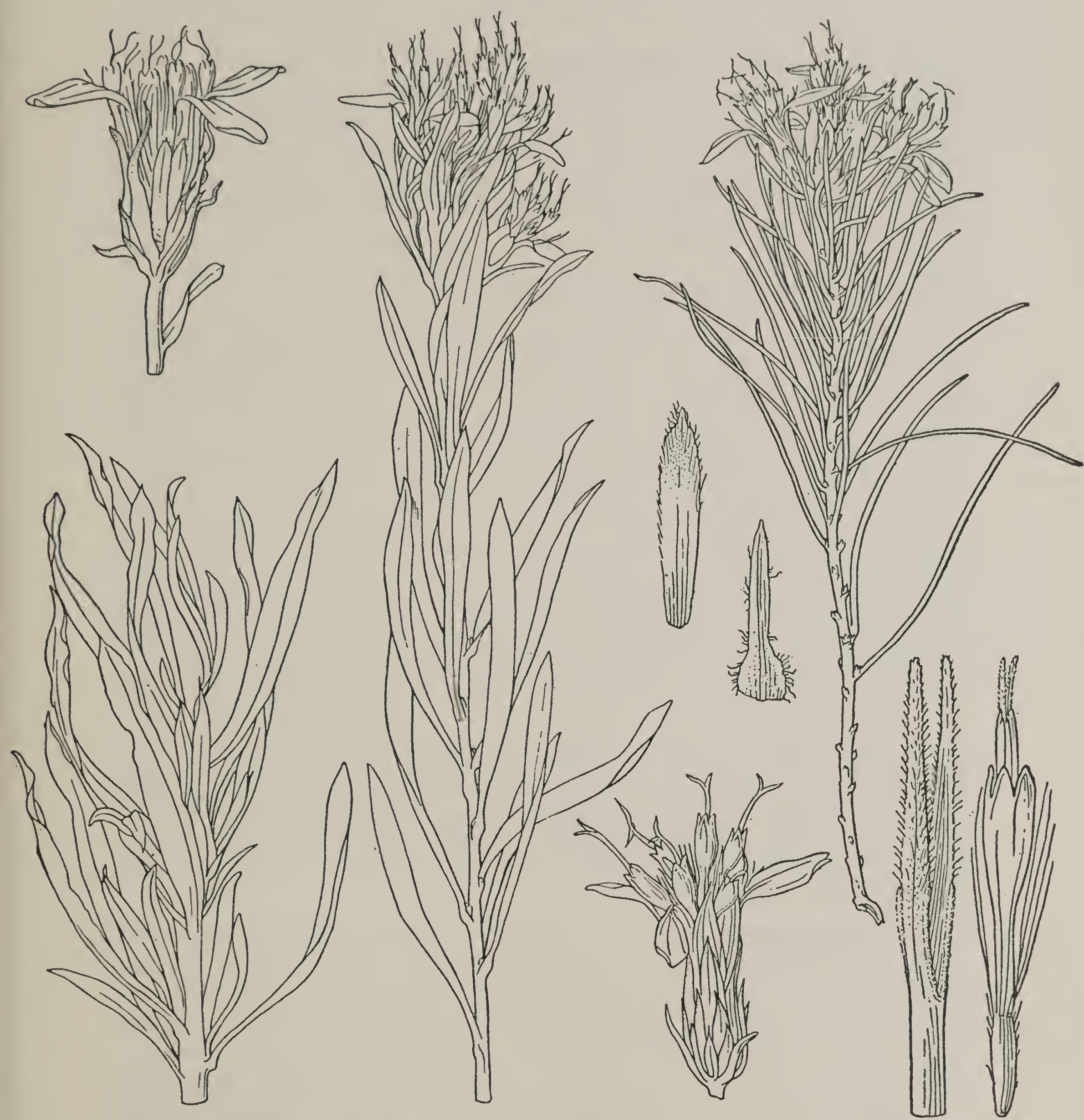

FIG. 66-Haplopappus bloomeri typicus

Fig. 67-Haplopappus bloomeri angustatus

\section{SUBSPECIES}

Key to the Subspecies of Haplopappus bloomeri

Achenes 6 to $7 \mathrm{~mm}$. long; style-branches 3 to $3.5 \mathrm{~mm}$. long; corolla-lobes about $1 \mathrm{~mm}$. long.

Herbage green, glandular, the tomentum confined to a sparse woolliness around the heads or more often completely wanting.

Leaves 2 to $4 \mathrm{~mm}$. wide, firm, straight or only somewhat falcate... (a) typicus 
Leaves 0.5 to $2 \mathrm{~mm}$. wide, flexuous, often curved or tortuous...... (b) angustatus Herbage gray or whitish with a copious tomentum. Leaves 0.5 to 3

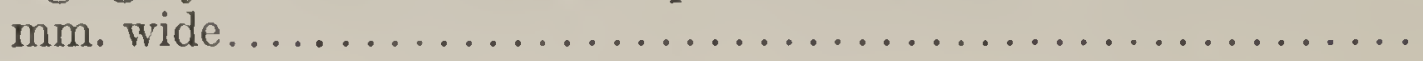

Achenes 7.5 to $10 \mathrm{~mm}$. long; style-branches 3.7 to $5 \mathrm{~mm}$. long; corolla-

(c) sonnei lobes 1.2 to $1.8 \mathrm{~mm}$. long. Southern Nevada.............. (d) compactus

40a. Haplopappus bloomeri typicus-Herbage green and more or less glandular, especially above, the peduncles, young leaves and involucres sometimes sparsely tomentulose, the inner bracts tomentulose at least on margins; leaves linear-oblong, 2.5 to $5 \mathrm{~cm}$. long except in minor variations 6 and 7, 2 to $4 \mathrm{~mm}$. wide, rather firm, mostly erect or ascending, seldom much curved; heads mostly 5 to 20 in each raceme-like terminal cluster; disk-flowers 7 to 12 ; disk-corolla 8 to $11 \mathrm{~mm}$. long; lobes 0.9 to $1.1 \mathrm{~mm}$. long; style-branches 3 to $3.5 \mathrm{~mm}$. long; achenes 6 to $7 \mathrm{~mm}$. long. $(H$. bloomeri Gray, Proc. Am. Acad. 6:540, 1865.) (Fig. 66.)

At middle and upper altitudes in the mountains of western Nevada, California (north from the Yosemite and Clear Lake districts), Oregon, and eastern Washington. Type locality, near Virginia City, Nevada. Nevada: Mount Davidson, 1864, Bloomer (Gr, marked "n. sp." by Gray and probably to be taken as the type); head of Fall Creek, Ormsby County, Baker 1498 (T); near Carson, Anderson (Gr); head of Little Valley, Washoe County, Heller 10664 (UC, DS, Del). CAlrfornia: slopes near White Wolf, Yosemite Park, Mason 764 (CI); Donner Lake, August, 1885, Brandegee (UC); Snow Mountain, Lake County, Purpus 1117 (UC, P, K, minor variation 7); Yolla Bolla Mountains, Merriam and Bailey (UC, minor variation 6); Jonesville, Butte County, Copeland 206 (DS); near Lassen Buttes, Plumas County, Brown 618 (Del); Warner Range, Manning 298 (UC); Humbug Mountain, Siskiyou County, Butler 1823 (DS). OREGON: rim of Crater Lake, Heller 12943 (UC, intermediate to H. greenei or possibly a hybrid); Alice Spring, near Crater Lake, Hall 11645 (UC, typical); Klamath County, Walpole 387 (US, type of Macronema walpoleanum, minor variation 11); Mount Hood, at Cloudcap Inn, Hall 10946 (UC); Wagontire Mountains, eastern Oregon, Cusick 2714 (UC, Del, P, K). Washington: Yakima region, Brandegee 843 (UC); Simcoe Mountains, September 1881, Howell (B).

40b. Haplopappus bloomeri angustatus (Gray)-Herbage green and nearly glabrous, but somewhat glandular above, where also very sparsely tomentulose in a few specimens, the inner bracts of the involucre tomentulose at least on margins; leaves linear to nearly filiform, 2.5 to $6 \mathrm{~cm}$. long, 0.5 to $2 \mathrm{~mm}$. wide, not firm but curved, spreading or sometimes tortuous; heads usually 5 to 20 in each terminal raceme; disk-flowers 4 to 10 ; diskcorolla 6.3 to $10.5 \mathrm{~mm}$. long; lobes 0.7 to $1.1 \mathrm{~mm}$. long; style-branches 3 to $3.5 \mathrm{~mm}$. long; achenes 6 to $7 \mathrm{~mm}$. long. (H. bloomeri var. angustatus Gray, Proc. Am. Acad. $7: 354,1868$. (Fig. 67.)

In the foothills and up to middle altitudes, from western Nevada and the southern Sierra Nevada Mountains of California to southeastern Washington. Type locality, Mount Shasta, California, at 1,830 meters altitude. Nevada: Hunter Creek, Washoe County, Kennedy 1900 (UC). CaliFORNIA: sandy, sunny slopes, at 2,400 to 2,700 meters altitude, Monache Meadows, Purpus 1694 (UC, P); Soda Spring Meadow, Kaweah River 
Basin, Hopping 75 (UC); Tamarack Bench, Fresno County, July 1914, Wieslander (UC); Sentinel Dome, Yosemite National Park, Hall 9668 (UC); Truckee, Nevada County, Heller 7094 (UC, DS, Del); type collection, "from dry, sunny hillsides," September 16, 1862, Brewer 1415 (Gr, UC); north of Goosenest Mountain, Siskiyou County, Butler 502 (UC); northern Modoc County, Hall 11667 (UC). Oregon: Sand Creek and Wheeler Creek, near Crater Lake, Hall 11655, 11656, 11657 (UC); east side of Klamath Marsh, Leiberg (UC); Jackson County, Walpole 386 (US, type of Macronema scoparium, minor variation 10). WashingTon: Glenwood, Klickitat County, Hall 11627 (UC); Mount Adams, August 1882, Howell (Del). Additional specimens are cited under minor variation 8 (Macronema filiforme).

40c. Haplopappus bloomeri sonnei (Greene)-Herbage gray or whitish with a loose woolly tomentum which extends to the involucres; leaves narrowly linear, sometimes almost filiform, 2 to $4 \mathrm{~cm}$. long, 0.5 to $3 \mathrm{~mm}$. wide, either firm and ascending or less rigid and more or less curved; heads few in terminal glomerules or up to 12 and short-racemose. Otherwise nearly as in typicus. (H. bloomeri var. sonnei Greene, Pitt. 2:17, 1889.)

At middle and lower altitudes in the mountains, northeastern California to southeastern Washington. Type locality, sandy soil about Donner Lake, in the Sierra Nevada. California: type collection, August 1889, Sonne (UC). OrEGON: Ashland, Walpole 370 (US, type collection of Macronema glomeratum, minor variation 9); Three-fingered Jack Mountain, Cascade Mountains, Coville and Applegate 685 (UC, a form with leaves 2 to $3 \mathrm{~mm}$. wide). WAShington: Yakima region, 1882, Brandegee 134 (UC); valley of the Swank River, Kittitas County, Sharples 244 (Gr, form with leaves $3 \mathrm{~mm}$. wide).

40d. Haplopappus bloomeri compactus subsp. nov.-Stems few or solitary, branching above the base to form rounded compact shrubs of globular outline; herbage pale, nearly glabrous, more or less viscid; leaves linear or linear-spatulate, entire, acute, 2 to $3.5 \mathrm{~cm}$. long, 2 to $3 \mathrm{~mm}$. wide, rather rigid, mostly erect or ascending, straight; heads 2 to 5 in each terminal cyme-like cluster, the peduncles 1 to $10 \mathrm{~mm}$. long; involucre narrowly campanulate, 10 to $11 \mathrm{~mm}$. high, about as broad; bracts loosely imbricated, lanceolate, either abruptly or gradually narrowed to a slender spreading tip, pale-chartaceous, the margins white-scarious and eroseciliate, the backs viscid; ray-flowers uniformly wanting; disk-flowers 10 to 12 ; disk-corolla 10.2 to $12 \mathrm{~mm}$. long, pubescent on tube (throat $2 \mathrm{~mm}$. in diameter); lobes lanceolate, erect, 1.2 to $1.8 \mathrm{~mm}$. long, glabrous; stylebranches 3.7 to $5 \mathrm{~mm}$. long, the slender appendage much longer than stigmatic portion; achenes slightly tapering from above middle to base, compressed, prominently 5-nerved, 7.5 to $10 \mathrm{~mm}$. long, glabrous except near summit, where slightly villous. (Fig. 68.)

Known only from the collections of Mr. Edmund C. Jaeger, made in the Charleston Mountains of southwestern Nevada. Ridge south of Charleston Park, 2,900 meters altitude, Charleston Mountains, Clark County, Nevada, September 12, 1925, Jaeger (Pomona College 71755, type; duplicate at University of California); Cathedral Rock, Charleston 
Mountains, September 6, 1927, Jaeger 2209 (UC); head of Lee Cañon, in open forest of Pinus ponderosa, September 4, 1927, Jaeger 2211 (UC).

According to the collector, this plant grows only above 2,700 meters altitude at the upper limits of the forest of Pinus ponderosa and upward through that of $P$. aristata. It avoids the exposed ridges, preferring shel-
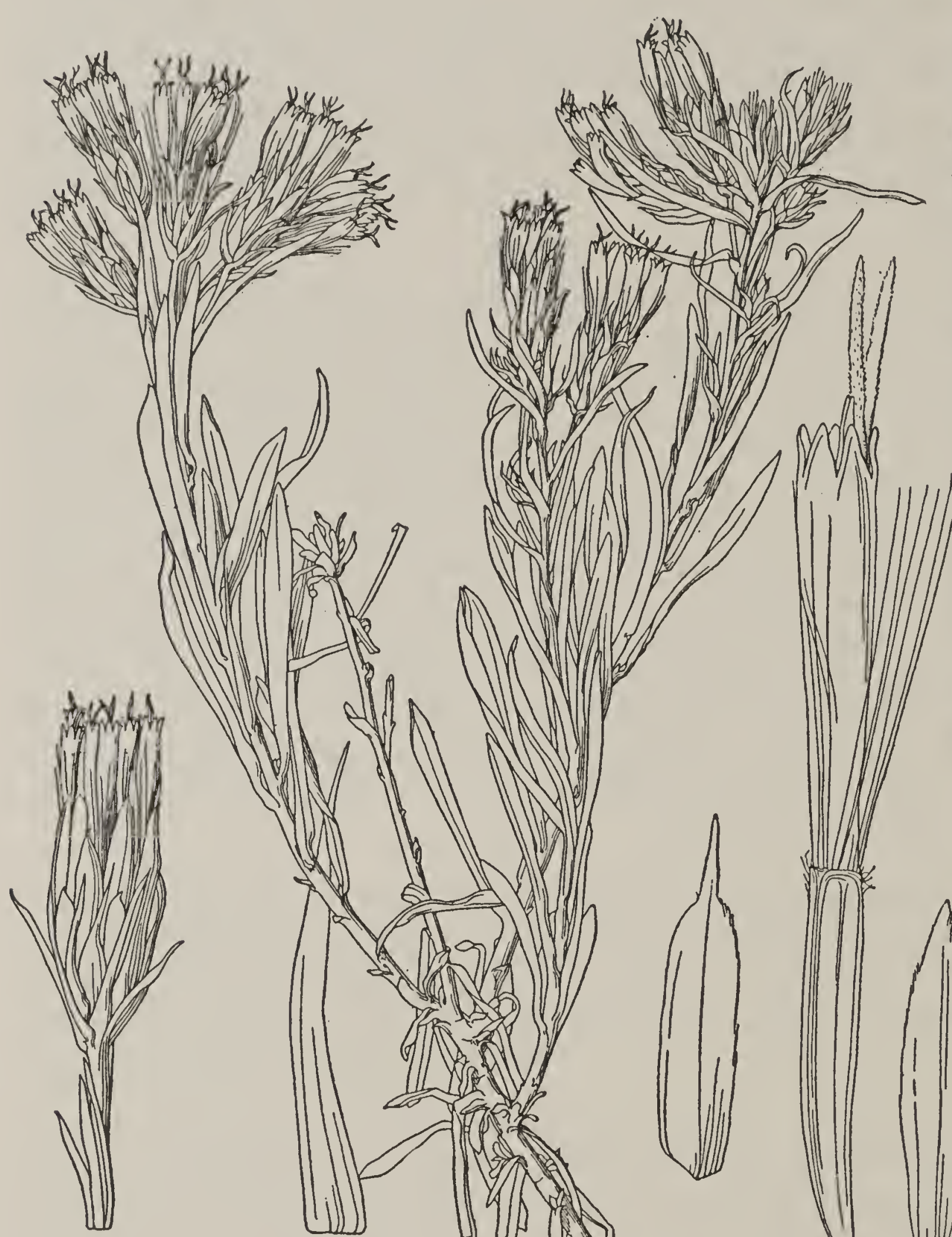
3. Ericameria bloomeri Macbr., Contr. Gray Herb. 56:36, 1918. A transfer from H. bloomeri Gray, the objections to which are given under the heading of Relationships.

4. E. erecta Klatt, Abh. Natürf. Ges. Halle 15:326, 1882. Referred by Gray to H. bloomeri, on the basis of description and habitat. The type is Cuming 111, said to come from California.

5. Haplopappus bloomeri var. angustatus Gray, Proc. Am. Acad. 7:354, 1868H. bloomeri subsp. angustatus.

5a. H. bloomeri var. sonnei Greene, Pittonia 2:17 1889-H. bloomeri subsp. sonnei.

6. H. bloomeri typicus, but with very short leaves and rather small heads. Foliage and inflorescence green, minutely glandular or viscid; leaves 1 to $1.5 \mathrm{~cm}$. long, 1.5 to $3.5 \mathrm{~mm}$. wide, oblong-spatulate, obtuse, mucronate; heads in terminal racemes, the number in each raceme varying on the same plant from 1 to 6 ; involucre 8 to $10 \mathrm{~mm}$. high, 8 to $10 \mathrm{~mm}$. broad, loosely imbricated; outer bracts oblong-lanceolate, green and viscid; middle and inner bracts lanceolate, mostly chartaceous but with widely spreading attenuate green tips, arachnoid-ciliate; ray-flowers few; disk-flowers about 15; diskcorolla $9 \mathrm{~mm}$. long including the lobes, these $1.2 \mathrm{~mm}$. long; the tube minutely and sparsely puberulent; appendage nearly 3 times as long as the stigmatic part; achenes appressed-villous. South Yolla Bolla Mountain, Trinity County, California, 150 meters below the summit, on the south slope, October 1916, Merriam and Bailey (UC). This variation may intergrade with the next following, but the small, decidedly racemose heads will serve to distinguish it.

7. H. bloomeri typicus, but with short pale leaves, the large heads few and terminally glomerate. Leaves 1.5 to $2.5 \mathrm{~cm}$. long, 3 to $5 \mathrm{~mm}$. wide, broadly spatulate, abruptly acute, glandular-scabrid; heads solitary or only 2 to 5 in each compact terminal cluster; involucre about $10 \mathrm{~mm}$. high, 10 to $12 \mathrm{~mm}$. broad, loose; outer bracts ovate-lanceolate, the tips green; middle and inner bracts oblong-lanceolate, green only at the attenuate tip, this more or less spreading, arachnoid-ciliate; ray-flowers few; disk-flowers 15 or more; disk-corolla about $10 \mathrm{~mm}$. long including the lobes, these about $1.2 \mathrm{~mm}$. long, the tube puberulent; style-appendage much exceeding the stigmatic portion; achenes appressed-villous. Yolla Bolla Mountain, Trinity County, California, September 20, 1892, Brandegee (UC, Gr, Boiss); Snow Mountain, Lake County, California, Purpus 1177 (UC, Paris, Kew). Field studies may demonstrate the subspecific or other taxonomic rank to which this form should be assigned. The inflorescence and involucre partake of the characters both of bloomeri and of greenei, while the foliage is very suggestive of the preceding minor variation from the same geographic area.

8. Macronema filiforme Nels. et Macbr., Bot. Gaz. 62:148, 1916. The extreme form of $H$. bloomeri angustatus, the leaves nearly filiform. (Erroneously printed as "filifomis.") The types are from the headwaters of the Deschutes River, Crook County, Oregon (Coville and Applegate 544, 545, US), but this same narrow-leaved form, which is not otherwise distinguishable from angustatus, into which it grades, occurs at many localities. Thoroughly typical of it are: Tumalo Valley, west of Bend, Oregon, September 26, 1919, Hall (UC); Big Creek Basin, Sierra Nevada of Fresno County, California, Peirson 69 (UC).

9. M. glomeratum Nels. et Macbr., 1. c. 149, 1916-H. bloomeri sonnei.

10. M. scoparium Nels. et Macbr., l. c.-H. bloomeri angustatus. In proposing this species the authors made no comparison with bloomeri nor with Macronema filiforme, published by them in the same paper. The latter is the extreme form of the plant described as scoparium, differing only in its more nearly filiform leaves. The only other tangible difference appearing in the descriptions is the statement that the achenes are glabrous. In the type specimens, however, the achenes, or at least most of them, are rather densely villous around the summit, the pubescence extending to midway of the body in some cases. The type locality is Hunt's Ranch, Jackson County, Oregon. 
11. M. walpoleanum Nels. et Macbr., 1. c.-H. bloomeri typicus. The type specimens at the National Herbarium differ in no way, except that the leaves average perhaps a trifle narrower and therefore suggest a connection with subspecies angustatus. The achenes are described as a little shorter than the pappus, but they measure only about one-third as long, this proportion being about the average for bloomeri. It is probable that bloomeri was overlooked when walpoleanum was proposed. The type locality of the latter is Klamath County, Oregon.

\section{RELATIONSHIPS}

As has been already shown, this species is probably the end of a phylogenetic line starting with Haplopappus suffruticosus and passing through or around $H$. greenei. The latter undoubtedly is its nearest relative. In fact, certain specimens of these two can be distinguished only with the greatest difficulty. This is especially true of forms growing where the ranges overlap in the mountains of southern Oregon. Here bloomeri is abundant at middle altitudes, especially with Pinus ponderosa, while greenei belongs to higher altitudes with $P$. albicaulis and $T$ suga mertensiana. At such places as Crater Lake and.on Mount Hood, near timber-line, the two mingle and here occur intermediate forms which may be hybrids. In most cases, bloomeri can be distinguished by the longer and narrower leaves, but only the characters of the involucre are reliable. This structure is generally narrower than in greenei, and the bracts are more obviously imbricated and less herbaceous. These bracts are more acuminate (see Figs. 65 to 68 ), with tips more inclined to spread or recurve, the margins are constantly ciliate or cobwebby, and the texture of all but the outermost is chartaceous. Except when stunted or otherwise abnormal, the heads have a tendency to form racemes, whereas in greenei they are always in short terminal clusters or solitary.

The relationship above noted was hinted by Gray, but apparently has escaped later authors. One recent writer goes so far as to transfer the species to Ericameria (Macbr., Contr. Gray Herb. 56:36, 1918), a disposal impossible of acceptance, not only because the species lacks the essential character of that section, namely, an impressed-punctate herbage, but also because no Ericameria possesses an involucre even suggesting that of bloomeri. From the genus Chrysothamnus, to which it was referred by Greene, Erythea $3: 115,1895)$, it differs in the absence of a vertical arrangement of the involucral bracts and in the presence of ray-flowers. The light tomentum mentioned by Greene as present in the young stages of some plants is very different from the heavy pannose tomentum of the twigs in species of Chrysothamnus most like this. The shape of the corolla, while resembling that of some Chrysothamni, is almost identical with the shape found in $H$. greenei and $H$. suffruticosus (see Fig. 64). The reduction in number of ray-flowers, also commented upon by Greene, is characteristic of this whole group of Haplopappus and furnishes still further evidence that phylogenetically bloomeri belongs here rather than with Chrysothamnus, in which the ray-flowers are always completely wanting.

Evolution within the species is tending to the formation of four types. One of the most primitive of these is subsp. typicus. A reduction in leaf, especially as to breadth, has produced angustatus, a form which intergrades with typicus to such an extent that there is some question as to the wisdom 
of accepting it as a subspecies. But its general restriction to lower or drier habitats indicates that it may be a geographic race, at least. The altitude as given on labels is sometimes as high as 2,700 meters, but at such places it grows only on warm, sandy, south exposures. The other derivative is subsp. sonnei, almost certainly an offshoot from angustatus, from which it differs in the presence of a copious tomentum on the herbage and reduced inflorescences. No intermediates as to pubescence are known and since the form occurs only at a few widely separated localities the evidence points strongly to polygenesis by mutation. This theory almost necessitates the assumption that the trichomes arise after the loss of an inhibiting agent, but even this is easier than to assume that either the broad-leaved, many-headed typicus or the narrow-leaved, manyheaded angustatus is the derived form. The Donner Lake specimens cited above as the type of subsp. sonnei represent a form with flowering twigs only 6 to $12 \mathrm{~cm}$. long and densely clothed with slightly narrower leaves. This habit is exactly matched in the type of subsp. angustatus, to which form the Donner plants would be positively referred were it not for their conspicuous tomentum. The reduced number of heads, used as basis for minor variation 9, is a variable character, as seen from specimens just mentioned (Donner Lake, August 1889, Sonne), for in this collection the inflorescences range from racemes with 5 to 12 heads down to terminal clusters of only 3 heads, and in some cases the head is solitary and terminal.

The subspecies compactus, here described for the first time, appears to be an carly derivative of typicus, stranded on the mountains of southern Nevada, perhaps in connection with climatic changes of the Pleistocene or Recent period. 'The long corollas and achenes suggest that it may be the original stock from which the others have been derived by reduction, but there is no direct evidence to support this view. Subspecies compactus is separated from all other forms of the species by $380 \mathrm{~km}$. of desert country unsuited to any form of the group. The specimens thus far collected indicate that it may be recognized on habital characters, such as the compact habit of branching above the base, which gives to the plant a distinctive globular outline. Also to be noted is the dense foliage, consisting of short, broad, heavy leaves of a very pale color.

Some of the characters used for the separation of the subspecies are given in table 8 .

\section{ECOLOGY AND USES}

This is an important seral shrub in the Sierran montane forest and extends northerly into the open forests of Pinus ponderosa of southeastern Washington. At a few places it passes into the subalpine forest, there associating with Tsuga mertensiana, as at Crater Lake, Oregon, while in one instance, namely, on Mount Hood, it ascends practically to timber-line. Zonally it is classed as essentially Transition, with frequent incursions into the Canadian. It is most plentiful in the arid mountains that border the Great Basin on the west and northwest. Here it occupies openings made by fire or other disturbing agents and persists for a long time, thus becoming subclimax to the Pinus association. The shrubs thus persisting in the forest take on a tall, slender habit as compared with the nicely rounded plants of open places, and the leaves are correspondingly narrow. These ecologic changes, emphasized by much 
competition, have formed the basis of one or two of the fictitious species recently described. Common associates in the open, subclimax forest are Pinus contorta, Artemisia tridentata, Wyethia mollis, and scattered bunchgrasses. The altitudinal range is from about 300 meters, on level areas of eastern Washington, to 3,000 meters on warm, southerly exposures in the southern Sierra Nevada. The soil where this Haplopappus grows is loose, well drained, and often of volcanic origin, especially in the Cascade Mountains. The plants possess the ability to throw up new shoots from the base when burned. They flower from July to September.

The herbage of Haplopappus bloomeri is browsed to a limited extent, but the shrubs are generally avoided, probably because of their resinous nature. The plants are quite attractive when in bloom and the green foliage is pleasing at all seasons. The species should therefore be brought into cultivation for use as an ornamental in temperate districts with moderate rainfall, the selection to be made from the form with numerous narrow leaves and a large number of showy ray-flowers.

\section{Haplopappus macronema Gray, Proc. Am. Acad. 6:542, 1866}

A subshrub, 1.5 to $4 \mathrm{dm}$. high, with numerous short branches from near base that spread to form a densely twiggy rounded bush; bark completely masked by the tomentum except on old branches, here brown and shreddy; twigs tough, very leafy, covered with a white pannose tomentum, this usually sparse or wanting near heads, the peduncles then glandularscabrid; leaves oblong or oblanceolate, or linear in one subspecies, ascending, entire or margins crisply undulate, either acute or somewhat obtuse and then mucronate, 1 to $3 \mathrm{~cm}$. long, 1.5 to $6 \mathrm{~mm}$. wide, 1-nerved, an additional pair of faint nerves sometimes present, glandular-scabrid or in one subspecies tomentulose; heads solitary and terminal or several and subracemose; involucre broadly campanulate, 9 to $13 \mathrm{~mm}$. high, 8 to $12 \mathrm{~mm}$. broad; bracts not imbricated, a few of the outer ones oblong, acute or somewhat obtuse, herbaceous, the others lanceolate, acuminate, chartaceous, all exposed parts of the involucre glandular-scabrous or tomentulose; ray-flowers wanting; disk-flowers 10 to 25; disk-corolla tubular-funnelform, 9 to $11 \mathrm{~mm}$. long, the throat longer than the very slender tube, puberulent on tube; lobes ovate, erect, 1 to 1.5 or $2 \mathrm{~mm}$. long, glabrous; style-branches long-exserted, the slender appendage much exceeding stigmatic portion; achenes slenderly prismatic, 5 or $6 \mathrm{~mm}$. long, densely villous; pappus about equaling corolla, soft, dull white. (Macronema discoideum Nutt., Trans. Am. Phil. Soc. II, $7: 322,1840$.) (Fig. 69.)

At high altitudes, Idaho and Colorado to the Sierra Nevada of California.

\section{SUBSPECIES}

Key to the Subspecies of Haplopappus macronema

Leaves oblong or oblanceolate, 3 to $6 \mathrm{~mm}$. wide, not tomentulose...... (a) typicus Leaves linear, $2 \mathrm{~mm}$. or less wide, more or less tomentulose........... (b) linearis

41a. Haplopappus macronema typicus-Branches and twigs stout; leaves oblong or oblanceolate, 3 to $6 \mathrm{~mm}$. wide, dull green, thickly beset with minute stiff hairs, most of which are gland-tipped, only rarely a trace of tomentum; inflorescence similarly pubescent; involucre 10 to $13 \mathrm{~mm}$. high. (Macronema discoideum Nutt., l. c.) (Fig. 69.) 
In the Rocky Mountains from Idaho to Colorado; also in the Sicrra Nevada of California, where more abundant, and on high mountains in the intervening territory. (Also in Montana and Arizona, according to Rydberg.) Type locality, "Banks of Lewis River and other streams of the Oregon." Specimens by Nuttall at Philadelphia are labeled "Colum-

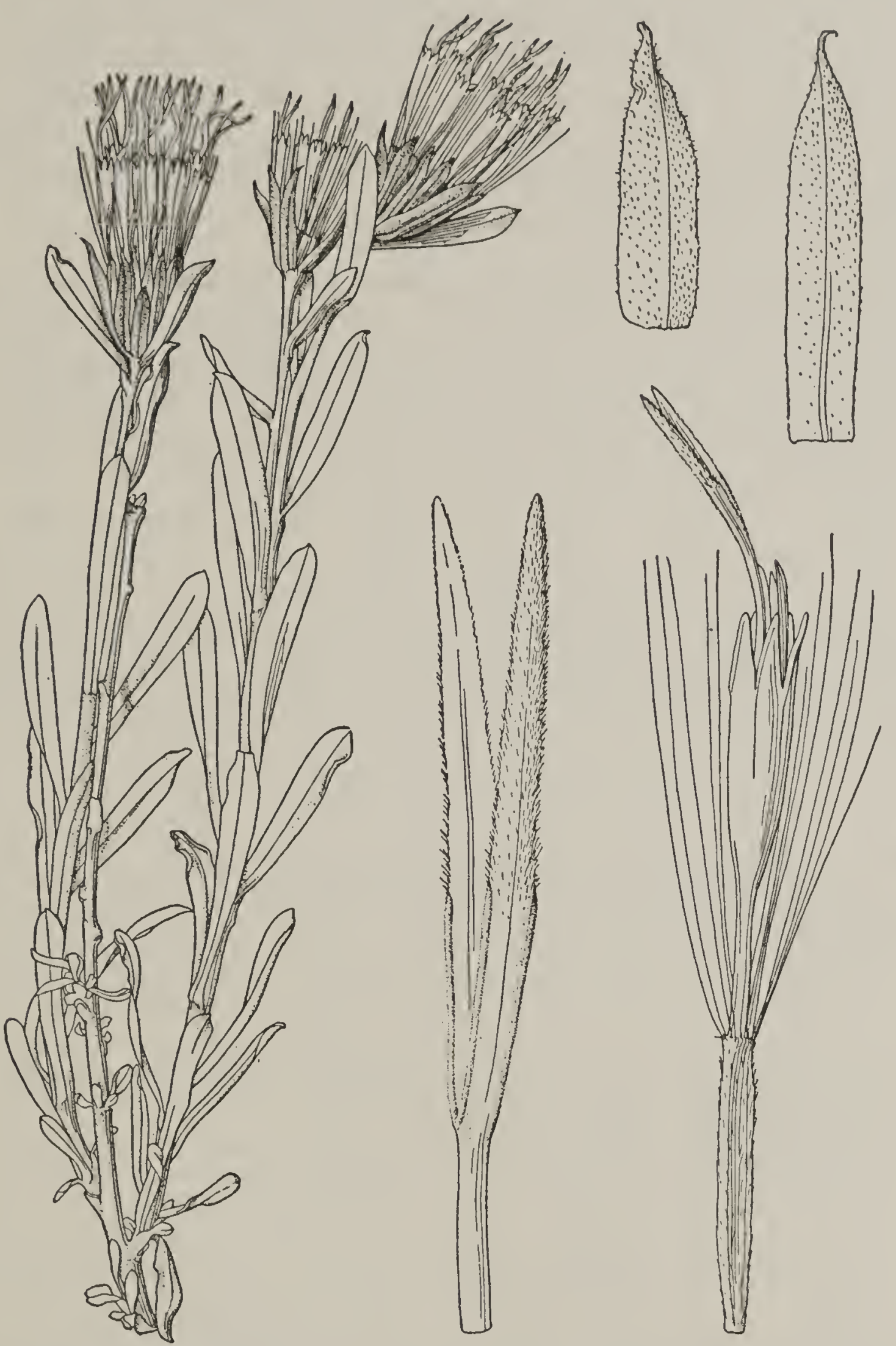

Fia. 69-Haplopappus macronema (minor variation 7, Macronema obtusum Rydb.)

bia Streams." IDAно: Josephine Lakes, Custer County, Macbride and Payson 3603 (Gr, US, R); Smoky Mountains, Blaine County, Macbride and Payson 3774 (Gr, US, R); Sawtooth Mountains, head of Pettit Lake, Henderson 3516 (US). Colonado: Central Mine, Clear Creek County, Clokey 3895 (Phila, Gr, US); South Cottonwood Gulch, Chaffee County, July 14, 1892, Sheldon (NY, type of Macronema obtusum, minor variation 7); near Mount Ouray, August 1897, Brandegee (UC, same variation); Twin Lakes, Wolf and Rothrock 457 (Gr); Marshall Pass, west central Colorado, 
Baker 891 (UC, US, Del, B, K). Utaн: Falls of Bullion Creek, Marysvale, Jones 5895 (R, UC, US); Big Cottonwood Cañon, Wasatch Mountains; Garrett 1654 (Phila, R, US); Mount Nebo, Rydberg and Carlton 7748 (US, R). Nevada: East of Ely, Hitchcock 1312 (US); Toiyabe Range, Lander County, Kennedy 4164 (UC, DS); West Humboldt Mountains, July 31, 1894, Greene (Greene); Mount Rose, Kennedy 1179 (UC). CauIFornia: Little Kern River, southern Sierra Nevada, Purpus 5148 (UC, Gr, P, K); Inyo County, A ustin 407 (UC); Leevining Creek, Mono County, Hall 10850 (UC); Mount Tallac, August 12, 1901, Chandler (UC). Oregon: Gayhart Buttes, Coville and Leiberg 272 (US). (Additional localities in California and a note on synonymy are given by Smiley, Univ. Calif. Pub. Bot. $9: 359,1921$.

41b. Haplopappus macronema linearis (Rydb.)-Branches and twigs slender; leaves linear, 1 to $2 \mathrm{~mm}$. wide, from light green and only obscurely tomentulose to whitish and densely tomentulose, glandular when the tomentum is minute and sparse; pubescence of the inflorescence similar to that of the leaves; involucre 9 to 11 or rarely $12 \mathrm{~mm}$. high. (Macronema lineare Rydb., Mem. N. Y. Bot. Gard. 1:384, 1900.)

Restricted to northwestern Wyoming. Type locality, Gros Ventre River. Wyoming: type collection, 2,130 meters altitude, Tweedy 55\% (NY); Teton Forest, 1897, Brandegee (UC); Kingman's Pass, August 30, 1888, Williams (NY); Yellowstone Lake, Nelson 6616 (NY, US, like the type but more branched) and 6603 (NY, R, US, white-tomentose or at least canescent, minor variation 7); La Barge, Uinta County, Stevenson 191 (US).

\section{MINOR VARIATIONS AND SYNONYMS}

1. Bigelovia macronema Jones, Proc. Calif. Acad. II, 5:693, 1895 . Based upon Macronema discoideum and therefore the same as $H$. macronema typicus.

2. Haplopappus discoideus Hall and Hall, Yosemite Fl. 246, 1912. This is the same as $H$. macronema Gray, which was cited as a synonym in the Yosemite Flora. Here Gray was erroneously given as the author of the new combination, $H$. discoideus. This was published also by Frye and Rigg in 1912 in their Northwest Flora (p. 381). Professor Frye writes that the date of issuance of that publication should be taken as September 12. The Yosemite Flora was issued April 8, 1912, as indicated on the reverse of the title page. The name $H$. discoideus is scarcely available because of its use by De Candolle in 1836 for a Mexican species now universally referred to $H$. venetus (or Isocoma veneta). DeCandolle's description was not based upon the type specimens of this, nor was venetus mentioned as a synonym. Since there is a slight possibility that the name discoideus may be requisitioned for this Mexican plant, its use for the present one is deemed undesirable. (See further under minor variation 9 of $H$. venetus.)

3. H. macronema typicus, but with straighter and more elongated branches and longer leaves. This is a Rocky Mountain variation. The specimens are for the most part very different in appearance from those of California and Oregon, but no definite criteria can be found. The leaves, in the specimens at hand from Colorado, are mostly 2 to $3 \mathrm{~cm}$. long, while in California they are mostly 1 to $2 \mathrm{~cm}$. long. But in one collection from the Sierra Nevada they average 2 to $2.5 \mathrm{~cm}$. (Mono Pass, Congdon, UC), and in another they are 2 to $3 \mathrm{~cm}$. long (Little Kern River, Purpus 5148, UC). The few collections available from the Rocky Mountains are all of the long-twigged, longleaved form. If further studies maintain this consistently, and especially if a few substantiating criteria can be found, a taxonomic segregation into two geographic subspecies would be desirable. 
4. Macronema discoideum Nutt., Trans. Am. Phil. Soc. II, 7:322, 1841-H. macronema typicus.

5. M. lineare Rydb., Mem. N. Y. Bot. Gard. 1:384, 1900-H. macronema linearis.

6. M. lineare canescens Nels. in Coult. et Nels. Man. Rocky Mt. Bot. 502, 1909. A form of H. macronema linearis. The original description is given entire as follows: "Leaves 2 to $3 \mathrm{~cm}$. long, acute, lightly canescent and nearly or quite destitute of resinous atoms; involucral bracts very finely lanate." No specific locality is mentioned, but the range is given as Yellowstone Park and adjacent Wyoming. The character of canescent foliage is not constant. Specimens from the Yellowstone (Nelson 6603, NY, R) are variable in the amount of tomentum and consequently in color of leaf and the type of linearis is sparsely tomentose on the leaves.

7. M. obtusum Rydb., Bull. Torr. Club 27:619, 1900.-The type specimens, from South Cottonwood Gulch, Chaffee County, Colorado, differ from typical H. macronema in the larger heads and the more obtuse outer bracts. This seems not to be an evolutionary form. In other specimens from Colorado the heads, when mature, are of exactly the same size but with the outer bracts decidedly acute (Baker 891, UC). In California the heads are mostly rather small and the outer bracts acutish, as in the original macronema. One collection from Nevada has the character of small heads united with that of obtuse bracts (Toiyabe Range, Kennedy 4164, UC); and in one from Utah the long heads have decidedly acuminate bracts (near Marysvale, Jones 5895, UC). All possible combinations of these two features are thus provided in the collections. (See further under No. 3.)

\section{RELATIONSHIPS}

When so conceived as to include the subspecies and minor variations just described, this becomes a very satisfactory species. The forms which comprise it are so intimately related that there can be no question as to their comprising one phylogenetic unit, and the species as a whole is sharply set off from its neighbors by obvious morphologic characters. The most important of these are the presence of a dense, white, felt-like

TABLE 9-Variation in Haplopappus macronema

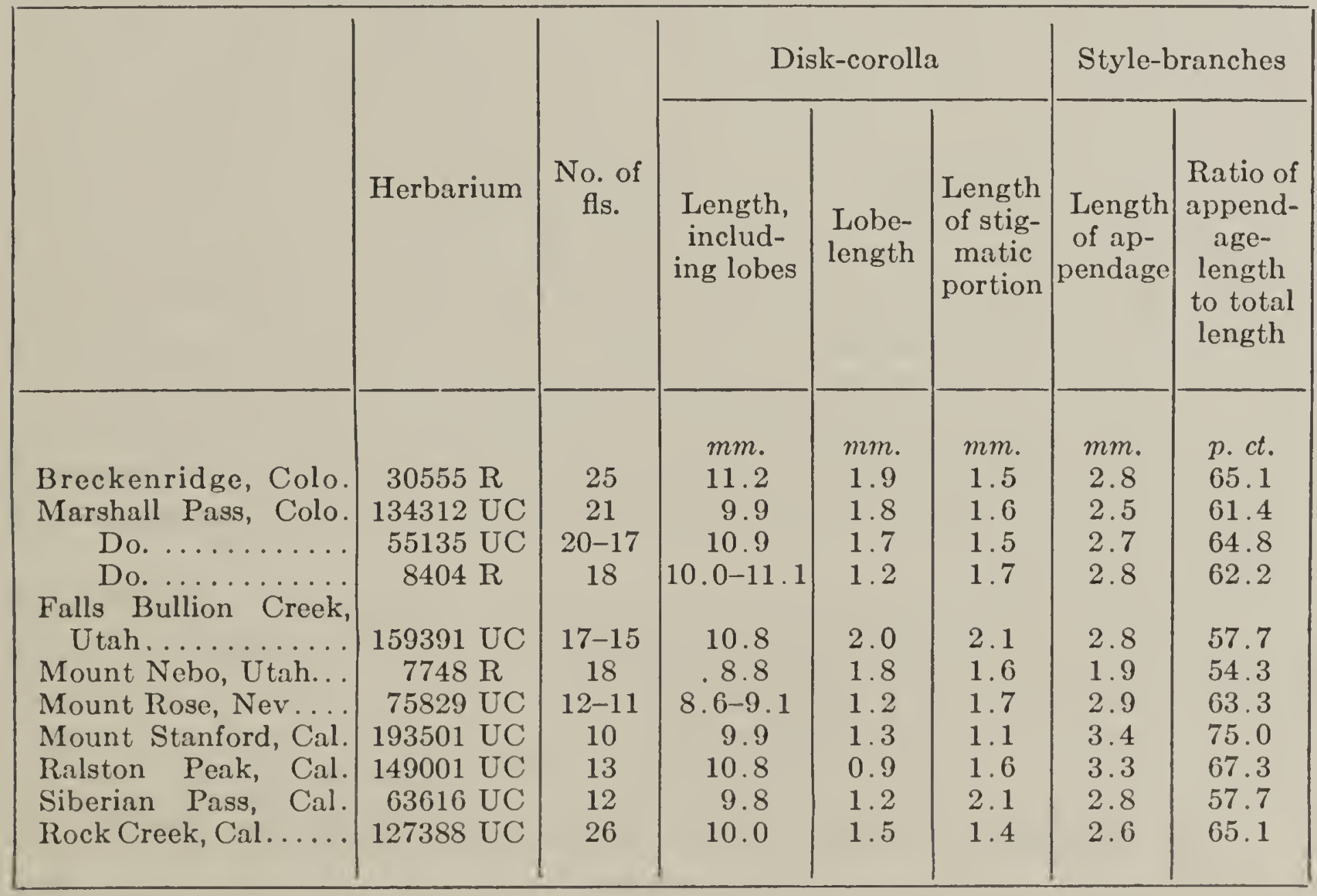


tomentum on the stems and the uniform absence of ray-flowers. The heavy tomentum quite certainly represents a development from glabrous or only glandular stems, for this feature is characteristic of highly developed types in related genera (especially Chrysothamnus nauseosus; see Hall and Clements, Carnegie Inst. Wash. Pub. 326:164 and 170, 1923). Even in Haplopappus, moderately tomentose forms seem to arise by mutation, as noted under $H$. greenei mollis. In the present species the tomentum is very dense and compact and no intermediate stage to the glandular or glabrous surface occurs.

The most closely related species is $H$. suffruticosus. A supposedly close connection with Chrysothamnus parryi bolanderi, which was assumed by some through the erroneous identification of specimens, has been discussed in detail by Hall and Clements (1. c., 160).

As a result of changes within the species there has been set off the slender, narrow-leaved, small-headed subspecies linearis. This is of rather local distribution in western Wyoming. There is some evidence also of a separation of the original stock into two branches, one of the Cascade and Sierra Nevada ranges, the other of the Rocky Mountains, but the evidence at hand does not justify a definite conclusion in this matter (see further under minor variation 3 ).

\section{ECOLOGY AND USES}

This low shrub is restricted to a narrow belt in the higher part of the mountains in western North America. It is most plentiful just above timber-line, but occurs also in openings in the subalpine forest, especially in forests of Pinus albicaulis. In California its most common associates are Pellaea breweri, Aquilegia pubescens, Potentilla monticola, Haplopappus suffruticosus, H. acaulis, Eriogonum incanum, E. marifolium, and other compact, deep-rooted perennials. Together with these it occupies stony, well-drained slopes, often working its way up through shale or between blocks of granite in the alpine fell-fields. In such situations the roots are found to be well established far beneath the rocky surface. Here they tap the supply of seepage moisture, without, however, losing the advantages of good drainage. The stems are frequently covered by gravel and then strike root from the lower portions. There is thus a constant effort to avoid inundation, but the stems finally emerge as gnarled, twisted trunks, often 3 or $4 \mathrm{~cm}$. thick and crowned with numerous crowded twigs. The dense, wool-like coating of the stems assists in maintaining a temperature suitable for the plant's metabolic processes. The leaves, which persist only for the season, are, on the other hand, entirely devoid of tomentum, so that photosynthesis in these organs is not interfered with. The resinous exudate from the foliage is very pleasantly fragrant. The blossoming period is July to September.

The forage value is reported by foresters and stockmen as negligible and the plants show but little evidence of browsing, even where sheep have been grazed. No other use is made of the species.

\section{SECTION 10. OREOCHRYSUM}

\section{Haplopappus parryi Gray, Am. Jour. Sci. II, 33:239, 1862}

An herbaceous perennial, usually 3 to $5 \mathrm{dm}$. high but much reduced in subalpine forms, spreading by slender rootstocks which connect the erect 
leafy stems, these either scattered or more often in small tufts; bark at first green but soon changing to reddish; stems firm but not rigid, striate, finely gray-puberulent above and sometimes to base; leaves oblanceolate to spatulate-obovate or the upper oblong or lanceolate, the lower tapering to a petiole-like base, the upper sessile and clasping, ascending or spreading, entire, obtuse, 6 to $15 \mathrm{~cm}$. long, 15 to $25 \mathrm{~mm}$. wide, or as much as $20 \mathrm{~cm}$. long by $50 \mathrm{~mm}$. wide in shade forms and reduced to $3 \mathrm{~cm}$. long by $8 \mathrm{~mm}$. wide on small exposed plants, with one principal nerve and several additional faint ones which looscly anastomose, the blade thin, glabrous or puberulent like the stems; heads cymose, the cymes varying from open and with long branches from near base of plant (minor variation 3 ) to a glomerule of only 2 or 3 heads (minor variation 2); involucre campanulate to nearly hemispheric, 10 to $11 \mathrm{~mm}$. high, 8 to $10 \mathrm{~mm}$. broad; bracts very loosely if at all imbricated, nearly equal, all shorter than disk, oblong and obtuse or lanceolately narrowed from middle and acute, the outer mostly herbaceous, the others pale and chartaceous except for the greenish tips, minutely and viscidly puberulent at least near margins; ray-flowers 12 to 20 , the palc-yellow ligules 5 to $7 \mathrm{~mm}$. long; disk-flowers about 30 to 50 or perhaps 60 ; diskcorolla with slender tube passing gradually into the narrowly tubular throat of greater length, 7.5 to $8.5 \mathrm{~mm}$. long, glabrous; lobes lanceolate, slightly over $1 \mathrm{~mm}$. long, erect, glabrous; style-branches well exserted, the slender acute appendage slightly exceeding stigmatic part or sometimes scarcely as long; achenes somewhat fusiform, being slightly rounded at summit and slenderly tapering toward base, 3.5 to $4.5 \mathrm{~mm}$. long, 4-angled, with 2 angles more prominent than the others and with faint intervening striac, glabrous or sometimes with scattered short hairs; disk-pappus exceeding corolla, rather copious, soft, white. (Fig. 70.)

Rocky Mountains from Wyoming and Colorado to Arizona and Chihuahua. Type locality, hillsides and pine woods, upper Clear Creck, Colorado. Wyoming: Centennial Valley, Nelson 8732 (Gr); Mount Wagner, southeast of Smoot, Payson and Armstrong 3745 (UC); Bridger Peak, Carbon County, Goodding 2007 (UC). Colorado: type collection, 1861, Parry 51 (Gr, Phila, Boiss, K); Grizzly Creek, Larimer County, Goodding 1858 (UC); Tolland, Ramaley 9093, 9101 (R); Minnehaha, Pike's Peak, Johnston 2699 (UC); Turquoise Lake, near Tennessee Pass, Hall 11058 (UC); Gray's Peak, August, Snow (UC); Elk Mountains, near Mount Marcellina, 1881, Brandegee (UC); Horn's Woods, Wet Mountain Valley, Custer County, 1877, Brandegee (UC); San Juan Mountains, Hall 11108, 11109 (UC). Uтан: Fish Lake, Jones 5793 (UC); Big Cottonwood Cañon, Salt Lake County, Garrett 1575a (Gr); Alta, Wasatch Mountains, Jones 1209 (Gr, type of var. minor, minor variation 2). New Mexico: Baldy Peak and vicinity of Ute Park, both in Colfax County, Standley 14365, 19975 (US); Mogollon Mountains, Socorro County, Metcalfe 507 (Gr); White Mountains, Wooton 349 (Gr, P, UC). Arizona: Bill Williams Mountain, Lemmon (Gr, UC); Pinos Altos Mountains, October 19, 1880 , Greene (K); Humphrey's Peak of San Francisco Mountain, MacDougal 589 (UC); Cariso Mountains, Brandegee 1273 (UC). Chinuahua: Sicrra Madre, Pringle 2014 (UC, Del, P, B). 

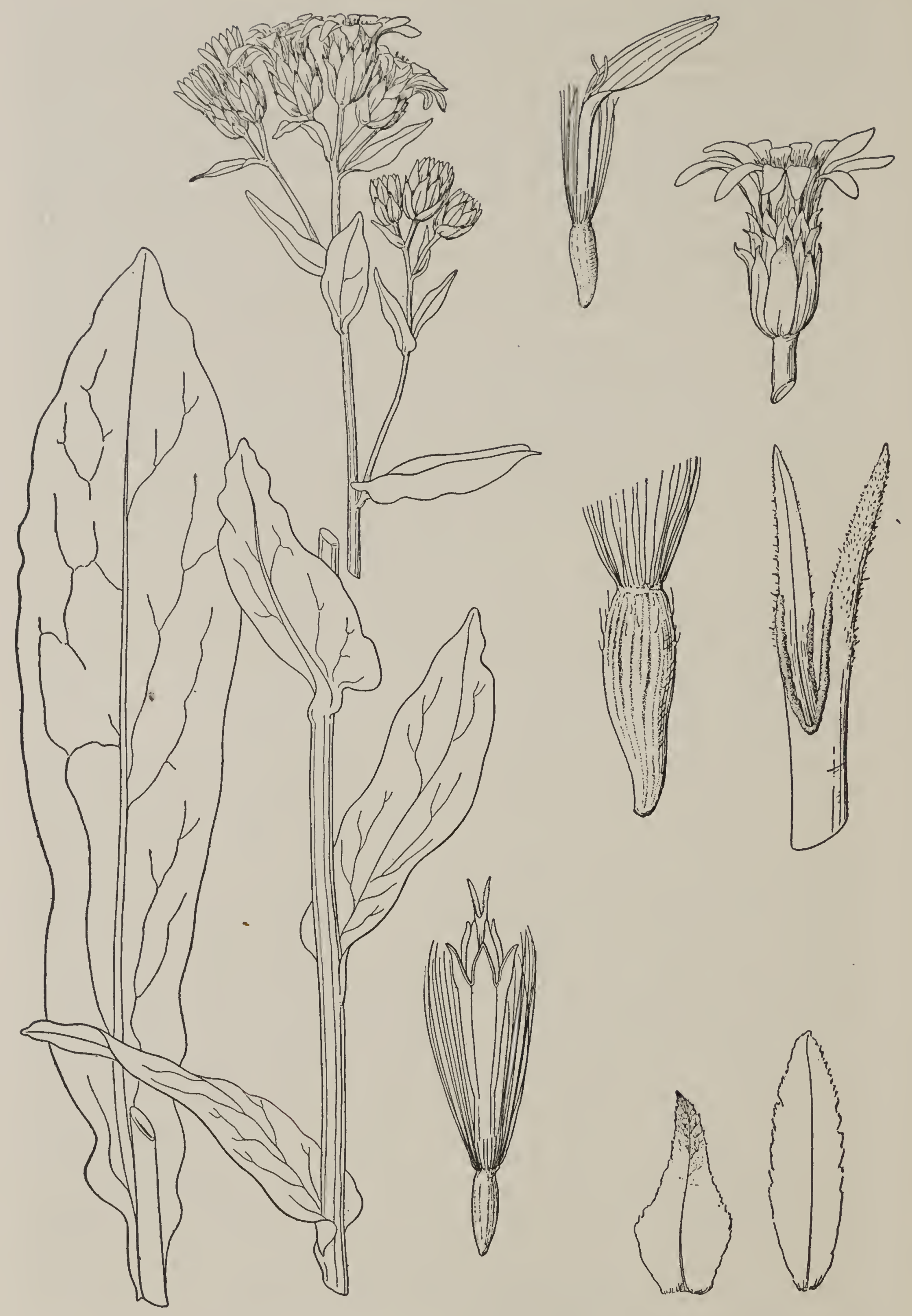

Fig. 70-Haplopappus parryi

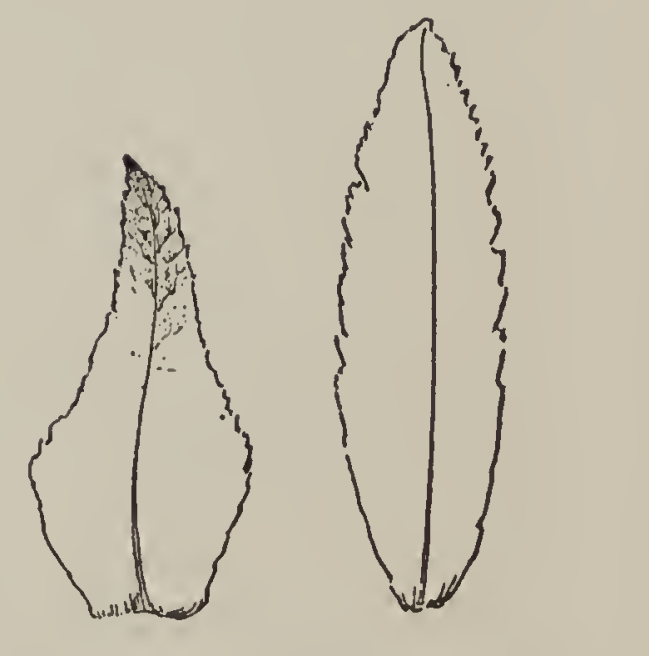




\section{MINOR VARIATIONS AND SYNONYMS}

1. Aster minor O. Kuntze, Rev. 316, 1891-H. parryi.

2. Haplopappus parryi var. minor Gray, Syn. Fl. $1^{2}: 131,1884$. Described only as a reduced subalpine form with leaves only 2.5 to $5 \mathrm{~cm}$. long and 2 or 3 narrower heads. The type is from the Wasatch Mountains, Utah, at 3,660 meters. Varies into typical parryi at lower altitudes, as will be shown under Ecology.

3. H. parryi. A form with numerous long-pedunculate heads has been labeled in herbaria as a variety but apparently the name has not been published. It comes from near Mount Marcellina, Elk Mountains, Colorado (1881, Brandegee, UC). This is almost certainly a temporary response and therefore will be discussed under Ecology.

4. Oreochrysum parryi Rydb., Bull. Torr. Club 33:152, 1906-H. parryi. The status of Oreochrysum has been previously considered (p. 39).

5. Solidago parryi Greene, Erythea 2:57, 1894. Based upon H. parryi. (See further on p. 39.)

6. S. parryi var. minor Greene, 1.c. Based upon H. parryi minor, which see in this list.

\section{RELATIONSHIPS}

Haplopappus parryi is so distinct from all other members of the genus that its phylogenetic connections are not easily made out. It is therefore placed in a section by itself, that is, in Oreochrysum, the relationships of which have been already discussed (p. 39). Because of its habit it is most likely to be confused with $H$. fremonti. From this it is best distinguished by the more copious pappus, this pure white, and by the involucre, the more chartaceous bracts of which are all shorter than the disk and without the long, tail-like attenuations so characteristic of the bracts of fremonti.

\section{ECOLOGY}

The normal form of this species is a moderately leafy perennial herb 3 to $7 \mathrm{dm}$. high. It grows in the petran forests in light shade of such conifers as Pinus contorta and Pseudotsuga taxifolia. Here, where the soil is moist but well drained, it grows either scattered or in loose beds, the flowering stems intermingled with conspicuous leafy tufts, or rosettes, to which they are connected by slender, often superficial rootstocks. Among its shade associates are Erigeron glabellus, Cystopteris fragilis, Thalictrum fendleri, and Solidago. It was this ecologically intermediate form that Gray took as his type for the species. There are many variations in habit, size of leaf, inflorescence, and pubescence, but all of these are believed to be due to differences in the environment.

The only named deviation from the typical form is the one from high altitudes which Gray called var. minor. The types of this are only 1.5 to 1.8 $\mathrm{dm}$. high, the leaves correspondingly reduced, and the heads but 2 or 3 in number. Other plants are even more reduced, some only $1 \mathrm{dm}$. high and with the largest leaves less than $4 \mathrm{~cm}$. long (Gray's Peak, Colorado, Snow), but at lower elevations it passes insensibly into typical parryi in all of its characters. A decidedly different variation is well represented by a plant from Elk Mountains, Colorado (minor variation 3). In this the plants and leaves are of average size, but the stems branch almost throughout and thus produce an open, flat-topped inflorescence of numerous heads. The whole plant is densely puberulent and apparently viscid. The habit, and perhaps also the pubescence, may be the result of exposure, as is suggested by still 
another form in which these features are combined with a stature of only 1.5 to $3 \mathrm{dm}$. and which comes from exposed roadsides at 2,750 meters altitude (San Juan Mountains, Hall 11109). In the same district and at even higher altitudes, but in the shade of subalpine forests, the simple-stemmed plants are 3 to $4 \mathrm{dm}$. high, nearly glabrous except near the top, and the few heads are in compact terminal clusters (Hall 11108). Throughout the range of the species there are numerous intermediates in which the size and shape of the leaves are also involved. In an extreme form the leaves are very thin and smooth and attain a diameter of nearly $5 \mathrm{~cm}$. Such plants grow in shade at average elevations where the soil is rich in humus and moist. This large number of variations, their apparent plasticity, and the ease with which the plants are vegetatively propagated suggest $H$. parryi as a promising species for experimental study.

The flowering period extends from the latter part of July through September.

\section{SECTION 11. ISOPAPPUS}

\section{PHYLOGENY OF THE SPECIES}

This section comprises but two species, one being the well-known and widely distributed Haplopappus divaricatus of the Gulf States; the other a new and local species of serpentine soils in California. The probable relationships between these will be discussed under $H$. occidentalis, the name proposed for the new species, where will be found also a tabulation of the differentiating features.

43. Haplopappus divaricatus (Nutt.) Gray, Pacif. R. R. Rept. 4:99, 1857

An erect annual herb, 2 to $7 \mathrm{dm}$. high, from a taproot, simple below, divaricately and cymosely branched above middle (branched at base if injured, see minor variation 11); stems striate, scabrous-pubescent, sometimes also glandular, especially near heads, rarely glabrate, more or less tinged with red; principal leaves rather equably distributed up to the inflorescence, spreading, rigid, linear-oblanceolate, beset with few spinulose teeth or entire (the margin varies to deeply dentate, the teeth up to $10 \mathrm{~mm}$. long and again toothed), mucronately acute, tapering to a petiole-like base, 3 to 7 $\mathrm{cm}$. long, 3 to $10 \mathrm{~mm}$.wide, (lower ones sometimes as much as $30 \mathrm{~mm}$. wide), with prominent midrib, often also reticulate, scabrid on both faces and sometimes coarsely stipitate-glandular, more or less setose-ciliate toward base; upper leaves reduced to linear or subulate, entire bracts subtending the branches; heads widely scattered in a cymose panicle, each terminating a naked, very slender peduncle-like branch; involucre turbinatecampanulate, rounded to base, 5 to $7 \mathrm{~mm}$. high, 4 to $6 \mathrm{~mm}$. broad; bracts about 20 to 40 , imbricated in 3 or 4 lengths, the outer about one-half as long as inner, the longest about equaling disk, linear-lanceolate, subulate-attenuate, the tips straight, the margins scarious, the middle portion green and scabrid to short-hispid and sometimes glandular, all strongly reflexed in age; ray-flowers 7 to 18 , the ligules 4.5 to $6 \mathrm{~mm}$. long; disk-flowers 8 to 25 or 30; disk-corolla slender, nearly cylindric but slightly and gradually ampliate upward, 4 to $5.2 \mathrm{~mm}$. long, usually glabrous; lobes lanceolate, 
acute, erect, about $0.6 \mathrm{~mm}$. long, usually scabrous or puberulent; stylebranches well exserted, 1 to $1.5 \mathrm{~mm}$. long, the linear-subulate appendage much exceeding stigmatic portion; ray-achenes fertile, cylindric-turbinate, sericeous-canescent, 1.5 to $2.5 \mathrm{~mm}$. long; disk-achenes fertile, similar to ray-achenes; ray-pappus of persistent bristles; disk-pappus of about 30 to 40 fine persistent bristles, equaling or exceeding disk-corolla and projecting slightly beyond involucre, ferruginous. (Chrysopsis divaricata Nutt., Genera $2: 152$, 1818.) (Fig. 71 and Plate 1, Fig. 2.)

Southern portions of the United States from South Carolina and Florida to Arkansas and Texas. Type locality, vicinity of Savannah, Georgia. South Carolina: near Batesburg, Lexington County, McGregor 266 (US); Eutawville, Eggleston 4975 (Gr). Georgia: Savannah (Phila, type); near Brunswick, Curtiss 1357 (US, B, K). Florida : River Junction, Curtiss 6005 (K, Gr); Lynn Haven, Bay County, October 13, 1921, Billington (US); Bellair, Leon County, Nash 2556 (US, B, K, Gr, NY); Quincy, Curtiss 1357 (UG); Aspalaga, Curtiss $998 a$ (B). AlaBAMA: dry pastures near Montgomery, 1885, Mohr (US); Auburn, Lee County, Earle 92 (US, Greene, R). Louisiana: New Orleans, Drummond 519 (K). Oklahoma: Canadian River, near Fort Reno, July 19, 1896, Blankinship (US); Sandy Creck Vallcy, near Shattuck, Stevens 2915 (US); Arkansas, Bush 1423 (Greene, B, K). Kansas: Sand Hills, Rice County, Hitchcock 223 (US, Gr) ; Medicine Lodge, July 14, 1888, Kellerman (US); Harper County, Oyster 3572 (SF); near Aetna, Ward 74 (US). Texas: Galloway, Seler 1008 (B); southwestern

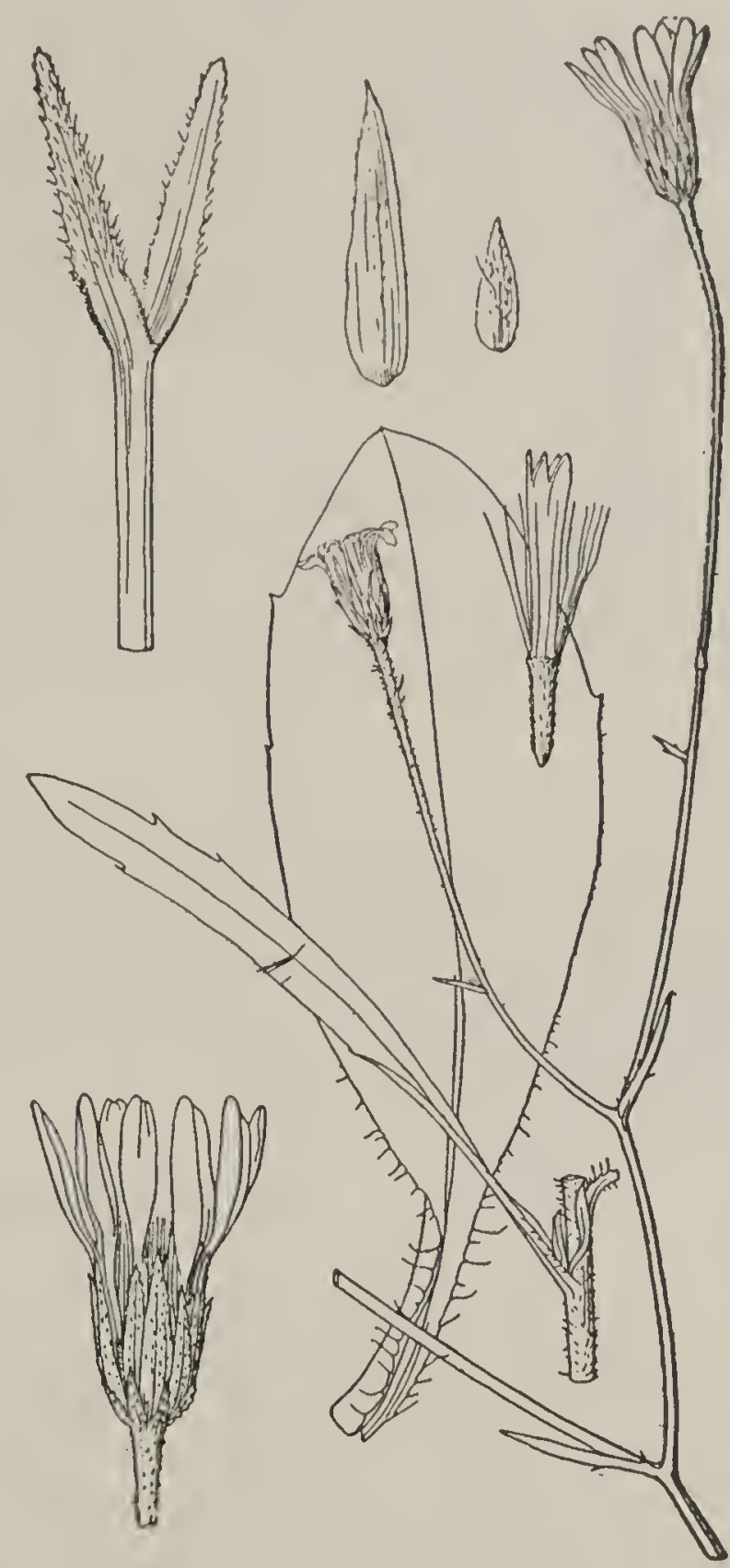

FIG. 71-Haplopappus divaricatus

Texas, Palmer 479 (K, Boiss); Houston, Fisher 5133 (US); Capano Bay, Palmer $475(\mathrm{~K})$; sand banks, Pease River bottoms, near Vernon, Ferris and Duncan 3347 (SF); Peña, Pringle 3688 (R, Gr); near Texarkana, Bowie County, Heller 4201 (Gr, NY).

\section{MINOR VARIATIONS AND SYNONYMS}

1. Aster divaricatus O. Kuntze, Rev. 318, 1891-H. divaricatus.

2. A. hookerianus O. Kuntze, Rev. 318, 1891. Based upon Isopappus hookerianus, which see.

3. Chrysopsis divaricata Ellis, Sketch $2: 338-H$. divaricatus.

4. Croptilon divaricatum Rafinesque, Fl. Tel. $2: 47,1836-H$. divaricatus.

5. C. hookerianum House, N. Y. State Mus. Bull. 233-234:61, 1921. Based upon Isopappus hookerianus, which see.

6. Diplopappus? (Chrysopsis) divaricatus Hook., Compan. Bot. Mag. 1:97, 1836H. divaricatus.

7. Haplopappus hookerianus Gray, Syn. Fl. 12:131, 1884. Based upon Isopappus hookerianus, which see. (Not H. hookerianus DC., 1838.) 
8. Heterotheca lamarcki DC., Prodr. 5:317, 1836. Haplopappus divaricatus, as to a portion of synonymy, but the first synonym is Inula subaxillaris Lamarck, which is a Heterotheca.

9. Inula divaricata Nutt., Genera 2:152, 1818-H. divaricatus.

10. Isopappus divaricatus Torr. et Gray, Fl. N. Am. 2:239, 1842-H. divaricatus. 11. I. hookerianus Torr. et Gray, Fl. N. Am. 2:239, 1842. Apparently a modification of $H$. divaricatus. Stems branching from the base, the few branches curved-ascending; lower leaves oblong-spatulate, obtuse but mucronate at apex, tapering to a petiole, up to $12 \mathrm{~mm}$. in width; foliage and involucres nearly glabrous. Type, Gonzales, Texas, Drummond 184 (Kew). Only a few plants were found and the form has not been re-collected. The weak taproot branches near the surface, which, with the broad, smooth leaves, suggests that this is a form of good soil and perhaps a ruderal. Plants otherwise typical of divaricatus sometimes branch from the base as a result of injury to the main stem (Texas, Lindheimer 254, Gr, in part, another plant of the same collection being simple below).

\section{RELATIONSHIPS}

The wide distribution in southerly districts and the numerous flowers, all of which are perfect and fertile, may be taken as presumptive evidence that this is the more primitive of the two species of Isopappus. The connections with Haplopappus occidentalis will be discussed later.

\section{ECOLOGY}

This is a common weedy plant of moderately dry sandy soil in warm districts, growing especially where the vegetation has been disturbed, as by grazing. It belongs almost exclusively to the humid portion of the Lower Sonoran Life-zone, where it develops in late summer and flowers from September to November.

\section{Haplopappus occidentalis sp. nov.}

An erect annual herb, 2 to $11 \mathrm{dm}$. high, from a taproot, widely branched and floriferous almost from base (as in type specimen) or simple below; stems striate, coarsely scabrous, most of the hairs gland-tipped, strongly tinged with red; principal leaves equably distributed along lower half of main stem, widely spreading, reflexed and persistent in age, rigid, lanceolate or linear-lanceolate or somewhat oblanceolate, entire or only slightly sinuate, mucronately acute, slightly narrowed to a sessile semiamplexicaul base, 4 to $8 \mathrm{~cm}$. long, 7 to $14 \mathrm{~mm}$. wide (smaller and especially narrower in dwarf plants), with prominent midrib and coarsely reticulate, scabrid and densely stipitate-glandular, not setose-ciliate; upper leaves reduced to linear or subulate bracts subtending the branches and peduncles; heads effusely scattered in a very open panicle, each head terminating a rather stout peduncle, this with few or several scale-like bracts; involucre cylindricturbinate, acute at base, 8 to $10 \mathrm{~mm}$. high, 2 to $3 \mathrm{~mm}$. broad; bracts about 30 to 40 , well imbricated in 4 or 5 lengths, the outer passing into scales of the peduncle, the longest exceeding disk, linear-attenuate, mostly with a slender spreading or recurved tip which ends in a thick gland (young heads with nearly straight glandless bracts), with green body and white-scarious margins, the inner with straight reddish tips, all with exposed parts viscid and glandular, not reflexed in age; ray-flowers 5 to 8 (normally 8), the ligules 6 to $6.5 \mathrm{~mm}$. long; disk-flowers 9 to 12 ; disk-corolla with very slender 
tube, abruptly expanding at about middle to a slightly broader throat, 4.6 to $5.2 \mathrm{~mm}$. long, glabrous; lobes lanceolate, acute, erect, 0.7 to $1.2 \mathrm{~mm}$. long, glabrous; style-branches included in disk-corolla, about $1.5 \mathrm{~cm}$. long, the linear acute appendage exceeding the obscure stigmatic portion; rayachenes fertile, subprismatic but narrowed below and somewhat compressed, the back rounded, the lateral edges with strong rib, the inner face 1-nerved, the achene therefore triangular in cross-section, 3.5 to $4 \mathrm{~mm}$. long, sericeous with upwardly appressed hairs, mottled with brown; diskachenes sterile, slenderly prismatic, 4 -angled, transparent, 3 to $3.5 \mathrm{~mm}$. long, glabrous; ray-pappus of about 5 or 6 slender deciduous bristles; diskpappus of few (1 to 8) unequal deciduous bristles, all much shorter than corolla and involucre, nearly white. (Fig. 72 and Plate 1, Fig. 1.)

East side of summit, Parkfield Grade, in the inner south Coast Ranges of western Fresno County, California, at 1,065 meters altitude, October 13, 1921, H. M. Hall 11\%69 (UC, 216904, type); same locality, June 12, 1915, Hall 10026 (UC), and September 24, 1926, Hall and Keck 12240 (UC); $2.5 \mathrm{~km}$. northeast of Cook, San Benito County, California, November 27, 1910, Hannibal (DS).

\section{RELATIONSHIPS}

This new species is far removed from the only other member of its section, both geographically and in technical characters. Some of these latter, such as the sterile disk-flowers, deciduous pappus, and differently shaped rayachenes, are of sectional value in other parts of the genus, but here the similarities in other features are so marked that there can be no thought of more than a specific segregation. The more important differences between the two species of Isopappus may be indicated as follows:

Haplopappus divaricatus

1. Leaves petiole-like at base, where mostly setose-ciliate.

2. Involucre rounded to the base, 5 to $7 \mathrm{~mm}$. high, 4 to $6 \mathrm{~mm}$. broad (to $8 \mathrm{~mm}$. high in Hitchcock 223).

3. Bracts with straight tips, not ending in a gland.

4. All braets strongly reflexed in age.

5. Disk-eorolla gradually enlarged upward.

6. Ray-achenes $2.5 \mathrm{~mm}$. or less long, subeylindrie.

7. Disk-achenes fertile, densely pubeseent.

8. Pappus of numerous bristles, usually exeeeding the involuere, persistent in ray and disk.

9. Widely distributed in sandy soil of Gulf States.
Haplopappus occidentalis

1. Leaves slightly narrowed at base, halfclasping, not setose-ciliate.

2. Involucre aeute at base, 8 to $10 \mathrm{~mm}$. high, 2 to $3 \mathrm{~mm}$. broad.

3. Outer bracts with tips recurved in age and ending in a large gland.

4. Bracts all permanently ereet (except tho tip).

5. Disk-eorolla abruptly enlarged near middle.

6. Ray-achenes 3.5 to $4 \mathrm{~mm}$. long, triangular in eross-seetion.

7. Disk-achenes sterile, glabrous.

8. Pappus of few bristles, much shorter than the involuere, deciduous in ray and disk.

9. Restricted to serpentine areas of inner south Coast Ranges, California.

It is of especial interest to inquire into the probable origin of Haplopappus occidentalis. Its development from divaricatus, which assumption seems justified, has been accompanied by numerous changes, but some of these are perhaps traceable to one, namely, the partial suppression of the disk-flowers. The cause of this can only be surmised, but it is conceivable that a disturbance in metabolism and the resulting competition between ray and disk led to an abortion of the latter. At any rate, functionless disk- 
flowers would be expected to have only short, imperfect stigmas and glabrous, sterile achenes, in consequence of which the pappus might fail of normal development and become early deciduous. Finally, these atrophied achenes occupy so little space that the heads remain narrow, especially at base, and the involucre does not reflex in age. The much drier climate would account for the excessive production of resin and this in turn for the terminal glands on the involucral bracts.

Such possibilities suggest that Haplopappus occidentalis may be only a modification resulting from a chance introduction of $H$. divaricatus into California, where it fell under the influence of poor, serpentine soil and an excessively arid climate. The restriction, as far as known, to two colonies is also suggestive, although at the Parkfield station the plants are abundant and distributed over both slopes of the range for a distance of at least $10 \mathrm{~km}$. On the other hand, there is considerable evidence that there has been a genuine phylogenetic separation of long duration. Among these may be noted the decidedly different shape of ray-achenes, together with their large size, and especially the fact that the pappus is reduced and early deciduous in ray as well as disk. Sterility can not here be invoked as an explanation of deciduousness. The broad-based, half-clasping leaves are also difficult of explanation, as are the recurved tips to the outer involucral bracts and the greater length of the involucre itself.

The differentiating characters have been experimentally tested by growing the two species under uniform conditions at Berkeley, California. Seeds of divaricatus, obtained from Texas through the kindness of Dr. B. C. Tharp, were germinated in flats and the young seedlings set out in a field with plants grown by the same methods from seeds of occidentalis obtained at the type locality. The plants of divaricatus (which may have been of an exceptionally vigorous strain) were very robust, finally attaining an average height of 5 to $8 \mathrm{dm}$. but did not come into flower until October. The lowest pair of leaves were broadly elliptic, averaging about $30 \mathrm{~mm}$. wide. (See Plate 1.) The comparatively slender plants of occidentalis averaged only $4.5 \mathrm{dm}$. high and were in full flower by August 15. The leaves of the lowest pair were narrowly oblanceolate and averaged 5 to $6 \mathrm{~mm}$. wide. The two sets of cultures were also differentiated by all of the 9 characters of the preceding enumeration, as well as by minor features. The experiment was repeated in another portion of Berkeley and also at Santa Barbara, with the same results. An additional set of cultures was grown in strongly serpentine soil, which retarded growth but had no other influence in modifying the characters under observation.

The results of these experiments confirm the opinion formed from comparative studies that Haplopappus occidentalis is much more than a temporary variant resulting from the influence of environmental factors. It appears more probable that occidentalis reached California from the Texan area in early times, perhaps in the Pleistocene, when the intervening territory was better suited to these annuals; that it later became separated from the parent stock in connection with climatic changes; and that it is now a relict limited to poor, serpentine soils of a small geographic area.

\section{ECOLOGY}

Haplopappus occidentalis is limited to a few areas in the extremely arid inner south Coast Ranges of California, within the area of serpentine soils. 


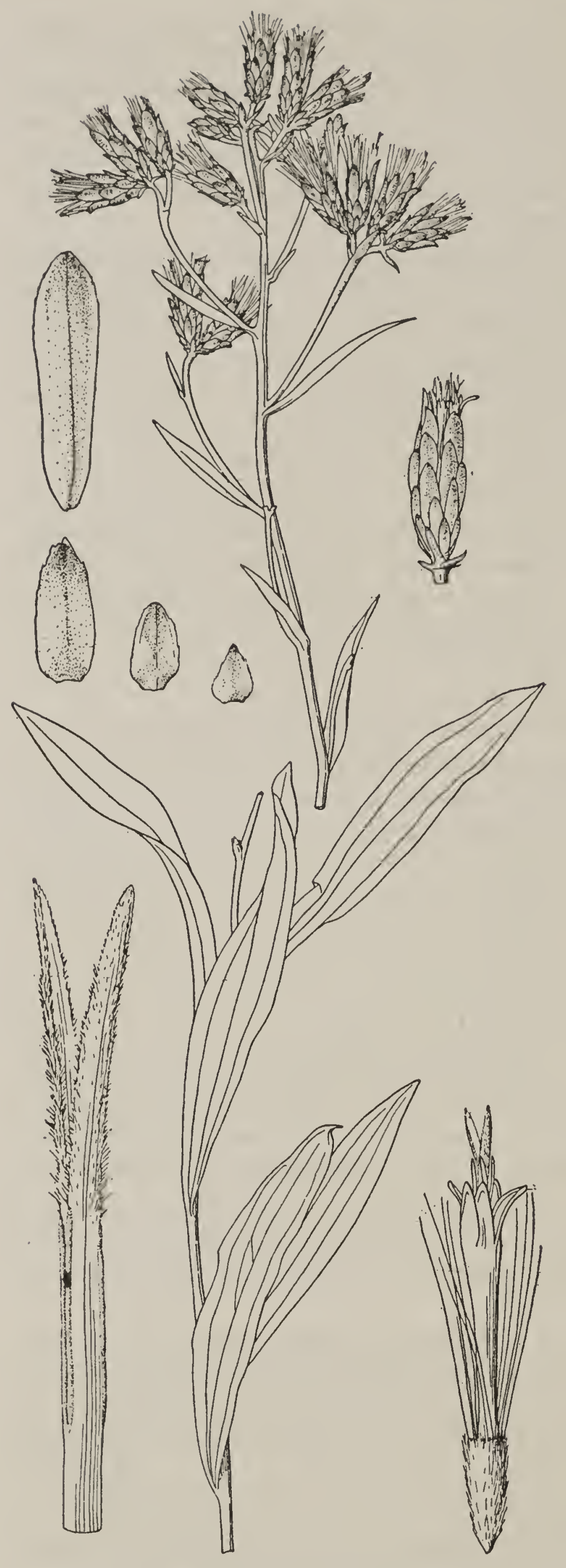

Fig. 73-Haplopappus scopulorum
This is in the Upper Sonoran Zone, where the open woodland is composed of Pinus coulteri, P. sabiniana, Quercuswislizeni, Aesculus californica, etc., but the Haplopappus grows only on exposed slopes and flats where there has been much disturbance by overgrazing, and especially where the surface is broken by trampling or erosion. Its commonest associates are ruderals, such as Centaurea, Eremocarpus, and Croton. The flowering period is June to October.

\section{SECTION 12.}

\section{HESPERODORIA \\ PHYLOGENY OF THE SPECIES}

This section comprises two relict species so unlike each other and each so distinct from those of any other group that little can be said as to their relationships. One is a rare species of arid districts in the southerly part of Great Basin area, the other, equally rare, is confined to semiarid slopes to the extreme northwest of the same area.

\section{Haplopappus scopulorum} (M. E. Jones) Blake, Contr. U. S. Nat. Herb. 25:546, 1925

A slenderly branched willowy subshrub, 3 to $6 \mathrm{dm}$. (or more?) high, very leafy below, less so above; bark smooth, white, shining; twigs hard, brittle, striate, glabrous; principal leaves linear-lanceolate to oblanceolate, ascending or spreading (resembling those of some grasses), strictly entire, acuminate, narrowed to base, 3 to 6 or $7 \mathrm{~cm}$. long, 3 to $8 \mathrm{~mm}$. wide, more or less rigid, submembranous, traversed by three longitudinal veins and with prom- 
inent cross-veinlets, glabrous, smooth except for scabrid margins, not resinous, without fascicled ones in the axils; heads in terminal glomerules of about three (as in the type) or in small cymes and these arranged in loose panicles; involucre cylindric-turbinate, 7 to $9 \mathrm{~mm}$. high, 3 to $5 \mathrm{~mm}$. broad; bracts imbricated in 5 or 6 lengths, the outer passing into scales of the peduncle, the inner nearly equaling disk, erect, oblong, chartaceous, the tips merely greenish, becoming brown, very obtuse except sometimes inner, glabrous; ray-flowers wanting; disk-flowers about 10 to 15; disk-corolla with long tube passing gradually into the throat, 7 to $8 \mathrm{~mm}$. long, glabrous; lobes linear-lanceolate, the tips recurved, about $2 \mathrm{~mm}$. long, glabrous; style-branches long-exserted, 3 to $4 \mathrm{~mm}$. long, the linear appendage much exceeding stigmatic portion; achenes slender, about 4-angled, silky-villous (not known in mature condition); pappus white, very fine and soft, nearly as long as the corolla, the bristles about equal. (Bigelovia menziesi scopulorum M. E. Jones, Proc. Calif. Acad. II, 5:692, 1895.) (Fig. 73.)

Southern Utah and northern Arizona. Type locality, cañon of the upper Virgin River, above Springdale, Utah. UTAH: type collection, M. E. Jones $60 \% 4$ (US, UC, considered by Jones as the type collection, verbal communication); near Cedar City, M.E. Jones 5204V (US); Armstrong and White cañons, near the natural bridges, Rydberg and Garrett 9453 (US), and 9454 (UC); Virgin River, Zion Park, October 10, 1923, W. W. Jones (UC). Arizona : rocks of the Virgin Range, Purpus 6170 (UC); Bright Angel Trail, Grand Cañon, October 22, 1905, Eastwood (US); Grand View Trail, Grand Cañon, Eastwood 3586 (SF).

\section{MINOR VARIATIONS AND SYNONYMS}

No taxonomic segregates appear for this species. The few collections at hand, however, indicate either that several forms are involved or that young and old plants are very unlike. In the types the well-formed heads are practically sessile in terminal glomerules. This describes also the specimen cited as Eastwood 3586 . In the other Eastwood specimen and in the one collected by Purpus, the small, immature heads are in part solitary on elongated peduncles, but some sessile. The W. W. Jones collection has the mature heads in rather loose glomerules, these long peduncled. There are some differences also in the texture of involucral bracts, but all these variations probably represent different stages of maturity. or the result of ecologic conditions. The following synonyms appear:

1. Bigelovia menziesi var. scopulorum Jones, Proc. Calif. Acad. II, 5:692, 1895.

2. Hesperodoria scopulorum Greene, Leaflets 1:173, 1906.

3. Isocoma scopulorum Rydb., Fl. Rocky Mts. 859, 1067, 1917.

\section{RELATIONSHIPS}

This species is very different from all others, especially in the foliage, which resembles that of some of the smaller species of Bambusa rather than of Haplopappus. The soft, white pappus and the long style-appendages furnish some justification for Greene's proposition of Hesperodoria as a new genus to accommodate this species and $H$. halli. His comparison with Solidago pumila Nutt., however, should be taken as only suggestive of a similarity in general appearance, particularly in foliage. This unusual type of foliage is found also in Chrysothamnus gramineus. It seems that something in the environment in these arid western districts has called forth a similar expression in the three plants, although there is no close phylogenetic connection between them. Although $H$. scopulorum has no immediate relatives, the shape of the involucre, the arrangement of the heads, and the white, 


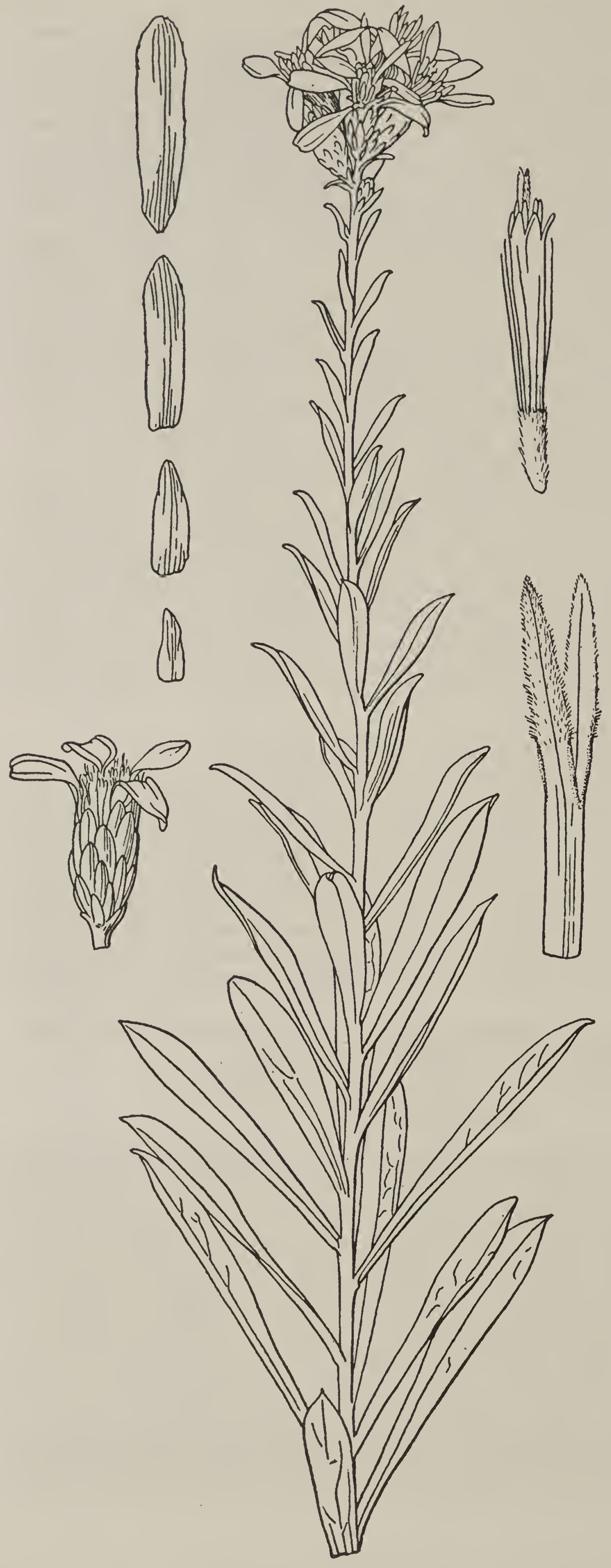

Fig. 74-Haplopappus halli brittle stems are suggestive of species of the section Isocoma. It was, in fact, first described as a variety of a species now referred to $H$. venetus, of that section, but it differs from this in such important features as elongated style-appendages, shape of corolla, long corolla-lobes, and a soft, white pappus.

\section{ECOLOGY}

This is a plant of gravelly slopes and stony places in arid districts of the Southwest, but it is not found on the desert proper. The altitudinal distribution as far as known is 1,200 to 1,800 meters. Although there may be extensions into the lower part of the Transition Zone, it belongs principally to the Upper Sonoran, where it grows in the belt of Pinus monophylla, Juniperus utahensis, and Artemisia tridentata. That it may invade even the Lower Sonoran is indicated by a note in connection with the W. W. Jones specimen that the plantswere in rather moist soil, not far from Prosopis juliflora, Celtis, and Vitis. The flowers mature in September and October. 


\section{Haplopappus halli Gray, Proc. Am. Acad. 8:389, 1872}

A woody-based perennial, much branched below, the branches strict, thus forming narrow erect bushes, 3 to $6 \mathrm{dm}$. high, very leafy throughout but leaves reduced in size toward heads; bark greenish, becoming dark below, finally breaking into fibers; twigs (erect branches) rigid, with prominent ridges running to the leaf-bases, microscopically scabrid; principal leaves oblanceolate, strictly entire, short-acuminate, narrowed to base, 3 to $5 \mathrm{~cm}$. long, 3 to $7 \mathrm{~mm}$. wide (rarely 10 or $12 \mathrm{~mm}$.), with thick midrib and of ten two fainter ribs from base, the lateral nerves divergent, thin, somewhat membranous, sparsely scabrid, with no fascicled ones in the axils; heads in terminal glomerules of 2 to 8 or short-racemose through elongation of the common peduncle; involucre cylindric-turbinate, about $8 \mathrm{~mm}$. high, 5 to $6 \mathrm{~mm}$. broad; bracts loose, regularly imbricated, of about 5 lengths, the longest equaling disk, erect, oblong, white-chartaceous with deep-green tip, rather obtuse (except small outer ones) but mostly short-mucronate, glabrous, resinous, shining as though varnished; ray-flower's normally 5 (about 10 according to Gray), the ligule 6 to $7 \mathrm{~mm}$. long, about $1 \mathrm{~mm}$. wide; diskflowers 15 to 25 or perhaps more; disk-corolla with slender tube passing gradually to a slenderly tapering throat, 6.5 to $7.5 \mathrm{~mm}$. long, hirtellous on tube; lobes ovate, acute, nearly erect, 1.0 to $1.3 \mathrm{~mm}$. long, glabrous; stylebranches about $2 \mathrm{~mm}$. long, the linear appendage much exceeding stigmatic portion; achenes subcylindric, truncate at summit, narrowed to base, about 5-angled, silvery-silky; pappus copious, of soft nearly white bristles, these nearly equal and fully as long as corolla. (Fig. 74.)

Confined to a limited area in southeastern Washington and adjacent Oregon. Type locality, bluffs of Columbia River at The Dalles, Oregon. Washington: White Salmon, Suksdorf $392(\mathrm{Gr})$; Falcon Valley, September 10, 1882, Suksdorf (B, UC); Columbia Bluffs, near White Salmon, H. M. Hall 11633 (UC). Oregon: type collection, 1871, Elihu Hall 257 (Gr); Cascade Mountains, October 8, 1881, Pringle (Gr); Wasco County, Howell 173 (US); near Breitenbush Hot Springs, Applegate 2755 (US).

\section{SYNONYMS}

The following names refer without exception to $H$. halli:

1. Aster howelli O. Kuntze, Rev. 316, 1891.

2. Hesperodoria halli Greene, Leaflets 1:174, 1906.

3. Hoorebekia halli Piper, Contr. U. S. Nat. Herb. 11:560, 1906.

4. Pyrrocoma halli Howell, Fl. N. W. Am. 1:299, 1900.

\section{RELATIONSHIPS}

Although placed in the same section as Haplopappus scopulorum, because of a close similarity in the involucres, style-branches, and pappus, these two species are decidedly unlike. Aside from the uniform presence of ligules to the ray-flowers in halli there are important differences in foliage, inflorescence, etc. The wide separation of this species from any other, both geographically and morphologically, probably means that its exact phylogenetic position never will be determined.

\section{ECOLOGY}

In growth habit Haplopappus halli is a narrow subshrub with many erect, very leafy stems from a much branched, woody base. It inhabits stony, 
well-drained slopes, especially those overlooking the Columbia River. Here it grows in the light shade of open groves, particularly of Quercus garryana and Pinus ponderosa, and belongs, therefore, to the Lower Transition Zone. The flowers appear in late summer and autumn.

\section{SECTION 13. ISOCOMA}

\section{PHYLOGENY OF THE SPECIES}

The species of this section are so few and so detached from one another that it is difficult to determine the sequence in which differentiating characters have been evolved. It is therefore assumed, somewhat arbitrarily, that ordinary, short-lobed corollas preceded those which are deeply cleft; that excessively short involucres are the result of reduction from longer, primitive ones; and that the presence of a definite resin-pocket on the involucral bracts indicates a recent, divergent development. When these premises are accepted, one is led inevitably to the selection of Haplopappus venetus as the most primitive species. Since the typical form of venetus comes from southern Mexico, this fits in with the generally accepted theory that the North American sections had their origin somewhere to the south.
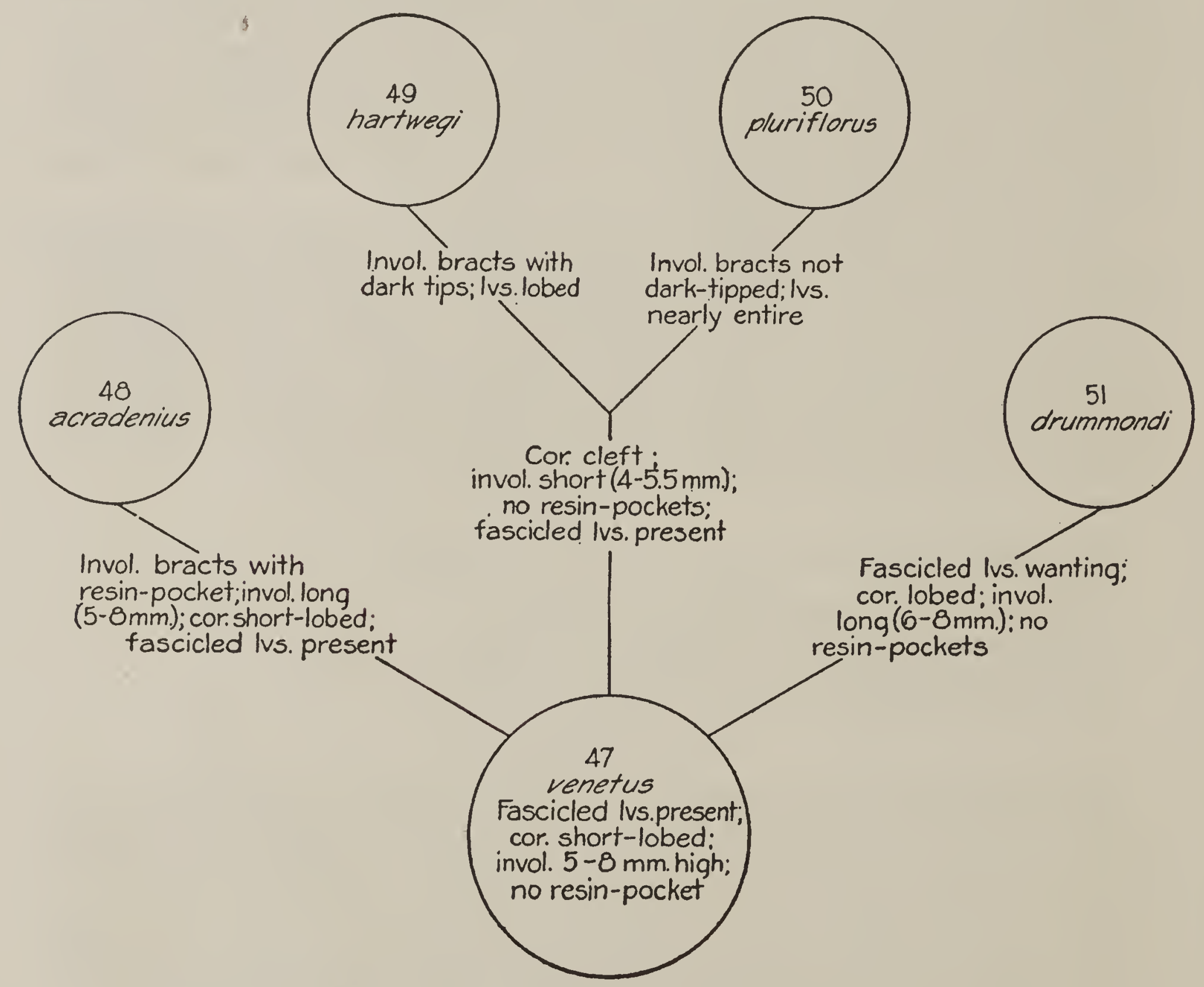

FIG. 75-Phylogenetic chart of the species of Haplopappus section Isocoma

The presence of the unique resin-pocket in the bracts of Haplopappus acradenius seems sufficient evidence that this is a derived species. There is no certain proof, however, that it has sprung directly from venetus. $H$. hartwegi and $H$. pluriflorus are very closely related to each other and both 
are remarkable in the depth to which the corollas are cleft. These apparently are direct northern derivatives of venetus. H. drummondi is unique in the section in that it has no secondary fascicled leaves in the axils of the primary ones. In appearance, and in most of its technical characters, it approaches very closely to acradenius. It is not impossible that the latter was derived from drummondi as a western variation.

\section{Haplopappus venetus(HBK.)} Blake, Contr. U. S. Nat. Herb. $23: 1492,1926$

An erect shrub, with numerous woody branches from near basc, usually 5 to $20 \mathrm{dm}$. high, lower in some Mexican forms, sometimes low and decumbent in maritime districts; bark gray, becoming nearly black, breaking longitudinally on old stems; twigs firm but not brittle, more or less striate, glabrous to tomentulose; principal leaves usually oblanceolate or spatulateoblong, but varying from rounded-obovate to almost linear, entirc to usually dentate, rarely lobed, acute or obtuse, 1 to 4 $\mathrm{cm}$. long, 2 to $10 \mathrm{~mm}$. wide, 1 nerved, glabrous or hirtellous, rarely tomentulose (especially minor variation 28), secondary fascicled leaves present in most of the axils; heads typically cymose, the clusters themselves often cymosely or paniculately arranged; involucre turbinate, 5 to $8 \mathrm{~mm}$. high, 4 to $6 \mathrm{~mm}$. broad; bracts regularly imbricated in about 4 lengths, all shorter than disk, erect, ovate to oblong, hard-coriaceous at base, the margins thin, the sum-

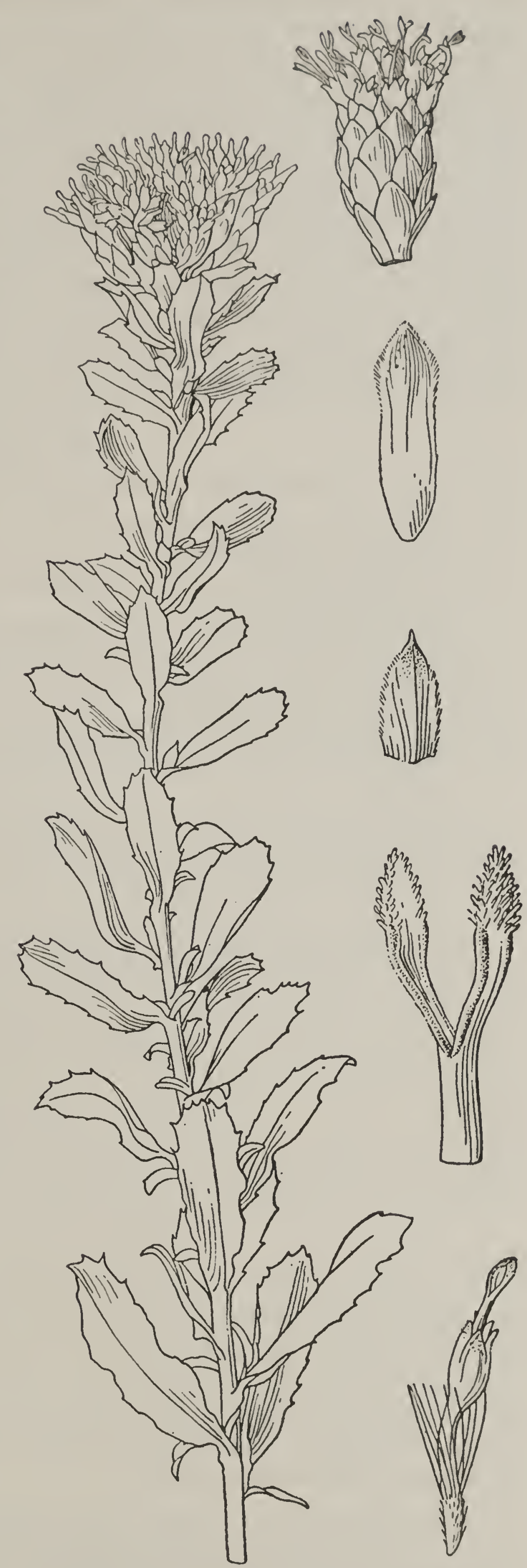

FIG. 76-Haplopappus venetus vernonioides 
mit with conspicuous greenish spot, resinous, glabrous or merely hirtellous (varying to tomentose in minor variation 28); ray-flowers wanting; diskflowers 15 to 25 or 30 ; disk-corolla ventricose above the slender tube, 5.5 to $7 \mathrm{~mm}$. long, glabrous or puberulent; lobes ovate, acute, erect, 0.5 to 1 $\mathrm{mm}$. long, glabrous; style-branches short-exserted, 1.2 to $1.8 \mathrm{~mm}$. long, the ovate-acute appendage much shorter than stigmatic portion (mostly less than one-half as long); achenes 2 to $4 \mathrm{~mm}$. long, about 4-angled, either slender and gradually tapering from summit to base or thicker and scarcely tapering (typicus), silky-villous; pappus of numerous slightly unequal brown bristles, the longest fully equaling corolla. (Baccharis ? veneta, HBK., Nov. Gen. et Sp. 4:68, 1820.) (Fig. 76.)

Western California, from San Francisco Bay southward; Mexico from Lower California and Coahuila to south of Mexico City.

\section{SUBSPECIES}

Key to the Subspecies of Haplopappds venetus

Leaves mostly dentate, lobed, or incised, obtuse to moderately acute or ending in an acute lobe.

Leaves merely dentate or if more deeply cut the lobes then rather equably distributed.

Achenes 2 to $3 \mathrm{~mm}$. long, thick. (Mexico)................ (a) typicus

Achenes 3 to $4 \mathrm{~mm}$. long, very slender. (California)............... (b) vernonioides

Leaves with 3 or 4 prominent lobes near apex, otherwise entire, very

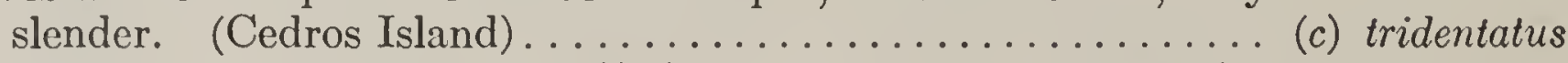

Leaves mostly entire, very acute or if obtuse then also very small (intermediates between $b$ and $d$ have entire but somewhat obtuse leaves).

Plant tall, erect; heads many, cymes openly paniculate; leaves mostly

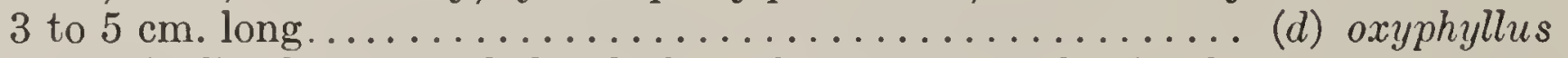

Plant low, inclined to spread; heads few, the cymes nearly simple, compact, rounded; leaves mostly 1 to 3 or $4 \mathrm{~cm}$. long......... (e) furfuraceus

47a. Haplopappus venetus typicus-Stems crect or ascending; herbage glabrous to hirtellous; leaves spatulate-oblong, acutish to obtuse, lowmucronate, 4 to $10 \mathrm{~mm}$. wide, mucronately dentate with few teeth (as in the type) to laciniate, the narrowed base commonly entire; heads in rounded terminal cymes; involucre 5 to $7 \mathrm{~mm}$. high; bracts with acute green tips, glabrous or the margins slightly hirtellous, resinous; achenes 2 to $3 \mathrm{~mm}$. long, thick, only slightly narrowed downward from the truncate summit. (Baccharis ? veneta HBK., Nov. Gen. et Sp. 4:68, 1820.)

Mexico, from southern Coahuila to Morelos. Type locality, near Cuernavaca, Morelos. Coahuila: Parras, Palmer 483( K). Hidalgo: near Tula, Pringle 6405 (UC, Gr, B, K, leaves pale, short, and otherwise atypical). SAN LUis Potosi: plains near the city, Pringle 3803 (UC, a form with incised foliage). Mexico: mountains near City of Mexico, Molina 587 or 687 (DC); same general locality, 1831, Alaman (DC); SANTA FÉ, Bourgeau 367 (K). Morelos: type collection, Humboldt and Bonpland (P). Puebla: Esperanza, Purpus 2633 (UC, a form with large heads and dark, incisely lobed leaves, see under minor variation 15$)$.

47b. Haplopappus venetus vernonioides (Nutt.) - Stems erect or ascending; herbage from nearly glabrous to hirtellous or villous, especially the stems (forms grade into minor variations 17 and 28, with conspicuous to- 
mentum); leaves spatulate-oblong, somewhat acute and mucronate, varying to obtuse, especially near the sea, 3 to 6 or $9 \mathrm{~mm}$. wide (see minor variations 16 and 28 for very narrow leaved forms), sparsely or irregularly spinulosedentate to serrate or even lobed, the petiole-like base commonly entire, or whole leaf rarely entire; heads in rounded terminal cymes, these either compact or lower branches elongated, but ultimate peduncles very short; involucre 5 to $7 \mathrm{~mm}$. high; bracts with green acutish tips, glabrous but resinous (villous in some variations), the margins often erose; achenes 3 to $4 \mathrm{~mm}$. long, very slender, gradually narrowed downward from a truncate summit. (Isocoma vernonioides Nutt., Trans. Am. Phil. Soc. II, 7 :320, 1841.) (Fig. 76.)

Western California from San Francisco Bay southward nearly to San Diego. Type locality, marshes near the sea, at Santa Barbara, Upper California. California: Morning Light, Solano County, September 16, 1891, Jepson (UC, minor variation 15 ); near Burlingame, west shore San Francisco Bay, Walker 3833 (UC); Milpitas, September, 1905, Smith (UC); Hollister, San Benito County, Hall 10950 (UC); Port Harford, San Luis Obispo County, Davy 2715B (UC); Santa Maria, November 1893, Blochman (Greene, type of Isocoma microdonta, minor variation 19); type collection, Nuttall (BM, K); Santa Cruz Island, August 1886, Greene (Greene, type of I. latifolia, minor variation 17); Anacapa Island, 1901, Hemphill (UC); Los Angeles, Braunton 645 (UC); San Bernardino Valley, Parish 178 (UC); Laguna, Orange County, Reed 3918 (UC); Oceanside, San Dicgo County, March 16, 1904, Berg (UC); Warner's Ranch, San Diego County, October' 21, 18s9, Orcutt (US, type of Isocoma leucanthemifolia, minor variation 18).

47c. Haplopappus venetus tridentatus (Greene)-Stems crowded, rigid, brittle; herbage glabrous, dark, covered with a resinous exudate; principal leaves crowded on the stems, spatulate in outline or linear-cuncate, acute, the larger ones 5 to $10 \mathrm{~mm}$. wide including the lobes, some entire except at the tridentate apex, others with several pairs of divergent teeth or lobes above middle; heads in small loose leafy cymes; involucre 5 to $6 \mathrm{~mm}$. high; bracts greenish or brown on exposed parts, very acute, mostly erect, squarrose in some old heads (these abnormal?), glabrous; achenes 2.3 to $2.6 \mathrm{~mm}$. long, slender, gradually narrowed below. (Bigelovia tridentata Greene, Bull. Torr. Club 10:126, 1883.)

Known only from Cedros Island, off the west coast of Lower California; type collection, 1885, Greene (UC, BM); 1896, Anthony 43 (UC); April 1, 1897, Brandegee (UC); Vealch (UC, part of type collection of Linosyris dentata, minor variation 29).

47d. Haplopappus venetus oxyphyllus (Greene)-Stems erect, robust, commonly 1 to 2 meters high; herbage (at least stems) loosely villous to nearly glabrous; leaves oblanceolate or spatulate-oblong, decidedly acute or acuminate (less so where the range meets that of vernonioides), all or nearly all entire, mostly 3 to $5 \mathrm{~cm}$. long, 3 to $6 \mathrm{~mm}$. wide, rather thin; heads numerous, in rounded cymes, these openly cymose or paniculate; involucre 6 to $7 \mathrm{~mm}$. high or rarely $8 \mathrm{~mm}$. (as in type); bracts acute, with conspicuous green tips, resinous, the margins more or less hirtellous, otherwise nearly glabrous. (Isocoma oxyphylla Greene, Leaflets 1:171, 1906.)

Warm valleys and coast of southwestern San Diego County, California, thence southward in Lower California, at least as far as Las Huevitas. Type locality, Jamul Valley, back of San Diego. California: type collection, 
1875, Palmer 134 (US, BM, UC); San Diego River, Abrams 3751 (UC); Mission Valley, December 1, 1883, Cleveland (UC). Lower California: Ensenada, 1893, Brandegee (UC); $9 \mathrm{~km}$. south of Ensenada, Hall 12255 (UC); foothills of San Pedro Martir, Robertson 50 (UC); Santa Maria, April 15, 1889, Brandegee (UC); Las Huevitas, 1889, Brandegee (UC).

47e. Haplopappus venetus furfuraceus (Greene)-Stems more or less curved or decumbent, low and much branched; herbage glabrous, the resinous exudate sometimes forming a scurf especially on foliage (leaves rarely puberulent, minor variation 10); leaves linear to linear-spatulate, acute or obtuse, entire or with a few minute teeth near apex, mostly 1 to 3 but sometimes $4 \mathrm{~cm}$. long, 1 to 3 or $4 \mathrm{~mm}$. wide, thick; heads few, in close rounded terminal cymes, these simple or compound; involucre 6 to 7 or $8 \mathrm{~mm}$. high; bracts mostly obtuse but mucronate, green-tipped, resinous, the thin margin erose (originally described as with tomentum, but this not found in type material). (Bigelovia furfuracea Greene, Bull. Calif. Acad. 1:87, 1885.)

Islands off the west coast of Lower California and maritime borders of the adjacent mainland; also on Santa Catalina and San Clemente Islands off southern California. Type locality not known. Rosalia Bay, August 22, 1896, Purpus (UC); Magdalena Island, January 13, 1889, Brandegee (UC); type collection (UC, two heads, 1 leaf and tracing of two others, this being all that is known of the type specimen); San Quentin Bay, January, 1889, Palmer 635 (US, type of $H$. fasciculatus, minor variation 10); San Clemente Island, August 25, 1894, Brandegee (UC, at least in part); Ballast Point, Santa Catalina Island, Millspaugh 6415 (UC).

\section{MINOR VARIATIONS AND SYNONYMS}

Among the variations here described will be found some with characters so striking that they may seem to merit subspecific if not, indeed, specific recognition. Such, for example, are Isocoma sedoides, with short, rounded, and succulent leaves; I. villosa, which, in its extreme form, has a truly tomentose involucre; and I. decumbens, with very small leaves on slender, decumbent branches. Such extremes, however, can not be given taxonomic standing in a phylogenetic arrangement until such time as more detailed field studies and experiment yield definite data as to geographic distribution, possibility of hybridization (even with species outside the genus), and effect of environmental factors. Above all, no additional classification should be attempted without first taking into consideration the numerous intermediate forms, these often forming connections between not only two but several subspecies.

1. Aster venetus O. Kuntze, Rev. 318, 1891-Haplopappus venetus typicus.

2. Baccharis? veneta HBK., Nov. Gen. et Sp. 4:68, 1820-H. venetus typicus.

3. Bigelovia furfuracea Greene, Bull. Calif. Acad. 1:87, 1885-H. venetus furfuraceus.

4. B. menziesi Gray, Proc. Am. Acad. 8:638, 1873. Based upon Pyrrocoma menziesi, which see.

5. B. tridentata Greene, Bull. Torr. Club 10:126, 1883-H. venetus tridentatus.

6. B. veneta Gray, l. c. - H. venetus typicus.

7. B. veneta var. decumbens Jepson, Man. Fl. Pl. Calif. 1029, 1925. A name published only in synonymy under Isocoma veneta var. decumbens Jepson (l. c.) and there accredited to Brandegee.

8. B. veneta var. sedoides Greene, Bull. Calif. Acad. 2:400, 1887. Later transferred by Greene to Isocoma sedoides, which see.

9. Haplopappus discoideus DC., Prodr. 5:350, 1836- $H$. venetus typicus. DeCandolle drew his description from several collections made by Alaman and others near the type locality of venetus but did not compare his new species with this, which, in the absence of specimens, was supposed to be a Bac- 
charis. The types of discoideus in the DeCandolle Herbarium differ in no essential from those of venetus in the herbarium of Hunboldt and Bonpland at Paris.

10. H. fasciculatus Vasey et Rose, Proc. U. S. Nat. Mus. 11:530, 1888--H. venetus furfuraceus. No differences can be found except that the leaves are sparsely and loosely pubescent, although originally described as glabrous. This applies to the type specimen, in which the entire leaves are 2 to $3 \mathrm{~cm}$. long by 2 to $3 \mathrm{~mm}$. wide, narrowly oblanceolate and acute, as in the type of furfuraceus. Type locality, San Quentin Bay, Lower California.

11. H. menziesi Torr. et Gray, Fl. 2:242, 1842. Based upon Pyrrocoma menzicsi, which see.

12. H. tridentatus Blake, Contr. U. S. Nat. Herb. $23: 1493,1926-H$. venetus tridentatus.

13. $\mathrm{H}$. venetus vernonioides, but the entire herbage covered with minute stipitate glands. The single specimen positively referred to this form is a plant labeled as coming from Cottonwood Creek Cañon, Inyo County, California (Purpus 3028), and therefore from far outside the known area of distribution of the species. There is at Kew a specimen from San Diego, California (Baker 1633), which also is somewhat stipitate-glandular and will therefore need to be taken into account if the Inyo form is given taxonomic recognition. The occurrence of any form so far out of the normal range requires verification and additional specimens would be essential for a satisfactory diagnosis.

14. H. venetus vernonioides, but the herbage nearly glabrous. This is the common form in the foothill districts of southern California at some distance from the coast. The foliage and inflorescence commonly are entirely glabrous or only glandular, but this varies into the typical form of the coast districts in which at least the stems are hirtellous. Along the coast are found still more strongly pubescent plants which pass into the forms sometimes classified as Isocoma villosa and $I$. latifolia.

15. Isocoma arguta Greene, Man. Bot. Reg. S. F. Bay 175, 1894. A form of $H$. venetus vernonioides in which the leaves are cleft into acute divergent lobes, these extending from summit to base of leaf. The involucre is 7 or $8 \mathrm{~mm}$. high, its bracts with conspicuous green tips and glabrous. The type locality is subsaline plains east of the Vaca Mountains, Solano County, California. This is the northernmost known station for the species, and all plants referable to this form are from the same district, although some from slightly farther south are deeply dentate and thus represent a gradation into genuine vernonioides. Subspecies typicus has a similar foliage form at the southern extreme of its area of distribution, but this is only a parallel variation in foliage.

16. I. decumbens Greene, Leaflets 1:172, 1906. A slender, decumbent form with narrow, entire or toothed, scattered leaves and few small heads, these either solitary and long-peduncled or loosely grouped into clusters of 2 or 3 , both heads and groups then slender-peduncled. The type is from clay depressions on the mesas near San Diego, California (Baker 3405). On near-by hillsides it is replaced by a counterpart, except that the stems are erect.

17. I. latifolia Greene, 1. c., 1906. A form of $H$. venctus vernonioides in which the very obtuse leaves are spatulate-obovate, 1 to $2 \mathrm{~cm}$. long, 7 to $10 \mathrm{~mm}$. wide, the stems villous-arachnoid, and the heads forming large compound but dense inflorescences. The type is from Santa Cruz Island, off thre coast of California, and the same form grows on San Miguel Island (September 1886, Greene, UC). An intermediate was cited by Greene from Santa Rosa Island. Other intermediates occur on the mainland (Ventura, October 19, 1919, Hall, UC), some of them closely approaching typical latifolia (San Luis Rey, July 1885, Brandegee, UC, in part; see further under I. sedoides).

18. I. leucanthemifolia Greene, Leaflets 1:171, 1906 . A large-leaved, large-headed form of $H$. venetus vernonioides, the leaves about $5 \mathrm{~cm}$. long, the involucres $8 \mathrm{~mm}$. high. In the type from Warner's Ranch, San Diego County, California (erroneously cited as Warren), the leaves are broadly oblanceolate, obtuse, coarsely serrate-toothed nearly to the base. They are viscid and 
scabrellous beneath and with long, loose hairs along the veins, but not "villous-arachnoid." The bracts of the involucre are very obtuse and mucronate, and although the subapical spot is prominent, it is not resinousthickened.

19. I. microdonta Greene, 1. c., 1906. A form of $H$. venetus vernonioides with small leaves scabrous on the margins, the faces glabrous, and with heads in open, leafy panicles. The type (not seen) was from Santa Maria, Santa Barbara County, California.

20. I. sedoides Greene, Leaflets 1:172, 1906. Based upon Bigelovia veneta var. sedoides, best taken as an extreme thick-leaved form of $H$. venetus vernonioides. But this is the most striking of the minor variations. The types, from Santa Cruz Island, off the Californian coast, are nearly glabrous, prostrate plants with very obtuse, obovate, succulent leaves and large heads crowded in terminal cymes. Such extremes would seem to represent a distinct evolutionary type, but before giving the form subspecific rank one must take into account other forms as well. For example, on these same channel islands grow pubescent forms with leaves intermediate in shape between those of sedoides and those of true venetus. Some of these have been designated as Isocoma latifolia (No. 17 of this list). Still more disturbing is a collection labeled as from San Luis Rey, San Diego County, California (July 1885, Brandegee, UC). This includes one specimen which is typical sedoides in every respect; also two longer and villous stems with heads similarly congested, the thinner leaves varying from obovate-oblong to oblanceolate but all very obtuse (latifolia), and one stem of the common venetus form of that district. (Recent explorations at this station have failed to discover any more plants of the sedoides form.) In view of such apparent gradations on the mainland, and the presence of numerous forms on the islands, the segregation of taxonomic units on the basis of present knowledge would possess but little merit.

21. I. tridentata Greene, Erythea 2:111, 1894-H. venetus tridentatus.

22. I. veneta Greene, l. c.-H. venetus typicus.

23. I. veneta var. arguta Jepson, Fl. W. Mid. Calif. 560, 1901. Based upon I. arguta, which see.

24. I. veneta var. decumbens Jepson, Man. Fl. Pl. Calif. 1029, 1925. Based upon I. decumbens, which see.

25. I. veneta var. sedoides Jepson, 1. c. Based upon I. sedoides, which see.

26. I. veneta var. vernonioides Jepson, Fl. W. Mid. Calif. 560, 1901-H. venetus vernonioides.

27. I. vernonioides Nutt., Trans. Am. Phil. Soc. II, 7:320, 1840-H. venetus vernonioides.

28. I. villosa Greene, Leaflets 1:172, 1906. A robust form of $H$. venetus vernonioides with villous-arachnoid stems and large, compact, cymose-paniculate inflorescences. The type was a garden plant originally from southern California, and judging from the description was intermediate to still more pubescent forms now at hand. In some of these the herbage is white-tomentose even to the involucres. The extreme case is a large plant from Lakeside, San Diego County, California (Hall $743 \%$, UC). In this the nearly entire leaves are narrowly spatulate-oblong, about $2 \mathrm{~cm}$. long by 3 or $4 \mathrm{~mm}$. wide and the heads irregularly glomerate-cymose. Growing with these plants are others exhibiting all gradations in pubescence, from heavily tomentose to glabrous, and with leaves varying from entire to evenly sharp-serrate (Hall 7447, $^{2}$ $7448,7449)$. Such conditions are suggestive of hybridization, perhaps with Corethrogyne filaginifolia as one of the parents, but the habit, style-branches, etc., are as in H. venetus. More probable is the breaking up of genetic units within venetus itself, but since this occurs without isolation of the resulting forms it is not followed by a sharp separation of taxonomic units. On some of the islands is found a low, tomentose form (island of Santa Rosa, June, 1888, Brandegee, UC) which seems to lead into Isocoma latifolia (minor variation 17). On the other hand there are found, in the San Diego district, slender, narrow-leaved plants with varying amounts of villous pubescence. These grow by the side of green forms but in poor, shallow soil and seem to 
be ecologic modifications. The extreme deviation in this direction is reached by a seemingly fixed form from northern Lower California $(6 \mathrm{~km}$. south of 'Tia Juana, Hall 12264, UC). This is a slender but erect plant with linearfiliform, heavily tomentose leaves, these entire save for a few sharp teeth near summit. It is suggestive of subspecies tridentatus of the islands farther south. The significance of the multitudinous forms involved can be determined only by intensive field studies in connection with transplant experiments.

29. Linosyris dentata Kellogg, Proc. Calif. Acad. 2:16, 1863. From the description this appears to be chiefly $H$. venetus tridentatus, but according to Greene (Bull. Torr. Club 10:126, 1883) the Veitch specimens from Cedros Island, on which dentata was founded, were a mixture. If two subspecies were involved, the second probably was furfuraceus. Although Kellogg's name is older than either tridentatus or furfuraceus, it is discarded because of the doubt that has been cast upon it.

30. L. mexicana Schlech., Linnaea 14 :Litt.-Ber. 128, 1840. This is universally referred as a synonym of $H$. venetus, to which species it seems to belong, juclging from the description in the place cited and from a colored plate previously published but without description (Ind. Sem. Hort. Hal. 1839:9, plate 4,1840$)$.

31. Pyrrocoma menziesi Hook. et Arn., Bot. Beech. Voy. 351, 1840-H. venetus vernonioides. The type was gathered by Menzies somewhere along the coast of California, probably near San Diego. This was the first collection of the subspecies and menziesi is the oldest specific name. Vernonioides, however, is here used because it has been generally employed for the form in both the varietal and specific category. The type specimen of menziesi at Kew is very similar to the type of vernonioides at the British Museum. The heads are a trifle larger, the bracts less acute, and the leaves more nearly entire, these having for the most part only two small teeth near the apex. In characters of foliage, however, it does not approach subsp. oxyphyllus. The differences just noted are covered by variations from a single locality, as shown particularly in specimens from Santa Barbara.

\section{RELATIONSHIPS}

In the phylogenetic arrangement this species is placed as basic to the section Isocoma. There are few facts at hand, however, to substantiate this hypothesis, although it finds some support in the southerly distribution of the typical form and in the shape of the achenes in this southern subspecies. Here the achenes approach the turbinate in shape and thus are very suggestive of the truly turbinate ones of the section Blepharodon. No other species of Isocoma exhibits a transition to any other section, and the acceptance of any other than Haplopappus venetus as basal would lead to insurmountable difficulties.

Evolutionary activity within the species has produced a perplexing array of overlapping forms. It is not surprising to find, therefore, that many species have been proposed from what is here accepted as one. None of these can be recognized taxonomically, however, without first taking into account all of the others. The setting up of isolated species or subspecies without attention to intermediate forms, hybrids, and geographic distribution makes only difficulties for those who follow, and renders impossible the construction of a key for their recognition. For these reasons, several strongly marked forms are here left among the minor variations until such time as a better understanding of their nature, limits, and relationships will make possible a phylogenetic arrangement. It seems that classification has now about reached the limits of its usefulness until such time as results may be obtained by experimental means. 
In addition to the interweaving variations just mentioned, there are others which have apparently become constant in their characters and which occupy fairly definite geographic areas. Wherever possible, these hereditary and geographic variants within the species are recognized as subspecies. Of these, typicus itself has the most isolated distribution. It possesses but one morphologic character, but this is a fundamental one, namely, the shape and size of the achene. In all other characters the type specimens of venetus may be closely matched by certain specimens from the coastal districts of California, and even in the type of vernonioides, which came from Santa Barbara. In comparing these two types the only differences found are that the achenes of venetus are $2 \mathrm{~mm}$. long, those of vernonioides $3 \mathrm{~mm}$. and much more slender; the dentations of the leaf in the former are slightly more spreading than in the latter, and the bracts slightly more acute; the corolla-lobes are $0.7 \mathrm{~mm}$. long in venetus, $0.8 \mathrm{~mm}$. in vernonioides; the inflorescence is the same except that vernonioides has more heads. The type of venetus was originally described as glabrous, but under a lens the leaves are seen to be scabrid. None of the characters just mentioned, with the exception of that of the achene, can have any taxonomic significance. In fact, it is quite remarkable, and indeed fortunate, that the type specimens of these well-known forms should be so much alike, even in their superficial features. The probability is that vernonioides is an ancient western derivative held pure as to its essential character through isolation, and that this and the parent venetus have since produced similar variations in such features as pubescence, foliage, etc.

The subspecies tridentatus probably is out of place in the serial arrangement here given, but it is too little known to be definitely placed. It is a most striking form because of the long, finger-like lobes found on some of the leaves. Other leaves, however, even on the type specimens, are entire and suggest those of subspecies furfuraceus, which, in turn, has occasional leaves with a few subterminal teeth. Subspecies tridentatus, probably a derivative of this, is now restricted to a few island habitats. In the original description, Greene said that tridentatus had the likeness of $H$. squarrosus, but this resemblance is not great except perhaps in the matter of habit. The two differ in essential characters, such as shape of corolla, and the heads of tridentatus, if detached from their peculiar subtending foliage, could scarcely be distinguished from those of other Isocomas.

In the warm San Diegan district and extending southward well into Lower California, there is common a form so well marked, even though only by foliage characters, that it is accepted as the subspecies oxyphyllus. It is difficult to differentiate by key characters, but seems to be a definite geographic subspecies with several well-marked tendencies. Probably it is a derivative from vernonioides rather than a direct descendant from typicus. It is most common near San Diego, which is also the center of distribution for numerous other variations. In its extension to the mainland of Lower California it has come to be the dominant form. From this area there has come but one collection which seems to belong rather to vernonioides. This may be a case of reversion or merely a chance introduction. 
The subspecies furfuraceus has every appearance of being a maritime form derived from subspecies oxyphyllus. Its low stature, more or less decumbent habit, small thick leaves, and congested inflorescence are just the characters which one would expect to find oxyphyllus taking on as it approaches the sca. There is no evidence that oxyphyllus itself inhabits the islands or immediate proximity of the ocean. This leaves furfuraceus with a distinct geographic range, and since definite intermediates are not at hand it is taken to represent a fixed phylogenetic unit. It has sometimes been supposed that the type of furfuraceus was referable to $H$. orcutti. It is, however, plainly an Isocoma of the venetus assemblage, as indicated especially by the involucral bracts, which are few, short, and in only 3 or 4 lengths, by the absence of glands on the herbage, and by the disposal of the heads. These last are decidedly cymose and have, therefore, an arrangement very unlike those of orcutti. The fragments of the type may be exactly matched, especially as to leaves, by complete specimens plainly referable to Isocoma (especially those of Purpus, already cited).

\section{ECOLOGY AND USES}

In Mexico the typical form of this species grows only at considerable altitudes in the mountains. Most of the collections thus far made have come from the Federal District of Mexico. In the State of Hidalgo the plants grow at an altitude of about 2,000 meters, according to data on the collectors' labels.

In California, subsp. vernonioides is a common, bushy shrub of coastal districts and immediately adjacent lower valleys. It belongs in the Upper Sonoran Zone and often grows in sand or disturbed areas, sometimes forming thickets of considerable extent. Various forms occur also on the islands, the most remarkable one being a semiprostrate plant with succulent foliage (minor variation 20). In the San Diegan district the species seems to be breaking up into a multitude of forms, each of which occupies a particular ecologic niche. Whether these are modifications representing immediate response to environment, or hereditary forms persisting only under suitable conditions, is a problem calling for experimental investigation.

In warm valleys from San Diego south, well into Lower California, the dominant form is subsp. oxyphyllus. This grows in abundance in valleys of the Lower Sonoran Zone, especially those below Enscnada and extending back toward the base of the San Pedro Martir Mountains. Here large areas are sometimes dominated by the yellow flowers and resinous odors of this plant.

The principal flowering season for all of the forms is late summer and autumn. In Lower California, as well as in Mexico proper, the greatest display of bloom is after the summer rains.

Various medicinal uses have been reported for this plant, but there is no evidence that it is of any real value. Apparently it is very slightly used, if at all, in California. It is said, however, that a decoction is sometimes employed in the form of baths as a remedy for rheumatism. The plant is sometimes called "damiana," but is not to be confused with the true damiana of druggists (Standley, Contr. U. S. Nat. Herb. 23:1492, 1926). 


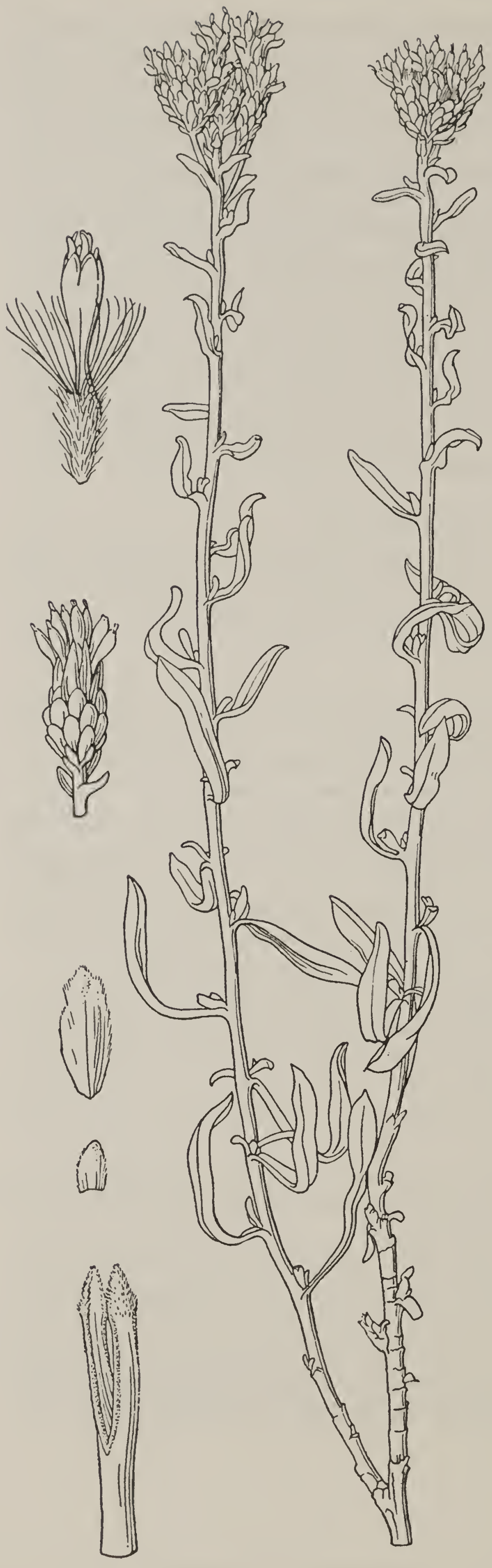

FIG. 77-Haplopappus acradenius typicus
48. Haplopappus acradenius (Greene) Blake, Contr. U. S. Nat. Herb. $25: 546,1925$

An erect subshrub with many woody basal branches which form rounded broomy tufts 3 to $10 \mathrm{dm}$. high, leafy to top; bark firm, smooth, white or straw color, changing to brown only on basal portions; twigs hard, brittle, striate, glabrous, sometimes granular; principal leaves narrowly oblanceolate or spatulate-oblanceolate, mostly entire, varying to deeply dentate (especially subsp. eremophilus), rather obtuse but mostly mucronate, 2 to $5 \mathrm{~cm}$. long, 3 , to $7 \mathrm{~mm}$. broad, 1 nerved, thick, smooth or scabrid, glabrous, minutely impressed-punctate; secondary fascicled leaves present in most of the axils but often small; heads in open paniculate cymes, but ultimate clusters compact (these of 2 to 8 heads); involucre obconic, 5 to $8 \mathrm{~mm}$. high, 4 to $6 \mathrm{~mm}$. broad; bracts regularly imbricated in about 4 lengths, the longest nearly equaling disk, erect, oblong, hard-chartaceous at base, with very narrow membranous margins, obtuse or inner acute, mostly ending in a prominent mucro, below which is a conspicuous thick subepidermal resin-pocket nearly as wide as bract and turning brown on drying, glabrous or granular; ray-flowers none; diskflowers 6 to 25; disk-corolla with narrow tube and short ventricose throat, 5.5 to 6.5 $\mathrm{mm}$. long, hirtellous to glabrous; lobes lanceolate-ovate, acute, erect, glabrous, 0.7 to $1.0 \mathrm{~mm}$. long; style-branches scarcely exserted, 1.2 to 1.5 $\mathrm{mm}$. long, the ovate appendage about one-half as long as stigmatic portion; achenes 3 to 4 
$\mathrm{mm}$. long, about 5-ribbed, subcylindric, tapering to base, approaching turbinate only when young, silvery villous; pappus of rather numerous slightly unequal yellowish bristles, the longest nearly equaling to slightly exceeding corolla. (Bigelovia acradenia Greene, Bull. Torr. Club 10:126, 1883.) (Fig. 77.)

Desert area of southern California extending slightly into adjacent States.

\section{SUBSPECIES}

\section{Key to the Subspecies of Haplopappus acradenius}

Leaves entire; involucre 5 to $6.5 \mathrm{~mm}$. high; flowers 6 to 13 . (Mohave
Desert and east)
(a) typicus

Leaves mostly denticulate or dentate; involucre 6 to $8 \mathrm{~mm}$. high; flowers

15 to 20 or more.

Leaves large, 2.5 to $5 \mathrm{~cm}$. long, denticulate to coarsely dentate. (Colorado Desert, California.)........................

Leaves smaller, mostly less than $2.5 \mathrm{~cm}$. long, entire or merely denticulate. (San Joaquin Valley, California.)................... (c) bracteosus

48a. Haplopappus acradenius typicus-Leaves glabrous or scaberulous, all entire, the principal ones 2 to $3 \mathrm{~cm}$. long; heads small, for the most part nearly sessile in the clusters but peduncles sometimes nearly $1 \mathrm{~cm}$. long; involucre 5 to $6.5 \mathrm{~mm}$. high; flowers 6 to 13 (Bigelovia acradenia Greene, Bull. Torr. Club 10:126, 1883.) (Fig. 77.)

Mohave Desert of California and southern Nevada. Type locality, Mohave Desert, California. CALifornia: near Rosamond, Antelope Valley, Davy 2949 (UC); Lancaster, October 21, 1919, Hall (UC); Mohave Desert, Parry 59 (DS, type collection?). Nevada: plains at Las Vegas, Clark County, Hall 10805 (UC).

48b. Haplopappus acradenius eremophilus (Greene)-Leaves smooth or only scaberulous, dentate or denticulate or some entire, the principal ones 2.5 to $5 \mathrm{~cm}$. long; heads large, from nearly sessile to long peduncled; involucre 6 to 7 or $8 \mathrm{~mm}$. high; flowers 15 to 20 , rarely 25. (Isocoma eremophila Greene, Leaflets 1:171, 1906.)

Colorado Desert of southern California, probably extending slightly into adjacent Arizona and Lower California. Type locality, southwestern part of the Colorado Desert, California. California: type collection, November 1, 1890, Orcutt (US); Banning, September 27, 1894, Toumey (UC); between Indio and Wolters, Schellenger 58 (UC); east base San Jacinto Mountains, Vandeventer 11 (UC); Imperial, Wales 17 (UC).

48c. Haplopappus acradenius bracteosus (Greene)-Leaves sparsely hispidulous to glabrous, mostly denticulate, 1 to $2 \mathrm{~cm}$. long or perhaps more, but the principal ones apparently dropping early; heads large, with a tendency to be scattered (as in the type specimen), the ultimate peduncle then up to $1 \mathrm{~cm}$. long, but heads often all nearly sessile in glomerules of 2 to 6 and the glomerules long-peduncled; involucre 7 to $8 \mathrm{~mm}$. high; flowers 15 to 22. (Isocoma bracteosa Greene, Leaflets 1:170, 1906.)

Southern end of the San Joaquin Valley, California. Type locality, Tulare County. Tulare County, August 27, 1889, C. S. Sheldon (US, type); north of Bakersfield, October 24, 1919, Hall (UC); Rosedale, near Bakersfield, Davy 2919 (UC). 


\section{MINOR VARIATIONS AND SYNONYMS}

1. Aster acradenius O. Kuntze, Rev. 317, 1891-H. acradenius typicus.

2. Bigelovia acradenia Greene, Bull. Torr. Club 10:126, 1883-H. acradenius typicus.

3. Isocoma acradenia Greene, Erythea $2: 111,1894-H$. acradenius typicus.

4. I. bracteosa Greene, Leaflets 1:170, 1906-H. acradenius bracteosus.

5. I. eremophila Greene, l. c.-H. acradenius eremophilus.

6. I. veneta var. acradenia Hall, Univ. Calif. Pub. Bot. 3:64, 1907-H. acradenius typicus.

\section{RELATIONSHIPS}

There has been a tendency among botanists working in California alone to associate this species with Haplopappus venetus, to which it has sometimes been assigned with varietal rank (Hall, Univ. Calif. Pub. Bot. 3:64, 1907). In taking into account all species of the section, however, it is found that it would be just as logical to connect it directly with $H$. drummondi. With the latter it shares its low, bushy habit, pale herbage, and in the typical form also the narrow, smooth, entire leaves. It differs, however, in having fascicled secondary leaves and is at once distinguished from all other Isocomas by the peculiar resin-pocket near the summit of each involucral bract. This pocket is especially well developed in extremely arid situations and on drying becomes rough and wart-like. As contrasted with venetus, the present species has, in addition to the resinpocket, thinner and more chartaceous bracts, harder, more brittle, white stems, and a unique habit. These features remain constant even when the plants are grown artificially within the habitat of venetus.

Three geographic subspecies are here described, although they appear to merge in all of their characters. The phylogenies of these are obscure, but it is interesting to note that the typical one, marked by its entire leaves, occupies a central position, the others, both with dentate leaves, occurring one to the north, the other to the south. It is believed, however, that further studies will demonstrate the presence of additional characters, especially for the separation of the northern subspecies (bracteosus), which is at present little known. The southern subspecies (eremophilus) would seem to be well set off by its coarsely toothed foliage, but on some plants the leaves are only denticulate, and it is probable that plants with all the leaves entire can be found within its area.

\section{ECOLOGY}

Haplopappus acradenius is a low, compact, bushy shrub of alkaline soils of the interior. It is confined to the Lower Sonoran Zone, where it is associated with Atriplex confertifolia, A. parryi, A. polycarpa, A. lentiformis, Distichlis spicata, Elymus condensatus, Artemisia spinescens, etc., the exact composition of the flora varying with the subspecies, these being geographic. The plants form open stands with those of other halophytes, and thus have room for the development of an ample root system. The ecologic relations obtaining in the Colorado Desert and the effects of different environments upon the plant characters have been discussed by Parish (Carnegie Inst. Wash. Pub. 193:112, 1913). September and October are the principal months for flowering. 
49. Haplopappus hartwegi (Gray) Blake, Contr. U. S. Nat. Herb.,

$23: 1492,1926$

An crect subshrub, with numerous woody branches from near base, 3 to $6 \mathrm{dm}$. (or more?) high, leafy to summit; bark brown or gray, breaking longitudinally on old woody portions; twigs hard, brittle, obscurely striate, scabrid; principal leaves oblong or. spatulate-oblong in outline but variously lobed or pinnately parted, usually into 5 to 11 remote linear lobes about as wide as rachis, each lobe tipped by a short mucro, the entire leaf (sessile by a lincar base) 1.5 to 4 $\mathrm{cm}$. long, 4 to $16 \mathrm{~mm}$. wide, 1-nerved, thick, more or less scabrid or hirtellous,rarely nearly glabrous, marked with superficial or depressed resin-dots (for forms with elongated lobes see minor variations 9 and 10); secondary fascicled leaves present in most axils; heads nearly sessile in compact rounded terminal cymes (the cymes sometimes racemosely arranged); involucre from narrowly to rather broadly turbinate, 4.5 to $5.5 \mathrm{~mm}$. high, 3 to $5 \mathrm{~mm}$. broad; bracts regularly imbricated in about five

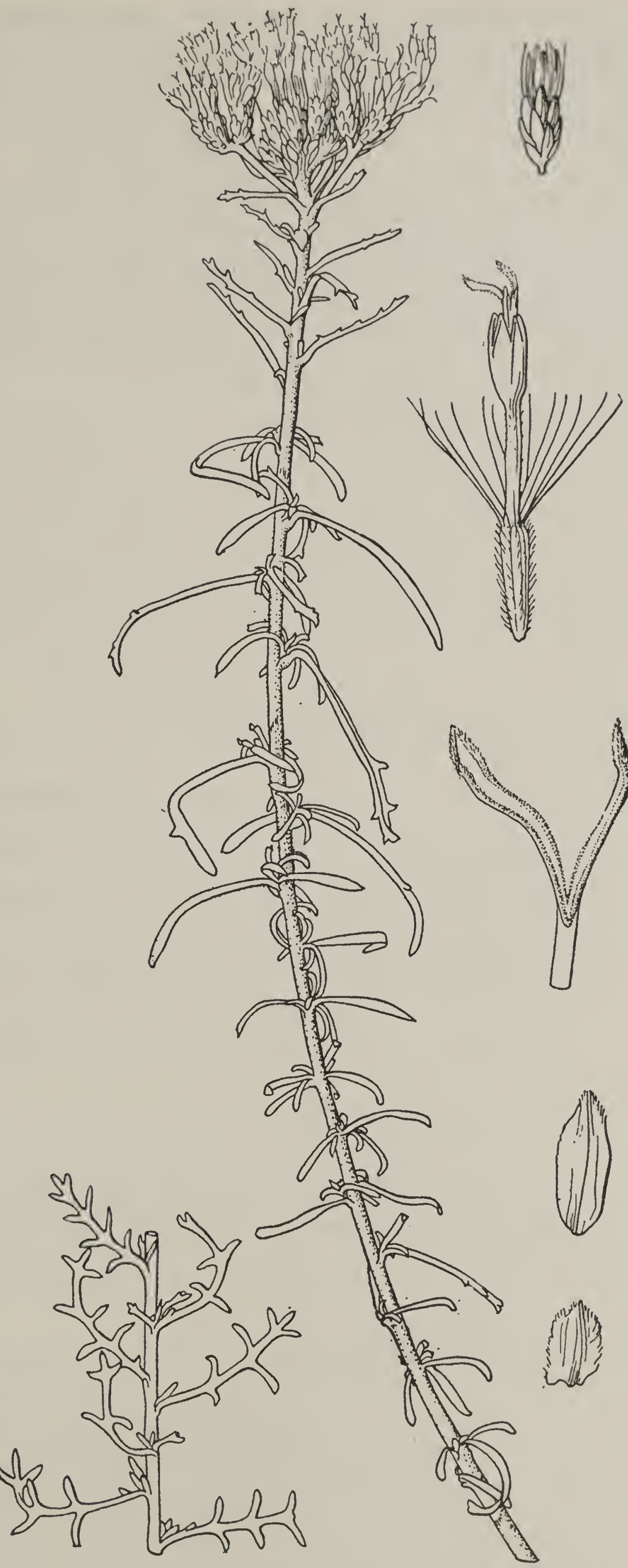

FIG. 78-Haplopappus hartwegi. The lower figure represents minor variation 10, Linosyris, coronopifolia 
lengths, all much shorter than disk, erect, oblong, stiffly chartaceous at base, the margins thin, the outer bracts with conspicuously resinousthickened greenish obtuse tips, the inner ones thin and acute, all glabrous or merely granular, mostly resinous-shining; ray-flowers wanting, diskflowers 10 to 15 or rarely 20; disk-corolla with slender tube enlarged to an inflated throat of about equal length, nearly closed at summit, 4.5 to $6 \mathrm{~mm}$. long, glabrous or puberulent; lobes lanceolate, acute, erect, 1 to $1.3 \mathrm{~mm}$. long, glabrous; style-branches barely exserted, 1 to $1.5 \mathrm{~mm}$. long, the ovate acute appendage less than one-half the length of stigmatic portion; achenes 3 to $4 \mathrm{~mm}$. long, nearly quadrangular-prismatic but slightly tapering to base, silky villous; pappus of numerous unequal brown bristles, the longest about equaling corolla. (Bigelovia hartwegi Gray, Syn. Fl. $1^{2}: 143,1884$.) (Fig. 78.)

Southern Texas and Arizona to southern Mexico. Type locality not positively stated, but Hartweg's plant, which may be taken as the type, was from Lagos, Jalisco. Texas: valley of the lower Rio Grande, Schott (Gr), also Wright 289 (Gr, type of Linosyris coronopifolia, minor variation 10); Eagle Pass, Havard 54 (Gr). Arizona: Tucson, November 1891, Brandegee (UC), also Thornber 73 (UC), and Shreve 4901 (UC); mesas near Tucson, September 25, 1884, Pringle (K, P, B, Gr, minor variation 9, Isocoma tenuisecta); Santa Catalina Mountains, Lemmon 3025 (UC); Dixie Cañon, Mule Mountains, Goodding $7(\mathrm{Gr})$. Sonora: MacDougal Pass, Pinacate Mountains, November 14, 1907, MacDougal (US, type of Isocoma fruticosa, minor variation 7). JALISCO: type collection, Hartweg $114(\mathrm{Gr})$.

\section{MINOR VARIATIONS AND SYNONYMS}

1. Aster coronopifolius O. Kuntze, Rev. 317, 1891. Based upon Linosyris coronopifolius, which see.

2. A. hartwegi O. Kuntze, Rev. 318, 1891-H. hartwegi.

3. Bigelovia coronopifolia Gray, Proc. Am. Acad. 8:638, 1873 . Based upon Linosyris coronopifolia, which see.

4. B. hartwegi Gray in Hemsley, Biol. Centr. Am. Bot. 2:115, 1881 (a nomen nudum) and Syn. Fl. $1^{2}: 143,1884-H$. hartwegi.

5. Haplopappus fruticosus Blake, Contr. U. S. Nat. Herb. 23:1493, 1926 . Based upon Linosyris coronopifolia and Isocoma fruticosa.

6. Isocoma coronopifolia Greene, Erythea 2:111, 1894. Based upon Linosyris coronopifolia, which see.

7. I. fruticosa Rose et Standl., Contr. U.S. Nat. Herb. 16:18, plate 13, 1912. Very close to typical $H$. hartwegi, which it resembles in the short leaf-lobes. All of the involucral bracts seem to be obtuse, but no other difference can be found. Type locality, Pinacate Mountains, Sonora.

8. I. hartwegi Greene, Erythea $2: 111,1894-H$. hartwegi.

9. I. tenuisecta Greene, Leaflets $1: 169,1906$. This was so described as to include several of the leaf-forms common around Tucson, Arizona, whence came the type specimens. All are referable to $H$. hartwegi, including its variant described as No. 10 of this list.

10. Linosyris coronopifolia Gray, Pl. Wright. 1:96, 1852. A form of $H$. hartwegi in which the leaf-lobes are slender, sometimes as much as $10 \mathrm{~mm}$. long. All gradations in this respect are common in southern Arizona and even the tendency toward elongation of the lobes is not a geographic feature, since some plants from Arizona (Lemmon 3025) have lobes even shorter than in the type of hartwegi from southern Mexico. The habit is given by Gray as suffrutescent for coronopifolia, suffruticose for hartwegi, but the type of the former (Wright 289, from the Rio Grande) is a branch, the base of which is not at present known. Other plants with leaf-lobes 5 to $10 \mathrm{~mm}$. long are decidedly woody (Tucson, Arizona, Brandegee, UC). Although older, as 
a specific name, than hartwegi, coronopifolia is not here taken up, because of H. coronopifolius DC. (1836). This last is a strict synonym for the still earlier 1 . glutinosus Cass., a South American species, but the name has been so much used that its application to a North American plant would lead to confusion (see further on p. 328).

\section{RELATIONSHIPS}

The connection between this species and the widespread Haplopappus venetus is very close, but it may be quite satisfactorily distinguished by the definitely lobed leaves and especially by the deeply cleft corollas. Because of the erroneous identification of certain classic specimens some botanists have been led to assume a closer connection than actually exists. These collections (from San Luis Potosi, Pringle 3803) are of a form of venetus in which the leaf-dentations are unusually prominent. The thin involucral bracts without green tips and the short corolla-lobes exclude them from hartwegi.

In Haplopappus venetus the corolla-lobes are 0.5 to $1 \mathrm{~mm}$. long; in $H$. hartwegi they are 1.0 to $1.3 \mathrm{~mm}$. But because of the short corolla of the latter, the difference is more important than these figures would seem to indicate. When expressed in the form of a ratio it is found that the lobes of venetus are from 10 to 16 per cent of the total corolla-length, while those of hartwegi are from 17 to 22 per cent.

\section{ECOLOGY}

Haplopappus hartwegi is one of the common half-shrubs of desert plains in southwestern United States and northern Mexico, where it belongs exclusively to the Lower Sonoran Zone. Here it sometimes is dominant or subdominant, especially in the open desert scrub of the Larrea-Flourensia association, coming into bloom after the summer rains and continuing in flower until winter. As to soil, it is moderately alkali-tolerant. According to Clements, it is a characteristic indicator of over-grazing in northwestern Mexico and Arizona on desert plains from the lowermost Prosopis valleys upward into the Bouteloua-Aristida grassland (Clements, Carnegie Inst. Wash. Pub. 290:300, 1920).

\section{Haplopappus pluriflorus (Gray)}

A woody-based perennial with numerous erect or ascending branches, these usually strict, 4 to $7 \mathrm{dm}$. (or more?) high, leafy throughout; bark white and shining, becoming dark and fibrous on basal portions; twigs (and stems) hard, brittle, faintly striate from leaf-bases, hirtellous to glabrous; principal leaves linear to linear-oblanceolate, entire or with a few short teeth, acute, sessile by a narrow base, 2 to $6 \mathrm{~cm}$. long, 1 to 4 or $5 \mathrm{~mm}$. wide, rather thick, only the midvein prominent, pale, glabrous or only scabrid or rarely hirtellous; secondary fascicled leaves usually present in many axils; heads numerous, in rounded terminal compound or reduced cymes (these 4 to $16 \mathrm{~cm}$. across); involucre turbinate, 4 to $5 \mathrm{~mm}$. high, 2 to $3 \mathrm{~mm}$. broad; bracts regularly imbricated in about four lengths, none more than one-half as long as disk, erect, oval to oblong, stiff and chartaceous but comparatively thin, the tips obscurely resinous-thickened, obtuse or more or less acute (especially inner), glabrous or slightly hirtellous especially on margins; ray-flowers wanting; disk-flowers about 8 to 16 ; disk-corolla with slender tube and ventricose throat, 5.5 to $7 \mathrm{~mm}$. long, glabrous or rarely puberu- 
lent; lobes linear-lanceolate, acute, erect, 1.2 to $2 \mathrm{~mm}$. long, mostly glabrous; style-branches moderately exserted, 1.5 to $2 \mathrm{~mm}$. long, the ovate acute appendage not one-half as long as stigmatic portion; achenes subprismatic, tapering to base, about $2 \mathrm{~mm}$. long, silky-villous; pappus of numerous sor-

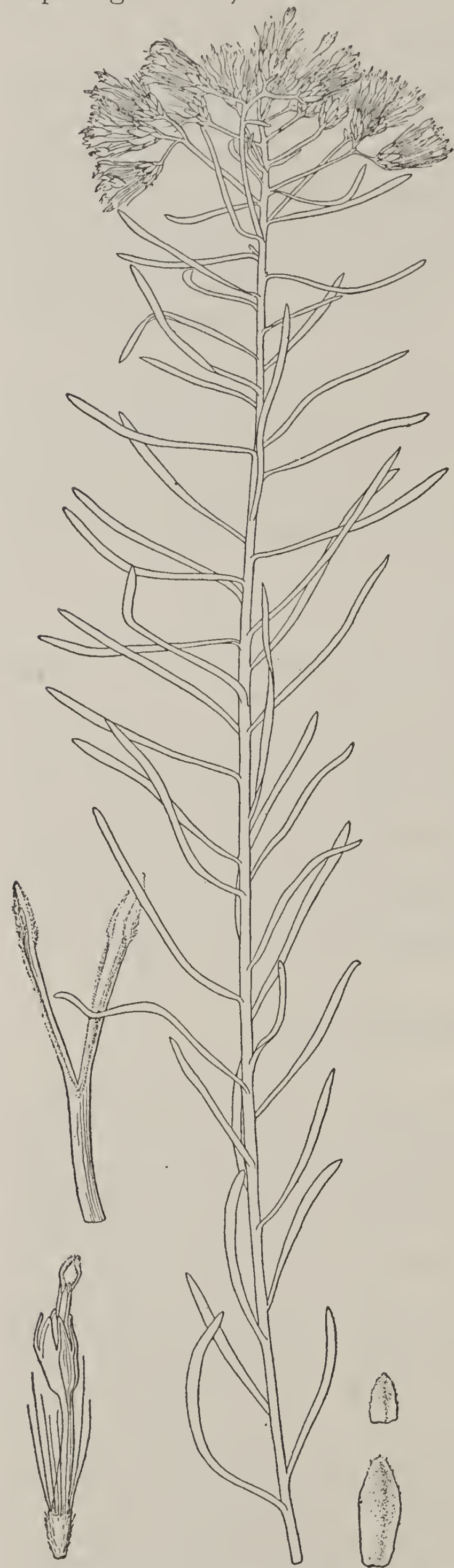

FIG. 79-Haplopappus pluriflorus did or brownish unequal bristles, the longest about equaling corolla. (Linosyris pluriflora Torr. et Gray, Fl. $2: 233,1842$.) (Fig. 79.)

Eastern Colorado to Arizona, south to Texas, Chihuahua, and Sonora. Type locality, probably in eastern Colorado (see further under minor variation 13). Type collection, James (NY, from the Long Expedition). ARIZONA: Gila River Hayes (Gr, minor variation 16); near Safford, Shreve 4287 (UC, near minor variation 13). New Mexico: Mesilla Valley, Dona Ana County, October 4, 1899, Wooton (UC); along Rio Grande, Rusby 228a (UC); Las Cruces, August 1881, Vasey (Gr, minor variation 16). Texas: EI Paso, July 28, 1887, Dunn (UC); valley of the Pecos, Wright 283 (Gr, type of Linosyris heterophylla, minor variation 13); valley of the Rio Grande, below El Paso, Wright 284 (Gr, type of Linosyris wrighti, minor variation 16); valley of the Limpia, Wright 285 (Gr, type of Linosyris hirtella, minor variation 14); southwestern Texas, Palmer 486 (US, type of Isocoma pedicellata, minor variation 10). Chinuahua: valley of the Rio Grande, Pringle 746 (B.P. minor variation 16); Paso del Norte, Pringle 746 (UC, minor variation 16); near San Diego, Lumholtz 759 (UC, Gr, $B$, minor variation 9); near White Water, Mearns 2281 (US, type of Isocoma oxylepis, minor variation 9). Sonora: Sonoyta, November 14, 1907, MacDougal (US, type of Isocoma limitanea, minor variation 8).

\section{MINOR VARIATIONS AND SYNONYMS}

So many connecting variations have been described in this species, mostly with specific names attached, that a synopsis of these is here presented. It is impossible to say, at the present time, which of these, if any, are of evolutionary significance and which are temporary modifications. Many of these 
named variations are connected to others by forms that have not yet received taxonomic treatment.

Bracts acute, heads many-flowered, peduncles short, leaves narrow. Typical pluriflorus.

Bracts acute, involucres short, peduncles long, leaves narrow, spreading. 9. Isocoma oxylepis.

Bracts obtuse (outer) to acute (inner), heads nearly sessile, leaves moderately wide. 8. Isocoma limitanea.

Bracts obtuse, involucre short, heads long-peduncled, leaves narrow. 10. Isocoma pedicellata.

Bracts obtuse, heads with average number of flowers (12) peduncles short, leaves rather wide. 13. Linosyris heterophylla.

Bracts obtuse, heads few-flowered, peduncles short, leaves broad. 16. Linosyris wrighti.

Bracts obtuse, heads few-flowered, peduncles short, herbage puberulent. 14 . Linosyris hirtella.

1. Aster heterophyllus O. Kuntze, Rev. 316, 1891. Based upon Linosyris heterophylla, which sec.

2. Bigelovia pluriflora Gray, Proc. Am. Acad. 8:639, 1873-H. pluriflorus.

3. B. wrighti Gray, l. c. Based upon Linosyris wrighti, which see.

4. B. wrighti var. hirtella Gray, Syn. Fl. $1^{2}: 142,1884$. Based upon Linosyris hirtella, which sce.

5. Haplopappus heterophyllus Blake, Contr. U. S. Nat. Herb. 25:546, 1925. Based upon Linosyris heterophylla, which sec.

6. Isocoma heterophylla Greene, Erythea 2:111, 1894. Based upon Linosyris heterophylla, which see.

7. I. hirtella Heller, Muhlenbergia 1:6, 1900. Based upon Linosyris hirtella, which see.

8. I. limitanea Rose et Standl., Contr. U. S. Nat. Herb. 16:18, plate 14, 1912. A form somewhat intermediate between genuine $H$. pluriflorus and its minor variation once called Linosyris heterophylla (which see in this list). The leaves are of average width, the herbage nearly glabrous, the heads in close terminal clusters, and the bracts vary from obtuse (outer) to acute (inner). Type locality, Sonoyta, Sonora. As intermediate may be taken a spccimen from Chihuahun with all the characters as just noted, except that the individual heads are obviously peduncled and arranged in very broad compound cymes (Pringle 746, UC).

9. I. oxylepis Wooton et Standl., Contr. U. S. Nat. Herb. 16:180, 1913. Close to typical pluriflorus, especially in the acute bracts of the involucre, but the leaves are weak and spreading, the heads distinctly peduncled in open cymes, and the involucres only about $4 \mathrm{~mm}$. high. It is very much like the form described as $I$. pedicellata, except for the acutc bracts. Typc locality, White Water, Chihuahua. (See further under Linosyris heterophylla.)

10. I. pedicellata Greene, Leaflets $1: 170,1906$. A form with small, long-peduncled heads in open cymes and obtuse bracts. The involucres in the type, which came from southwestern Texas, are about $4 \mathrm{~mm}$. high. The connections with typical pluriflorus are through forms described as I. oxylepis and Linosyris heterophylla.

11. I. pluriflora Greene, Erythea 2:111, 1894-H. pluriflorus.

12. I. wrighti Rydb., Bull. Torr. Club $33: 152,1906$. Based upon Linosyris wrighti, which sec.

13. Linosyris heterophylla Gray, Pl. Wright. 1:95, 1852. The common form, with involucral bracts mostly obtuse and leaves 2 to $4 \mathrm{~mm}$. wide. In the type of pluriflorus the lanceolate bracts are acute, the heads 15- to 18-flowered, and the leaves more narrowly linear. This typc was collected by James, on Long's first expedition, and since James traveled up the Arkansas River and down the Platte only, the type locality is either in or adjacent to castern Colorado. No subsequent collections have been made in these districts, so that the genuine form is but little known. There are several collections, however, of acutc-bracted, narrow-leaved plants from within the area of 
heterophylla, so that the retention of the latter in specific rank would give the one species (pluriflorus) a widely disjuncted distribution overlapping that of the other (heterophyllus). This, taken in connection with a considerable variation in the characters mentioned, seems to dispose of heterophylla as a distinct species. Collections from far south but referable to true pluriflorus because of the narrow leaves and acute bracts include the type of Isocoma oxylepis (minor variation 9), and as intermediate may be cited the type of $I$. limitanea (minor variation 8 ), the latter with moderately obtuse outer bracts and acute inner ones. The assignment of specific rank to heterophylla would necessitate a similar treatment for each of these, a course which would be impossible in view of the numerous steps involved.

14. L. hirtella Gray, 1. c. Later united by Gray with L. wrighti (see minor variation 4) but there given varietal rank. From this it differs in the more or less pubescent herbage. Type locality, valley of the Limpia.

15. Linosyris pluriflora Torr. et Gray, Fl. 2:233, 1842-H. pluriflorus.

16. L. wrighti Gray, Pl. Wright. 1:95, 1852. A form with broad leaves and fewflowered involucres with obtuse bracts; later united by its author with Linosyris heterophylla (which see in this list). Type locality, valley of the Rio Grande, below El Paso, Texas.

\section{RELATIONSHIPS}

The most useful distinguishing features of this species include the deeply cleft limb of the corolla, the pale involucral bracts, these destitute of any pronounced resinous thickening, the cymose arrangement of the heads, and the essentially entire leaves. Each of these characters may be noted in related species, but the combination exists in none of them and in none are the corolla-lobes quite so elongated in proportion to the throat.

The most closely related species is Haplopappus hartwegi, but as contrasted with that, pluriflorus is quite conservative, especially as regards its entire leaves, undifferentiated involucral bracts, and general absence of special features. That it is not a static species, however, is evidenced by the considerable number of variations, some of which have been variously named by taxonomists, and by its fairly broad geographic distribution.

\section{ECOLOGY}

This half-shrub grows on low plains in the Lower Sonoran Zone, perhaps always on areas disturbed by grazing or other agencies, but its ecologic relations have not been well worked out. The flowering season is August to October.

\section{Haplopappus drummondi (Torr. et Gray) Blake, Contr. U. S. Nat.} Herb. $23: 1491,1926$

A woody-based perennial with many erect or ascending branches, these mostly simple above base, 2 to $5 \mathrm{dm}$. high, leafy to inflorescence; bark dull white, darkening only on basal portions, apparently not becoming fibrous; twigs hard, brittle, grooved or coarsely striate, glabrous or only granular; principal leaves linear or narrowly linear-spatulate, mostly entire, the lower sometimes with a few prominent divergent lobes, acute, narrowed to base, 3 to $5 \mathrm{~cm}$. long, 2 to $5 \mathrm{~mm}$. wide, thickish, with prominent whitish midrib or this obscure, the lateral nerves seldom evident, pale, glabrous but more or less resinous-granular; secondary fascicled leaves almost universally absent; heads rather few, peduncled in rounded terminal cymes (these usually 3 to $6 \mathrm{~cm}$. across); involucre broadly turbinate, 6 to $8 \mathrm{~mm}$. high, 4 to $5 \mathrm{~mm}$. broad; bracts regularly imbricated in 4 or 5 lengths, the 
longest approximating disk, erect (the outer with spreading tips in the types), lanceolate-oblong, coriaceous at base, with conspicuous thick green or greenish tips (these turning brown), the outer ones obtuse, the inner more or less acute, glabrous or nearly so; ray-flowers wanting; disk-flowers 15 to 30 or even 35 ; disk-corolla with elongated slender tube and short ventricose throat, 6 to $7.5 \mathrm{~mm}$. long, glabrous or scabrid; lobes lanceolate, acute, erect, 0.6 to 1.2 $\mathrm{mm}$. long, glabrous; style-branches moderately exserted, 1.2 to nearly $2 \mathrm{~mm}$. long, the ovate acute appendage one-third to one-half as long as stigmatic portion; achenes slenderly prismatic-pyramidal, silky pubescent, not known in mature condition; pappus rather soft, of numerous brownish unequal bristles, the longest of which nearly equal corolla. (Linosyris drummondi Torr. et Gray, Fl. N. Am. $2: 233$, 1842.) (Fig. 80.)

Southwestern Colorado and Arizona to Texas (and northern Mexico?). Type locality, Texas. Colorado: near the Utah line, southwestern Colorado, Brandegee 1208 (UC). UтAн: along San Juan River, near Bluffs, Rydberg and Garrett 10000 (UC). Arizona: Navajo Indian Reservation, near north end Carrizo Mountains, Standley 7434 (UC, Gr); Holbrook, August 20, 1883, Rusby 651 (UC, Gr, US, type collection of Isocoma rusbyi, minor variation 4); Little Colorado River, August 20, 1883, Rusby (Gr.). Texas: Corpus Christi Bay, Nueces County, Heller 1557 (UC); type collection, Drum-

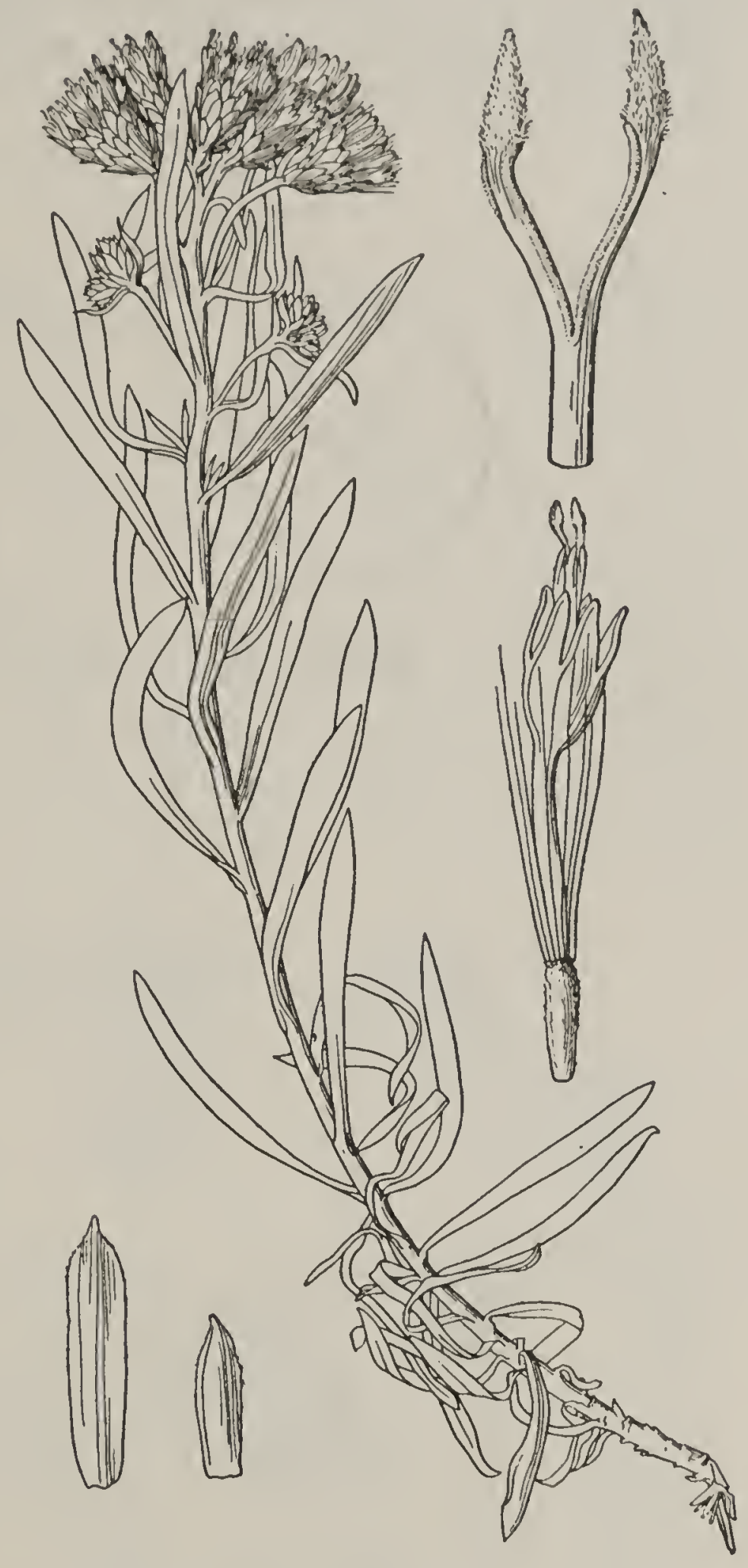

FIG. 80-Haplopapmes drummondi mond 223 (Gr, K, one specimen carrying the additional data "San Felipe").

\section{MINOR VARIATIONS AND SYNONYMS}

1. Aster berlandieri O. Kuntze, Rev. 315, 1891-H. drummondi.

2. Bigelovia drummondi Gray, Proc. Am. Acad. 8:639, 1873-H. drummondi.

3. Isocoma drummondi Greene, Erythea 2:111, 1894-H. drummondi.

4. I. rusbyi Greene, Leaflets $1: 170,1906$. No characters have been found, either in the description or in the types, whereby this can be separated from $H$. drummondi. The involucre has more strictly appressed bracts and these have a suggestion of puberulence on the tips, but the differences are not marked. Type locality, Holbrook, Arizona.

5. Linosyris drummondi Torr. et Gray, Fl. 2:233, 1842-H. drummondi. 


\section{RELATIONSHIPS}

The absence of secondary fascicled leaves furnishes a convenient feature for the recognition of this species from all others of its section. It is feared, however, that this may have but little phylogenetic significance and that additional collections will prove it to be inconstant. But Haplopappus drummondi is well set off from its neighbors, as seen from other characters. The large, many-flowered heads separate it from hartwegi and pluriflorus and at the same time indicate the improbability of its derivation from

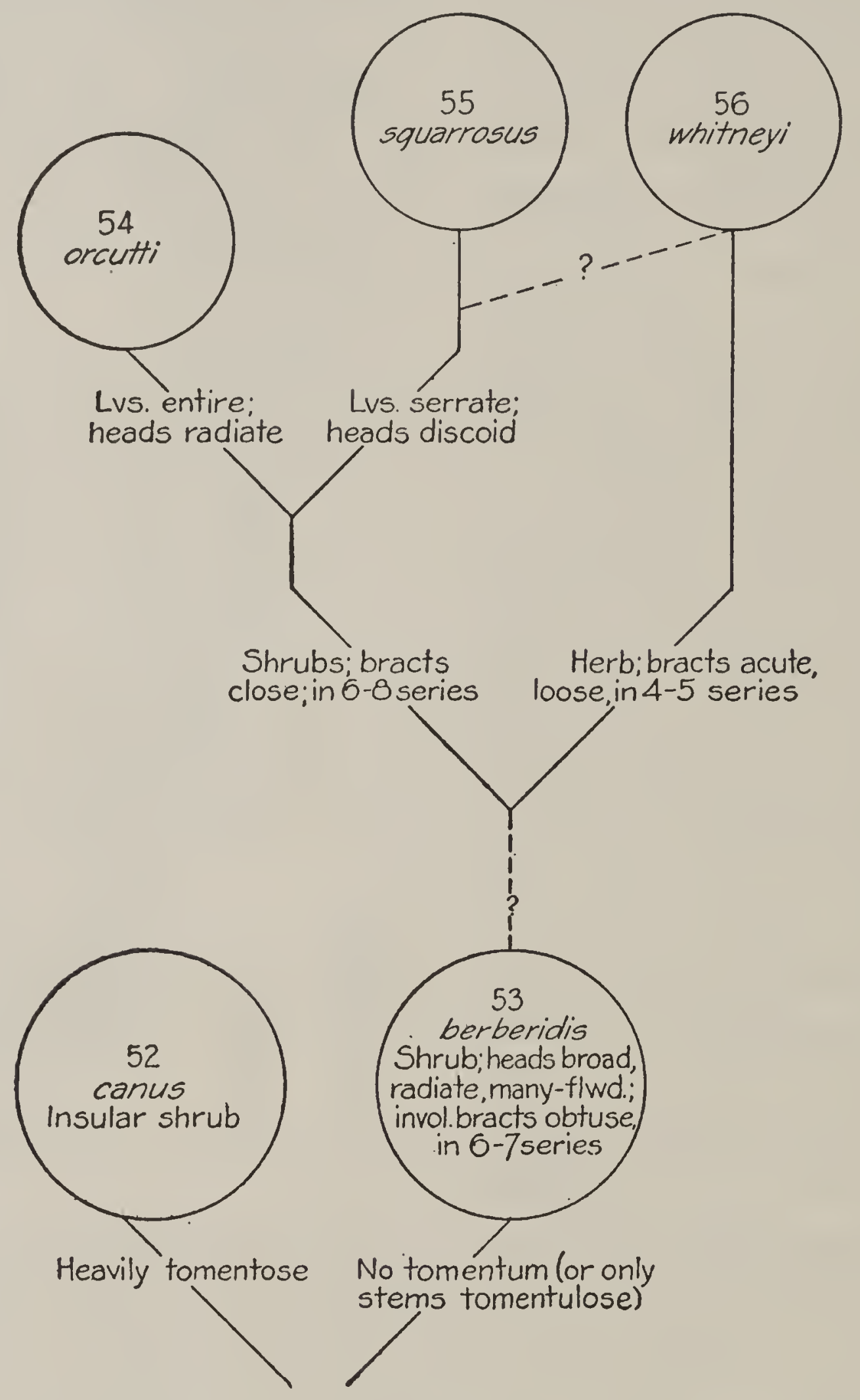

Frg. 81-Phylogenetic chart of the species of Haplopappus section Hazardia

either of these. An origin from venetus has been assumed on the chart, but the connections are not well established. In habit and general appearance the plants are much like the far western acradenius, but the specialized features of this, particularly the peculiar bracts of the involucre, are wanting. It is not unlikely that hybrids occur in Arizona between this species and $H$. hartwegi. 


\section{ECOLOGY}

In Arizona and Utah, at least, this is a plant of strongly alkaline soils. It here belongs to the Lower Sonoran Zone and blossoms from midsummer on. The type specimens, which came from southern Texas, are closely similar except for their much darker involucres; but Heller has collected a form along Corpus Christi Bay which has the appearance of an ecologic dwarf, the densely leafy and crowded stems being only about $1.5 \mathrm{dm}$. high. The saline environment may be responsible for this unusual habit.

\section{SECTION 14. HAZARDIA}

\section{PHYLOGENY OF THE SPECIES}

This section comprises two primitive species, Haplopappus berberidis and $H$. canus, of Lower California and nearby islands, and three others which give evidence of being more highly specialized. Of these latter, $H$. orcutti is also southern and although possibly derived from some berberidis-like ancestor, possesses also certain features suggestive of a connection with the section Ericameria. The two remaining species are much more northerly in their distribution, one, $H$. squarrosus, occupying the coastal districts of California, while the other, $H$. whitneyi, is of the Sierra Nevada and northern California. The latter is perhaps the most highly developed of all the Hazardias, as indicated by its long style-appendages and nearly herbaceous habit, but its involucre is less highly organized than that of squarrosus and it is not so actively producing new forms. (Fig. 81.)

52. Haplopappus canus (Gray) Blake, Contr. U. S. Nat. Herb. $24: 86,1922$

A loosely branched shrub, of ten 1 meter or more high, leafy to inflorescence, the main stems rough and irregular; bark brown underneath the tomentum, becoming rough and gray in age; twigs stout, soft-woody, densely lanate-tomentose; principal leaves obovate to oblanceolate or somewhat spatulate, entire to sharply serrate, obtuse, tapering to a petiole or this sometimes broad and half-clasping, 4 to $11 \mathrm{~cm}$. long 15 to $30 \mathrm{~mm}$. wide, thick, pinnately-veined, densely whitetomentose or tomentum deciduous from upper surface; heads usually cymose, each cyme $1 \mathrm{dm}$. or more across, or racemose, the racemes only a few centimeters broad, the ultimate peduncles 1 $\mathrm{cm}$. or less long or the head sometimes sessile; involucre

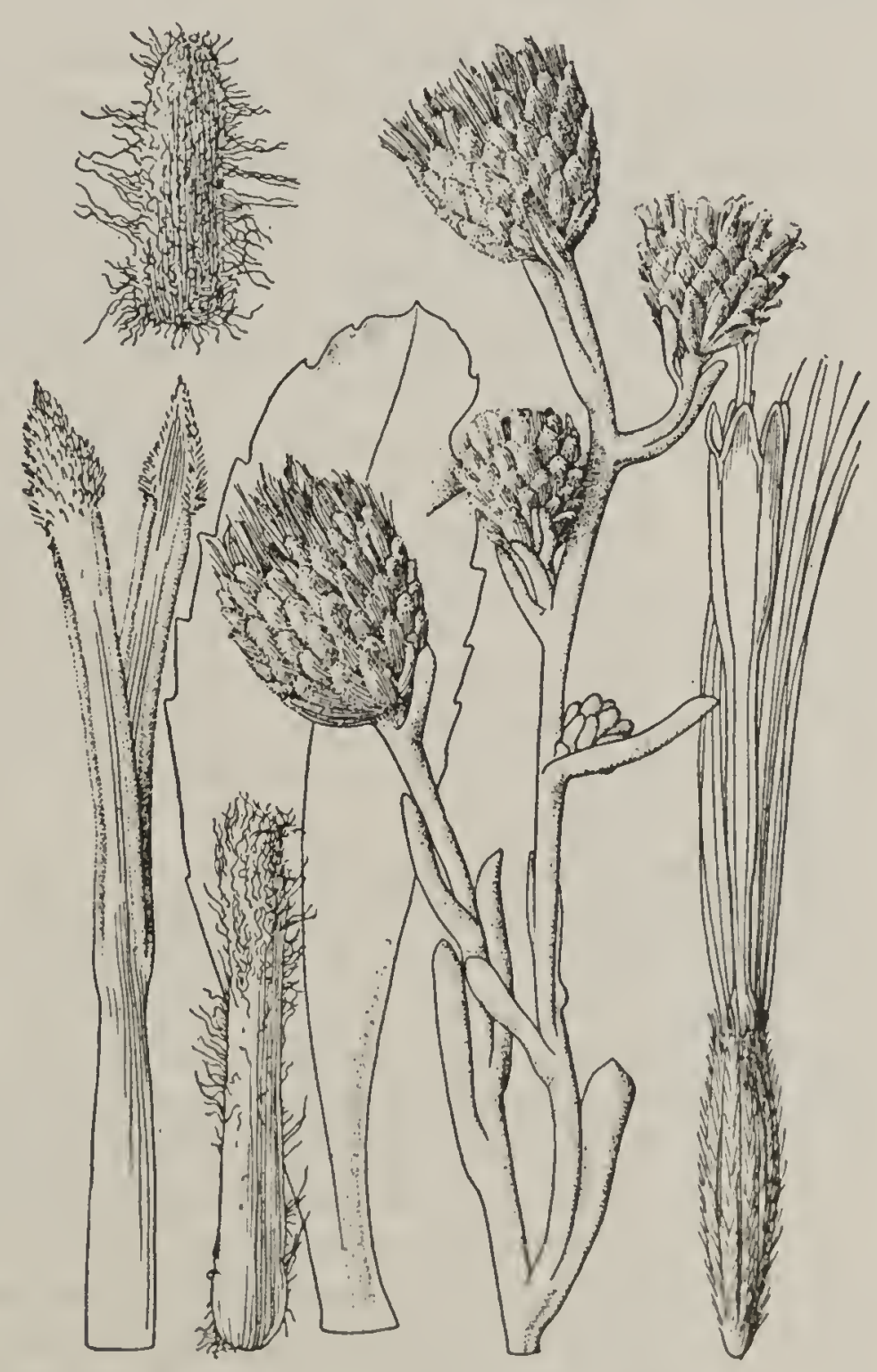

Fig. 82-Haplopapmus canus broadly turbinate, 10 to $12 \mathrm{~mm}$. high, 8 to $12 \mathrm{~mm}$. broad; bracts 
closely and regularly imbricated mostly in six lengths, the longest nearly equaling disk, appressed, oblong, acute, appearing obtuse because of the heavy lanate tomentum; ray-flowers said to be 4 to 6 and with very short ligules turning from yellow to purple, but heads usually discoid; diskflowers usually 40 or more (originally described as 12 to 20); disk-corolla gradually enlarged upward, 8 to $10 \mathrm{~mm}$. long, usually puberulent near middle, sometimes with long loose hairs, yellow, turning purplish; lobes lanceolate, acute, nearly erect, 0.8 to $1.4 \mathrm{~mm}$. long, scabrid or glabrous; style-branches long-exserted, about 1.5 to $2.2 \mathrm{~mm}$. long, the ovate-acute appendage much shorter than stigmatic portion; achenes 4 to $5 \mathrm{~mm}$. long, somewhat fusiform but 4-angled, striate between angles, canescent; diskpappus slightly exceeding corollas, slender, fragile, copious, dark-brown, sometimes becoming almost red. (Diplostephium canum Gray, Proc. Am. Acad. 11:75, 1876.) (Fig. 82.)

Islands off the coast of southern California and northern Lower California. Type locality, Guadalupe Island. California: Island of Santa Rosa, June 1888, Brandegee (UC, minor variation 2, Corethrogyne detonsa); island of Santa Cruz, July, August, 1886, Greene (UC 32195, same variation); Friar's Harbor, island of Santa Cruz, September 3, 1903, Grinnell (UC, same variation); island of Santa Cruz, July, August 1886, Greene (UC 32197, probably the type of Hazardia serrata, minor variation 6); San Clemente Island, August 25, 1894, Brandegee (UC). Lower CaliFornia: Guadalupe Island, Anthony 257 (UC); same island, April 24, 1885, Greene (UC).

\section{MINOR VARIATIONS AND SYNONYMS}

1. Corethrogyne cana Greene, Bull. Calif. Acad. 1:223, 1885-II. canus.

2. C. detonsa Greene, Bull. Torr. Club 10:41, 1883. This is a common form of H. canus as it grows on Santa Cruz, Santa Rosa, and probably other islands off the coast of Santa Barbara County, California. The leaves are thicker than in typical canus and sometimes more coarsely serrate. But collections now at hand from these islands and from the type locality of canus exhibit so much variation in shape and serration of leaves that a separation on such characters is thought not to be a natural one. On the other hand, the thick foliage is a constant feature of these more northern plants, while those from San Clemente and Guadalupe Islands have leaves much thinner and almost membranous after the early disappearance of the tomentum from the upper surface. The disk-corollas in the detonsa form are 9 to $9.7 \mathrm{~mm}$. long; in the only flowering specimen available of the thin-leaved form they are only 7.5 to $8 \mathrm{~mm}$. long. If this is found to be constant it might be used in addition to the foliage characters to serve for the restoration of detonsa as a distinct species.

3. Diplostephium canum Gray, Proc. Am. Acad. 11:75, 1876.-H. canus.

4. Hazardia cana Greene, Pittonia 1:29, 1887-Haplopappus canus.

5. H. detonsa Greene, 1. c. Based upon Corethrogyne detonsa, which see.

6. H. serrata Greene, 1. c. 30 . A form of Haplopappus canus with thick, coriaceous leaves, these coarsely and sharply serrate. The types are from two bushes found growing on the south side of Santa Cruz Island, off the coast of California, and are probably the specimens preserved at the University of California under No. 32197 (July-August, 1886, Greene, named as Hazardia serrata in Greene's handwriting). These have oblong-spatulate rather than obovate leaves, some of which have lost nearly all the tomentum from both faces, as described by Greene. But old leaves of typical canus from Guadalupe Island are also glabrate. Even if separable from the true canus, which is possible on the basis of leaf-texture, perhaps aided by corolla-size, this form can not be specifically distinguished from Corethrogyne detonsa, an earlier segregate also from Santa Cruz Island (No. 2 of this list). 


\section{RELATIONSHIPS}

This species is so distinct in its characters that it can be definitely connected with no other. It is most like Haplopappus berberidis, especially in its large, many-flowered heads, and like it probably represents a former connection with ancient types from which also certain South American groups have been developed. The restriction to coastal islands, with consequent isolation, is perhaps responsible for the absence of connecting forms.

\section{ECOLOGY}

Notwithstanding its island habitat, Haplopappus canus has the characteristics of a xerophyte, as is particularly noticeable in the heavy coating of tomentum. Nothing is known as to the exact conditions under which the plants grow, except that they inhabit rocky slopes which are extremely dry at most scasons of the year. All flowering specimens at hand were collected in July and August.

\section{Haplopappus berberidis Gray, Syn. Fl. $1^{2}: 126,1884$}

An erect bushy shrub, 0.5 to 2 meters high, leafy throughout, the main stems commonly $3 \mathrm{~cm}$. or more thick; bark smooth, firm, hard, brown changing to gray; twigs brittle, hard, striate, sparsely villous-tomentulose at least when young; principal leaves oblong to obovate-oblong, acutely or even spinosely serrate throughout, or the base entire when narrow, very obtuse, sessile and more or less clasping by either a broad or a narrowed base, 2 to $5 \mathrm{~cm}$. long, 10 to $18 \mathrm{~mm}$. wide, rigid, pinnately veined, sparsely pubescent when young, soon glabrate; heads thyrsoidly or simply racemose or solitary and terminal (as in type), the peduncles in branched forms $3 \mathrm{~cm}$. or less long and leafy-bracted or heads sessile in leaf-axils; involucre broadly turbinate or campanulate, 12 to $18 \mathrm{~mm}$. high, 10 to $15 \mathrm{~mm}$. broad (more when pressed); bracts regularly imbricated in 6 or 7 lengths, all shorter than disk, appressed, oblong, very obtuse, mostly stiff and chartaceous but with a
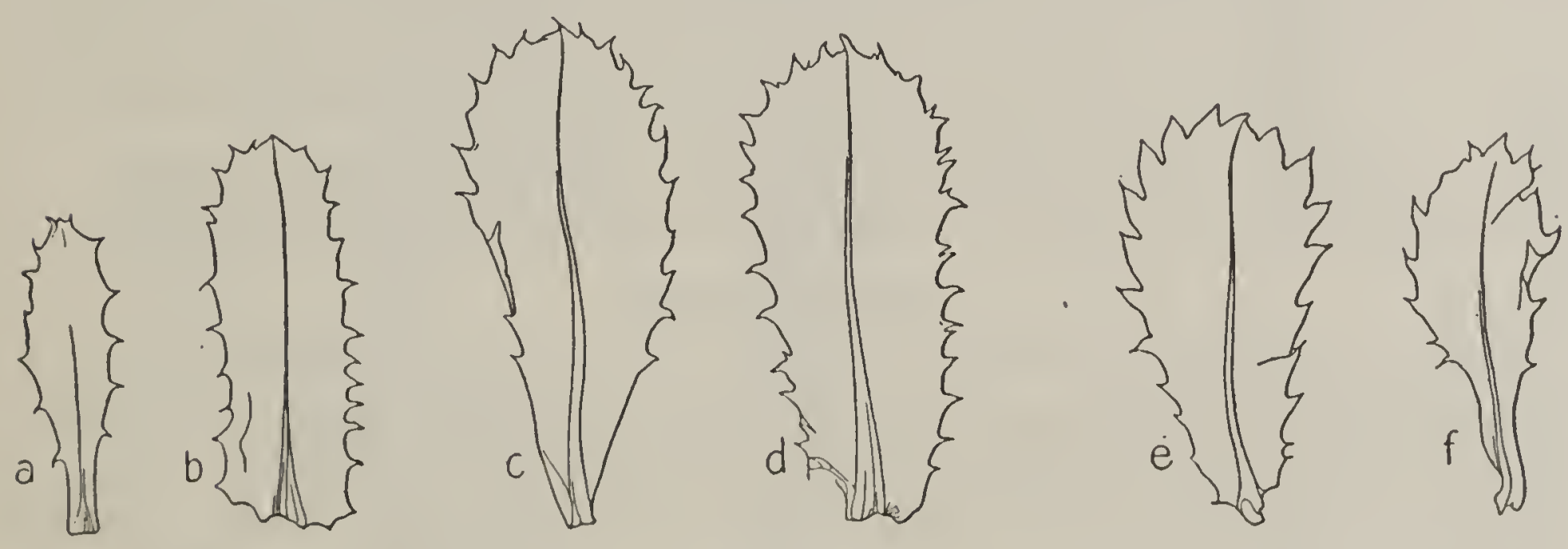

FIG. 83-Leaf variation in Haplopappus berberidis: $a, b$, lower and middle leaves respectively from a single twig of the mainland (295979 UC); $c, d$, two leaves from a single twig from Coronados Islands, minor variation $2, H$. cruentus Greene ( $86606 \mathrm{UC}) ; \varepsilon, f$, two leaves from a single twig from Todos Santos Island (86607 UC).

conspicuous green area near summit, glabrous or only granular; ray-flowers 15 to 20 or even 30 , their achenes fertile, the ligules 6 to $9 \mathrm{~mm}$. long and permanently yellow or changing to saffron; disk-flowers 20 to 45 or more; diskcorolla very gradually enlarged upward, 9.0 to $10.5 \mathrm{~mm}$. long, glabrous, 
yellow, changing to brown or saffron; lobes oblong-lanceolate, acute, nearly erect, nearly 1 to $1.5 \mathrm{~mm}$. long, glabrous; style-branches short-exserted, 1.8 to $2.4 \mathrm{~mm}$. long, the linear acutish appendage from decidedly shorter to somewhat exceeding stigmatic portion; achenes 5 to $5.5 \mathrm{~mm}$. long, somewhat compressed but 4 -angled, striate between angles, slightly tapering to base, glabrous; disk-pappus about as long as corolla, slender, fragile, copious, yellowish-brown to nearly red. (Figs. 83 and 84.)

Northwestern Lower California. Type locality, Todos Santos. Coronados Islands, April 1894, Anthony (UC, minor variation 2, H. cruentus); same locality, Millspangh 4414 (UC, same variation); $42 \mathrm{~km}$. south of Tijuana, Hall 12250 (UC); type collection, July 1882, Fish (Gr); Ensenada, August 27, 1893, Brandegee (UC); Todos Santos Island, March 10, 1897, Brandegee (UC); $9 \mathrm{~km}$. south of Ensenada, Hall 12256 (UC); foothills of San Pedro Martir, Robertson 53 (UC, only one specimen found).

\section{MINOR VARIATIONS AND SYNONYMS}

In addition to the following, there is to be noted a hybrid between Haplopappus berberidis and $H$. orcutti. This will be described under the latter.

1. Aster berberidis O. Kuntze, Rev. 317, 1891-H. berberidis.

2. Haplopappus cruentus Greene, Pittonia 2:17, 1889. There are no constant characters for the separation of this from typical $H$. berberidis. It was based upon specimens from Coronados Islands, in which the heads were solitary and the leaves spatulate-obovate. All plants from Coronados Islands thus far collected are monocephalous, but it will be strange if this feature does not vary there as it does on the mainland. This mainland form commonly has the heads racemosely arranged, but the racemes are often reduced to 2 or 3 heads or not infrequently to a solitary one, as in the type specimen of berberidis. A specimen from Todos Santos Island (March 10, 1897, Brandegee, UC) has a terminal raceme with remnants of 8 heads of the preceding year, but a new shoot from the same branch has a single terminal head. It is probable that seasonal conditions have much to do with the number of heads produced. The leaf-shape, sometimes used for the separation of the two supposed species, is likewise untrustworthy. The cruentus form is supposed to have leaves more narrowed to the base, and this narrowed portion entire. But all variations are found both on the islands and on the mainland, and they sometimes occur even on a single stem. It is usually the lower leaves that are narrowed and entire at base. Something of the situation is indicated in the accompanying figures.

3. Hazardia berberidis Greene, Erythea 2:112, 1894-Haplopappus berberidis.

4. H. cruentus Greene, 1. c. Based upon Haplopappus cruentus, which see.

\section{RELATIONSHIPS}

If this plant grew in Chile, it would be accepted as a member of section Polyphylla and placed near the mucronatus-deserticolus group. In foliage, shape of involucre, and style-branches, the similarity is very close Haplopappus berberidis does, to be sure, differ from these in the more numerous and more closely imbricated bracts of the involucre, and there is no evidence that the flowers of the South American species turn saffron-colored in age, and several minor differences could be pointed out. The essential agreement in important characters is such as to justify a suspicion that the present species represents a former phylogenetic connection with South American ones and therefore stands near the beginning of the North American section to which it is assigned. This conclusion is supported by the data of geographic distribution, berberidis being the most southerly 
species of its section, and by the comparatively primitive nature of its characters. In this latter connection are to be noted the large, racemose heads, with numerous flowers in both ray and disk, and the short style-

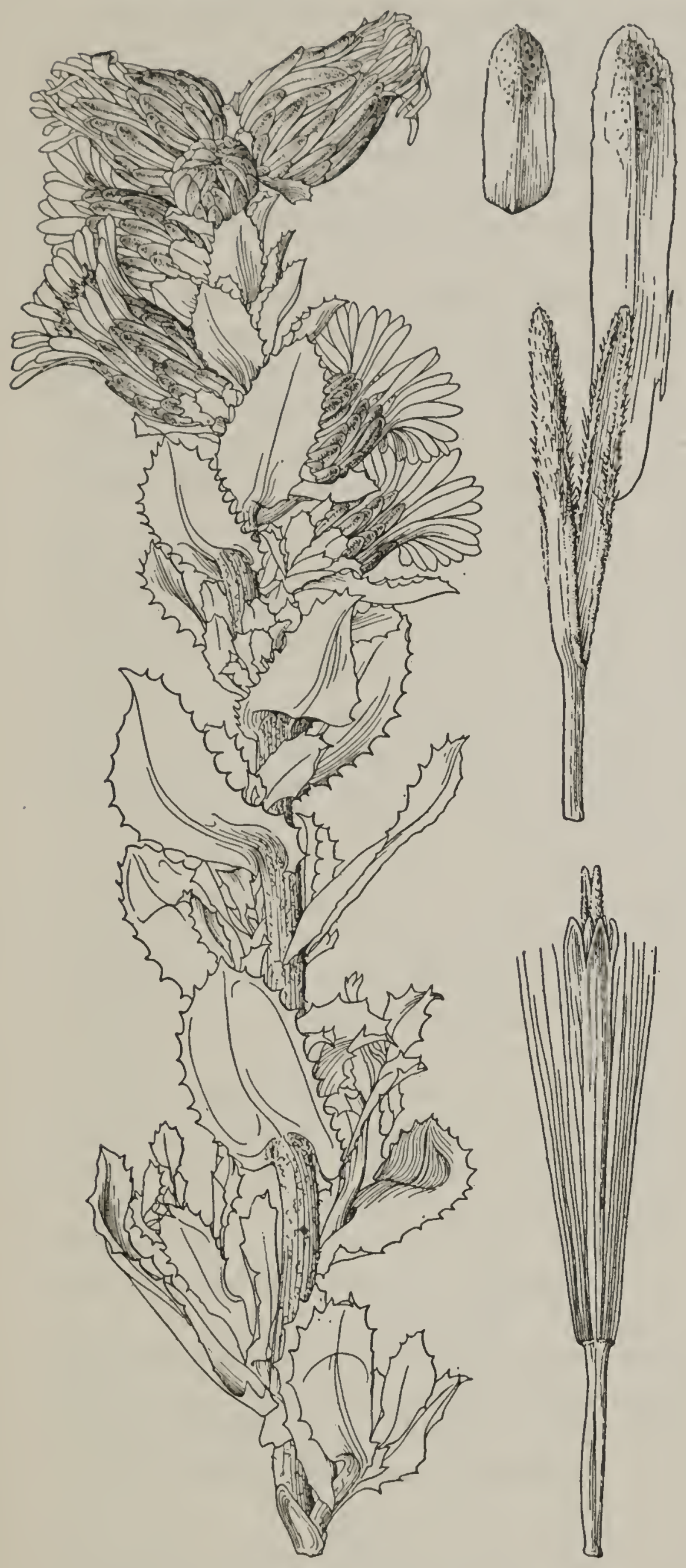

FIG. 84-Haplopappus berberidis

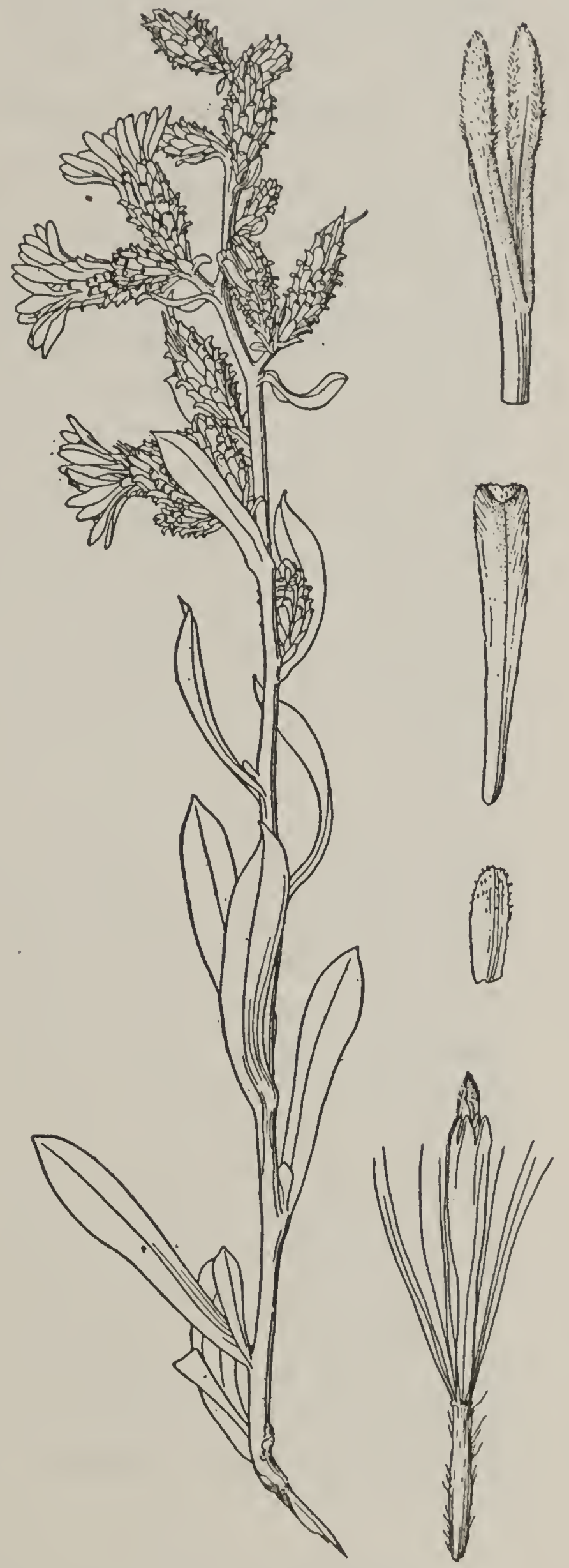

FIG. 85-Haplopappus orcutti

appendages. Its glabrous achenes militate against the derivation of all the other species directly from this one, but their origins doubtless were from some closely similar stock. 


\section{ECOLOGY}

This is a low shrub of stony soil and disturbed banks on the plains and low hills near the west coast of Lower California. Here, in the Lower Sonoran Zone, it associates with other low shrubs, such as Euphorbia miser, Eriogonum fasciculatum, Rhus integrifolia, Isomeris arborea, and Opuntia engelmanni. On Coronados Islands, the "cruentus" form of this species and Atriplex canescens are the most common shrubs, according to Millspaugh. The flowering season follows the summer rains.

\section{Haplopappus orcutti Gray, Proc. Am. Acad. 20:297, 1885}

An erect shrub, about 0.5 to 1 meter high, leafy up to the inflorescence, the main stem mostly $3 \mathrm{~cm}$. or less thick, the few and open branches erect or ascending; bark firm, smooth, at first brown, later pale gray, breaking only in age; twigs woody, brittle, with a few striae or ridges, glabrous, smooth and shining as though varnished or slightly resinous-roughened; principal leaves spatulate-lanceolate to narrowly obovate, mostly entire, some of the lower occasionally with a few pungent teeth, either acute or obtuse but always mucronate, narrowed to a sessile more or less clasping often decurrent base, 2 to $4.5 \mathrm{~cm}$. long, 6 to $15 \mathrm{~mm}$. wide, firm, thick-coriaceous, only the midvein prominent, glabrous, resinous-punctate; heads in narrow thyrsoid or simple racemes, these sometimes assembled into large pyramidal panicles (inflorescence usually 3 to $10 \mathrm{~cm}$. long, 2 or $3 \mathrm{~cm}$. broad, but up to $50 \mathrm{~cm}$. long and $20 \mathrm{~cm}$. broad in robust paniculate forms), the ultimate peduncles very short or wanting; involucre narrowly turbinate or obconic, 7 to $9 \mathrm{~mm}$. high, 4 to $6 \mathrm{~mm}$. broad; bracts regularly imbricated in about 6 to 8 lengths, even the longest shorter than disk, appressed except at tip, this either erect or squarrose, linear, obtuse or acutish, stiff, chartaceous up to the distinctly herbaceous-thickened and resinous-scabrid tip; rayflowers 8 to 12 or apparently sometimes reduced in number, fertile, the ligule 3 to $4.5 \mathrm{~mm}$. long by about $1.5 \mathrm{~mm}$. broad, scarcely exceeding disk, yellow, apparently not changing in age; disk-flowers 10 to 20 ; disk-corolla subcylindric, slightly ampliate upward, 5.5 to $7 \mathrm{~mm}$. long, glabrous, yellow, slightly if at all changing in age; lobes ovate-lanceolate, acute, erect, about $0.8 \mathrm{~mm}$. long, glabrous, style-branches short-exserted, 1.5 to $2 \mathrm{~mm}$. long, the broadly lanceolate and somewhat obtuse appendage shorter than or nearly equaling stigmatic portion; achenes 3 to 4 or nearly $5 \mathrm{~mm}$. long, nearly prismatic, about 5 -angled, sparsely pilose; disk-pappus shorter than corolla, of unequal slender brown bristles. (Fig. 85.)

Confined to the northwest coast of Lower California. Type locality, All Saints' Bay. Type collection, September 22, 1882, Orcutt 1230 (Gr, UC); Ensenada, October 5, 1902, Brandegee (UC); 4 km. north of Ensenada, Hall 12261 (UC); near La Salina, $72 \mathrm{~km}$. south of Tijuana, Hall 12252 (UC).

\section{MINOR VARIATIONS AND SYNONYMS}

1. Haplopappus orcutti $\times$ berberidis. This hybrid grows abundantly on the slopes just south of La Salina, near the west coast of Lower California. On low, level ground the plants are mostly genuine orcutti; passing up the slopes the plants take on more and more the characters of berberidis, the leaves being rigidly serrate but still resinous-punctate, the heads large and many-rayed, but not quite so large as in berberidis. Some of the plants have a bushy habit strongly contrasting with the narrow shrubs of the plains below. The 
achenes are pubescent in all plants studied. Typical berberidis grows a few kilometers distant, but apparently there is not enough of it near La Salina to prevent its characters getting swamped by the much more plentiful orcutti.

2. Hazardia orcutti Greene, Erythea 2:112, 1894-Haplopappus orcutti.

\section{RELATIONSHIPS}

An anomalous situation presents itself in connection with this species. Its technical characters, or rather those commonly used in keys, are those of section Ericameria, but the obvious phylogenetic connections are with section Hazardia. The foliage is resinous-dotted, the resin forming open crateriform depressions simulating those characteristic of the former section. This seems to indicate a common origin, but the histological features of the pits have not been compared in detail. The flowers are permanently yellow or turn only to brownish, not to saffron as in most Hazardias. With this latter section, however, orcutti shares the features of sessile, halfclasping leaves and a characteristically thyrsoid arrangement of the heads very unlike the cymose clusters of those species of Ericameria (parishi, etc.) which it most closely resembles in other features. Perhaps more important than this is the large number of involucral bracts arranged in numerous series. The connections with true Hazardia are also suggested by natural hybrids with $H$. berberidis (see under minor variation 1). Aside from the hybrids, which pass all the way from one to the other parent, these two species are not very similar, the present one being a narrower, more erect shrub with smaller heads, fewer flowers in both ray and disk, and with nearly all the leaves entire.

\section{ECOLOGY}

Haplopappus orcutti is a narrow, openly branched shrub of gently sloping mesas and valleys near the sea in Lower California. Here it unites with other woody perennials to form a low and very open chaparral. Its most common associates are Eriogonum fasciculatum, Euphorbia miser, and a dwarf form of Artemisia californica. It appears to be increasing slowly in numbers, perhaps because of overgrazing, which is effectively reducing the grasses and thus encouraging the non-palatable shrubs, of which this is one.

The soil is a mixture of gravel and loam and is deeper than that of the stony ravines and upper slopes where $H$. berberidis is more common. In good soil the plants sometimes become very robust, especially when growing without competition, and produce large, paniculate inflorescences very unlike the narrow ones of the taxonomically typical form. It is noted, also, that the number of flowers in the head increases with improved soil conditions. Probably the controlling factor in these phenomena is the water relation, for the district is exceedingly arid notwithstanding the proximity of the sea. The flowers appear in abundance in September and October, following summer rains.

55. Haplopappus squarrosus Hook. et Arn., Bot. Beech. Voy. 146, 1833

A low shrub, freely branched throughout, sometimes loose and open, often compact and densely bushy, especially in exposed places, 4 to $10 \mathrm{dm}$. high, leafy up to heads; bark gray or brown, breaking longitudinally on all 


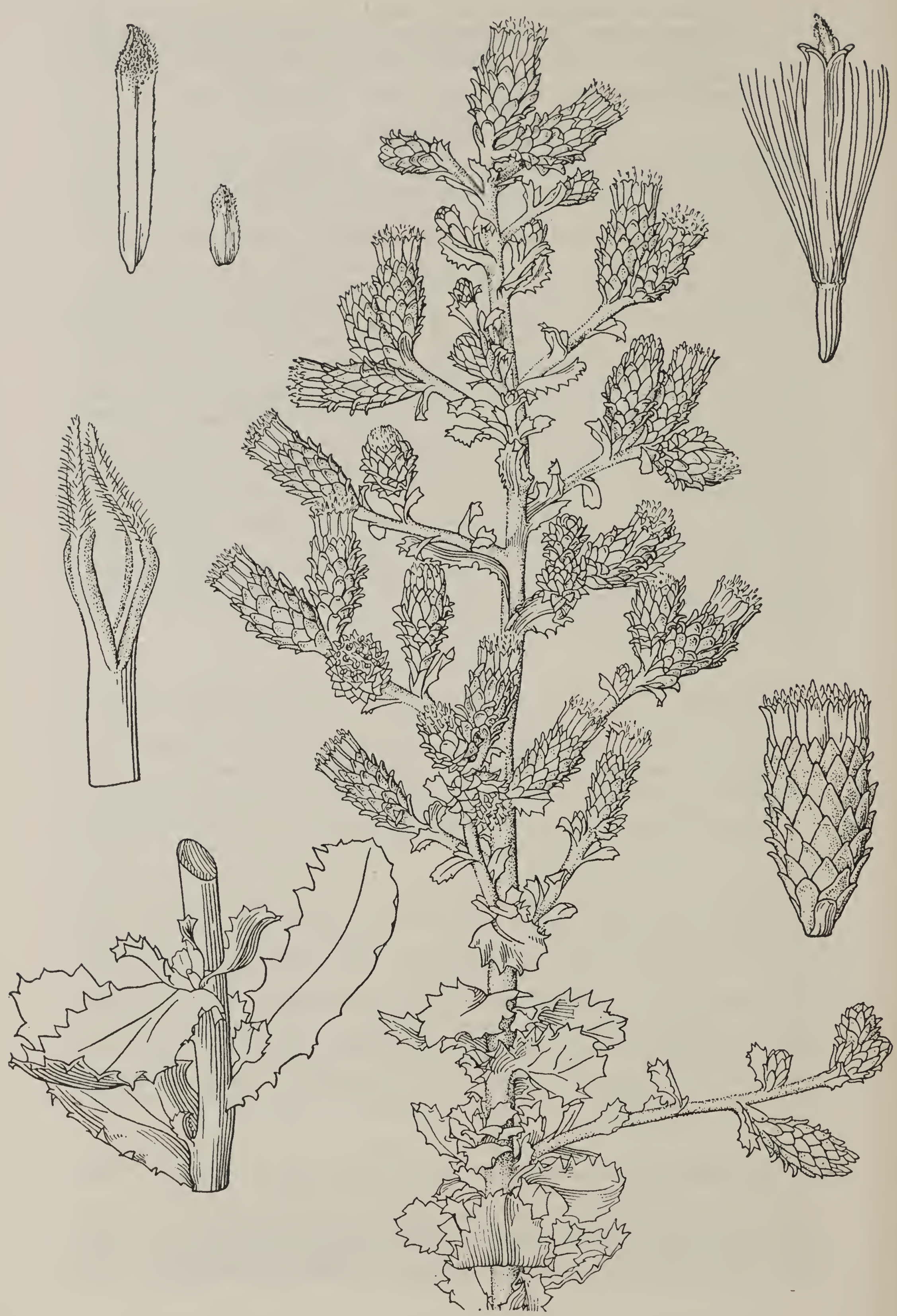

FIa. 86-Haplopappus squarrosus typicus (minor variation 5) 
branches; twigs brittle, strongly striate, tomentulose or hirtellous to scabrid or rarely glabrous, viscid; principal leaves oblong to obovate-oblong, sharply serrate throughout with mucronulate teeth, very obtuse, sessile and clasping at the broad base, 1.5 to $5 \mathrm{~cm}$. long, 7 to $20 \mathrm{~mm}$. wide, stiffly chartaceous, pinnately veined, at least the midrib prominent, puberulent or glabrous; heads densely spicate or glomerate-spicate, the spikes rarely with open branches forming a pyramidal panicle; involucre turbinate or subcylindric, 8 to $15 \mathrm{~mm}$. high, 4 to $8 \mathrm{~mm}$. broad; bracts regularly imbricated in 6 to 8 lengths, all shorter than disk, oblong or lanceolate to linear-acuminate, obtuse or acute, the tips erect to strongly squarrose, chartaceous at base, the upper portion herbaceous and glabrous to cinereous, of ten also glandular; ray-flowers wanting; disk-flowers 4 to 30; corolla subcylindric, slender, very gradually enlarged upward, 8 to $10 \mathrm{~mm}$. long, glabrous, yellow or reddish; lobes lanceolate, acute, 0.6 to $1.2 \mathrm{~mm}$. long, glabrous; stylebranches well-exserted, about 2.5 to $3 \mathrm{~mm}$. long, the appendage shorter than or rarely equaling stigma (much longer in occasional plants of subspecies stenolepis, these perhaps abnormal); achenes fusiform, 5-ribbed, striate between the ribs, 5 to $8 \mathrm{~mm}$. long, glabrous or sparsely pubescent; pappus rather rigid, the outer bristles slightly shorter than inner ones, which exceed corollas, brown or fuscous. (Figs. 86 to 89.)

Western California, from the vicinity of Monterey to the northern borders of Lower California.

\section{SUBSPECIES}

\section{Key to the Subspecies of Haplopappus squarrosus}

Bracts of the involucre oblong or linear-oblong; flowers 9 to 30 ; heads rather broad.

Bracts short-acute, at least some of the tips usually squarrose, mostly

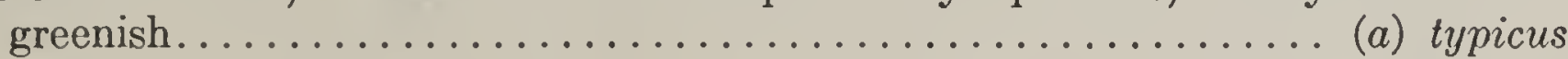

Bracts very obtuse (except the inner), mucronate, the tips not squarrose, pale and chartaceous........................... (b) obtusus

Bracts of the involucre linear-acuminate (not squarrose); flowers 4 to 6 ; heads very narrow.......................................... stenolepis

55a. Haplopappus squarrosus typicus-Stems moderately woody at base, frecly and openly branched, hirtellous to finely and sparsely tomentulose toward the heads, also finely stipitate-glandular; leaves obovate to oblong or oblong-spatulate, 2 to $5 \mathrm{~cm}$. long, 10 to $20 \mathrm{~mm}$. wide, obtuse but mucronate; heads in close terminal racemes (as in type) to glomerateracemose or even racemose-paniculate; the entire inflorescence sometimes up to $20 \mathrm{~cm}$. long by $8 \mathrm{~cm}$. broad; involucre gradually enlarged upward, 8 to $15 \mathrm{~mm}$. high; bracts closely imbricated, oblong, acute, with conspicuous green tips, these either erect or squarrose (especially the outer) and minutely glandular, often also cinereous; flowers 9 to 30 ; corolla 9 to $11 \mathrm{~mm}$. long; achenes glabrous or sparsely pubescent. (H. squarrosus Hook. et Arn., Bot. Beech. Voy. 146, 1833.) (Figs. 86 and 88.)

Coastal slope of California from Monterey to San Diego, probably extending slightly into Lower California. Type locality, not definitely stated but probably vicinity of Monterey. (All collections here cited, except the first four, are of minor variation 5.) Type collection, Beechey Voyage (K); Monterey, near Carmel Bay, Elmer 4026 (UC, B); Pismo Beach, San Luis Obispo County, Hall 12267 (UC); Ventura, October 20, 1919, Hall 
(UC); Jolon, Monterey County, September, 1894, Eastwood (UC); inland slopes, San Luis Mountain, San Luis Obispo County, Summers 391 (UC); near Santa Barbara, Eastwood 200, 201 (UC); Santa Cruz Island, 1886, Greene (UC, with numerous flowers, as in type, but other features as in
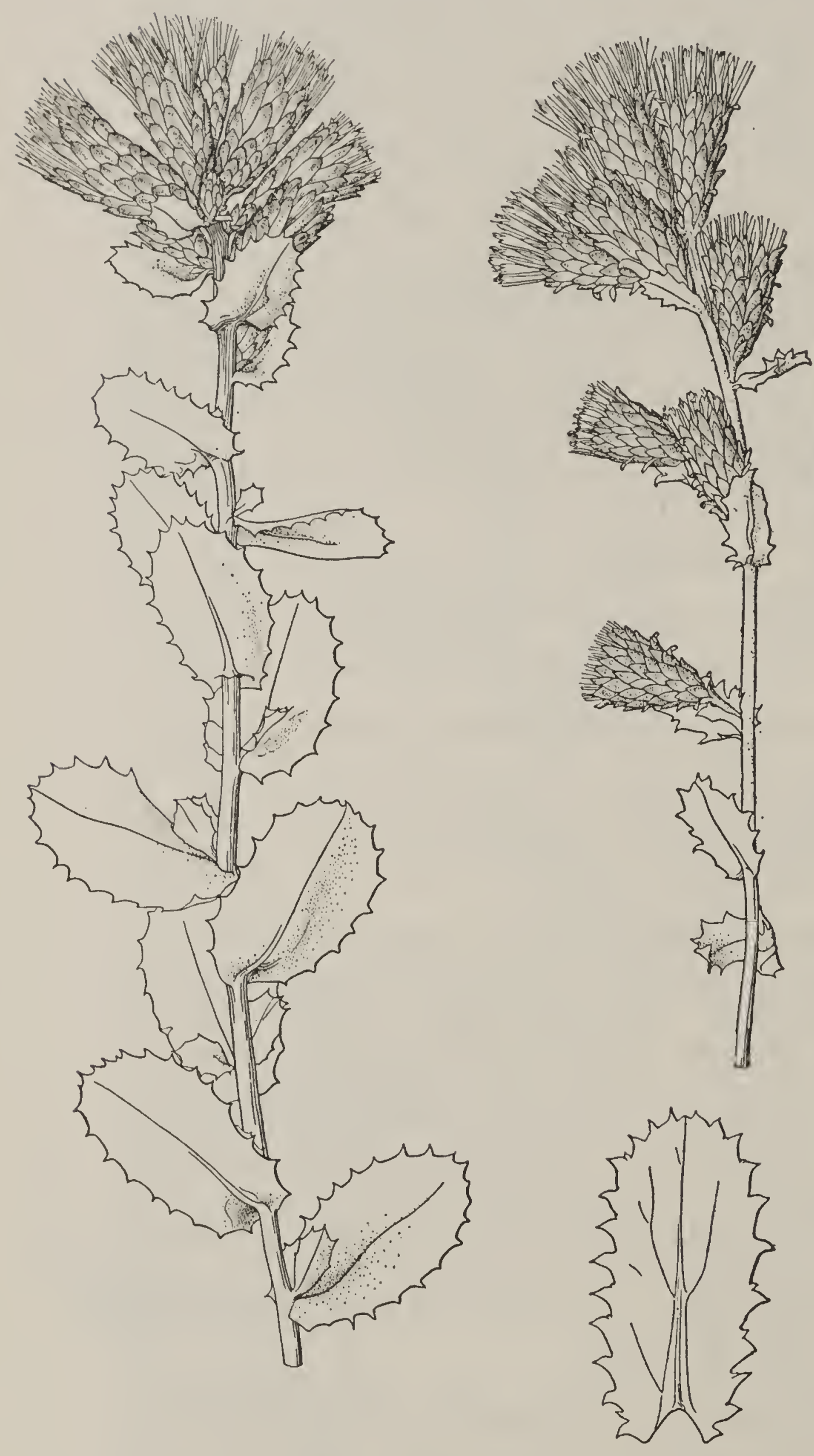

FIG. 87-Haplopappus squarrosus obtusus
FIG. 88-Haplopappus squarrosus typicus (genuine form from Pismo, California)

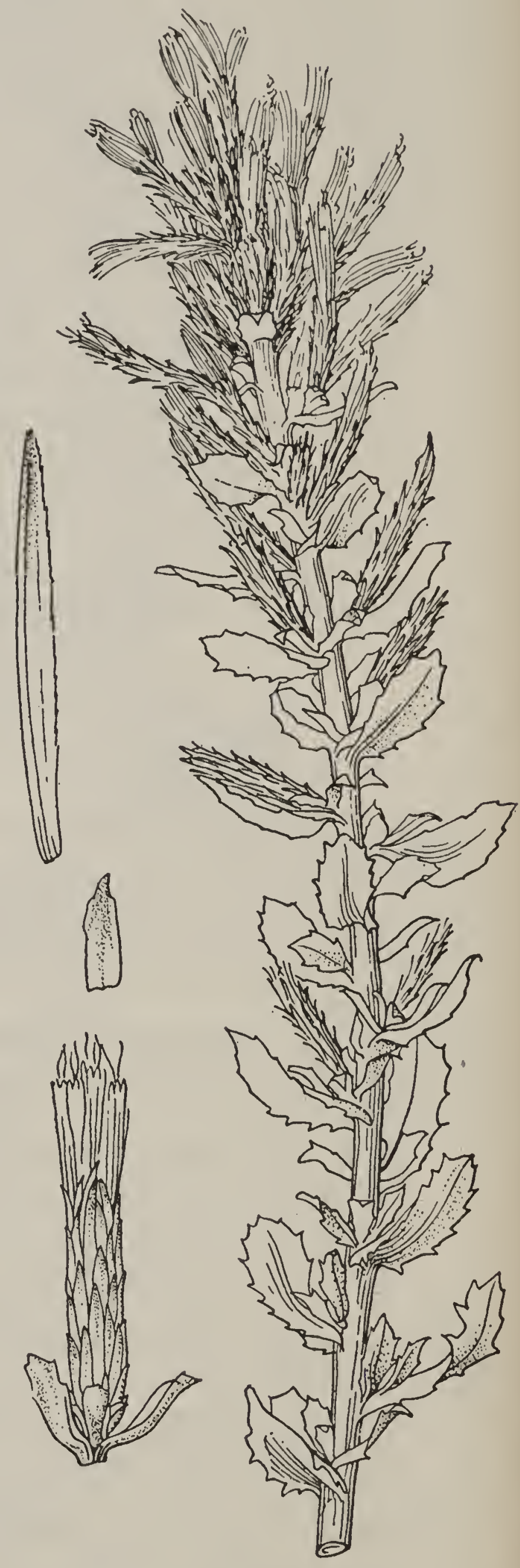

FIG. 89-Haplopappus squarrosus stenolepis, from type locality 
minor variation 5); Santa Catalina Island, September 1, 1916, Grant (UC, in part); near Soldier's' Home, Los Angeles County, September 1905, Adams (UC); San Antonio Cañon, Los Angeles County, Baker 3732 (UC, K); foothills near San Bernardino, Parish 575 (UC, Paris, B); San Diego, Baker 3426 (UC); Potrero Grade, Mount Tecate, San Diego County, Parish 8714 (UC).

55b. Haplopappus squarrosus obtusus (Greene) - Stems woody at base, openly branched to form plants mostly broader than high, either scabrid, as in the type, or glabrous, but always resinous; leaves obovate or broadly oblong, 2 to $2.5 \mathrm{~cm}$. long, 10 to $18 \mathrm{~mm}$. wide, very obtuse and rounded at apex; heads in close terminal racemes, these 4 to $12 \mathrm{~cm}$. long, 3 or $4 \mathrm{~cm}$. broad, leafy bracteate at least below, occasionally branching at base; involucre broad but compact, 13 to $15 \mathrm{~mm}$. high; bracts closely imbricated, oblong, all very obtuse except a few of the inner ones, mucronate, straight, pale, chartaceous almost throughout, resinous-granular; flowers 18 to 25; corolla about $10 \mathrm{~mm}$. long; achenes glabrous. (Hazardia obtusa Greene, Fl. Franciscana 375, 1897.) (Fig. 87.)

Confined to a limited area of the inner South Coast Ranges, California, bordering upon the San Joaquin Valley. Type locality, San Emigdio Cañon, Kern County. Type collection, 1894, Eastwood (Greene, UC); near mouth of Grapevine Cañon, Kern County, Hall 12247 (UC).

55c. Haplopappus squarrosus stenolepis subsp. nov.-Stems very woody at base, much branched to form dense leafy shrubs, these often broader than high, the twigs minutely scabrid; leaves oblong or oblongspatulate, 1.5 to $2.5 \mathrm{~cm}$. long, 7 to $10 \mathrm{~mm}$. wide, obtuse but ending in a mucronately acute tooth; heads spicately arranged or some in glomerules of 2 or 3 heads each and these glomerules in narrow spikes, the inflorescence 3 to $7 \mathrm{~cm}$. long, 2 or $3 \mathrm{~cm}$. broad; involucre very narrow, 10 to $12 \mathrm{~mm}$. high; bracts regularly but loosely imbricated, linear, pungently acuminate or mucronately acute, straight or slightly curved, chartaceous for most of their length, only the midrib and a small spot near summit herbaceous, somewhat viscid but glabrous; flowers 4 to 6 ; corolla about $9 \mathrm{~mm}$. long; achenes glabrous. (Fig. 89.)

Serpentine soil on the eastern slope of Parkfield Grade, inner South Coast Ranges of Fresno County, California, October 13, 1921, Hall 1176y (UC, type); same district but on westerly slope, in Monterey County, Hall 11 rin 1 (UC).

The foregoing description was drawn from the type specimen. In this the style-branches are 2.5 to $3 \mathrm{~cm}$. long, and the appendage is somewhat shorter than the stigmatic portion, as is usual in other forms of Haplopappus squarrosus. But in two plants collected in September 1926, from the west side of Parkfield Grade (Hall 12246) the length of the appendage exceeds that of the stigmatic portion by 50 to 100 per cent. This unusual proportion was found in both of the plants collected, although others from the same colony taken in previous years (Hall 117\%1) had nolmal style-branches. The proposed subspecies is abundant on exposed serpentine slopes from the summit down the westerly side of the range nearly to the hamlet of Parkfield. There is little variation in essential characters, but the leaves are often larger than in the type and the inflorescence more clongated. 


\section{MINOR VARIATIONS AND SYNONYMS}

1. Aster grindelioides O. Kuntze, Rev. 316, 1891. Based upon Pyrrocoma grindelioides, which see. (Not Aster grindelioides O. Kuntze, 1. c. 318.)

2. Hazardia obtusa Greene, Fl. Franciscana 375, 1897-Haplopappus squarrosus obtusus.

3. H. squarrosa Greene, Erythea 2:112, 1894-Haplopappus squarrosus typicus.

4. H. squarrosa var. obtusa Jepson, Man. Fl. Pl. Calif. 1030, 1925-Haplopappus squarrosus subsp. obtusus.

5. Pyrrocoma grindelioides DC., Prodr. 5:350, 1836. This was described from a collection made by Douglas somewhere in California. In proposing his new species, DeCandolle overlooked the slightly earlier Haplopappus squarrosus, which was not represented in his herbarium. The type of grindelioides (this in any event would be an untenable name under Haplopappus), represents a common form which may be distinguished from genuine squarrosus as follows: heads small, the involucre 8 to $12 \mathrm{~mm}$. high; flowers 9 to 16; corolla 9 to $9.5 \mathrm{~mm}$. long; distribution general on mainland and islands off the coast of southern California. As contrasted with this, typical squarrosus has involucres 11 to $15 \mathrm{~mm}$. high, 20 to 30 flowers in each head, corollas 10 to $11 \mathrm{~mm}$. long, and is confined to a narrow strip close to the sea, from Monterey to Ventura. Intermediate forms are of such a nature as to prevent the recognition of two subspecies. Along the coast of southern California are plants with large involucres but with only about 15 flowers to the head (San Pedro, 1923, Brandegee); from Santa Cruz and San Clemente islands comes a form with involucres only 9 to $10 \mathrm{~mm}$. high and foliage as in common grindelioides form, but with as many as 23 flowers in the head (Santa Cruz, July, August, 1886, Greene, Santa Catalina, September 1, 1906, Grant, in part). In view of such evidence, it appears that the large-headed genuine typicus may be a fluctuating modification, perhaps influenced by edaphic and climatic conditions obtaining along sandy ocean shores. This is now being tested by means of transplant experiments.

\section{RELATIONSHIPS}

The consistently discoid heads, with comparatively few flowers, the glabrous achenes, and the northern distribution, indicate this as one of the most highly specialized species of the section Hazardia. Its origin seems to have been through Haplopappus berberidis, from which it differs especially in the increased number of heads, a partial reduction in the number of disk-flowers, and the complete elimination of the ray.

The plant first described as Haplopappus squarrosus is quite different from the form that usually passes under this name. It was gathered on the Beechey voyage somewhere along the coast of California. The type, now in the Hooker Herbarium at Kew, is a broad-leaved, large-headed plant, with rather coarsely pubescent twigs and stipitate-glandular involucres. The principal leaves are $2.5 \mathrm{~cm}$. long by $15 \mathrm{~mm}$. wide and very obtuse, the flowers appear to be at least 20 in each head, and the involucres are about $15 \mathrm{~mm}$. high. Plants of this form are now known from a number of maritime stations in California, and at first seem quite unlike the common smaller-headed form. Both, however, are here included under subsp. typicus, since the variations appear to be largely influenced by environmental conditions. (See further under minor variation 5.)

The subspecies obtusus has the large heads and numerous flowers of genuine typicus, but it differs markedly in its long and pale almost cylindric involucres, the outer and middle bracts of which are very obtuse. It differs also in pubescence, this varying from scabrous, as in the type, to perfectly glabrous. The involucres are always glabrous and although strongly resin- 
ous the herbage entirely lacks the stalked glands so abundant in typicus. This subspecies is confined to a small area of the inner South Coast Ranges. Of the same general region, but exactly opposite in its foliage and involucral characters, is subsp. stenolepis, here described for the first time. This is easily recognized by the very narrow and acuminate involucral bracts (these glabrous and not at all squarrose), and by the narrow, few-flowered heads. Elsewhere in the genus such differences would suffice as criteria for specific rank, but here one encounters so much variation in characters of the involucre that these become of only subspecific significance. Ecologic relations also are to be considered. The new subspecies is restricted to serpentine soils and here occupies a limited habitat within the much more extensive area of typicus. Its characters, as just noted, are so remarkable that they are believed to indicate a distinct hereditary variation especially suited to and selected by this environment. To be especially noted in this connection is the greatly reduced number of flowers, such reduction being definitely associated with the serpentine type of soil. No true intergradations to other subspecies have been found, but sometimes typicus has heads so small and narrow that they suggest those of stenolepis. Such a form is one from Ramona, San Diego County (October 17, 1894, Brandegee), but even here the heads are 9-flowered and the somewhat wider bracts have, for the most part, strongly squarrose tips.

The permanence of the characters used for the differentiation of these three subspecies is now being investigated by means of transplant experiments.

\section{ECOLOGY}

The loosely-branched, half-shrubby form of this species is common in the open chaparral of the coastal slope of southern California. It here grows as isolated individuals among the other species, never forming pure thickets of its own. Sometimes it is lightly shaded by taller associates, such as Adenostoma fasciculatum, Quercus agrifolia, and Photinia arbutifolia; at other places its long, lithe branches spread out over such low shrubs as Artemisia californica and Eriogonum fasciculatum. In the proximity of the sea the plants often are fully exposed and here they take on a more leafy appearance and the large, many-flowered heads are borne in short, dense clusters. This coastal form may prove to be a distinct genetic type, as is the low, compact, and very bushy form of serpentine soils in the dry inner Coast Ranges. This latter, the subspecies stenolepis, forms green tufts on overgrazed hillsides, where it is fully exposed. The normal flowering season of all the subspecies and forms is September and October and the zonal position is Upper Sonoran with slight intrusions into the Lower Sonoran.

\section{Haplopappus whitneyi Gray, Proc. Am. Acad. 7 :353, 1868}

A perennial herb, more or less suffrutescent at base, 1.5 to $5 \mathrm{dm}$. high, with several or many ascending to erect stems, broad-leafy to top; bark firm, becoming smooth, pale brown or reddish; twigs and stems herbaceous but rigid, coarsely few-striate, short-villous and glandular; principal leaves oblong or slightly spatulate, spinulose-serrate, somewhat acute, sessile and clasping by a broad base, 2.5 to $5 \mathrm{~cm}$. long, 8 to $15 \mathrm{~mm}$. wide, thin-coriaceous, reticulate, glandular-scabrid; heads solitary and terminal or in short 
terminal glomerules or spicate-racemose, the lower peduncles sometimes 1 to $4 \mathrm{~cm}$. long, leafy-bracted; involucre broadly obconic, 12 to $13 \mathrm{~mm}$. high, 10 to $12 \mathrm{~mm}$. broad (up to $18 \mathrm{~mm}$. as pressed); bracts very loosely imbricated in 4 or 5 lengths, the longest nearly equaling disk, lanceolate or linear-lanceolate, acute to acuminate, the outer ones more or less herbaceous, the middle and inner mostly chartaceous and white or pink but with greenish midrib, granular on exposed parts; ray-flowers about 5 to

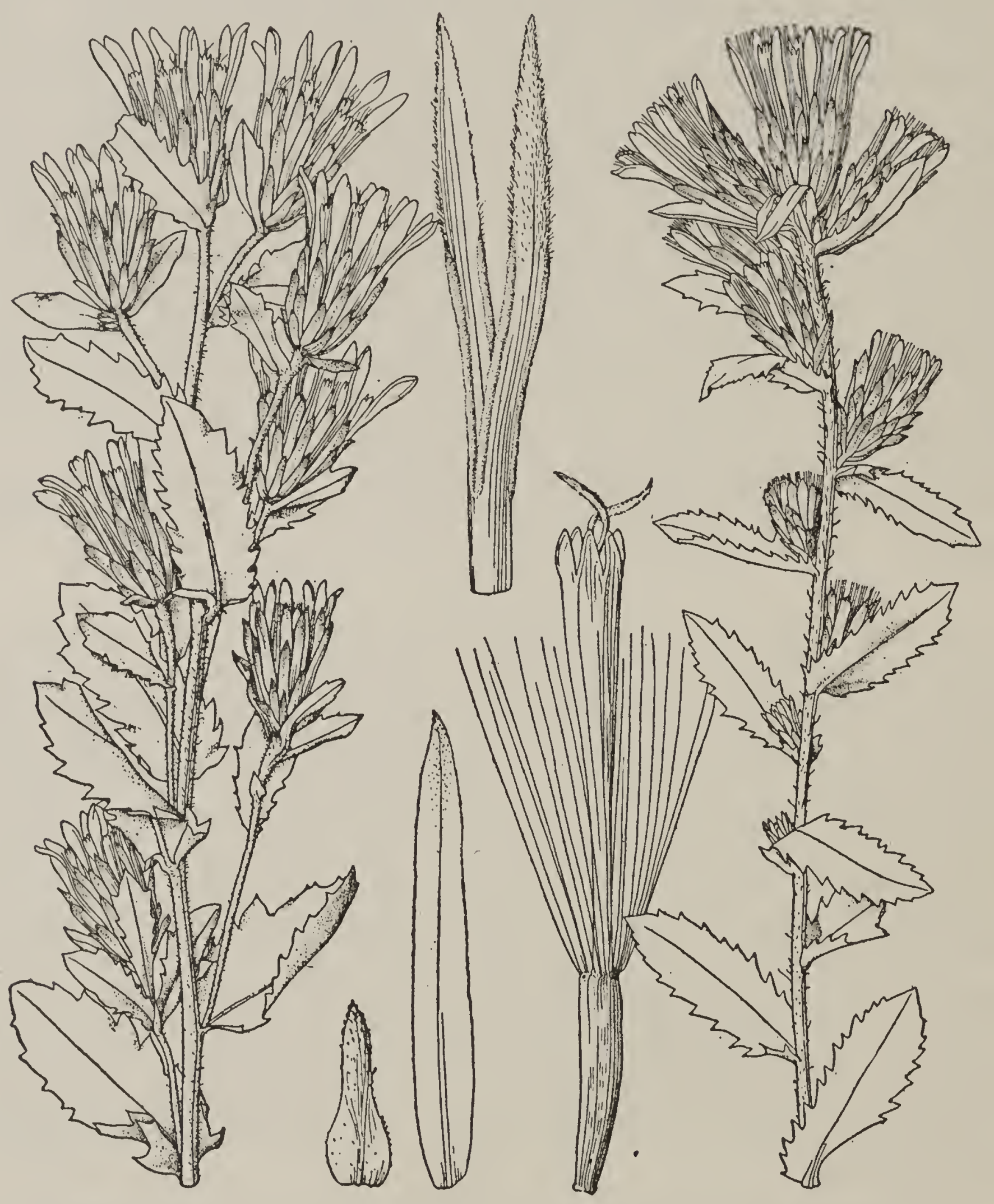

FIG. 90-Haplopappus whitneyi

15 , fertile, the ligule 5 to $7.5 \mathrm{~mm}$. long by about $1 \mathrm{~mm}$. wide, permanently yellow, or ray-flowers rarely wanting; disk-flowers about 15 to 30 or perhaps more; disk-corolla with slender tube, ampliate from middle upward, 8.5 to $11 \mathrm{~mm}$. long, glabrous or minutely scabrid, permanently yellow; lobes lanceolate, acute, erect, 0.7 to 1 or rarely $1.5 \mathrm{~mm}$. long, granularscabrid; style-branches long-exserted, 2 to $3 \mathrm{~mm}$. long, the nearly subulate 


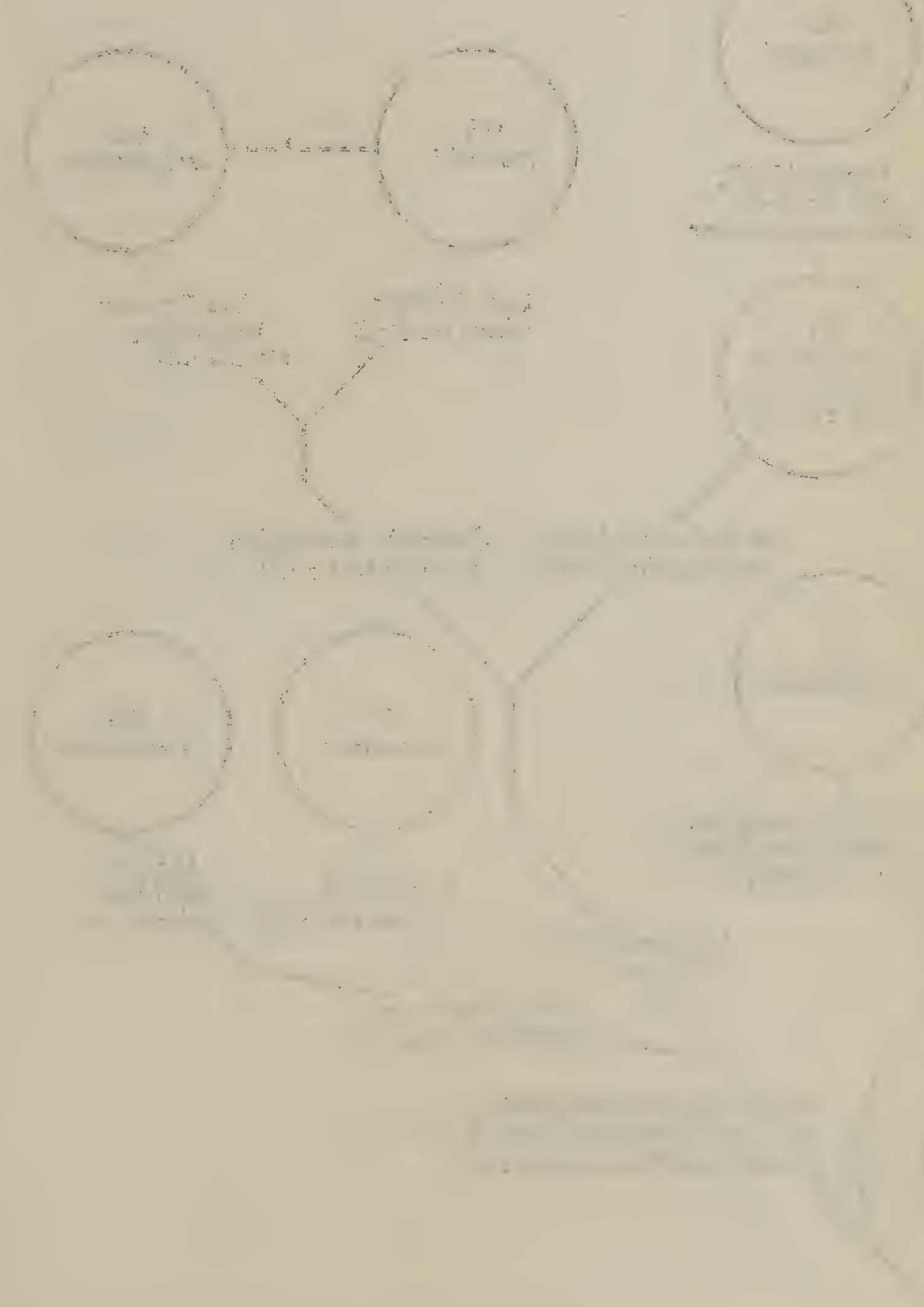




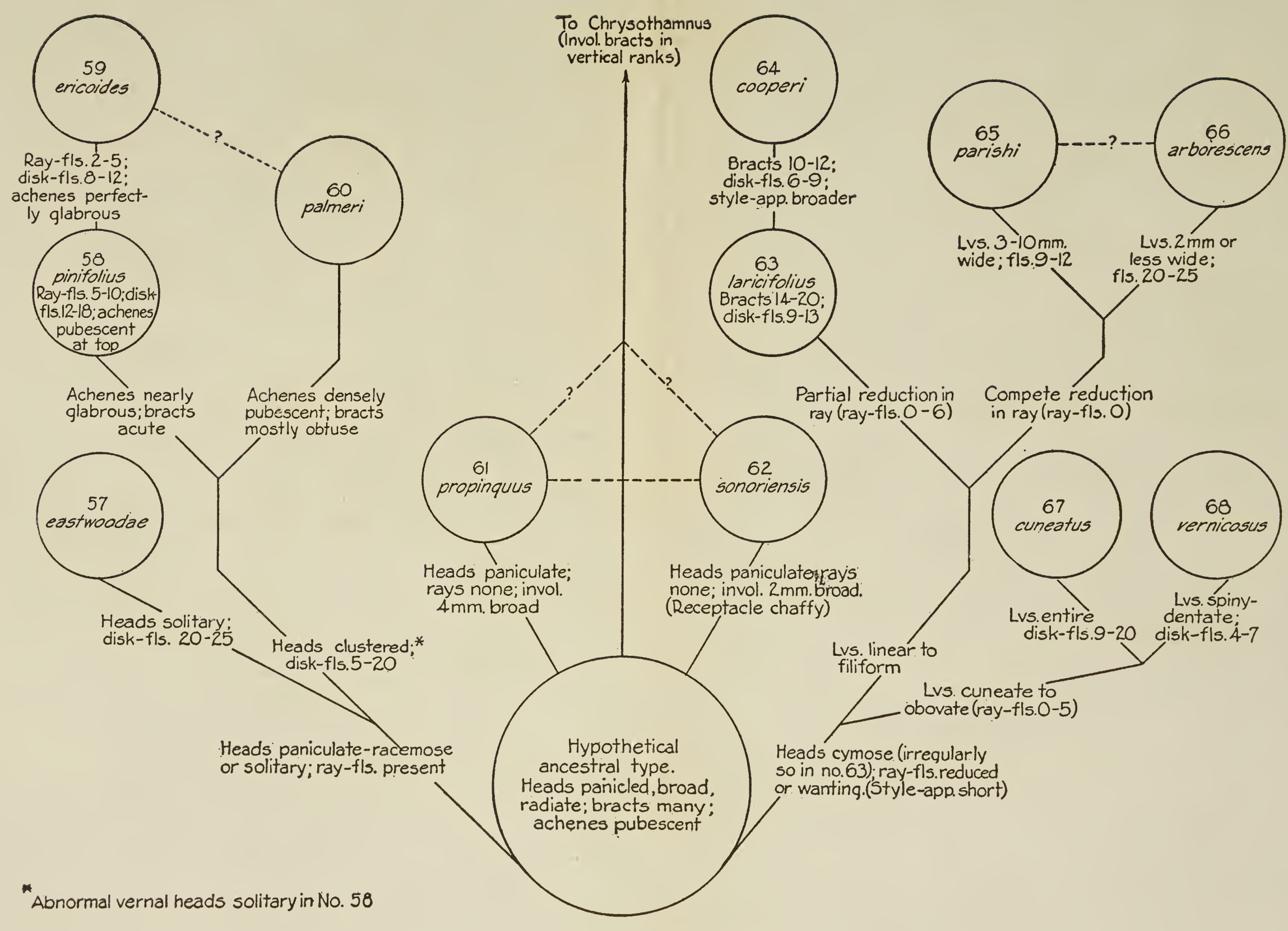

FIG. 91-Phylogenetic chart of the species of Haplopappus section Ericameria. The suggested connection between $H$. palmeri and $H$. ericoides would pass through subsp. pachylepis of the former 
appendage moderately longer than stigmatic portion or rarely somewhat shorter; achenes 6 to $7.5 \mathrm{~mm}$. long, fusiform-cylindric and compressed, 5 -ribbed, striate between ribs, glabrous; pappus equaling or slightly exceeding the disk-corolla, rigidulous, rufous. (Fig. 90.)

Sierra Nevada and north Coast Ranges of California. Type locality, Mono Trail and Sonora Pass at 2,750 meters altitude. Mountains about headwaters of Sacramento River, September 1, 1882, Pringle (UC, eradiate form); Mount Dyer, Big Meadows, 1880, Austin (UC); Smith Peak, near Hetch-Hetchy Valley, Hall 11841 (UC); Mono Pass, 2,750 meters altitude, State Survey 600S (UC, type collection?); Mariposa Grove, Hall and Babcock 1558 (UC); road to Huntington Lake, Fresno County, August 1914, Brandegee (UC); near Farewell Gap, Tulare County, Culbertson 4584 (UC); Little Kern River, Tulare County, Purpus 2031 (UC, P); Snow Mountain, Lake County, Purpus 1270 (UC, K, cradiate form).

\section{SYNONYMS}

1. Aster whitneyi O. Kuntze, Rev. 318, 1891-Haplopappus whitneyi.

2. Hazardia whitneyi Greene, Pittonia 3:43, 1896-Haplopappus whitneyi.

\section{RELATIONSHIPS}

In habit and in its assemblage of characters, this species is very unlike any other. In those features usually accepted as specific, it comes nearest to Haplopappus squarrosus, and the two are probably divergent branches from a common stock. While squarrosus has retained in the south its geographic connections with other Hazardias, whitneyi has broken away from them completely and is now the most northerly of all members of the section. It is unlike all others also in its essentially herbaceous habit. This is plainly a reduction from the shrubby type, as suggested by the definitely woody base, which changes abruptly to the herbaceous or only half-woody stems, and by the bushy habit of branching. The styleappendages are longer and more slender than elsewhere in the section, except for occasional specimens of squarrosus or berberidis in which these structures are so exceptionally developed that they exceed the shortest of those found in whitneyi. The long style-branches have led some to associate this species with the section Macronema, but the coarse, rufous pappus and spinulose-serrate leaves are unlike anything in that group.

\section{ECOLOGY}

The rounded bush-like tufts of this plant grow in rocky, well-drained soil at middle and upper altitudes in the Sicrra Nevada, where it is not uncommon, and on a few peaks of the North Coast Ranges in California. The altitudinal distribution is 2,100 to 3,000 meters and the zonal position is Canadian and Hudsonian. In most cases the plants are more or less shaded by a sparse growth of pines (Pinus monticola and P. contorta) or by shrubs of the surrounding thickets, these composed of such plants as Castanea sempervirens, Quercus vaccinifolia, Arctostaphylos patula, and Prunus emarginata. The list of more depressed associates includes Eriogonum wrighti, Chrysopsis breweri, and Ribes montigenum. The flowers appear from late July to October. 


\section{SECTION 15. ERICAMERIA}

\section{PHYLOGENY OF THE SPECIES}

This section comprises two natural groups and in addition two detached species which seem to have had independent origins. There are thus four coordinate lines of development, and although these by necessity are arranged in a lineal sequence in key and text, the chart of phylogenies shows them as having no definite relation one to another except as regards their common origin. The central position of the two detached species, Haplopappus propinquus and $H$. sonoriensis, is therefore without significance.

Taking first the group with heads in panicles or racemes, there is encountered at the outset a form (Haplopappus eastwoodae) with inflorescences reduced to single heads, but with other features apparently of a primitive nature. Much too little is known of this species to justify detailed discussion, but it may be noted that the reduction in number of heads is compensated by the large number of flowers in each of these. In the two larger groups already mentioned, there is noted a parallelism between evolutionary development and ecologic relations. Thus the advanced species, such as $H$. ericoides and $H$. palmeri are more xerophilous than the less reduced $H$. pinifolius. Similarly, in the second main group, $H$. cooperi, which marks the end of an important phylogenetic line, occupies a more arid habitat than its predecessor, $H$. laricifolius. This last should, perhaps, occupy a more basal position than has been assigned to it, since in many respects it seems to furnish a starting-point for the first as well as for the second main group.

Although Haplopappus parishi and $H$. arborescens exhibit complete reduction in the matter of ray-flowers, the peculiar foliage of the former and the large number of disk-flowers of the latter suggest that these were derived from no existing species. Haplopappus cuneatus is even more outstanding in its features and thus represents an ideal species from a taxonomic point of view. The tables accompanying the discussions of relationships of several of the species supply a part of the statistics upon which the foregoing hypotheses are based.

\section{Haplopappus eastwoodae nom. nov.}

A stout dense round-topped shrub, with several main stems and ascending branches; bark soon changing from greenish to brown, loose and shreddy even on rather young stems; twigs short, erect, crowded, densely leafy, striate, either glabrous or with a sparse puberulence, resinous; principal leaves terete or slightly flattened, mucronate, ascending or spreading, deflexed in age, straight or curved, 1 to $2 \mathrm{~cm}$. long, 0.8 to $1.5 \mathrm{~mm}$. wide, grooved on back except when very narrow, resinous-punctate, obscurely puberulent or glabrous, nearly all with fascicles of much shorter ones in their axils; heads solitary or cymose to subracemose at ends of twigs, the ultimate peduncles 5 to $15 \mathrm{~mm}$. long, leafy-bracted; involucre turbinate, 6 to $7 \mathrm{~mm}$. high, 6 to $8 \mathrm{~mm}$. broad; bracts 22 to 26 , in 4 or 5 series, much shorter than disk, loosely but regularly imbricated, the inner ones oblong, acute, the outer lanceolate or ovate, subacuminate, all scarious and pale yellow, the midrib of ten brownish toward top, erose-ciliolate and 
the backs sometimes minutely puberulent, resinous; ray-flowers only 1 or 2 , apparently wanting on some heads, the ligules 5 to $6.5 \mathrm{~mm}$. long, 2 to $3 \mathrm{~mm}$. wide; disk-flowers about 20 to 25 ; disk-corolla gradually enlarging from tube to throat, 8 to 10 $\mathrm{mm}$. long, puberulent on tube; lobes erect, lanceolate, acute, about $1.5 \mathrm{~mm}$. long, glabrous; stylebranches long-exserted, 2 to $2.5 \mathrm{~mm}$. long, the very slender appendage shorter than stigmatic portion; achenes subcylindric, tapering to base, $3.5 \mathrm{~mm}$. long, densely clothed with long silky white upwardly appressed hairs, ribbed or striate under the pubescence; disk-pappus rather longer than corolla, abundant, soft, sordid to rufous. (Chrysoma fasciculata Eastw., Bull. Torr. Club $32: 215, \quad 1905$; not Haplopappus fasciculatus Vasey et Rose, 1888.) (Fig. 92.)

Restricted to the sand dunes in the vicinity of Monterey and Carmel Bays, California. Type locality, along the coast near Monterey. Type collection, August 25, 1904, Abbott (SF); Del Monte, Monterey, Elmer 4027 (UC, US, B, K); Seaside Station, near Monterey, August 27, 1908, Brandegee (US, UC, in part).

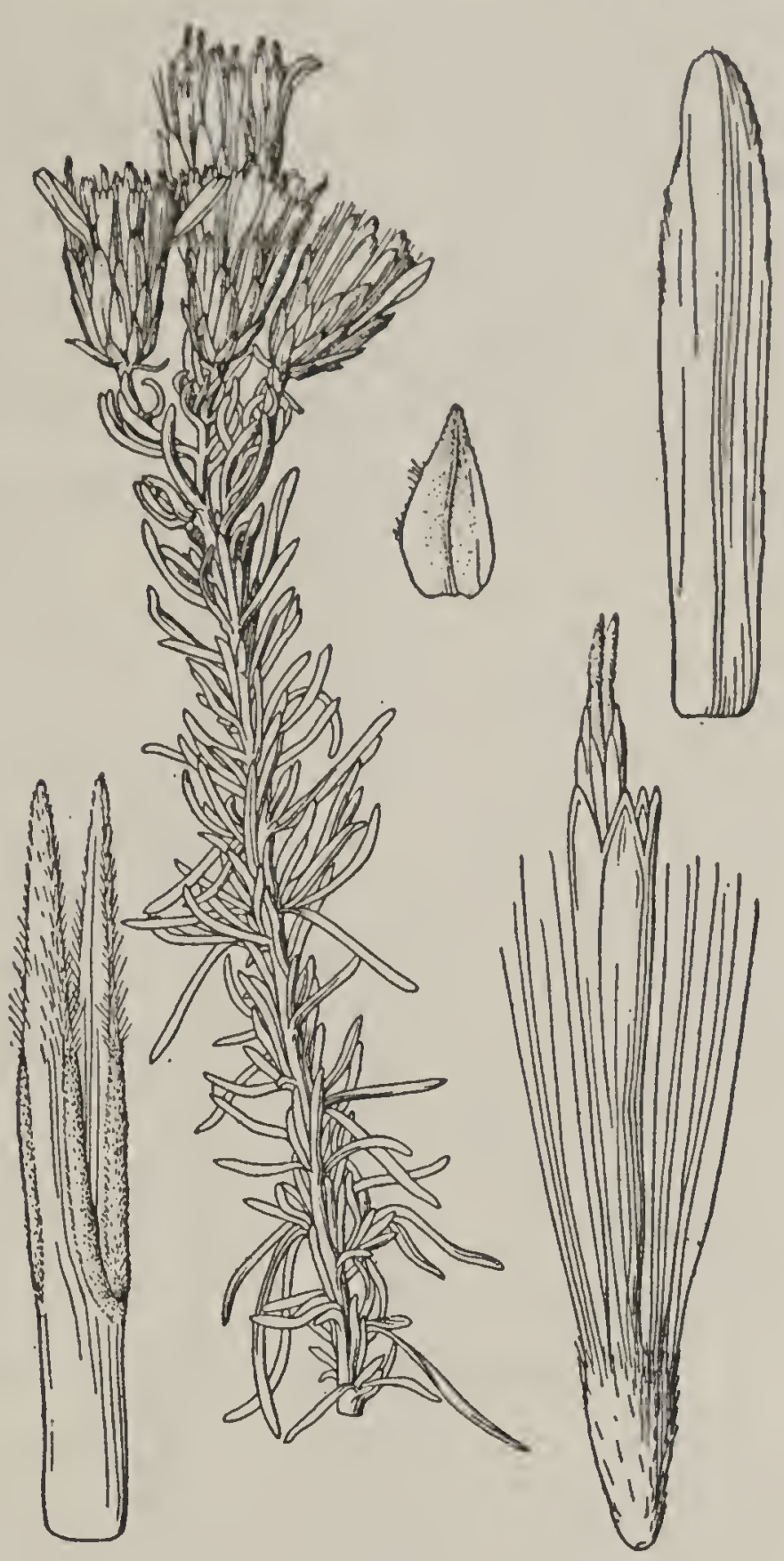

FIG. 92-Haplopappus eastwoodae

\section{SYNONYMS}

1. Chrysoma fasciculata Eastw., Bull. Torr. Club 32:215, 1905. In transferring this to Haplopappus it is necessary to adopt a new specific name, to avoid confusion with $H$. fasciculatus $\nabla$ asey et Rose, a species still retained by some authors. It is a pleasure to now name the present species in honor of Miss Alice Eastwood, curator of the herbarium of the California Academy of Sciences and the first botanist to recognize its characters.

2. Ericameria fasciculata Macbr., Contr. Gray Herb. 56:36, 1918. Based upon Chrysoma fasciculata.

\section{RELATIONSHIPS}

Although this species inhabits a district frequently visited by botanists, from the days of the early Californian explorers down to the present, it was not discovered until 1904 . This fact, together with its very limited distribution, suggests a mutant origin from the only related species of the same area, namely, Haplopappus ericoides. This, however, is highly improbable in view of the large number of differentiating characters, the more important of which are listed in table 10. Moreover, as compared not only with ericoides, but also with the other two species of this table, the 
characters of eastwoodae are almost without exception those associated with older and less highly developed forms. Notable among these features are the shortness of the fascicled secondary leaves, the larger heads with more numerous bracts and flowers, the short style-appendages, and the pubescent achenes. ${ }^{1}$ Only in a slight reduction in number of ray-flowers and in the simplified inflorescence does the present species exhibit what may be considered a modern tendency.

Since practically no character of $H$. eastwoodae is that of a highly evolved species, it is probable that it is either a representative of the primitive Ericameria or a reversional derivative of $H$. ericoides.

TABLE 10-A comparison of the characters of Haplopappus eastwoodae and its immediate relatives

\begin{tabular}{|c|c|c|c|c|}
\hline & ericoides & castwoodae & palmeri & $\begin{array}{l}\text { pinifolius (au- } \\
\text { tumnal stage) }\end{array}$ \\
\hline Secondary leaves & $\begin{array}{l}\text { Nearly } \\
\text { as long as }\end{array}$ & $\begin{array}{c}\text { Much } \\
\text { shorter than }\end{array}$ & $\begin{array}{l}\text { Shorter } \\
\text { than }\end{array}$ & $\begin{array}{l}\text { Shorter than } \\
\text { primary }\end{array}$ \\
\hline Involucral bracts. & $\begin{array}{l}\text { primary } \\
16 \text { to } 22\end{array}$ & $\begin{array}{l}\text { primary } \\
22 \text { to } 26\end{array}$ & primary & 20 to 26 \\
\hline Ray-flowers...... & 2 to 5 & 1 or 2 & 1 to 8 & 5 to 10 \\
\hline Disk-flowers. . . . . . . . . & 8 to 12 & 20 to 25 & 5 to 20 & 12 to 18 \\
\hline Length of disk-corolla, mm & 6.0 to 7.0 & 8.0 to 10.0 & 5.0 to 8.0 & 6.0 to 7.5 \\
\hline Corolla-lobes............. & Spreading. & Erect. & Spreading. & Spreading. \\
\hline $\begin{array}{l}\text { Ratio of length of appendage } \\
\text { to total length of style- }\end{array}$ & & & & \\
\hline branch, p. ct............. & 60 to 70 & 42 to 48 & 40 to 60 & 50 to 65 \\
\hline Achenes.............. & Glabrous. & Pubescent. & Pubescent. & Nearly glabrous. \\
\hline
\end{tabular}

58. Haplopappus pinifolius Gray, Proc. Am. Acad. 8:636, 1873

A stout open bushy shrub, 6 to $30 \mathrm{dm}$. high, the main stems trunk-like and becoming 2 to $6 \mathrm{~cm}$. thick; bark at first green but light-brown by end of first year, darkening with age, breaking longitudinally and becoming shreddy; twigs long, fastigiately crowded, densely leafy, striate especially below, not punctate, glabrous; principal leaves very narrowly linear or filiform, often curved, mucronate, 1.5 to $3.5 \mathrm{~cm}$. long, less than $1 \mathrm{~mm}$. wide, thick, 1-nerved, obscurely resinous-punctate, often puberulent when young but soon glabrate, nearly all with shorter secondary leaves fascicled in the axils; vernal heads solitary, terminating short leafy branchlets; autumnal heads cymose-paniculate, often congested, or the panicle elongated and racemelike, the peduncles 3 to $30 \mathrm{~mm}$. long and leafy bracteate; involucre of vernal heads hemispheric, 7 to $10 \mathrm{~mm}$. high, 8 to $15 \mathrm{~mm}$. broad, surrounded by long slender acuminate leaves simulating an outer involucre; involucre of autumnal heads turbinate, 5 to $7 \mathrm{~mm}$. high, 5 to $7 \mathrm{~mm}$. broad, less leafy-bracted; bracts (of autumnal heads, the vernal similar) 20 to 26 , in about four series, moderately shorter than disk, imbricated, the inner ones oblong and only acute, the outer ones lanceolate-acuminate, all thin and chartaceous but outer with greenish tips, the margins mostly membranous and woollyciliolate; ray-flowers of vernal heads 15 to 30 , of autumnal heads 5 to 10 , the ligules 3.5 to $5 \mathrm{~mm}$. long, 1.5 to $2 \mathrm{~mm}$. wide; disk-flowers 12 to 18 (much more numerous in vernal heads); disk-corolla slender, gradually tapering

${ }^{1}$ The probable sequence of the appearance of these characters has been discussed under Criteria, p. 16. 
from lobes to tube, 6 to $7.5 \mathrm{~mm}$. long, puberulent on tube; lobes spreading or recurved, linear-lanceolate, acute, 1.2 to $1.6 \mathrm{~mm}$. long, glabrous; style-branches long-exserted, 2 to $2.5 \mathrm{~mm}$. long, the subulate appendage usually longer than stigmatic portion, rarely only equaling it; achenes subcylindric, 4.5 to $5 \mathrm{~mm}$. long, striate or ribbed, sparsely and lightly pubescent and either entirely glabrate or with a zone of persistent hairs at summit; disk-pappus exceeding corolla, copious, soft, reddish or at least sordid. (Fig. 93.)

Coastal slope of southern California, extending eastward to the desert borders south of San Jacinto Mountain. Type locality, near Los Angeles, in a dry river-bed. Newhall, Los Angeles County, Nevin (UC); Santa Monica, Parish 1131 (DS); Altadena, October 20, 1918, Pierson (DS); Claremont, Baker 4076 (UC, DS); Cajon Pass, Abrams and McGregor 696 (DS); Mesas of San Bernardino Valley, Parish 938 (DS, UC, Gr, US, P); Van Deventer Flat, borders of Colorado Desert, Hall 2157 (UC); Laguna Mountains, San Diego County, June 20, 1904, Brandegee (UC).

\section{SYNONYMS}

The following refer without exception to $H$. pinifolius: 1891.

1. Aster pityphyllus O. Kuntze, Rev. 316,

2. Chrysoma pinifolia Greene, Erythea 3:12, 1895 .

3. Ericameria pinifolia Hall, Univ. Calif. Pub. Bot. 3:54, 1907.

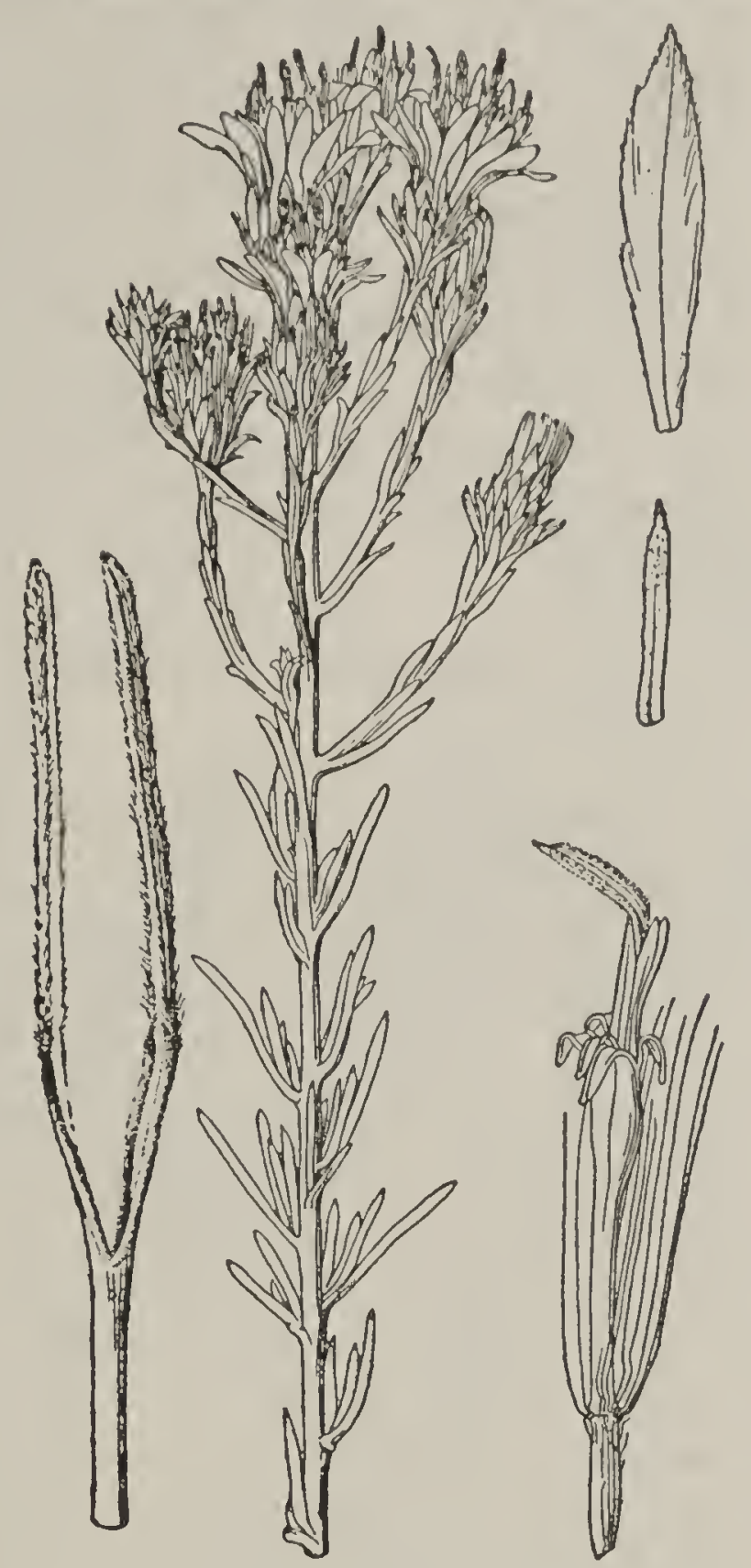

FIG. 93-Haplopappus pinifolius

\section{RELATIONSHIPS}

This appear's to be one of the less highly specialized species of the section Ericameria, as is indicated particularly by the paniculate inflorescence and by the fairly high number of involucral bracts and flowers. It is most often confused with Haplopappus palmeri pachylepis and with $H$. ericoides and, indeed, it seems to stand somewhat between these in the phylogenetic sequence. From the former it is at once distinguished by the very acute or acuminate outer bracts of a different texture, by the nearly glabrous achenes, by the longer style-appendages, and by the production of large, solitary heads during spring months. It differs notably from ericoides in its larger heads with more numerous flowers and in traces of pubescence on the achenes. A tabulation of contrasting characters is given under H. eastwoodae.

\section{ECOLOGY}

Haplopappus pinifolius is a prominent element in the coastal sagebrush formation of southern California. It here occupies disturbed areas where 
the soil is broken, stony, and well-drained and is especially common along streamways where they emerge from the lower foothills, these streamways being dry most of the time, and on bench lands built of rubble and detritus brought down by winter freshets. Frequent associates are Artemisia californica, Eriogonum fasciculatum, Salvia apiana, Rhamnus crocea, Opuntia engelmanni, and $O$. parryi. Although sometimes as much as 3 meters high, the plants are bushy in habit, with many ascending stems from the base, and therefore not tree-like. They grow scatteringly among the other shrubs or rarely in groups to form small thickets.

A unique feature of this species is the biseasonal period of blossoming. The normal heads, of a size and shape similar to those of other Ericamerias, appear in panicles from September to December. But in early spring and on toward summer the plant puts out scattered heads apparently of much larger size and hemispheric in outline. These vernal "heads," however, are themselves composite, as evidenced by the numerous bracts scattered over the receptacle.

59. Haplopappus ericoides (Less.) Hook. et Arn., Bot. Beech. Voy. 146,1833

A compact but spreading heather-like shrub, 3 to 8 or rarely $15 \mathrm{dm}$. high, with several main stems 2 to $7 \mathrm{~cm}$. thick and divergent branches, the tops often flat and densely twiggy as a result of strong winds; bark brown, becoming dark, firm but breaking and subshreddy in age; twigs rather short, crowded, stout, densely leafy, prominently striate, sparsely tomentulose, resinous; principal leaves filiform, obtuse or ending in a short cusp, spreading, deflexed in age, straight or curved, 0.5 to $1.2 \mathrm{~cm}$. long, about $1 \mathrm{~mm}$. wide, mostly with a groove on back where the revolute margins meet, resinous-punctate, tomentulose but glabrate or the tomentum sometimes hidden by the copious resinous exudate, often nearly equaled by the secondary leaves densely fascicled in the axils; heads cymose-paniculate, the inflorescences from globoid to much elongated, the ultimate peduncles ( 1 to 30 $\mathrm{mm}$. long) closely bracted; involucre broadly turbinate, 5 to $6 \mathrm{~mm}$. high, 5 to $6 \mathrm{~mm}$. broad; bracts 16 to 22 , in 3 or 4 series, much shorter than disk, regularly imbricated, the inner ones oblong and acute, the outer ones lanceolate or ovate and acute to acuminate, all scarious and yellowish but with a green tinge which deepens along midrib and sometimes toward apex, tomentulose-ciliolate, the outer ones also more or less puberulent on back; rayflowers 2 to 6 , the ligules 4 to $5.5 \mathrm{~mm}$. long, 1.3 to $2 \mathrm{~mm}$. wide; disk-flowers 8 to 12 ; disk-corolla gradually passing from a slender tube to the throat of scarcely greater breadth, 6 to $7 \mathrm{~mm}$. long, sparsely crisp-puberulent on tube; lobes outwardly curved, lanceolate, acute, 1 to nearly $1.5 \mathrm{~mm}$. long, glabrous; style-branches long-exserted, about $2 \mathrm{~mm}$. long, the filiform-subulate appendage about twice the length of stigmatic portion; achenes subcylindric, tapering to base, about $3 \mathrm{~mm}$. long, glabrous, 8- to 10-ribbed or 8- to 10-striate; disk-pappus at least equaling corolla, copious, dull white. becoming brown. (Diplopappus ericoides Less., Linnaea 6:117, 1831), (Fig. 94.)

Sand dunes along the California coast, from Bolinas to Los Angeles. Type locality, California. Bolinas Bay, September 16, 1887, Greene (UC); type collection, 1836, Chamisso (DC, B); Point Lobos, San Francisco, 

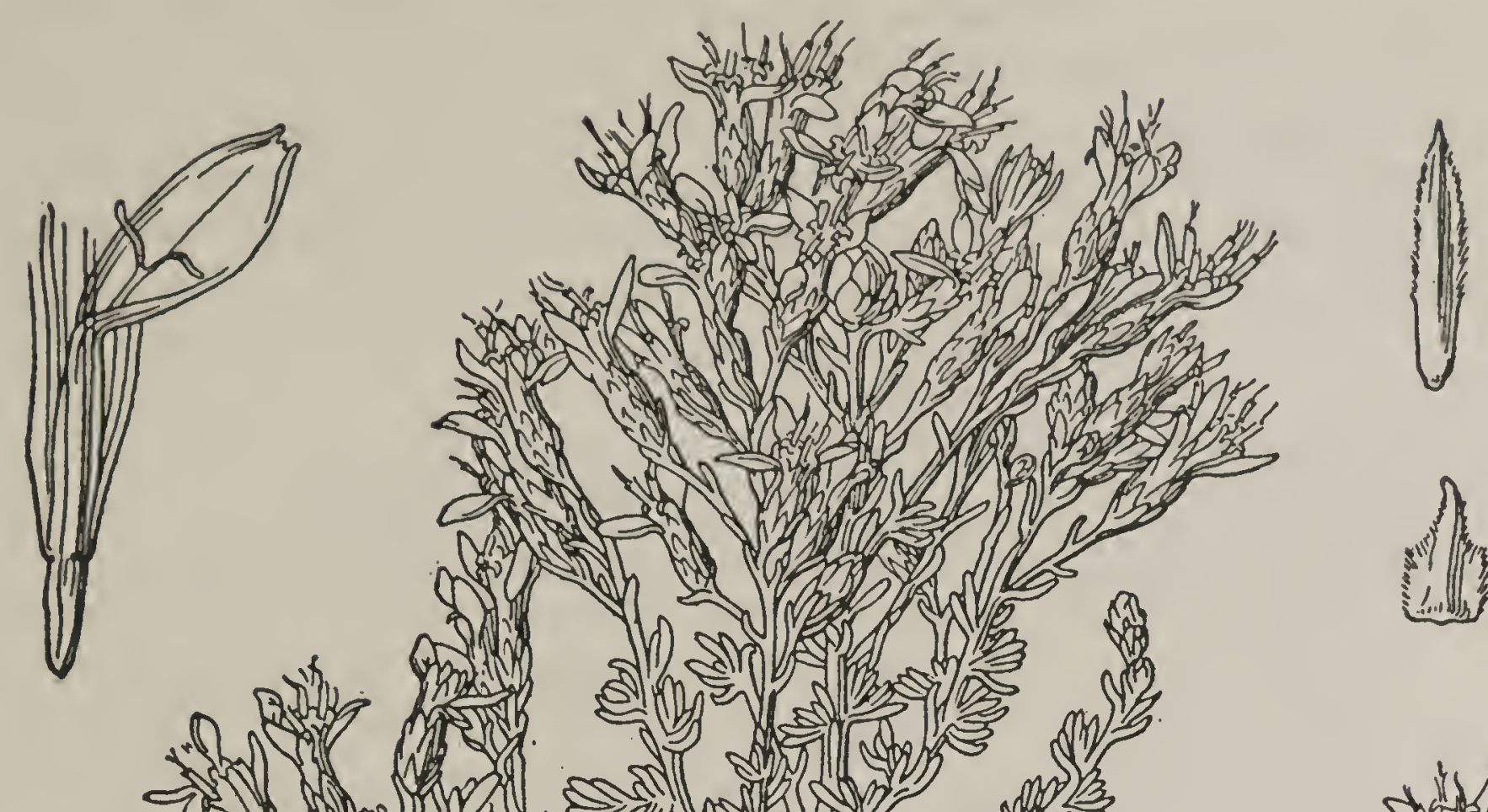

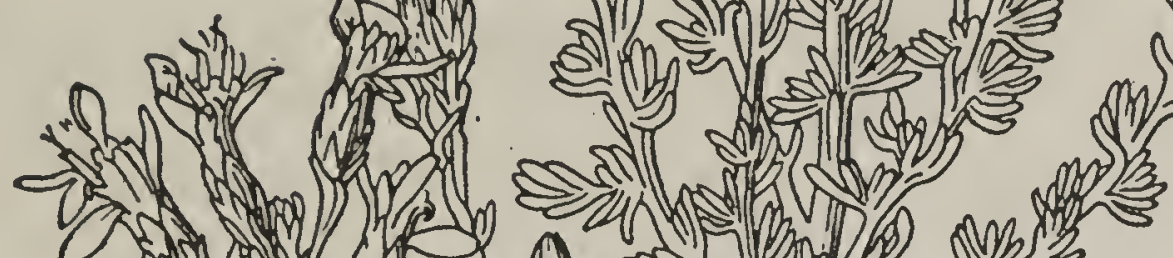

7 (1)

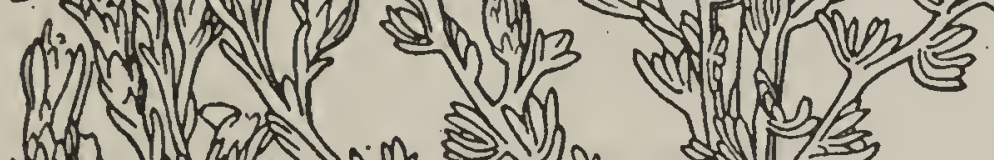
matcon

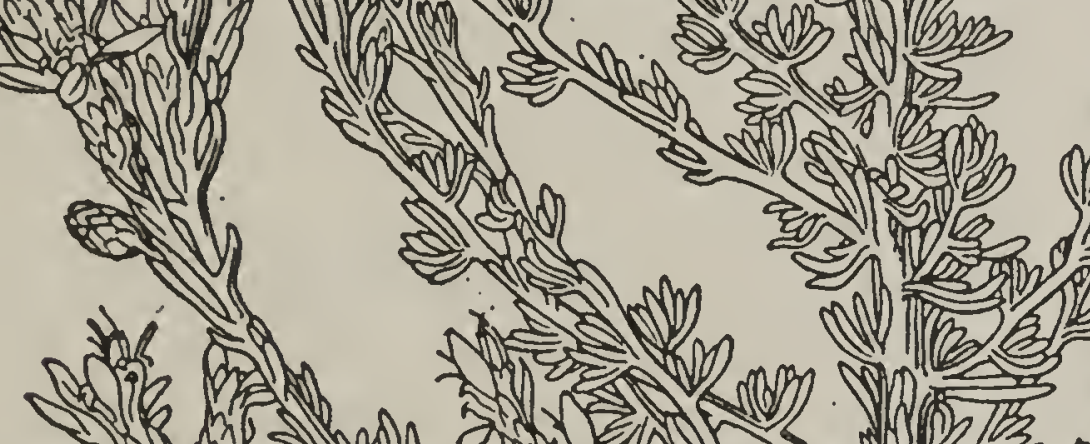

wis

(1) Wh

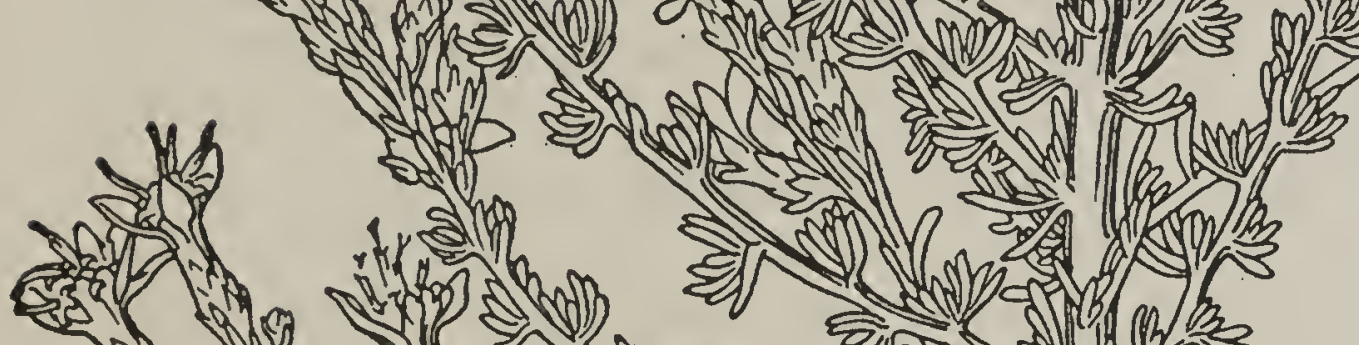
N.
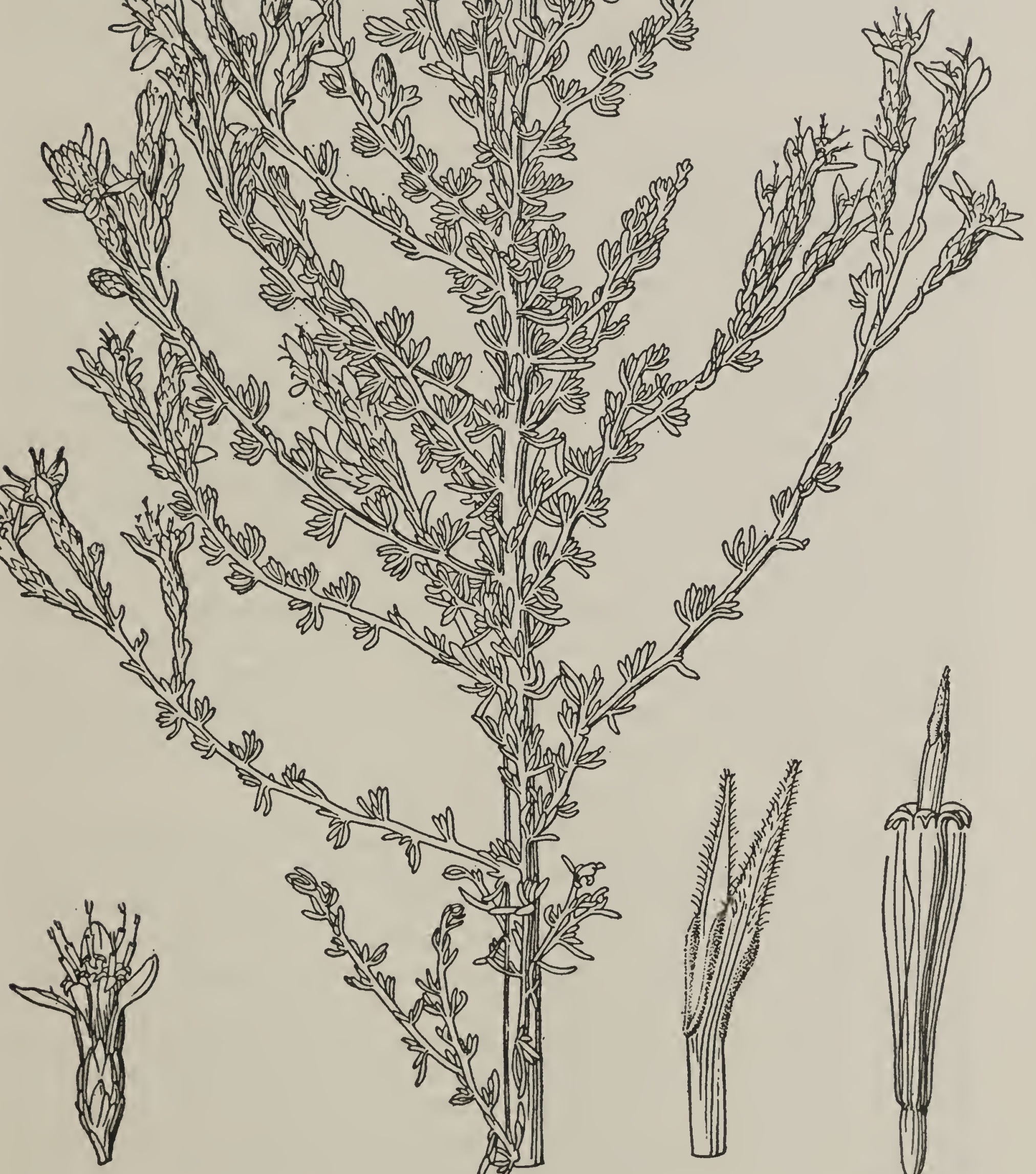

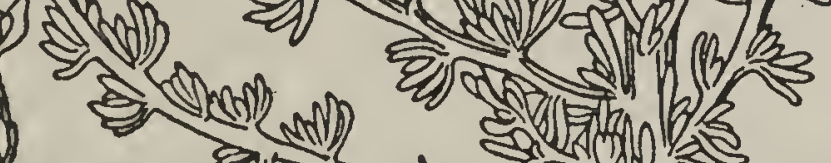
सै।

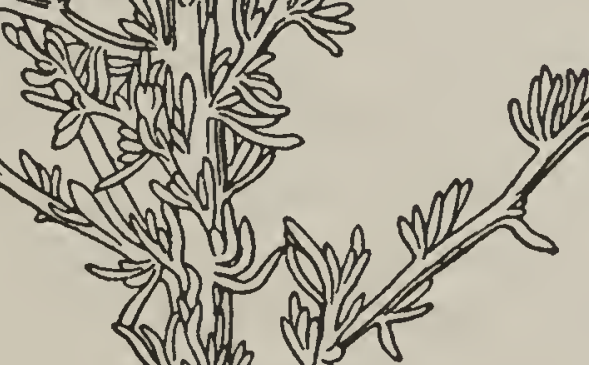

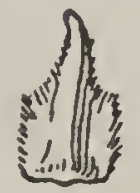


September 10, 1895, Tidestrom (UC); mountains north of Santa Cruz, State Geological Survey 816 (UC); Monterey, Elmer 4025 (UC); Morro Bay, San Luis Obispo County, October 7, 1886, Summers (UC); near Santa Barbara, Eastwood 221 (UC, US); near Soldiers' Home, Los Angeles County, September 1905, Adams (UC). (Reported from San Miguel Island, off the coast of Santa Barbara County, by Greene, Pittonia 1:89, 1887.)

\section{SYNONYMS}

1. Aster ericina O. Kuntze, Rev. 313, 1891-H. ericoides.

2. Chrysoma ericoides Greene, Erythea 3:11, 1895-H. ericoides.

3. Diplopappus ericoides Less., Linnaea 6:117, 1831-H. cricoides.

4. Ericameria ericoides Jepson, Fl. W. Mid. Calif. 559, 1901-H. ericoides.

5. E. microphylla Nutt., Trans. Am. Phil. Soc. II, 7:319, 1840-H. ericoides. Nuttall was at this place merely transferring the species to his new genus, Ericameria, and in so doing he took occasion to change the specific name, doubtless in order to avoid tautology. He cites $H$. ericoides DC. as a synonym, but this combination was first made by Hooker and Arnott in order to transfer the species from Diplopappus.

\section{RELATIONSHIPS}

All of the evidence points to the conclusion that Haplopappus ericoides occupies a high phylogenetic position. Although of close consanguinity with $H$. pinifolius and $H$. palmeri, it possesses certain unique features which almost certainly stamp it as a type more advanced than either of these. Of especial interest in this connection may be mentioned the greater reduction of the principal leaves and the higher development of secondary fascicled ones, this giving to the plant a decidedly ericoid appearance. Other advanced features include the loss of all pubescence from the achenes, highly developed style-appendages, and adaptation to an unusual type of environment. In geographic position, as in phylogenetic, this species has reached the frontiers, for it is restricted to dunes and sandy soil along a narrow belt near the coast of southern and middle California. This limitation of a highly modern type to a narrow geographic area, which may be noted also in connection with $H$. cooperi and $H$. pinifolius, is in line with the requirements of the age and area hypothesis of Willis; but it may be questioned if the restriction of the present species may not be due to inability to compete with others outside its own peculiar edaphic and climatic habitat. This inability may in turn be accounted for by the absence of variation within the species, which is thus seen to suffer from its own high specialization.

\section{ECOLOGY AND USES}

Haplopappus ericoides is a heather-like shrub restricted to sand dunes and sand fields in the immediate proximity of the ocean. Here, in the Upper Sonoran Life-Zone, the xerosere is initiated by Franseria chamissonis, Abronia latifolia, etc., which are followed by a more or less stable subclimax, in which the present species is an important element, together with such other shrubs as Lupinus variicolor, L. arboreus, Baccharis pilularis (in the prostrate consanguineus form), and the low, maritime form of Rhamnus californica. The most common of the deep-rooted perennial herbs and subshrubs that enter into the make-up of this secondary sere are Eriophyllum staechadifolium, Artemisia campestris pycnocephala, and Eriogonum latifolium. In such situations Haplopappus is an important element in 
dune fixation, for the lower parts of the stems and branches endure considerable submergence by the sand, while the wind-beaten, twiggy, and densely leafy tops afford shelter on the leeward side for other species. Where Haplopappus is itself protected, it assumes a more nearly erect habit, the tops are more open, and it is here that the tallest plants are found.

In altitudinal distribution Haplopappus ericoides has a usual range from sea-level to only about 40 or 50 meters. There is, however, a report of one collection from about 600 meters in the mountains north of Santa Cruz (California State Survey 816) and Nuttall refers to a collection by himself from rocks in a mountainous situation near Santa Barbara. It is probable that even these collections were from plants growing in sandy soil. The flowering season is from August to November.

Rubber occurs in the tissues of this plant, as has been demonstrated by chemical and microscopic analysis. A detailed study of one plant indicates that the distribution in the stem and root is the reverse of that found in the closely related Chrysothamnus, for, while the stems carried only a fraction of 1 per cent, the amount gradually increased in the root with the depth until at $5 \mathrm{dm}$. below the soil-line the percentage was 3.92. (See further in Hall and Goodspeed, Univ. Calif. Pub. Bot. $7: 270$, 1919, where plants reported upon as of this species but collected at Duarte and Claremont in winter condition may have been erroneously determined.)

60. Haplopappus palmeri Gray, Proc. Am. Acad. 11:74, 1876

A low-bushy or arboreous shrub, 5 to $30 \mathrm{dm}$. high, with several or numerous ascending branches, these 0.5 to $8 \mathrm{~cm}$. or more thick at base; bark firm, gray, changing to dark brown, becoming shreddy near base of plant; twigs ascending or spreading, leafy, obscurcly striate, resinous, punctate when young, glabrous or nearly so; principal leaves narrowly linear to revolute-filiform, spreading, acute, 1 to $4 \mathrm{~cm}$. long, $1 \mathrm{~mm}$. or less wide, thick, 1-nerved, resinous and impressed-punctate, glabrous or sparsely puberulent when young, mostly with shorter ones fascicled in their axils; heads numerous, in elongated often pyramidal panicles or some in simple racemes, commonly secund on spreading or horizontal branches, the ultimate peduncles 1 to $20 \mathrm{~mm}$. long and scaly-bracteate; involucre obconic or approaching cylindric, 5 to $7 \mathrm{~mm}$. high, 3.5 to $4.5 \mathrm{~mm}$. broad (more when pressed); bracts 16 to 24 , in 4 or 5 series, all much shorter than disk, imbricated, the outer ones regularly shorter, oblong, obtuse, or the inner acute (minor variation 4), chartaceous, with resinous-thickened yellowishgreen midrib and white-scarious border, the tips erose or subciliate; rayflower's 1 to 8 , fertile, the ligules 4 to $6 \mathrm{~mm}$. long, 1.2 to $1.5 \mathrm{~mm}$. wide; disk-flowers 5 to 20 ; disk-corolla with slender tube passing gradually into a throat of greater breadth, 5 to 7 or $8 \mathrm{~mm}$. long, slightly puberulent; lobes lanceolate, acute, moderately spreading, about 1 to $1.5 \mathrm{~mm}$. long, essentially glabrous; style-branches well exserted, 1.5 to $2.5 \mathrm{~mm}$. long, the slender appendage from shorter than to slightly exceeding stigmatic portion; achenes subcylindric, tapering to base, 3 to $4 \mathrm{~mm}$. long (immature?), about 5-angled, appressed-pubescent with long hairs; disk-pappus exceeding corolla, copious, soft, brown. (Figs. 95 and 96.)

Southern California, from desert borders nearly to the coast, southward into Lower California. 


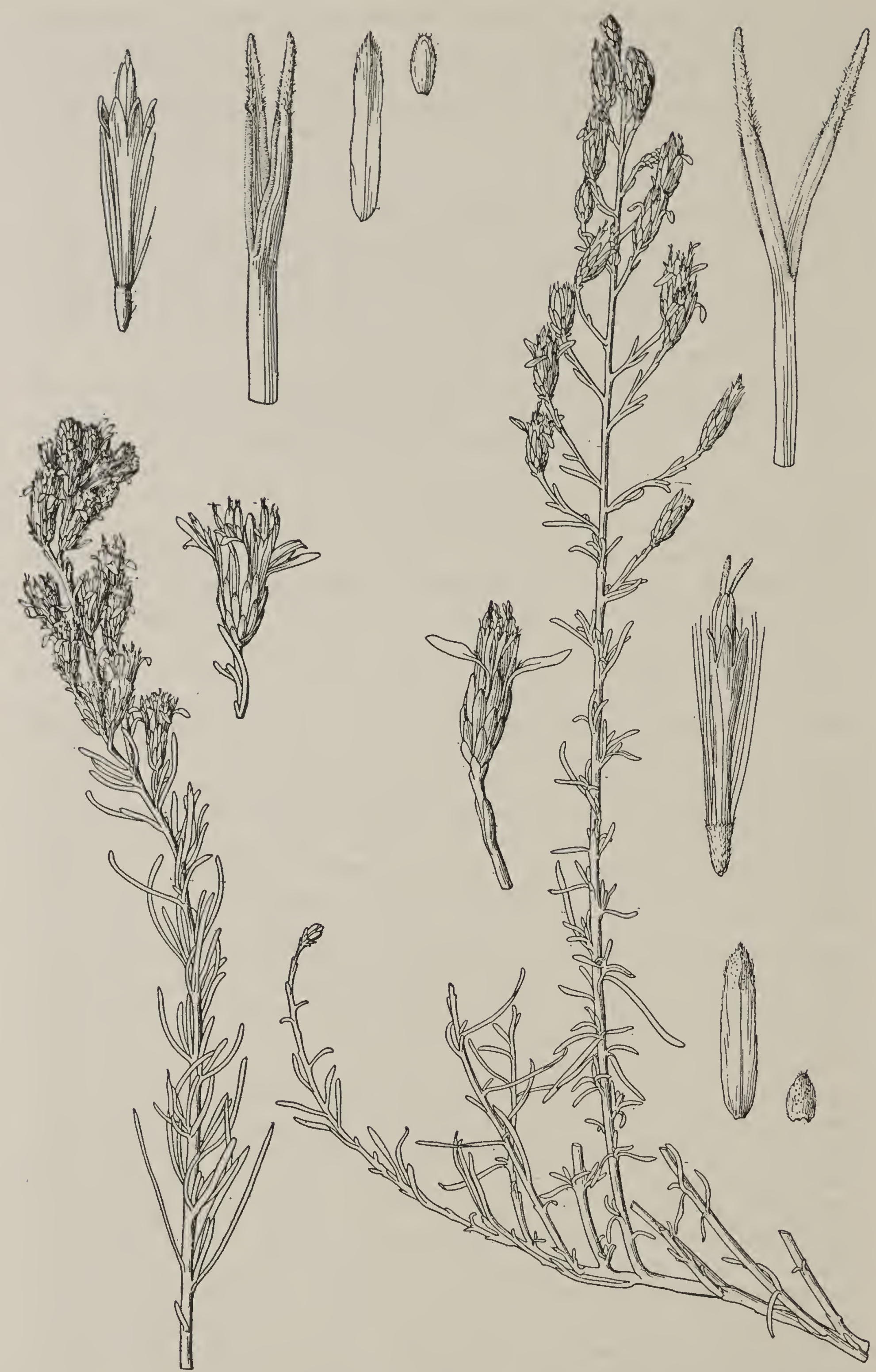

FIG. 95-Haplopappus palmeri typicus

FIg. 96-Haplopappus palmeri pachylepis, from type material 


\section{SUBSPECIES}

Key to the Subspecies of Haplopappus palmeri

Involucre 5 to $6.5 \mathrm{~mm}$. high, its bracts thin; shrub 10 to $30 \mathrm{dm}$. high, arboreous when well developed; leaves mostly 2 to $4 \mathrm{~cm}$. long...... Involucre 6 to $7 \mathrm{~mm}$. high, narrower, its bracts thick; shrub 5 to $15 \mathrm{dm}$.

(a) typicus

high; leaves 1 to 2 or rarely $3 \mathrm{~cm}$. long................... bachylepis

60a. Haplopappus palmeri typicus-A tall shrub, 10 to $30 \mathrm{dm}$. high, sometimes arboreous, the stems sometimes $8 \mathrm{~cm}$. or more thick and with spreading upper branches; principal leaves often curved, 2 to $4 \mathrm{~cm}$. long; involucre obconic, 5 to $6.5 \mathrm{~mm}$. high, 3.5 to $4.5 \mathrm{~mm}$. broad (more when pressed); bracts 18 to $24,0.5$ to $0.8 \mathrm{~mm}$. wide (middle ones, as dried), typically obtuse but sometimes acute, especially the inner, very thin, the yellowish-green resinous-thickened midrib not prominent; ray-flowers 4 to 8; disk-flowers 9 to 20. (H. palmeri Gray, l. c.) (Fig. 95.)

Southwestern San Diego County, California, southward into Lower California at least as far as San Vicente. Type locality, Tecate Mountains, Lower California. California: Las Alturas, $10 \mathrm{~km}$. east of San Diego, Hall 12310 (UC); $58 \mathrm{~km}$. east of San Diego, Hall (UC). Lower CaLIForNia: type collection, 1875, Palmer (Gr, UC as No. 131, P as No. 131); $15 \mathrm{~km}$. west of Tecate, Hall 12304 (UC); about $6 \mathrm{~km}$. south of Tijuana, Hall 12249, 12263 (UC); Ensenada, October 5, 1902, Brandegee (UC); Todos Santos Bay, Orcutt 1229 (UC, Gr); 9 km. south of Ensenada, Hall 12254 (UC); San Vicente Rancho, October 28, 1905, Brandegee (UC).

60b. Haplopappus palmeri pachylepis subsp. nov.-A bushy shrub, 5 to $15 \mathrm{dm}$. high, the main stems 0.5 to $2 \mathrm{~cm}$. thick at base, chiefly erect; principal leaves nearly straight, spreading, 1 to 2 or rarely $3 \mathrm{~cm}$. long; involucre cylindric-turbinate, 6 to $7 \mathrm{~mm}$. high, 3.5 to $4 \mathrm{~mm}$. broad (5 to 6 $\mathrm{mm}$. broad when pressed); bracts 16 to 18 , all oblong, 0.8 to $1.2 \mathrm{~mm}$. wide (as dried), very obtuse, rather thick, with chartaceous base and resinousthickened yellowish-green midrib; ray-flowers 1 to 6 ; disk-flowers 5 to 15 . (Fig. 96.)

Rather common on foothills and plains of the coastal slope of southern California, north of San Diego County, occasionally extending through the passes eastward to the desert borders. Summit of Box Springs Grade, near Riverside, California, September 30, 1926, David D. Keck 262 (UC, type); Bouquet Cañon, near Saugus, Munz 7789 (Po); Santa Monica, Davy 2729 (UC); Oak Knoll, Los Angeles, Braunton 733 (UC, US); near Pomona, November 1902, Babcock (UC); near San Bernardino, Parish 3820 (UC, US, Del, B); Morongo Pass, November 15, 1921, Jaeger (Po, a form of desert borders, the whole herbage very pale, the young foliage almost cinereous with a fine puberulence); Temescal Wash, near Glen Ivy, Hall 12297 (UC); Murietta, Riverside County, Hall 12299 (UC).

\section{MINOR VARIATIONS AND SYNONYMS}

1. Aster nevini O. Kuntze, Rev. 316, 1891-H. palmcri.

2. Chrysoma palmeri Greene, Erythea 3:12, 1895-H. palmeri.

3. Ericameria palmeri Hall, Univ. Calif. Pub. Bot. 3:53, 1907. Based upon $H$. palmeri, which is cited in synonymy. The description applies mostly to subsp. pachylepis. 
4. Haplopappus palmeri typicus, but the involucral bracts somewhat acute, especially the inner ones. This variation includes certain collections from near the California-Lower California border (Hall 12304, 12309, 12310) and two from near Ensenada (Orcutt 1229; October 27, 1899, Brandegee). In most other collections, including the type, even the inner bracts are obtuse, as represented in the text-figure, but a few specimens, from diverse localities, have bracts intermediate in shape.

\section{RELATIONSHIPS}

The placing of Haplopappus palmeri in any evolutionary plan is attended with much difficulty. The species of this group are so closely similar and at the same time so positively separated morphologically from one another that it is impossible to draw satisfactory phylogenetic lines. It appears most probable, however, that the present one is a derivative of some form similar to $H$. pinifolius, but with marked reduction in size of heads. On the other hand, the retention of achenial pubescence places it as the lower of the two as regards this feature, so that a direct derivation of either one from the other meets with difficulties. It becomes necessary, therefore, to interpose a hypothetical common ancestor with large heads and pubescent achenes. It is for this reason that palmeri is indicated on the phylogenetic chart as arising from a point just below the origin of pinifolius. An occasional specimen with involucres somewhat as in palmeri but with habit, foliage, and other features of propinquus suggests also a recent connection with the latter species.

The subspecies pachylepis is best recognized by the elongated involucre and by the thick and broad, very obtuse, regularly imbricated bracts, each of which has a prominent greenish or brownish central area that contrasts sharply with a narrow white border. The midrib is much enlarged toward the summit and forms a sort of longitudinal resin-pocket, which often splits down the back at maturity. In growth-form the new subspecies, which is always a low shrub, appears to be a reduction from the larger subspecies typicus, which in its best development is almost arboreous. Near the northern limits of typicus, where it most nearly approaches geographically to pachylepis, the plants are intermediate in size, so that the variation in this respect parallels that of many other species which have arboreous forms in Lower California but only shrubby ones farther north.

If subspecies pachylepis has been developed as a northern variation from typicus, as the evidence seems to indicate, this has been accompanied by isolation. The geographic hiatus between the two is about $80 \mathrm{~km}$. and this neutral zone is traversed by the Santa Ana and Palomar mountain ranges. These are separated by a rather low pass, but even this seems sufficient to serve as a barrier to these forms, which are but poorly provided with means of dissemination and which are adapted to a very limited range of climatic and edaphic conditions.

\section{ECOLOGY}

This shrub inhabits well-drained, gravelly and alluvial soils in the Lower Sonoran Zone of the coastal slope of Lower California and southern California. Here it grows scatteringly in open situations and is subclimax to such species as Artemisia californica and Eriogonum fasciculatum. Other associates include Rhus laurina, Rhamnus crocea ilicifolia, Salvia apiana, 
and Haplopappus berberidis. As contrasted with $H$. pinifolius, which is a shrub primarily of dry, stony streamways, this inhabits soils of more even texture, often closely packed, and it commonly follows partial denudation through grazing, burning, or agricultural practice. The plants come into flower in the spring and remain in bloom throughout summer and autumn. In Lower California the flowers of subspecies typicus are borne in great abundance from September to December, often weighing down the upper branches, which thus come to assume a horizontal or even drooping position.

61. Haplopappus propinquus Blake, Contr. U. S. Nat. Herb. 23:1490, 1926

A rigidly branched spreading shrub, usually 12 to 20 $\mathrm{dm}$. high, the main stems hard-woody and brittle; bark either gray or reddish-brown, darkening with age, sometimes nearly black, peeling in strips when old; twigs short, crowded, densely leafy, obscurely or not striate, glabrous but punctate and very resinous; principal leaves filiform or shightly flattened, short-acute or obtusish, erect from an outwardly curved base, 1 to 2 $\mathrm{cm}$. long, $1 \mathrm{~mm}$. or less wide, grooved on back where the revolute margins meet, strongly resinous-punctate, glabrous, many with short fascicled ones in their axils; heads racemose among the upper leaves or narrowly paniculate, the peduncles 5 to $20 \mathrm{~mm}$. long and scalybracted or short-leafy; invohucre turbinate, 4.5 to 5.5 $\mathrm{mm}$. high, 4 to $6 \mathrm{~mm}$. broad; bracts 16 to 22 , in about 3 series, much shorter than disk, scarcely exceeding mature achenes, loosely imbricated, the inner ones oblong-lanceolate, obtuse or only acutish, the minute outer ones lanceolate-acute,

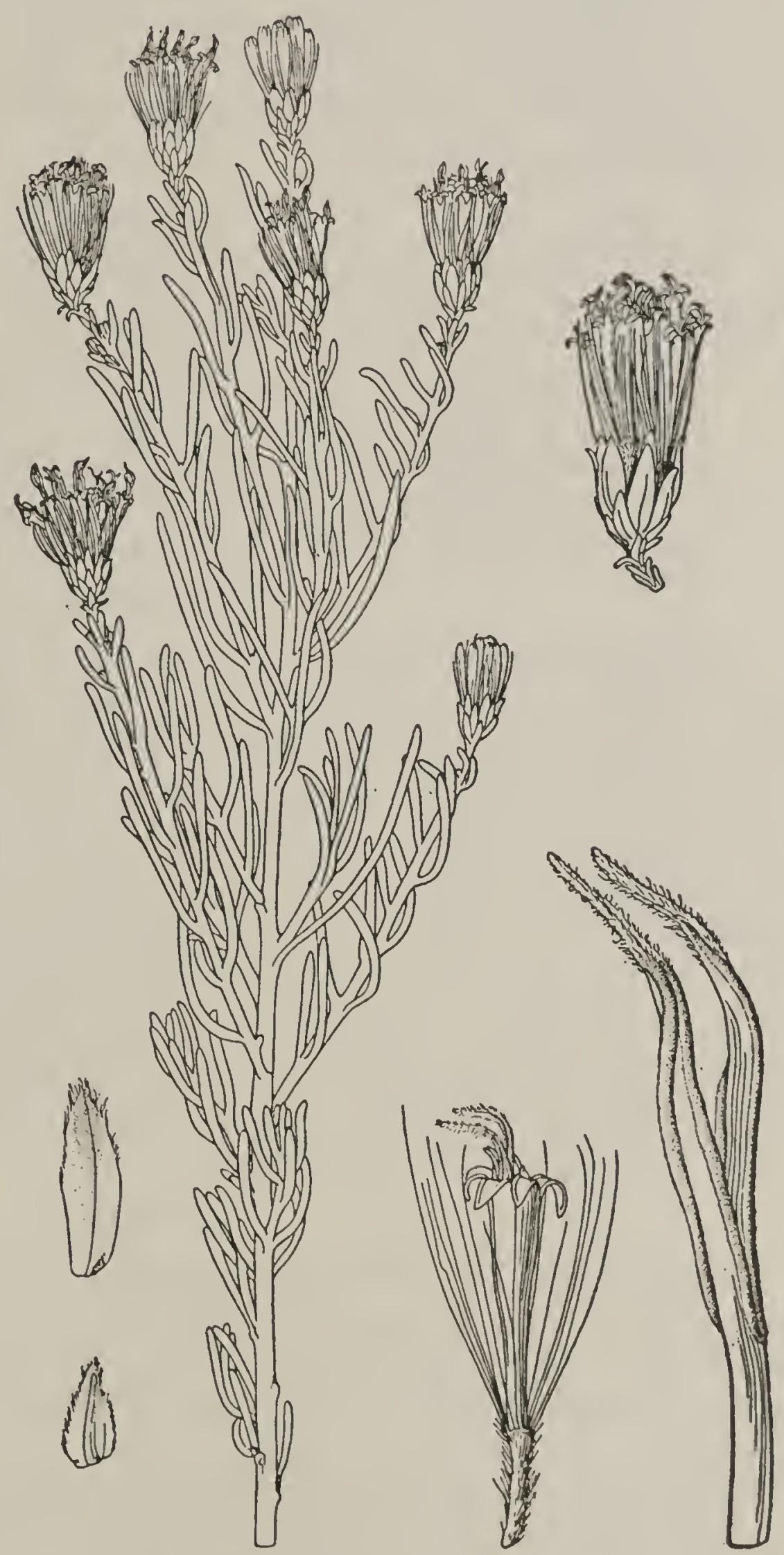

FIG. 97-Haplopappus propinquus all with a brown resinous medial ridge and white-scarious edges, glabrous; 
ray-flowers wanting; disk-flowers about 10 or 12; disk-corolla slender, nearly cylindric, 6 to $7 \mathrm{~mm}$. long, puberulent (or glabrous?); lobes spreading, lanceolate, acute, about $1 \mathrm{~mm}$. long, glabrous; style-branches long-exserted, 2 to $2.5 \mathrm{~mm}$. long, the very slender appendage longer than stigmatic portion; achenes linear, $4 \mathrm{~mm}$. long (immature), densely villous with long ascending hairs; disk-pappus about equaling the corolla, rather scanty, soft, white or somewhat sordid. (Bigelovia brachylepis Gray, Bot. Calif. 1:614, 1876, not H. brachylepis Philippi.) (Fig. 97.)

Southwestern San Diego County, California, and adjacent Lower California. Type locality, "Larkens' Station, 80 miles east by north of San Diego." California: type, 1875, Palmer (Gr); El Campo, April 10, 1882 , Orcutt (UC); Potrero, Cleveland (UC); Warner's Ranch, Hayes 391 (Gr); Dos Cabesas, southwestern part Colorado Desert, Orcutt 2224 (US). Lower California: Cedros Island, Veatch (UC, an imperfect specimen apparently belonging here, notwithstanding the occasional development of ligulate marginal corollas).

\section{SYNONYMY}

All of the following except the second were based upon Bigelovia brachylepis and are therefore synonymous with $H$. propinquus. The combination $H$. brachylepis is untenable for this species because of the South American H. brachylepis Phil., 1894.

1. Aster brachylepis O. Kuntze, Rev. 317, 1891.

2. Bigelovia brachylepis Gray, Bot. Calif. 1:614, 1876.

3. Chrysoma brachylepis Greene, Erythea 3:12, 1895.

4. Ericameria brachylepis Hall, Univ. Calif. Pub. Bot. 3:56, 1907.

5. Haplopappus brachylepis Hall, 1. c., 7:273, 1919; not H. brachylepis Phil., 1894.

\section{RELATIONSHIPS}

The characters exhibited by this species are, for the most part, those of a primitive Ericameria. Among these are especially to be mentioned the paniculate inflorescence, the rather large heads with numerous bracts and flowers, and the pubescent achenes. On the other hand, the long style-appendages and complete suppression of ray-flowers suggest that it is a type from which none of the other species could have originated. It should be remembered, however, that Haplopappus propinquus is known from but a few imperfect collections and that a study of its variations may lead to a different conclusion. The relations to $H$. sonoriensis, which in some respects appears like a reduced derivative of $H$. propinquus, are to be especially considered, and a possible connection with $H$. palmeri has been suggested under that species.

\section{ECOLOGY}

Although of very limited distribution, this species is an important element in the hard chaparral of the small area within which it grows. This is on the border-line between the coastal chaparral of southern California and the desert scrub. Here it forms small colonies in the belt of Quercus agrifolia, but only where fully exposed or where the shade is very thin. It grows in well-drained granitic soil, and often on rocky hillsides. The more conspicuous associates, in addition to the oak, are Adenostoma fasciculatum, A. sparsifolium, Quercus dumosa, Eriogonum fasciculatum, Rhus ovata, and Ceanothus cuneatus. The flowers appear in autumn and persist on into winter. 
62. Haplopappus sonoriensis (Gray) Blake, Contr. U. S. Nat. Herb. $23: 1490,1926$

A diffusely branched shrub, probably of rounded outline, commonly 8 to $24 \mathrm{dm}$. high, with several or numerous main stems, these rather soft; bark changing from green to light brown, firm, not known in old condition; twigs short, crowded, very slender, densely leafy, striate, glabrous, faintly punctate, resinous; principal leaves filiform or slightly flattened, rather obtuse or with a short mucro, erect from a curved base or straight and spreading, 0.5 to $3 \mathrm{~cm}$. long, about $0.5 \mathrm{~mm}$. wide, lined or grooved on back where the revolute margins meet, minutely resinous-punctate, glabrous, occasionally with smaller ones fascicled in the axils; heads effusely panicled, each of the numerous branchlets terminating in a rounded or oblong cluster, the ultimate peduncles naked or sparsely scaly-bracted; involucre narrowly turbinate, 4 to $4.5 \mathrm{~mm}$. high, 2 to $2.5 \mathrm{~mm}$. broad; bracts 8 to 12 , in 3 scries, shorter than disk, well exceeding the achenes, imbricated, the inner ones oblong and obtuse, the middle ones half as long and often short-mucronate, the outermost reduced to minute lanceolate-acute scales, all with greenish thickened subapical spot and pale scarious margins, glabrous; (receptacle with several awns, each 0.5 to 1 $\mathrm{mm}$. long); ray-flowers wanting (solitary according to Bentham); disk-flowers 4 to 6; disk-corolla slender-funnelform, 4 to 5 $\mathrm{mm}$. long, puberulent on tube; lobes irregularly spreading, elongated-lanceolate, acute, 1.2 to $1.5 \mathrm{~mm}$. long, glabrous; stylebranches long-exserted, $2 \mathrm{~mm}$. or less long, the ovate-acute appendage much shorter than stigmatic portion; achenes linear-turbinate, angled, about $1.5 \mathrm{~mm}$. long, whitevillous; disk-pappus exceeding corolla, rather scanty, soft, sordid or brownish. (Ericameria diffusa Benth., Bot. Sulph. 23, 1844; not $H$. diffusus DC., 1836; Linosyris sonoriensis Gray, Proc. Am. Acad. 8:291, 1870.) (Fig. 98.)
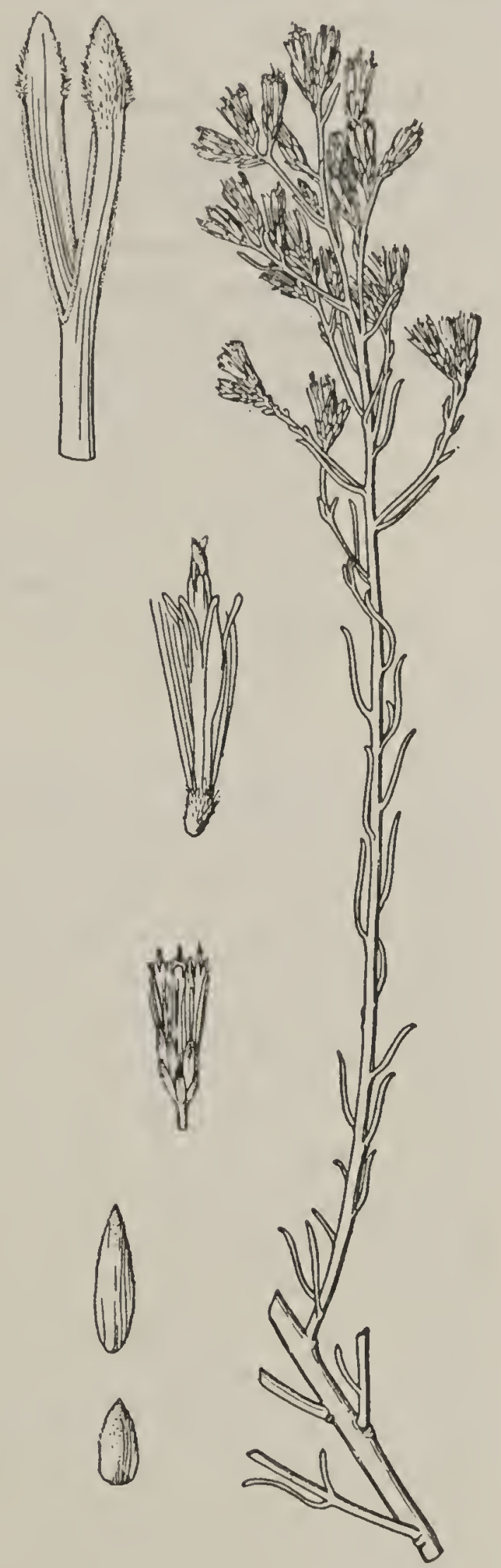

Fra. 98-Haplopappus sonoriensis

Northwestern Mexico, from Sonora and Sinaloa to the islands off the west coast of Lower California. Type locality (of Linosyris sonoriensis), district of the Yaqui River, Sonora. Sonora: Guaymas, Palmer 2121/2 (US, K, UC); Yaqui River, 1869, Palmer 11 (Gr, probably the type); San Carlos Bay, Johnston 4384 (SF). SinaloA: Altata, vicinity of Culiacan, November 20, 1904, Brandegee (US, UC); Agiabampo, Palmer 815 (US, 
B, UC). Lower California: San Marcos Island, Johnston 4181 (SF); Ildefonso Island, Johnston 3748 (SF); Loreto, Johnston 3777 (SF); Carmen Island, Palmer 839 (US, K, UC); Agua Verde Bay, Johnston 4385 (SF); Espiritu Santo Island, Bryant (UC); La Paz, November 5, 1890, Brandegee (UC); San José del Cabo, October 10, 1899, Brandegee (UC); Magdalena Bay, Barclay (K, type of Ericameria diffusa, minor variation 3); Santo Domingo, Nelson and Goldman 7173 (S); San Gregorio, February 3, 1889, Brandegee (UC); Cedros Island, 1885, Greene (UC).

\section{MINOR VARIATIONS AND SYNONYMS}

1. Aster sonoriensis O. Kuntze, Rev. 317, 1891. Based upon Ericameria diffusa and Linosyris sonoriensis, which see.

2. Bigelovia diffusa Gray, Proc. Am. Acad. 8:640, 1873. Based upon Ericameria diffusa.

3. Chrysoma diffusa Greene, Erythea 3:10, 1895. Based upon Ericameria diffusa.

4. Ericameria diffusa Benth., Bot. Sulph. 23, 1844. The earliest name. See under next synonym.

5. Linosyris sonoriensis Gray, 1. c. 291, 1870. The types of this are indistinguishable from the type of the earlier Ericameria diffusa Benth., from Magdalena Bay, west coast of Lower California. It is probable that Gray overlooked the latter when proposing the species. At any rate, he later cited his species as synonymous with the earlier one of Bentham. It is inadvisable, however, to take up the name diffusa under Haplopappus, because of $H$. diffusus DC, a species now referred to the genus Leucopsis.

6. Solidago diffusa Gray, Proc. Am. Acad. 5:159, 1861. Based upon Ericameria diffusa, which see.

\section{RELATIONSHIPS}

In its obvious external characters this shrub closely resembles the species of Chrysothamnus, section Punctati, and there is little doubt that once there was a rather close connection with this group. The similarity is so pronounced that Gray at one time classed all of these species as members of the genus Bigelovia. Notably similar are the inflorescences of small heads, the involucral bracts, each with a greenish subapical thickening, and the impressed-punctate herbage. On the other hand, the present species exhibits only an occasional tendency toward the most distinctive and phylogenetically significant feature of the Punctati, namely, the vertical arrangement of the bracts of the involucre. It seems that this feature was developed somewhere in the group now under discussion, but that the line leading to Haplopappus sonoriensis was scarcely if at all concerned in this. Instead of progressing in that direction it has taken on or retained certain other features which now serve to distinguish it. Most notable among these are the short style-appendages, the small size of the corolla with its deeply cleft limb, and the reduced number of involucral bracts. According to the original description by Bentham (under Ericameria diffusa), there should be a difference due to the presence of ray-flowers, and Gray also appears to have found suggestions of ligules on some of the marginal corollas. But careful dissections of a number of collections, including a fragment of Bentham's type, fail to reveal these structures. If ray-flowers actually occur they are of sporadic appearance and of evolutionary significance only in that they more closely fix the position of the species in Haplopappus, ray-flowers being unknown in the genus Chrysothamnus. A connection with Solidago, as once asserted by Gray, seems impossible, not 
only because of the shrubby habit and the inflorescence, but also because of the obvious relation to other members of Haplopappus and the absence of any species of Solidago with which a relationship can be demonstrated.

The direct derivation of this species from the little-known Haplopappus propinquus is one of the possibilities. This origin would account for the small size of the heads, and the increased number of these would be a phenomenon of correlation. But the presence of persistent receptacular scales (remnants of walls of the alveoli?) and the very short style-appendages in sonoriensis prevent the unqualified acceptance of this hypothesis.

\section{ECOLOGY}

But little is known concerning the ecology of this plant. It is very common in slightly alkaline ground at a number of places on the west side of the Gulf of California and on some of the adjacent islands, according to Johnston (Proc. Calif. Acad. Sci. IV, 12:1191, 1924). All of the collections thus far made are from warm maritime districts, of scanty and irregular rainfall, which comes mostly from October to January. The shrubs burst into bloom after each rain and therefore their periods of flowering are as erratic as is the climate itself.

\section{Haplopappus laricifolius Gray, Pl. Wright. 2:80, 1853}

A fastigiately branched erect leafy shrub, 5 to $10 \mathrm{dm}$. high, the hard woody main branches 0.5 to $2 \mathrm{~cm}$. (or more?) thick; bark (green on twigs) from cinnamon color to dark brown, nearly black in age, breaking longitudinally on the surface but not becoming shreddy; twigs short, crowded, leafy, striate from the leaf-bases, conspicuously resinous-punctate, glabrous; principal leaves broadly linear, straight, from mercly acutish to shortacerose, entire, 1 to $2 \mathrm{~cm}$. long, 1 to $1.8 \mathrm{~mm}$. wide, thick but midrib usually evident, all conspicuously impressed-punctate, glabrous, glutinous or viscid, occasionally with much smaller ones fascicled in the axils; heads in small densely bracted irregular cymes; involucre turbinate-campanulate, 3 to $5 \mathrm{~mm}$. high, 3 to $5 \mathrm{~mm}$. broad; bracts 12 to 20 , in about 3 series, all much shorter than disk and scarcely equaling mature achenes, rather firmly imbricated, the outer ones short, all linear or linear-lanceolate and very acute, thin, the middle portion brownish yellow, the margins whitescarious, glabrous except that edges are sometimes puberulent; ray-flowers 3 to 6 (sometimes fewer or wanting), the ligules 4 to $5 \mathrm{~mm}$. long, 1.5 to 2 $\mathrm{mm}$. wide; disk-flowers 9 to 16 ; disk-corolla with slender tube passing gradually into the narrowly funnelform throat, 5 to $6 \mathrm{~mm}$. long, glabrous or minutely puberulent; lobes lanceolate, acute, widely spreading, about $1 \mathrm{~mm}$. long, glabrous; style-branches long-exserted, 2 to $2.5 \mathrm{~mm}$. long, the linear-filiform acuminate appendage much shorter than stigmatic portion; achenes slender, slightly tapering from the truncate summit, 3.5 to $4 \mathrm{~mm}$. long, obscurely 4-angled, densely white-villous; disk-pappus about equaling corolla, slender, fragile, scanty, light brown. (Fig. 99.)

Arizona to western Texas and adjacent Mexico. Type locality, on mountains at Guadalupe Pass, New Mexico. Arizona: Chloride, Mohave County, Goldman 3004 (US); Kingman, Goldman 2978 (US); Soldicr Cañon, Santa Catalina Mountains, Shreve 5119 (UC); Manning trail, 
Rincon Mountains, Blumer 3614 (DS,UC); Clifton, Graham County, Davidson 202 (DS, UC); Chiricahua Mountains, near Fort Bowie, Blumer

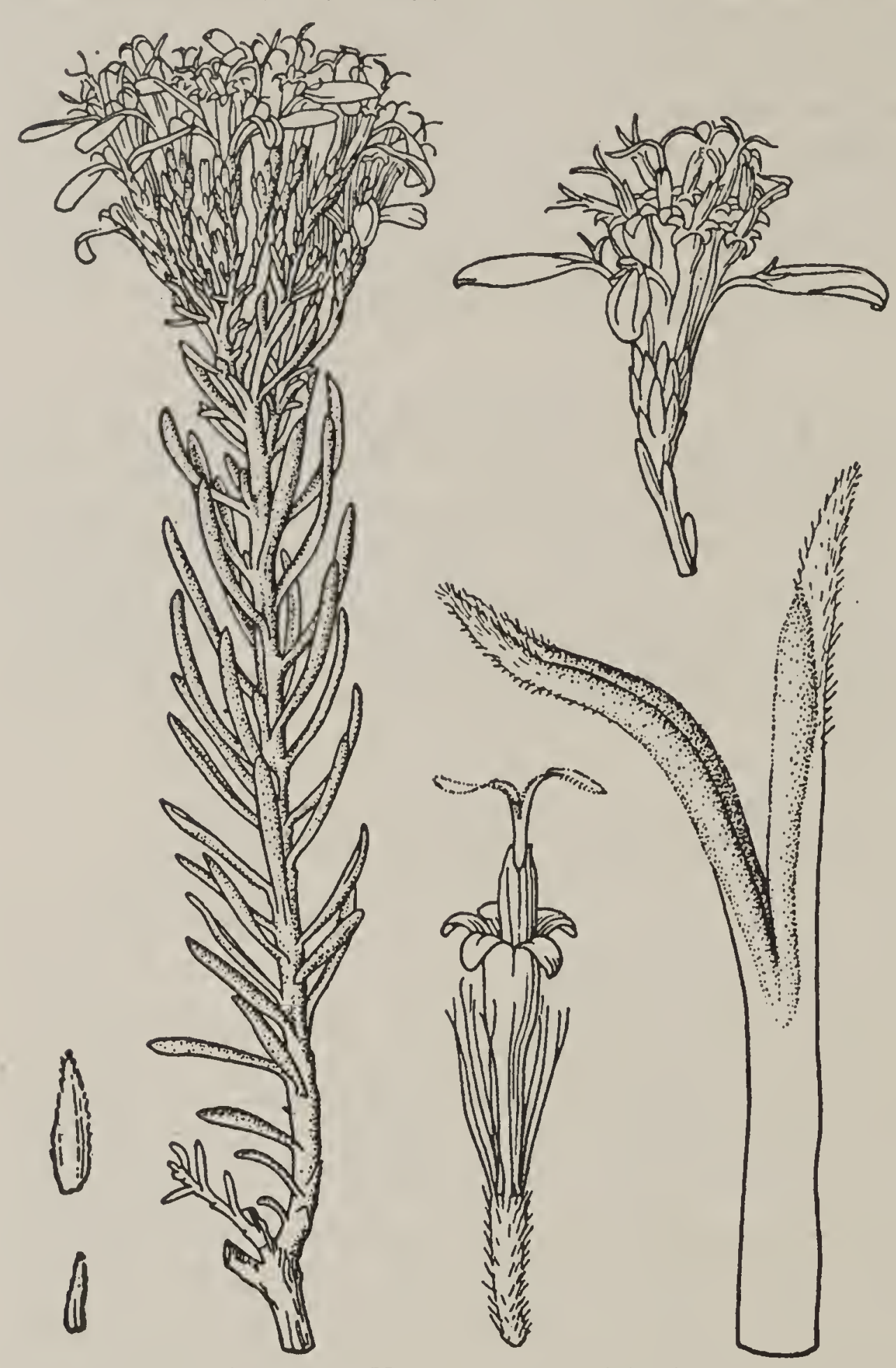

FIG. 99-Haplopappus laricifolius

1243 (US, B); Harquebala Mountains, Goldman 3009 (US). NEw Mexico: Bear Mountain, Grant County, Metcalf 748 (US) Burro Mountains, Rusby 218 (US); Florida Mountains, Goldman 1485 (US); Dog Spring, Dog Mountains, Mearns 2384 (US); Organ Mountains, September 23, 1906, Wooton and Standley(US). Texas: Franklin Mountains, February, 1903, Gant (US). Chinuahua : Sierra Madre, Nelson 6494 (Gr, US, minor variation 2, Bigelovia nelsoni); Candelaria, Stearns 288 (US, similar variation); near Ciudad Juarez, 1911, Stearns (NY, similar variation). SoNORA: Guadalupe Cañon, Merton 2065 (US, no flowers).

\section{MINOR VARIATIONS AND SYNONYMS}

1. Aster laricifolius O. Kuntze, Rev. 318, 1891-H. laricifolius.

2. Bigelovia nelsoni Fernald, Proc. Am. Acad. 36:505, 1901. This appears to be a form of laricifolius in which the large heads are solitary and subsessile at tips of short, lateral, leafy branches. The type is Nelson 6494 from the Sierra Madre of Chihuahua. An examination of this at the Gray Herbarium reveals the following characters: Involucre short and broad (5 to $5.5 \mathrm{~mm}$. high by about 6 or $7 \mathrm{~mm}$. broad), of about 35 acuminate narrow bracts; ray-flowers 12 to 15 , with often misshapen ligules; receptacle chaffy, each flower subtended by a bract of about its own length; disk-flowers variously deformed, some incompletely ligulate, apparently none with regular 5-toothed corollas; stamens wanting (at least in most flowers); style-branches short, destitute of stigmas. In other characters, such as nature of bark, habit of twigs, foliage, and especially in shape and texture of involucral bracts, this form is so much like laricifolius that its assignment to this species is made with but little hesitation. Although the type is hypertrophic this is not true of other collections of nelsoni from Chihuahua. One from mountains near Ciudad Juarez (Stearns, NY) and another from Candelaria (Stearns 288, US), have normal flowers and no receptacular chaff; but the heads are partly in small, 
loose, leafy cymes and partly solitary. There are also collections from Arizona and New Mexico in which the large heads are partly solitary and partly cymose, so that the retention of nelsoni in specific rank would be attended by difficulties.

3. Chrysoma laricifolia Greene, Erythea 3:11, 1895-H. laricifolius.

4. Ericameria nelsoni Blake, Contr. Gray Herb. 52:26, 1917. Based upon Bigelovia nelsoni, which see.

\section{RELATIONSHIPS}

The more or less definitely cymose arrangement of the heads places Haplopappus laricifolius in the second of the two principal divisions of Ericameria, where it belongs also because of its obvious connection with $H$. cooperi, as will be brought out in the treatment of this species. The geographic position and absence of notable reduction in any part indicate that it probably carries over the traits of the primitive Ericameria type better than any of the other forms.

\section{ECOLOGY AND USES}

Haplopappus laricifolius is a low shrub of foothill slopes and mesas in the proximity of desert areas. It grows especially in broken or stony soil, as along embankments and in dry streamways. Here it mixes with other shrubs and perhaps never becomes dominant. As with most plants of the Southwest, the flowering period depends upon the rains, but the period of greatest bloom is from September to November, following the principal rainy season.

Analyses of five plants from near Tucson, Arizona, indicate that this species carries perhaps more rubber than any other Haplopappus except $H$. nanus, and that more rubber is contained in the roots than the stems. The amount found in these plants was from 2.01 to 5.16 per cent (Hall and Goodspeed, Univ. Calif. Pub. Bot. $7: 272,1919)$.

\section{Haplopappus cooperi (Gray)}

A much branched leafy usually round-topped shrub, 3 to 12 or rarely $20 \mathrm{dm}$. high, the main branches very woody and often 2 to $8 \mathrm{~cm}$. thick; bark brown, changing to dark gray or almost black, breaking longitudinally and becoming shreddy; twigs short, crowded, leafy, more or less striate, resinous-punctate, minutely puberulent; principal leaves linear or linear-spatulate, straight, acute, 0.5 to $2 \mathrm{~cm}$. long, $1 \mathrm{~mm}$. or less wide, thick, the nerves obsolete, some or all impressed-punctate, minutely puberulent, at least the lower with smaller ones fascicled in the axils; heads in open rounded cymes terminating all the branchlets, the peduncles 3 to 15 $\mathrm{mm}$. long and usually with a few small bracts; involucre narrowly campanulate, 4 to $5 \mathrm{~mm}$. high, 3 to $4 \mathrm{~mm}$. broad; bracts 10 to 14 , in about 3 series, all much shorter than disk, loosely imbricated, the inner ones broad-oblong and obtuse (all acute in minor variation 9), the outer ones much shorter and varying to ovate-acute, all thin, with greenish middle portion and white-scarious border, more or less puberulent; ray-flowers 1 or 2 or entirely wanting in some heads, occasional plants with all heads discoid, the ligules when present 5 to $6 \mathrm{~mm}$. long, about $2 \mathrm{~mm}$. wide; disk-flowers 5 to 8 (or 10?); disk-corolla with slender tube passing gradually to the throat, 4 to $5 \mathrm{~mm}$. long, conspicuously puberulent to nearly glabrous; lobes lanceo- 
late, acute, widely spreading, 1 to $1.5 \mathrm{~mm}$. long, glabrous; style-branches little exserted, 1.5 to $2.2 \mathrm{~mm}$. long, the ovate to linear-lanceolate appendage much shorter than stigmatic portion; achenes slightly tapering from the truncate summit, 3 to $3.5 \mathrm{~mm}$. long, obtusely 4-angled, densely whitevillous; disk-pappus nearly equaling corolla, slender, fragile, scanty, dull white. (Bigelovia cooperi Gray, Proc. Am. Acad. 8:640, 1873.) (Fig. 100.)

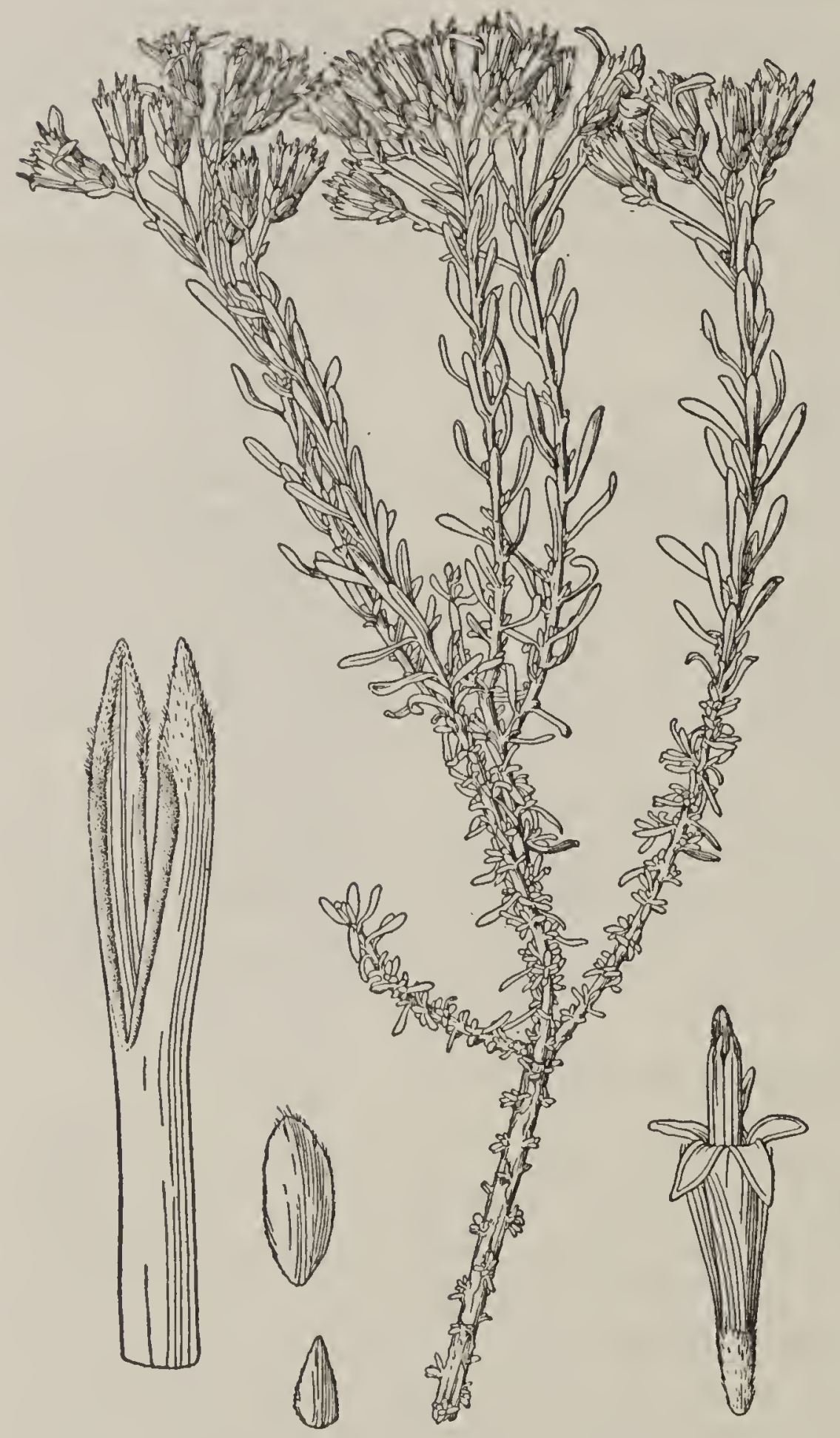

FIG. 100-Haplopappus cooperi

Chiefly in eastern California, from Inyo County to the southern borders of the Mohave Desert, but a few also on the coastal slope of southern California, an atypical form in southwestern Nevada, and one collection from Lower California. Type locality, southeastern California, on the eastern slope of Providence Mountain. California: hills west of Big Pine, Inyo County, Heller 8263 (US, P, DS, UC); Greenwater Flats, Inyo County, Parish 10057 (DS, UC); New York Mountains, Parish 10339 (DS, UC); type collection, Cooper (Gr); South Fork Kern River, Purpus 5401 (K); Mohave, Kern County, Heller 7753 (US, DS); borders of Mohave Desert, 1876, Palmer (Gr, type of Haplopappus monactis, minor variation 10 ); Tejon Pass, Los Angeles County, Hall 6312 (DS, UC); north base San Bernardino Mountains, Parish 1246 (DS, UC); south side of Cajon Pass,

Munz, Harwood, and Johnston 4069 (DS, UC). Nevada: Rhyolite, Nye County, Heller 9633 (DS, Nev, bracts of the involucre rather acute, minor variation 9); Rhyolite, Shockley 71 (DS, UC, same variation); Fish Lake Valley (near the California line), Purpus 5811 (Po). Lower California: Alamo, Goldman 1139 (US).

\section{MINOR VARIATIONS AND SYNONYMS}

1. Acamptopappus microcephalus Jones, Contr. W. Bot. 7:30, 1898. The type of this differs in no essential from $H$. cooperi. The heads have a few rayflowers, as in the stage described as $H$. monactis.

2. Aster cooperi O. Kuntze, Rev. 317, 1891-H. cooperi.

3. Aster monactis O. Kuntze, Rev. 318, 1891. Based upon H. monactis, which see. 
4. Bigelovia cooperi Gray, Proc. Am. Acad. 8:640, 1873-H. cooperi.

5. Chrysoma cooperi Greene, Erythen 3:12, 1895-H. cooperi.

6. Chrysothamnus corymbosus Elmer, Bot. Gaz. 39:50, 1905. The type specimen (Lancaster, California, Elmer 3668) has been seen at Stanford University and positively identified as $H$. cooperi. The heads have a few ray-flowers, as in the form named as $H$. monactis. The involucral bracts are not in vertical rows, nor are the other characters those of the genus Chrysothamnus.

7. Ericameria cooperi Hall, Univ. Calif. Pub. Bot. 3:56, 1907-H. cooperi.

8. E. monactis McClatchie, Erythea 2:124, 1894. Based upon H. monactis, which see.

TABLE 11-Characters of Haplopappus laricifolius and H. cooperi

\begin{tabular}{|c|c|c|c|c|c|}
\hline & \multirow[b]{2}{*}{ Bracts } & \multirow[b]{2}{*}{$\begin{array}{l}\text { Ray- } \\
\text { flowers }\end{array}$} & \multirow[b]{2}{*}{$\begin{array}{l}\text { Disk- } \\
\text { flowers }\end{array}$} & \multicolumn{2}{|c|}{ Style-branches } \\
\hline & & & & $\begin{array}{l}\text { Total } \\
\text { length }\end{array}$ & $\begin{array}{l}\text { Ratio of } \\
\text { appendage- } \\
\text { length } \\
\text { to total } \\
\text { length }\end{array}$ \\
\hline $\begin{array}{l}\text { H. laricifolius: N. Mex. and } \\
\text { Ariz., } 5 \text { collections...... } \\
\text { H. cooperi: (intermediate } \\
\text { form, see minor variation } \\
\text { 9), Rhyolite, Nev....... } \\
\text { H. cooperi: Barstow and } \\
\text { Victorville, Calif...... } \\
\text { H. cooperi: California, } 5 \\
\text { additional collections.... }\end{array}$ & $\begin{array}{l}12 \text { to } 20 \\
\text { av. } 16 \\
12 \\
10 \text { to } 12 \\
\text { av. } 11 \\
10 \text { to } 14 \\
\text { av. } 12\end{array}$ & $\begin{array}{l}0 \text { to } 3 \\
\text { av. } 1 \\
0 \text { to } 2 \\
\text { av. } 1\end{array}$ & $\begin{array}{c}6 \\
6 \text { to } 9 \\
\text { av. } 7 \\
6 \text { to } 9 \\
\text { av. } 7\end{array}$ & $\begin{array}{c}2.0 \\
2.2 \\
\text { av. } 2.2 \\
\text { 1. } 2 \text { to } 1.9 \\
\text { av. } 1.5\end{array}$ & $\begin{array}{c}40 \\
23 \text { to } 36 \\
\text { av. } 30 \\
24 \text { to } 30 \\
\text { av. } 27\end{array}$ \\
\hline
\end{tabular}

9. Haplopappus cooperi, but with the bracts of the involucre almost as narrow and acute as in $H$. laricifolius, the stigmas and their appendages also narrowed somewhat as in this species but not to so great an extent. The best representatives of this form are from Rhyolite, western Nevada (Shockley 71 and Heller 9633), which may be considered as neutral ground, since it is about where the ranges of the two species meet, although neither is known to grow in the vicinity. These plants have the open, nearly bractless cymes, fewflowered heads, puberulence, and general appearance of cooperi. Their origin through hybridization is strongly suggested, but conclusive evidence is lacking. Against this theory is the occasional collection of similar forms from well within the area occupied exclusively by cooperi (Barstow, Hall 6169 , and many others). In these collections both bracts and style-branches exhibit all graduations in shape. Something of the variation and intermediate position of this form between true cooperi and laricifolius are suggested in table 11 and in figure 101.

10. H. monactis Gray, Proc. Am. Acad. 19:1, 1883-H. cooperi. On the assumption that the earlier Bigelovia cooperi was a distinct species, the names Haplopappus monactis and Ericameria monactis have been the ones almost universally employed for the common form now included in $H$. cooperi. But on examining the types of cooperi and monactis it is found that they represent almost identical forms of the same species. In the former the ray-flowers appear to be entirely suppressed and the style-appendages are perhaps narrower than the average. It is now well known that on single plants of typical "monactis" the number of ray-flowers in a head will vary from several to none. Since the number of perfect heads on the single collection of cooperi thus far made (Providence Mountains, California, Cooper) is less than a dozen, the absence of ray-flowers from these does not 
furnish a convincing criterion. It may be surmised that some of these, or at least other heads on the same plant, originally had a few ray-flowers, for this is true of all other plants from both east and west of the type locality. The style-appendages of cooperi have been described by Gray at different times as deltoid-ovate and as ovate-subulate. The former describes also the shape in typical "monactis." In the single flower from the type of cooperi at present available, the shape is lanceolate, about as shown for one of the forms of monactis in the illustration (Fig. 101, $f$, from Barstow). The necessity of merging monactis into cooperi has been decided upon independently by Dr. S. F. Blake, of the United States National Herbarium.

11. Tumionella monactis Greene, Leaflets 1:173, 1906. Based upon H. monactis, which see.

\section{RELATIONSHIPS}

The phylogenetic connection between Haplopappus cooperi and the other species of section Ericameria is so close that earlier attempts to set the former off into a genus or section by itself must now be abandoned.
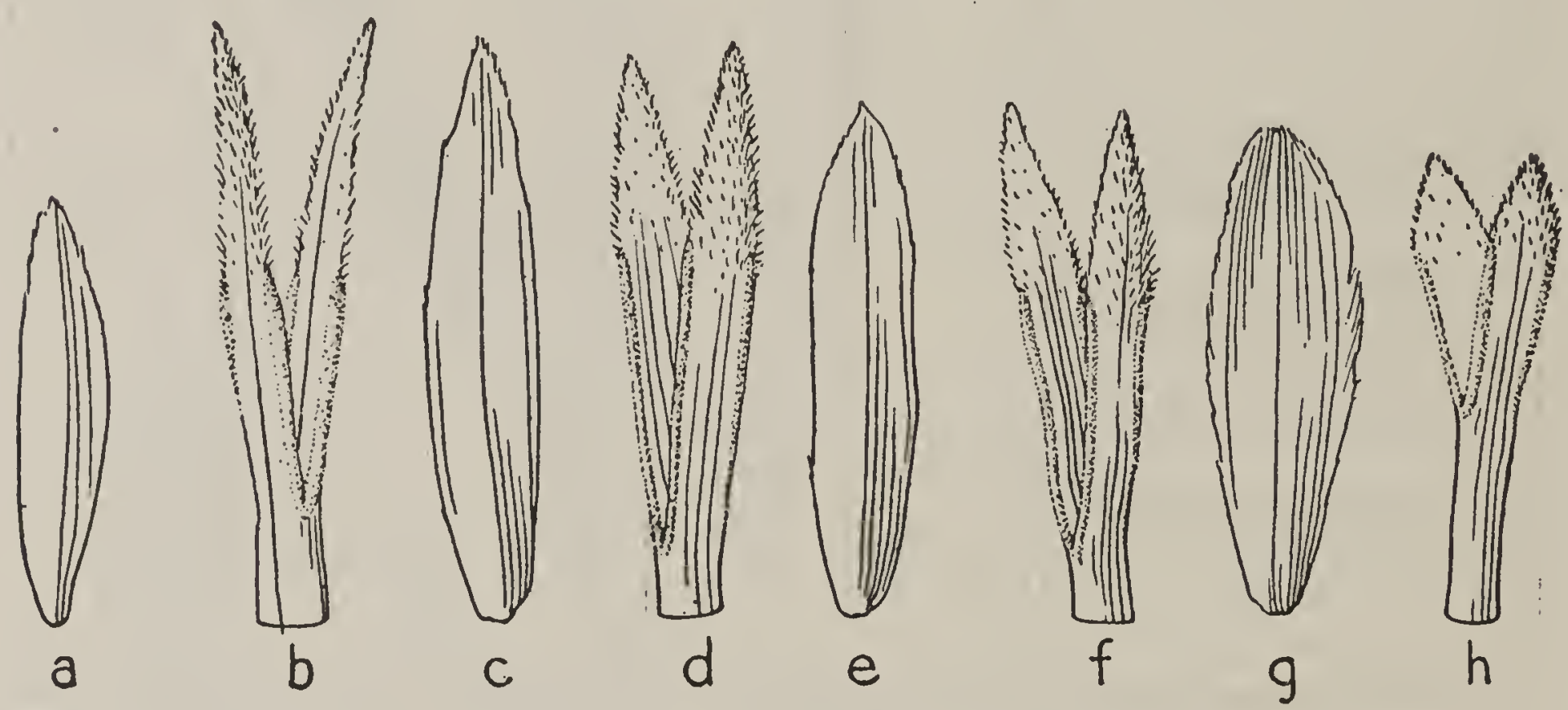

FIG. 101-Variation in bracts of the involucre and in style-branches; $a, b$, Haplopappus laricifolius from Arizona (86643 UC) ; $c, d, H$. cooperi, minor variation 9, from southern Nevada (149609 UC); $e, f, H$. cooperi from Barstow, California (68921 UC); $\theta, h, H$. cooperi from Elizabeth Lake, California (68939 UC)

Greene's genus Tumionella, set up for the accommodation of this species alone, was not characterized, but it differs from the true Ericamerias only in its short, flat, ovate-acute stigmatic appendages and by certain vegetative features of little importance. Although the shape of the appendage is of much significance in some groups, it is here so variable that it serves better as a mark of affinity than as a generic or sectional criterion. Under minor variation 9 it has been shown that plants from near the center of the area occupied by cooperi and undoubtedly to be referred to this species have style-branches, including their appendages, somewhat intermediate in shape between those of genuine cooperi and those of laricifolius, the latter being a species always accepted as an Ericameria. This interspecific connection is further attested by similarities in habit and in reduction in involucre and ray. In all of these features there is evidence that cooperi has advanced over all of the other Ericamerias except that the reduction in number of ray-flowers, apparently now in progress, has not reached the stage of complete elimination, as it has in parishi and arborescens. 
The relation of Haplopappus cooperi to H. laricifolius is of much interest. Starting with the latter as it occurs in its extreme form in New Mexico, farther west it is found to become more definitely cymose in the arrangement of the heads and to undergo slight reductions, especially in number of flowers. Then, after the dropping of a few links, the chain of variations is again picked up in southwestern Nevada as minor variation 9 of $H$. cooperi and continued westward across the Mohave Desert of California. A few of the stages in this progressive series are concisely set forth in table 11, and in figure 101, where, however, it is impossible to express all of the evidence available from the large number of collections now at hand.

Notwithstanding the close approach to each other of the two species here under discussion and although they are sometimes confused in herbaria, there is nevertheless a real distinction between them. The principal differences may be stated as follows:

\footnotetext{
Haplopappus laricifolius

1. Style-branch and its appendage linearfiliform

2. Ray-flowers 0 to 6 ; disk-flowers 9 to 13

3. Bracts 12 to 20

4. Inner bracts linear, very acute

5. Heads usually cymose but the cymes of ten irregular or the heads racemosely or paniculately arranged, leafy bracted
}

6. Herbage glabrous

7. Bark firm, not shreddy

\section{Haplopappus cooperi}

1. Style-branch oblong-linear, the appendage ovate to linear-lanceolate

2. Ray-flowers 0 to 2 ; disk-flowers 6 to 9

3 . Bracts 10 to 12 , rarely 14

4. Inner bracts oblong, obtuse, varying to acute

5. Heads regularly cymose, nearly naked

6. Herbage puberulent

7. Bark becoming shreddy

The conclusion from the foregoing considerations is that Haplopappus cooperi is still undergoing change, but without the formation of welldifferentiated subspecies; that it is a derivative of a more widespread southerly form, probably $H$. laricifolius; and that its specific separation is now complete.

\section{ECOLOGY}

Haplopappus cooperi is a shrub of the desert borders. It grows in the belt of Larrea divaricata and Yucca brevifolia, and belongs, therefore, to the upper part of the Lower Sonoran Zone. Other common associates are Salazaria mexicana, Haplopappus linearifolius interior, and Salvia carnosa. It is never dominant, but grows as scattered individuals in the desert scrub, especially along dry, stony streamways and on disturbed slopes. The few known stations on the coastal slopes are exceptionally warm and protected places and its occurrence here is believed to indicate that the species once extended farther to the Southwest than it does to-day. This seems more probable than that these plants are the result of chance introductions from the desert area at times when local conditions were especially favorable to ecesis. Such relicts are to be found at West Riverside (May, 1901, Hall), in Rubio Cañon, back of Los Angeles (according to McClatchie, Erythea 2:124, 1894), and along Lytle Creek, not far from San Bernardino (Parish).

The strongly xerophytic character of the shrubs is evidenced by the much reduced, almost heath-like foliage and by the abundant resinous exudate. Rubber in small amounts occurs in the stems and probably in the roots. The flowering period is from April to June. 


\section{Haplopappus parishi (Greene) Blake, Contr. U. S. Nat. Herb.,} $23: 1491,1926$

A closely branched shrub, 15 to $50 \mathrm{dm}$. high, commonly arborescent, the main stems trunk-like; bark changing from green to light brown, firm, perhaps shreddy in age; twigs elongated, erect, stout, leafy, striate, not noticeably pitted, more or less resinous, glabrous (rarely with a slight puberulence in inflorescence); principal leaves oblanceolate-oblong, straight and rigidly ascending (upwardly curved on depressed twigs), entire, acute, 3 to 6 $\mathrm{cm}$. long, 3 to $10 \mathrm{~mm}$. wide, strongly 1 -nerved, conspicuously impressedpunctate, glabrous, thick and drying leathery, rather crowded but without secondary ones in the axils; heads regularly cymose, the rounded cymes (3 to $9 \mathrm{~cm}$. across) terminating all branches, the ultimate peduncles 1 to $5 \mathrm{~mm}$. long, bracteate with scales similar to those of the involucre; involucre turbinate, 4 to $5.5 \mathrm{~mm}$. high, 3 to $4 \mathrm{~mm}$. broad; bracts about 20 , in 4 series, slightly shorter than disk, imbricated, lanceolate, acute, pale and chartaceous but with thick brown midrib, glabrous or obscurely puberulent; ray-flowers wanting; disk-flowers 9 to 12 ; disk-corolla tubular-funnelform, 5 to $6 \mathrm{~mm}$. long, obscurely puberulent; lobes linear-lanceolate, acute spreading, 1 to $1.5 \mathrm{~mm}$. long, glabrous; style-branches well exserted, 1 to $1.5 \mathrm{~mm}$. long, the appendage shorter than or equaling stigmatic portion; achenes about $2 \mathrm{~mm}$. long, slightly angled, narrowed to base, densely appressed-pubescent; disk-pappus exceeding corolla, slender, fragile, copious, dull white to brown. (Bigelovia parishi Greene, Bull. Torr. Club $9: 62,1882$.) (Fig. 102.)

Coastal slope of southern California from near Los Angeles southward and extending into northern Lower California; occasional also on the desert slope. Type locality, San Bernardino Mountains. California: Sturtevant's Camp Trail, back of Pasadena, Grant 177 (UC); Spring Hill, San Antonio Cañon, Munz 6418 (UC); Lytle Creek, October 12, 1909, Wilder (UC); type collection, September 1881, Parish $5 \% 1$ (Gr); east slope of San Jacinto Mountains at 2,100 meters altitude, Jaeger 1004 (DS); Coldwater Cañon, Santa Ana Mountains, Zumbro 436 (UC); Cuyamaca Peak, October 15, 1894, Brandegee (UC). Lower California: San Pedro Martir, Robertson 48 (UC).

\section{SYNONYMS}

All of the following were based upon $H$. parishi:

1. Aster parishi O. Kuntze, Rev. 318, 1891.

2. Bigelovia parishi Greene, Bull. Torr. Club 9:62, 1882.

3. Chrysoma parishi Greene, Erythea 3:10, 1895.

4. Ericameria parishi Hall, Univ. Calif. Pub. Bot. 3:55, 1907.

\section{RELATIONSHIPS}

Haplopappus parishi is without doubt a very close relative of $H$. arborescens. It scarcely differs except in the decidedly smaller number of flowers and in the broad leaves. The former character is plainly a matter of reduction. Broadening of the leaf might be considered as the result of an unrolling and flattening of the margins of a closely revolute leaf, such as that of arborescens. The acceptance of this hypothesis, together with a consideration of the reduced number of flowers, would lead to the placing of parishi as a derivative of arborescens. This may, indeed, be the true explanation, 
but it implies the reversal of an earlier evolutionary process, namely, the process which resulted in the revolute foliage of arborescens. It would also be contrary to what one would expect from the data of geographic distribution. In North America the more primitive types of Haplopappus are toward the south, the derived types toward the north, but arborescens occurs only to the north of parishi. For these reasons the course of evolution here remains in doubt, as has been indicated on the phylogenetic chart, where the two species in question have been placed as coordinate divergent branches.

A connection with Chrysothamnus is suggested by the general habit and the nicely rounded, compact inflorescences. The most fundamental differences are found in the arrangement of the bracts of the involucre and in the more numerous flowers to each head (in parishi). It has been already shown that Chrysothamnus may have had its origin from somewhere near IIaplopappus sonoriensis, but it seems that in parishi there also persist some of the features which went into the makeup of this neighboring genus.

\section{ECOLOGY}

Haplopappus parishi is a rare shrub in the coastal sagebrush association of southern California and northern Lower California. It is nowhere dominant, but comes in sparingly on disturbed areas, especially near dry and stony streamways and on hot, exposed hillsides where the climax vegetation has been removed. The altitudinal distribution is from 600 to 1,500 meters and the zonal position is Upper Sonoran. The flowering season extends from August to October, although erratic blooming sometimes occurs as a result of rainfall at unusual seasons.

66. Haplopappus arborescens (Gray) Hall, Univ. Calif. Pub. Bot. $7: 273,1919$

A fastigiately branched erect usually round-topped shrub, 10 to $30 \mathrm{dm}$. high, the main stems of ten trunk-like and 5 to $15 \mathrm{~cm}$. thick; bark at first yellowish green, changing to brown, darker in age, firm but breaking and somewhat shreddy on old stems; twigs elongated, slender, leafy, striate, roughened by a resinous exudate which masks the pits, glabrous; principal leaves narrowly linear or closely revolute and thus becoming filiform, nearly straight, entire, acute, 3 to $6 \mathrm{~cm}$. long, $2 \mathrm{~mm}$. or less wide, thick, 1-nerved, conspicuously impressed-punctate, glabrous, much crowded but only rarely with a few shorter leaves fascicled in the axils; heads regularly cymose, the rounded cymes (1.5 to $5 \mathrm{~cm}$. across) terminating all branches, the ultimate peduncles 1 to $10 \mathrm{~mm}$. long, more or less bracteate with scales similar to those of the involucre; involucre turbinate, 4 to $5 \mathrm{~mm}$. high, 4 to $4.5 \mathrm{~mm}$. broad; bracts 20 to 25 , in 3 or 4 series, all much shorter than disk, very loosely imbricated, lanceolate, acute, thin and chaffy but with brown midrib, glabrous or obscurely puberulent; ray-flowers wanting (rarely an outer corolla slightly irregular and with abortive anthers); disk-flowers 20 to 25; disk-corolla with slender tube enlarging to a much broader throat, 4.7 to $5.5 \mathrm{~mm}$. long, puberulent on tube; lobes linear-lanceolate, acute, spreading, 1 to $1.2 \mathrm{~mm}$. long, glabrous; style-branches well exserted, about $1.5 \mathrm{~mm}$. long, the filiform or subulate appendage shorter than or scarcely equaling stigmatic portion; achenes $2 \mathrm{~mm}$. long, turgid, obtusely about 5-angled, 


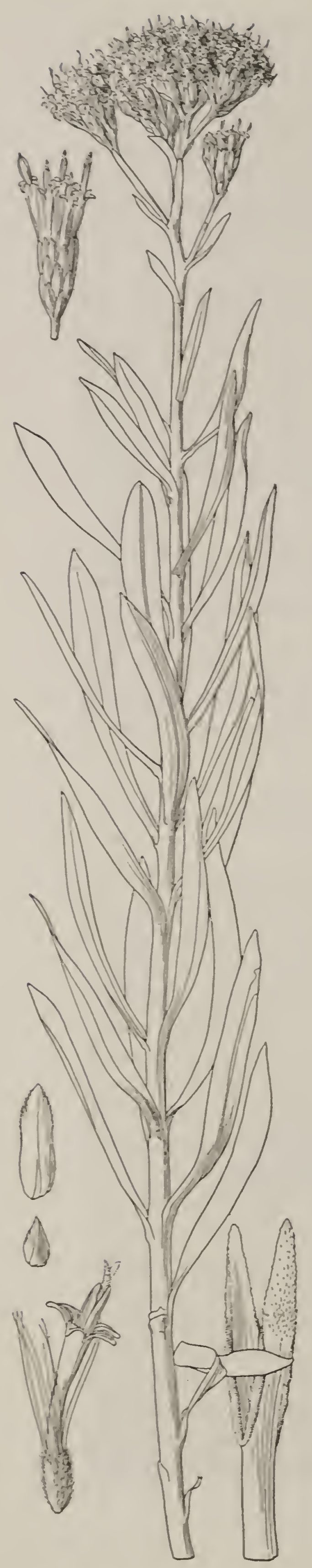

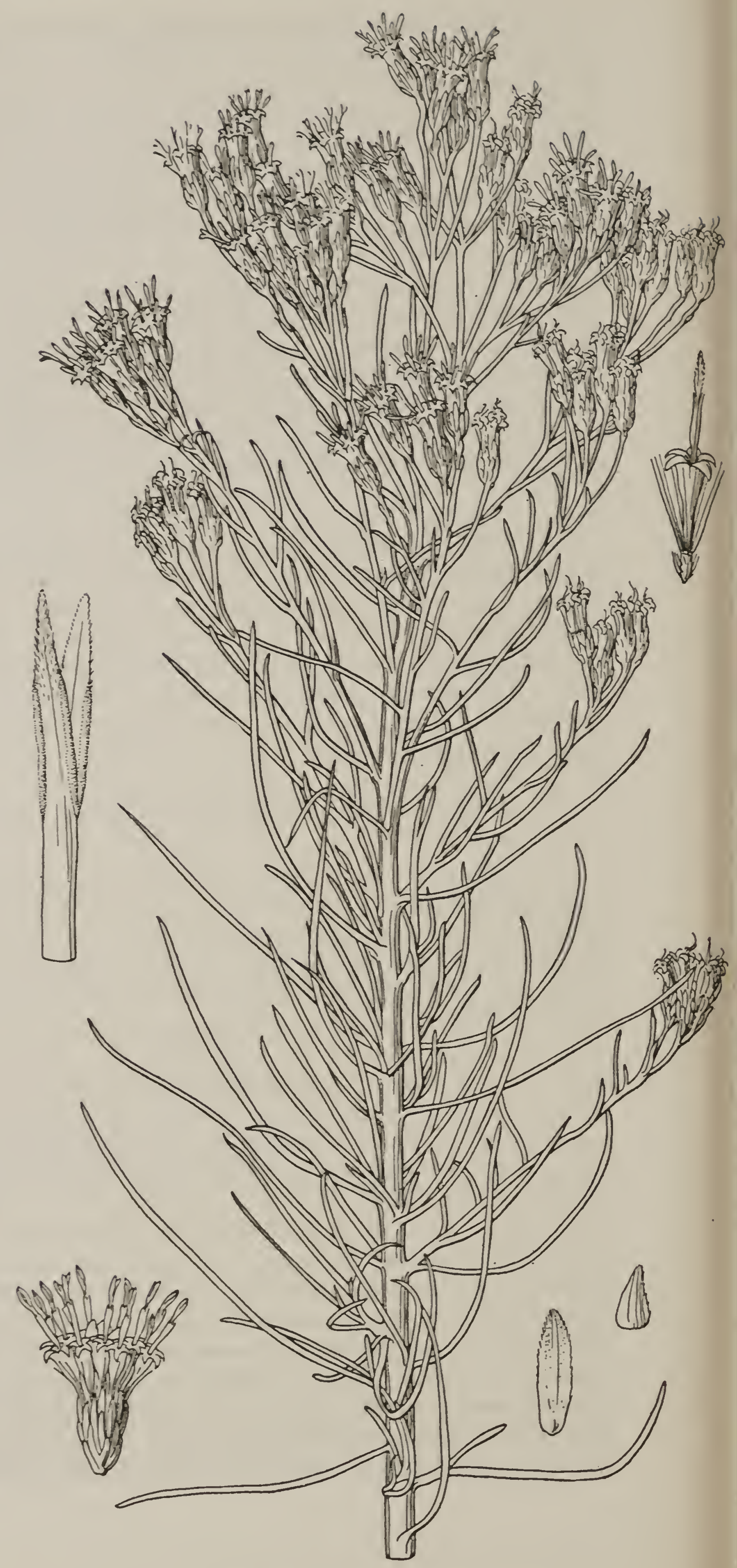

FIG. 103-Haplopappus arborescens 
narrowed to base, densely appressed-pubescent; disk-pappus exceeding corolla, slender, fragile, copious, dull white. (Linosyris arborescens Gray in Torr., Bot. Mex. Bound. 79, 1859.) (Fig. 103.)

California, in the Coast Ranges from the Oregon line to Santa Barbara County and on the westerly slopes of the Sierra Nevada at low altitudes. Type locality, California. Grant's Pass road, south of State line, Blake 10381 (US); near Cummings, Mendocino County, Tracy $612 \gamma$ (UC); Mount St. Helena, September 9, 1900, Eastwood (UC, US); Mount Tamalpais, Bolander 2609 (UC, US); dry mountains near Santa Cruz, California State Survey S17 (UC); Redwood, Santa Lucia Mountains, Palmer $19 \tau$ (UC); La Cumbre Peak, Santa Inez Mountains, Abrams 4317 (DS); Placerville to Eldorado, Abrams 6853 (DS); vicinity of Ione, Amador County, Braunton 1239 (UC, US); Big Oak Flat Road, above South Fork Tuolumne River, Hall 11 \%2S (UC); west of Princeton, Mariposa County, Ward 46 (US); East Fork Kaweah River, near Oak Grove, Tulare County, Hall and Babcock $5 \% 10$ (UC).

\section{SYNONYMS}

All of the following were based upon $H$. arborescens:

1. Aster chrysothamnus O. Kuntze, Rev. 315, 1891.

2. Bigelovia arborescens Gray, Proc. Am. Acad. 8:640, 1873.

3. Chrysoma arborescens Greene, Erythea 3:10, 1895.

4. Ericameria arborescens Greene, Man. Bot. Reg. S. F. Bay 175, 1894.

5. Linosyris arborescens Gray in Torr., Bot. Mex. Bound. 79, 1859.

\section{RELATIONSHIPS}

The perfectly cymose inflorescence, short involucres, and poorly developed appendages to the style-branches definitely place this species in the group with Haplopappus laricifolius and $H$. cooperi. It is more primitive than either of these if the large number of flowers is taken as a criterion, but it exceeds both in the practically complete elimination of ray-flowers. It is impossible, therefore, to place arborescens as a derivative of these, and it is equally impossible to consider it as antecedent to them. For such reasons it is taken as the beginning of an independent phylogenetic line with parishi as one of its branches.

The occurrence of ray-flowers in Haplopappus arborescens is looked upon as a case of reversion, but the phenomenon is so rare that no detailed studies have been made. It is even possible that the so-called ray-flowers are merely abortive and misshapen disk-flowers and thus have no phylogenetic significance.

\section{ECOLOGY}

This robust shrub is a decided xerophyte. In the Coast Ranges of California it associates with Eriodictyon californicum, Dendromecon rigidum, Garrya elliptica, and other species of disturbed areas, especially on burns. Here the surrounding chaparral is composed of such characteristic shrubs as Adenostoma fasciculatum, Ceanothus cuneatus, and several species of Arctostaphylos. In the foothills of the Sierra Nevada, where it is much less common, the ecologic sequence is the same, but the digger pine (Pinus sabiniana) is a more common associate in the climax. In both ranges the zonal position is Upper Sonoran and the altitudinal distribution from about 90 to 1,000 meters. The flowers appear from July to October. 
67. Haplopappus cuneatus Gray, Proc. Am. Acad. 8:635, 1873

A dwarf shrub, 1 to 5 or rarely $10 \mathrm{dm}$. high, intricately branched and flat-topped except when growing on exposed rocks, then often much reduced and irregular; bark changing from green to brown, ultimately becoming dark, firm, irregularly breaking on old stems; twigs either curved or straight, rather pliable, leafy, faintly ridged but not striate, glabrous, more or less glutinous when young, faintly or not punctate; principal leaves ascending or spreading, straight, cuneate oblanceolate or obovate, entire but inclined to be undulate, obtuse, often retuse and usually mucronate at summit, cuneate or spatulate at base, 0.5 to 1.5 or $2 \mathrm{~cm}$. long, 3 to $10 \mathrm{~mm}$. wide, thick, 1-nerved, mostly impressed-punctate, glabrous, resinous, rarely with small secondary leaves in the axils; heads in small compact cymes or some solitary, the ultimate peduncles 2 to $8 \mathrm{~mm}$. long; involucre turbinate, 5 to $7 \mathrm{~mm}$. high, 3 to $4 \mathrm{~mm}$. broad; bracts 20 to 30 , imbricated in about five series, all much shorter than disk, the inner ones linear-oblong and obtuse, the outer lanceolate acute and passing into minute scales of the peduncle, all chartaceous, but the inner with white membranous margins, the outer more or less greenish but none with herbaceous tips, all glabrous but sometimes resinous; ray-flowers 1 to 3 or usually wanting, the ligules when present less than $5 \mathrm{~mm}$. long, about $1 \mathrm{~mm}$. wide; disk-flowers 9 to 20 (usually 15 to 20 except in minor variation 2); disk-corolla with long slender tube and scarcely wider throat, 5.5 to $7 \mathrm{~mm}$. long, usually puberulent on tube; lobes lanceolate-attenuate, erect, 0.7 to $1 \mathrm{~mm}$. long, glabrous; style-branches long-exserted, about $2 \mathrm{~mm}$. long, the appendage usually a little shorter than stigmatic portion; achenes 2.5 to $3 \mathrm{~mm}$. long, slenderly prismatic, about 4-angled, silky-pubescent; pappus decidedly shorter than corolla, fragile, scanty, brown. (Fig. 104.)

Rocky slopes and summits from northern Arizona to Lower California, thence through upper California to the middle Sierra Nevada and the Inyo Range. Type locality, "California, in Bear Valley, alt. 4500 feet." Arizona: San Francisco Mountains, November 1, 1880, Greene (K, Gr, type collection of minor variation 2, Bigelovia rupestris); Union Pass, August 1870, Palmer (US); Santa Catalina Mountains, near Fort Huachuca, Lemmon 302h (Gr); Bear Stronghold, Rincon Mountains, Blumer 3493 (Gr, UC). Lower California: Ubi, May 8, 1889, Brandegee (UC). California: Jacumba, San Diego County, June 23, 1885, Cleveland (UC); Tantillas Cañon, San Diego County, 1875, Palmer (Gr, type of Bigelovia spathulata, minor variation 3); hear Tahquitz, San Jacinto Mountains, Hall 2327 (UC); Cucamonga Mountains, Parish 1027 (US, P, UC); Caliente Creek, Kern County, October 12, 1902, Merriam (SF, type of Chrysoma merriami, minor variation 6); near Keene Station, Tehachapi Pass, Hall 10962 (UC); Mount Whitney, Purpus 1510 (P, B); Tehipite Valley, Fresno County, Hall and Chandler 485 (UC); Santa Barbara County, June 1887, Ford (Gr); Yosemite, October 27, 1896, Congdon (UC); type collection, Bolander (Gr); Placer County, Carpenter 1893 (UC); Benton Range, Mono County, Hall 10648 (UC); Silver Cañon, Inyo Range, Hall 10632 (UC); Providence Mountains, May 26, 1902, Brandegee (UC); Slate Range, Inyo County, Coville and Funston 185 (US); Surprise Cañon, Panamint Mountains, Coville and Funston 599 (US). 


\section{MINOR VARIATIONS AND SYNONYMS}

Several forms have been taxonomically segregated from Haplopappus cuncatus, but there is no evidence that any of these represent evolutionary tendencies, except perhaps Chrysoma merriami. The form most commonly collected is one with discoid heads and may therefore be classed as No. 3 of the following list. Specimens from Arizona are sometimes small-lieaded and thus belong to variation 2. Broad-leaved plants from the borders of the California deserts are cared for under variation 6 . No floral or involucral characters have been found that can serve as a basis for these segregations, and since their distribution is erratic and intermediates common, their treatment as subspecies at this time would lead only to confusion.

1. Aster cuneatus O. Kuntze, Rev. 317, 1891-H. cuncatus.

2. Bigelovia rupestris Greene, Bot. Gaz. 6:183, 1881. Described from specimens "growing in dense hemisplerical tufts from crevices of perpendicular cliffs which crown the highest San Francisco Mountains in Arizona." The heads are discoid and described as about 12-flowered; the leaves as obovatelanceolate and $7 \mathrm{~mm}$. long. Similar small-leaved plants with only 9 to 12 flowers in a head are common in Arizona, but the leaves are even smaller in many collections from other places, notably the Sierra Nevada of California. The heads of these California plants with reduced foliage are sometimes discoid, sometimes radiate, and the number of disk-flowers often drops to 15 or perhaps lower. It seems very doubtful, therefore, if rupestris represents more than the chance combination of fluctuating characters.

3. B. spathulata Gray, Proc. Am. Acad. 11:74, 1876. This is the common eradiate form first separated on the basis of a collection from the entrance to Cantillas Grand Cañon, Lower California, but later united by Gray with cuneatus (Gray, Syn. Fl. 12:133, 1884). As far as known, radiate heads are found only in the Sierra Nevada from Yosemite north, and here both radiate and discoid forms occur. The ray-flowers, when present, are 1 to 3 in number and often misshapen. It seems that suppression of the ray has taken place over most of the area covered by the species, but that it still is incomplete in some localities, especially in the outlying districts toward the north. Other characters assigned to spathulata include broad leaves obscurely when at all punctate, non-carinate bracts of the involucre, and shorter silky achenes. The abundant material now at hand shows that these features are not concomitant among themselves nor with the absence of ray-flowers. The statement that the pappus is clavellate-thickened in cuneatus was doubtless due to an error in observation. No thickened bristles have been found in any of the available specimens, including the type.

4. Chrysoma cuneata Greene, Erythea 3:11, 1895-H. cuneatus.

5. C. cuneata spathulata Greene, 1. c. Based upon Bigelovia spathulata, which see.

6. C. merriami Eastw., Bull. Torr. Club $32: 215$, 1905. This was described from specimens gathered at Caliente Creek, Kern County, California. It was said to differ from typical cuneatus chiefly in its larger leaves, larger, rayless heads, and less densely hairy achenes. The leaves are obovate and, in their best development, are 1.5 or even $2 \mathrm{~cm}$. long by 10 or $12 \mathrm{~mm}$. wide. When attention is focused upon the broad leaves alone, this becomes a recognizable form of the mountains bordering the deserts of southern and Lower California (see references among specimens cited). This suggests that merriami may be a geographic race or subspecies occupying a central area surrounded by typical cuneatus. There are, of course, all gradations in size of leaf. Moreover, some of the broadest-leaved plants have very small heads (Colorado Desert, November 1887, Orcutt), and the achenes are variable in the density of their pubescence, so that these features can not be satisfactorily used as substantiating criteria.

7. Ericameria cuneata McClatchie, Erythea 2:124, 1894-II. cuneatus.

8. E. cuneata spathulata Hall, Univ. Calif. Publ., Bot., 3:52, 1907. Based upon Bigelovia spathulata, which see.

9. Haplopappus cuneatus spathulatus Blake, Contr. U. S. Nat. Herb. 23: 1849, 1926. Based upon Bigelovia spathulata, which see. 


\section{RELATIONSHIPS}

There is no obvious connection between this and any other species. The strongly punctate leaves, the involucre, and the relatively short appendages to the style-branches all throw it definitely into the section Ericameria. Here it is plainly of the group with cymose inflorescences, but in leaf-shape it is very different from any of the others except Haplopappus vernicosus, from which it differs radically in size of heads and in the entire leaves.

In growth-form and in general appearance, as also in involucres, it resembles species of the section Asiris, especially the larger forms of Haplopappus nanus, but the poorly developed stylar appendages, as well as the impressed-punctate foliage indicate that the natural relationship is not very close. It is more probable that similar environmental conditions have resulted in a parallel development of superficial features and that this is responsible for the resemblance between cuneatus and members of the section Asiris.

\section{ECOLOGY}

This low shrub is one of the first to colonize rock surfaces after there has been sufficient weathering to afford a foothold. Under these conditions it is much depressed and of irregular growth, but when in open gravelly soil, as at the foot of cliffs, it sometimes attains a height of a meter and may be broader than high. It belongs essentially to the Upper Sonoran Life-zone and more particularly to exposed rocky places in the piñon-juniper woodland. On the west slopes of the Sierra Nevada it grows in the essentially similar belt of Pinus sabiniana, while both here and on the coastal slope of southern California it is of frequent occurrence on rock ledges in the upper part of the subclimax chaparral. At its upper distributional limits, in both California and Arizona, it invades the next higher belt of Pinus ponderosa and because of this is sometimes said to belong also to the Transition Zone. But the small rocky areas which it here inhabits are warmer than the surrounding forest of pine and, therefore, may be considered as Upper Sonoran "islands." At any rate, they often support peculiar mixtures of species from the upper and lower zones. The shrubs are in flower from September to December.

68. Haplopappus vernicosus Brandegee, Proc. Calif. Acad. II, 2:168, 1889

A dwalf shrub, 3 to $5 \mathrm{dm}$. high, with slender intricate branches forming clumps; bark brown, darkening on lower parts; twigs curved, brittle, leafy up to heads, sharply angled from leaf-margins and midrib downward, glabrous, very resinous and granular; principal leaves widely spreading or upcurved, cuneate-obovate or cuneate-oblanceolate, with 2 to 7 spinulosetipped teeth, the triangular apex rigidly mucronate, the entire petiole-like base wide at insertion and narrowly decurrent, 6 to $9 \mathrm{~mm}$. long, 4 to $5 \mathrm{~mm}$. wide, thick, 1-nerved, impressed-punctate but pits obscured by abundant resin, glabrous, mostly with minute secondary fascicled leaves in the axils; heads mostly in glomerules of three, each glomerule terminating a short lateral peduncle (this 3 to $15 \mathrm{~mm}$. long), some heads solitary in axils, mostly equaled or exceeded by subtending leaves; involucre cylindric- 
turbinate, 5 to $6 \mathrm{~mm}$. high, 3 to $4 \mathrm{~mm}$. broad; bracts about 20 , imbricated in 4 or 5 lengths, the longest nearly equaling disk, oblong, obtuse, the inner ones thin and stramineous, the outer with greenish resinous-punctate tips, mostly ciliate; ray-flowers 3 to 5 , fertile, the ligule about $2 \mathrm{~mm}$. long by $1 \mathrm{~mm}$. broad; disk-flowers 4 to 7 (sterile?); disk-corolla nearly cylindric, about $5 \mathrm{~mm}$. long, puberulent; lobes ovate, acute, about $0.6 \mathrm{~mm}$. long,

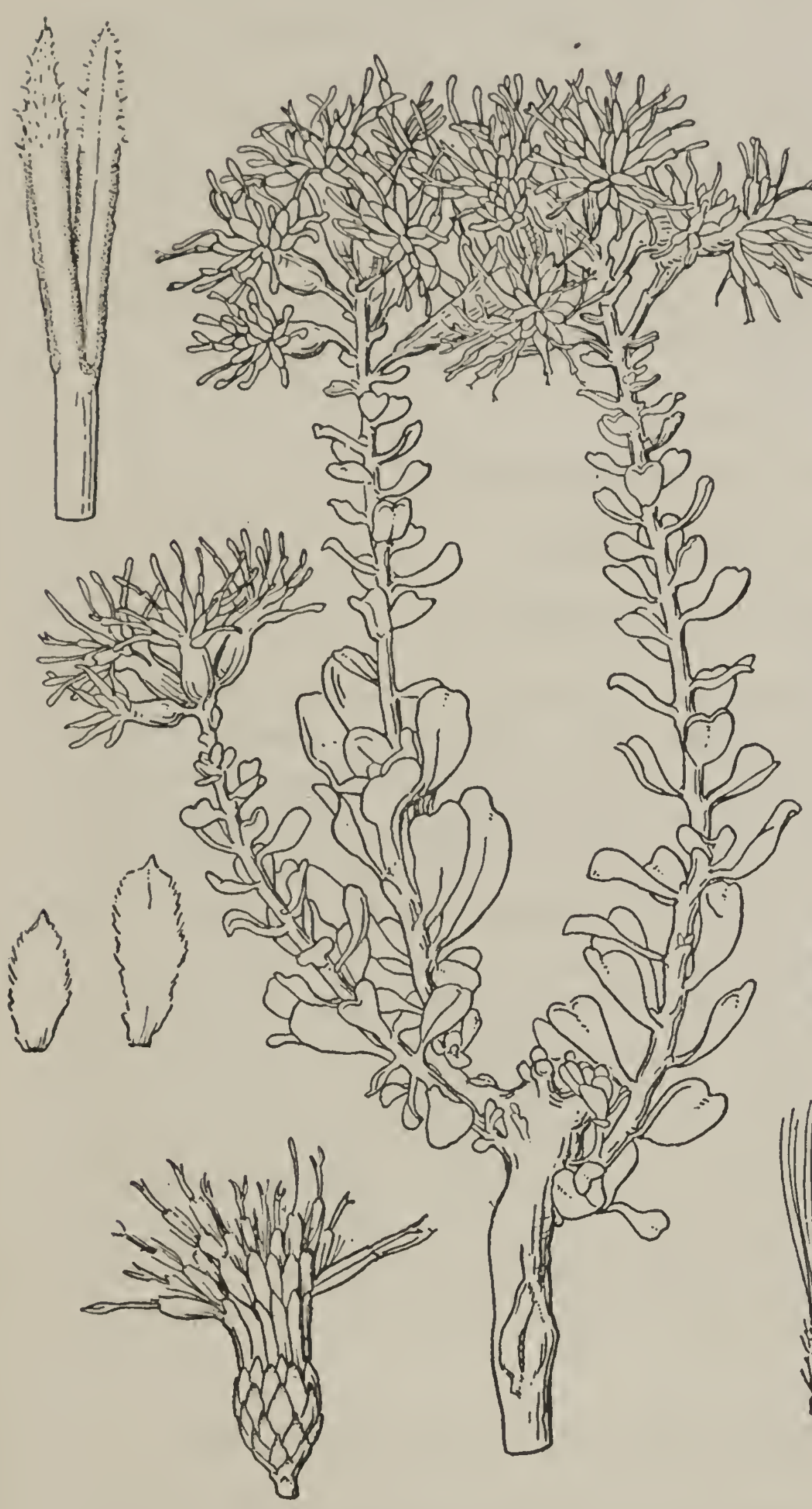

Fig. 104-Haplopappus cuncatus

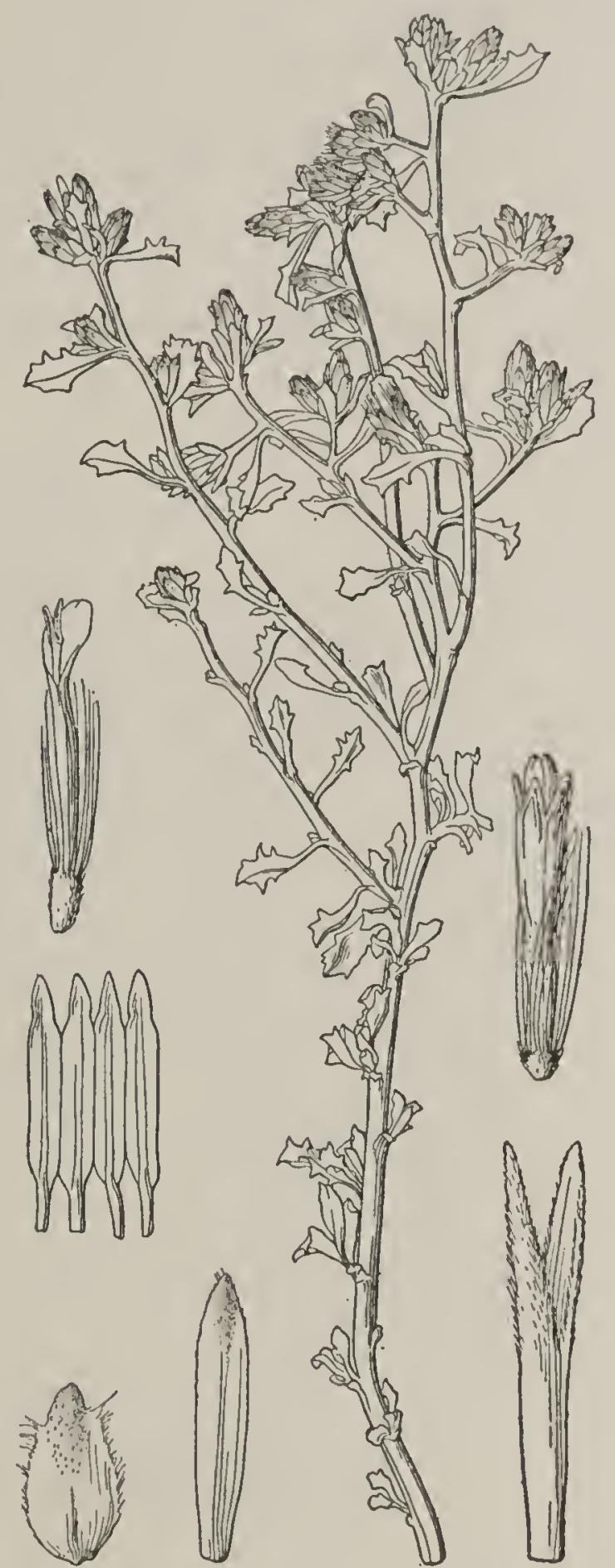

FIG. 105-Haplopappus vernicosus

slightly puberulent; style-branches of disk-flowers (as far as known) acute, pubescent on back for their entire length, with no sharp distinction between stigma and appendage; achenes obscurely angled, truncate, densely silky, those of the ray about $1 \mathrm{~mm}$. long (young), of the disk $0.5 \mathrm{~mm}$. or less; pappus shorter than corolla, rather sparse, fragile, brown. (Fig. 105.)

Known only from the type collection, this from El Rosario, Lower California, May 20, 1889, Brandegee (UC, Gr, the former the type). 


\section{RELATIONSHIPS}

The herbage of Haplopappus vernicosus is not so clearly impressedpunctate as in other Ericamerias, but this may be due in part to the abundant resinous exudate which flows over the surface and masks the depressions. This poor development of the resin-pits would cast some doubt upon the sectional placing of the species were it not that in certain other features it exhibits an affinity with $H$. cuneatus. The similarities include habit, leafshape, and especially the short, brownish pappus. The material at hand is too scanty and young to permit of a definite conclusion as to the achenes and style-branches, but it seems that only the ray-flowers are fertile, those of the disk being reduced to minute, turbinate bodies, apparently without embryos. This may account for the absence of a differentiation of the style-branches of the disk-flowers into stigmatic and sterile portions. Most of the flowers, however, have been injured by insects, so that an exact determination of these points is not at present possible.

\section{ECOLOGY}

Nothing is known of the ecology of this rare species.

\section{SECTION 16. ASIRIS}

\section{PHYLOGENY OF THE SPECIES}

The species of this section fall naturally into three groups, as indicated by the main lines of the accompanying chart. The first group exhibits a conspicuous pubescence and one of its species, Haplopappus watsoni, has larger heads and more numerous flowers than are found elsewhere in the section. This is assumed to indicate primitiveness and watsoni is therefore placed first in the sequence. This species appears to be a relict of the mountain ranges of Nevada, while its nearest relative, $H$. rydbergi, is a more modern type of the mountains of northern Utah. The second group consists of forms with little if any true pubescence, and narrow, fewflowered heads. Haplopappus cervinus perhaps gave rise directly to the more northern and more abundant $H$. nanus through reduction in foliage and inflorescence. On the other hand, $H$. resinosus, a species inhabiting a portion of the area occupied by nanus, possesses both primitive and specialized features and is therefore looked upon as a remnant of an older line. So little is known of the Mexican $H$. purpusi that one can only guess at its phylogenetic position.

\section{Haplopappus watsoni Gray, Proc. Am. Acad. 16:79, 1880}

A subshrub, 1 to $3 \mathrm{dm}$. high, irregularly branched and spreading close to the ground; bark yellowish brown, becoming gray and broken on old stems; twigs becoming brittle, leafy, striate from the leaf-bases, not pitted, coarsely pubescent, the hairs spreading and gland-tipped; principal leaves oblanceolate to broadly spatulate, ascending, entire, obtuse but prominently cuspidate, 1 to $2.3 \mathrm{~cm}$. long, 3 to $7 \mathrm{~mm}$. wide, 1-nerved, rather thin, glandular-pubescent on both faces but not punctate, the glands always stalked, only rarely with secondary leaves in the axils; heads few in each loose terminal cyme or solitary, the ultimate peduncles 1 to $10 \mathrm{~mm}$. long; in- 
volucre turbinate to campanulate, 6 to $8 \mathrm{~mm}$. high, 4 to $6 \mathrm{~mm}$. broad; bracts 25 to 30, loosely imbricated, in about 4 series, the outer ones usually shorter but one or more of these commonly loose, foliaceous, sometimes exceeding the inner and resembling uppermost leaves, the principal bracts linear-lanceolate, attenuate, or some of the inner ones abruptly short-acute, chartaceous, some green and glandular on exposed parts; ray-flowers 4 to 8 , the broadly elliptic ligules 5 to $7 \mathrm{~mm}$. long, about $2 \mathrm{~mm}$. wide; disk-

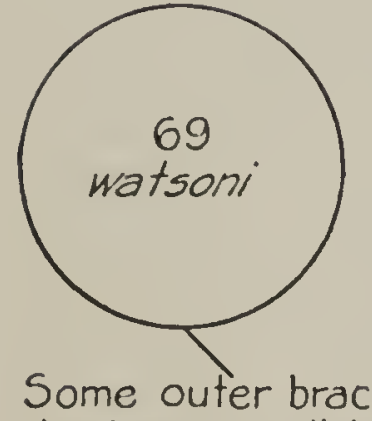

Some outer bracts fls. $20-25$

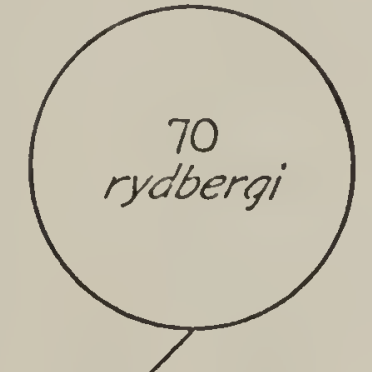

Bracts all chartaceous: diskfls. $10-15$

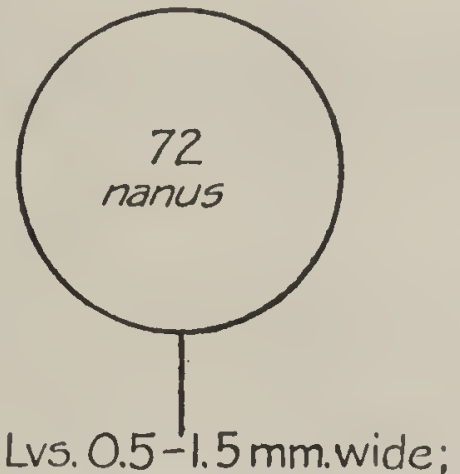

Lvs. 0.5-1.5 mm.wide

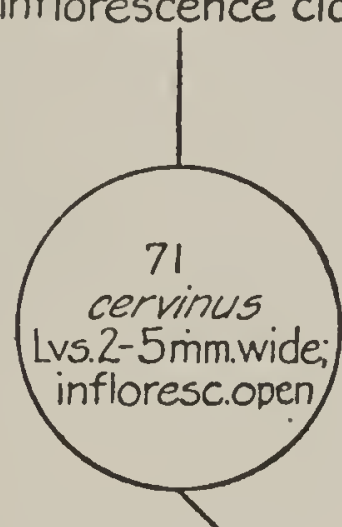

Disk-fls. 4-11; lobes less than Imm. long

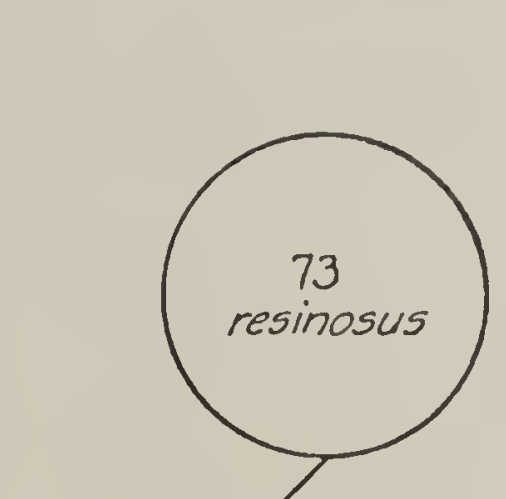

Disk-fls. I1-16; lobes $1-2 \mathrm{~mm}$.

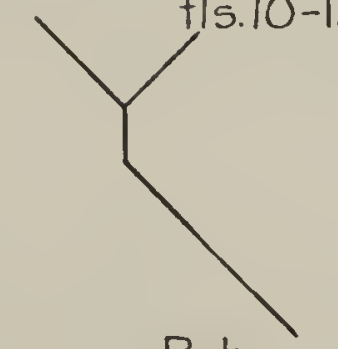

Pubescent and stipitate-glandular long

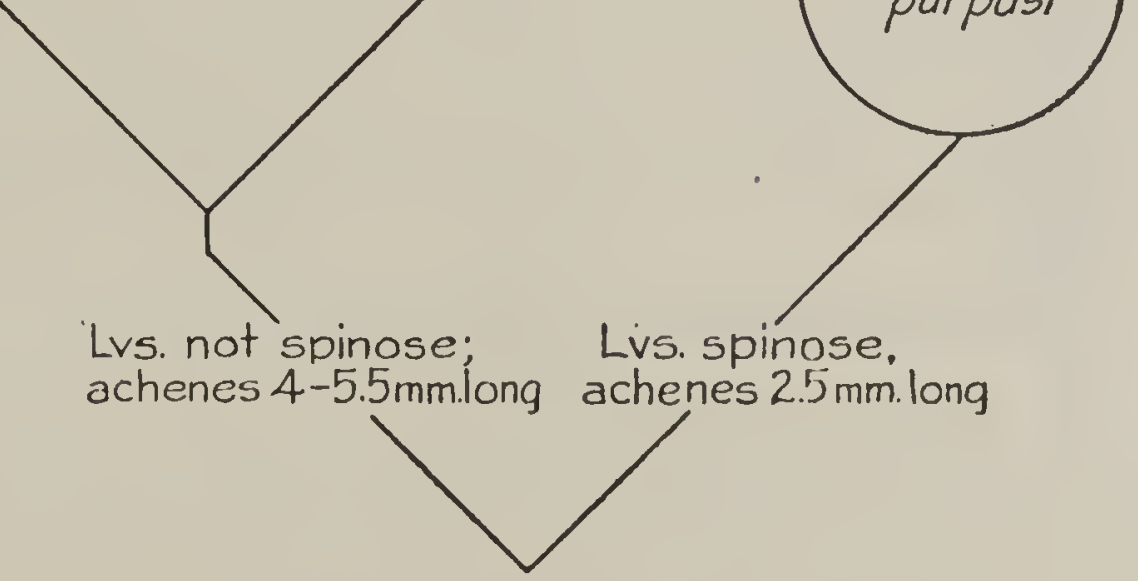

FIG. 106-Phylogenetic chart of the species of Haplopappus section Asiris

flowers 15 (?) to 25; disk-corolla subcylindric, slightly enlarged upward, 5.5 to $7 \mathrm{~mm}$. long, coarsely puberulent to glabrous on tube; lobes 0.5 to $1.2 \mathrm{~mm}$. long, lanceolate, erect, glabrous; style-branches well exserted, 2 to $3 \mathrm{~mm}$. long, the subulate appendage longer than stigmatic portion; achenes slenderly prismatic, about $4 \mathrm{~mm}$. long (immature), pubescent with rigid ascending hairs; pappus mostly longer than corolla, fragile, scanty, brown. (Fig. 107.) 
In the mountains of eastern Nevada, perhaps also in adjacent Utah or Arizona. Type locality, northern Nevada. Nevada: type collection, Fremont's Pass, Humboldt Mountains, "7000 feet," Watson 572 (Gr); Camp Halleck, Palmer 203 (Gr, UC, Boiss, Po); among granite rocks, Table Mountains, Purpus 6389 (UC, US, P, K); Reveille Range, Purpus 6346 (UC, P, K); Fish Creek, near Eureka, August 1885, Brandegee (Gr); Morey Peak, Purpus 6361 (UC).

\section{SYNONYMS}

1. Aster serenoi O. Kuntze, Rev. 317, 1891-H. watsoni.

2. Macronema watsoni Greene, Erythea $2: 74,1894-H$. watsoni.

\section{RELATIONSHIPS}

This species was originally confused with Haplopappus suffrutescens, of the section Macronema, doubtless because of the habit and the herbaceous development of a few of the outer bracts of the involucre. But the heads are much too narrow and the flowers too few for that section and there is no evidence of a connection with any of its species. It seems, therefore, that Gray was right in his opinion that it is nearer to nanus (Gray, Syn. Fl. $\left.1^{2}: 135,1884\right)$. When the herbaceous character of the bracts is poorly developed the plants can scarcely be distinguished from some forms of nanus, except by the notable stipitate-glandular pubescence. Since all the other species of the section Asiris have chartaceous bracts, the herbaceous ones of watsoni can be accounted for only as a reversional trait or as a relict from some unknown ancestor outside the section. This latter hypothesis gains support from the fact that the species is perhaps the most primitive of its section, as is suggested by the comparatively large number of flowers and the correspondingly broader heads.

\section{ECOLOGY}

Haplopappus watsoni is a low, closely branched subshrub confined to rocky places and crevices of the mountains of the Great Basin at altitudes of about 1,500 to 2,100 meters. The roots draw upon soil moisture conserved by the rocky covering, but the tops are often fully exposed to the sun. In keeping with the arid habitat, the herbage is more coarsely and densely pubescent and more glandular than in related species. Flowering plants have been collected from July 25 to October 7 .

70. Haplopappus rydbergi Blake, Contr. U. S. Nat. Herb. 25:545, 1925

A subshrub, 2 to $4 \mathrm{dm}$. or more high, irregularly and rigidly branched to form rounded or flat-topped bushy plants; bark at first pale brown, changing to ash-colored, in age dark and breaking irregularly; twigs very brittle, conspicuously pubescent and stipitate-glandular when young; principal leaves broadly oblanceolate to obovate, entire (the margins more or less undulate), cuspidate or pungently acuminate at apex, attenuate to base, 1 to $2.5 \mathrm{~cm}$. long, 5 to $10 \mathrm{~mm}$. wide, 1-nerved or 3-nerved, rather thin, densely puberulent on both faces, most of the hairs gland-tipped, not punctate, occasionally a few small secondary leaves in the axils; heads in small loose terminal cymes or rarely solitary, the ultimate peduncles 1 to $7 \mathrm{~mm}$. long; involucre cylindric-turbinate, 7 to $8 \mathrm{~mm}$. high, 3 to $4 \mathrm{~mm}$. broad; 
bracts about 25 , regularly imbricated in about 5 series, all shorter than disk, the outer ones linear-acuminate and with straight or spreading tips, the inner ones linear-oblong and abruptly acute, mostly chartaceous and glabrous but at least the short outer ones tinged with green and sometimes glandular-puberulent; ray-flower's 5 to 10 , the broadly elliptic or oblance-

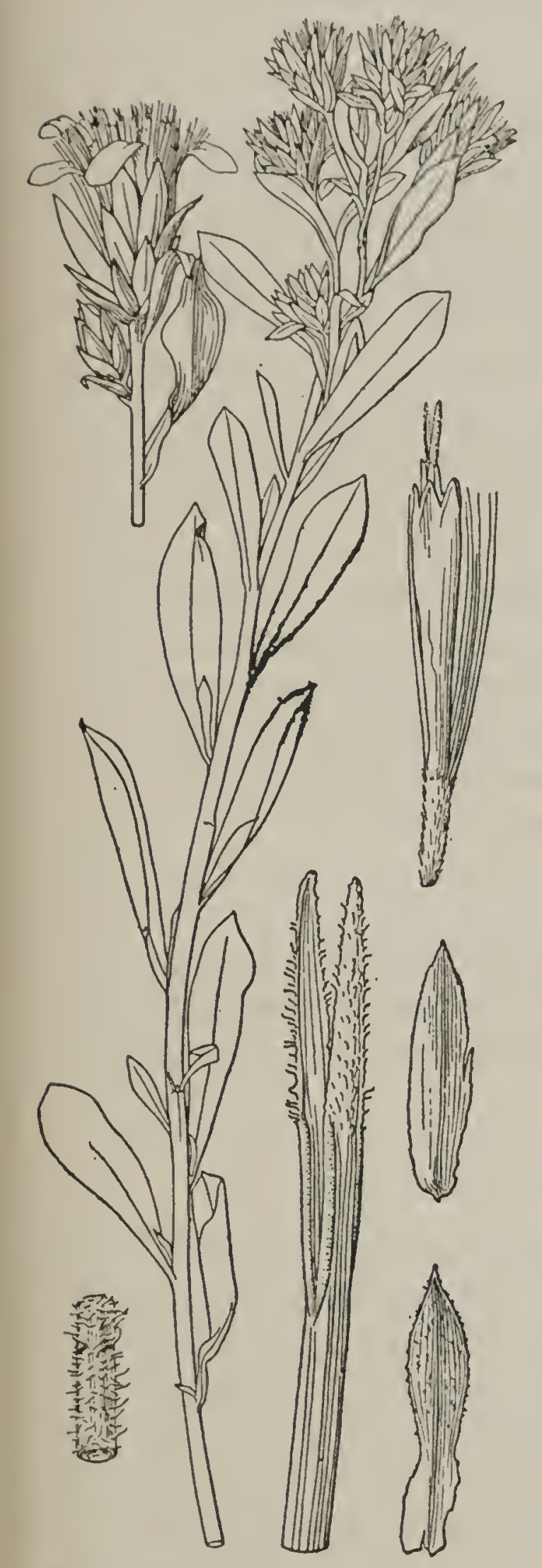

FIG. 107-Haplopappus watsoni

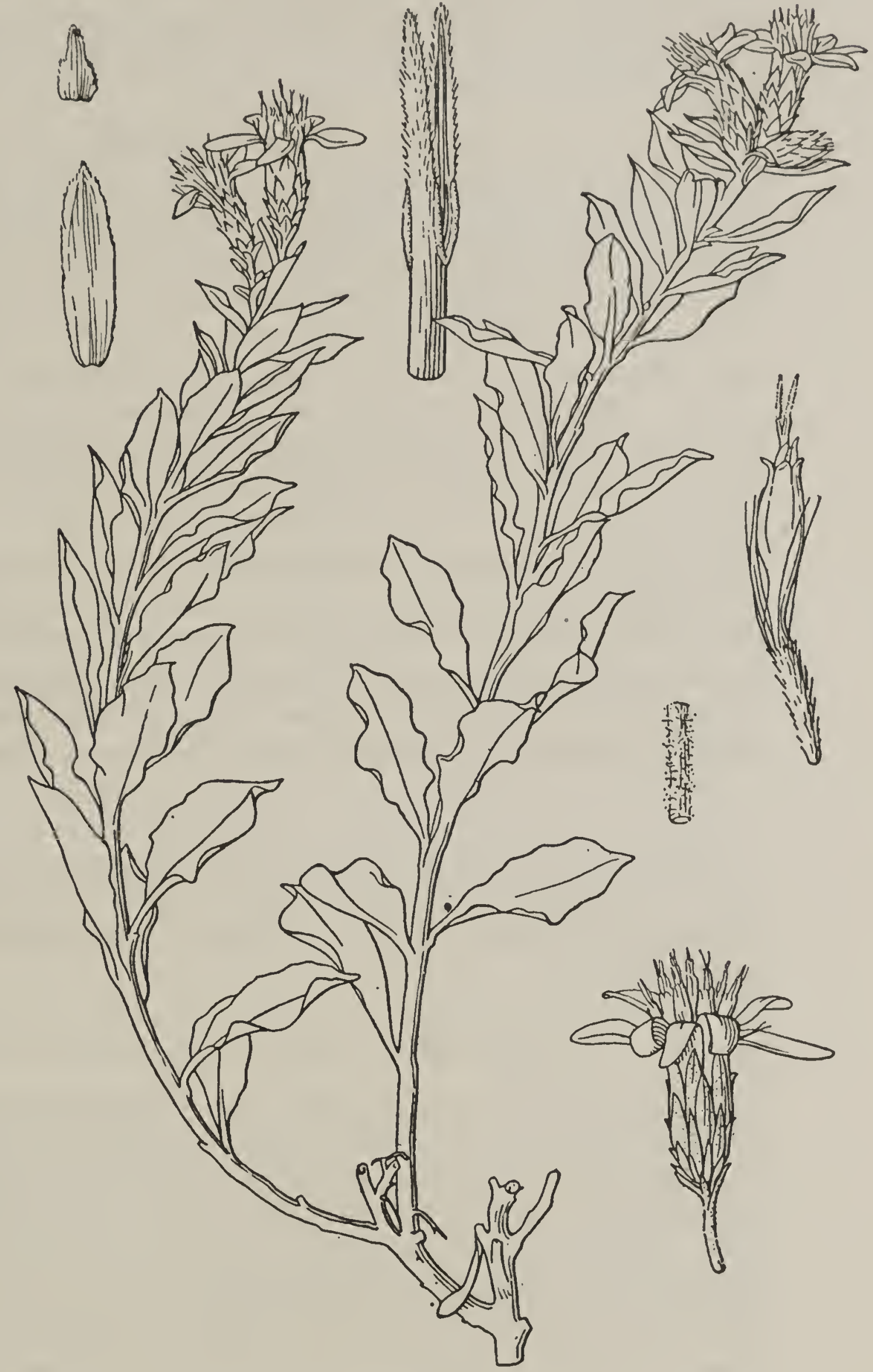

Fı. 108-Haplopappus rydbergi

olate ligules 4 to $6 \mathrm{~mm}$. long, 1.5 to $2 \mathrm{~mm}$. wide; disk-flowers 10 to 15 or apparently sometimes only 5 to 10 ; disk-corolla gradually tapering downward from the slender throat, 5.5 to $6.5 \mathrm{~mm}$. long, glabrous or tube sparsely puberulent; lobes 0.5 to $0.8 \mathrm{~mm}$. long, ovate, erect, glabrous; style-branches long-exserted, 1.5 to $2 \mathrm{~mm}$. long, the subulate appendage about twice as long as stigmatic portion; achenes about $4 \mathrm{~mm}$. long (immature), nearly prismatic, faintly about 4-angled, rather sparsely appressed-pubescent; 
pappus about as long as corolla, fragile, scanty, pale brown. (Macronema obovatum Rydb., Bull. Torr. Club 27:618, 1900, not Haplopappus obovatus Phil., 1894.) (Fig. 108.)

Restricted to cañons in the Wasatch Mountains, northern Utah. Type locality, City Creek Cañon, at 1,600 meters altitude. Utar: Weber Cañon, September 13, 1919, Hall (UC); type collection, Jones 1081 (NY, US, B, BM); Parley's Cañon, back of Salt Lake City, Jones 510 (UC); near Garfield, August 21, 1912, Jones (UC, Po); East Bountiful, September 22, 1909, Clemens (Po, NY).

\section{RELATIONSHIPS}

Until recently this species has been confused with both Haplopappus watsoni and H. cervinus. From the former, with which it shares the unusual character of a stipitate-glandular pubescence, it is at once distinguished by the uniform absence of herbaceous outer bracts and the narrower heads with only 5 or 10 to 15 disk-flowers. There are also differences in habit and foliage, such as the very brittle twigs and undulate leaves of the present species. The leaves are often wider than in the type of $H$. watsoni and the inner bracts are more often abruptly acute, but that species is itself so variable in these characters that they do not constitute positive criteria. Haplopappus cervinus is a much smoother plant with very obscure if any true pubescence. It entirely lacks the stipitate glands of $H$. rydbergi, but the small globules of resin sometimes so constrict themselves at base as to simulate these. As here defined, the three species under discussion occupy each its own geographic range; $H$. watsoni on the mountains of Nevada (possibly reaching the borders of Utah or Arizona), H. rydbergi in northern Utah, and $H$. cervinus in southern Utah and adjacent Arizona.

\section{ECOLOGY}

This is a species of mountain cañons at moderate altitudes, that is, near the lower edge of the belt of Pinus ponderosa. It grows in rocky situations, but, as far as known, is not a cliff plant. The flowers appear from August to October.

\section{Haplopappus cervinus Wats., Am. Nat. $7: 301,1873$}

A subshrub, 1 to $4 \mathrm{dm}$. high, with numerous openly spreading and ascending branches, the whole forming a globoid or flat-topped bushy plant; bark light brown, darkening in age and then irregularly breaking; twigs straight or ascending, rather pliable, leafy, not striate but with faint ridges from each leaf-base, not pitted, glabrous but roughened by the resinous exudate; principal leaves oblanceolate (broadly so in type), straight or curved-ascending, entire, rigidly acute or cuspidate at apex, attenuate to base, 1 to $2.5 \mathrm{~cm}$. long, 2 to $5 \mathrm{~mm}$. wide, with prominent midrib and usually 2 faint nerves from base, without resin dots, glabrous but resinous-scabrid, the secondary fascicled leaves obsolete; heads few in each very open terminal cyme, the ultimate peduncles 3 to $10 \mathrm{~mm}$. long; involucre cylindricturbinate, 7 to $8 \mathrm{~mm}$. high, about $4 \mathrm{~mm}$. broad; bracts about 25 , imbricated in about 5 series, all shorter than disk, the outer ones linear-acuminate and with straight or spreading tips, the inner ones linear-oblong, acute or cuspidate with short erect tips and more or less erose or lacerate, all char- 
taceous or the short outer ones tinged with green, glabrous but resinous; ray-flowers about 5 to 7 , the oblanceolate ligules 3 to $4 \mathrm{~mm}$. long, scarcely $1 \mathrm{~mm}$. wide; disk-flowers 5 to 11 ; disk-corolla gradually enlarging from the broad tube to a scarcely broader throat, the whole 6 to $8 \mathrm{~mm}$. long, glabrous or the tube sparsely puberulent; lobes ovate, erect, 0.5 to $0.8 \mathrm{~mm}$. long, glabrous; style-branches long-exserted, 1.5 to $2 \mathrm{~mm}$. long, the subulate appendage about twice as long as stigmatic portion; achenes about $4 \mathrm{~mm}$. long (immature), nearly prismatic, faintly about 4-angled, rather sparsely appressed-pubescent; pappus about as long as corolla, fragile, scanty, pale brown. (Fig. 109.)

Lower mountains of southern Utah and northern Arizona. Type locality, Antelope Cañon, Utah. UTAн: type collection, 1872, Wheeler (Gr); Clear Creek Cañon, Jones 6106 (UC, doubtfully placed here, the peduncles very short). Arizona: head of Bright Angel Trail, Grand Cañon, Hall 11191 (UC); Grand View, Grand Cañon, Hall 11190 (UC).

\section{SYNONYMS}

1. Ericameria cervina Rydb., Fl. Rocky Mts. 853, 1917-H. cervinus.

2. Haplopappus nanus var. cervinus Gray, Syn. Fl. $1^{2}: 134,1884-H$. cervinus.

\section{RELATIONSHIPS}

This species is so close to Haplopappus nanus that perhaps the two were better taken as one, as has been done by Gray. It is easily distinguished, however, by the broader and longer leaves, by the much more open inflorescence, and by the somewhat larger heads. So few collections have been made that little is known concerning its habit, but, at least as far as plants from the Grand Cañon of the Colorado are concerned, the stems are much more numerous and spreading than in nanus and the whole plant gives less evidence of reduction. Whether treated as a distinct species or as a subspecies under nanus, there is little doubt that the latter is a derivative by reduction. This change has doubtless come about as a response to a more xerophytic habitat, for although it has a more northerly distribution, nanus grows in more exposed and more arid situations. The effect of this is reflected in the reduced foliage, compact habit, and smaller number of flowers.

The type specimen of Haplopappus cervinus is so fragmentary that detailed studies of the heads, especially as to number of flowers, is scarcely possible. But it almost certainly belongs specifically with the other specimens cited and these latter have been chiefly used in drawing up the foregoing description. The only obvious difference is in shape of leaves. In the type some of these are so broad $(5 \mathrm{~mm}$.) as to approach obovate, while others are only oblanceolate. Most of them show evidence of crinkling or of undulate margins. In the other specimens cited the leaves are narrowly oblanceolate ( 2 to $4 \mathrm{~mm}$. wide) and plane.

\section{ECOLOGY}

Haplopappus cervinus belongs to the upper part of the belt of Pinus edulis and Artemisia tridentata. In Arizona it grows with these species along the south rim of the Grand Cañon of the Colorado at altitudes of 2,000 to 2,300 meters. Here it occurs scatteringly among limestone rocks, and although the plants are 2 to $4 \mathrm{dm}$. high and several times as broad where the 
soil is loose, they are much condensed when growing from crevices in the rock itself. Collections in full bloom were made here in late September.

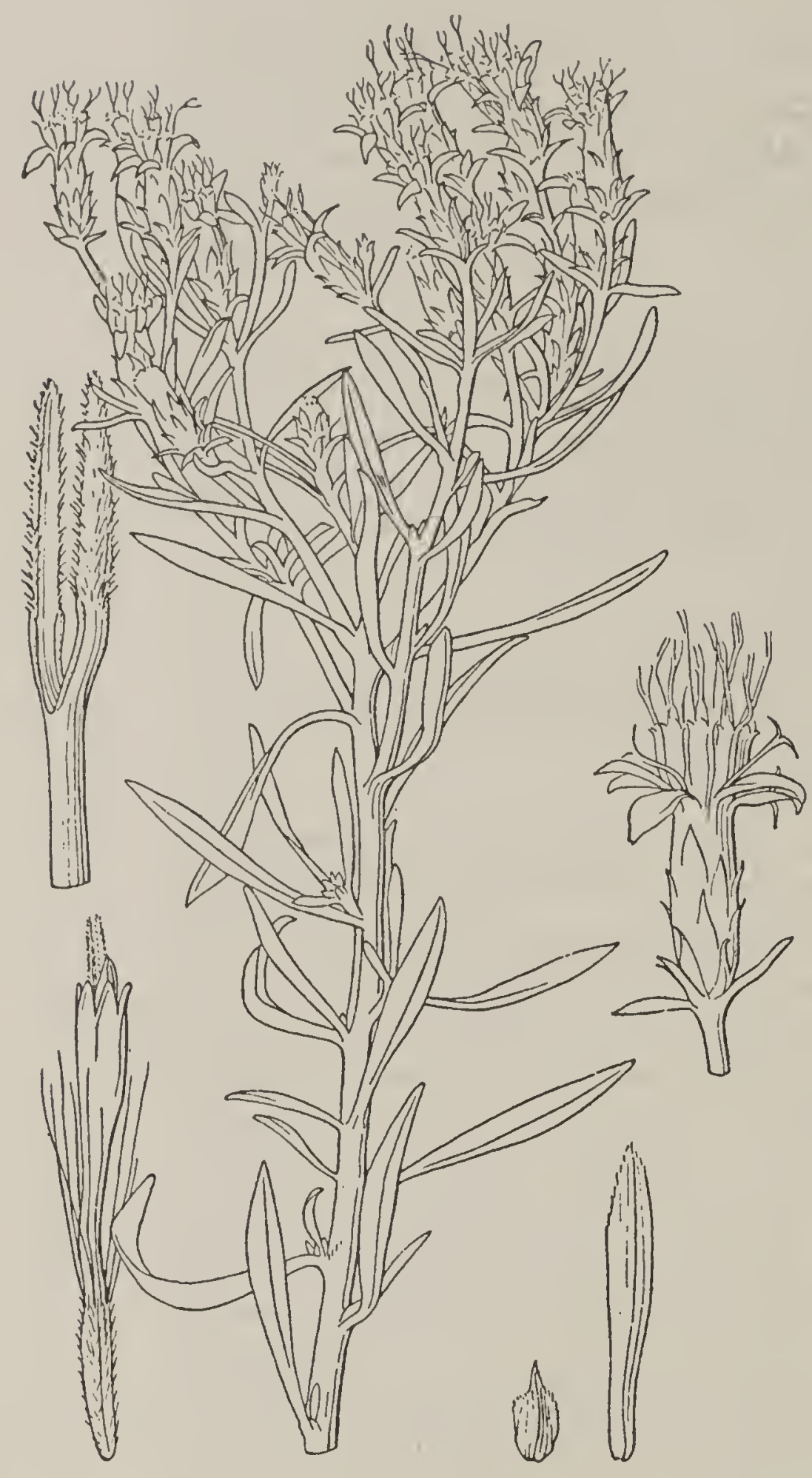

FIg. 109-Haplopappus cervinus

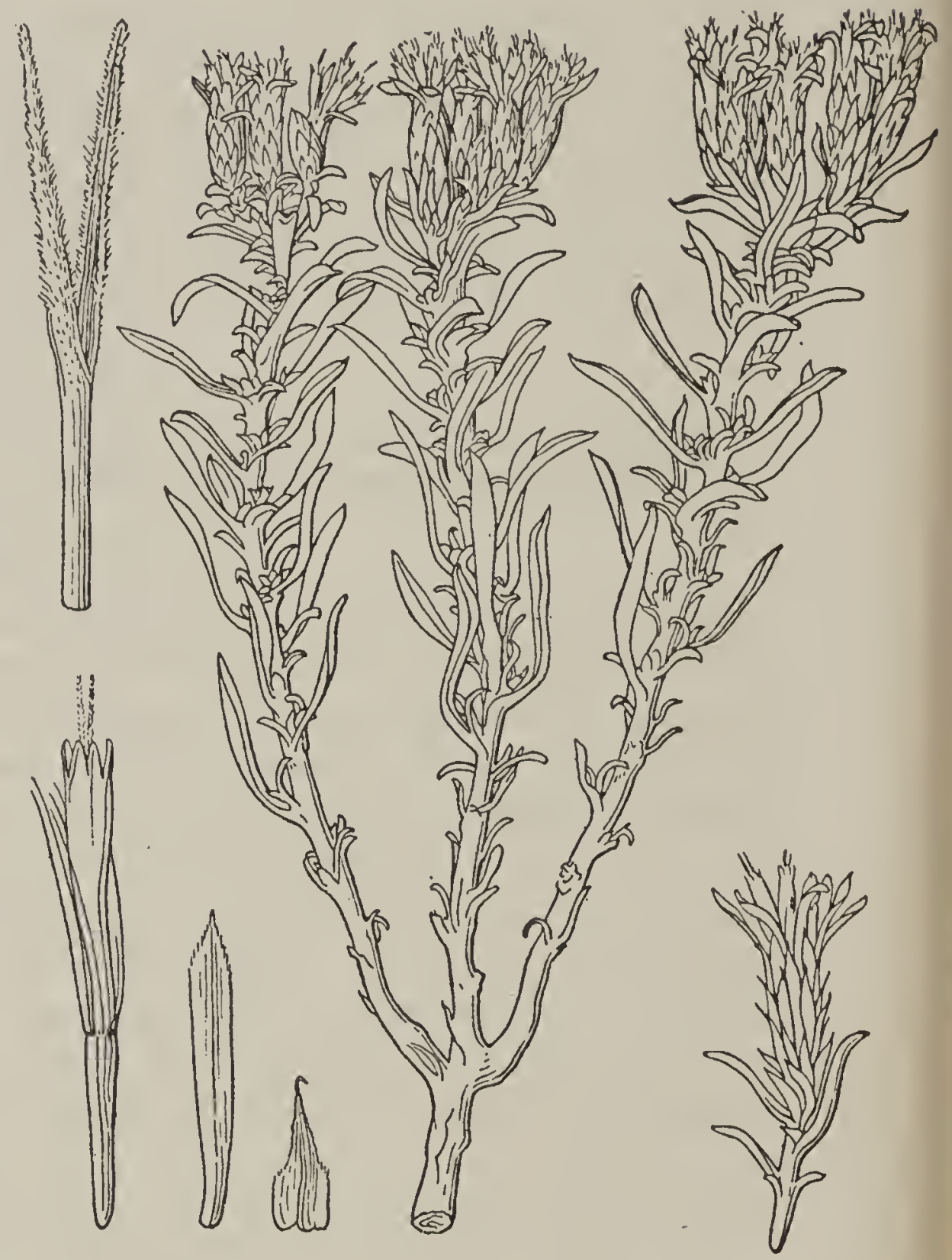

FIG. 110-Haplopappus nanus

72. Haplopappus nanus (Nutt.) D. C. Eaton, Bot. King's Expl. 159, 1871

A compact dwarf shrub, 1 to $5 \mathrm{dm}$. high, with numerous short gnarled thick branches forming round-topped or flattish small bushes; bark soon changing from brown to dark gray or black and becoming thick, irregular, and resinous-corky; twigs short, irregularly spreading or curved, brittle, leafy, not striate but with grooves running down from leaf-bases, not pitted, glabrous, resinous; principal leaves linear or very narrowly spatulate, variously curved or rarely straight and ascending, entire, acute, 1 to $1.5 \mathrm{~cm}$. long, 0.5 to $1.5 \mathrm{~mm}$. wide, the midnerve obscure, the edges commonly upturned, entirely devoid of impressed resin-dots, glabrous, more or less glutinous, thick, usually with very short or poorly developed secondary leaves fascicled in the axils; heads in small compact leafy terminal cymes, these sometimes reduced to solitary heads, the ultimate peduncles very short or 
wanting; involucre turbinate, 5.5 to $7.5 \mathrm{~mm}$. high, 3 to $4 \mathrm{~mm}$. broad; bracts about 22 to 30 , loosely imbricated in 4 or 5 series, the inner nearly as long as disk, lanceolate, acute or acuminate, pale and chartaceous but at least the outer ones with green middle portion, this light brown in drying, glabrous; ray-flower's 1 to 7 , the ligules 2 to $3 \mathrm{~mm}$. long, 1 to $1.3 \mathrm{~mm}$. wide; disk-flowers 4 to 10 ; disk-corolla with slender tube gradually passing to a throat of equal length, the whole corolla 4.5 to $6.5 \mathrm{~mm}$. long, granular or glabrous; lobes lanceolate, acute, spreading, 0.5 to $0.8 \mathrm{~mm}$. long, glabrous; style-branches long-exserted, 1.2 to $2 \mathrm{~mm}$. long, the linear-filiform appendage much exceeding stigmatic portion; achenes 4.5 to $5.5 \mathrm{~mm}$. long, apparently terete but faintly about 5 -angled, densely villous or perfectly glabrous and then with 5 longitudinal ridges (minor variation 5); disk-pappus about equaling corolla, fragile, scanty, pale brown. (Ericameria nana Nutt., Trans. Am. Phil. Soc. II, 7 :319, 1840.) (Fig. 110.)

Mountains and hills of the Great Basin, from Utah and southern Nevada to eastern California, thence to northeastern Oregon (and Washington?). Type locality, shelving rocks on the Blue Mountains of Oregon. UTAH: Marysvale, Jones 5971 (US, BM, UC). Nevada: Palisade, Jones 2191 (US, Boiss); 37 km. west of Austin, Hall 12148 (UC); Cactus Spring, Cactus Range, Monnet 962 (US); Reveille Range, Purpus 6403 (US, UC); Juniper Mountains, Purpus 6267 (K, UC); Morey Peak, Purpus 6364 (US, UC); near Caliente, August 27, 1912, Jones (UC); Goldfield, Hall 10531 (UC); $2 \mathrm{~km}$. southeast of Candelaria, on Mineral-Esmeralda County line, Hall 10665 (UC); near Fallon, Ross 49 (UC). California: Benton Range, Mono County, Hall 10651 (UC). Oregon: type collection, Nuttall (Phila, Gr, BM). Washington: Yakima region, 1882, Brandegee (UC, doubtful). IdAнo: Shoshone Falls, Hall 10940 (UC); Big Butte Station, Palmer 482 (Gr, US); Picabo, Macbride and Payson 2998 (Gr, US).

\section{MINOR VARIATIONS AND SYNONYMS}

1. Aster resinotus O. Kuntze, Rev. 317, 1891-H. nanus.

2. Chrysoma nana Greene, Erythea $3: 10,1895-H$. nanus.

3. Chrysothamnus nanus Howell, Fl. N. W. Am. 302, 1900-H. nanus.

4. Ericameria nana Nutt., l. c.-H. nanus.

5. Haplopappus nanus, but the achenes perfectly glabrous and with 5 prominent, longitudinal ridges. Collections of this variation are indicated in table 12 (p. 298). In the original description of $H$. nanus Nuttall says that the achenes are "subhirsute," or "slightly hirsute when mature" and it has been generally assumed that they gradually lost their pubescence with age. It seems, however, that two hereditary types may be involved, for long and apparently mature achenes are sometimes pubescent and, on the other hand, short and immature achenes are sometimes glabrous. Furthermore, all of the achenes on a single plant and, so far as observed, on different plants of a single collection, are similar in this respect, that is, they are either densely pubescent, sparsely pubescent, or perfectly glabrous.

\section{RELATIONSHIPS}

The compact habit, small leaves, and narrow, few-flowered heads indicato that this is one of the most reduced species of the section Asiris and therefore of comparatively recent development. Its derivation from Haplopappus cervinus has been already discussed and the differentiating criteria whereby it may be distinguished from $H$. resinosus will be taken up under the latter species. 


\section{ECOLOGY AND USES}

Haplopappus nanus belongs to the open and arid piñon-juniper woodland association of the Great Basin area of western North America, but also ranges down into regions where Artemisia tridentata is dominant. It inhabits gravelly soil among granitic and other rocks in the Upper Sonoran Zone, often sending its roots deeply through fissures in the rock itself. In a strict sense it has almost no associates, for it grows under conditions unfavorable for most other species, but the list of perennials most often found in the immediate vicinity includes Artemisia tridentata, Chrysothamnus viscidiflorus lanceolatus, Grayia spinosa, and Atriplex canescens. The flowering period is from July to October.

The utilization of this species as a source of rubber is one of the possibilities. Five collections have been analyzed and found to contain from 5 to 10 per cent of rubber (Hall and Goodspeed, Univ. Calif. Pub. Bot. $7: 269,1919)$. This is a higher percentage than that of any other North American shrub except guayule (Parthenium argentatum), but because of the small size of the plants as well as their scarcity, the use of the wild shrub is out of the question. What the plants would do under cultivation is not known, but since the dwarf habit apparently is the result of a deficient water-supply and other unfavorable ecologic conditions it may be assumed that they would make a more rapid growth and attain a larger size. A further possibility which should be tested by experiment is the production of a fertile hybrid with some of the subspecies of the rubber-yielding Chrysothamnus nauseosus, to which it is rather closely related.

\section{Haplopappus resinosus (Nutt.) Gray, Bot. Calif. 1:313, 1876}

A rather loosely branched subshrub, 3 to $5 \mathrm{dm}$. or more high, with many slender and open branches forming more or less open round-topped bushes;

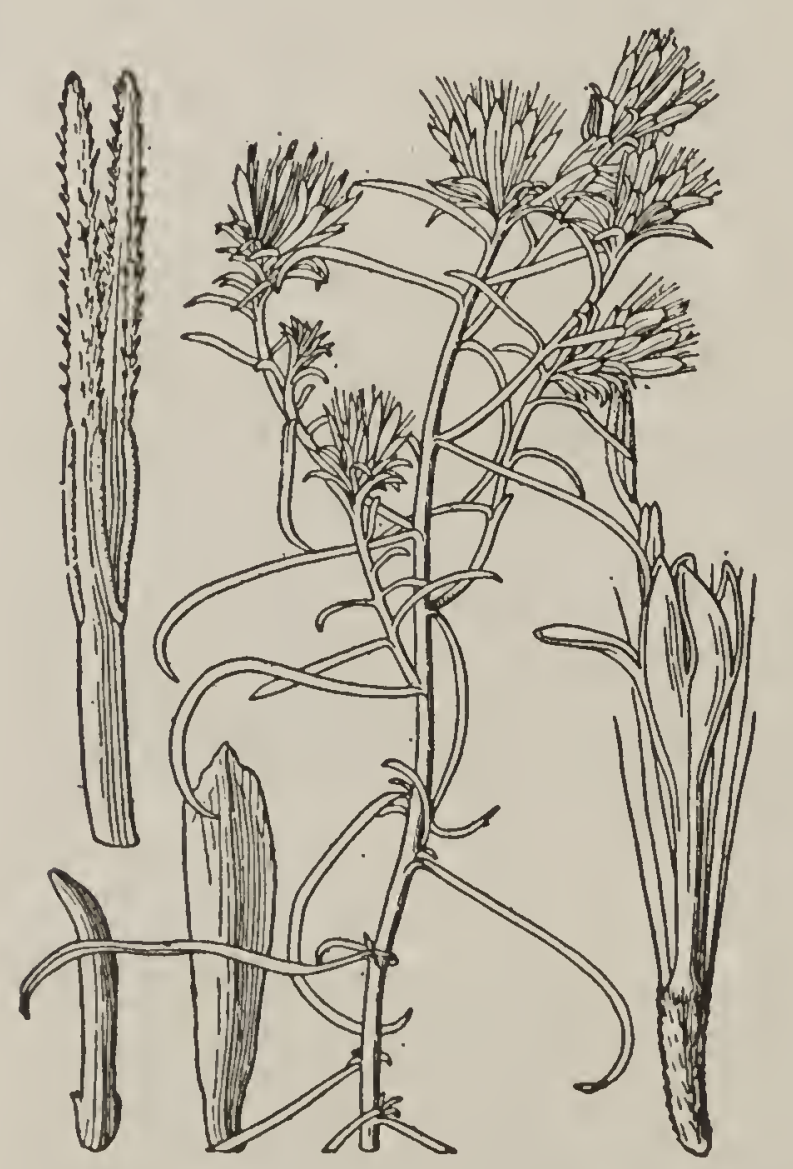

FIG. 111-Haplopappus resinosus twigs short or long, ascending or erect, brittle, leafy, lined with grooves from the leaf-bases, not pitted, glabrous, resinous; principal leaves linear-spatulate to linearfiliform, ascending or spreading, the tips mostly recurved, acute, entire, 0.5 to $3 \mathrm{~cm}$. long, 0.5 to $1.5 \mathrm{~mm}$. wide, channeled above, devoid of impressed resin-dots, glabrous, resinous, mostly with a few very short secondary leaves fascicled in the axils; heads mostly solitary and terminating short leafy twigs, sometimes in open cyme-like clusters of 2 or 3 heads each; involucre broadly turbinate, 6 to 8 $\mathrm{mm}$. high, about $5 \mathrm{~mm}$. broad; bracts about 30 , in 4 or 5 series, the inner nearly as long as disk, loosely imbricated, lanceolate, the tips acute to subulate, pale and chartaceous except for a brown or greenish middle portion, the shorter outer ones mostly 'green and more or less squarrose, glabrous to obscurely 
puberulent; ray-flowers 3 to 7 , the ligules 3 to $6.5 \mathrm{~mm}$. long, 1.2 to $2 \mathrm{~mm}$. wide (usually or perhaps always pale yellow to white); disk-flowers 11 to 16 ; disk-corolla with slender tube passing gradually to a throat of about equal length, the whole corolla 5.5 to $7.5 \mathrm{~mm}$. long, the tube puberulent; lobes lanceolate, acute, spreading, 1 to $2 \mathrm{~mm}$. long, glabrous; style-branches long-exserted, 1.5 to $2.5 \mathrm{~mm}$. long, the subulate appendage well exceeding stigmatic portion; achenes 4.5 to $5 \mathrm{~mm}$. long, subterete, faintly 5 -angled, moderately to densely villous (or glabrous?); disk-pappus about as long as corolla, fragile, scanty, pale brown. (Ericameria resinosa Nutt., Trans. Am. Phil. Soc. II, $7: 319,1840$.) (Fig. 111.)

Eastern Washington, eastern Oregon, and adjacent Idaho. Type locality said to be the same as for H. nanus, that is, shelving rocks on the Blue Mountains of Oregon. Washington: Klickitat County, on dry cliffs of the Columbia River, September 24, 1884, Suksdorf (UC, US, Gr); Yakima region, Brandegee 845 (UC, Gr). Oregon: type collection, "Blue Mts. and rocks of the Columbia," Nuttall (BM); cliffs near Snake River, Cusick 2125 (UC, US, Del, Gr, type collection of H. hamatus Gandoger, minor variation 4); near fork of Cottonwood Cañon, Lillian County, Leiberg 880 (UC, US); basaltic cliffs, Blue Mountains, Cusick 3637 (NY, US); Lygh Valley, Wasco County, July 26, 1894, Lloyd (NY); south cañon of Birch Creck, Umatilla County, Cusick 3637 (US). IDAHo: cliffs of Snake River, near Ballard's Landing, Cusick 2343a (Gr); Snake River Cañon south of Zaza, Nez Perces County, St. John 9118 (Pullm, UC).

\section{MINOR VARIATIONS AND SYNONYMS}

1. Chrysothamnus resinosus Howell, Fl. N. W. Am. 303, 1900-H. resinosus.

2. Ericameria resinosa Nutt., l. c.-H. resinosus.

3. Haplopappus gummiferus Gandoger, Bull. Soc. Bot. France $65: 38$, 1918. A form of $H$. resinosus differing from the type as described by Nuttall only in having straight instead of squarrose outer bracts to the involucre. Gandoger's description in full is as follows: "Valde glutinoso-gummifluus, folia late linearia recta, cymae multiflorae, phylla involucri recta, pappus lutescens. Washington ad Bingen (Suksdorf 5884)."

4. H. hamatus Gandoger, l. c. A form of H. resinosus in which the tips of the long and slender leaves are hamately recurved. The pappus is described as white, but in duplicates of the type collection it is as sordid as in the form described by Gandoger as gummiferus. The original description in full is as follows: "Vix glutinosus, folia linearia apice curvato-hamata, cymae pauciflorae, phylla involucri recurvata, pappus albus. Oregon, ad Snake River (Cusick 2125)."

\section{RELATIONSHIPS}

This species is one of the small group to which Haplopappus cervinus and $H$. nanus also belong. In the comparatively large number of flowers it would seem to be primitive to these, but the deeply cleft corollas and the tendency toward squarrose involucral bracts suggest that it is itself a modified type and therefore a divergent variation from the common stock.

In some of its variations it is so much like $H$. nanus that the two have been united by various authorities. There still is need of much field observation and garden experiment in order finally to determine the status and relationships of the several forms involved, but the accumulating evidence is in support of Nuttall's view that we here have two distinct species. The most reliable characters for the recognition of resinosus as distinct from 
nanus are, (1) the slender open habit, especially of the inflorescence, (2) the large heads with 11 or more disk-flowers each, and (3) the deeply cleft limb of the disk-corollas. Additional features serve to indicate certain tendencies within each of the species, but they do not vary in unison with the ones just mentioned. For example, although the outer bracts are squarrose in typical resinosus, they are quite as straight as the inner ones in specimens which must be classed here because of their habit, numerous disk-flowers, and long corolla-lobes (Columbia River, Suksdorf, see minor variation 3). As far as known the ligules are always pale in resinosus and yellow in nanus, but authentic reports from the field as to this character are much too few to permit a statement as to its constancy. The more important criteria used for the differentiation of the species and the extent to which they may be used are indicated in table 12 .

\section{ECOLOGY}

There is little information at hand as to conditions under which this plant grows except that it inhabits cliffs of the Snake and Columbia Rivers. Cusick has indicated on one of his labels that it inhabits basaltic cliffs and that the earlier report of its growing on limestone was doubtless a mistake. Distributionally it is much more restricted than its close relative, Haplopappus nanus. The growth-forms of the two are closely similar, but the present species is usually taller, more slender, and more openly branched, differences which suggest that it perhaps occupies less exposed habitats.

TABLE 12-Variation in Haplopappus nanus and H. resinosus

\begin{tabular}{|c|c|c|c|c|c|c|c|c|}
\hline & & & & & & Disk- & orolla & \\
\hline . & Iferbariun & $\begin{array}{c}\text { of } \\
\text { longest } \\
\text { leaves }\end{array}$ & $\begin{array}{l}\text { involucral } \\
\text { bracts }\end{array}$ & $\begin{array}{l}\text { disk- } \\
\text { flowers }\end{array}$ & Ligules & $\begin{array}{l}\text { Length, } \\
\text { including } \\
\text { lobes }\end{array}$ & $\begin{array}{l}\text { Lobe- } \\
\text { length }\end{array}$ & Achenes \\
\hline Haplopappus nanus: & & $m m$. & & & & $m m$ & $m m$ & \\
\hline $\begin{array}{l}\text { Morey Peak, Nevada.. } \\
\text { Cane Spring Moun- }\end{array}$ & 86512 UC & 14 & Erect. & 10 & Yellow. & $6.39-5.45$ & $0.85-0.75$ & Pubescent. \\
\hline tains, California..... & 6509 UC & 12 & Do. & 10 & & $6.30-6.49$ & $0.75-0.75$ & Do. \\
\hline Shoshone Falls, Idaho. & 216889 UC & 15 & Do. & 8 & & $5.64-5.73$ & $0.56-0.66$ & Do. \\
\hline Near Candelaria, Nev. & 194535 UC & 15 & Do. & $10 ?$ & & $6.58-6.67$ & $0.75-0.75$ & Glabrous. \\
\hline Caliente, Nev......... & $175972 \mathrm{UC}$ & 15 & Do. & $8-9$ & & 6.11 & 0.56 & Pubescent. \\
\hline Do.......... & 203089 UC & 13 & Do. & 4 & Yellow. & 4.51 & 0.66 & Do. \\
\hline Pahroe Range, Nev ... & 86514 UC & 10 & Do. & & & $4.32-5.08$ & $0.66-0.47$ & Glabrous. \\
\hline $\begin{array}{r}\text { Juniper Mountains, } \\
\text { Nev............. }\end{array}$ & $29563 \mathrm{UC}$ & 12 & Do. & & Yellow. & - & 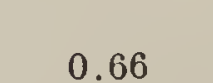 & Pubescent. \\
\hline $\begin{array}{l}\text { Churchill County, Ne- } \\
\text { vada. }\end{array}$ & $12148 \mathrm{CI}$ & 15 & $\begin{array}{l}\text { Curved, } \\
\text { squarrose. }\end{array}$ & $7-8$ & Do. & $5.08-5.64$ & $0.56-0.66$ & Glabrous. \\
\hline $\begin{array}{l}\text { Fallon, Nev.......... } \\
\text { H. resinosus: }\end{array}$ & 205835 UC & 10 & Erect. & & Do. & 5.92 & 0.75 & Pubescent. \\
\hline $\begin{array}{l}\text { Near Snake River, Ore- } \\
\quad \text { gon............... }\end{array}$ & 86508 UC & 24 & Squarrose. & $13-14$ & White. & $7.52-7.33$ & $2.16-1.60$ & Do. \\
\hline $\begin{array}{l}\text { Do................ } \\
\text { Yakima region, Wash- }\end{array}$ & $29564 \mathrm{UC}$ & 25 & Do. & 11 & Do. & $6.58-5.64$ & $2.16-1.88$ & Do. \\
\hline 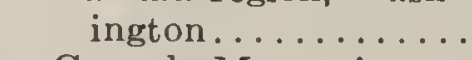 & 172279 UC & 12 & Erect. & & & $7.33-7.8$ & $1.60-1.60$ & Do. \\
\hline Cascade Mountains... & $169163 \mathrm{UC}$ & & Do.? & 16 & & $6.02-6.30$ & $1.60-1.50$ & Do. \\
\hline ington............ & $193497 \mathrm{UC}$ & 10 & Do. & $11-12$ & White. & $5.92-5.55$ & $1.08-1.13$ & Do. \\
\hline $\begin{array}{c}\text { Cottonwood Cañon, } \\
\text { Oregon.................... }\end{array}$ & $175954 \mathrm{UC}$ & 14 & $\begin{array}{c}\text { Slightly } \\
\text { squarrose. }\end{array}$ & 16 & & $5.64-4.98$ & $1.41-1.69$ & Do. \\
\hline
\end{tabular}


74. Haplopappus purpusi (Brandegee) Blake, Contr. U. S. Nat. Herb. $23: 1491,1926$

A closely branched rigid shrub of unknown habit; bark hard, soon changing from pale green to white but ultimately becoming brown; twigs short, crowded, rigid, hidden when young by foliage, marked by several low longitudinal ridges, not punctate, obscurely scaberulous when young; principal leaves linear-subulate, straight, rigid, at first appressed, later spreading, 0.5 to $0.7 \mathrm{~cm}$. long, $1 \mathrm{~mm}$. or less wide, with strong decurrent midrib, the margins also decurrent, densely but finely scabrid, not punctate, with crowded fascicles of minute leaves in the axils after first season; heads terminating leafy branches of short terminal cymes; involucre turbinate, 5 to $6 \mathrm{~mm}$. high, 4 to $5 \mathrm{~mm}$. broad; bracts 12 to 16, in 4 or 5 series, slightly shorter than disk, regularly imbricated, the inner ones oblong and short-acute or only minutely cuspidate, the middle ones slightly shorter and more definitely acute, the outer ones ovate-acute and passing insensibly into bracts of the peduncle, all chartaceous but with exposed tips greenish or brownish, the midrib prominent, slightly scabrid and obscurely ciliate; ray-flowers wanting; diskflowers 10 to 12 (or more?); disk-corolla tubular, 5 to $6 \mathrm{~mm}$. long, glabrous; lobes unequal and irregularly spreading, linear-lanceolate, acute, about 1.2 to $1.4 \mathrm{~mm}$. long, glabrous; style-branches moderately exserted, about 2 to $2.5 \mathrm{~mm}$. long, the lanceolate appendage longer than stigmatic portion; achenes seemingly turgid, nearly prismatic but narrowed from summit to base, obtusely angled, about $2.5 \mathrm{~mm}$. long, densely sericeous-villous with long upwardly pointing white hairs which

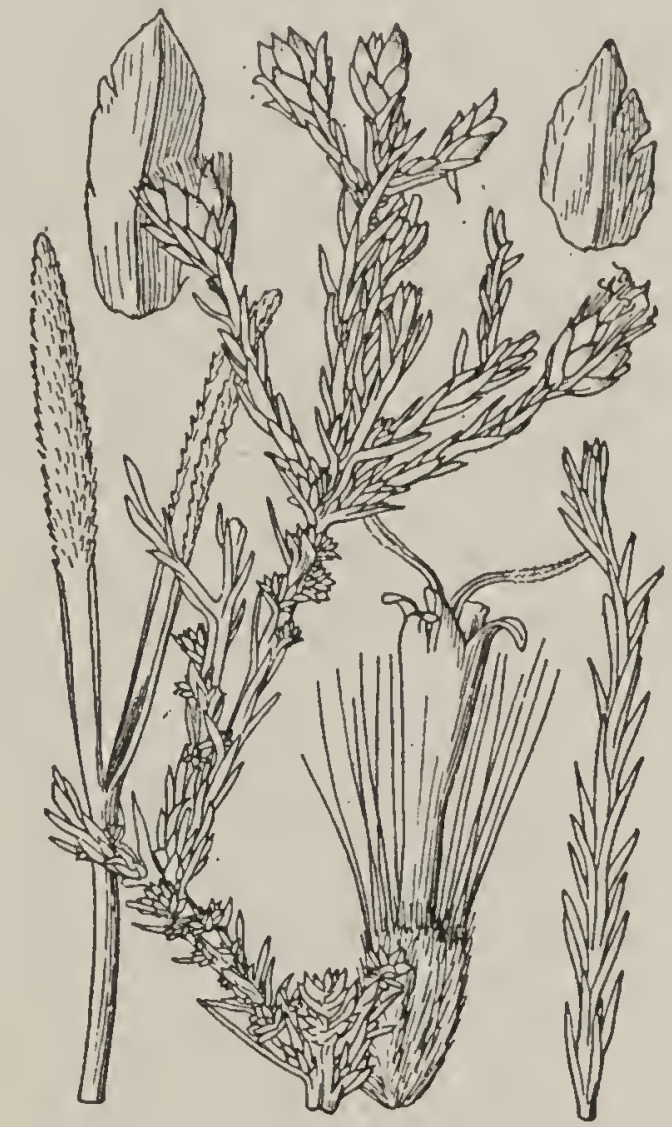

Fig. 112-Haplopappus purpusi give to the achene the appearance of being turbinate (angles hidden by dense pubescence and surface perhaps also striate, since inner walls have about 15 longitudinal strengthening fibers); pappus slightly shorter than corolla, moderately unequal, copious, of somewhat unequal yellowish bristles. (Ericameria purpusi Brandegee, Univ. Calif. Pub. Bot. 4:191, 1911.) (Fig. 112.)

Known only from the type collection, namely, Cerro de Macho, Coahuila, June 1910, Purpus 4479 (UC).

\section{RELATIONSHIPS}

Since nothing is known as to the variations of this species, and since it is so scantily represented in herbaria that satisfactory dissections are not possible, nothing positive can be said as to its relationships. Possibly it is not even a Haplopappus. The peculiar achenes, especially, suggest some other genus, but there seems to be none with which it is more closely allied. In connection with the original description, Brandegee noted that technically its rayless heads would place it in Bigelovia as elaborated by Gray, while 
its habit and appearance are those of an Ericameria, and the opinion was expressed that it would be abnormal in any described genus. The present retention in the section Asiris is largely a matter of convenience and is done to avoid confusion that would arise if placed elsewhere. Although the characters of involucre, corolla, and style-branches may be almost duplicated in species of this section, it differs from all of them in the notably turgid, long-hairy achenes.

\section{ECOLOGY}

The characters of this species indicate that it is a marked xerophyte of the evergreen chaparral. Nothing is known as to the conditions under which it grows. 


\title{
III. THE SOUTH AMERICAN SPECIES OF HAPLOPAPPUS
}

\author{
HISTORICAL SUMMARY
}

In South America the genus Haplopappus is confined to the western and southern parts of the continent. A large majority of the species are Chilean, but a few of them extend into or are confined to western Argentina, and one doubtful section (Diplostephioides) ranges northward to Colombia.

Since it has been impossible for the author to conduct field studies in these regions, the South American forms can not be treated in such detail as have those of the northern hemisphere. It happens, however, that, at least as far as nomenclatorial matters are concerned, a foundation for such treatment must be laid in Europe, since only there are to be found type specimens of the earlier species. The first of these was Conyza punctata Willd., 1804, now transferred to Haplopappus. Then, in 1828, Cassini proposed the genus Haplopappus with $H$.glutinosus, of Chile, as its sole representative, and five years later eight more South American species were described by Lessing, under the genus Diplopappus. Both of these botanists based their work upon collections of Poeppig, whose plants were so well labeled and distributed among European herbaria that there is no doubt as to what forms the author had in mind when drawing his descriptions. Then followed, in 1836, two important publications on the group, one by Hooker and Arnott (Comp. Bot. Mag. 2:45-47), the other by DeCandolle (Prodr. 5:345-351), based upon collections at Kew and Geneva, respectively; and in 1849 appeared Remy's contribution in the botanical part of Gay's comprehensive Historia Fisica y Politica de Chile, based largely upon Gay's collections, as represented at Paris. The work of the Kew botanists and of DeCandolle was done independently, so that some duplication and confusion resulted. Remy carefully described 40 species of Haplopappus and Pyrrocoma. He studied the plants in the DeCandolle herbarium as well as in the herbaria assembled at Paris, but apparently he entirely overlooked the work of Hooker and Arnott. In view of this unsatisfactory condition in which the group was left by European workers, it is not surprising to find that Chilean and other recent botanists have misunderstood and of ten redescribed many of the older species.

The first objective of the present treatment is to present the results of studies in European herbaria in such a way as to make better known the species of the early botanists and to propose a basis for their classification into sections and minor groups. The disposal of more recent species, especially the numerous proposals of $R$. A. Philippi, is made with much reluctance, although they are for the most part represented in the herbaria consulted. A proper understanding of them and the organization of all South American forms according to natural relationships must be left to some future worker who can examine the Philippi types at Santiago and, what is of much more importance, who has opportunity for extensive field studies. 


\section{DIAGNOSES OF THE SECTIONS}

Section 17.1 Euhaplopappus DC., Prodr. 5:347, 1836-Stems either woody or herbaceous but always from a perennial root. Herbage glabrous to tomentose. Leaves only moderately numerous, sometimes crowded, especially in cespitose species, but not densely so, rigid, serrate or dentate, rarely pinnatifid or entire. Heads medium-sized to large, solitary and terminal (short-racemose in $H$. ochagavianus, subpaniculate in $H$.philippi). Involucre hemispheric or broad-campanulate (approaching obconic in $H$. poeppigianus and $H$. reicheanus); bracts imbricated, narrow $(0.5$ to $2 \mathrm{~mm}$. wide, much wider only in $H$. baylahuen), decidedly acute to acuminate, thin-chartaceous or scarious, the middle portion often green (the bracts nearly foliaceous in $H$. marginalis). Ray-flowers usually present and fertile, wanting in a few species. Type species (of the genus): H. glutinosus Cass., not DC.

Section 18. Steriphe (Phil.) Reiche, Fl. Chil. 3:327, 1902-Stems woody at base, very densely leafy (perhaps always cespitose?). Herbage glabrous to sericeous. Leaves congested, long and narrow. Heads mediumsized or rather large, solitary, peduncled (the peduncles terminating corymbosely disposed branches in $H$. pedunculosus). Involucre broadly obconic to hemispheric, 9 to $15 \mathrm{~mm}$. high; bracts imbricated, narrow $(1.5 \mathrm{~mm}$. or less wide), acuminate, thinnish, at least the middle portion green or purplish. Ray-flowers sterile, the ligules scarcely exceeding involucre (or entirely wanting?). (Steriphe Phil., Anal. Univ. Santiago 23:383, 1863, and Linnaea 33:141, 1864-5, as genus.) Type species: Steriphe corymbosa Phil. (= Haplopappus pedunculosus Remy).

This is a very homogeneous section, based both upon habit and upon technical characters. The extent to which the ligules develop may, however, be expected to vary, and it seems that some species which evidently belong here may entirely lack the ray-flowers (compare $H$. setiger). The foliage is remarkably pitted in certain species (especially $H$. punctatus, $H$. pedunculosus, $H$.humilis, and $H$. setiger). The pits are formed from the minute reticulations and are not to be confused with the resin-pits of some North American sections.

SEction 19. Polyphylla sect. nov.-Stems woody, at least at base. Herbage glabrous and glutinous or only moderately short-pubescent. Leaves abundant and rather broad, crowded up to the heads in typical species. Heads large, solitary or paniculate, sessile or peduncled. Involucre broadcampanulate or hemispheric, 12 to $17 \mathrm{~mm}$. high; bracts imbricated, wide (2 to $3 \mathrm{~mm}$., as far as known), obtuse (except inner), firm, the edges scarious, the middle portion herbaceous. Ray-flowers either present or wanting. Type species: $H$. foliosus DC.

The most pubescent species of this section are $H$. kingi, H. mucronatus, and $H$. deserticolus. The leaves are very narrow in $H$. linifolius, which is perhaps a Steriphe, and moderately narrow in $H$. meyeni.

SECTION 20. Xylolepis sect. nov.-Stems woody at base. Herbage glabrous or nearly so, glutinous or resinous. Leaves numerous but narrow, mostly rather short. Heads rather small, in elongated spikes or in panicles. Involucre narrowly to broadly obconic, 8 to $12 \mathrm{~mm}$. high; bracts imbricated, wide (2 to $3 \mathrm{~mm}$.), obtuse, firm, thick-chartaceous, appearing woody when dry. Ray-flowers wanting. Type species: H. parvifolius DC.

${ }^{1}$ The numbering follows that of the North American sections, diagnosed on p. 33. 
Apparent exceptions to the foregoing diagnosis include the following: The leaves are wide and rounded in $H$. reticulatus, which, however, may not belong to this section. The young herbage is tomentulose in $\mathrm{H}$. macraeanus. The heads approach the campanulate shape in $H$. bezanillanus, but are no broader and with no more flowers than the others. Some bracts in $H$. pristiphyllus are acute. In $H$. cerberoanus the bracts are narrow.

Section 21. Diplostephioides (Benth. et Hook.) Blake, Am. Jour. Bot. 14:108, 1927-Stems woody, sometimes scandent. Herbage tomentose or tomentulose, at least the lower leaf-surface. Leaves not crowded, large, entire or dentate, rigid. Heads long but narrow, numerous, in terminal fastigiate cymose panicles. Involucre subcylindric to obconic; bracts imbricated, wide (1.5 to $3 \mathrm{~mm}$.), acute or abruptly tipped, dry, substramineous. Ray-flowers wanting. Disk-corollas 5-cleft (lobes $2 \mathrm{~mm}$. or more long). (Chrysothamnus sect. Diplostephioides Benth. et Hook., Gen. Pl. 2: 255, 1873. Neosyris Greene, Erythea $3: 115,1895$, as genus.) Type species: H. hypoleucus Turcz.

\section{PHYLOGENY AND STATUS OF THE SECTIONS}

In this austral portion of the genus, evolution has proceeded along lines some of which are quite different from those followed in the north. There has been no development of elongated stylar appendages nor of special resin-pockets; the truly herbaceous habit is here almost unknown and there are no deciduous pappus-bristles nor ventricose disk-corollas.

Reduction in the number of flowers in the head, with a consequent narrowing of the involucre, is evident in a few sections, but on the whole the tendency has been to produce few heads, each of these very broad and with numerous flowers. There is also noted the development of peculiar types of habit, especially in section Steriphe, perhaps as a result of unusual ecologic conditions. In section Diplostephioides, which is so outstanding that it should perhaps be excluded from the genus, are found the largest plants of all and the only ones with a scandent habit. These also are the only ones in which the heads are assembled into regularly cymose clusters, a feature very characteristic of certain sections in North America.

Characters much used by some botanists, but now known to be of little value as taxonomic criteria, include the presence or absence of ray-flowers and of hairs on the achenes. The former has been used as the mark of the section, or genus, Pyrrocoma. The type of this, however, is from North America, where the feature is so inconstant, even within the type species, that its use has been abandoned. In Chile, also, are found radiate and discoid forms of plants otherwise identical (in $H$. velutinus, $H$. donianus, etc.), and the use of this character widely separates such obviously related species as $H$. pulchellus and $H$. illinitus or $H$. foliosus and $H$. multifolius. Following DeCandolle, most workers have assigned those species with glabrous achenes to his section Leiachenium. But the remarks just made in regard to suppression of the ray-flowers apply also here. In $H$. foliosus the achenes vary from perfectly glabrous to glabrous except at base (type) and thence through sparsely pilose to sericeous in neighboring species, and similar variation is encountered elsewhere in the genus (especially within $H$. angustifolius and $H$. anthylloides). Philippi early discovered the unsatisfactory nature of groupings based upon this character and was led to the abandonment of Leiachenium (Anal. Univ. Santiago 87:587, 1894). 
It thus develops that neither Pyrrocoma nor Leiachenium are natural or serviceable sections as far as the South American species are concerned, and since they were based upon highly variable characters their use may well be discontinued.

The five sections here adopted, three old and two new, are believed to be natural, notwithstanding the difficulty in some cases of finding simple key characters for their identification. They are best recognized by the assemblage of features and by obvious tendencies among their species. At the present time little can be said as to relationships existing between them. Euhaplopappus shows only occasional elimination of the ray-flowers and the least reduction in number of disk-flowers. The frequently recurring presence of a purple pigment in the ligules may be taken also as a hint of its relatively primitive position, for this seems to indicate an early connection with Aster, where heterochromy is now the rule. But purplish ligules are nearly always associated with a cespitose habit of growth, which in itself certainly is a derived trait, so that if Euhaplopappus is to stand at the beginning of the series it would present two equally primitive branches, one of the cespitose species, the other of the non-cespitose. There is no proof, however, that the cespitose habit has not arisen at several remote places within the section.

Steriphe is too close to Euhaplopappus for a good section. It is doubtful if its best feature, the sterile ray-flowers, will prove constant, for in North America it varies within a single species. This criterion seems, however, to be associated in Chile with a distinctive habit of growth and leaf-arrangement, so that this section may stand at least until further evidence from the field is available.

Polyphylla and Xylolepis are now set apart not only because of their obtuse involucral bracts, which make them easy of recognition, but also because of the firm texture and broad shape of these structures, as well as certain marked evolutionary tendencies within each of the groups. Polyphylla is placed first, since the typical species, with large, solitary heads, are most like Euhaplopappus. In Xylolepis there is encountered a reduction in number of flowers, with a consequent narrowing of the head. This, however, is associated with the arrangement of the heads in spikes or panicles, a feature which perhaps preceded reduction to the solitary-headed state, so that there is here much doubt as to the direction of evolution.

The section Diplostephioides is so unlike the others that its independent origin is strongly suspected, and its exclusion from the genus, as proposed by Greene, may ultimately become a necessity.

\section{Key to the South American Sections and Species of Haplopappus}

a. Disk-corollas 5-dentate, the teeth less than 2 $\mathrm{mm}$. long; involucre obconic to hemispheric; heads solitary, spicate, racemose, or paniculate; leaves either glabrous or about equally pubescent on the two sides.

$b$. Bracts of the involucre decidedly acute, narrow ( 0.5 to about $2 \mathrm{~mm}$. wide), or wider in only one species (baylahuen); heads solitary (subracemose in ochagavianus, subpaniculate in philippi, subcymose in pedunculosus). 
c. Ray-flowers fertile (?) and with well-developed ligules (heads sometimes discoid in Nos. 80, 82, 86, 87, 110); leaves oblong or broader, or if narrow then not congested at bases of peduncles. . Sect. $17 .{ }^{1}$ Eunaplopappus (p. 305)

c. Ray-flowers sterile and the ligules usually short, apparently wanting in some species (especially setiger); leaves linear or linear-oblanceolate, congested on the short branches, the peduncles arising directly from these dense masses of foliage.............. Sect. 18. Steriphe (p. 309)

$b$. Bracts of the involucre obtuse (except sometimes the inner), wide ( 2 to $3 \mathrm{~mm}$. at base); heads solitary racemose or paniculate.

d. Involucre campanulate to hemispheric, 12 to $17 \mathrm{~mm}$. high; leaves rather wide; heads solitary or paniculate; bracts thin, with herbaccous middle portion. (Heads discoid except in Nos. 122, $127,129,130,131$, doubtful in 121.). Sect. 19. Polyphylla (p. 309)

$d$. Involucre obconic, 8 to $12 \mathrm{~mm}$. high; leaves narrow; heads spicate or paniculate; bracts thick, only the apex herbaceous. (Heads always discoid.)... Sect. 20. Xrlolepis (p. 310)

a. Disk-corollas 5 -cleft, the lobes $2.5 \mathrm{~mm}$. or more long; involucre turbinate (obconic) to subcylindric; heads fastigiate-cymose; leaves densely tomentose or tomentulose beneath, less so or glabrous above. (Heads discoid.)....................... Sect. 21. Diplostephioldes (p. 311)

\section{SECTION 17. EUHAPLOPAPPUS}

A. Plants not cespitose, and leaves not densely clustered near base.

$B$. Leaves more or less petioled or with narrow, petiole-like base; branches ending in nearly naked peduncles.

C. Involucral bracts straight or only recurved, not squarrose; peduncles glabrous or only puberulent except in Nos. 86 and 87.

$D$. Leaves pinnatifid or bipinnatifid, at least the upper.

$E$. All the leaves pinnatifid into linear lobes......................

$E$. Lower leaves only dentate.........

$D$. Leaves not pinnatifid.

$F$. Foliage overlapping but not densely crowded.

$G$. Herbage glabrous to canescent or even subtomentose.

H. Apex of leaf from short-acuminate to obtuse.

I. Leaves prominently dentate, plainly nerved and reticulate; outline of leaf obovate or oblanceolate.

1 The numbering in these keys is a continuation from that of the North American sections and species.

75. H. pectinatus (p. 311)

76. H. araucanus (p. 312) 
$J$. Herbage puberulent to glabrous, never lanate; teeth of the leaves forward pointing.

$K$. Peduncles nearly naked toward the heads, the bracts few and much reduced............

$K$. Peduncles bearing larger

77. H. chrysanthemifolius (p. 312) bracts, these gradually reduced from the upper leaves...........

$J$. Herbage white-lanate when young; teeth of the leaves spreading or recurved...

I. Leaves merely crenate-denticulate, or rarely with more prominent but very slender teeth, pinnately veined but only the midrib prominent; outline spatulate or oblanceolate-spatulate.

$L$. Petiole short or wanting. (See also arbutoides, with leaves only 1.0 to $1.5 \mathrm{~cm}$. long.)

$M$. Apex of leaf obtuse; outline broadly oblanceolate or nearly obovate....

$M$. Apex of leaf acute or with a tendency to be acute; outline spatulate.....

$L$. Petiole very slender, nearly as long as blade.......... $H$. Apex of leaf slenderly acuminate, the pungent tip nearly entire; foliage and peduncles more slender.

$N$. Involucral bracts linear-subulate.

$O$. Leaves 5 to $7 \mathrm{~mm}$. wide.....

$O$. Leaves 2 to $5 \mathrm{~mm}$. wide; plant more slender..........

$N$. Involucral bracts somewhat obtuse or only short-mucronate................

(Here $H$. pedunculosus might be sought.)

$G$. Herbage densely tomentose even to the involucre.

$P$. Involucre broad-obconic, $13 \mathrm{~mm}$. high................

$P$. Involucre hemispheric, 10 to 11 $\mathrm{mm}$. high..............

$F$. Foliage densely crowded on the lower parts of the branches, to form tufts. (See also Nos. 80 and 81.)

Q. Leaves spreading, comparatively soft, finely and evenly serrate.

$R$. Bracts linear-acuminate, closely imbricated...............

78. H. hirtellus (p. 315)

79. H. uncinatus (p. 315)

80. H. velutinus (p. 316)

81. H. illinitus (p. 318)

82. H. elatus (p. 318)

83. H. pulchellus (p. 319)

84. H. donianus (p. 319)

85. H. stolpi (p. 320)

86. H. poeppigianus (p. 320)

87. H. canescens (p. 321)

88. H. bustillosianus (p. 322) 
$R$. Bracts lanceolate-acuminate, few and loose...............

Q. Leaves stiffly erect, rigid, pungently acute, entire or nearly so (sce $H$. punctatus, No. 114).

C. Involucral bracts (at least in part) squarrose from about the middle; peduneles subtomentose.

S. Shrub; leaves oblanceolate, with spreading or recurved teeth............

$S$. Herbs; leaves broader, with forwardpointing teeth.

$T$. Outer bracts of the involucre linearacuminate, dark but not foliace-

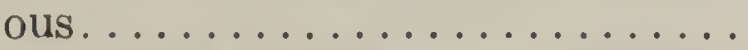

T'. Outer bracts lanceolate, somewhat foliaccous..................

$B$. Leaves sessile by a partly clasping base, only the lower ones somewhat narrowed at base. (Leaves sharp-dentate, but meyeni with entire leaves might be sought here.) $U$. Involucre $15 \mathrm{~mm}$. or less high; bracts linear-acuminate or narrowly lanceolate, $2 \mathrm{~mm}$. or less wide (perhaps larger in reicheanus).

$V$. Herbage glabrous or scabriusculous, not stipitate-glandular.

W. Heads solitary; involucre 11 to $14 \mathrm{~mm}$. high.

$X$. Heads short-peduncled; involucral bracts straight. (See also Nos. 90 and 91, with leaves more petiole-like at base and some involucral bracts squarrose.)...

$X$. Heads sessile among upper leaves; involucral bracts reflexed at tip.

$W$. Heads somewhat paniculate, small; involucre only 8 to $9 \mathrm{~mm}$. high....

$V$. Herbage coarsely pubescent and stipitateglandular, at least near heads.

$Y$. Leaves oblong-spatulate or oblanceolate; heads solitary.

$Z$. Achenes more or less villous.......

Z. Achenes glabrous..............

$Y$. Leaves round-obovate, very obtuse, heads commonly several and sub-

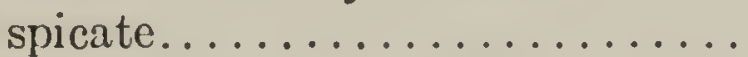

$U$. Involucre 17 to $25 \mathrm{~mm}$. high; bracts ovate or ovatc-lanceolate (except inner), 4 to $5 \mathrm{~mm}$. wide at base. (Achenes

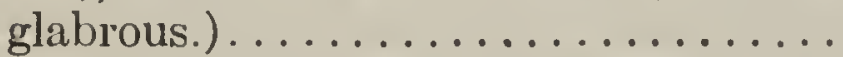

A. Plants loosely to densely cespitose, lower, 0.5 to

2 or rarely $3 \mathrm{dm}$. high; leaves clustered or tufted on short branches near the ground, the peduncles arising from these basal leafy shoots.

a. Leaves sessile or short-petioled, never exceeding the heads (somewhat petioled but much shorter than peduncles inglutinosus).

b. Margins deeply lobed, the leaves often appearing to be pinnatifid or bipinnatifid.
89. H. patagonicus (p. 322)

79. H. uncinatus (p. 315)

90. H. grindelioides (p. 323)

91. H. marginalis (p. 323)

92. H. decurrens (p. 324)

93. H. reicheanus (p. 324)

94. H. philippi (p. 325)

95. H. rigidus (p. 325)

96. $H$. villaneuvae (p. 325)

97. H. ochagavianus $(\mathrm{p}, 326)$

98. H. baylahuen (p..326)

99. H. glutinosus (p. 327) 
b. Margins entire to dentate.

$c$. Involucral bracts oblong; peduncles short, leafy-bracted................

c. Involucral bracts linear-subulate; peduncles long, nearly naked.

$d$. Dentations of leaves bristle-tipped, uniform in size and shape from summit to base.

e. Leaf obovate, obtuse, 8 to $20 \mathrm{~mm}$. wide................. 101. H. macrocephalus (p. 330)

e. Leaf oblanceolate, acute, narrow.... 102. H. scaposus (p. 331)

d. Dentations not bristle-tipped but sometimes very acute or cuspidate, somewhat uneven, and base of leaf entire.

f. Bracts of the involucre with erect or slightly spreading tips. (Here might be sought $H$. patagonicus, recognized by its open habit and narrow elongated leaves.)

g. Dentations of leaves rather obtuse or only acutish, the reticulations not prominent; involucre 10 to 12 or $13 \mathrm{~mm}$. high.

$h$. Leaves elliptic-obovate, finely and evenly denticulate, puberulent (always?) .........

$h$. Leaves cuneate-obovate, irregu100. H. rosulatus (p. 329) larly few-toothed, glabrous and glutinous.

$i$. Involucral bracts glabrous or only granular............

$i$. Involucral bracts glandular-
ciliate, the external ones

scrobiculate.......... 105. H. scrobiculatus (p. 333)

g. Dentations of leaves pungently

103. H. arbutoides (p. 331) acute, the reticulations prominent; involucre 11 to $15 \mathrm{~mm}$. high.

$j$. Leaves nearly obovate, 4 to 12 $\mathrm{mm}$. wide, some obtuse; involucral bracts 1.2 to 1.8 mm. wide.............

j. Leaves oblanceolate, 2 to $6 \mathrm{~mm}$. 106. H. diplopappus (p. 334) wide, all rigidly acute; involucral bracts 1 to $1.2 \mathrm{~mm}$. wide...................

f. Bracts of the involucre with slender recurved tips................ 104. H. cuneifolius (p. 332) 107. H. anthylloides (p. 335)

108. H. paucidentatus (p. 336)

$a$. Leaves long-petioled, some equaling or overtopping the short-peduncled heads.

$k$. Heads terminating erect peduncles or leafy stems.

l. Ray-flowers present.............. 109. H. prunelloides (p. 337)

l. Ray-flowers wanting............... 110. H. chrysocephalus (p. 337)

$k$. Heads sessile, surrounded by rosettes of basal leaves................... 111. H. ameghinoi (p. 338) 


\section{SECTION 18. STERIPHE}

a. Peduncles numerous, terminating short leafy twigs; involucre 9 to $10 \mathrm{~mm}$. high.

b. Leaves 5 to $8 \mathrm{~cm}$. long, plane; involucral bracts acuminate...................112. H. pedunculosus (p. 338)

b. Leaves 2 to $5 \mathrm{~cm}$. long, undulate; bracts merely acute.................... 113. I. rosmarinifolius (p. 339)

(Here also might be sought pristiphyllus, recognized by its spicate heads and broad involucral bracts.)

a. Peduncles single or few, simple, each one arising directly from the dense mass of foliage. (See also pinea (p. 362), with linear, entire leaves.)

c. Leaves entire to remotely denticulate, often pungent but not setigerous.

d. Peduncles much exceeding leaves except in occasional reduced forms.

$e$. Bracts of the involucre with tips erect or nearly so. (Leaves 1 to $3 \mathrm{~mm}$. wide.)

f. Principal leaves 3 to $5 \mathrm{~cm}$. long....... 114. H. punctatus (p. 339)

f. Principal leaves 1.5 to $2 \mathrm{~cm}$. long..... 115. H. breviradiatus (p. 340)

$e$. Bracts of the involucre with strongly recurved tips.

g. Leaves glabrous or only obscurely puberulent; involucre not glandular. 116. H. integerrimus (p. 340)

g. Leaves sericeous; involucre glandular.. 117. H. sericeus (p. 341)

d. Peduncles scarcely exceeding leaves, heads scattered over prostrate leafy mats . 118. H. humilis (p. 342)

c. Leaves mostly pinnatifid or serrate (rarely entire), each lobe ending in a slender white

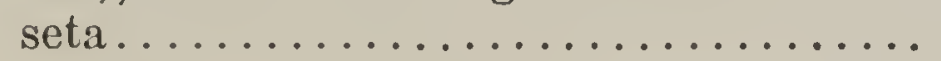

119. H. setiger (p. 342)

\section{SECTION 19. POLYPHYLLA}

a. Margins of leaves entire, the blade elliptic to linear.

b. Heads long-peduncled; leaves 1 to $2 \mathrm{~mm}$. wide. 120. H. linifolius (p. 344)

b. Heads sessile; leaves 5 to $10 \mathrm{~mm}$. wide...... 121. H. meyeni (p. 344)

a. Margin of leaves sharply dentate, the blade broader.

c. Leaves densely crowded up to the heads, hiding the stems.

d. Dentations coarse and uneven.

e. Heads radiate; leaves 10 to $15 \mathrm{~mm}$. wide. 122. H. foliosus (p. 344)

$e$. Heads discoid; leaves 20 to $25 \mathrm{~mm}$. wide (narrower in phyllophorus).

f. Involucre large, $15 \mathrm{~mm}$. or more broad, about as high.

g. Stems glabrous, resinous.

$h$. Leaves about $3 \mathrm{~cm}$. long, with many teeth. (Santiago.)........ 123. H. multifolius (p. 345)

$h$. Leaves about $1.5 \mathrm{~cm}$. long, the teeth about 5 to each margin. (Atacama.)............ 124. H. phyllophorus (p. 345)

g. Stems hirsute, not resinous; heads more paniculate............ 125. H. kingi (p. 346)

f. Involucre smaller, about $10 \mathrm{~mm}$. broad and high. (Herbage glabrous; leaves round-obovate.).............126. H. ischnos (p. 346)

d. Dentations very fine and of uniform size

(leaves thin, nearly orbicular)...... 127. H. rengifoanus (p. 346) 
c. Leaves numerous but the upper ones not crowded, these erect or spreading, the stems exposed. (See also kingi and ischnos.)

$i$. Heads closely subtended by large, suborbicular bracts; leaves orbicular-obovate, 18 to $40 \mathrm{~mm}$. wide. (Heads discoid.)....

$i$. Heads subtended by obovate or narrower bracts or naked; leaves oblong oblanceolate or elliptic, $20 \mathrm{~mm}$. or less wide.

$j$. Peduncles comparatively stout or wanting, leafy-bracted, or the heads nearly sessile in the axils; heads radiate.

$k$. Achenes pubescent; leaves oblong or oblanceolate. (Middle Chile.)

l. Heads mostly peduncled; leaves 15 to $20 \mathrm{~mm}$. wide..............

l. Heads mostly sessile, except sometimes the terminal one; leaves 10 mm. or less wide........... 130. H. platylepis (p. 348)

$k$. Achenes glabrous; leaves broadly oblong or obovate. (Northern Chile.)... 131. H. deserticolus (p. 349)

(See also rosulatus, with much smaller leaves and prostrate habit.)

$j$. Peduncles long, slender, naked for most of their length, the heads naked or closely subtended by a much reduced bract; heads discoid................ 132. H. remyanus (p. 349)

128. H. rotundifolius (p. 347 )

129. H. mucronatus (p. 347)

\section{SECTION 20. XYLOLEPIS}

a. Heads subspicate or glomerate-spicate, shortpeduncled or sessile, leafy-bracted.

$b$. Herbage glabrous or only puberulent.

c. Leaves finely serrulate above the middle... 133. H. bezanillanus (p. 350)

c. Leaves dentate nearly to base, the teeth spreading.

d. Achenes hispid or villous throughout.

e. Leaves lanceolate to oblanceolate, about $10 \mathrm{~mm}$. or less wide.

$f$. Involucral bracts obtuse or barely acute, the largest $2 \mathrm{~mm}$. wide; leaves merely acute.......... 134. H. saxatilis (p. 351)

f. Involucral bracts acuminate, the largest $3 \mathrm{~mm}$. wide; leaves with long spiny-acuminate tips......... 135. H. pristiphyllus (p. 351)

e. Leaves orbicular-obovate, about $20 \mathrm{~mm}$. wide................... 136. H. reticulatus (p. 352)

$d$. Achenes glabrous or with only a few hairs at very base.

g. Leaves oblanceolate to cuneate-obovate, mostly obtuse ......... 137. H. parvifolius (p. 352)

g. Leaves narrowly oblong, acute....... 138. H. angustifolius (p. 353)

b. Herbage at first white-tomentulose, especially

the stems....................... 139. H. macraeanus (p. 354)

a. Heads on long slender peduncles, these naked or the bracts reduced to scales.

$h$. Leaves nearly obtuse, 1 to $3 \mathrm{~cm}$. long (upper);

heads many in the panicle........... 140. H. cerberoanus (p. 354)

$h$. Leaves very acute, 3 to $5 \mathrm{~cm}$. long; heads few in the panicle or solitary............ 141. H. stelliger (p. 355) 


\section{Section 21. DIPLOSTEPHIOIDES}

Involucre broadly turbinate, 6 to $8 \mathrm{~mm}$. high; bracts in about 3 lengths; leaves rounded at base (except uppermost).

Leaves evenly low-denticulate or repand-denticulate throughout, thin, submembranous. 142. H. assuensis (p. 355)

Leaves entire, firm, coriaceous............ 143. H. fuligineus (p. 356)

Involucre cylindric-turbinate, 9 to $12 \mathrm{~mm}$. high; bracts in 4 or 5 lengths; leaves narrowed at base.

Flowers 8 to 10 or more in each head, rarely only 7......................... 144. H. hypoleucus (p. 356)

Flowers 3 to 6 .

Achenes densely hispidulous as well as glandular.......................... 145. H. rufescens (p. 358)

Achenes glandular, sometimes also sparsely hispidulous.

Leaves oblong or elliptic-oblong, 7 to $14 \mathrm{~cm}$. long, 20 to $40 \mathrm{~mm}$. wide, the veins evident beneath.

Branches persistently tomentose; leaves densely tomentose beneath; lateral veins spreading nearly at right angles to midrib..................... 146. H. lehmanni (p. 358)

Branches glabrate; leaves finely and thinly tomentose beneath; lateral veins less widely spreading.

Leaves acute or short-acuminate...... 147. H. caucanus (p. 359) Leaves decidedly acuminate at each end. 148. H. lucidulus (p. 359)

Leaves elliptic, 3 to $5 \mathrm{~cm}$. long, 8 to $15 \mathrm{~mm}$. wide, the veins concealed beneath by the heavy tomentum............. 149. H. ledifolius (p. 359)

\section{SECTION $17 .{ }^{1}$ EUHAPLOPAPPUS}

75. ${ }^{1}$ Haplopappus pectinatus Phil., Anal. Univ. Santiago 21:381, 1862, and Linnaea $33: 140,1864-65$

Stems woody at base, much branched, 0.5 to $1 \mathrm{~m}$. high, moderately leafy almost to the heads; herbage glabrous, green, glaucous; leaves sessile by a narrow base, pectinately pinnatifid or bipinnatifid, the rachis and acute segments linear, the larger leaves of rounded outline and about 5 to $10 \mathrm{~cm}$. long by 20 to $40 \mathrm{~mm}$. wide, the simply pinnatifid upper ones reduced and narrow, some entire; heads radiate, solitary, terminal; peduncles 10 to 45 $\mathrm{cm}$. long, somewhat corymbosely arranged, leafy-bracted on lower part, naked or with reduced and distant bracts above; involucre hemispheric, 8 to $9 \mathrm{~mm}$. high; bracts closely imbricated in about four lengths, the outer ovate, the inner lance-linear, all acute or short-acuminate, the largest about $2 \mathrm{~mm}$. wide, erect, dark green at tip, glabrous; ligules 1 to $1.5 \mathrm{~cm}$. long, yellow; achenes compressed, the edges thin, the faces striate, glabrous; pappus brownish (or white?).

Sandy places of western middle Chile from the Rio Maipo to Biobio and perhaps farther south; also apparently in western Argentina. Type locality, near Chonchoral, between Rio Itata and Rio Nuble. Rio Maipo,

1 The numbers are continued from those of the North American sections and species, the last of which appear on pp. 288 and 299 , respectively. 
Meyen (B); Talca, Philippi (K); Prov. Maule, Cuming 848 (K, type of Diplopappus pinnatifidus); Araucania, ded. Philippi (B, K); on dunes in Biobio Valley, November 1896, Niger (B).

1. Diplopappus pinnatifidus Hook. et Arn., Comp. Bot. Mag. 2:48 1836 . (Not Haplopappus pinnatifidus Nutt., Trans. Am. Phil. Soc. II, 7:330, 1841.) The first description of this species, but the name has since been used under Haplopappus. Type locality, Prov. Maule.

2. Aster pectinatus O. Kuntze, Rev. 318, 1891.

3. Haplopappus anethifolius Phil., Anal. Univ. Santiago 87:595, 1894. Described from specimens with large bipinnatifid lower leaves. Type locality, near San Javier, south of Rio Maule. It is probable that the lower leaves in pectinatus are always twice cut, except in dwarf plants.

4. H. moyanoi Speg., Rev. Agron. La Plata 3:609, 1897. Apparently a form of pectinatus with leaves less divided and a deciduous pappus. Type locality, near Lago Fontana, Ter. Chubut, Argentina.

5. Aster anethifolius O. Kuntze, Rev. 3:129, 1898. Based upon H. anethifolius Phil.

6. Haplopappus pectinatus var. anethifolius Reiche, Fl. Chil. 3:298, 1902. Based upon $H$. anethifolius Phil.

The phylogenetic position of this species is very uncertain. It is assigned to Euhaplopappus on the basis of the acute bracts, although these are much wider than in typical members of the section. The pinnatifid foliage suggests some forms of $H$. spinulosus, of North America, but the long, glabrous, compressed achenes, the straight involucral bracts, and other features indicate that the similarity is only superficial.

\section{Haplopappus araucanus Phil., Anal. Univ. Santiago 43:491, 1873}

Habit and characters similar to those of $H$. pectinatus, except that the leaves vary from nearly entire, especially the lower, to pinnatifid with 3 or 4 acute lobes on each side, the upper ones passing into entire bracts of the peduncle. (Aster araucanus O. Kuntze, Rev. 317, 1891.)

Known only from the type collections made near Antuco and Cupulhue, in the Andes of Chile. (Not seen.)

77. Haplopappus chrysanthemifolius (Less.) DC., Prodr. 5:348, 1836

Stems woody, with ascending leafy branches ending abruptly in nearly naked peduncles; herbage from nearly glabrous (as in type) to densely scabrid-puberulent; principal leaves narrowed to a short petiole or petiolelike base, obovate-spatulate to oblanceolate, obtuse but mucronate or with an acute terminal tooth, 2 to $4 \mathrm{~cm}$. long, 6 to $12 \mathrm{~mm}$. wide, mucronateserrate, with 3 to 6 teeth on each margin, 1 -veined and finely reticulate or with several veins from base and these anastomosing above, thin, rigid; heads terminal, radiate; peduncle 8 to $16 \mathrm{~cm}$. long, bearing a few linearsubulate bracts, the lower bracts commonly dentate and leaf-like; involucre hemispheric, 11 to 13 or $14 \mathrm{~mm}$. high; bracts loosely imbricated in about 4 lengths, linear-acuminate, the largest 1.5 to $1.7 \mathrm{~mm}$. wide, the outer acicular ones spreading or recurved and sometimes more herbaceous than the rigidly erect inner ones, these with narrow or wide white margins, glabrous or puberulent; ligules 30 to 50 , about $10 \mathrm{~mm}$. long by $3 \mathrm{~mm}$. wide, yellow; achenes 3 to $4 \mathrm{~mm}$. (or more?) long, sericeous; pappus reddish (at first white?). (Plate 2.) 
Coastal districts of Chile, from about Province Coquimbo to Maule, also far north (if labels are correct). Type locality (of Diplopappus chrysanthemifolius), "in rupibus maritimis pr. Concon Chilensium."

Type collection, Poeppig 243 (B); "Tarapaca" (B, labeled H. formosus by Philippi); Coquimbo, Cuming S92 (K, type of Diplopappus coquimbensis); Coquimbo, 1856, Harvey (K, the "lanceolatus" form); Illapel, February 1912, Geisse (UZ); Campaná de Quillota, 1856-57, Germain (K); near Valparaiso, Macrae (K, B, the former included in Diplopappus coquimbensis by Hooker and Arnott); near Valparaiso, Cuming 502 (Univ. Cambridge, the "berteri" form, referred to Diplopappus grindelioides Less. by Hooker and Arnott, Comp. Bot. Mag. 2:46, 1836, but very different from that); near Valparaiso, Bertero 103s, in part (DC, type of H. berteri DC., the leaves glabrous except on margins); Valparaiso, Bertero 1035 (P, same form); Colchagua (UW, labeled $H$. acanthodon by Philippi); Talcaregue, Gay (DC, peduncles only $2 \mathrm{~cm}$. long); high Andes of Talcaregue, 1831, Gay (Del, the "lanceolatus" form); Cord. Maule, 1855, Germain (Del, the "berteri" form); valley of Rio Colorado, January 1906, Fierz (UZ).

The wide variety of ecologic conditions under which this species grows has permitted the development of a large number of forms, some of which are perhaps of evolutionary significance. None of these now appear to be of specific value, but perhaps future taxonomists, working in the field, and with due consideration to geographic distribution, may be able to group them into minor categories or to demonstrate the falsity of our position. The characters involved, and which present a puzzling array of combinations even in the comparatively limited number of herbarium specimens at hand, are chiefly those of leaf-shape, especially width, pubescence, density of foliage, abruptness of transition from foliage leaves to bracts of the peduncle, and shape and density of the bracts of the involucre. These involucral features will doubtless be found of greater value than the others. Pubescence furnishes a character easy of use but of doubtful significance. In some collections the plants have glabrous leaves, while in others the leaves are scabrid on both faces, and there are gradations from glabrous to decidedly pubescent peduncles. It is probable that a series of genetic experiments would demonstrate the presence of several biotypes differing from one another in amount and distribution of pubescence.

The earlier botanists were led to unnecessary descriptions of supposedly new species in this group, not only by the richness of forms, but also through a lack of understanding of species described by others. In some cases this has led to the use of different names for almost identical variations. These are all accounted for in the following numbered list. The more outstanding variations, with the names given to them, may be arranged as in the following synopsis:

Involucre of numerous rigid bracts, all nearly alike as to texture and color, all chartaceous.

Leaves mostly 10 to $12 \mathrm{~mm}$. wide, broadly oblanceolate and tending to be obtuse.

H. chrysanthemifolius (Less.) DC., sensu strictu. Leaves obovate or broadly oblanceolate, with cuneate base, rather obtuse, 2 to $3 \mathrm{~cm}$. long, 10 to $12 \mathrm{~min}$. wide, nearly glabrous but margins scabrid, 1-veined and minutely reticulate, membranaceous; involucral bracts all rigid, linear-subulate, dark, the pale margins being almost obsolete. (Plate 2, Fig. 1.)

$H$. berteri DC. Leaves of same shape as in typical chrysanthemifolius, of, about same size ( 3 to $3.5 \mathrm{~cm}$. by $12 \mathrm{~mm}$.), and pubescence same in types, with several veins from base, these anastomosing above, subcoriaceous; twigs perhaps more elongated and foliage therefore less dense; involucre as in typical form except that the bracts are prominently white-edged. (Plate 2, Fig. 3.)

Leaves mostly 6 to $10 \mathrm{~mm}$. wide, oblanceolate, acute.

$H$. berteri var. lanceolatus DC. Leaves oblanceolate, the terminal lobe acute, 3.5 to $4 \mathrm{~cm}$. long, 6 to $10 \mathrm{~mm}$. wide, scabrid on both faces or nearly glabrous but margins scabrid, the veining and texture as in berteri; involucral bracts all rigid, linear-subulate, white-margined. (Plate 2, Fig. 4.) 
Involucre of fewer and looser bracts, the outer bracts greener and not rigid.

Diplopappus coquimbensis Hook. et Arn. Leaves oblanceolate, obtuse but of ten with acute terminal lobe, about $2.5 \mathrm{~cm}$. long, 5 to $10 \mathrm{~mm}$. wide, finely and densely puberulent, passing abruptly into scale-like bracts of the peduncle, the peduncle therefore long; outer involucral bracts not recurved, more herbaceous than inner ones. (Plate 2, Fig. 2.)

$H$. hirtellus Phil. Leaves oblanceolate, elongated, with slender base, acute, 3 to 4 $\mathrm{cm}$. long, 10 to $12 \mathrm{~mm}$. wide, almost cinereous but not tomentulose, passing gradually into bracts of the peduncle; outer involucral bracts inclined to recurve, more herbaceous than the rigid inner ones. (This form is retained beyond in specific rank but probably should be reduced into chrysanthemifolius.)

1. Grindelia glutinosa Bert., Merc. Chil. for 1829, p. 646 (and trans. in Am. Jour. Sci. $23: 84,1832)$. According to DeCandolle this is the same as his $H$. berteri (No. 6 of this list). At the place cited Bertero does not publish the name as new, but merely refers to G. glutinosa Dunal, with a brief description, at the same time expressing his doubts as to the identification.

2. Andromachia alternifolia Kuntze in Poeppig, Syn. Pl. Am. Austr. MSS. Diar. 328. A name published only in synonymy by Lessing, Iinnaea 6:115 1831.

3. Diplopappus chrysanthemifolius Less., Linnaea 6:115, 1831.

4. D. inuloides Hook. et Arn., Comp. Bot. Mag. 2:46, 1836. This includes two forms of the preceding synopsis. The first specimen cited (cliffs, Valparaiso, Bridges) is practically identical with the type of $H$. berteri lanceolatus DC. The other cited specimen (same locality, Cuming 404) is the same as the type of $H$. berteri DC., except that the leaves are more scabrid on the margins. The description is mostly of this second specimen.

5. D. coquimbensis Hook. et Arn., l. c. A pubescent form described in the preceding synopsis. Type locality, Coquimbo.

6. Haplopappus berteri DC., Prodr. 5:348, 1836 (September?). A form with somewhat leathery, veiny leaves and white-margined involucral bracts. Type locality, rocky, maritime places near Valparaiso.

7. H. berteri $\beta$ ? lanceolatus DC., l. c. A narrow-leaved and puberulent form of $H$. berteri, with which it was collected.

8. Aster berteri O. Kuntze, Rev. 317, 1891. Based upon H. berteri DC.

9. Haplopappus hirsutus Phil., Anal. Univ. Santiago 87:600, 1894. Not seen, but from the description apparently a somewhat hirsute form of $H$. chrysanthemifolius. The leaves are broad, each margin with about 10 teeth which tend to recurve, as in H. uncinatus. Type locality, Concon, near Valparaiso.

10. H. formosus Phil., Anal. Univ. Santiago 87:601, 1894. This is exactly the "berteri" form of $H$. chrysanthemifolius, judging from the original description and from specimens named by Philippi. The type was from an unknown habitat.

11. H. acanthodon Phil., l. c. 603,1894 . One of the forms intermediate between $H$. berteri and its variety lanceolatus, but the leaves slightly more spinydentate than in either. The type, from near Cahuil, Prov. Colchagua, is described as hirtellous. In specimens named by Philippi the peduncles are hirtellous but the leaves are glabrous except for the scabrous margins. The leaf-shape is that of lanceolatus. Philippi assigns the remarkable length of $18 \mathrm{~mm}$. to the involucral bracts.

12. H. leucanthemifolius Phil., Anal. Univ. Santiago 87:605, 1894. Philippi hesitated to unite this with $H$. chrysanthemifolius because of its naked peduncles and the pubescent tube of the ray-flowers. But the peduncles of the older species are only remotely bracteate, and the pubescence character is of little value. Type locality, near Valparaiso.

13. H. hirtellus var. hirsutus Reiche, Fl. Chil. 3:321, 1902. Based upon H. hirsutus Phil.

Apparently this is one of the commonest species of middle Chile, where it has passed for the most part under the name of $H$. berteri DC. This confusion has arisen from the fact that DeCandolle did not clearly understand the Diplopappus chrysanthemifolius of Lessing, there being none of the type 
material in his herbarium. He was therefore led to redescribe this earlier species under the name berteri at the same time that he made the proper transferral of chrysanthemifolius to Haplopappus.

\section{Haplopappus hirtellus Phil., Linnaea 28:726, 1856}

Stems woody, with elongated erect branches, leafy nearly to heads; herbage rather densely hirtellous; principal leaves attenuate to a petiole, ascending, oblong-spatulate, obtuse to acuminate, 2.5 to $3.5 \mathrm{~cm}$. long, 9 to $12 \mathrm{~mm}$. wide, deeply mucronate-serrate, faintly 1-nerved and minutely reticulate; upper leaves narrower, more acute, gradually reduced to bracts; heads terminal, radiate; peduncles 5 to $10 \mathrm{~cm}$. long beyond the leaf-like bracts, bracteate with 2 to 6 nearly entire scales; involucre hemispheric, 9 to $10 \mathrm{~mm}$. high; bracts comparatively few, loosely imbricated in about 4 lengths, linear-acuminate, the largest $1.5 \mathrm{~mm}$. wide, the outer spreading ones dark and herbaceous, the erect inner ones more rigid and whitemargined, mostly puberulent; ligules about $10 \mathrm{~mm}$. long, yellow; achenes sericeous; pappus reddish.

Chile, in Province Coquimbo. Type locality, rocky places near La Serena, ded. Philippi (B).

1. Aster hirtellus O. Kuntze, Rev. 318, 1891.

2. Haplopappus vidali Phil., Anal. Univ. Santiago 87:601, 1894. From the description this appears inseparable from $H$. hirtellus. Type locality, Pan Azucar, Atacama.

3. H. limarensis Phil., 1. c. 602 , 1894. Not seen, but apparently close to if not identical with $H$. hirtellus. The leaves have exceptionally large dentations. Type locality, mouth of Rio Limari, Prov. Coquimbo.

4. H. hirtellus var. limarensis Reiche, Fl. Chil. 3:321, 1902. Based upon $H$. limarensis.

The leaves of this species are more deeply serrate than those of most specimens of $H$. chrysanthemifolius and the upper ones are more gradually reduced to bracts of the peduncle. It is very doubtful, however, if these differences will be found sufficiently constant for specific criteria.

\section{Haplopappus uncinatus Phil., Linnaea 28:728, 1856}

Stems woody, much branched, densely leafy below, ending above in nearly naked 1-headed peduncles; herbage at first densely white-lanate, becoming ałmost glabrous; principal leaves narrowed to a petiole, oblanceolate or narrower, acute, 3 to $5 \mathrm{~cm}$. long, 6 to $12 \mathrm{~mm}$. wide, each margin with about 6 large teeth, these spreading or somewhat recurved and mucronate, coriaceous; heads terminal, radiate; peduncles 6 to $15 \mathrm{~cm}$. long, with a few linear or acerose small bracts; involucre hemispheric, 9 to $11 \mathrm{~mm}$. high; bracts imbricated in about 4 lengths, subulate-linear, dark and mostly herbaceous, white-edged, pubescent, glabrate, viscid, the very slender outer ones inclined to recurve; ligules many, yellow; achenes sericeous; pappus becoming reddish.

Chile, in the central and northern provinces. Type locality, near the Las Arañas silver mine. Colchagua, ded. Philippi (B); Province Santiago, 1862, Philippi (Del); Santiago 1856 and 1857, Germain (Del); Cerro de Renca, near Santiago, Philippi (K); Copiapó, Gay 944 (P); Tarapacá, Philippi (K); Chilean Andes, Cuming 17\%, and Baths of Collina, Macrae (K, types of Diplopappus canescens Hook. et Arn.). 
1. Diplopappus canescens Hook. et Arn., Comp. Bot. Mag. 2:47, 1836. (Not Haplopappus canescens (Phil.) Reiche.) Exactly the same as H. uncinatus, which it antedates, but the specific name is now untenable under Haplopappus.

2. Aster uncinatus O. Kuntze, Rev. 318, 1891.

3. Haplopappus candollei Phil., Anal. Univ. Santiago 87:599, 1894. Not seen, but all of the outstanding features, as described, are those of uncinatus (to which Reiche has already reduced it as a variety) except that the leaves are only $6 \mathrm{~mm}$. wide. Specimens from the type locality, namely, Cerros de Renca, near Santiago, have been named by Philippi as uncinatus.

4. H. uncinatus var. candollei Reiche, Fl. Chil. 3:317, 1902. Based upon $H$. candollei Phil.

This is doubtfully distinct from $H$. chrysanthemifolius, since its sole constant differentiating feature is the tomentulose pubescence. But along with this go certain tendencies, such as the usually recurved teeth of the leaves. It also resembles pulchellus, but the involucral bracts are more herbaceous and the tomentum is distinctive, while from grindelioides, to which it is more closely related, it differs in the narrower leaves and bracts.

\section{Haplopappus velutinus Remy in Gay, Fl. Chil. 4:57, 1849}

Stems woody, brittle, branching to form rounded shrubs sometimes 5 $\mathrm{dm}$. high, the ultimate leafy twigs erect and changing abruptly to nearly naked erect peduncles; herbage from densely hirtellous to glabrous and resinous; leaves sessile by a narrow petiole-like base, elliptic-obovate, very obtuse, 2.5 to $5 \mathrm{~cm}$. long, 8 to 16 or $20 \mathrm{~mm}$. wide, evenly denticulate with forward-pointing mucronate teeth (minutely soft-puberulent in most types, varying to glabrous and glutinous in forms named virgatus and longipes), pinnately veined but only the midvein prominent, rigid; heads solitary, terminal, radiate or discoid; peduncles 10 to $20 \mathrm{~cm}$. long, rigid bearing 1 to 4 short subulate bracts; involucre hemispheric, 11 to $15 \mathrm{~mm}$. high; bracts very numerous, imbricated in about 6 lengths, linear-subulate, the very slender tips curved, $1.3 \mathrm{~mm}$. or less wide at base, pale-chartaceous, with dark or pinkish medial line and tip, externally roughened by minute glands; ligules about $6 \mathrm{~mm}$. long, caducous; achenes brown-sericeous; pappus brown. (Plate 3, Fig. 1.)

Chilean Andes from about Coquimbo south at least to Curicó. Type locality, not exactly stated, but see following citation of types. Talcaregue, Prov. Colchagua, Gay 22, 307 (P, types, in part, ray-flowers mostly wanting); Cord. Ovalle, Gay (P, one of the types, ray-flowers present); Prov. Santiago, ded. Philippi (B, the form called H. virgatus Phil.); rocky cliff, Copada, Prov. O'Higgins, Pennell 12248 (Gr), the form called Pyrrocoma longipes (Phil.); Cord. San Fernando, Philippi (B, the same form); Cord. Curicó, January 1897, Reiche (B, as H. virgatus Phil., but nearer the form named $H$. longipes Phil.).

1. Pyrrocoma longipes Phil., Linnaea 28:733, 1856. An obscurely hirtellous form, described as without ray-flowers. Type locality, Andes near San Fernando.

2. Haplopappus virgatus Phil., Anal. Univ. Santiago 43:491, 1873. A glabrous. form. Type locality, Hacienda Principal, in the Andes.

3. Aster gayanus O. Kuntze, Rev. 316, 1891. Based upon H. velutinus Remy.

4. A. scopiformis O. Kuntze, Rev. 317, 1891. Based upon H. virgatus Phil.

5. A. longipes O. Kuntze, Rev. 318, 1891. Based upon Pyrrocoma longipes Phil.

6. Haplopappus subandinus Phil., l. c. $87: 598,1894$. Apparently belongs either here or near $H$. arbutoides, the habit not stated. Remarkable for its very short peduncles, these only $2 \mathrm{~cm}$. long. Type locality, Prov. Linares. 
7. H. baccharidifolius Phil., 1. c. 606,1594 . Apparently a glabrous form, but the leaves reticulate and thus suggesting the berteri form of H. chrysanthemifolius. The leaf-margins, however, are only serrate-crenate, as in the present species. Philippi suspected the ray-flowers of being sterile. Type locality, Prov. Coquimbo.

8. Haplodiscus ? zañartui Phil., 1. c. 618,1894 . Apparently similar to velutinus, but leafy nearly to the heads. Because of injury by insects it is not known whether the heads are radiate or discoid, and the achenes also are not known.

9. H. longiscapus Phil., 1. c. 620,1894 . Referred by Reiche to Haplopappus longipes. If properly described it should be easily separable on the basis of its double pappus and outer calyculate "involucre." Type locality, Andes of Curicó.

10. H. fallax Phil., 1. c. 622,1894 . Described as of same habit and foliage as $H$. longipes, but with small heads and flowers, the pappus only $6 \mathrm{~mm}$. long, and the outer involucral bracts lanceolate. Plants with small parts are to be expected in $H$. velutinus. In the closely related $H$. illinitus the disk-flowers are sometimes only 6 or $7 \mathrm{~mm}$. long and the pappus is of about the same length. Type locality, Cajon de los Cipreses, Andes of Central Chile.

11. Haplopappus longipes Reiche, Fl. Chil. 3:295, 1902. Based upon Pyrrocoma longipes Phil.

12. H. fallax Reiche, 1. c. 296, 1902. Based upon Haplodiscus fallax Phil.

13. H. zañartui Reiche, l. c. Based upon Haplodiscus zañartui Phil.

Haplopappus velutinus, including its segregated variants, listed above, forms with $H$. illinitus an easily recognized group of the Andes of central Chile. The principal characters used in the separation of "species" in this group are: Shape of leaves, whether broadly oblanceolate or spatulate; apex of leaf, whether obtuse or acute; pubescence, whether fine, dense, and "velvety" or wanting and the surface then glutinous; and presence or absence of ray-flowers. It is believed that all possible combinations of these features will be found. The most nearly constant characters seem to reside in the shape of the leaf, and we therefore provisionally retain two species, velutinus and illinitus, based upon this feature.

Taking velutinus, with typically broad-oblanceolate or narrow-obovate obtuse leaves it is found that the pubescence is dense (though minute), as in a portion of the type; or the pubescence nearly fails, as in other portions of the type collection. In $H$. longipes the nearly glabrous feature unites with the absence of ray-flowers. In $H$. virgatus the leaves are glabrous, but there are well-developed ray-flowers, according to the original description.

TABLE 13-Characters of four of the named forms of the Haplopappus velutinus group

\begin{tabular}{|c|c|c|c|c|}
\hline Taxonomic form & Leaf-shape & Apex of leaf & Pubescence & Ray-flowers \\
\hline $\begin{array}{l}\text { Typical } H . \text { velu- } \\
\text { tinus. }\end{array}$ & $\begin{array}{l}\text { Broadly oblance- } \\
\text { olate or nearly } \\
\text { obovate, } 8 \text { to }\end{array}$ & Obtuse...... & Pubescent.... & $\begin{array}{l}\text { Present, decid- } \\
\text { uous }\end{array}$ \\
\hline H. longipes..... & $\begin{array}{c}\text { Same, } 10 \text { to } 14 \\
\text { mm. wide. }\end{array}$ & Obtuse...... & $\begin{array}{l}\text { Obscurely pu- } \\
\text { bescent. }\end{array}$ & Absent \\
\hline II. virgatus. & $\begin{array}{c}\text { Same, about } 16 \\
\text { mm. wide. }\end{array}$ & Obtuse... & $\begin{array}{l}\text { Glabrous and } \\
\text { glutinous. }\end{array}$ & $\begin{array}{l}\text { Present (ac- } \\
\text { cording to } \\
\text { Philippi) }\end{array}$ \\
\hline H. illinitus..... & $\begin{array}{l}\text { Spatulate, } 5 \text { to } 11 \\
\text { mm. wide. }\end{array}$ & $\begin{array}{l}\text { Acute or with } \\
\text { tendency to } \\
\text { be acute. }\end{array}$ & $\begin{array}{l}\text { Glabrous, glu- } \\
\text { tinous, pu- } \\
\text { bescent on } \\
\text { edges. }\end{array}$ & Present \\
\hline
\end{tabular}


However, in specimens named by Philippi the heads appear to be discoid. Still other specimens are typical velutinus in all features except that the rayflowers are either wanting or very early deciduous.

In the second species, as here accepted, that is, Haplopappus illinitus, the leaves are more elongated, almost exactly spatulate, or cuneate with a much narrowed and elongated base. In the type specimens the apex is acute, but in others, which must be referred here because of the leaf-shape and the copious glutinous exudate, the apex varies from acute to obtuse (Bridges 225, Cuming 285). As far as known, these illinitus plants, with elongated nearly glabrous leaves, are always radiate.

\section{Haplopappus illinitus Phil., Linnaea 28:727, 1856}

A low shrub very similar to $H$. velutinus; herbage glabrous and very glutinous, as though varnished (typical form), varying to puberulent or even subtomentose in forms not otherwise separable; leaves oblong-spatulate, 3 to $6 \mathrm{~cm}$. long, 5 to $16 \mathrm{~mm}$. wide, mucronate-denticulate; peduncles, heads, etc., as in velutinus, but the ray-flowers always present and persistent (as far as known), their yellow ligules about $10 \mathrm{~mm}$. long. (Plate 3 , Fig. 2.)

Andes of middle Chile. Type locality, near Linares. Linares, ded. Philippi (B); Hacienda Monte Grande, Prov. Curicó, Werdermann 537 (UC); Prov. Cortadera, Santiago, Werdermann 490 (UC, a tomentose and tardily glabrate form).

1. Aster illinitus O. Kuntze, Rev. 318, 1891.

2. Haplopappus stenophyllus Phil., Anal. Univ. Santiago 87:604, 1894. (Not $H$. stenophyllus Gray, 1874.) Referred here by Reiche, and apparently not to be distinguished. The linear-oblong or almost oblanceolate leaves are only $2.5 \mathrm{~cm}$. long by $7 \mathrm{~mm}$. wide, and the entire plant is glabrous and somewhat viscid. Type locality, central provinces of Chile, of which Linares is mentioned.

3. H. glutinosus var. illinitus Reiche, Fl. Chil. 3:315, 1902.

A comparison of $H$. illinitus with $H$. velutinus, from which perhaps it should not be separated, will be found under the latter. Both forms are subject to much variation in pubescence, so that the specific names are not always appropriate. The second Werdermann specimen cited above (No. 490) has exactly the leaf-shape of the present species, but the leaves are covered with a soft, almost tomentose pubescence which in age is deciduous, exposing the green, viscid surface of the typical form. Variation is evident also in $H$. velutinus, which passes from the typically puberulent form, through those which are only hirtellous, to forms in which the leaves are glabrous except for the scabrid margins, and thence to perfectly glabrous examples.

\section{Haplopappus elatus (Phil.) Reiche, Fl. Chil. 3:293, 1902}

Stems woody, with elongated virgate branches, the shrub 1 meter or more high; herbage obscurely puberulent, glabrate, not resinous; leaves long-petioled, the lower spatulate, 3 to $4.5 \mathrm{~cm}$. long, about $13 \mathrm{~mm}$. wide, serrate with 6 to 8 teeth on each margin, the upper nearly entire; heads solitary, discoid or with short rays; peduncle nearly naked, erect; involucre hemispheric, about $20 \mathrm{~mm}$. broad; bracts numerous, imbricated in about 
3 lengths, linear-lanceolate, acute to filiform-attenuate (inner), the outcr green, the inner pale except at tip; achenes $5 \mathrm{~mm}$. long, sparsely whitehairy; pappus reddish. (Haplodiscus elatus Phil., Anal. Univ. Santiago $87: 617,1894$.)

Known only from the type, collected near Coquimbo, Chile.

This appears to be a very distinct species, best marked by the slender petioles, large heads, and elongated, nearly glabrous achenes.

\section{Haplopappus pulchellus DC., Prodr. 5:347, 1836 (September?)}

Stems woody below, with many erect and ascending branches, herbage glabrous or pubcrulent, glutinous; leaves much narrowed at base, lanceolate, acuminate, 3 to $6 \mathrm{~cm}$. long, 5 to $7 \mathrm{~mm}$. wide, acutely but remotely serrulate (3 to 7 teeth on each margin), pinnately veined, only the midvein prominent, plainly reticulate, coriaceous; heads solitary, terminating corymbosely arranged peduncles, radiate; peduncles 6 to $12 \mathrm{~cm}$. (or more?) long beyond the leafy base, naked or with only 1 or 2 subulate bracts; involucre hemispheric to campanulate, 10 to $11 \mathrm{~mm}$. high; bracts numerous, loosely imbricated in about four lengths, linear-subulate, tip of ten curved, the largest ones $1 \mathrm{~mm}$. wide at base, all pale and chartaceous except on upper part of midrib, glandular-granular and some also puberulent; ligules 5 to $8 \mathrm{~mm}$. long, yellow; achenes sericeous; pappus rufous. (Plate 3, Fig. 3.)

Western middle Chile. Type locality, Rancagua. Type collection, Bertero 314 (Montpell, DC, P); Valparaiso, Bertero 1037 (P); Illapel, Geisse (UZ).

1. Grindelia pulchella Bert., Merc. Chil. for 1829:646, 1829 (translated in Am. Jour. Sci. 23:84, 1832), non Dunal according to DeCandolle. At the place cited, Bertero does not publish the name as new but merely refer's his plants to $G$. pulchella Dunal. He mentions also two varieties which he thinks might merit specific recognition and if so to be called $G$. acerosa and $G$. canescens. These are, therefore, nomina nuda. (See further under these names, p. 341 and p. 321, respectively.)

2. Diplopappus punctatus Less. An herbarium name not published until mentioned as a synonym of $H$. pulchellus by DeCandolle (Prodr. $7: 280,1838$ ). The collection cited by DeCandolle, namely Poeppig 205, belongs to H. punctatus, at least as regards the specimens at Berlin, Vienna, and Paris.

3. Aster valparaisanus O. Kuntze, Rev. 317, 1891.

84. Haplopappus donianus (Hook. et Arn.) Reiche, Fl. Chil. 3:294, 1902

Characters as in $H$. pulchellus, from which perhaps not separable, except as follows: More slender in all its parts and more inclined to be puberulent; leaves only 2 to $5 \mathrm{~mm}$. wide; peduncles 8 to $18 \mathrm{~cm}$. long; bracts of the involucre very slender, the largest ones $0.8 \mathrm{~mm}$. wide at base; heads either radiate or discoid. (Plate 4, Fig. 1.)

Western middle Chile. Type locality, Valparaiso. Type collection, Cuming 785 (K); same locality, Hohenacker 391 (B, K); also Philippi 391 (Del, P); near Valparaiso, Cuming 786 (K, heads discoid).

1. Diplopappus donianus Hook. et Arn., Comp. Bot. Mag. 2:47, 1836 (July?).

2. Haplodiscus tenuifolius Phil., Anal. Univ. Santiago $87: 613$, 1894. The discoid form. Type locality, near Valparaiso.

Assuming that the heads were discoid, Reiche threw this species into his section Haplodiscus, thus distantly separating it from Haplopappus pulchellus, of which it appears to be only a slender form. But donianus was 
first described as radiate and the type specimens have well developed rayflowers. The discoid form was included in the species by Hooker and Arnott, but described without designation other than by the Greek $\beta$. There is some doubt as to the effective publication by Reiche of the combination here adopted, since he failed to cite Diplopappus donianus as a synonym. But his description is exactly that of the discoid form of this and his crediting of the new combination to "Sch. Bip.," following herbarium labels, leaves no doubt as to his intention.

In case Haplopappus donianus and $H$. pulchellus are united it should probably be done under the former name, since Diplopappus donianus Hook. et Arn. apparently antedates $H$. pulchellus DC. by a few months (according to penciled memoranda on copies of the publications at Kew and at the DeCandolle Herbarium).

\section{Haplopappus stolpi Phil., Anal. Univ. Santiago 78:594, 1894}

Stems woody at base, openly branched, the ultimate twigs mostly erect; herbage glabrous (according to Philippi) or scabro-puberulent, glutinous; leaves sessile but attenuate to base, linear-lanceolate, acuminate, 3.5 to 5 $\mathrm{cm}$. long, 4 to $5 \mathrm{~mm}$. wide, remotely and acutely serrate, pinnately veined and conspicuously reticulate, coriaceous; heads solitary, terminal, radiate; peduncles about $10 \mathrm{~cm}$. long, rigid, with 1 or several scale-like bracts; involucre campanulate to obconic, about $10 \mathrm{~mm}$. high $(12 \mathrm{~mm}$. in type, according to Philippi); bracts well imbricated in about five lengths, linear, short-acute or obtusish and mucronate, about $1.2 \mathrm{~mm}$. wide, pale and chartaceous but with dark-green middle portion and tip and with thin white membranous margins, resinous; ligules narrow, $6 \mathrm{~mm}$. or more long, pale yellow; achenes sericeous; pappus yellowish white.

Middle Chile. Type locality, near Pocillas, Prov. Maule. In hillside grove, Concepcion, Prov. Concepcion, Pennell 12858 (Gr).

This species closely simulates $H$. donianus as to foliage and probably as to habit, but in shape and arrangement of the involucral bracts it is entirely different. The green portion of the bract is much larger and the white membranous border is also distinctive.

86. Haplopappus poeppigianus (Hook. et Arn.) Gray, Proc. Am. Acad. 5:121, 1861; not Reiche, Fl. Chil. 4:329, 1902

Stems woody, much branched, moderately leafy up to the peduncle; herbage canescent or tomentose-sericeous; leaves tapering to a short winged petiole, ascending and spreading, narrowly elliptic-lanceolate, acute, 3 to 5 (or 6?) $\mathrm{cm}$. long, 3 to $6 \mathrm{~mm}$. wide, entire, 1-nerved or the nerve obscure; heads discoid, solitary and terminal but sometimes several peduncles from the same leafy branch; peduncles 7 to $15 \mathrm{~cm}$. long, leafy-bracteate only at base, but with several scattered subulate bracts $1 \mathrm{~cm}$. or less long; involucre broadly obconic, about $13 \mathrm{~mm}$. high; bracts loosely imbricated in about four lengths, linear-subulate, the tips erect, less than $1 \mathrm{~mm}$. wide, mostly green but pale-tomentulose, the margins white; achenes sericeous; pappus reddish. (Diplopappus poeppigianus Hook. et Arn., Comp. Bot. Mag. $2: 47,1836$.$) (Plate 4, Fig. 2.)$ 
Mountains of Chile. The types (Cuming 203, K) are labeled merely "Cordilleras." The following belong bere, or perhaps some belong to $H$. canescens if that is maintained: Santiago, 1856-57, Germain (K, not to be confused with collections of $H$. sericeus Phil., bearing the same data); Cerro de San Cristobal, May 14, 1882, Ball (K, Gr); dry hills near "S. Tago" (Santiago?), Philippi (Hohenacker) 558 (P, K).

The combination here adopted as the name of this species was only incidentally made by Gray, who attempted to transfer the specific name from Diplopappus at the same time that he described as new a supposed variety "radiatus." Gray cited $H$. sericeus Phil. as synonymous with his "var. radiatus," and his brief description of the latter shows that this identification was correct, but neither sericeus nor Gray's var. radiatus is at all like the original Diplopappus poeppigianus, indicating that Gray had a misconception as to this last. The types of poeppigianus have leaves rather numerous but not at all congested, the pubescence is loosely silky or canescent, and the bracts of the involucre have straight tips. On the other hand, sericeus has the congested foliage of section Steriphe, the leaves are appressed silky-pubescent, and the glandular bracts have strongly recurved tips. The heads of the former are (always?) discoid; those of the latter have sterile ray-flowers with ligules varying from obsolete to longer than the disk. The combination $H$. poeppigianus is therefore retained for the plant first described as Diplopappus poeppigianus, while the very different "var." radiatus is now referred to $H$. sericeus Phil.

\section{Haplopappus canescens (Phil.) Reiche, Fl. Chil. 3:288, 1902}

Plant closely resembling $H$. poeppigianus but differing as follows: Lower leaves remotely serrate-dentate; pubescence perhaps looser and paler; peduncles often several, sometimes subcorymbosely arranged and then only 4 to $6 \mathrm{~cm}$. long; heads smaller, the involucre hemispheric and only 10 to 11 mm. high. (Not H. ? canescens DC., 1836. See p. 364.)

Foothills of middle Chile. Type locality, not exactly stated, but Philippi reported the species as frequent on dry hills, Prov. Santiago. Santiago, Philippi (K); same locality, Philippi 565 (B).

1. Grindelia canescens Bert., Merc. Chil. for 1829: 646, 1829 (translated in Am. Jour. Sci. 23:84, 1832). A nomen nudum which apparently refers to this species. (See further under G. pulchella, p. 319.)

2. Haplopappus argenteus Steud., Nomen. ed. 2, 1:112, 1840. Based upon Grindelia canescens Bert.

3. Chroilema subcanescens Bernh., Del. Sem. Hort. Erf. 1840, and Linnaea 15, Litt.: 90,1841 , is doubtfully referred here by Reiche.

4. Pyrrocoma canescens Phil., Linnaea 28:730, 1856.

5. Aster griseus O. Kuntze, Rev. 316, 1891.

6. Haplodiscus exserens Phil., Anal. Univ. Santiago 87:614, 1894. Appears scarcely to differ except in the narrower (turbinate?) involucre and pale ligules. Type locality, near Valparaiso.

7. H. polycladus Phil., l. c. 622,1894 . Reduced to $H$. canescens by Reiche, and seemingly belongs here or with $H$. poeppigianus. The leaves are described as entire, the lower ones narrowly oblong and $33 \mathrm{~mm}$. long by $10 \mathrm{~mm}$. wide, which, if correctly stated, indicates a shape quite different from those of the other species just mentioned. Type locality, Province Maule.

8. Haplopappus canescens var. exserens Reiche, Fl. Chil. 3:288, 1902. Based upon Haplodiscus exserens Phil. 
Further collections or field studies may necessitate the inclusion of this species in $H$. poeppigianus, but the evidence at hand suggests that this might lead to confusion between two distinct forms. The involucral differences seem to be the most important, if not due merely to differences in age.

\section{Haplopappus bustillosianus Remy in Gay, Fl. Chil. 4:49, 1849}

Stems woody, much branched to form low, densely leafy bushes, from the ends of which abruptly arise the nearly naked peduncles; herbage glabrous or only scurfy, somewhat resinous; leaves sessile by a narrowed base, narrowly oblanceolate, obtuse or acutish, 2 to $3 \mathrm{~cm}$. long, 4 to $6 \mathrm{~mm}$. wide, rather evenly serrate with 5 or 6 callous-tipped teeth to each margin, moderately veined and reticulate (prominently veined, according to Remy); heads terminal, solitary, radiate; peduncles 6 to $8 \mathrm{~cm}$. long (in type), with only a few subulate entire bracts; involucre hemispheric, 12 to $14 \mathrm{~mm}$. high; bracts numerous, closely and regularly imbricated in 5 or 6 lengths, linearacuminate, the largest about $1 \mathrm{~mm}$. wide, the outer herbaceous and inclined to spread, the inner white-scarious but with dark medial line and tip and rigidly erect, all glabrous or granular; ligules narrow, about $8 \mathrm{~mm}$. long, yellow; achenes sericeous; pappus reddish. (Aster bustillosianus O. Kuntze, Rev. 317, 1891.) (Plate 4, Fig. 3.)

Chile, said by Remy to grow in Provinces Valdivia, Osorno, Ranco, etc. and by Kuntze to occur also in Patagonia (Kuntze, Rev. 3:129, 1898). The only specimen seen is one without locality, Gay (P, type).

This species is remarkable for the very abrupt manner in which the densely leafy branches pass into essentially naked peduncles. It appears to be a derivative of chrysanthemifolius and somewhat resembles the "lanceolatus" form of that species; but the leaves are even narrower and of different outline, and the involucre is much more regularly and neatly imbricated.

89. Haplopappus patagonicus Phil., Linnaea 28:726, 1856. (Not H. patagonicus Speg., 1897.)

Much like $H$. bustillosianus but differing as follows: plants low and subcespitose, the leafy portion 0.5 to $1 \mathrm{dm}$. high; leaves only $2 \mathrm{~cm}$. long in type but varying to $4 \mathrm{~cm}$.; peduncles 8 to $14 \mathrm{~cm}$. long; involucral bracts loosely and irregularly imbricated, linear-subulate, at least the margins of the outer ones tinged with red.

Middle Chile and adjacent Argentina. Type locality, near Lake Nahuelhuapi, Argentina. Coihulco, Province Valdivia, Werdermann 334 (UC); San Carlos de Bariloche, Lake Nahuelhuapi, February 23, 1905, Buchtien $(\mathrm{MW})$.

1. Aster patagonicus O. Kuntze, Rev. 318, 1891.

2. Haplopappus australis Phil., Anal. Univ. Santiago $87: 598,1894$. Referred here with much doubt. The involucral bracts are described as lacking the white border and as subsquarrose. These features suggest H. paucidentatus, but also in patagonicus the bracts are sometimes reddish or dark even to the margins, and the tips occasionally spread, although they are never squarrose. Philippi's comparison with $H$. coronopifolius ( $H$.glutinosus Cass.), especially as to habit, seems to indicate the present group rather than paucidentatus. Type locality, Andes of Valdivia.

3. H. prostratus Phil. in Reiche, Fl. Chil. 3:320, 1902. Published only in synonymy. 
The leafy portion of Haplopappus patagonicus is so low and so much branched that, on basis of habit, the species might be classed with those described as cespitose. The growth is more open, however, than in any of those, and the features of foliage, involucre, etc., ally it with bustillosianus. Reiche has doubtfully united $H$. paucidentatus with the present species, but aside from involucral differences, which themselves seem sufficiently important, paucidentatus differs in its cuneate leaves, dentate only around the summit, and is therefore identified with the older Diplopappus glutinosus Less. If this is correct, then paucidentatus is a decidedly cespitose and compact plant, in no manner connected with the larger patagonicus with its elongated many-toothed leaves.

\section{Haplopappus grindelioides (Less.) DC., Prodr. 5:348, 1836}

Stems herbaceous, or only suffrutescent near base, 0.5 to $2.5 \mathrm{dm}$. high, erect; herbage pubcrulent (leaves with appressed hairs, as in type, or these only ciliate, the stems crisp-puberulent), subtomentose toward heads; leaves sessile and sometimes scmiamplexicaul by a narrowed base (this 1.5 to $3 \mathrm{~mm}$. wide), obovatc-spatulate, obtuse but with an acute terminal tooth, 3 to $5 \mathrm{~cm}$. long, 10 to $13 \mathrm{~mm}$. wide, unevenly spinulose-scrrate, 1 -veined at base, strongly reticulate, chartaceous; heads terminal, solitary, radiate; peduncle 2 to $5 \mathrm{~cm}$. long, either naked above or bracteate nearly to head; involucre hemispheric, 10 to $11 \mathrm{~mm}$. high; bracts nearly uniform, weakly imbricated, linear-subulatc, the largest $1.5 \mathrm{~mm}$. wide, mostly chartaceous, pale or reddish, a few (especially outer) wholly herbaceous, some squarrose, hirsute-puberulent or ciliate; ligules 8 to $10 \mathrm{~mm}$. long, yellow; achenes scriceous; pappus brownish. (Platc 5, Fig. 1.)

Southern Chile, in dry, exposed places. Type locality, not specifically given. Dry foothill slopes near Antucens, southern Chile, Poeppig 202 (B, P, type collection?); Cord. Chillan, ded. Philippi (MW); Baños de Chillan, Prov. Nuble, on rocky slopes at 1,700 to 1,800 meters, Pennell 12388 (Gr, leaves glabrous but ciliate); near same locality, Pennell 12404 (Gr, leaves puberulent and ciliate).

1. Diplopappus grindelioides Less., Linnaea, 6:115, 1831.

2. Haplopappus reflexus Phil., Linnaea 28:728, 1856. Described as fruticose and much branched, but perhaps no more so than in robust plants of grindelioides, with which it shares all essential features. Type locality, near La Florida, Prov. Concepcion.

3. Aster reversus O. Kuntze, Rev. 317, 1891. Based upon H. reflexus Phil.

4. A. grindelioides O. Kuntze, Rev. 318, 1891. (Not Aster grindelioides O. Kuntze, 1. c. 316.$)$

5. Haplopappus tiltilensis Phil. in Reiche, Fl. Chil. 322, 1902. Not finally placed but apparently a form of grindelioides with several spreading stems from a common base. Type locality, Altos de Tiltil, Province Santiago, which is much farther north than any known station for true grindelioides.

\section{Haplopappus marginalis Phil., Anal. Univ. Santiago 18:63, 1861,} and Linnaea $33: 139,1864-65$

Characters as in $H$. grindelioides but the plant more leafy, the upper leaves reaching ncarly to the head; outer involucral bracts lanceolate and decidedly foliaceous.

In the Andes of Nuble, Chile; perhaps also in neighboring provinces. Type locality, Prov. Nuble. Chillan, ded. Philippi (B). 
1. Aster marginalis O. Kuntze, Rev. 318, 1891.

2. Haplopappus heterophysus Phil., Anal. Univ. Santiago 87:607, 1894. Reduced by Reiche to a variety under marginalis, from which it differs in the short (2.5 $\mathrm{cm}$. long) leaves. The original description makes no mention of the involucral bracts being squarrose, a mark of marginalis. Philippi described the ray-flowers as sterile, but according to Reiche this is erroneous. Type locality, Prov. Curicó.

3. Haplopappus heterocomus Phil., 1. c. 608 . Closely similar to heterophysus, but the inner involucral bracts purplish, as is common in grindelioides and marginalis. Type locality, Andes of Curico.

4. H. corniculatus Phil., l. c. 609 . Based upon a fragment from Province Curic6. The ligules are more deeply tridentate than usual, recurved, and purplish. Perhaps this is only an abnormal or unusual form of marginalis.

5. H. marginalis var. heterophysus Reiche, Fl. Chil. 3:323, 1902. Based upon $H$. heterophysus Phil.

Haplopappus marginalis is too close to $H$. grindelioides for a satisfactory species, but the more leafy habit and more foliaceous outer bracts of the involucre may serve to distinguish it until its status can be determined in the field.

\section{Haplopappus decurrens Remy in Gay, Fl. Chil. 4:58, 1849}

Stems woody, parted into strongly striate branches, these leafy almost to the heads; herbage short-hispid as to twigs, lightly scabrid as to foliage; leaves sessile, semiamplexicaul, decurrent, oblong, the lower slightly narrowed toward base, 3 to $4 \mathrm{~cm}$. long, 12 to $16 \mathrm{~mm}$. wide, deeply and somewhat doubly serrate, pinnately veined and strongly reticulate, rigid; heads terminal, radiate; peduncles 1 to $4 \mathrm{~cm}$. long, bearing 1 or 2 serrate or "pinnatifid" bracts; involucre globoid, about $12 \mathrm{~mm}$. high; bracts numerous, loosely imbricated in 4 or 5 lengths, linear-lanceolate, some abruptly acuminate, straight, the largest ones $2 \mathrm{~mm}$. wide, the outer greenish, the inner entirely scarious except midrib and sparingly lacerate-ciliate, all scabriusculous on exposed parts; ligules numerous, about equaling disk (longer when mature?), yellow; achenes pubescent; pappus reddish. (Aster remyanus O. Kuntze, Rev. 317, 1891.) (Plate 5, Fig. 2.)

Central and northern provinces of Chile, according to Remy, who gives no specific type locality. Known to us only from the type specimen, Colchagua, ded. Gay (P).

\section{Haplopappus reicheanus nom. nov.}

Stems woody, branched and densely leafy; herbage very resinous; leaves short-attenuate at base, obovate-oblong, obtuse, 1.5 to $2 \mathrm{~cm}$. long, spinydentate, reticulate, rigid; heads solitary, terminal, sessile and surrounded by upper leaves, radiate; involucre turbinate; bracts loosely imbricated, linear, mucronate, the tip reflexed; ligules long, yellow; achenes white-sericeous; pappus reddish. (H. vernicosus Reiche, Fl. Chil. 3:312, 1902. Not $H$. vernicosus Brandegee, 1889.)

Reported only from the type locality, Altos de Tiltil, Prov. Santiago, Chile.

The foregoing description is adopted from the original one by Reiche, no specimens having been seen. 


\section{Haplopappus philippi (O. Kuntze)}

Stems woody only at base, which divides into several erect or ascending herbaceous branches $5 \mathrm{dm}$. or less long; herbage glabrous; leaves sessile, oblong or linear-oblong, acute, about $3 \mathrm{~cm}$. long by $10 \mathrm{~mm}$. wide including the large rigidly divaricate teeth, thick, obscurely veined; heads panicled, radiate; peduncles $3 \mathrm{~cm}$. and less long, with a few small bracts; involucre hemispheric, 8 to $9 \mathrm{~mm}$. high; bracts numerous, loosely imbricated in about 5 lengths, linear-acuminate, scarcely $1 \mathrm{~mm}$. wide at base, coriaceous, with prominent greenish middle portion, pale margins, and reddish tips, scaberopuberulent; achenes sericeous; pappus reddish.

Province Atacama and adjacent Coquimbo, Chile. Type locality, near Yerbas Buenas, east of Carrizal Bajo. Huasco, ded. Philippi (B).

1. Haplopappus paniculatus Phil., Anal. Univ. Santiago 43:490, 1873. The original publication of the species, but the name antedated by $H$. paniculatus (Nutt.) Gray, Proc. Am. Acad. 7:354, 1868.

2. Aster philippi O. Kuntze, Rev. 316, 1891. Based upon $H$. paniculatus Phil.

Several collections distributed by Philippi as of this species have obtuse involucral bracts and probably belong to $H$. cerberoanus. These two species may be more closely related than their position in the present synopsis would seem to indicate.

95. Haplopappus rigidus Phil., Fl. Atacam. 30, 1860, and Viage des Atacam. 204, 1860

Stems very woody, rigid, irregularly branched, densely leafy near bases of peduncles; herbage glandular-scabrid, the pubescence coarse on peduncle; leaves sessile, semiamplexicaul, oblong, the lower narrowed to base, obtuse, 1.5 to $2.5 \mathrm{~cm}$. long, 6 to $12 \mathrm{~mm}$. wide, coarsely dentate, the triangular teeth spine-tipped, rigidly coriaceous, strongly reticulate; heads solitary, radiate; peduncles 2 to $6 \mathrm{~cm}$. long, nearly naked; involucre hemispheric, about $10 \mathrm{~mm}$. high; bracts closely imbricated in 4 or 5 lengths, lance-acuminate, the tips not recurved, dark green, the base pale, the inner with pinkish scarious tips, all outer ones densely stipitate-glandular; ligules 30 or more, about $1 \mathrm{~cm}$. long, yellow; achenes sparingly villous; pappus reddish.

Desert districts of northern Chile. Type locality, central part of Atacama Desert. Atacama Desert, Philippi 584 (B); Alto de Varas, ded. Philippi (MW); Sierra de Varas, Prov. Antofagasta, Werdermann $1001^{-}(\mathrm{Gr})$; Rio Frio, January 31, 1901 (BM, as H. villaneuvae Phil., but the achenes villous).

1. Haplopappus doellianus Phil., Anal. Univ. Santiago 43:489, 1873. Leaves less reticulate and less strongly spiny-dentate, according to Reiche, who remarks that the type is too fragmentary to permit of a final decision.

2. Aster atacamensis O. Kuntze, Rev. 315, 1891. Based upon H. rigidus Phil.

3. A. doellianus O. Kuntze, Rev. 318, 1891. Based upon H. doellianus Phil.

96. Haplopappus villaneuvae Phil., Anal. Univ. Santiago 87:592, 1894

Stems woody, rigid, densely leafy below; herbage coarsely pubescent with very viscid or gland-tipped hairs, especially on peduncles; leaves sessile, semiamplexicaul and subdecurrent, oblong-spatulate, obtuse, 1 to $3 \mathrm{~cm}$. long, 2 to $8 \mathrm{~mm}$. wide (22 $\mathrm{mm}$. wide, according to Philippi), coarsely den- 
tate, the triangular teeth spine-tipped, coriaceous, very rigid; heads solitary, radiate; peduncles elongated, bracteate, the lower bracts passing gradually into leaves; involucre hemispheric; bracts loosely imbricated, linear, acuminate or mucronate (tips of the outer ones recurved), dark green with narrow scarious margin, stipitate-glandular; ligules 30 to 40, long, yellow; achenes glabrous.

Desert of Atacama. Type locality, Acerillos. Cord. Rio Figueroa, Prov. Atacama, Werdermann $982(\mathrm{Gr})$.

\section{Haplopappus ochagavianus Phil., Linnaea 28:725, 1856}

Stems woody, branching to form low shrubs leafy nearly to heads; herbage coarsely scabrid (leaves) to hirsute (peduncles) and stipitate-glandular; leaves sessile, semiamplexicaul, round-obovate, very obtuse, 2.5 to $3.5 \mathrm{~cm}$. long, 20 to $25 \mathrm{~mm}$. wide, coarsely dentate and the teeth spine-tipped, prominently pinnate-veined and reticulate, coriaceous; heads few, in short racemes (or subcorymbose or perhaps some solitary), radiate; peduncle 2 $\mathrm{cm}$. or less long (or up to $6 \mathrm{~cm}$.?), each from the axil of a leaf-like bract; involucre campanulate, about $14 \mathrm{~mm}$. high; bracts loosely imbricated, linear-acuminate, the tips sometimes reflexed, 1 to $1.2 \mathrm{~mm}$. wide, mostly scarious, the midrib and tip green and stipitate-glandular; ligules numerous, narrow, about $15 \mathrm{~mm}$. long; achenes sericeous; pappus brownish. (Aster ochagavianus O. Kuntze, Rev. 318, 1891.)

Western middle Chile, apparently rare. Type locality, near Quillota, Prov. Valparaiso. Campaña de Quillota, Germain (Kew, part of type collection?).

The original description is not clear as to whether the heads are solitary and long-peduncled or very openly racemose. The specimen above cited has 3 heads in a short, leafy-bracted raceme.

\section{Haplopappus baylahuen Remy in Gay, Fl. Chil. 4:42, 1849}

Stems woody, low, much branched from base and somewhat prostrate, densely leafy to the peduncles; herbage very glutinous, sometimes also stipitate-glandular, especially on leaf-margins and near the heads, or the peduncles even shaggy with gland-tipped hairs (H. domeykoi); leaves sessile by a narrow base, semiamplexicaul, at first ascending, later reflexed, oblanceolate to obovate-spatulate, obtuse or acute, 1.5 to $3 \mathrm{~cm}$. long, 6 to $16 \mathrm{~mm}$. wide, sharply dentate with few teeth to nearly entire, rigid, faintly 1-nerved or pinnately veined, thick, not reticulate; heads radiate, solitary, terminal; peduncle erect, 5 to $15 \mathrm{~cm}$. long, with a few leaf-like bracts; involucre campanulate, 17 to $24 \mathrm{~mm}$. high; bracts imbricated in 4 or 5 lengths, ovate (outer and middle) to linear (inner), acute or some almost obtuse, the largest 4 to $5 \mathrm{~mm}$. wide, the outer becoming recurved from above the middle, chartaceous at base, middle and tip yellowish green, glutinous or stipitateglandular; ligules 1 to $1.5 \mathrm{~cm}$. long, exceeding the disk (including type specimen!), yellow; achenes subcylindric, narrowed at apex, 9 to $10 \mathrm{~mm}$. long when mature, with 10 to 15 nerves, glabrous; pappus brown, becoming reddish. (Plate 5, Fig. 3.)

Northern provinces of Chile and adjacent Argentina. (Specimens labeled as from Santiago probably came from farther north.) Type locality, high 
Andes of Hurtado, Prov. Coquimbo. All of the following are from Chile except the last: Andes of Chapilca, Prov. Coquimbo, Gay 397 (P, types, since no specimens here are labeled Hurtado); Chile, without data, Gay (P, type of $H$. lastarrianus); Potrero de Toledo, Rio Laguna Grande, Prov. Atacama, Johnston 5896 (UC, Gr, a form approaching $H$. domeykoi but less pubescent); Rio Laguna Grande, Prov. Atacama, Werdermann 251 (BM, UC, similar but leaves broader and more dentate); Ola Pampa, between Pedernales and Maricunga, Prov. Atacama, 1922, Harding (Gr, see discussion under $H$. lastarrianus); Cord. Figucroa, Prov. Atacama, Werdermann 967 (Gr, the " $H$. domeykoi" form); vicinity of Baños San Crispin, Andes of northwestern San Juan, Argentina, Johnston 612/4 (UC, Gr, a form similar to 5896).

1. Haplopappus lastarrianus Remy in Gay, Fl. Chil. 4:45, 1849. A form with rather broad and nearly entire somewhat veiny leaves, the herbage strongly resinous and viscid but not stipitate-glandular. The type specimens, said to be from northern Chile, have leaves 8 to $16 \mathrm{~mm}$. wide, mostly with 1 to 4 minute teeth on each margin. The characters may be compared with those of typical baylahuen and domeykoi as follows:

H. baylahuen: leaves dentate, moderately wide (8 to $12 \mathrm{~mm}$.); peduncle and involucre glabrous, glutinous.

$H$. lastarrianus: leaves nearly entire but with a few denticulations, wide (8 to $16 \mathrm{~mm}$.); peduncle and involucre glabrous, glutinous.

H. dorneykoi: leaves nearly entire but with 1 or 2 denticulations to each margin, narrow ( $7 \mathrm{~mm}$. wide); peduncle and involucre glandular-pubescent.

It is very doubtful if a specific separation on the preceding lines will be found useful. The few collections already at hand indicate gradation in all characters and exhibit combinations of characters other than those given. For example, in a single collection (Johnston 6124) the leaves vary from entire through denticulate with 1 to 3 low teeth on each side, to dentate with 3 teeth on each side, these teeth nearly as large as in typical baylahuen. The combination of strongly glandular-pubescent peduncles and deeply cut foliage is found on a single plant (Ola Pampa, Harding), while on another plant minutely stipitate-glandular peduncles are combined with nearly entire and narrow leaves (Johnston 5896). For these reasons, both lastarrianus and domeykoi are here reduced to baylahuen.

2. H. medicinalis Phil., Linnaea $28: 729,1856$. This appears to be the form, occasionally seen in herbaria, with broad leaves, these deeply dentate, the involucral bracts also slightly toothed. Otherwise it resembles $H$. lastarrianus. The reduction to baylahuen has been made by Reiche. Type locality, Chapilio, Coquimbo.

3. H. domeykoi Phil., Anal. Univ. Santiago 87:590, 1894. A form best marked by the notably glandular-pubescent peduncles. (See discussion under $H$. lastarrianus.)

4. H. fluehmanni Phil., l. c. Not seen, but apparently a form of $H$. baylahuen with small leaves ( $1 \mathrm{~cm}$. long, 4 to $5 \mathrm{~mm}$. wide) and somewhat narrow heads. It resembles the lastarrianus form in its glabrous herbage and nearly entire leaves, but the latter are without apparent nerves. Type locality, Atacama Desert and road between San Andres and Coipa.

5. Aster baylahuen O. Kuntze, Rev. 317, 1891.

6. A. lastarrianus O. Kuntze, Rev. 318, 1891.

This is the plant which, in its various forms, is most often called "baylahuen" in Chile, where it is used for the healing of wounds, especially of domestic animals.

99. Haplopappus glutinosus Cass., Dict. d. Sci. Nat. 56:169, 1828

Plant loosely cespitose, the slender woody basal branches spreading to form leafy mats 5 to $15 \mathrm{~cm}$. thick, the entire plant commonly 2 to $3 \mathrm{dm}$. 
high (including heads); herbage glabrous or only hirtellous on peduncles and leaf-margins, moderately glutinous; leaves narrowed to an attenuate petiole, oblong or elliptic in outline, 1.5 to 3 or $4 \mathrm{~cm}$. long, 4 to 8 or $10 \mathrm{~mm}$. wide including lobes (the body 1 to $3 \mathrm{~mm}$. wide), from lobed to pinnately parted nearly to midrib into 1 to 4 linear-acute segments on each side, or the apex merely sharp-dentate, faintly 1-nerved and reticulate; heads terminal, solitary, radiate; peduncles simple, scape-like, 2 to $16 \mathrm{~cm}$. long, naked or with very few acicular bracts; involucre hemispheric, about 10 to $12 \mathrm{~mm}$. high; bracts imbricated in 4 or 5 lengths, linear-acuminate, $1 \mathrm{~mm}$. or less wide, the tips erect or the outer recurved in age but not squarrose, the base chartaceous, the body and tip green, or inner bracts mostly chartaceous, glutinous but glabrous, rarely subciliate; ligules 5 to $10 \mathrm{~mm}$. long, yellow (or sometimes pink?); achenes 4 to $5 \mathrm{~mm}$. long, sericeous; pappus reddish. (Plate 6, Fig. 1.)

In Chile and Argentina, from about the latitude of Concepcion southward and eastward at least to Chubut. Type locality, not positively known, but Cassini based his description upon specimens probably collected by d'Urville, who is known to have found the species at Concepcion (see p. 23). Chile: Concepcion, 1823-26, d'Urville (P, DC, probably part of type collection); dry fields, Concepcion, Poeppig 63 (P, B, BM); stony streamways, Valdivian Andes, January 1897, Neger (B); near Arguilue, Cordillera de Ranco, Lechler 830 (Del, P, Leiden); Puerto Saavedra, Boroa, Hollermayer 145 (B). Argentina: San Carlos de Bariloche, Rio Negro Terion, February 23, 1905, Buchtien (Leiden); Nirikó, near Bariloche, Hosseus 1433 (B); Rio Corcovado, Chubut Ter., Illin 20 and 159 (Brux).

1. Diplopappus coronopifolius Less., Linnaea 6:112, 1831. Exactly synonymous with $H$. glutinosus, which was cited as a synonym.

2. Haplopappus coronopifolius DC., Prodr. 5:347, 1836. Based upon Diplopappus coronopifolius Less., which was mentioned in synonymy, although the description was modified to include minor variations in the DeCandolle herbarium.

3. H. coronopifolius var. laxus Phil., Linnaea 33:140, 1864-65. Described as a glaucous, less leafy form. Type locality, foot of the Andes, in Valdivia.

4. Aster senebierifolius O. Kuntze, Rev. $3^{2}: 131,1898$. Based upon H. coronopifolius DC.

This is the type species of the genus and must therefore bear its original name of Haplopappus glutinosus. Three years after it was first described, Lessing, in transferring it to the genus Diplopappus changed the specific name to coronopifolius, presumably because he considered this more descriptive and also because he desired to apply the name glutinosus to a very different and much more glutinous species at that time still unchristened. This he then described as Diplopappus glutinosus Phil. Then, five years after Lessing's paper, DeCandolle accepted Cassini's genus, Haplopappus, but in restoring to it its type species he retained the later name proposed by Lessing, making the new combination, Haplopappus coronopifolius; and on the same page he used $H$. glutinosus for Diplopappus glutinosus Less.

In order to set matters right, in accordance with modern codes of nomenclature, it is therefore necessary to restore Haplopappus glutinosus Cass. as the name of the present species with deeply dentate to pinnately parted leaves and to find another name for $H$. glutinosus (Less.) DC. (This latter is now doubtfully identified with the later $H$. paucidentatus. See Plate 8 Fig. 4.) 
In its typical form, Haplopappus glutinosus is perhaps the most easily recognized of all the South American species, chiefly because of its subpinnatifid foliage. This character appears elsewhere only in $H$. pectinatus and $H$. araucanus, both of which have a very different habit. But unfortunately the lobes in glutinosus are sometimes very short, so that the leaves are only dentate. While this does not merge the species into any other, it renders the character not entirely trustworthy for key purposes.

100. Haplopappus rosulatus sp. nov.

Plant fruticose, depressed, cespitosely much branched; flowering branches leafy to summit, 1.0 to $1.5 \mathrm{dm}$. high, sparingly white-tomentose; leaves rosulate, the upper alternate, sessile, obovate or oblanceolate, obtuse, attenuate at base, 0.9 to $1.4 \mathrm{~cm}$. long, 4 to $6 \mathrm{~mm}$. wide, sparsely setose-

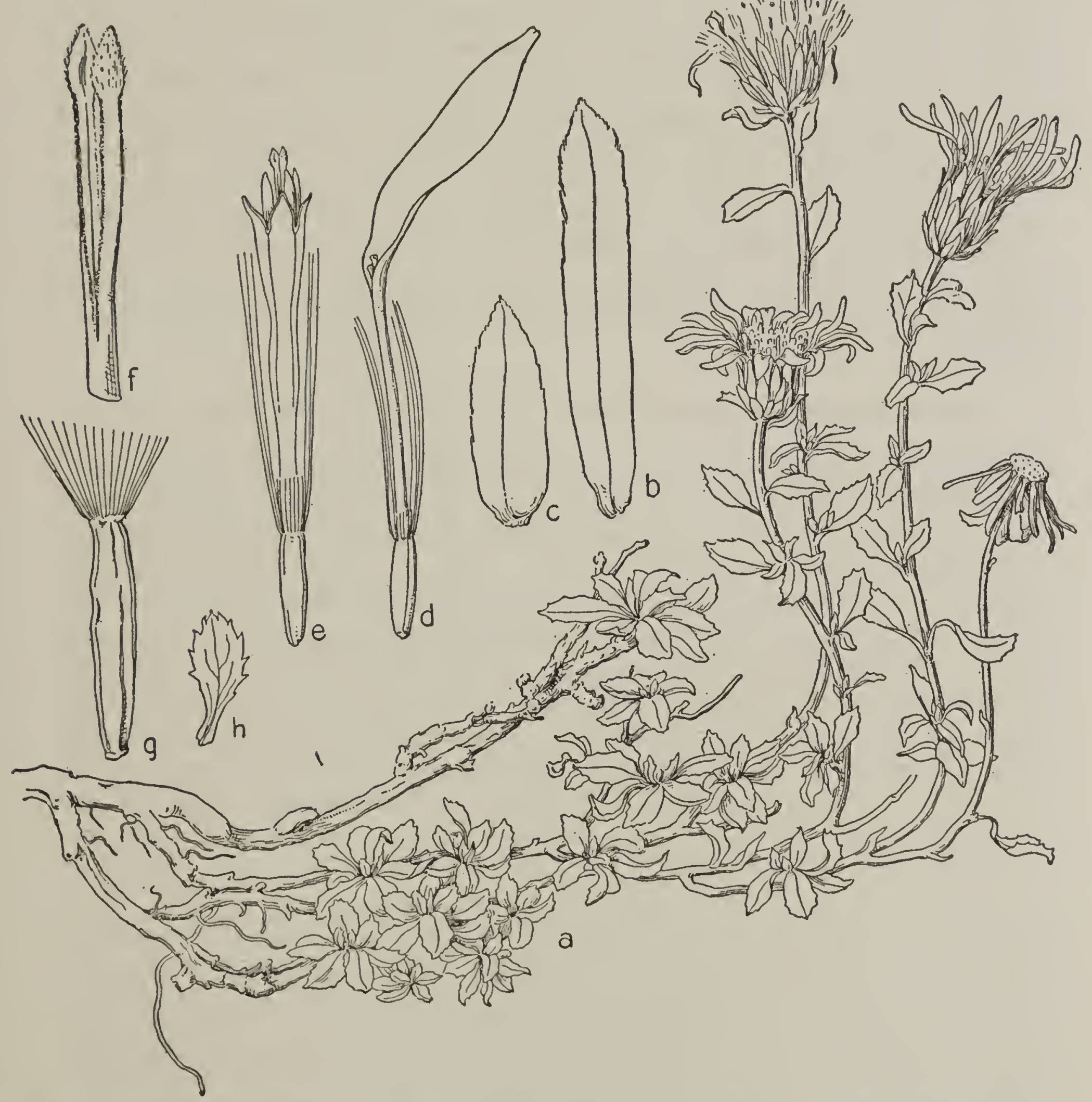

FIG. 113-Haplopappus rosulatus. $a$, habit $\times 1 ; b$, inner bract of involucre $\times 4$; , outer bract of involucre $\times 4 ; d$, ray-flower $\times 4 ; e$, disk-flower $\times 4 ; f$, style-branches $\times 16 ; 0$, disk-achene with base of pappus $\times 7 ; h$, leaf $\times 1$. Drawn from the type specimen 
denticulate, ciliate near base, obscurely veined and reticulate, drying chartaceous, hirtellous; heads terminal, solitary, leafy-bracted, radiate; involucre hemispheric-campanulate, about $10 \mathrm{~mm}$. long, 8 to $10 \mathrm{~mm}$. broad; bracts imbricated in 4 series, oblong, about $2 \mathrm{~mm}$. wide, obtuse or acutish, red-chartaceous, the apex herbaceous, glabrous or the tip puberulent; rayflowers 25 to 30 ; ligules about $10 \mathrm{~mm}$. long, yellow; disk-flowers numerous; disk-corolla cylindric, 8 to $9 \mathrm{~mm}$. long, its teeth ovate and acute; styleappendage subovate, obtuse, much shorter than stigmatic part; achenes striate, about $5 \mathrm{~mm}$. long, glabrous; pappus-bristles about 50, brown, rigid, scabrid, 8 to $9 \mathrm{~mm}$. long. (Fig. 113.)

Vicinity of Aguada Grande, near Antofagasta-Atacama provincial boundar'y, about lat. $26^{\circ} 2^{\prime}$ S., Chile, December 16 to 18,1925 , Ivan M. Johnston, 5815 (type Herb. Gray; duplicate in Herb. Univ. Calif.).

This is given its present position in the sequence of species because of the cespitose habit and leaf characters. It is unlike all the others of this group, however, in the leafy-bracted peduncles and almost obtuse involucral bracts. This latter character suggests a possible connection with Polyphylla, but otherwise it is very unlike any member of that section. In characters it most nearly approaches $H$. diplopappus, a cespitose species of Euhaplopappus from near the regions of perpetual snow in the southern provinces, but differs notably in the obtuse or merely acute bracts of the involucre, in the tomentose, non-glandular stems, and in the less strongly reticulated leaves. According to the collector's notes, the proposed species is perfectly prostrate, forming mats 3 to $6 \mathrm{dm}$. broad, and was found in only three colonies, these on gravelly flats at summit of a high, fog-bathed sea-cliff.

\section{Haplopappus macrocephalus (Less.) DC., Prodr. $5: 348,1836$}

Plant closely cespitose, the numerous short basal branches densely leafy, the whole plant 0.5 to $3 \mathrm{dm}$. high; herbage hispidulous to nearly glabrous; leaves sessile, obovate-spatulate, obtuse, narrowed below to a slender petiolelike base, 2 to $5.5 \mathrm{~cm}$. long, 8 to $20 \mathrm{~mm}$. wide, evenly serrulate all around with forward-pointing bristle-tipped teeth, pinnately veined and reticulate, coriaceous, scabrid at least near margins; heads terminal, solitary, radiate; peduncles scape-like, 2 to $30 \mathrm{~cm}$. long, with 1 to 3 linear bracts or naked; involucre hemispheric, 10 to $14 \mathrm{~mm}$. high; bracts numerous, imbricated but nearly equal in length, linear-subulate, $1.5 \mathrm{~mm}$. or less wide, the very slender tips inclined to spread, chartaceous only at base, the body mostly green, the tips and margins often pinkish, granular to hispidulose; ligules 6 to 8 $\mathrm{mm}$. long, purplish or roseate, rarely yellow; achenes densely sericeous; pappus brownish. (Plate 6, Fig. 2.)

In open and often in rocky places in the central provinces of Chile. Type locality, not definitely stated, but labels with the type collection read: "In Chil. austr. rupibus subalpinus ad Antuco" (DC). Campaña de Quillota, Germain (K); Cord. Santiago, ded. Philippi (B, UW, K); mountains of La Leona, Rancagua, Bertero 315 (DC, P); Cerro Echaurrina, San Fernando, Prov. Colchagua, Montero 10 (Gr); Cord. Colchagua, Philippi (Del, MW); Hacienda Monte Grande, Prov. Curicó, Werdermann 555 (UC); thickets on hills above Rio Claro, Prov. Talca, Elliot 388 (B, see under H. scaposus); 
Prov. Maule, Cuming 840 (K); Cord. Maule, 1856-57, Germain (Del); Cord. Linares, Reiche (B); Chillan, ded Philippi (B); Cord. Chillan, 1855, Germain (Del, K); Cord. Las Arañas, December 1854, Germain (B).

1. Diplopappus macrocephalus Less., Linnaea 6:114, 1831.

2. Haplopappus caespitosus Nutt., Trans. Am. Phil. Soc. II, 7:331, 1840. The type of this, gathered somewhere in Chile by Dr. Styles and now at the Philadelphia Academy of Sciences, differs in no essential from the duplicate types and original description of $H$. macrocephalus. The leaves are of average width, very obtuse, and densely hispidulose on both faces; the solitary peduncle is $16 \mathrm{~cm}$. long, and the involucral bracts, which are mostly greenish, have tips either erect or spreading. (Plate 6, Fig. 2.)

3. Aster macrocephalus O. Kuntze, Rev. 318, 1891.

This is a common species in central Chile, but through a misunderstanding of its characters collections have commonly been named $H$. scaposus and even $H$. diplopappus, so that $H$. macrocephalus itself has been considered rare. No other cespitose species has such very obtuse leaves regularly setose-serrate down to the very base.

According to the original description, Haplopappus macrocephalus should have thick rhizomes, but doubtless this statement was due to a misinterpretation of the short, spreading, non-rooting stems of the closely cespitose plants. No true rhizomes have been found on any of the specimens studied.

102. Haplopappus scaposus Remy in Gay, Fl. Chil. 4:50, 1849. (Not H. scaposus DC., 1836. See p. 365.)

Close to $H$. macrocephalus but described as with acute leaves only about $7 \mathrm{~mm}$. wide and glabrous on both faces.

Type locality, Chile, among rocks of San Antonio (Prov. Santiago) and at Topocalma (Prov. Colchagua), etc.

This appears to be only a variant of Haplopappus macrocephalus. The type can not now be located at Paris. Most specimens seen in European and North American herbaria under this name certainly are macrocephalus, as indicated by the broad, very obtuse, and more or less pubescent leaves. Variation in shape of leaves is noted in a collection from Panamovida, Chile (December 19, 1919, Holway, Gr), in which the leaves on some plants are acute, while on others they are more rounded and obtuse. There is also a collection from Talca (Elliot 388, B) in which some leaves are oblanceolate and acute, others round-obvate and very obtuse. But in these specimens the leaves are also exceptionally small, perhaps as the result of an abnormal development, so that their evidence as a connection between the two forms should be used with caution.

\section{Haplopappus arbutoides Remy in Gay, Fl. Chil. 4:53, 1849}

Plant loosely cespitose, much branched at base to form leafy mats 0.5 to $2 \mathrm{dm}$. high, from the top of which arise the scape-like peduncles, the whole plant 1 to $3 \mathrm{dm}$. high; herbage minutely but densely puberulent, at least the foliage, sometimes varying to glabrous (as originally described), glutinous; leaves short-petioled, elliptic-obovate, very obtuse, 1.0 to 1.5 $\mathrm{cm}$. long, 6 to $12 \mathrm{~mm}$. wide, serrulate around summit and one-half to twothirds the way to base, thick, with obscure midrib, finely reticulate; heads terminal, solitary, radiate; peduncles simple, 3 to $16 \mathrm{~cm}$. long, naked or 
nearly so; involucre campanulate, 10 to $12 \mathrm{~mm}$. high; bracts regularly imbricated in four or five lengths, linear, acuminate, less than $1 \mathrm{~mm}$. wide, the tips erect, thin, scarious and pale or brownish, only the midrib green, lightly hirtellous (or glabrous?), somewhat glutinous; ligules about $10 \mathrm{~mm}$. long, yellow; achenes $5 \mathrm{~mm}$. or more long, white silky-villous; pappus reddish. (Plate 6, Fig. 3.)

Chilean Andes from Coquimbo southward. Type locality, Cord. Ovalle. Type specimens (?), 1839, Gay (P); Cortadera, Cord. Santiago, Werdermann 489 (UC, in part, the remainder being $H$. illinitus Phil.); Talcaregue, Gay 306 (P).

1. Haplopappus glabratus Phil., Linnaea $28: 727,1856$. Doubtfully referred here, following Reiche. Plantlow; leaves as in arbutoides but up to $1.8 \mathrm{~cm}$. long, very sharply dentate, scabrid-ciliate but glabrous, as also the involucre. From the Andes of Province Santiago. Some specimens in European herbaria (B, MW) received from Philippi under this name belong to another species.

2. Aster arbutoides O. Kuntze, Rev. 317, 1891.

3. A. glabratus O. Kuntze, Rev. 318, 1891. Based upon H. glabratus Phil.

4. Haplopappus arbutoides var. glabratus Reiche, Fl. Chil. 3:314, 1902. Based upon $H$. glabratus Phil.

Although here placed in the cespitose group, where it seems to be of close relationship with $H$. cuneifolius, this species appears also to connect with $H$. velutinus and $H$. illinitus. It has almost exactly the involucre of these, but the leaves are much shorter, more obtuse, and broader in proportion to their length. The original description of $H$. arbutoides calls for glabrous leaves, but the only sheet at Paris named by Remy has two specimens, one with glabrous leaves, the other with leaves finely but densely puberulent.

104. Haplopappus cuneifolius Nutt., Trans. Am. Phil. Soc. II, $7: 330$, 1841

Plant low-cespitose, the stems ascending or prostrate, often rooting if covered, the entire (above-ground) plant 0.5 to $1.5 \mathrm{dm}$. high; herbage glabrous, glutinous, sometimes granular on peduncles and involucres but not pubescent; leaves sessile, cuneate-obovate or broadly spatulate, very obtuse, 1 to $1.5 \mathrm{~cm}$. long, 5 to $10 \mathrm{~mm}$. wide, remotely denticulate around summit with low acute or mucronate teeth, or some nearly entire, thick, obscurely if at all veined or reticulate; heads terminal, solitary, radiate; peduncles simple, 0.5 to $5 \mathrm{~cm}$. long, usually with one small bract; involucre hemispheric to campanulate, 11 to $13 \mathrm{~mm}$. high; bracts not numerous, loosely imbricated in about four lengths, linear-lanceolate, very acute, 1.2 $\mathrm{mm}$. or less wide, chartaceous, mostly pink but outer with greenish middle portion and the inner ones pale toward base, glabrous or only granular; ligules about 25 or 30 (about 12 in original specimen, this perhaps defective), 8 to $12 \mathrm{~mm}$. long, yellow; achenes sericeous; pappus brown or reddish. (Plate 7.)

Middle Chile and western Argentina. Type locality, in the former. CHIle: type collection, Styles (Phila); Cord. Ovalle, Gay 33, 969 (P, probably types of $H$. densifolius); Illapel, Prov. Coquimbo, 1886 (BM); Los Ojos de Agua, Bridges 224 (K); Juncal, $33^{\circ}$ S., January 23, 1903, Buchtien (B, Leiden); Rio San Francisco, Prov. Santiago, Werdermann 634 (UC); Cordillera of Chile, Cuming 233 (K, BM, Cosson, type collection of 
Diplopappus bellidifolius). Argentrina: Horcones Valley, Upper Aconcagua, 1896-97, Gosse (K); Puenta del Inca, Mendoza, Rogers (K); Baños del Inca, January 15, 1886 (BM). Indefinite: both sides of the Cumbre of the Cordillera, Gillies (K, types of Diplopappus cuneatus).

1. Diplopappus cuneatus Hook. et Arn., Comp. Bot. Mag. 2:46, 1836. (Not Haplopappus cuncatus Gray, 1873)-Scarcely more than a habit-form of $H$. cuncifolius, differing only in its rather broad leaves, these 6 to $10 \mathrm{~mm}$. wide. The types were collected by Gillies, on the Cumbre of the Cordillera. There are several specimens at Kew of this collection, made from both sides of the Cumbre. The one here illustrated (Plate 7, Fig. 3) has an exceptionally large head, but it is over-mature. The involucre itself measures $13 \mathrm{~mm}$. high. The other plants are of almost the same form but with smaller heads.

2. Haplopappus diversifolius Don in Hook. et Arn., 1. c. A manuscript name published only in synonymy under Diplopappus cuneatus.

3. Diplopappus bellidifolius Hook. et Arn., 1. c. (not Haplopappus bellidifolius Phil., 1894). No differences can be found between the type of this (Cuming 293) and the type of cuneifolius. As compared with D. cuneatus, described on the same page, the leaves of bellidifolius are somewhat narrower and the heads appear smaller and less distended, but this is due to their juvenile condition. The involucre is 12 to $13 \mathrm{~mm}$. high. The species has been doubtfully referred to $H$. glutinosus (Less.) DC. (=H. paucidentatus Phil. of this work), but that has much smaller heads, more attenuate and strongly squarrose bracts, a different leaf-shape, etc. (Plate 7, Fig 2.)

4. Haplopappus densifolius Remy in Gay, Fl. Chil. 4:53, 1849. A low, compact form of $H$. cuneifolius (which was unknown to Remy), based upon Gay's collections from the Cordillera d'Ovalle. The peduncles in these specimens are only 0.5 to $1.5 \mathrm{~cm}$. long, the heads thus scarcely arising above the mass of foliage. The heads are young and therefore small, but the involucres measure 11 to $12 \mathrm{~mm}$. high. (Plate 7, Fig. 4.)

5. Aster cuneifolius O. Kuntze, Rev. 317, 1891.

6. A. densifolius O. Kuntze, Rev. 317, 1891. Based upon H. densifolius Remy.

In its low, compact habit, thick foliage, and large heads, this species exhibits adaptations to the rigorous conditions under which it grows. Altitudes given on collectors' labels are from 2,300 to 2,600 meters, but it doubtless ranges both above and below these contours. It is well set off from all other species unless it is found to approach the scarcely known $H$. scrobiculatus. If further study demonstrates a direct connection it will then be necessary to take up this older name for the inclusive species. At present, however, scrobiculatus seems distinct on the basis of the glandularciliate and perhaps scrobiculate bracts of the involucre.

\section{Haplopappus scrobiculatus (Nees) DC., Prodr. 5:348, 1836}

Plant low, somewhat woody, procumbent, the stems fasciculately divided above; herbage glutinous, shining, rough; leaves crowded, obovatespatulate, obtuse, narrowed to a short petiole, mucronate-denticulate around summit, subcoriaccous, "glandular-punctate;" heads terminal, solitary, radiate; peduncles simple, $4 \mathrm{~cm}$. or less long, with a few lincar bracts; involucral bracts imbricated in several series, lanceolate, erect, acute, chartaceous, glandular-ciliate, the external ones scrobiculate; ligules yellow; achenes strigose-sericcous, silvery; pappus ferruginous.

Known to the writer only from the original description, unless to this species is to be referred a collection from Ojos de Agua, Prov. Aconcagua, November 1827, Poeppig (Bois, MW). In this the bracts are plainly 
scabro-ciliate but scarcely scrobiculate. The type locality was given only as the Cordillera of Chile and no specimen was cited.

1. Diplopappus scrobiculatus Nees, Gen. et Sp. Ast. 284, 1832.

2. Aster scrobiculatus O. Kuntze, Rev. 318, 1891.

106. Haplopappus diplopappus Remy in Gay, Fl. Chil. 4:56, 1849

Plant low-cespitose, somewhat creeping, with many short leafy branches passing into short simple peduncles, 0.5 to $1.5 \mathrm{dm}$. high; herbage glabrous (typical), varying to short-villous (H. villosus Phil.); leaves sessile, obovate or oblong-spatulate (the upper sometimes narrower and approaching oblanceolate), mostly obtuse, the upper acute, narrow at insertion, 1.5 to $3 \mathrm{~cm}$. long, 4 to $14 \mathrm{~mm}$. wide, spiny-serrate with prominent teeth, some leaves nearly entire, pale, very rigid, strongly veined and with prominent reticulations; heads terminal, solitary, radiate; peduncles 1 to $5 \mathrm{~cm}$. long, with a few linear entire bracts passing gradually below into ordinary leaves; involucre hemispheric, about $15 \mathrm{~mm}$. high; bracts imbricated in about four lengths, lanceolate, acute to acuminate, with erect tips, 1.2 to 1.8 $\mathrm{mm}$. wide, thin, mostly scarious and pink or the outer ones green, glabrous to short-villous; ligules 12 to $15 \mathrm{~mm}$. long, yellow; achenes typically sericeous but varying to glabrous; pappus light brown. (Plate 8, Figs. 1 and 2.)

High Andes of middle Chile to middle and southern Argentina. Type locality, Andes of Talcaregue, close to perpetual snow. ChILE: Campaña de Quillota, Germain (B, MW, BM, K, the villous form, $H$. villosus, but achenes pubescent on lower half only, at least in some of the Kew specimens); near Rio Coya, above El Teniente, Prov. O'Higgins, Pennell 12291 (Gr); Talcaregue, Prov. Colchagua, February 1831, Gay 304 (P, probably the type collection); Volcano of Peteroa, Prov. Curicó, Werdermann 591 (UC, Gr); Cord. Talca, February 1879, F. Philippi (B, BM, type collection of $H$. pallidus); lower Andes, near Cauquenes, Reid (K, see under $H$. villosus); Andes near Aculeo, ded. Philippi (B, the villous form, H.villosus); Valle del Yeso ( $\mathrm{K}$, ex-Reed, form near $H$. villosus but achenes mostly glabrous, some with a few long hairs even to summit). Argentina: Mendoza, Gillies 83 (BM); las Cuevillas, Andes of Mendoza, Gillies 71 (K, type of Diplopappus spinulosus); Port Desire, Darwin 310 (K, cited by Hooker and Arnott as D. spinulosus $\beta$., pubescent as in minor variation $H$. villosus); Port Desire, Middletown (K, same variation).

1. Diplopappus spinulosus Hook. et Arn., Comp. Bot. Mag. 2:46, 1836 (not $H$. spinulosus DC.). This can not be specifically distinguished from H. diplopappus. The peduncles are slightly pubescent, thus approaching the form described by Philippi as $H$. villosus, and the achenes are sericeous. A variation with leaves hirsute-pubescent was designated as $D$. spinulosus $\beta$.

2. Haplopappus reticulatus Phil., Linnaea 28:725, 1856. From the description this appears to be intermediate between typical $H$. diplopappus (to which Reiche has reduced it) and the form described as $H$. villosus Phil. It is like the latter in its pubescent peduncles but the leaves are glabrous except on the margins. Type locality, Andes of San Fernando, Chile.

3. H. villosus Phil., Linnaea $28: 725,1856$. A form with densely villous peduncles and pubescent achenes. Type locality, in the Andes near Aculeo. In all specimens seen the leaves also are short-villous at least near margins. Although the pubescence is very striking in this form, it is much too variable a character to justify the retention of villosus in specific rank. For example, 
in a collection from near Cauquenes (Reid, $\mathrm{K}$ ) the peduncles are villous on two plants but nearly glabrous on a third, and the achenes are glabrous except at base.

4. Aster venosus O. Kuntze, Rev. 317, 1891. Based upon H. reticulatus Phil.

5. A. villiger O. Kuntze, Rev. 317, 1891. Based upon H. villosus Phil.

6. A. diplopappus O. Kuntze, Rev. 318, 1891.

7. Haplopappus pallidus Phil., Anal. Univ. Santiago 87:596, 1894. Exactly the same as $H$. diplopappus, judging from the description and from a portion of the type collection, from Andes of Talca, Chile. The name emphasizes the pale color of the foliage, but in the type of $H$. diplopappus the leaves are fully as pale.

8. H. peteroanus Phil., Anal. Univ. Santiago 87:609, 1894. Described from a small branch collected in the Andes of Peteroa, Chile, and probably a form of $H$. diplopappus with stems leafy nearly to the heads, that is, with short peduncles. The peduncles are pubescent and the achenes sparsely scriceous.

A remarkable variation in the pubescence of the herbage and especially of the peduncles has led to the description of several "species" from what is here included under one, and the variation from sericeous to glabrous achenes has led some botanists to classify these forms in widely separated groups. An attempt to convey some idea of the variable nature of these features has been made in connection with the foregoing citation of specimens and in the enumeration of minor variations and synonyms.

107. Haplopappus anthylloides Meyen et Walp., Nov. Act. Acad. Caes. Leopold 19 (suppl. 1):261, 1843, and Walper's Rep. 6:130, 1846

Plant closely cespitose and creeping, rooting from the nodes, forming leafy mats from which arise the short-peduncled heads, the whole plant 0.5 to $1.5 \mathrm{dm}$. high; herbage mostly glabrous but with some spreading pubescence at least on margins or backs of leaves; leaves subimbricate, sessile, oblanceolate, rigidly acute, moderately narrowed toward base, 1 to $2 \mathrm{~cm}$. long, 2 to $6 \mathrm{~mm}$. wide, deeply spinose-serrate, pale, very rigid, prominently veined and reticulate; heads terminal, solitary, radiate; peduncle 0.5 to $3 \mathrm{~cm}$. long, with 1 or 2 linear-lanceolate entire bracts passing abruptly below into ordinary leaves; involucre campanulate, 12 to $15 \mathrm{~mm}$. high; bracts regularly imbricated in four or five lengths, linear-lanceolate, acuminate, the tips erect or some of the outer ones spreading, 1 to $1.2 \mathrm{~mm}$. wide at base, thin, mostly scarious but greenish on exposed parts, the margins and tips pale or violet, glabrous or only granular or short-ciliate; ligules less than $10 \mathrm{~mm}$. long, yellow; achenes typically sericeous but varying to glabrous ( $H$. radicans); pappus brown or reddish. (Plate 8, Fig. 3.)

Andes of Chile, south of Santiago. Type locality, Rio Maipo, at 3,050 meters altitude. Cord. Santiago, 1856-57, Germain (K, achenes glabrous except at base); Rio Maipo, 3,050 meters altitude, March 1831, Meyen (Cusson, part of type collection, achenes glabrous except at base); Copada, Prov. O'Higgins, Pennell 12234 (Gr, achenes glabrous); Cord. San Fernando, Meyen (B, achenes glabrous except at base); Chile, without specific locality, Gay 39, 970 (P, types of $H$. radicans Remy, the achenes nearly glabrous).

1. Haplopappus radicans Remy in Gay, Fl. Chil. 4:45, 1849. This differs only in its glabrous achenes. There is much variation in this feature, however, as noted in the preceding citation of specimens. The original description of 
$H$. anthylloides calls for sericeous achenes, but in plants of the type collection they are sericeous only near the base. Most collections exhibit this restriction of hairs to the basal portion, and even in the types of $H$. radicans a few hairs are tufted at the extreme base of the achene.

2. Aster anthylloides O. Kuntze, Rev. 317, 1891.

3. A. radicans O. Kuntze, Rev. 318, 1891. Based upon H. radicans Remy.

The relationships of this species are undoubtedly with $H$. diplopappus, of which it at times seems to be but a narrow-leaved form. But the leaves are also more regularly dentate, the base is less narrowed to the insertion, and the apex is never obtuse. There is also to be noted the abrupt transition from ordinary leaves to the much narrowed bracts of the peduncle, and the involucral bracts are narrower than in diplopappus. Both are species adapted to a high Andean habitat.

\section{Haplopappus paucidentatus Phil., Anal. Univ. Santiago 43:492, 1873}

Stems slightly or not woody at base, low and compact, the plant therefore cespitose, the leafy portion less than $1 \mathrm{dm}$. high; herbage glabrous, very glutinous; leaves sessile, obovate-cuneate, obtuse, 1.5 to $3 \mathrm{~cm}$. long, 4 to $10 \mathrm{~mm}$. wide, coarsely dentate around summit and down to about the middle with 5 to 8 ovate-mucronate teeth, coriaceous, 1-nerved; heads terminal, solitary, radiate; peduncles about $6 \mathrm{~cm}$. long, with 1 or few linear bracts toward base; involucre campanulate, 8 to $9 \mathrm{~mm}$. high; bracts numerous, imbricated in many series but nearly equal, linear-subulate, less than $1 \mathrm{~mm}$. wide, the base closely appressed, the tips squarrose, dark green even to margins, often purplish at tip, glabrous, very glutinous; ligules about 30 to 40, yellow; achenes sericeous; pappus reddish, shorter than disk-corolla. (Plate 8, Fig. 4.)

Chilean Andes of Arauco, Valdivia, and neighboring provinces. Type locality, near Trapatrapa, Prov. Arauco. Pico de Pilque, Andes of Antuco, Poeppig 203 (DC, P, B, MW, probably the type collection of Diplopappus glutinosus); Andes of Antuco, in 1828 (MW); near Valdivia, on rocks in dry valleys of the Andes, 1897, Neger (B).

1. Diplopappus glutinosus Less., Linnaea $6: 113,1831$. The earliest description but the specific name untenable under Haplopappus because of $H$. glutinosus Cass., the type species of the genus. Type locality, Chile (see preceding citations).

2. Haplopappus glutinosus DC., Prodr. 5:347, 1836, not Cass., 1828. Based upon Diplopappus glutinosus, which see.

3. Aster oligodontus O. Kuntze, Rev. 316, 1891.

4. A. glutinosus O. Kuntze, Rev. 3:129, 1898. Based upon H. glutinosus DC.

Although the type specimen of this species has not been seen, the concept of paucidentatus is here taken to include the better known plant originally described as Diplopappus glutinosus Less. (not Haplopappus glutinosus Cass.). Both are small plants, with cuneate, few-toothed leaves crowded near base, and with decidedly squarrose, slender tips to the involucral bracts of the small heads. Much too little is known of the habit of these forms, and further studies may demonstrate the specific separation of Diplopappus glutinosus. In this case, it possibly may take the name $H$. australis Phil. (p.322), but if that also is distinct it will be necessary to rename this early species of Lessing. A comparison with $H$. patagonicus is given on page 322 . 


\section{Haplopappus prunelloides (Less.) DC., Prodr. $5: 346,1836$}

Plant herbaceous, perennial, with thick rhizomes emitting short leafy branches which form mats 0.5 to $1 \mathrm{dm}$. high, leafy to the heads; herbage glabrous or short-villous; leaves long-petioled (or with elongated narrow petiole-like base), broad-spatulate, obtuse, tapering to the petiole, 2 to 4 $\mathrm{cm}$. long, 7 to $15 \mathrm{~mm}$. wide, obtusely dentate around summit or obtusely lobed, thick, smooth, pinnately veined but only the midnerve prominent, not reticulate; heads solitary, terminal, radiate; peduncles $2 \mathrm{~cm}$. or less long or obsolete, the stems being leafy nearly to the heads, which seldom exceed the foliage; involucre campanulate, 10 to $12 \mathrm{~mm}$. high; bracts imbricated in about four nearly equal series, oblong, the outer ones oblongovate, acute or obtuse and mucronate, the largest about $2 \mathrm{~mm}$. wide, thick and greenish (outer) to chartaceous and pale (inner), the margins (especially of inner) thin and purplish, all glabrous; ligules well developed, yellow; achenes glabrous; pappus yellowish. (Plate 8, Fig. 5.)

Andes and high pampas, from Linares, Chile, to Chubut, Argentina. Type locality, Chile. Chile: Antuco, around La Cueva, Poeppig 204 (DC, P, B, Brux, probably type collection); Cord. Valdivia, ded. Philippi (B, leaves pubescent near margins). Argentina: Comparia Naphophocuel, Ter. Chubut, Illin 241 (Brux, UC); Travesia de Rawson, Ter. Chubut, Illin 25 (UC); high plateaus of Argentina, April 1897, Neger (B).

1. Diplopappus prunelloides Less., Linnaea 6:111, 1831.

2. Aster prunelloides O. Kuntze, Rev. 318, 1891.

3. Haplopappus prunelloides var. sphaerocephalus Reiche, Fl. Chil. 3:300, 1902. Described as a compact form with leaves serrate at apex to lyrate-pinnatifid, the large heads almost globose. Type locality, Cordillera de Linares.

This is the best known of a small group of species marked by their peculiar habit, the herbaceous stems being very short, spreading and rhizomatous at base, and leafy nearly to the heads, which are thus often overtopped by upper leaves. The other species are chrysocephalus and ameghinoi. Although the leaves are here described as petiolate, the "petiole" consists merely of the elongated, ribbon-like lower portion, but this structure is characteristic of the three species taken as a group. The stems were originally described as villous-hirsute, but most specimens seen are perfectly glabrous. An exception is the one cited from Valdivia. Philippi has also noted a pubescent specimen (Anal. Univ. Santiago $87: 589,1894)$.

\section{Haplopappus chrysocephalus Reiche, Fl. Chil. $3: 287,1902$}

Plant with a polycephalous crown, compact, the lower part of stem crowded with vestiges of old leaves, about $1 \mathrm{dm}$. high; herbage hirtellous or glabrate; leaves in rosettes, petiolate (the petiole flat, 1 or $2 \mathrm{~cm}$. long), broad-spatulate, obtuse, narrowed to the petiole, 2 to $4 \mathrm{~cm}$. long (including petiole), 8 to $10 \mathrm{~mm}$. wide, deeply lobed above middle (lobes obtuse), thick, obscurely veined, not reticulate; heads solitary, terminal, discoid; peduncles from the basal tufts of leaves, which they equal or somewhat exceed, 3 to $7 \mathrm{~cm}$. long, with a few linear bracts; involucre hemispheric, about $12 \mathrm{~mm}$. high; bracts imbricated in about four lengths, oblong-linear, acute, the largest about $2 \mathrm{~mm}$. wide, erect, chartaceous, the tips and often the 
margins violet, hirtellous (bracts green, according to Reiche); achenes glabrous; pappus pale yellow.

Known with certainty only from the type collection made in the high Andes of Linares, Chile. (Specimen No. 564 at Berlin, named as this by F. Philippi, is probably a duplicate type.)

1. Pyrrocoma aurea Phil., Linnaea 28:733, 1856. Name changed by Reiche to $H$. chrysocephalus because of $H$. aureus Gray, 1849 .

2. Aster chryseus O. Kuntze, Rev. 315, 1891.

In habit, foliage, and involucre, this species very closely resembles $H$. prunelloides, of which it may be only a discoid form.

111. Haplopappus ameghinoi Speg., Anal. Soc. Cient. Argentina 48:180, 1899, and Nov. Add. Fl. Pat. (repr.) 1: 74, 1901

Plant herbaceous, perennial from a taproot, much reduced, the leaves all in basal tufts surrounding the sessile heads; herbage glabrous, granular; leaves long-petioled, the flattened petiole 1 to $2 \mathrm{~cm}$. long, the blade 0.5 to $1.5 \mathrm{~cm}$. long, 4 to $8 \mathrm{~mm}$. wide, oblanceolate or spatulate, dentate or lobed, thick, obscurely veined, not reticulate; heads solitary, sessile, radiate; involucre campanulate, about $9 \mathrm{~mm}$. high; bracts imbricated in about three lengths, ovate-oblong, acute, nearly $2 \mathrm{~mm}$. wide, mostly chartaceous but with green middle portion; the margins of inner ones membranous and white or pink; ligules short, yellow; achenes glabrous; pappus nearly white.

A species known to the present author only from a collection made in 1905 by Dusén, "in valle Nivali Arro. Pelque," Patagonia (B, K). Type locality, Chonkenk-aik, Rio Chio, Patagonia.

\section{SECTION 18. STERIPHE}

\section{Haplopappus pedunculosus Remy in Gay, Fl. Chil. 4:51, 1849}

Stems woody, much branched throughout, probably forming rounded densely leafy shrubs of considerable size; herbage glabrous, resinous; leaves sessile, not clasping, spreading and soon reflexed or recurved (often from the middle), linear, acute, 5 to $8 \mathrm{~cm}$. long, 2 to $3 \mathrm{~mm}$. wide, mostly entire, sometimes with a few short spine-tipped teeth, rigid, pale, 1-nerved, pitted by the minute reticulations, scaberulous on margins; heads short-radiate, solitary, terminating corymbose branches; peduncles numerous, from the scarcely reduced upper leaves, 6 to $13 \mathrm{~cm}$. long, naked except for minute scattered acicular bracts; involucre broadly obconic, 9 to $10 \mathrm{~mm}$. high; bracts regularly imbricated in four or five lengths, lance-linear, acuminate, the very slender tip occasionally recurved, the largest bracts $1 \mathrm{~mm}$. wide, thin-chartaceous but with green resinous middle portion or tip, glabrous; ray-flowers few, the yellow ligules not longer than the disk; achenes elongate-turbinate, about $3 \mathrm{~mm}$. long, somewhat angled, densely sericeous; pappus reddish. (Plate 9, Fig. 1.)

In Chile, from Colchagua, whence the type, to Malleco. Colchagua, Gay (Gr, probably the type collection); San Fernando, Prov. Colchagua, in streamways of Tinguiririca, February 1831, Gay 299 (P); same region Philippi 958 (P, B, as Steriphe corymbosa Phil.); lower Andes near Cauquenes, May 1882, Ball (B, K); Chillan, in dry, steppe-like pastures, Elliot 993 (B). 
1. Steriphe corymbosa Phil., Anal. Univ. Santiago 23:383, 1863. Philippi's rather full description, and specimens labeled by him as S. corymbosa, leave little doubt that this is exactly $H$. pedunculosus. The type localities appear to be the same, namely, along the Rio Tinguiguirica, near San Fernando, Province Colchagua. In his Flora of Chile, Reiche separates the two in his key on the basis of the involucral bracts, giving them as acuminate for pedunculosus, acute for corymbosus. But in his descriptions the bracts of both species are described as acuminate-acute, indicating that the supposed difference is illusionary. Hoffman (in Engler and Prantl, Pflanzenfam. $4^{5}$ : 151,1894 ) has identified corymbosus with $H$. pulchellus DC., but this is much less leafy, has few peduncles, and produces fertile ray-flowers with long ligules.

2. Aster pedunculosus O. Kuntze, Rev. 318, 1891.

3. Haplopappus corymbosus Reiche, Fl. Chil. 3:330, 1902. Based upon Steriphe corymbosa.

This species is recognized by the numerous, slender peduncles arising from the densely tufted foliage. It resembles pulchellus and donianus of Section Euhaplopappus in foliage and involucre, but the habit is much more compact and the peduncles more crowded.

The only specimen now in the Museum of Natural History at Paris, and named in Remy's hand, is one collected by Gay and labeled merely "Chile." This, which is taken as the type, has exactly the habit, dentate leaves, and other characters of specimens at Paris, Geneva, etc., from the same collector and labeled as coming from Rio de Tinguiririca and San Fernando, which are in Province Colchagua. The similarity is so close that all are suspected of being parts of a single collection, which, if true, makes San Fernando the type locality.

\section{Haplopappus rosmarinifolius Reiche, Fl. Chil. 3:329, 1902}

Closely similar to $H$. pedunculosus except as follows: Leaves only 2 to 5 $\mathrm{cm}$. long, about $1.5 \mathrm{~mm}$. wide, entire but the margins undulate, sharp-pointed, the midrib especially prominent above; involucral bracts merely acute; pappus sordid; achenes not known.

Cordillera de Curicó, Chile, according to Reiche.

\section{Haplopappus punctatus (Willd.)}

Stems erect, woody; herbage glabrous but minutely scabrid, especially the leaf-margins; leaves sessile by a scarcely narrowed base, densely crowded, erect and somewhat appressed (at least when young), straight, narrowly linear, rigidly acuminate, 3 to $5 \mathrm{~cm}$. long, 1 to $3 \mathrm{~mm}$. wide (upper), entire or rarely with 1 or 2 minute teeth, thick, traversed by one rib, this obscure on upper surface, both surfaces divided into minute bordered areas by the fine reticulations and thus "punctate"; heads short-radiate, solitary, terminal; peduncles erect, several from the summits of densely leafy branches, 10 to $25 \mathrm{~cm}$. long, nearly naked but with a few short acicular bracts; involucre broadly obconic, 11 to $12 \mathrm{~mm}$. high; bracts imbricated in about six lengths, linear-attenuate, the tips straight but short outer bracts recurving in age, the largest about $1 \mathrm{~mm}$. wide, green, the narrow margins whitescarious, glabrous; ray-flowers with very short ligules, sterile; achenes sericeous; pappus reddish. (Conyza punctata Willd., Sp. Pl. 3:1937, 1804.)

(Plate 9, Fig. 2.) 
Southern Chile, the type locality not specifically stated. Type specimen, in Herb. Willdenow (B); Andes of southern Chile, Poeppig 829 (P); southern Chile, at Antuco, Poeppig 205 (P, B, MW).

1. Conyza punctata Willd., Sp. Pl. 3:1937, 1804.

2. Diplopappus chamissonis Less., Linnaea $6: 111,1831$, as to synonymy, but the description includes a broader-leaved and somewhat puberulent plant.

3. Haplopappus chamissonis DC., Prodr. 6:347, 1836. Based upon Diplopappus chamissonis Less. and Conyza punctata Willd.

4. Aster adelberti O. Kuntze, Rev. 315, 1891. Based upon H. chamissonis DC.

This was the first-described of a series of species characterized by, having the narrow and elongated leaves massed near the summits of the branches, and by the elongated, erect, and nearly naked peduncles which arise from these leafy tufts. From Haplopappus punctatus, with leaves only 2 to $3 \mathrm{~mm}$. wide and practically entire, there is an almost continuous series of forms to the pinnatifid foliage of setiger. This series passes through integerrimus, with leaves 3 to $6 \mathrm{~mm}$. wide and entire (Bridges 222), or of same size but varying from entire to dentate with 1 to 4 sharp teeth to each margin (Bridges 258), and on through forms with all the leaves pectinate-dentate (Chile, Philippi) to true setiger. The bracts of the peduncle and of the involucre vary somewhat parallel with leaf characters, becoming the most rigid and setose in setiger.

The type specimen of $H$. punctatus has linear-acuminate leaves $5 \mathrm{~cm}$. long by 2 to $2.5 \mathrm{~mm}$. wide, "these entire except that one leaf exhibits a single tooth. (More extensive specimens of this collection doubtless would show a tendency to larger and more dentate leaves.) No ray-flowers are now found in the heads, which, however, do not permit of satisfactory dissection. Willdenow's classification of this species as a Conyza, and the close similarity to plants with short rays, suggest that ray-flowers actually are present.

115. Haplopappus breviradiatus Reiche, Fl. Chil. 3:326, 1902

Stems numerous, straight, forming bushes about $5 \mathrm{dm}$. high, densely leafy below the peduncles; herbage glabrous, resinous; leaves sessile, linear, 1.5 to $2 \mathrm{~cm}$. long, 1.5 to $2 \mathrm{~mm}$. wide, with about 4 short teeth perpendicular to each margin; heads on lateral branches, radiate; peduncles 3 to $4 \mathrm{~cm}$. long, with several narrowly linear leaves; involucre turbinate, about $10 \mathrm{~mm}$. high; bracts narrowly lanceolate, setose-acuminate, the margins purplish; ligules about equaling the disk; achenes villous; pappus yellowish.

Vallenar, Prov. Atacama, Chile; not otherwise known. (Not seen.)

Although Reiche does not state that the ray-flowers are sterile, his reference to short ligules and dense foliage leaves little doubt that this is a species of Steriphe. It is even possible that it merges directly into $H$. punctatus, but its final placement must be left for more detailed field studies.

\section{Haplopappus integerrimus (Hook. et Arn.)}

Stems woody, branched near ground, the plants probably cespitose; herbage glabrous to obscurely puberulent, glutinous; leaves sessile, congested near ends of branches, straight, at first nearly erect, spreading to reflexed in age, linear-oblanceolate, rigidly acuminate, 3 to $6 \mathrm{~cm}$. long, 3 to 6 or $8 \mathrm{~mm}$. wide, entire or remotely denticulate, thick, pinnately nerved as seen from 
below but nerves faint or only midnerve obvious, not punctate; heads shortradiate, solitary, terminal; peduncles erect, 1 to several from the leafy tufts, 8 to $25 \mathrm{~cm}$. long, nearly naked to moderately bracteate, the bracts short and acicular; involucre nearly hemispheric, about 13 to $15 \mathrm{~mm}$. high; bracts very numerous, imbricated in 6 to 8 lengths, linear-attenuate, the cuspidate tips of all but innermost recurved, the largest bracts scarcely $1 \mathrm{~mm}$. wide, mostly green but with thin white margins, nearly glabrous; ray-flowers scarcely exceeding disk, few, sterile; achenes white-sericeous; pappus reddish. (Diplopappus integerrimus Hook. et Arn., Comp. Bot. Mag. 2:47, 1836.) (Plate 10, Figs. 1 and 2.)

In the lower Andes of middle Chile. Type locality (of first specimen cited), San Felipe de Aconcagua. Type collection, Bridges 222 (K, leaves entire); Andes of Chile, Cuming 258 (Kew, leaves dentate to entire); foothills of the Andes, Elliot 395 (BM); Santiago, ded. Philippi (B, MW, K, apparently belongs here, but the bracts abruptly mucronate and ligules exceeding the disk); Prov. Coquimbo, Gay 980, 982 (P).

1. Grindelia acerosa Bertero, Merc. Chil. 1829; Am. Jour. Sci. 23:84, 1833. A nomen nudum. (See under G. pulchella, p. 319.)

2. Diplopappus integerrimus Hook. et Arn., Comp. Bot. Mag. 2:47, 1836.

3. Haplopappus pulchellus var. elongatus Remy in Gay, Fl. Chil. 4:51, 1849. A specimen (Gay 46P), apparently without ray-flowers, labeled as this by Remy, is very distinct from pulchellus, but agrees in all essentials with integerrimus. Another (Gay 323, P), also labeled by Remy, is pulchellus, and probably he had both before him in drawing his description, which, however, is principally that of integerrimus.

4. H. acerosus Phil., Linnaea 28:724, 1856. The description is exactly that of $H$. integerrimus as represented by the type specimen (Bridges 222) but with shorter leaves. Type locality, dry, stony pastures of Rio Maipo.

5. Steriphe acerosa Phil., Anal. Univ. Santiago $87: 678,1894$. Based upon $H$. acerosus Phil.

The recurved tips to the involucral bracts readily distinguish this from both $H$. punctatus and $H$. setiger, but in foliage characters it occupies a middle position, as explained under the former. The Philippi description calls for entire leaves only $3 \mathrm{~cm}$. long, but on most specimens which obviously belong here some of the leaves are sparsely dentate (see under citation of specimens) and they so uniformly exceed this measurement that an error is suspected.

\section{Haplopappus sericeus Phil., Linnaea 28:724, 1856. (Not $H$.} sericeus DC., 1836 . See p. 365.)

Stems low, somewhat woody, cespitosely branched, densely leafy; herbage (leaves) pale, sericeous; leaves sessile, at first erect, later reflexed from base, linear-oblanceolate, pungently acute, 3 to $4 \mathrm{~cm}$. long, 2 to $4 \mathrm{~mm}$. wide, entire, rigid, pale, 1-nerved but the nerve sometimes hidden by the appressed silvery pubescence; heads radiate, solitary, terminal; peduncles 1 or several from each leafy branch, erect, 10 to $15 \mathrm{~cm}$. long (or also much shorter?), with several linear-subulate bracts 0.5 to $1.5 \mathrm{~cm}$. long; involucre campanulate or hemispheric, 10 to $12 \mathrm{~mm}$. high; bracts regularly imbricated in about five lengths, lance-acuminate, the slender tips recurved (except innermost), $1.5 \mathrm{~mm}$. or less wide at base, green or reddish except toward base, glandular on exposed parts; ray-flowers numerous or few, the yellow ligules sometimes 6 or $7 \mathrm{~mm}$. long and exceeding disk, sometimes much reduced; achenes angled, sericeous; pappus whitish or only pale brown. 
Cordillera of Santiago, Chile. Type locality, mines of Las Arañas, Cordillera of Santiago, 1862, Philippi (Del); same locality, Philippi 790 (MW), and 1856-57, Germain (K, BM, not to be confused with specimens of $H$. poeppigianus bearing same data). CHILE, Wilkes Exped. (P, in part); mountains above Rio Colorado, Hastings 443 (UC); Rio San Francisco, Fierro Carrera, Werdermann 633 (UC, Gr, a form with broad heads on peduncles only 4 to $8 \mathrm{~cm}$. long); Valparaiso, Philippi 589 (B, see under Steriphe navarri); Andes of Chile, Wilkes Exped. (Gr, type of $H$. poeppigianus var. radiatus).

1. Haplopappus poeppigianus var. radiatus Gray, Proc. Am. Acad. 5:121, 1862.

2. Aster schumanni O. Kuntze, Rev. 317, 1891.

3. Haplopappus armerioides Phil., Anal. Univ. Santiago 87:597, 1894. The original description gives no satisfactory characters for separating this from $H$. sericeus Phil. The heads are described as hemispheric but only $14 \mathrm{~mm}$. broad, and the pappus as whitish. The type was from the Andes of Prov. Santiago (Las Condes). (Not H. armerioides Gray, 1884.)

4. Steriphe navarri Phil., l. c. 677, 1894. A specimen at Berlin (Philippi 589) labeled in the handwriting of R. A. Philippi as of this species, is exactly $H$. sericeus. Reiche, who doubtless saw both types, has already united the two. Although sericeous and with well, developed ligules, as in this species, the description calls for much larger heads, as in acerosus, with which it was compared by Philippi. 'Type locality, Las Condes, in the Andes of Province Santiago.

The silky foliage readily distinguishes this species from all others of Section Steriphe. The glandular involucres and pale, often nearly white pappus are also noteworthy features. A confusion with the very different $H$. poeppigianus is explained under the latter.

118. Haplopappus humilis (Phil.) Reiche, Fl. Chil. 3:328, 1902

Stems much branched on the ground to form cespitose mats about $1 \mathrm{dm}$. high by $1.5 \mathrm{dm}$. and more broad, slightly woody, very leafy; herbage scabropuberulent (originally described as glabrous), gray; leaves sessile, erect or reflexed, linear-oblanceolate, pungently acuminate, 1.5 to $2 \mathrm{~cm}$. long, 3 to 4 $\mathrm{mm}$. wide, entire, rigid, 1-nerved and reticulate-pitted; heads obscurely radiate, solitary among the leaves; peduncles mostly erect, 0.5 to $2 \mathrm{~cm}$. long, clothed with several lanceolate very acute appressed bracts; involucre obconic, about $10 \mathrm{~mm}$. high (10 to $12 \mathrm{~mm}$. broad); bracts regularly imbricated in five or six lengths, linear, acute or abruptly short-acuminate, the tips erect, the base about $1 \mathrm{~mm}$. wide, yellowish green, edged with a narrow thin white border, granular on exposed parts; ray-flowers few (sometimes wanting?), sterile, the ligules shorter than disk; achenes 4-angled, 5 to $6 \mathrm{~mm}$. long, white-bristly; pappus reddish. (Haplodiscus humilis Phil., Anal. Univ. Santiago $87: 621,1894$.)

Known only from the Andes of Colchagua, Chile. Colchagua, Philippi (BM).

119. Haplopappus setiger (Phil.) Meigen; Engler's Bot. Jahrb. $17: 281,1893$

Stems woody below, much branched near the ground to form densely leafy-cespitose plants; herbage scaberulous, otherwise glabrous, glutinous; leaves sessile, congested on the short branches, straight or upcurved, reflexed 
in age and then densely clothing the short stems, linear, acuminate, rigid, 5 to $7.5 \mathrm{~cm}$. long, about $2 \mathrm{~mm}$. wide (rachis) or 5 to $12 \mathrm{~mm}$. including lobes, pinnatifid or varying to nearly or quite entire, the ascending or spreading lobes and tip rigid-setigerous, strongly 1-nerved from base, often with fainter secondary nerves and cross-veinlets; heads discoid (?) or with obsolete rayflowers, solitary, terminal; peduncles rigidly erect, 1 or several from the basal leaf-clusters, 5 to $15 \mathrm{~cm}$. long (occasionally only 2 to $5 \mathrm{~cm}$. as in types of Diplopappus setiger), provided with subulate-setigerous bracts, these 10 $\mathrm{mm}$. and less long; involucre nearly hemispheric, 13 to $14 \mathrm{~mm}$. high ; bracts very numerous, imbricated in about 5 lengths, tapering from a narrowly lanceolate base to a straight clongated awn (outer sometimes recurved), 1 $\mathrm{mm}$. or less wide, green, the margins and awn white, glabrous; ray-flowers much reduced if present; achenes subturbinate, densely white-villous; pappus reddish brown. (Plate 10, Figs. 3 and 4.)

Lower Andes of middle Chile. Type locality, dry hills near Santiago. The first 3 collections here cited constitute the types of Diplopappus setiger Hook. et Arn. Baths of Colina, Macrae ( $\mathrm{K}$, basal shoot, with leaves only); Questa de Chacabuco, Bridges 221 (K); Chilean Andes, Cuming 178 (K); Chile, Styles (Phila, type of H. pinnatifidus Nutt.); Santiago, Philippi (K, leaves nearly entire); near Santiago, Philippi (Del, Boiss, B, Kew, form with subpinnatifid leaves); Cerro de San Cristobal, May 14, 1882, Ball (K, similar form); San Fernando, Gay 338 (P, with peduncles no longer than leaves).

1. Diplopappus setiger Hook. et Arn., Comp. Bot. Mag. 2:47, 1836. The first description of the species, based upon the first 3 collections above cited. This is the common form with deeply dentate to pinnatifid foliage. Variations in this feature lead directly into the form later described as Pyrrocoma setigera Phil., in which the more scabrid leaves are entire (according to description) or with a few short, setigerous teeth (as in a specimen at Kew named by Philippi). In naming his new species, Philippi did not intend to transfer the specific name used by Hooker and Arnott, whose work apparently was not known to him, but by chance he hit upon the same very descriptive word. In transferring Philippi's species to Haplopappus, Meigen also overlooked Diplopappus setiger, so that the citation of Hooker and Arnott, even in parenthesis, is not permissible.

2. Haplopappus pinnatifidus Nutt., Trans. Am. Phil. Soc. II, $7: 330,1841$. Described from Chilean material as the type of the new section Gymnocoma, but exactly the same as Diplopappus setiger Hook. et Arn.

3. Pyrrocoma nuttalli Remy in Gay, Fl. Chil. 4:67, 1849. Based upon Haplopappus pinnatifidus Nutt.

4. P. setigera Phil., Linnaea 28:733, 1856. (See note under No. 1.)

5. Aster andinus O. Kuntze, Rev. 315, 1891. Based upon Pyrrocoma nuttalli Remy.

6. A. setiger O. Kuntze, Rev. 318, 1891. Based upon Pyrrocoma setigera Phil.

It is not certain that ray-flowers occur in this species, although their presence is hinted by Hooker and Arnott, who refer to them as obsolete. Whether present and much suppressed, or entirely wanting, the species obviously connects with others, such as acerosus, in which the ray-flowers are short and sterile but nevertheless obvious. The connection is indicated by habit, involucre, and intermediate forms as to leaves, and even, in some specimens, by the peculiar bordered pits formed by the reticulate venation, which pits have given the name punctatus to one of these related species. The relation of setiger to punctatus has been discussed under the latter. 


\section{SECTION 19. POLYPHYLLA}

\section{Haplopappus linifolius (Phil.) Reiche, Fl. Chil. 3:286, 1902}

Stems woody, much branched, densely leafy; herbage almost glabrous, resinous; leaves sessile, linear, acutish, entire, 3 to $4 \mathrm{~cm}$. long only 1 to $2 \mathrm{~mm}$. wide, very coriaceous; heads discoid, terminal on long ( 8 to $10 \mathrm{~cm}$.) nearly naked peduncles; involucre obconic; bracts imbricated in about five lengths, ovate (outer) to linear (inner), obtuse, greenish, shining, the apex dark, the margins membranous; achenes glabrous; pappus dull white or yellowish.

Known only from the original collection at Arcos, Province Coquimbo, Chile.

1. Pyrrocoma linifolia Phil., Linnaea 28:730, 1856.

2. Aster linoides O. Kuntze, Rev. 316, 1891.

The affinities of this species are not understood. Possibly it belongs in Section Steriphe, with H. pinea (p. 362).

121. Haplopappus meyeni Walp., Nov. Act. Acad. Caes. Leopold. 19 (suppl. 1):261, 1843, and Rep. 6:130, 1846

Stems herbaceous, densely leafy to summit; herbage glandular (or glabrous?); leaves sessile, semiamplexicaul, oval-elliptic and obtuse or linearlanceolate (and acute?), $2.5 \mathrm{~cm}$. or more long, 5 to $10 \mathrm{~mm}$. wide, all entire; heads radiate (?), solitary, terminal, sessile, hidden by the upper (linear) leaves; involucre campanulate, about $15 \mathrm{~mm}$. high; bracts imbricated in four or five lengths, oblong, obtuse but often terminated by a mucro, greenish and glandular on back, the margins and tip scarious and turning purplish; achenes glabrous (as far as known); pappus reddish. (Aster meyeni $\mathrm{O}$. Kuntze, Rev. 318, 1891.)

The type collection was from the Cordillera de San Fernando, Chile. This we have not seen. The foregoing description is therefore based upon that of Walpers, but so modified as to include a nearly glabrous specimen which probably belongs here (Chile, Gay 381, P). The involucral bracts are said by Walpers to be linear-lanceolate and acuminate, whereas in the specimen by Gay the outer bracts are broadly oblong and obtuse but abruptly narrowed to a mucro, the inner ones much narrower and subacute. The apparent differences may be merely in the descriptions, or possibly two distinct species are involved.

\section{Haplopappus foliosus DC., Prodr. 5:346, 1836}

Stems thick, woody at base where much crowded (plant therefore cespitose when low), 1 to $5 \mathrm{dm}$. or more high, almost hidden by the dense foliage, even to the heads; herbage glutinous, puberulent when young; leaves broadly sessile, spreading, reflexed in age, obovate-spatulate, very obtuse, 2 to $3 \mathrm{~cm}$. long, 10 to $15 \mathrm{~mm}$. wide, irregularly spiny-dentate, rigid, thick, scarcely nerved or reticulate; heads radiate, solitary, terminal, sessile among upper leaves; involucre hemispheric, about $15 \mathrm{~mm}$. high; bracts imbricated in 4 or 5 lengths, oblong, obtuse but mostly mucronate, the largest $3 \mathrm{~mm}$. wide, chartaceous but exposed parts and tips green, glabrous, granular, the inner ones narrower subacute and pale; ligules about 50, 
about $2 \mathrm{~cm}$. long, yellow; achenes subcylindric, not strongly nerved, glabrous or usually sparsely pilose at least at base; pappus reddish brown. (Plate 11, Fig. 1.)

Maritime districts of middle Chile, especially among rocks. Type locality, near Valparaiso. Type collection, January 1830, Bertero 1035 in part (DC, P); Valparaiso, Mertens (B); fissures of rocks, Villa del Mar, Bridges 202 (K, type of Diplopappus foliosus).

1. Diplopappus foliosus Hook. et Arn., Comp. Bot. Mag. 2:45, 1836. This part of the Companion to the Botanical Magazine appears to have been published in July 1836, and if so it antedates DeCandolle's description, which did not appear until September of the same year. It is fortunate that DeCandolle hit upon the same name as that employed by Hooker and Arnott. An examination of the two types shows them to be identical.

2. Haplopappus polyphyllus Phil., Linnaea 30:192, 1859, and 33:139, 1864. Appear's to be exactly $H$. foliosus except that the achenes are described as sericeous. A specimen at the British Museum named by Philippi as $H$. polyphyllus is identical with $H$. foliosus even to the glabrous achenes. It is now well known that the amount of achenjal pubescence varies in this species. Type locality, near Llico, Prov. Colchagua.

3. Aster polyphyllus O. Kuntze, Rev. 318, 1891. Based upon H. polyphyllus Phil.

4. A. foliosus O. Kuntze, Rev. 318, 1891.

The densely crowded leaves, masking the stems and closely subtending the large terminal heads, readily mark this well-known species. In sheltered places the plants sometimes become as much as a meter high, but when exposed they often form low mats only $1 \mathrm{dm}$. or so thick. The species doubtless is a maritime adaptation through $H$. multifolius from some more openly branched interior form like $H$. mucronatus.

123. Haplopappus multifolius Reiche, Fl. Chil. 3:291, 1902

Stems thick, woody at base, densely leafy to the heads; herbage glabrous, very resinous; leaves sessile, obovate, very obtuse, about $3.5 \mathrm{~cm}$. long (average, according to Reiche), 20 to $25 \mathrm{~mm}$. wide, unevenly spiny-dentate with many teeth, thick, rigid; heads discoid, solitary or several, sessile or subsessile among the upper leaves; involucre hemispheric, 12 to $15 \mathrm{~mm}$. high; bracts imbricated in four or five lengths, broad-linear, obtuse, 3-nerved, chartaceous but green or dark in middle and at summit; achenes densely silky-hirsute; pappus reddish.

On the lower Cordillera of Santiago, Chile, the type from Salto de Agua.

1. Pyrrocoma foliosa Phil., Linnaea 28, 732, 1856.

2. Aster multifolius O. Kuntze, Rev. 316, 1891.

The foregoing description is based upon that of Pyrrocoma foloosa by Philippi, with minor changes by Reiche. According to Philippi, the heads are solitary and only six lines long. Possibly Reiche has confused with this some specimens of the large-headed $H$. rotundifolius, or perhaps this should be united with multifolius, especially if the stems of Pyrrocoma foliosa are not so leafy as Philippi's description leads one to belicve. Both of these species differ from $H$. foliosus D. C. in having discoid heads, glabrous achenes, and more rounded upper leaves.

\section{Haplopappus phyllophorus Reiche, Fl. Chil. $3: 291,1902$}

Stems woody, densely leafy to the heads; herbage glabrous; leaves sessile, semiamplexicaul, obovate, obtuse, about $1.5 \mathrm{~cm}$. long by $10 \mathrm{~mm}$. wide, ser- 
rate with about 5 teeth to each margin, rigid, closely reticulate; heads discoid, short-peduncled, 1 to 3 at the end of each branch; involucre hemispheric, about $15 \mathrm{~mm}$. broad; bracts imbricated in about four lengths, broadly linear, obtuse (inner mucronate), coriaceous with dark apex; achenes sericeous; pappus reddish. (Haplodiscus densifolius Phil., Anal. Univ. Santiago $87: 624,1894$.

Known only from the type collection made in Province Atacama, Chile.

\section{Haplopappus kingi (Phil.) Reiche, Fl. Chil. 3:291, 1902}

Probably close to $H$. multifolius in habit and character, but differing as follows: herbage hirsute-pubescent, at least the stems and along the nerves of lower side of leaves, not resinous; heads in a narrow irregular leafy panicle, the lower peduncles $3 \mathrm{~cm}$. long. (Haplodiscus kingi Phil., Anal. Univ. Santiago $87: 615,1894$.

Province Atacama, Chile. Type locality, near Carrizal. (Not seen.)

\section{Haplopappus ischnos (Phil.) Reiche, Fl. Chil. $3: 292,1902$}

Stems woody, erect, branched, densely leafy to the heads; herbage glabrous, resinous; leaves sessile, semiamplexicaul (upper), orbicular-obovate, obtuse, about $2.5 \mathrm{~cm}$. long or longer, dentate with large triangular acute teeth, coriaceous; heads discoid, small, in a contracted leafy panicle; lateral peduncles about as long as the heads; involucre "turbinate," $10 \mathrm{~mm}$. or less high; bracts linear, obtuse, dark purplish with pale margins; achenes sericeous; pappus reddish.

Chile, in Coquimbo, and perhaps in adjacent provinces. Type locality, Cerro Huatulame, Department Ovalle. (Not seen; perhaps related to $H$. reticulatus.)

1. Haplodiscus ischnos Phil., Anal. Univ. Santiago 87:616, 1894.

2. H. landbecki Phil., l. c. Reduced to Haplopappus ischnos by Reiche, and the two seem to be very close, although landbecki (which has priority of position) has a more contracted inflorescence. Type locality, near Choapa, Province Aconcagua.

127. Haplopappus rengifoanus Remy in Gay, Fl. Chil. 4:43, 1849

Stems woody, closely branched to form dense shrubs often 1 to $1.5 \mathrm{~m}$. high, almost hidden by the dense foliage, even to the heads; herbage glabrous, glutinous; leaves closely sessile by a slightly narrowed base, orbicularobovate, very obtuse, 2 to $4 \mathrm{~cm}$. long, 12 to $25 \mathrm{~mm}$. wide, evenly serrulate, chartaceous, the midrib prominent, reticulate; heads short-radiate, solitary, sessile among the leaves; involucre campanulate, about $12 \mathrm{~mm}$. high; bracts imbricated in four lengths, oblong and obtuse (outer) to lanceolate and acute (inner), the largest nearly $3 \mathrm{~mm}$. wide, thick-chartaceous except on the membranous margins, pale save for the green tip, glabrous; ligules numerous, $6 \mathrm{~mm}$. or less long, sometimes obscure (or wanting?); achenes 4-angled and striate, about $5 \mathrm{~mm}$. long, glabrous; pappus reddish. (Plate 11, Fig. 2.)

Chile, in Provinces Coquimbo and Colchagua. Type locality, not definitely stated, but the original description was based upon the following: Prov. Coquimbo, Gay 189 (P); Prov. Colchagua, "saxis maritimis," Gay 303 (P). 
1. Aster rengifoanus O. Kuntze, Rev. 318, 1891.

2. Haplodiscus pachyphyllus Phil., Anal. Univ. Santiago 87:614, 1894. From the description this appears to be a large-leaved form of the present species, to which Reiche has reduced it. The largest leaves are $4.4 \mathrm{~cm}$. long by $28 \mathrm{~mm}$. wide. The largest leaves on type specimens of rengifoanus are $4 \mathrm{~cm}$. by $20 \mathrm{~mm}$. and $3.4 \mathrm{~cm}$. by $25 \mathrm{~mm}$. (Gay 189).

This is undoubtedly of the foliosus-multifolines group, but is readily distinguished from both these species by the nicely rounded, suborbicular leaves, the margins of which are finely and evenly serrulate.

\section{Haplopappus rotundifolius nom. nov.}

Stems woody, erect at least in upper portions, sparsely leafy to summit, the upper leaves longer than internodes but not hiding them; herbage glabrous, resinous; middle and upper leaves sessile, obovate-orbicular, very obtuse, 2 to $4 \mathrm{~cm}$. long, nearly as wide, coarsely spiny-dentate all around, rigidly coriaceous, obscurely veined, resinous-roughened; heads discoid, in short terminal leafy racemes, the uppermost sometimes glomerate, some heads equaled by their subtending bracts, the peduncles (in types) $2 \mathrm{~cm}$. and less long; involucre broadly campanulate, 14 to $17 \mathrm{~mm}$. high; bracts imbricated in four or five lengths, oblong, obtuse, the largest $3 \mathrm{~mm}$. wide, thinchartaceous, longitudinally nerved, green and granular on exposed parts but with conspicuous pale border; achenes 5-ribbed, moderately appressed-villous; pappus reddish. (Diplopappus ilicifolius Hook. et Arn., Comp. Bot. Mag. 2:253, 1837; D. foliosus Hook. et Arn., l. c. 2:46, 1836, by error.) (Plate 11, Fig. 3.)

Andean region of middle Chile and adjacent Argentina. Type locality, Andes of Mendoza. Type collection, Gillies 56 (K); Cord. de Santiago, Germain (K); San Nicolas, Cord. Chile (BM, ex-herb. Miers); lower Andes, Aconcagua Valley, May 1882, Ball (K).

The exceptionally broad and rounded leaves, which approach the orbicular in shape, have suggested the new name assigned to this species. A transfer of the name ilicifolius is precluded, since it has been already twice used in this group as follows: (1) for Haplopappus ilicifolius Remy, now tentatively united with the earlier H. mucronatus Hook. et Arn.; and (2) for Pyrrocoma ilicifolia Remy, which has been replaced by Haplopappus remyanus Weddell.

129. Haplopappus mucronatus Hook. et Arn., Bot. Beech. Voy. 147, 1833

Stems probably woody at base, mostly erect, moderately leafy to summit but upper leaves shorter than internodes; herbage scaberulous, sometimes tomentulose toward the heads (in H. ilicifolius Remy); middle leaves sessile by a half-clasping base, oblong or broadly oblanceolate, obtuse or shortacute, 3 to $6 \mathrm{~cm}$. long, 15 to $20 \mathrm{~mm}$. wide, evenly spiny-dentate, rigid, strongreticulate; heads radiate, long-peduncled and racemose-paniculate, each subtended by 1 or 2 toothed bracts, these nearly as long as head; involucre hemispheric, 14 to $16 \mathrm{~mm}$. high; bracts imbricated in about four lengths, broad-oblong, obtuse, the inner acute, the largest $2 \mathrm{~mm}$. wide, chartaceous at base, greenish toward summit, glabrous except for the subciliate apex; ligules conspicuous, yellow; achenes densely sericeous; pappus reddish. (Baccharis mucronata Hook. et Arn., Bot. Beech. Voy. 30, 1830.) (Plate 12.) 
Province of Coquimbo, Chile. Type locality, Coquimbo. Chile, Cuming 73 (K); Chile, in 1839, Gay ( $\mathrm{P}$, type of H. ilicifolius Remy); Coquimbo (Del); vicinity of Coquimbo, Field (Brux).

1. Baccharis mucronata Hook. et Arn., Bot. Beech. Voy. 30, 1830. The original publication of the species.

2. Diplopappus mucronatus Hook. et Arn., Comp. Bot. Mag. 2:45, 1836.

3. Baccharis hookeriana DC., Prodr. 5:414, 1836, Based upon B. mucronata.

4. Haplopappus hookerianus DC., Prodr. $7: 280,1838$. Based upon Baccharis hookerianus DC.

5. H. ilicifolius Remy in Gay, Fl. Chil. 4:55, 1849.

6. Aster ilicifolius O. Kuntze, Rev. 318, 1891.

7. Haplopappus foncki Phil., Anal. Univ. Santiago 87:606, 1894. Based upon a fragment from La Higuera, Coquimbo, referred by Reiche to $H$. ilicifolius Remy.

This is the plant which usually passes as $H$. ilicifolius Remy, but no essential difference can be found between Remy's types and the earlier mucronatus, which seems to have been overlooked. The type of mucronatus, by Lay and Collie, can not now be found at Kew, but the Cuming plant cited above was accepted by Hooker and Arnott as its equivalent. This is a somewhat coarser plant than the type of ilicifolius, with less spreading branches, and the peduncles are only scabrid (tomentulose in the other).

There is some question as to the effective publication of the combination, Haplopappus mucronatus. At the place above cited, Hooker and Arnott state that their Baccharis mucronata belongs to the genus Haplopappus, but they fail to make the combination. This, however, is given by J. D. Hooker in the Index Kewensis $(1: 162,1895)$, with Hook. et Arn. as the authority.

\section{Haplopappus platylepis Phil., Anal. Univ. Santiago 87:591, 1894}

Stems woody below, erect, elongated, leafy to summit but upper leaves much reduced and shorter than internodes; herbage nearly glabrous, obscurely or not resinous; middle leaves sessile by an attenuate base, narrowly elliptic or oblanceolate, mostly acute, 2 to $3 \mathrm{~cm}$. long, about $4 \mathrm{~mm}$. wide (the lower $4 \mathrm{~cm}$. long by $10 \mathrm{~mm}$. wide), sinuate-dentate with spiny-mucronate teeth, rigid, reticulate; heads radiate, sessile or short-peduncled along the short-leaved branches or the terminal one long-peduncled, the subtending bracts very small; involucre broad-campanulate, about $14 \mathrm{~mm}$. high; bracts imbricated in about 4 lengths, broad-oblong, obtuse, nearly $3 \mathrm{~mm}$. wide, chartaceous, with greenish area near summit, glabrous or only scurfy, the thin margins erose-ciliate near apex; ligules showy, yellow above, purplish beneath (according to Philippi); achenes rounded to summit, narrow at base, with 4 or 5 prominent nerves and intervening striae, lightly and sparsely villous; pappus reddish.

Type locality, "in monte Frai Jorje ad ostium fluminis Limari," Chile. Specimens seen from Philippi, locality not stated (B, K).

1. Haplopappus litoralis Phil., l. c. 610,1894 . Not seen but apparently belongs either here or with $H$. mucronatus. The lower leaves are described as 6 to $7 \mathrm{~mm}$. wide, those surrounding the heads as $9 \mathrm{~mm}$. long. The involucre is given as $17 \mathrm{~mm}$. high, its bracts obtuse, and the achenes as villous. Type locality, Quinteros, near Valparaiso.

2. H. ilicifolius var. platylepis Reiche, Fl. Chil. 3:311, 1902. 
Reiche's reduction of this species to varietal rank under Haplopappus ilicifolius Remy, here taken as H. mucronatus, may be justified in the light of field experience. The type specimens differ from mucronatus, however, in the much smaller leaves, particularly of the branches, in the subspicate arrangement of the heads, and especially in the sparsely pubescent, ribbed, and striate achenes. There is no indication that the achenes of mucronatus would exhibit ribs even if the dense pubescence were removed.

\section{Haplopappus deserticolus Phil., Anal. Univ. Santiago, 87:592, 1894}

Stems woody, 3 to $15 \mathrm{dm}$. high, leafy to summit; herbage pilose (as to stems) and scabrid (as to leaves, at least the margins), glutinous; leaves sessile, amplexicaul and decurrent, erect, broad-oblong, slightly narrowed toward base, obtuse but cuspidate, 2.5 to $4 \mathrm{~cm}$. long, 10 to $20 \mathrm{~mm}$. wide, spiny-dentate, strongly 1-nerved, finely reticulate, gland-dotted, scabrid on margins and sometimes on faces; heads radiate, few, sessile or short-peduncled in the upper axils (subracemose) or terminal and leafy-bracted; involucre broad-campanulate, 12 to $14 \mathrm{~mm}$. high; bracts few, loosely imbricated in about four lengths, lance-oblong, obtuse (outer) or acutish (inner), the tips erect, the largest $2.5 \mathrm{~mm}$. wide, chartaceous at base, the summit dark resinous and subciliate; ray-flowers yellow, the ligules about $8 \mathrm{~mm}$. long; style-branches about $2 \mathrm{~mm}$. long, the ovate appendage much shorter than stigmatic portion; achenes 4 -angled, striate between the angles, about $5 \mathrm{~cm}$. long, glabrous; pappus reddish. (Plate 13, Fig. 1.)

Desert districts of northern Chile. Type locality, Breas. All of the following are from Prov. Antofagasta, Department Taltal: Quebrada de San Ramon, north of Taltal, Johnston 5151 (UC, Gr); vicinty of Aguada de Miguel Diaz, Johnston 5892 (UC, Gr); rocky ledge near Aguada Perales, vicinity of Paposo, Johnston 5603 (UC, Gr); vicinity of Aguada Grande ("Cachinal de la Costa" of Philippi), near Antofagasta-Atacama provincial boundary, Johnston 5752 (UC, Gr).

1. Haplopappus involucratus Phil., l. c. 593, 1894. This appears to be a form in which the sessile heads are surrounded by the subtending leaves and thus themselves involucrate, and the leaves are perhaps more narrowed at base. A specimen at the British Museum labeled as this by Philippi but without data has the upper heads sessile, the others short-peduncled. Type locality, near Cachinal, at the edge of the Atacama Desert, whence comes one of the specimens above cited as $H$. deserticolus.

Haplopappus deserticolus has been compared with $H$. rengifoanus, but that has rounder, scarcely clasping leaves. It is much closer to mucronatus, from which it is doubtfully separated by its perfectly glabrous achenes and usually broader leaves, which tend to be more obovate and more definitely decurrent.

\section{Haplopappus remyanus Weddell, Chloris. And. 1:210, 1855}

Stems (woody?) crowded and densely leafy toward base, but with loose slender nearly naked branches above; herbage glabrous, very resinous; leaves sessile by a broad base, broadly elliptic or oblong, obtuse, about 3 to $4 \mathrm{~cm}$. long, 12 to $20 \mathrm{~mm}$. wide, coarsely sharp-serrate, coriaceous, nerves obscured by resin; heads discoid, solitary, terminating slender pedunculiform 
branches, the subtending bract small or wanting; involucre broad-campanulate, 11 to $13 \mathrm{~mm}$. high; bracts imbricated in four or five lengths, broadoblong, very obtuse, mucronate, up to $3 \mathrm{~mm}$. wide, green, with broad scarious border, rough with resin-dots, faintly 3-nerved (the inner narrow, acutish, scarious); achenes silky; pappus reddish brown. (Plate 13, Fig. 2.)

Provinces of Coquimbo and Colchagua, Chile. Type locality, "Cordilleras de San Fernando." Cord. Ovalle, Gay 460 (P); Talcaregue, Cerro del Pareiso, Colchagua, February, $1831(\mathrm{P})$. The only specimens at Paris labeled by Remy are those here cited and one other from Talcaregue (Gay 43). All of these appear to belong to the same species, but the foregoing description is drawn from this last specimen.

1. Pyrrocoma ilicifolia Remy in Gay, Fl. Chil. 4:67, 1849. (Not Haplopappus ilicifolius Remy, l. c. 55.) The specific name was changed by Weddell (1. c.) to avoid a conflict with $H$. ilicifolius Remy.

2. Aster remyanus O. Kuntze, Rev. 318, 1891. (Not A.remyanus O. Kuntze, 1. c. 317.)

3. Haplopappus prinophyllus Phil., Anal. Univ. Santiago 87:613, 1894. Based upon Pyrrocoma ilicifolia Remy.

This species is recognized by the large, resinous leaves crowded about the bases of the nearly naked and mostly simple flowering branches. The broad bracts of the involucre are distinctively bordered by a continuous white membrane.

\section{SECTION 20. XYLOLEPIS}

\section{Haplopappus bezanillanus (Remy) Reiche, Fl. Chil. 3:289, 1902}

Stems woody below, the erect flowering branches moderately leafy, the leaves gradually reduced in size up the stem; herbage obscurely hirtellous, very glutinous; leaves sessile, erect or ascending, oblanceolate, acute, 4 to 6 $\mathrm{cm}$. long, 5 to $10 \mathrm{~mm}$. wide, remotely serrulate above middle or nearly entire, rigid, pinnately nerved, obscurely reticulate, the margins scabrid; heads discoid, in terminal spikes or in small sessile glomerules, each head or glomerule subtended by a leaf-like bract of about equal length; involucre broadly campanulate, about $10 \mathrm{~mm}$. high; bracts imbricated in four lengths, linearoblong, obtuse (inner acute), the largest about $2 \mathrm{~mm}$. wide, chartaceous except for the greenish tip, with narrow thin margins, subciliate around apex; achenes gradually tapering from summit to base, about $5 \mathrm{~mm}$. long, about 10-costate, some of the nerves rib-like, villous with upwardly appressed hairs; pappus reddish. (Plate 14, Fig. 1.)

Central provinces of Chile, according to Remy. At Paris there are two specimens sent by Gay, and said to be from "Chili austral," but without precise data.

1. Pyrrocoma bezanillea Remy in Gay, Fl. Chil. 4:65, 1849.

2. Aster bezanillanus O. Kuntze, Rev. 317, 1891.

The position of this species in the phylogenetic sequence is uncertain because of its great difference from all the others. It has the broad, almost hemispheric involucre of the mucronatus group, but the rigid, straight, almost woody bracts are rather those of parvifolius and its allies. From both these groups it differs in the shorter involucre and especially in the slender, erect, finely serrulate leaves. 
Stems woody, much branched, the branches ascending, leafy to the top; herbage microscopically puberulent but early glabrate, resinous; principal leaves sessile, narrowly elliptic or oblanceolate, acute or ending in an acute lobe, 2 to $3 \mathrm{~cm}$. long, 5 to $7 \mathrm{~mm}$. wide (the lower probably much larger), often with smaller ones fascicled in the axils, remotely but saliently sharpdentate, the teeth inclined to recurve, rigid, 1-nerved or faintly 3-nerved, minutely reticulate; heads discoid, spicately arranged on short terminal twigs, the whole forming leafy panicles; involucre obconic, about $12 \mathrm{~mm}$. high; bracts few, loosely imbricated in three or four lengths, linear-oblong, concave, rather obtuse, the largest $2 \mathrm{~mm}$. wide, hard-chartaceous, stramineous, the tip greenish and subglandular, otherwise glabrous and shining; achenes turgid, narrowed at base, about $5 \mathrm{~mm}$. long, 10-nerved, moderately white-hispid throughout; pappus reddish. (Plate 14, Fig. 2.)

Known only from the type specimens, Cerros de Polpayco, Prov. Santiago, Chile, growing among rocks, Gay $342(\mathrm{P})$.

1. Pyrrocoma saxatilis Remy in Gay, Fl. Chil. 4: 64, 1849.

2. Aster saxatilis O. Kuntze, Rev. 318, 1891.

3. Haplodiscus sphacelatus Phil., Anal. Univ. Santiago 87:613, 1894. Described from a branch sent from near Matanzas, Prov. Curico. The largest leaves are $3.5 \mathrm{~cm}$. long, $12 \mathrm{~mm}$. wide, but otherwise the plant seems to belong here. It has been compared with $H$. angustifolius, from which it differs in the sericeous achenes and in the involucral bracts, the latter said to be only 2 $\mathrm{mm}$. wide.

4. Haplopappus sphacelatus Reiche, Fl. Chil. 3:290, 1902. Based upon Haplopappus sphacelatus.

This appears to be the most primitive of a group of three closely related species. The others, Haplopappus angustifolius and H. parvifolius, seem to have undergone reduction through narrowing of the inflorescence and through loss of achenial pubescence.

\section{Haplopappus pristiphyllus (Remy)}

Stems woody, probably crowded, the foliage congested near bases of flowering branches and extending well up among the heads; herbage glabrous, glutinous, shining; principal leaves sessile, lanceolate, rigidly acuminate, 3 to $4 \mathrm{~cm}$. long, 8 to $10 \mathrm{~mm}$. wide, reflexed, remotely and saliently spinydentate, very rigid, 1-nerved, minutely reticulate, the margin scabrous; heads discoid, in terminal spikes (2 dm. long in type) or on short lateral spicate branches of a narrow panicle, the subtending leaf-like bracts mostly as long as involucre, narrow-campanulate, about $14 \mathrm{~mm}$. high; bracts imbricated in about four lengths, oblong-lanceolate, rigidly acuminate or attenuate, some tips spine-like, the largest over $3 \mathrm{~mm}$. wide, hard-chartaceous, stramineous, the tip greenish and subglandular, otherwise glabrous and shining; achenes turgid, narrowed at base, about $5 \mathrm{~mm}$. long, 5 -ribbed and multistriate, white-villous with upwardly appressed hairs. (Pyrrocoma pristiphylla Remy in Gay, Fl. Chil. 4:65, 1849.) (Plate 14, Fig. 3.)

Known only from the type collection, Chile, without definite locality, Gay 49 (P).

1. Pyrrocoma pristiphylla Remy in Gay, Fl. Chil. 4:65, 1849.

2. Aster pristiphyllus O. Kuntze, Rev. 318. 1891. 
Reiche, in his flora of Chile, has tentatively reduced this species to Haplopappus saxatilis, basing his opinion on the original descriptions. If he could have seen the types his judgment doubtless would have been quite different. The present species apparently differ's in habit, having the leaves much congested and reflexed and the heads in very narrow spikes or racemes; but it is best differentiated from saxatilis by its rigidly acuminate leaves and much broader but spine-tipped bracts of the involucre. The involucre itself is larger and the flowers apparently are more numerous.

\section{Haplopappus reticulatus (Phil.) Reiche, Fl. Chil. $3: 290,1902$}

Stems woody, leafy throughout; herbage glabrous, resinous; leaves sessile, semiamplexicaul, orbicular-obovate, obtuse, about $3 \mathrm{~cm}$. long by 18 to 20 $\mathrm{mm}$. wide, coarsely dentate (teeth subspinose), rigid, reticulate; heads discoid, subspicate, sessile at the ends of short lateral leafy branches (8 to 11 $\mathrm{mm}$. high); involucre obconic, bracts imbricated in three or four lengths, linear, obtuse, with white-scarious margins and dark apex; achenes sericeous; pappus reddish.

Known only from the type collection, Cauquenes, Chile, Gay 724 (not seen).

1. Pyrrocoma reticulata Phil., Linnaea 28:731, 1856.

2. Aster retinervius O. Kuntze, Rev. 317, 1891.

The broad, rounded leaves of this species are unlike those of any other member of Section Xylolepis and an examination of the type may show that it belongs rather to Section Polyphylla, perhaps close to $H$. ischnos.

\section{Haplopappus parvifolius (DC.) Gray, Proc. Am. Acad. 5:122, 1861}

Stems woody, the branches erect from a shrubby base, sometimes 5 to 15 $\mathrm{dm}$. high, mostly hidden by the dense foliage but at least partially exposed in the inflorescence; herbage glabrous, notably glutinous; leaves sessile, spreading or reflexed, somewhat amplexicaul, oblanceolate to cuneate-obovate, very obtuse or with an acute terminal lobe, 1 to $2 \mathrm{~cm}$. long, 8 to $16 \mathrm{~mm}$. wide (upper leaves smaller, especially in type), many with smaller ones fascicled in the axils, each margin with several sharp triangular divergent teeth, rigid, 1-nerved, not reticulate or the reticulations very fine; heads discoid, glomerate-racemose being nearly sessile in groups of 2 to 5 heads, each group sessile or short-peduncled along the central axis, the whole inflorescence usually 1 to $3 \mathrm{dm}$. long (rarely reduced and the heads simply spicate or racemose), each head subtended by a leaf-like bract of less than half its length; involucre obconic, 10 to $11 \mathrm{~mm}$. high; bracts imbricated in four lengths, oblong and obtuse or barely acute (outer), or lanceolate and acute (inner), the largest about $1.8 \mathrm{~mm}$. wide, rigidly erect, the outer ones mostly green but with thin and narrow pale or reddish border, the inner ones chartaceous and nearly white, all glabrous; achenes about 5-ribbed, striate between ribs, about $4 \mathrm{~mm}$. long, glabrous; pappus reddish; (style-branches well exserted, the ovate-acute appendage, much shorter than stigmatic part). (Plate 15, Fig. 1.)

Central and northern provinces of Chile. Type collection, without exact locality (DC, ex-herb. Haenke); Chile, Gay 50 (P); Los Llanos, Estero de 
Guanta, Prov. Coquimbo, January 17-18, 1926, Johnston 6243 (Gr, UC); Coquimbo, Prov. Coquimbo, January, 1924, Werdermann 269 (UC); near Coquimbo, 1882, Ball (K).

1. Pyrrocoma parvifolia DC., Prodr. 5:351, 1836. Described under "Sect. II ? Chromochacta."

2. Aster parvifolius O. Kuntze, Rev. 318, 1891.

This is a more robust and more densely leafy plant than $H$. angustifolius, with which it has been compared. There is much variation in density of foliage, but the two forms mentioned by Reiche are not geographic, as he supposed. Doubtless local conditions are responsible for differences as regards this feature. The outer involucral bracts, heretofore described as acute, are decidedly obtuse in most specimens and they are somewhat so even in the duplicate type at the DeCandolle Herbarium.

\section{Haplopappus angustifolius (DC.) Reiche, Fl. Chil. 3:286, 1902}

Stems subwoody, mostly erect, moderately leafy up to the lower heads, striate, stramineous; herbage glabrous or only minutely puberulent, glutinous; principal leaves sessile, narrowly oblong, acute, 3 to $8 \mathrm{~cm}$. long, 5 to $30 \mathrm{~mm}$. wide, mostly with smaller ones fascicled in the axils, each margin with a few sharp slender divergent teeth, rigid, thick, 1-nerved, not reticulate; heads discoid, sessile or subsessile in terminal spicate racemes, often equaled by the bracts of the peduncle; involucre obconic (broader in age), 10 to $12 \mathrm{~mm}$. high; bracts loosely imbricated in about three lengths, oblonglanceolate, obtuse, the largest $3 \mathrm{~mm}$. wide, thick and very firm-chartaceous, pale and shining except at tip, glabrous; achenes terete, about $5 \mathrm{~mm}$. long, prominently about 5 -nerved, glabrous or sometimes slightly villous at base (as in type); pappus rigid, reddish. (Plate 15, Fig. 2.)

Provinces Atacama and Coquimbo, Chile (perhaps southward to Concepcion, see under $H$. durus in the following list). Type from Cord. Chile Haenke (DC). Province Coquimbo, 1838, Gay (P); Chile, without exact locality, Gay (K).

1. Pyrrocoma angustifolia DC., Prodr. 5:351, 1836.

2. P. rigida Phil., Linnaea $28: 732$, 1856. A distinct form or species, discussed under No. 5 of this list. (Not P. rigida Rydb., 1900.)

3. Aster atenes O. Kuntze, Rev. 315, 1891. Based upon Pyrrocoma rigida Phil.

4. A. stewardensis O. Kuntze, Rev. 317, 1891.

5. Haplopappus durus Reiche, Fl. Chil. 3:287, 1902. Based upon Pyrrocoma rigida Phil. Perhaps a good species, but very imperfectly understood. The heads are sessile among upper leaves, the involucre is rather larger than in typical angustifolius, and the achenes are costate. The type is from near Angeles, Province Concepcion.

The type specimen of $H$. angustifolius (in herb. Haenke) is represented in the DeCandolle Herbarium by merely a flowering twig about $35 \mathrm{~cm}$. long, on which even the largest leaves are only about $2.7 \mathrm{~cm}$. long by $5 \mathrm{~mm}$. wide. But this is sufficient for identifying with it more nearly complete specimens with leaves up to $8 \mathrm{~cm}$. long by $30 \mathrm{~mm}$. wide, such as those collected by Gay and now at Kew. Although described by DeCandolle as absolutely glabrous, some of the leaves are minutely puberulent as seen under the lens, indicating that young parts may be noticeably so. The species is abundantly distinct, however, from $H$. parvifolius, which is much more glutinous and has leaves of a quite different shape and dentation. 
139. Haplopappus macraeanus (Remy) Reiche, Fl. Chil. 3:296, 1902

Stems probably woody at base, erect or ascending, leafy up to base of raceme; herbage at first white-tomentulose, especially the young shoots, the foliage and heads only puberulent at maturity; leaves sessile by a narrow but semiamplexicaul base, oblanceolate or obovate (those near the heads oblong and sessile by a broader base), acute or obtusish, about $4 \mathrm{~cm}$. long, 10 to $15 \mathrm{~mm}$. wide, coarsely and acutely dentate, soft but becoming coriaceous, with strong midrib and fine reticulations; heads (discoid?) in an elongated $(18 \mathrm{~cm}$.) spike, each subtended by an oblong leaf-like bract, this about as long as head; involucre probably broad-turbinate, and about $11 \mathrm{~mm}$. high; bracts oblong-linear (the largest about $2 \mathrm{~mm}$. wide?), obtuse, rigid, coriaceous, greenish only near summit, glabrate; achenes not known; pappus tawny. (Plate 15, Fig. 3.)

The only specimen seen by us is the one first mentioned by Remy, namely, hills of La Serena, Prov. Coquimbo, Chile, 1836, Gay 191 (P). A collection was made by Macrae near Valparaiso, according to Remy (who saw it in herb. DC.).

1. Pyrrocoma macraeana Remy in Gay, Fl. Chil. 4:64, 1849.

2. Aster macraeanus O. Kuntze, Rev. 318, 1891.

The combination, Haplopappus macraeanus, is accepted for this species notwithstanding its earlier use by Gray in a partially different sense (Gray, Proc. Am. Acad. 5:122, 1861). Gray, who gave no description and listed no specimens, cited Pyrrocoma angustifolia DC. as his first synonym. This has since properly become $H$. angustifolius (DC.) Reiche. The combination, H. macraeanus, is thus available for the plant first described as $P$. macraeana Remy, which name was cited by Gray as his second synonym.

With both types before one, there can be no thought of uniting the present species with $H$. angustifolius, as proposed by Gray. It differs in the much broader, less rigid leaves and in the white tomentum of the young shoots.

140. Haplopappus cerberoanus (Remy) Reiche, Fl. Chil. 3:292, 1902

Stems woody, much branched throughout; herbage glabrous but viscid; leaves sessile by a narrow base, ascending, oblong-cuneate, the upper linear, somewhat obtuse, 1 to $3 \mathrm{~cm}$. long, 2 to $6 \mathrm{~mm}$. wide, with 3 to 6 short spreading acute teeth on each margin, often with fascicles in the axils, rigid, dark, 1-nerved, somewhat pitted by the fine reticulations; heads discoid, solitary or openly paniculate at the ends of sparsely leafy branches; peduncles 1 to $10 \mathrm{~cm}$. long, slender, numerous, each from the axil of a leaf-like bract and bearing 1 or 2 reduced subulate bracts; involucre campanulate, 7 to $8 \mathrm{~mm}$. high; bracts imbricated in four or five lengths, linear, obtuse, $1.5 \mathrm{~mm}$. and less wide, pale-chartaceous on borders, an oblong greenish and granular area near summit; achenes 4-nerved, sericeous; pappus reddish. (Plate 16, Fig. 1.)

Northern Chile. Type locality not specifically stated, but probably in Province Coquimbo. Chile, Gay (P, named by Remy); Prov. Coquimbo, 1838, Gay (P, same as preceding but not named by Remy); Atacama (K, from Philippi). 
1. Pyrrocoma cerberoana Remy in Gay, Fl. Chil. 4:66, 1849.

2. P. denticulata Phil., Linnaea 28:730, 1856. Based upon Gay 805 from Ovalle; not seen by present author. Possibly belongs here, but with linear acute leaves about $2.5 \mathrm{~cm}$. long.

3. Aster cerberoanus O. Kuntze, Rev. 317, 1891.

4. A. denticulatus O. Kuntze, Rev. 317, 1891. Based upon Pyrrocoma denticulata Phil.

5. Haplopappus denticulatus Reiche, Fl. Chil. 3:293, 1902. Based upon Pyrrocoma denticulata Phil.

This species appears to be closely connected with no other. The foliage and heads suggest those of Haplopappus parvifolius, but the elongated, slender, and of ten curved peduncles are very distinctive. From H. pedunculosus it differs in the short leaves and in the entirely different arrangement of the peduncles. It is immediately distinguished from both these species also by the obtuse involucral bracts.

\section{Haplopappus stelliger Remy in Gay, Fl. Chil. 4:52, 1849}

Stems woody, much branched to form dense rigid leafy shrubs, from the summits of which arise the scattered peduncled heads; herbage very resinous and viscid, thus holding foreign matter, also puberulent; leaves sessile, upcurved from a spreading base, deflexed in age, narrowly lanceolate, pungently acute, 3 to $5 \mathrm{~cm}$. long, 4 to $6 \mathrm{~mm}$. wide, remotely serrate, with perpendicular teeth, rarely with small leaves fascicled in the axils, 1 -nerved, yellowish green; heads probably discoid, solitary, terminating the branches; peduncles 5 to $10 \mathrm{~cm}$. long, mostly with a few leaf-like bracts 0.5 to $2 \mathrm{~cm}$. long or nearly naked; involucre broadly obconic, 9 to $11 \mathrm{~mm}$. high; bracts imbricated in about five lengths, broadly oblong, very obtuse, some shortmucronate, the largest ones nearly $3 \mathrm{~mm}$. wide, with greenish middle portion and broad white-scarious wing-like margins, glutinous; achenes sparsely pilose; pappus reddish. (Aster stelliger O. Kuntze, Rev. 318, 1891.) (Plate 16, Fig. 2.)

Type specimens, Prov. Coquimbo, Chile, Gay (P); not otherwise known.

The original description as an Haplopappus by an author who recognized Pyrrocoma on the basis of its discoid heads, has led to the assumption that this species was radiate and to its placement in the marginalis group. No description of the ray-flowers has ever been given, however, and no rays are now evident on the type specimens. The species probably is discoid and belongs in the present section.

The stellate bodies which gave the species its name are not parts of the plant itself but foreign matter held by the abundant resinous exudate. This is indicated by their uneven distribution and by the ease with which they are removed from the surface. Stellate hairs are not known in Haplopappus.

\section{SECTION 21. DIPLOSTEPHIOIDES}

142. Haplopappus assuensis (HBK.) Blake, Am. Jour. Bot. 14:109, 1927

An arboreous shrub; branches moderately leafy, at first puberulent, glabrate; leaves petioled, the petiole about 10 to $15 \mathrm{~mm}$. long; leaf-blade oblong, acute, rounded at base, not revolute, about 10 to $13 \mathrm{~cm}$. long, 30 to $45 \mathrm{~mm}$. wide, remotely denticulate throughout, thin (submembranous); 
upper surface glabrous, pinnately veined; lower surface yellowish tomentulose, the tomentum not hiding the prominent veins, which make an angle of about $90^{\circ}$ with midrib; heads few, in leafy terminal cymes, the ultimate peduncles 5 to $15 \mathrm{~mm}$. long; involucre broad-turbinate, about 8 $\mathrm{mm}$. high; bracts few, very loosely imbricated in three lengths, ovateoblong, acute or acutish, 2 to $2.5 \mathrm{~mm}$. wide, glabrous, minutely lacerateciliate near tip; receptacle probably naked; flowers about 9 ; corolla-lobes linear, about $3.5 \mathrm{~mm}$. long; achenes (immature) $3 \mathrm{~mm}$. long, sessile-glandular and densely short-hispidulous; pappus reddish. (Baccharis assuensis HBK., Nov. Gen. et Sp. 4:67, 1820.)

Known only from the type, Assuay, Ecuador, Bonpland 3268 (P).

This species is recognized by the broadly oblong, denticulate leaves, these rounded to base. The heads were originally described as 13-flowered, but two heads from the type yielded, on a recent examination, only 9 flowers each. It is unlikely that any had fallen out previous to the count, for the heads were in good condition.

\section{Haplopappus fuligineus (HBK.) Blake, Am. Jour. Bot. 14:110, 1927}

A tall shrub; branches leafy (only the flowering tips known), striate, puberulent, glabrate; leaves petioled, the petiole 6 to $10 \mathrm{~mm}$. long; leafblade oblong, acute, rounded to the petiole, revolute, about $8 \mathrm{~cm}$. long by $20 \mathrm{~mm}$. wide, entire, coriaceous; upper surface glabrous, shining, pinnately veined; lower surface densely tomentose, prominently veined, the veins making an angle of about $90^{\circ}$ with midrib; heads in leafy rounded terminal cymes, the ultimate peduncles $6 \mathrm{~mm}$. and less long; involucre broadly turbinate, 6 to $8 \mathrm{~mm}$. high; bracts about 15, very loosely imbricated in about 3 lengths, ovate, acutish, about $2.5 \mathrm{~mm}$. wide, glabrous, minutely lacerateciliate near apex; receptacle either naked or with 1 or 2 paleae; flowers 7 or 8 ; corolla-lobes linear, about $4 \mathrm{~mm}$. long; achenes angular, minutely hispid and sessile-glandular; pappus reddish.

Known only from the type, this said to be from the same locality as that of $H$. assuensis, namely, Assuay, Ecuador, Bonpland (P).

1. Baccharis fuliginea HBK., Nov. Gen. et Sp. 4:68, 1820.

2. Bigelovia fuliginea Gray, Proc. Am. Acad. 8:638, 1873.

3. Neosyris fuliginea Greene, Erythea 3:115, 1895.

The taxonomic position of this species is in much doubt because of the fragmentary nature of the single collection thus far made. The short, spreading involucre of essentially glabrous bracts is most like that of Haplopappus assuensis, but the entire leaves suggest $H$. hypoleucus, with which Blake was tempted to unite it. Only upper leaves are present. The largest of these are rounded at base, as in assuensis, but, as in all these species, some of the small upper ones are acute at each end. The foliage is much more rigid and brittle than in either of these related species

144. Haplopappus hypoleucus Turcz., Bull. Soc. Nat. Mosc. 24¹:177, 1851

Described as a scandent shrub but perhaps only ascending; branches leafy, few-striate, densely covered with a fine close tomentum; leaves petioled, the petiole 2 to $10 \mathrm{~mm}$. long; leaf-blade lanceolate, acute to acuminate 
at each end and more or less revolute, 8 to $12 \mathrm{~cm}$. long, 8 to $22 \mathrm{~mm}$. wide, entire or some denticulate, coriaceous; upper surface glabrous or only hirtellous, green, shining, pinnately veined; lower surface densely tomentose, the veins prominent (nearly concealed in form named $H$. soratensis) and making an angle of about $90^{\circ}$ with midrib; heads in rounded terminal compound cymes 5 to $10 \mathrm{~cm}$. across, the ultimate peduncles 4 to $12 \mathrm{~mm}$. long; involucre subcylindric, 9 to $11 \mathrm{~mm}$. high; bracts imbricated in 4 or 5 lengths, ovate and obtuse (outer) to lanceolate and acute (inner), 2 to $2.5 \mathrm{~mm}$. wide, the outer ones densely tomentulose, the inner mostly smooth but puberulous on margins; receptacle sometimes bearing 1 or 2 paleae, sometimes naked (in same collection); flowers 7 to 10 (or 13 according to Blake); corolla-lobes linear, acuminate, 2.5 to $4 \mathrm{~mm}$. long, spreading in age; achenes angled and nerved, about $4 \mathrm{~mm}$. long, densely sessile-glandular and often also short-hispid (especially in typical form); pappus brown.

Ecuador and Bolivia. Type locality, Andes of Quito, Ecuador, at 3,350 meters altitude. EcuAdor: type collection (?), Jameson (Gr); Corazon, 3,200 meters altitude, André 3698 (Field, Gr); Pangor, Pallatanga, 1891, Sodiro (US); Mount Pichincha, 3,300 meters altitude, Mille 444 (US); Andes, Spruce $5139(\mathrm{Gr})$. Bolivia: rocky places near Sorata, between Nasacara and Lacatia, 3,400 to 3,700 meters altitude, Mandon 233 (Gr, type of $H$. soratensis).

1. Linosyris (Dolichogyne) mandoni Sch. Bip., Bull. Soc. Bot. France 12:81, 1865, and Linnaea 34:534, 1865-66. A nomen nudum referring to the form, or species, listed below as $H$. soratensis.

2. L. mandoni Benth. et Hook., Gen. Pl. 2:255, 1873. H. hypoleucus is cited as a synonym of this by Bentham and Hooker, the name L. mandoni being thus effectively published for the first time. But the plant Schultz had in mind when suggesting the name was a slightly different form, as noted under No. 1.

3. Bigelovia hypoleuca Gray, Proc. Am. Acad. 8:638, 1873.

4. Neosyris hypoleuca Greene, Erythea 3:115, 1895.

5. Haplopappus soratensis Blake, Am. Jour. Bot. 14:109, 1927. This was separated from $H$. hypoleucus chiefly on the basis of the more prominent denticulations of some of the leaves and the more dense tomentum of the lower leaf-surface. The type consists of three flowering pieces broken from ends of branches. The largest of these has leaves prominently denticulate, even the small ones of the inflorescence, while on the others (from another plant?) all the leaves are entire. This feature thus appears to be too variable for use as a specific criterion and it will be surprising if more abundant collections will not show the amount of pubescence to be also variable. It is well known that density of tomentum in related genera, especially Chrysothamnus, and even within Haplopappus (uniflorus, canescens, etc.) varies independently of all other characters. In the type (Mandon 233, as above cited) the corolla-lobes are only 2.5 to $3 \mathrm{~mm}$. long, while in the material of hypoleucus at present available the lobes are 3 to $4 \mathrm{~mm}$. long. Possibly a better character may be found in the achenes. These are densely glandular and lack the hispid pubescence of typical hypoleucus.

Haplopappus hypoleucus appears to be the most common species of its section and is particularly common in the high Andes of Ecuador around Quito. It is recognized by the slender, essentially entire leaves, which are gradually narrowed to each end, green above but densely tomentose beneath, and by the long and nearly cylindric involucres. 
145. Haplopappus rufescens Blake, Am. Jour. Bot. 14:111, 1927

A strictly branched shrub; branches leafy, somewhat angled, yellowish tomentose; lèaves petioled, the petiole 3 to $8 \mathrm{~mm}$. long; leaf-blade ellipticoblong, somewhat acute at apex and base, obscurely or not revolute; 5 to 9 $\mathrm{cm}$. long, 15 to $25 \mathrm{~mm}$. wide, entire, subcoriaceous; upper surface graytomentose, soon glabrate, pinnately veined with impressed costae; lower surface very densely and closely tomentose, the veins mostly concealed by the tomentum but evident in age; heads many, in fastigiate rounded terminal panicles, the ultimate peduncles 10 to $15 \mathrm{~mm}$. long; involucre cylindric-

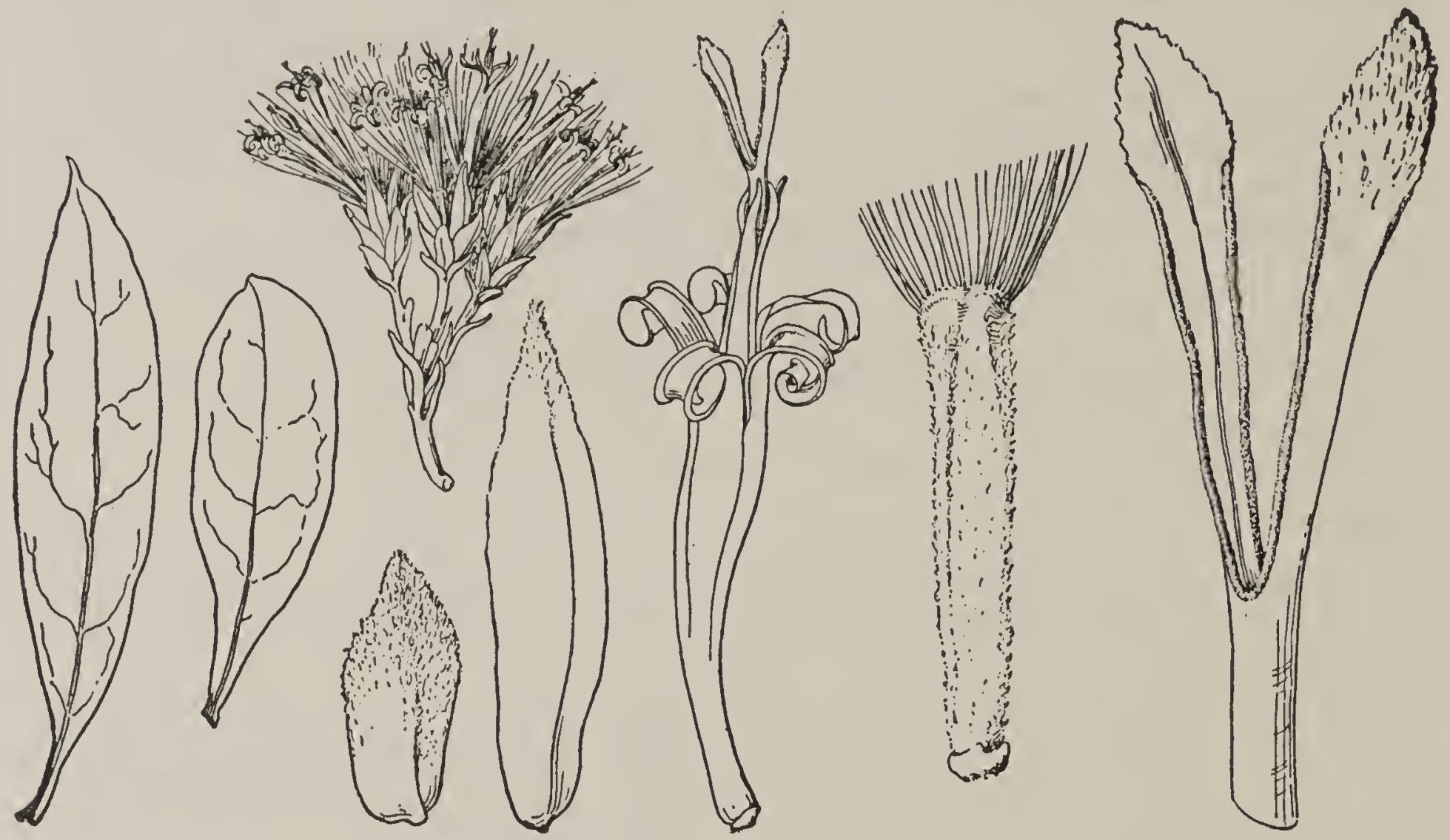

FIG. 114-Haplopappus rufescens, from the type collection (Ex-Herb. Berlin)

turbinate or somewhat campanulate, 10 to $12 \mathrm{~mm}$. high; bracts closely imbricated in about 4 lengths, lanceolate (small outer) to oblong (inner), acutish to acuminate, 2.5 to $3 \mathrm{~mm}$. wide, thinly tomentose on exposed parts, the inner glabrate except at tip (sometimes in vertical rows, according to Blake); receptacle naked; flowers 4 to 6 ; corolla-lobes linear, recurved at tip, about $4 \mathrm{~mm}$. long; achenes nerved, about $4.5 \mathrm{~mm}$. long, densely hispidulous and glandular; pappus reddish. (Fig. 114.)

Known only from the type collection, Llacnabamba, Prov. Pataz, Peru, Weberbauer 7209 (Field, B).

It is doubtful if this can be maintained as a species distinct from Haplopappus hypoleucus. The number of flowers is given by Blake as four or five, but an additional count disclosed six flowers in a head of the type and it is not unlikely that the number overlaps that of hypoleucus, which begins at seven. The achenes in both are typically hispid as well as glandular and the leaf-margins in rufescens have a tendency to become revolute, the latter being a feature which is quite variable even in the type collection of hypoleucus.

146. Haplopappus lehmanni (Hieron.) Blake, Am. Jour. Bot. 14:113, 1927

A tall shrub; branches leafy, angulate, densely gray-tomentulose; leaves petioled, the petiole 4 to $8 \mathrm{~mm}$. long; leaf-blade elliptic-oblong (lanceolate, according to Hieronymus), acute or short-acuminate, moderately narrowed at base, narrowly revolute, 6 to $13 \mathrm{~cm}$. long, 20 to $35 \mathrm{~mm}$. wide, entire or 
with a few teeth near apex, chartaceous, upper surface glabrous, green, shining, pinnately veined; lower surface densely tomentose, the veins (not concealed) spreading almost at $90^{\circ}$ to midrib; heads in open rounded cymose panicles 10 to $30 \mathrm{~cm}$. across, the ultimate peduncles $4 \mathrm{~mm}$. or less long, or some heads sessile; involucre cylindric-turbinate, 9 to $10 \mathrm{~mm}$. high; bracts loosely imbricated in about 5 lengths, short-oblong and obtuse (outer) to oblong and acute (inner), tomentulose or the inner only puberulent, the largest about $2 \mathrm{~mm}$. wide; receptacle naked; flowers 3 to 5 ; corolla-lobes linear, revolute in age, 3 to $4 \mathrm{~mm}$. long; achenes about 5-angled, 2.5 to $3 \mathrm{~mm}$. long, densely covered with sessile glands, sometimes also puberulent; pappus brown. (Bigelovia lehmanni Hieron., Engler, Bot. Jahrb. 28:583, 1901.)

Ecuador and Colombia. Type locality, in wooded mountains in Páramo of Tinajillas and Chorones, Prov. Cuenca, Ecuador, 3,000 to 3,500 meters. Colombra: Chico, Ariste-Joseph A120 (US); near Salto de Tequendama, Ariste-Joseph $A 3$ and $A 4$ (US).

147. Haplopappus caucanus Blake, Am. Jour. Bot. 14:113, 1927

Characters as in Haplopappus lehmanni except as follows: branches glabrate or glabrescent; leaves coarser, up to $40 \mathrm{~mm}$. wide, the petioles 5 to 13 $\mathrm{mm}$. long, the tomentum of lower surface very fine and compact, the leaf thus appearing smooth, the lateral veins less divergent; involucral bracts only ciliate, even the outer ones devoid of tomentum.

Colombia. Type locality, "Canaan," Mount Purace, Cord. Central, Cauca, 3,300 to 3,400 meters altitude. Type, Pennell and Killip 6517 (US); Las Escaleretas, Cauca, Pittier 1384 (US).

This scarcely differs from Haplopappus lehmanni except in the reduction of pubescence. It is not unlikely that further collections will supply a complete series in this regard, running all the way from typical lehmanni through caucanus to an extreme form in which the lower leaf-surface is green and only puberulous. This extreme is now represented only by a collection from Dept. Santander, western slope of Páramo Rico, Colombia, in woods at 3,300 to 3,600 meters altitude (Killip and Smith 17816, US).

148. Haplopappus lucidulus Blake, Am. Jour. Bot. 14:114, 1927

Very close to $H$. lehmanni but differing as follows: branches usually glabrate except in the leaf-axils; leaves more densely compactly and therefore smoothly tomentose beneath; the lateral veins more acutely divergent (makabout $70^{\circ}$ with midrib, instead of about $90^{\circ}$ as in lehmanni), and the leaves more acuminate at both ends.

Unduavi, North Yungas, Bolivia, Buchtien 3080 (US), type.

149. Haplopappus ledifolius Blake, Am. Jour. Bot. 14:112, 1927

A shrub about 1 meter high; branches terete, leafy, lanate-tomentose; leaves petioled, the petiole $5 \mathrm{~mm}$. or less long; leaf-blade elliptic, acute at each end or obtuse at apex, narrowly revolute, 3 to $5 \mathrm{~cm}$. long, 8 to $15 \mathrm{~mm}$. wide, entire, coriaceous; upper surface glabrous, obscurely veined, the veins making an acute angle with midrib; lower surface densely lanate-tomentose, the veins concealed; heads nearly sessile in dense rounded terminal compound cymes about $6 \mathrm{~cm}$. across; involucre subcylindric, about $10 \mathrm{~mm}$. 
high; bracts closely imbricated in about 5 lengths, oblong, the short outer ones obtuse, the inner somewhat acute, mostly tomentose on exposed parts, the largest about $1.5 \mathrm{~mm}$. wide; receptacle naked or with a single palea; flowers 5; corolla-lobes linear, about $4.5 \mathrm{~mm}$. long; achenes densely sessileglandular; pappus reddish.

Known only from the type specimen, this from Huaycani (Huaycoma, Bolivia?), 3,000 to 3,500 meters altitude, May 1866, Pearce (US), a fragment and photograph of type which is in the Kew herbarium.

Possibly this is only an extreme variant of Haplopappus lehmanni, but the heavy, compact foliage and the inflorescence seem distinctive. 


\section{SOUTH AMERICAN SPECIES NOT SUFFICIENTLY KNOWN}

1. Haplopappus axilliflorus Phil., Anal. Univ. Santiago 87:611, 1894. Known only from a terminal fragment (according to Reiche). Leaves very small, obovate, narrow at base, very coriaceous; heads short-peduncled in the upper axils, radiate; involucral bracts linear, obtuse; achenes pubescent. Type locality, near Valparaiso, Chile.

2. H. bellidifolius Phil., 1. c. 593, 1894. Apparently close to H. diplopappus, but the leaves described as crenate-dentate at summit and somewhat arachnoid-pubescent, the involucral bracts as almost $3 \mathrm{~mm}$. wide, and the pappus as white. Based upon a collection made at Lake Guayeltué in the Araucanian Andes.

3. H. brachylepis Phil., l. c. 594, 1894. Reduced by Reiche (Fl. Chil. $3: 301,1902)$ to $H$. bellidifolius var. brachylepis. Leaves incise-dentate at summit, glabrate; involucral bracts broad at base and short. Type locality, the same as for $H$. bellidifolius Phil.

4. H. graveolens (Phil.) Reiche, Fl. Chil. 3:294, 1902. Not known in perfect condition and even the section can not be determined. The plants form large, rounded masses, with densely crowded, oblong, obtuse leaves 6 to $7 \mathrm{~cm}$. long and serrate above the middle. The heads are on long, naked peduncles (as in H. remyanus) and have obtuse but mucronate involucral bracts. (Haplodiscus graveolens Phil., 1. c. 619.) Type locality, Rio Colorado, Prov. Santiago, Chile.

5. H. illini Speg., Anal. Soc. Cient. Argentina 48:181, 1899, and Nov. Add. Fl. Pat. (repr.) 1:75, 1901. A Patagonian species diagnosed by Spegazzini as follows:

Leiachenium; perennis glaber, pulvinato-caespitosus, ramis valde abbreviatis apice rosulato-foliiferis, foliis obovato-spathulatis, limbo petiolum non aequante crenato-dentato, dentibus obtusis integerrimis, capitulis acrogenis solitariis subsessilibus haemisphaerico-subturbinatis, bracteis numerosis 4-seriatis lanceolatis glabris discum aequantibus, floribus 40-50, ligulatis longe radiantibus aurantiacis.-In rupestribus siccis inter choiquelauen et Lago Musters, Jan. 1899 (Illin).

6. H. latifolius (Phil.) Reiche, Fl. Chil. 3:294, 1902. A glabrous, resinous shrub with oblong-cuneate leaves similar to those of $H$. illinitus; but the outer involucral bracts are described as short and obtuse. (Haplodiscus latifolius Phil., Anal. Univ. Santiago 87:623, 1894; type locality, Andes of Ovalle, Chile.) Here Reiche includes Haplodiscus vernicosus Phil., 1. c. 618, from the Andes of Illapel, and its var. geissei Phil., l. c.

7. H. mustersi Speg., Anal. Soc. Cient. Argentina 48:183, 1899, and Nov. Add. Fl. Pat. (repr.) 1:77, 1901. A Patagonian species diagnosed by Spegazzini as follows: 
Leiachenium; perennis glaber humilis, caespitoso-relaxatus, ramis elongatulis simplicibus v. vix ramulosis, monocephalis, crebre sed relaxate foliiferis, foliis elongato subspathulatis v. linearibus, limbo petiolis duplo triplove breviore, inferis grosse 3-5-dentato-lobatis, superis integris $\mathrm{v}$. integerrimis, capitulis solitariis hemisphaericis majusculis, bracteis $5-6$ serialibus lanceolatis glabris discum aequantibus, floribus ultra 120, ligulatis longe radiantibus aureis.-Ad marginem fontium manantiales vocatarum in altiplanitie inter choique-lauen et Lago Musters, Dec., 1898 (Illin).

8. H. obovatus Phil., Anal. Univ. Santiago 87 :604, 1894. Probably an abnormal specimen of $H$. chrysanthemifolius or some similar species of section Euhaplopappus. The peduncles are only $3 \mathrm{~cm}$. long and the involucre $7 \mathrm{~mm}$. high. Type locality, Andes of Curicó, Chile.

9. H. patagonicus Speg., Rev. Agron. La Plata 3:528, 1897. Not $H$. patagonicus Phil., 1856. A Patagonian species perhaps not of this genus, diagnosed by Spegazzini as follows:

Leiachenium, perennis, laxe ramosus, ramis elongatis gracilibus subnudis e prostrato adscendentibus, ramulis subsimplicibus virgatulis pruinulosis monocephalis, foliis pulverulentis inferis hine inde fasciculatis subspathulatis utrinque margine 2-4-dentatis, superis remotis parvulis rigidulis obovatis pinnatilobis, lobis subalternis integris $\mathrm{v}$. dentatis spinuloso-mucronatis, capitulis mediocribus, squamis pluriserialibus linearibus integris acutis mucronatis pulverulentis, acheniis glabris, setis 1-seriatis caducis denticulatis.-Non rarus in dumosis aridis prope Santa Cruz, anno 1882 (Ameghino) et prope Rio Deseado, anno 1894 (Spegazzini).

The name was later changed to $H$. tehuelches Speg., Anal. Soc. Cient. Argentina 48:184, 1899, to avoid confusion with $H$. patagonicus Phil., 1856.

10. H. pinea (Phil.) Reiche, Fl. Chil. $3: 285,1902$. A woody plant with linear, entire leaves densely tufted near ends of the branches, the discoid heads terminal and sessile. These characters suggest section Steriphe, but possibly the species belongs near $H$. linifolius, of section Polyphylla. $H$. pinea was first described as Pyrrocoma pinea Phil., Linnaea 28:731, 1856 (Aster pineus O. Kuntze, Rev. 318, 1891). Type locality, subandean region of Antuco, Chile.

11. H. spinulosus Phil., Anal. Univ. Santiago 43:490, 1873. (Not $H$. spinulosus DC.) The name has been changed to $H$. serrulatus by Reiche (Fl. Chil. $3: 312,1902$ ), who suggests that it may be the same as H.cuneifolius Nutt. Specimens in European herbaria, identified by Philippi, have the foliage rather of $H$. diplopappus, but the involucral bracts have conspicuous white spine-like tips, these sharply reflexed. Type locality, near Hacienda Principal, in the Andes of Santiago. (Aster spinuliger O. Kuntze Rev. 317, 1891.)

12. H. struthionum Speg., Rev. Agron. La Plata 3:529, 1897. A Patagonian species diagnosed by Spegazzini as follows:

Euhaplopappus, perennis, humilis, breviter densiusculeque hispido-setulosus, caulibus subterraneis, ramulis breviter terra exertis foliosis, foliis obovatis eximie nervoso-reticulatis subcoriaceis apice acutis spinuloso-mucronatis, utrinque grosse 3-5-dentatis, dentibus spinuloso-mucronatis, mar- 
gine ciliolatis; capitulis in apice ramulorum solitariis majusculis, squamis lanceolatis hispidulis, intimis scariosis glabris, ligulis elongatis aurantiacis patentibus, pappi setis sub-1-scriatis albo-pallescentibus tenuibus-denticulatis.-In campis aridis glareosis secus Rio Santa Cruz, anno 1882 (Spegazzini) et secus Rio Deseado, anno 1894 (Ameghino).

13. H. taeda Reiche, Fl. Chil. $3: 295,1902$. Similar to H. graveolens but with acute leaves as much as $7.5 \mathrm{~cm}$. long and dentate to base. Type locality, in the Andes of Chile, Province Curacó. (Haplodiscus peteroanus Phil., Anal. Univ. Santiago 87:620, 1894. Not Haplopappus peteroanus Phil. 1894.) 


\section{EXCLUDED NAMES}

This list includes those species and varieties which have received names under Haplopappus but which are now excluded from the genus. A few names under related genera, but which might be sought here, are also included.

Bigelovia oppositifolia Gray, Proc. Am. Acad. 15:32, 1880. This Mexican plant is exactly Eupatorium mygindaefolium Gray, as noted by E. L. Greene on a sheet of the type collection at Kew.

Chrysoma pauciflosculosa (Michx.) Greene, Erythea 3:8, 1895. (Solidago pauciflosculosa Michx., Fl. 2:116, 1803.) Hoffman (in Engler u. Prantl, Pflanzenf. 45:150, 1894) accepts this as a Solidago, in which genus it was first described. Certainly it is not congeneric with the species of Haplopappus and Chrysothamnus included in Chrysoma by Greene, beginning with his No. 3 and ending with No. 15.

Diplopappus diffusus Hook. et Arn., Comp. Bot. Mag. 2:48, 1836. See under Haplopappus diffusus, which was based upon the same plant.

Diplopappus sericeus Less., Linnaea 6:110, 1831. This was treated by DeCandolle (Prodr. 5:349, 1836) as Haplopappus sericeus and by O. Kuntze (Rev. 316, 1891) as Aster haplopappus. Reiche states that the ligules are red but change to yellowish on drying. In the type collection, as represented at the DeCandolle herbarium, the ligules are now saffron, this doubtless due to ageing from an original purple. The aspect is that of Aster rather than of Haplopappus. Additional synonymy includes Leucopsis sericea Baker (in Mart., Fl. Bras. 63:7, 1882), and Noticastrum haplopappus Remy (in Gay, Fl. Chil. 4:19, 1849).

Eriocarpum coloradense Greene, Erythea 2:110, 1894. A species of Aster, section Xylorrhiza.

Haplopappus ? acuminatus DC., Prodr. 5:348, 1836. In the DeCandolle herbarium there is only a pocket with one leaf and a few loose involucral bracts. The leaf is loosely tomentulose in a manner not known in Haplopappus. In addition to this, the distribution (southern Brazil) suggests that the plant is not of this genus. Baker includes it in his Leucopsis sericea (Baker in Mart., Fl. Bras. 63:7, 1882). It is the first species described by DeCandolle under his section Leucopsis, all the members of which are now excluded from Haplopappus.

H. alpigenus Torr et Gray, Fl. N. Am. 2:241, 1842. Now referred to Asterpulchellus Eaton.

H. baccharoides Benth., Bot. Sulph. 24, 1844. Correctly referred by Gray (Syn. Fl. $\left.1^{2}: 160,1884\right)$ to Solidago occidentalis Nutt.

H. bellidioides Hook. f., in Hook. Lond. Jour. Bot. 6:112, 1847. A form of Erigeron pappochroma Labill.

H. blanchetianus Sch. Bip. An herbarium name on plants referred to Podocoma blanchetiana Baker in Mart., Fl. Bras. $6^{3}: 15,1882$.

H. calendulaceus Griseb., Goett. Abh. 24:179, 1879. An Aster of Uruguay transferred to Leucopsis calendulacea Baker in Mart., Fl. Bras. 63:9, 1882.

H. ? canescens DC., Prodr. 5:349, 1836 . This has been transferred to Chrysopsis villosa DC. as a variety by Gray (Syn. Fl. $1^{2}: 123,1884$ ). The pappus on at least some of the achenes in the type specimens at the DeCandolle herbarium is plainly double and also in all other features the plants closely resemble Texas forms of C. villosa.

H. cineraria efolius Sch. Bip. A nomen nudum referred to Leucopsis tweediei Baker in Mart., Fl. Bras. 63:9, 1882.

H. ? diffusus DC., Prodr. 5:349, 1836. Based upon Erigeron diffusus Pers., transferred to Leucopsis diffusa Baker in Mart., Fl. Bras. 63:8, 1882. The single specimen in the DeCandolle herbarium came from Brazil (hb. Mus. Reg. Bras. 1022) and plainly is not an Haplopappus.

H. ? filifolius DC., Prodr. 7:280, 1838. Based upon Diplopappus filifolius Hook., which is an Erigeron.

H. florifer Hook. et Arn., Bot. Beech. Voy. 351, 1836-38. A species of Townsendia ( $T$. florifera Gray).

H. gramineus Benth., Pl. Hartweg. 65:1839. Chrysopsis graminifolia Nutt., there being a very short outer pappus in addition to the longer bristles. (Hartweg 476, Del.)

H. gunni Hook. f., l. c. 111, 1847. A form of Erigeron pappochroma Labill. 
H. ? haenkei DC., Prodr. 5:349, 1836. An examination of the type specimen shows that this is exactly Corethrogyne filaginifolia (Hook. et Arn.) Nutt., as first pointed out by Gray (Syn. Fl. 12:170, 1884. It is the typical form distinguished by the almost complete absence of glands. Since the specimen consists of but a single stem broken off well above the base, DeCandolle was misled into describing it as an annual. Haplopappus haenkei is the only species included by DeCandolle in his "Sect. VI ? Pyrochaeta."

H. hispidulus DC., Prodr. 5:348, 1836. This has the yellow ray-flowers of Haplopappus, but in every other feature the plant is more like an Erigeron. The involucre is hemispheric, with narrow bracts, the inner of which are loosely arranged, as in many Erigerons. The style-branches are included, but the shape of the appendage, which may furnish the crucial test, has not been determined. The type is from Province Coquimbo, Chile (Gaudichaud 87, DC).

H. ? hoorebekia DC., Prodr. 5:346, 1836. Based upon Hoorebekia chiloensis, which see.

H. lanatus Hook., Trans. Linn. Soc. 20:215, 1847. An Aster from the Galapagos Islands, apparently of the Leucopsis group. A. lanatus O. Kuntze, Rev. 318, 1891.

H. marginatus Griseb., Cat. Pl. Cub. 149, 1866. A West Indian plant with whitish ray-flowers, referred to the genus Aster by Gray (Proc. Am. Acad. 8:635, 1873). The transfer has been made by Britton as A. grisebachi Britt., Bull. Torr. Club 41:14, 1914. The plant is also known as Hysterionica marginata Gómez, Ann. Hist. Nat. Madrid $19: 272,1890$.

H. nealleyi Coult., Contr. U. S. Nat. Herb. 1:40, 1890. Clappia sp. and Stanfieldia nealleyi Small, Fl. S. E. U. S. 1188, 1903.

H. niveus Wats., Proc. Am. Acad. 23:277, 1888. Referred to Chrysopsis nivea Greene, Pitt. 3:43, 1896. There is a slightly manifest outer pappus of a few short bristles. These are one-fourth to one-third as long as the inner copious ones and are sharp-pointed, indicating that they are not remnants of long bristles. The style-tips are similar in shape to those of $C$. oregana but the appendage is shorter than the stigma, while in oregana it is much longer and still more slender. In the center of each areola of the receptacle there is a stipe-like column, not noted in either genus.

H. pappochroma Hook. f., l. c.=Erigeron pappochroma Labill.

H. ramulosus DC., Prodr. 5:350, 1836 . Transferred to Baccharis by Gray (Pl. Nov. Thurb. 301, 1854, and in Torr. Bot. Mex. Bound. 84, 1859). The type at the DeCandolle herbarium is a fragment too small to permit positive verification of Gray's opinion, which, however, appears correct.

H. ? scaposus DC., Prodr. 5:350, 1836. A Brazilian plant transferred to Leucopsis scaposa Baker in Mart., Fl. Bras. 63:6, 1882, and to Inulopsis scaposa O. Hoffm. in Engler u. Prantl, Pflanzenf. $4^{5}: 149,1894$. The type specimen (Brazil, Vauthier 315) in the DeCandolle herbarium plainly does not belong to Haplopappus.

H. ? sericeus DC., Prodr. 5:349, 1836. Based upon Diplopappus sericeus Less., which see.

H. sphaerocephalus Gray, Pl. Fendl. 76, 1849. Later taken by Gray as the basis for his new genus, Acamptopappus, distinguished chiefly by its short, somewhat paleaceous pappus.

H. stellatus Hook. f., l. c. 112, 1847. A form of Erigeron pappochroma Labill.

H. tasmanicus Hook. f., l. c. 110, 1847. A form of Erigeron pappochroma Labill.

H. texanus Coult., Contr. U. S. Nat. Herb. 1:40, 1890 and 2:241, 1892.=Haploesthes greggi Gray.

H. tortifolius Torr. et Gray, Jour. Bost. Soc. Nat. Hist. 5:109, 1845. Transferred to Aster tortifolius Gray, Proc. Am. Acad. 7:353, 1868 (not A. tortifolius Michx., 1803) and to Aster abatus Blake, Contr. U. S. Nat. Herb. 25:562, 1925.

Hoorebekia chiloensis Cornel., in Mussche, Hort. Gand. for 1817:120, 1817. A species of Grindelia discussed on p. 24

Linosyris ramulosa Gray, Pl. Wright. 2:80, 1853. Based upon Haplopappus ? ramulosus DC., which see.

Prionopsis ? chapmani Torr. et Gray, Fl. N. Am. 2:245, 1842. Aster eryngiifolius Torr. et Gray, according to Gray, Syn. Fl. 12:174, 1884. Heleastrum chapmani Greene, Pitt. 3:49, 1896. 



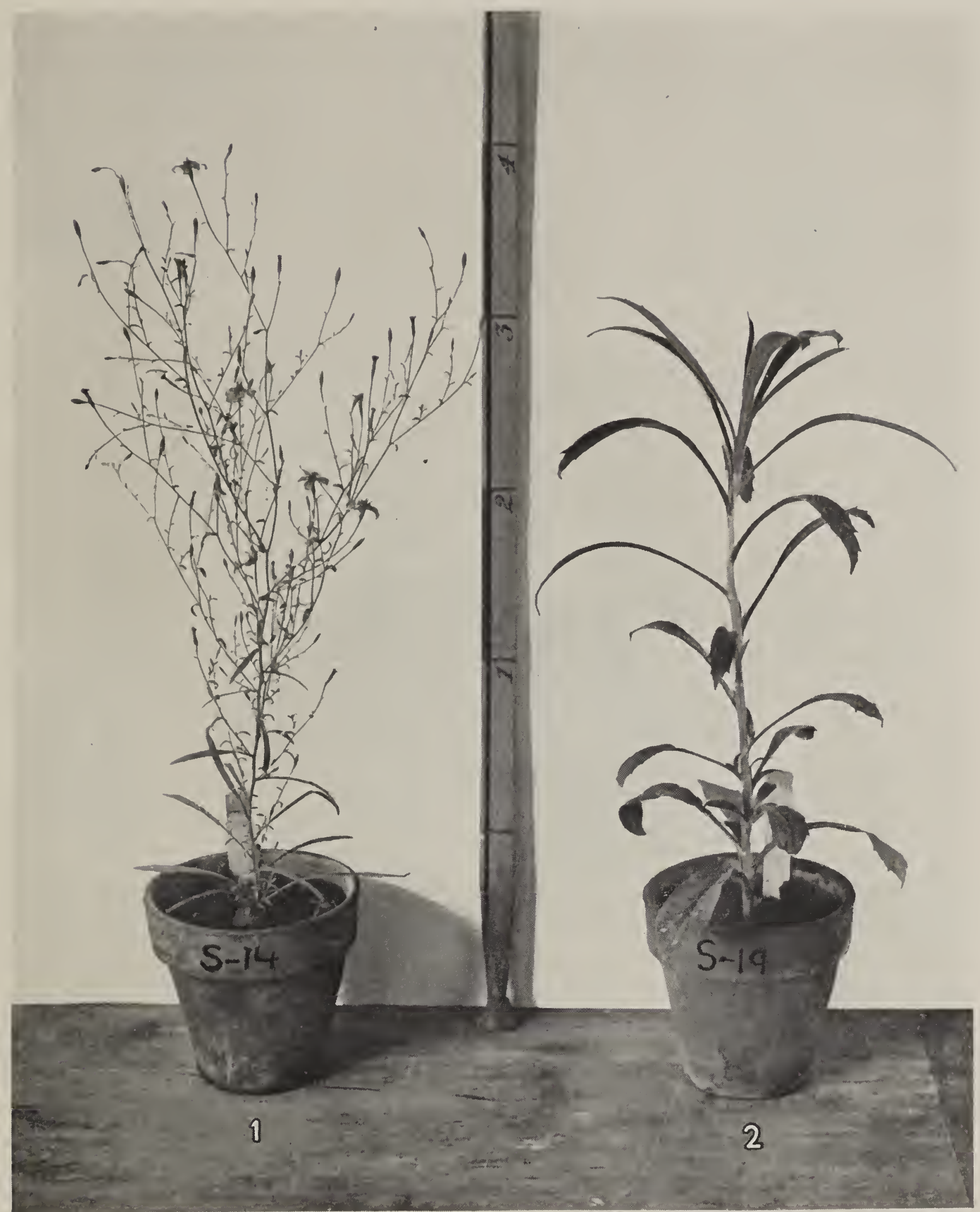

1. Haplopappus occidentalis Hall. Grown from seed gathered at type locality. Photographed August 17, 1927.

2. Haplopapmus divaricatus (Nutt.) Gray. Grown from Texas seed under same conditions as plant in Fig. 1 and photographed at same time. This plant came into flower six weeks later, when about $5.5 \mathrm{dm}$. high. 


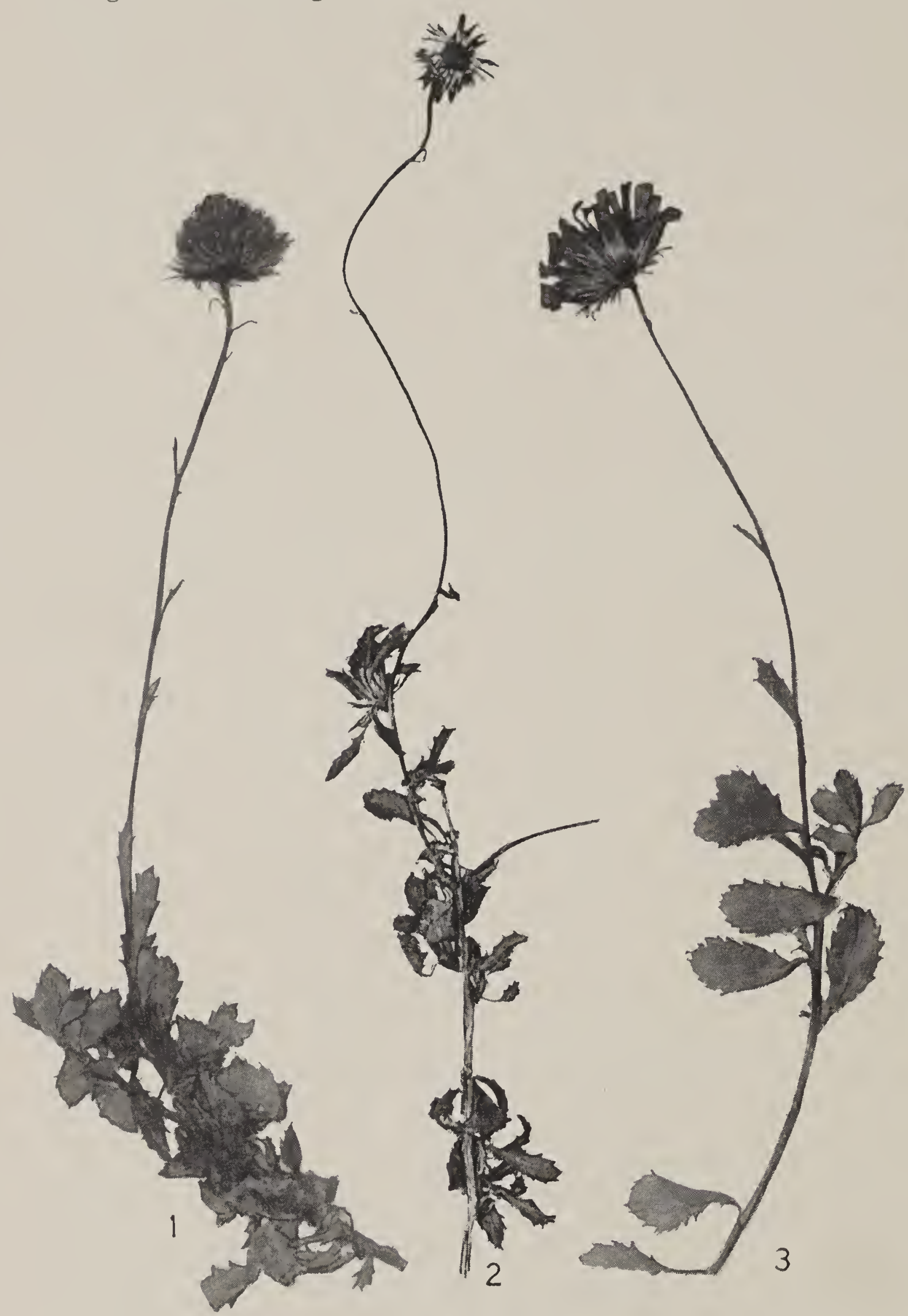

Haplopappus chrysanthemifolius (Less.) DC.

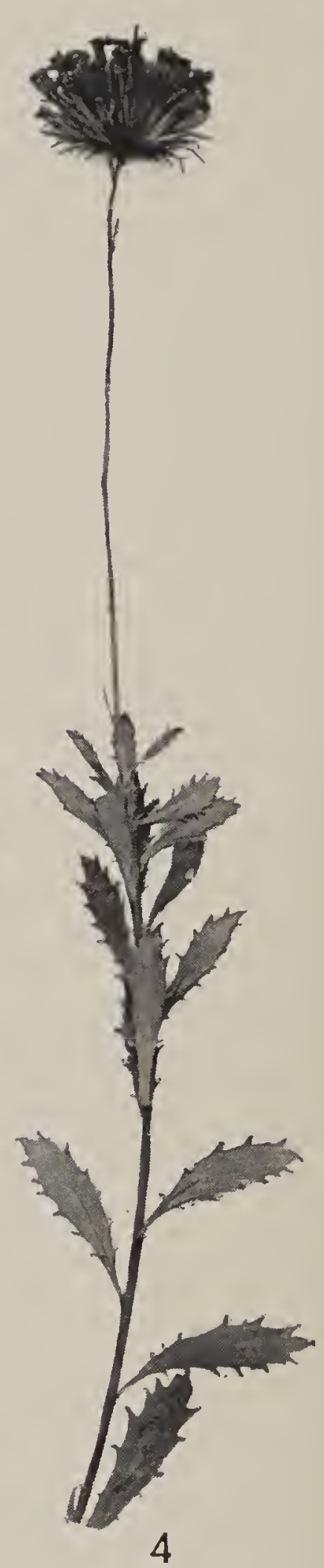

1. From the type collection, Poeppig 243 (in Herb. Berlin). $\times 0.5$

2. Portion of the type of Diplopappus coquimbensis Hook. et Arn., Cuming 892 (in Herb. Kew). $\times 0.5$.

3. Portion of the type of $H$. berteri DC., Bertero 1038, in part (in Herb. DC.). $\times 0.5$.

4. Portion of the type of $H$. berteri $\beta$ ? lanceolatus DC., Bertero 1038, in part (in Herb. DC.). $\quad \times 0.5$. 

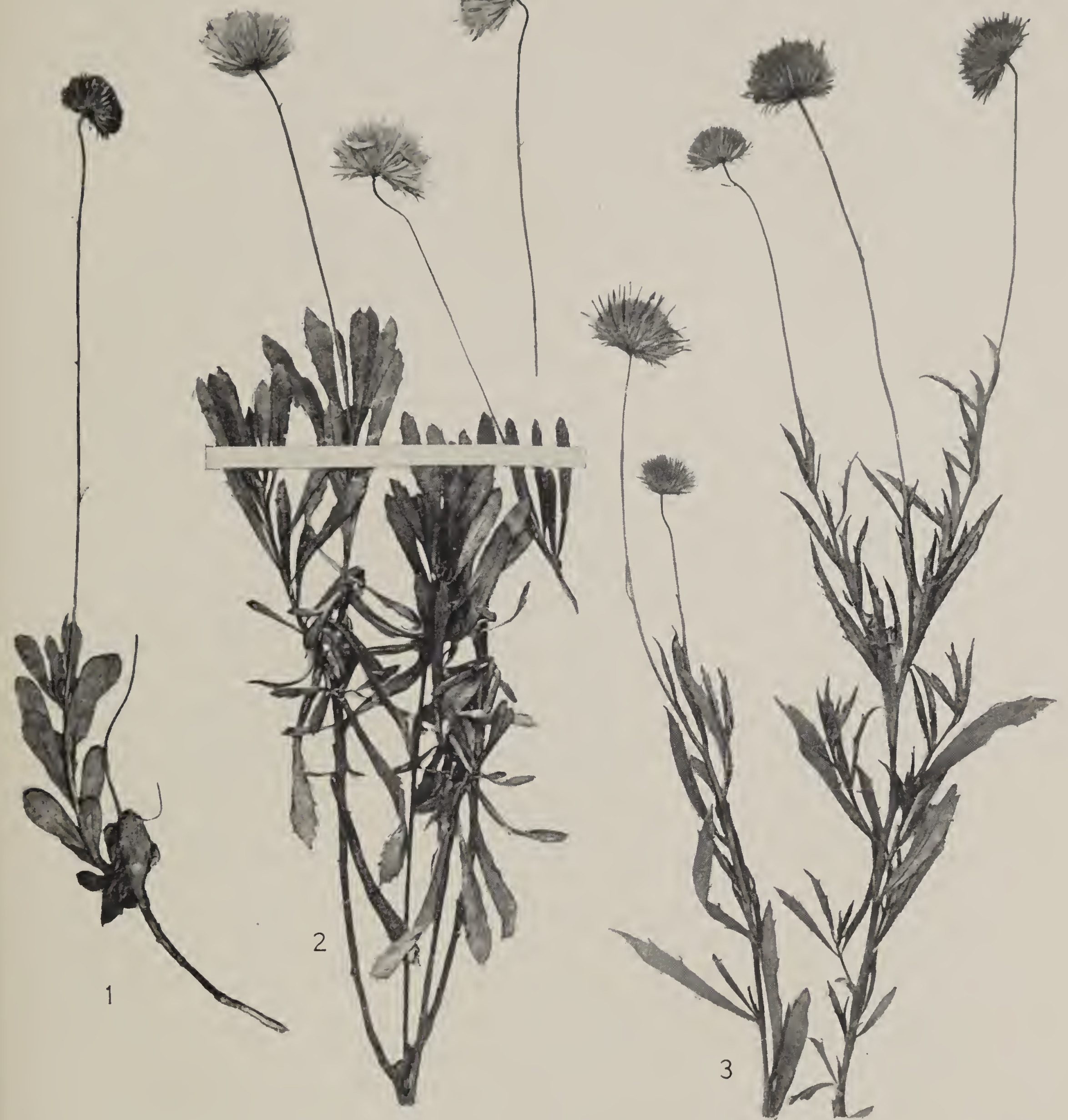

1. IIaplopappus velutimus Remy; from one of the two type sheets, Talcaregue, Chile; pubescence nearly wanting and

ligules short, but other types labeled by Remy are densely puberulent and some now lack the ligules (in Herb. Mus. Paris). $\times 0.4$

2. Haplopapmes illinitus Phil.; from Curicó, Chile, Werdermann $53 \%$ (in Herb. Univ. Calif.). $\times 0.5$.

3. Haplopapmes pulchellus DC.; portion of the type, Bertero 314 (in Herb. D(.). $\times 0.5$. 

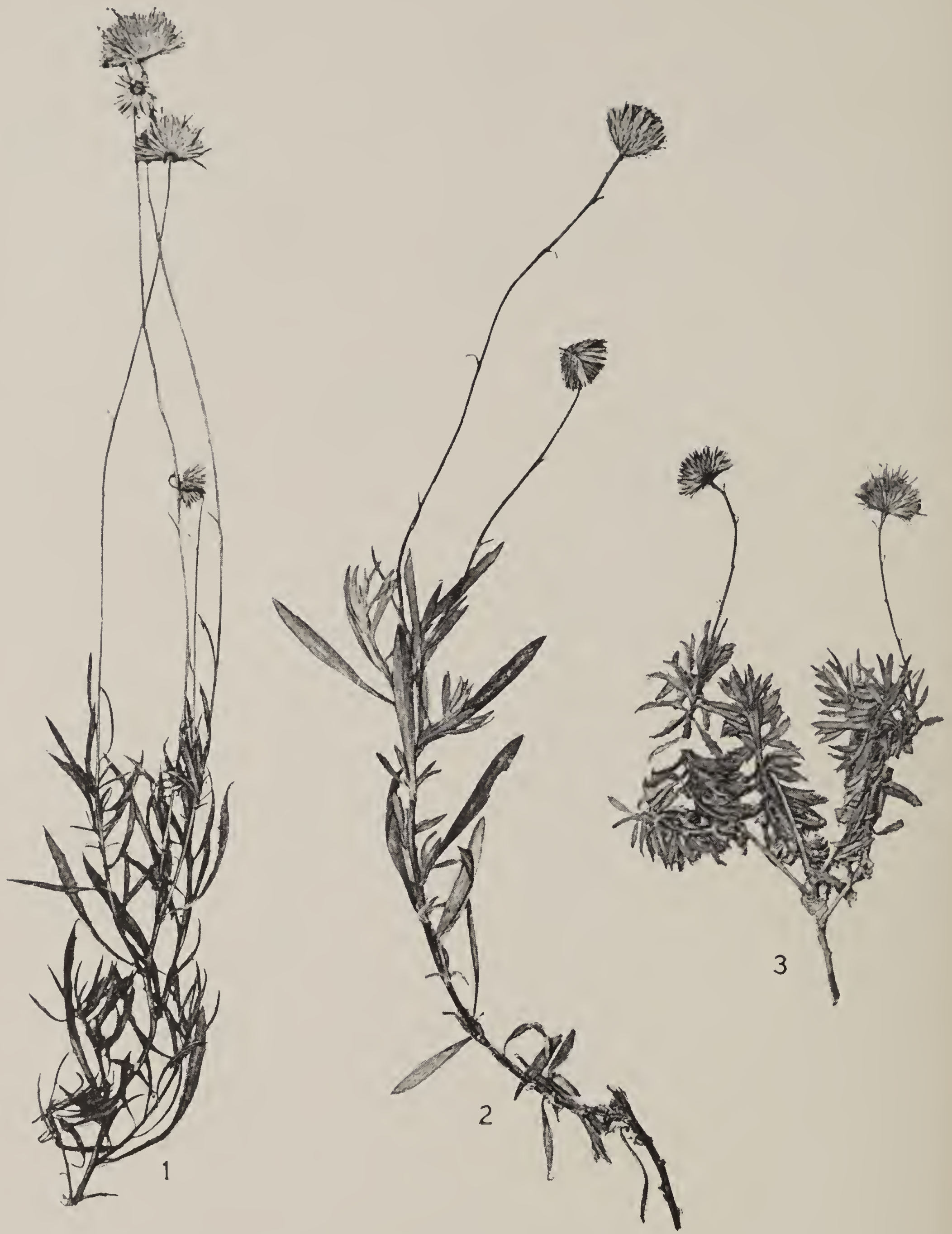

1. Haplopappus donianus (Hook. et Arn.) Reiche; portion of the type, Cuming $\approx 85$ (in Herb. Kew, labeled by Hooker as Diplopappus donianus). $\times 0.5$.

2. Haplopappus poeppigianus (Hook. et Arn.) Gray; from the type, Cuming 203 (in Herb. Kew). X 0.5.

3. Haplopappus bustillosianus Remy; portion of the type, named by Remy (in Herb. Mus. Paris). $\times 0.4$. 

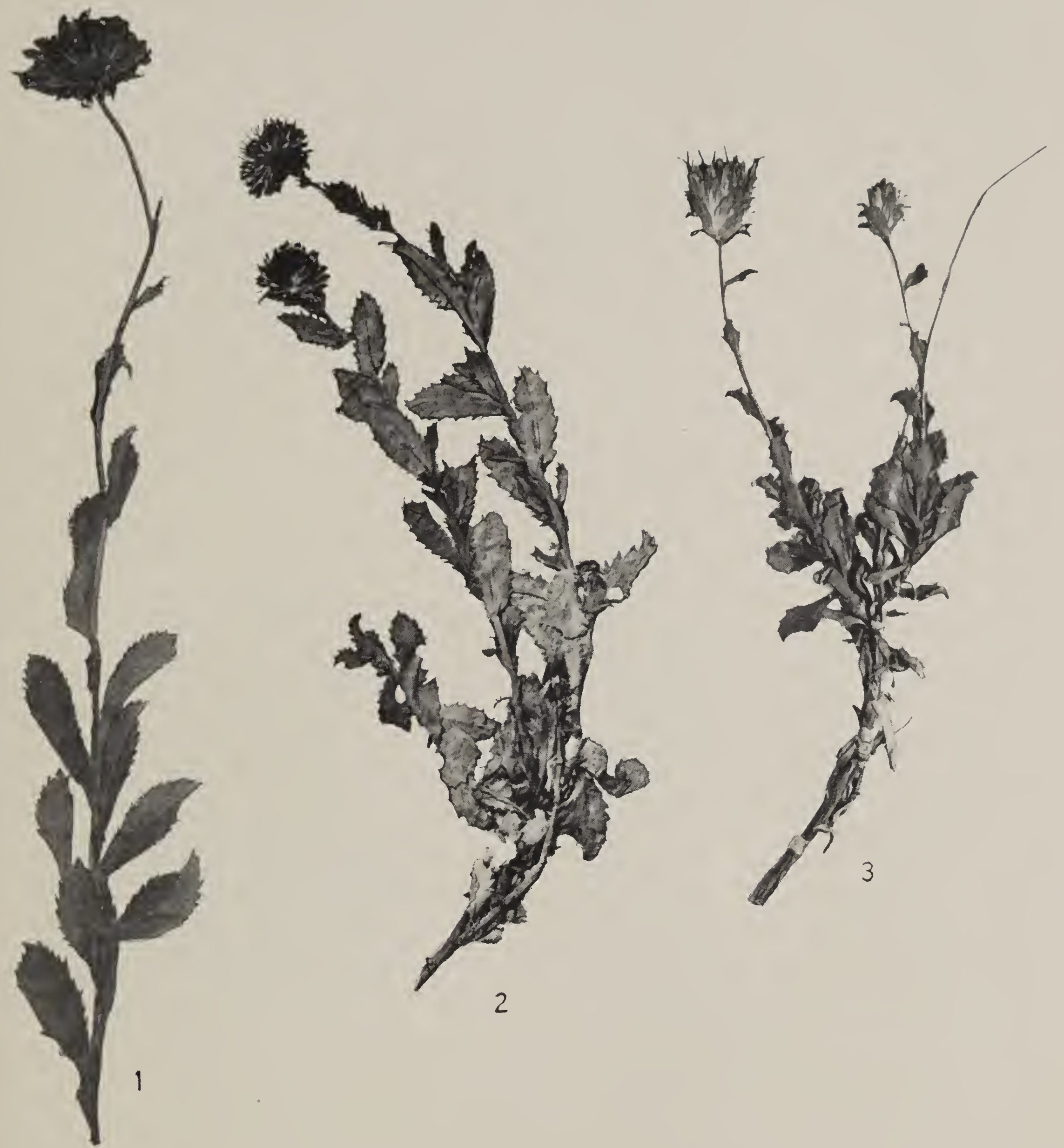

2

1. Haplopappus grindelioides (Less.) DC.; from the type collection, Poeppig 202 (in Herb. Berlin). $\times 0.5$.

2. Haplopappus decurrens Remy; the type, from Colchagua, Chile, named by Remy (in Herb. Mus. Paris). $\times 0.4$.

3. Haplopappus baylahuen Remy; from Vallenar, Province Atacama, Chile, Werdermann 251 (in Herb. Univ. Calif.). $\times 0.5$. 


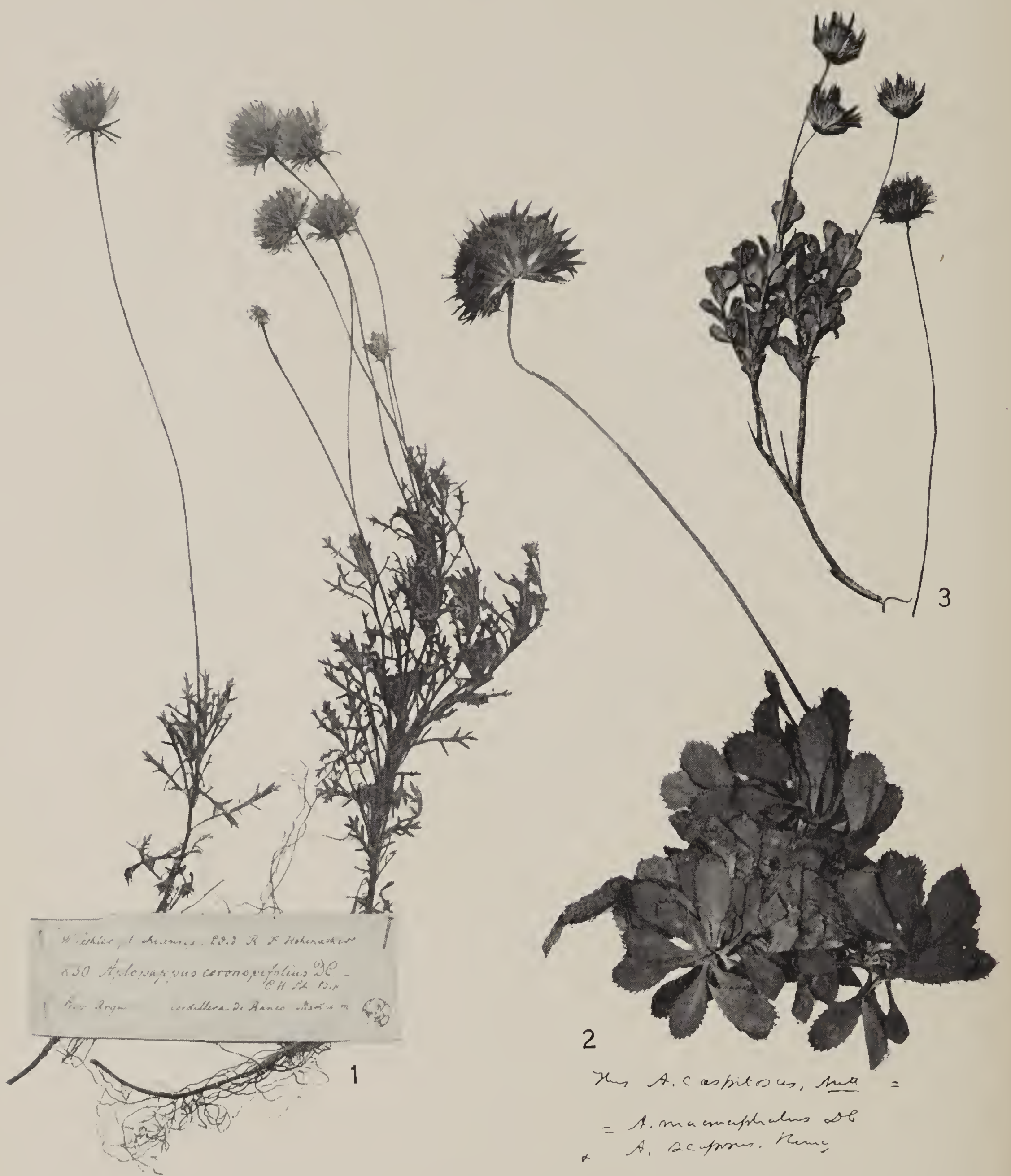

1. Haplopappus glutinosus Cass. (not DC.); from Cordillera de Ranco, Chile, Lechler 830 (in Herb. Del.). X 0.5.

2. Haplopappus macrocephalus (Less.) DC.; the type of H. cespitosus Nutt., from Chile, Styles (in Herb. Phila. Acad.). $\times 0.5$

3. Haplopappus arbutoides Remy; from specimen so named by Remy and to be taken as one of the types, but leaves densely puberulent (in Herb. Mus. Paris). $\times 0.4$. 


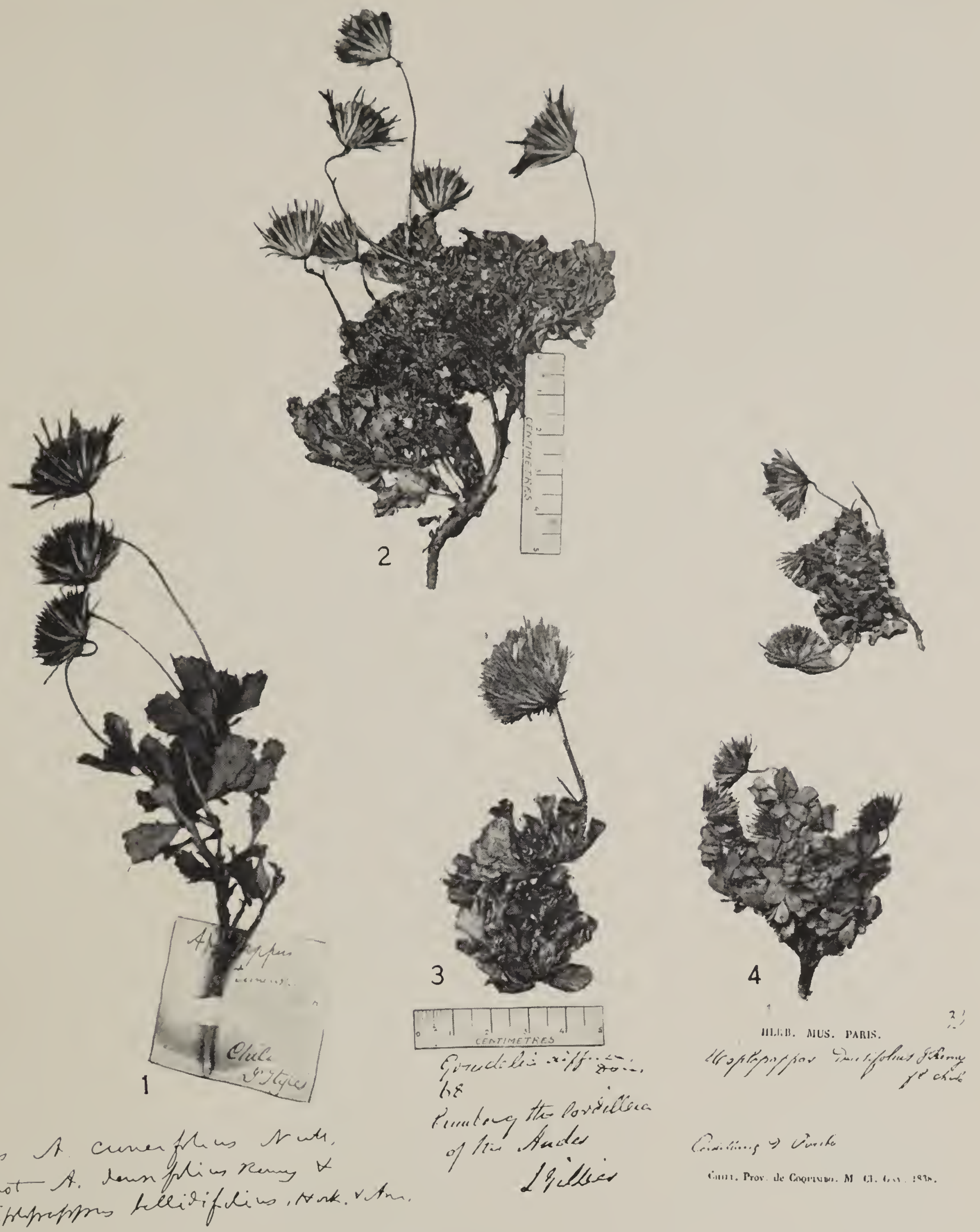

Haplopappus cuncifolius Nutt.

1. The type, Chile, Styles, with note on synonymy by Gray (in Herb. Phila. Acad.). $\times 0.6$.

2. One of the types of Diplopappus bellidifolius Hook. et Arn., Cordillera de Chile, Cuming 233 (in Herb. Kew). $\times 0.5$.

3. One of the types of Diplopappus cuncutus Hook. et Arn., Cumbre of the Cordillera, Chile, Gillies fis (in Herb. Kew). X 0.5 .

4. Two pieces from one of the type sheets of Haplopappus densifolius Remy, Cordillera d'Oville, Chile (in Herb. Mus. Paris). $\times 0.4$. 

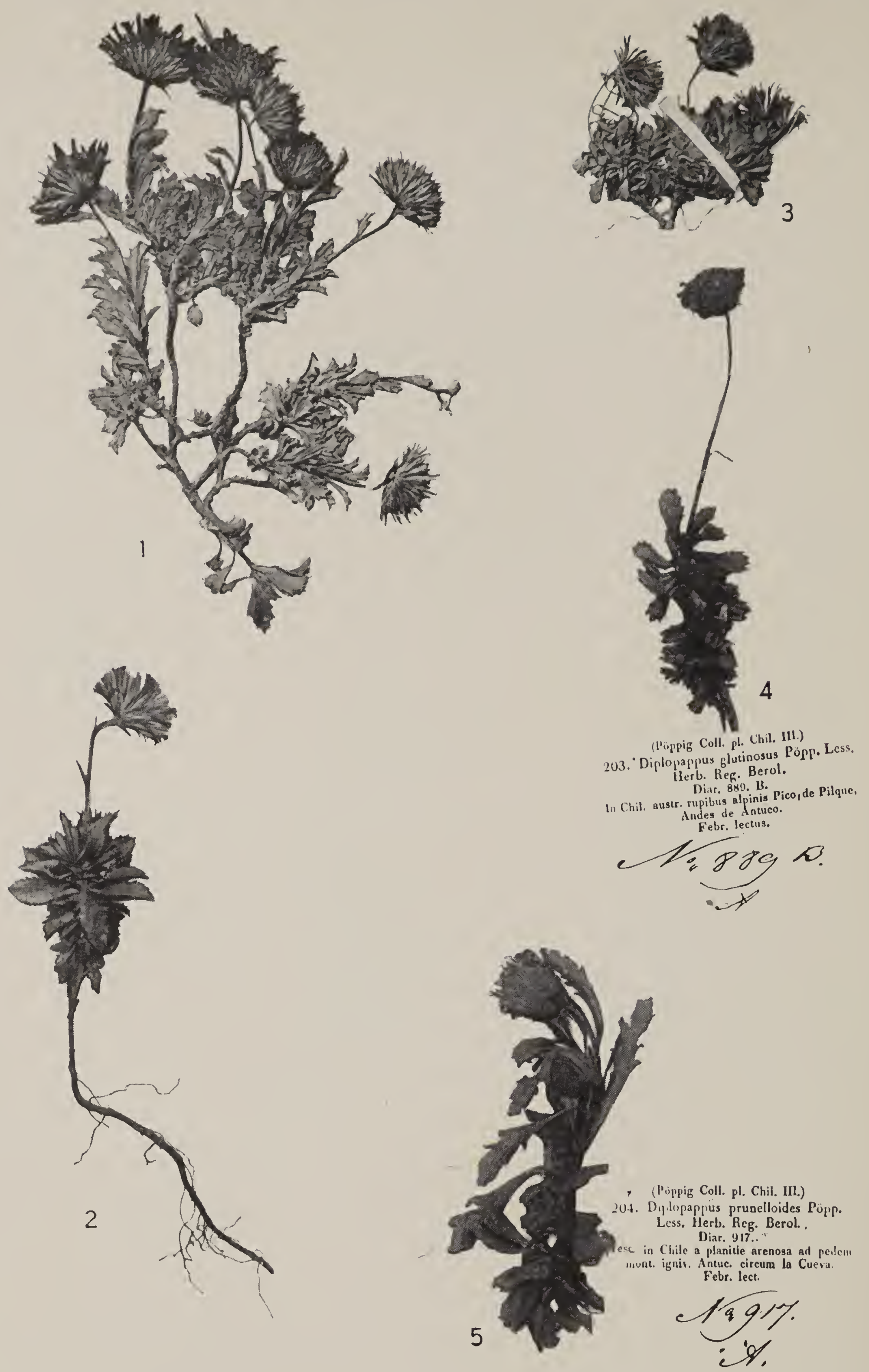

1. Haplopappus diplopappus Remy; one of the types, Talcaregue, Chile, named by Remy (in Herb. Mus. Paris). $\times 0.4$.

2. Haplopappus diplopappus Remy; the "villosus" form from Cordillera d'Aculeo, Chile (in Herb. Berlin). $\times 0.5$.

3. Haplopappus anthylloides Meyen et Walp.; one of the types of $H$. radicans Remy, so named by Remy (in Herb. Mus. Paris). $\times 0.4$.

4. Haplopappus paucidentatus Phil. (?); from the type collection of $H$. glutinosus (Less.) DC., not Cass. $\times 0.5$.

5. Haplopappus prunelloides (Less.) DC.; probably of the type collection (in Herb. DC.) $\times 0.5$. 

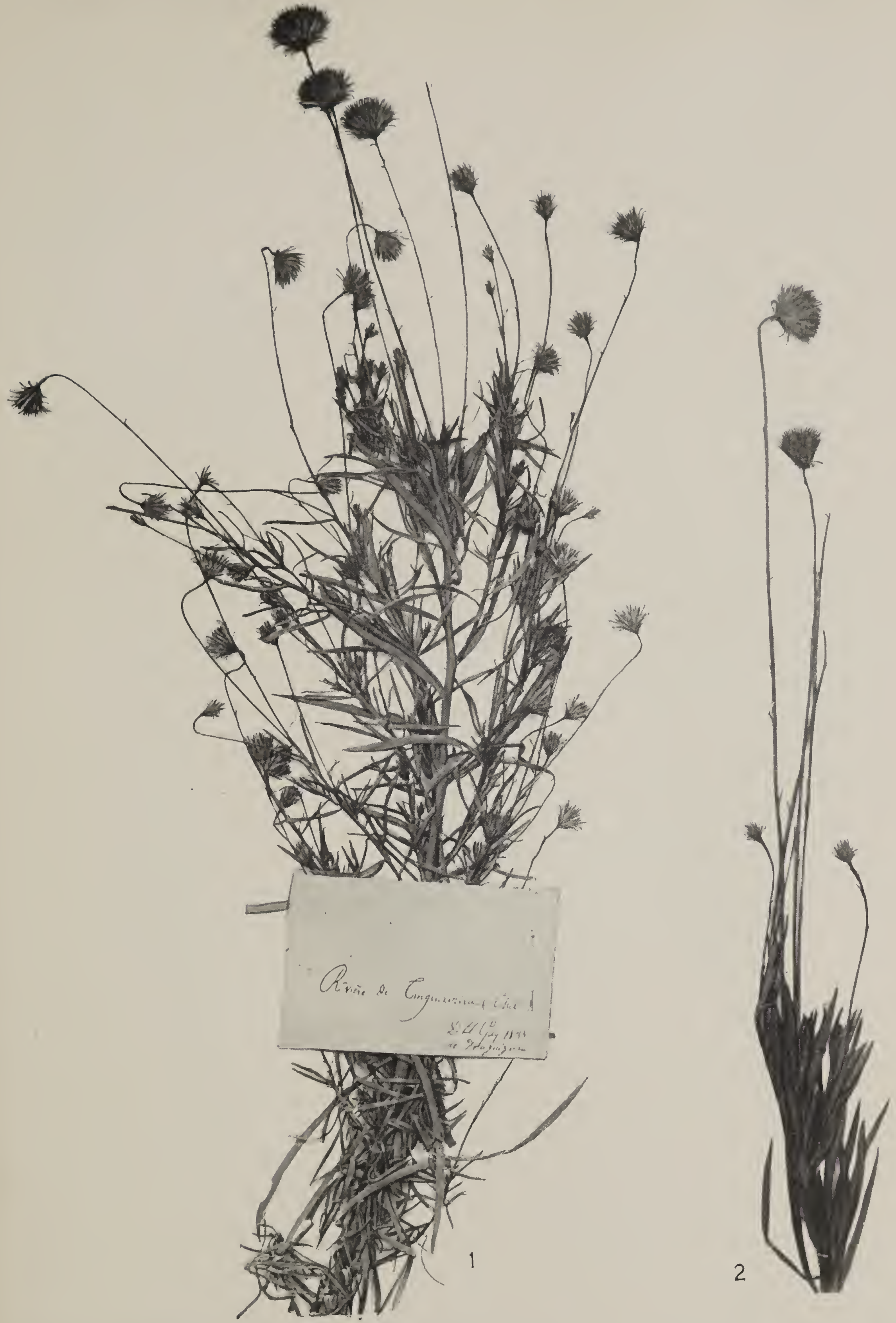

1. Haplopappus pedunculosus Remy; exactly like the type and perhaps from same 'plant; Rio Tinguiririca, Chile (in Herb. DC.). $\times 0.5$.

2. Haplopappes punctatus (Willd.) Hall; type (in Herb. Willd., Berlin). $\times 0.5$. 

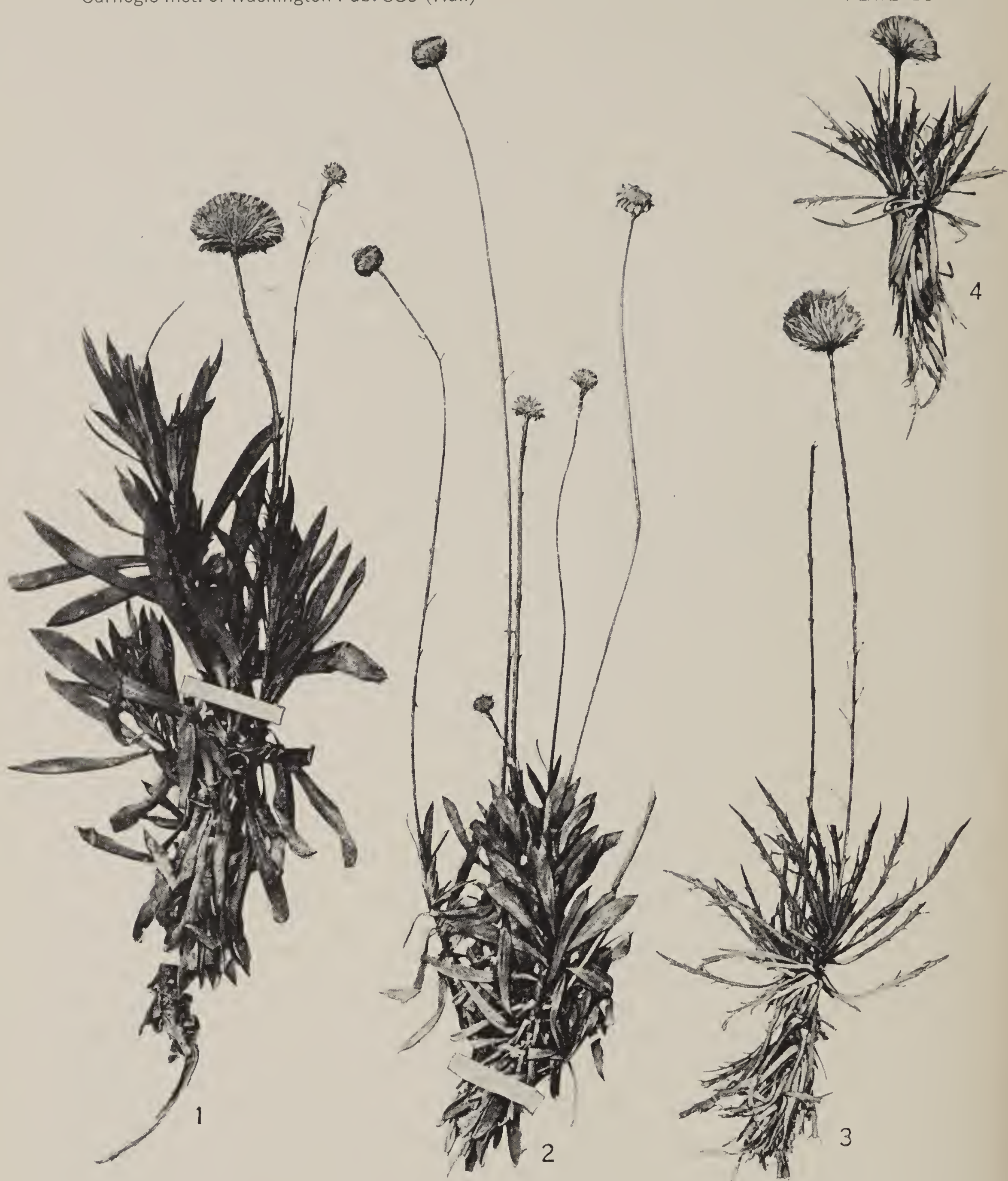

1, 2. Haplopappus integerrimus (Hook. et Arn.) Hall; two specimens from one of the type sheets of $H$. pulchellus var. elongatus Remy, named by Remy (Gay 46, in Herb. Mus. Paris). $\times 0.4$.

3, 4. Haplopappus setiger (Phil.) Meigen; from one of the type sheets of Diplopappus setiger Hook. et Arn., Questa de Chuenboco, Chile, Bridges 221 (in Herb. Kew). $\times 0.5$. 

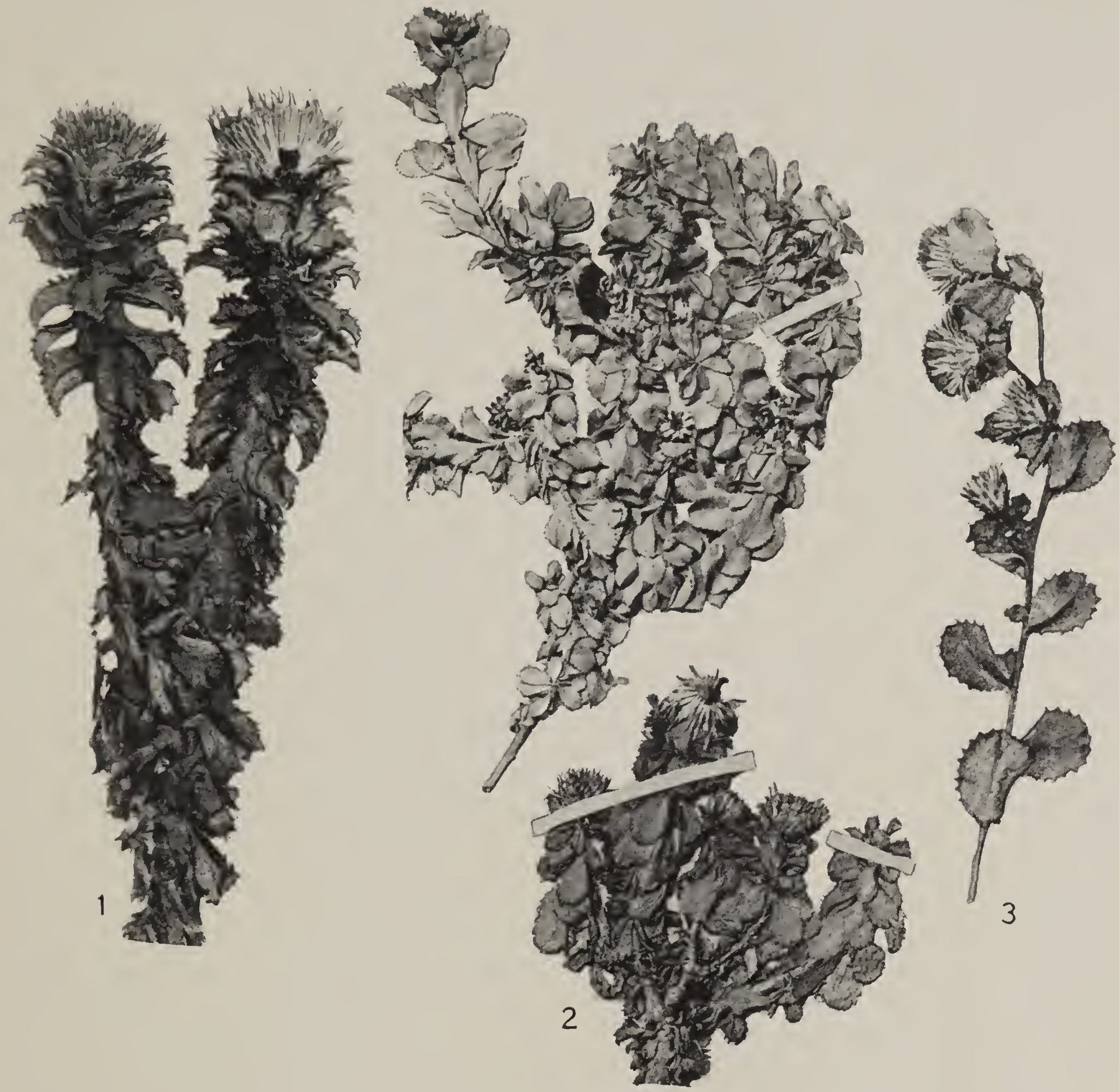

1. Haplopappus foliosus DC.; the type, Valparaiso, Chile, Bertero 1035 in part (in Herb. DC.). $\times 0.5$.

2. Haplopappus rengifoanus Remy; two pieces from one of the three type sheets, Province Colchagua, Gay 303 (in Herb. Paris). $\times 0.4$.

3. Haplopappus rotundifolius Hall; one of three pieces on type sheet (of Diplopappus ilicifolius Hook. et Arn.). Andes of Mendoza, Argentina, Gillies 56 (in Herb. Kew). $\times 0.5$. 


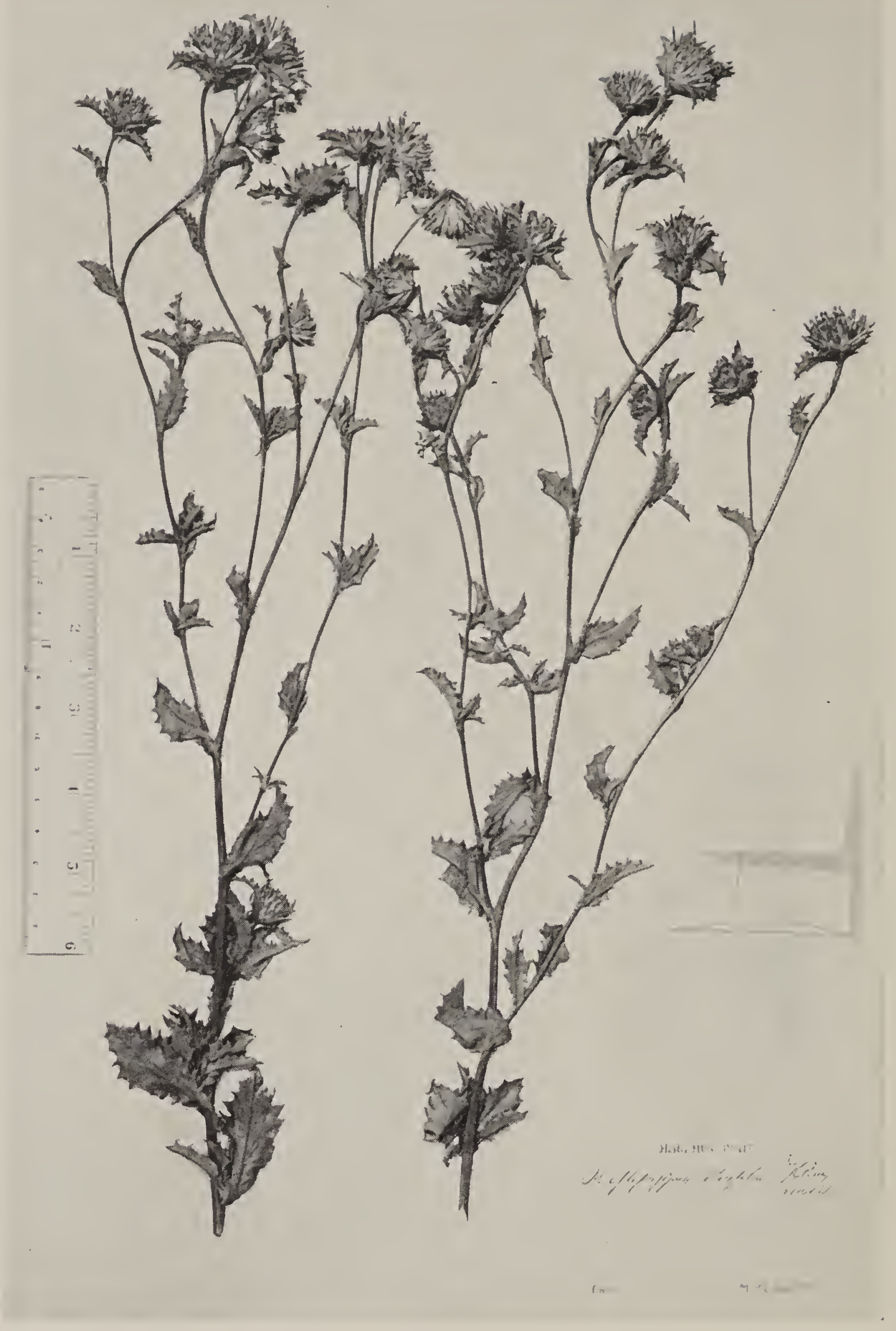

Haplopappus mucronatus Hook. et Arn.; one of the type sheets of H. ilicifolius Remy, so named by Remy (in Herb. Mus. Paris). $\times 0.4$ 


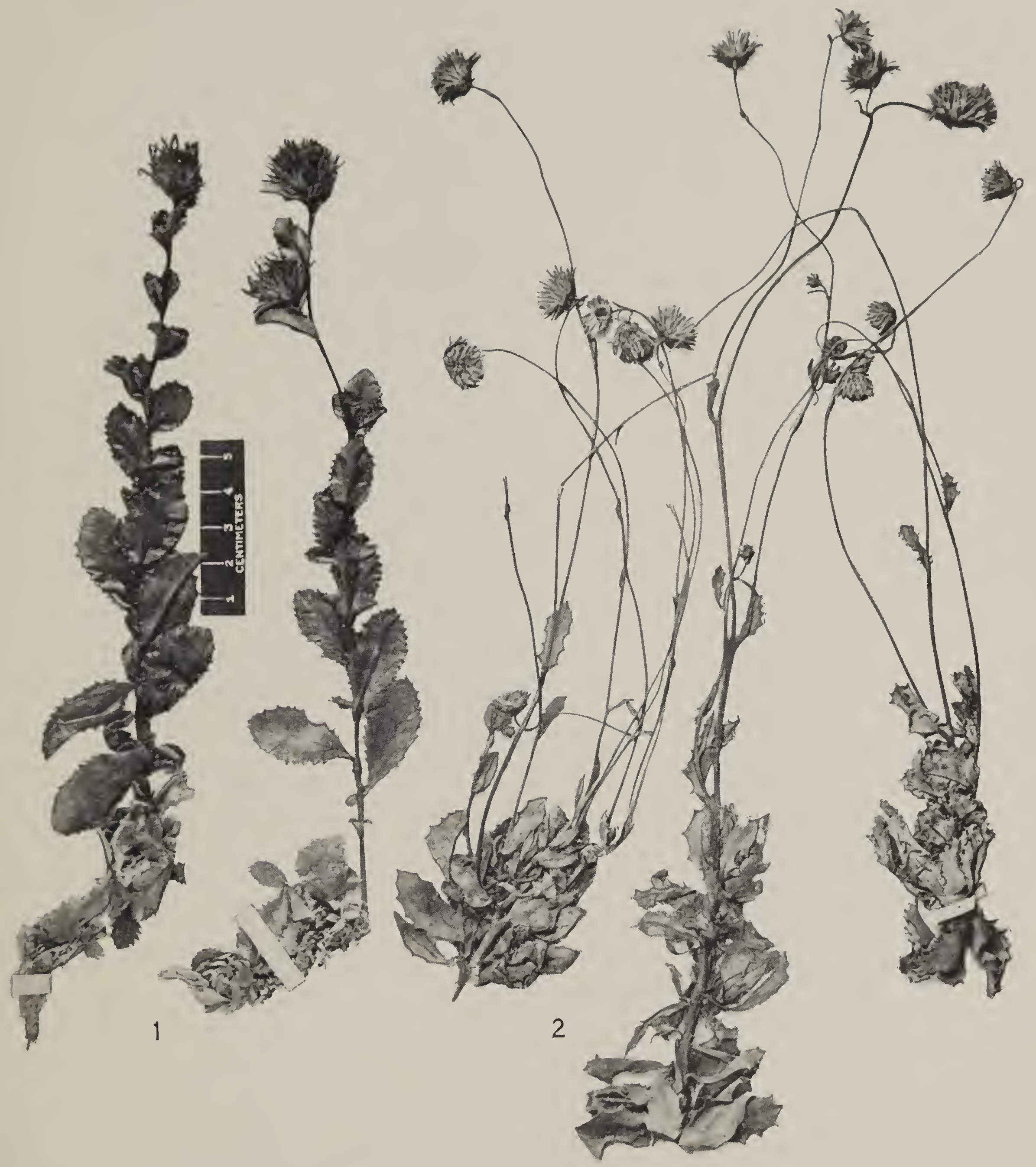

1. Haplopapmes deserticolus Phil.; from Quebrada de San Ramon, north of Taltal, Province Antofagasta, Chile, Johnston 5151 (in Herb. Univ. Calif.). $\times 0.5$.

2. Haplopapmes remyanus Weddell; one of the two type sheets (Gay 43), named by Remy as Pyrrocoma ilicifolia Reny (in Herb. Mus. Paris). $\times 0.4$. 


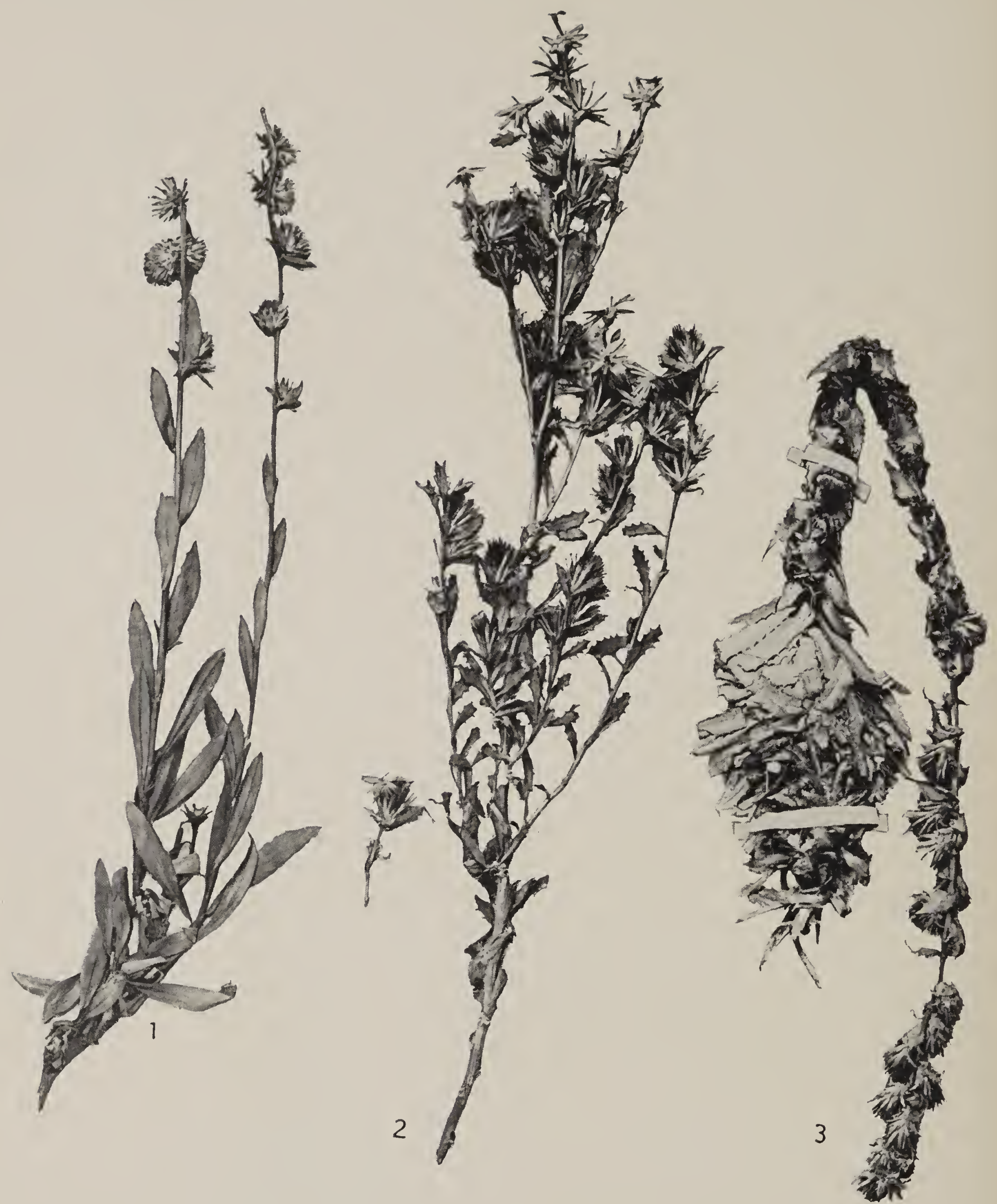

1. Haplopappus bezanillanus (Remy) Reiche; a portion of one of the type sheets (in Herb. Mus. Paris). $\times 0.4$

2. Haplopappus saxatilis (Remy) Reiche; one of the types, labeled "342 in Saxis" by Gay, and "51 Pyrrocoma saxatilis J. Remy, fl. Chil." by Remy (in Herb. Mus. Paris). $\times 0.4$.

3. Haplopappus pristiphyllus (Remy) Hall; a specimen labeled by Remy as Pyrrocoma pristiphylla and probably one of the types (in Herb. Mus. Paris). $\times 0.4$. 

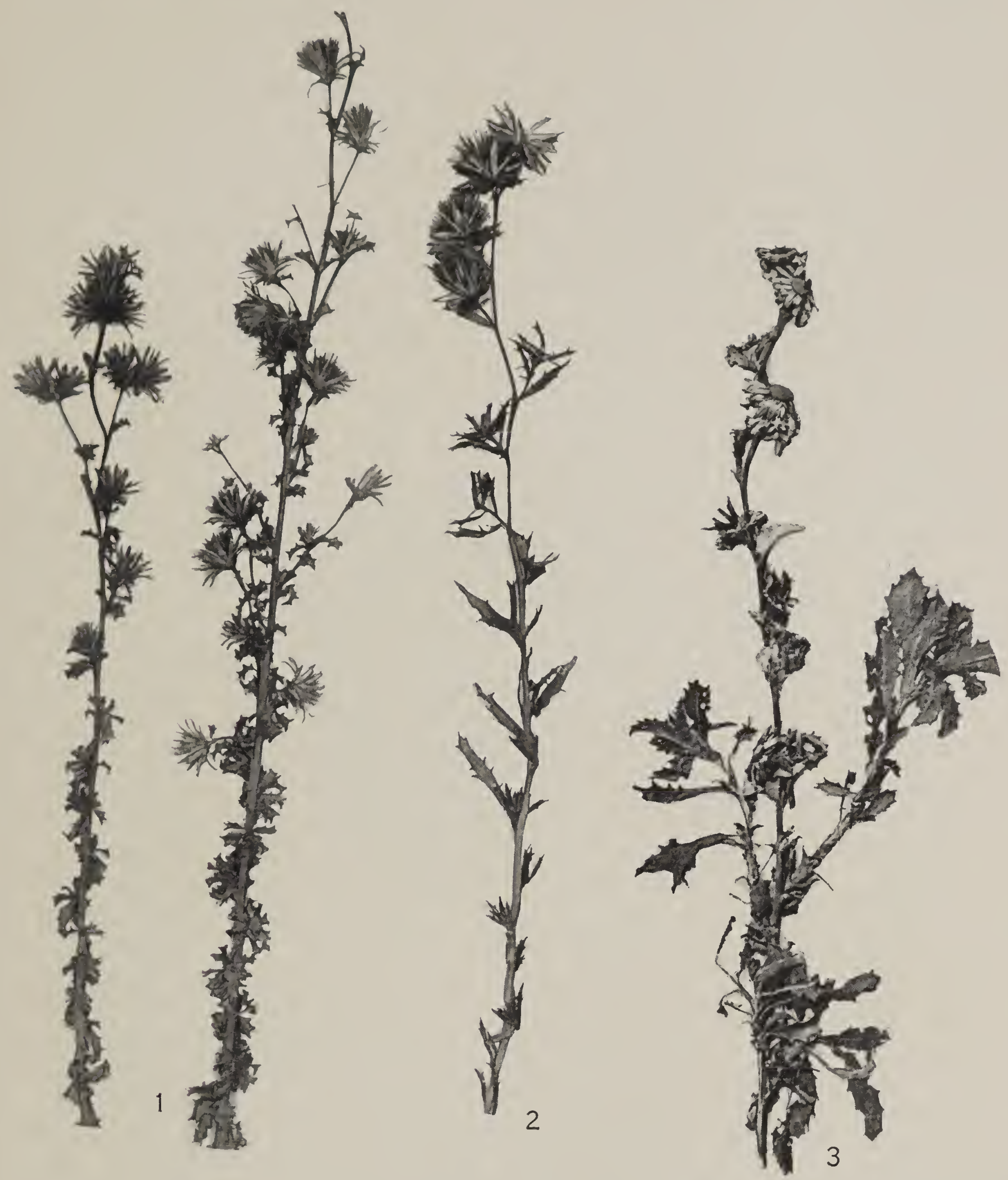

1. Haplopapmes parrifolius (DC.) Gray; the types from Chile named as Pyrrocoma parvifolia DC. by DeCandolle (in Herb. DC.). $\times 0.5$.

2. Haploparmis angnstifolius (DC.) Reiche; the type, labeled "Cordillera, Haenke" and named as Pyrrocoma angustifolia by DeCandolle (in Herb. DC., the only specimen). $\times 0.5$.

3. Haplopapmes macraeanus (Remy) Reiche; one of the types "Sur les collines, Serena, Prov. de Coquimbo", Gay 191, named by Remy as Pyrrocoma macracana Remy (in Herb. Mus. Paris). $\times 0.4$. 


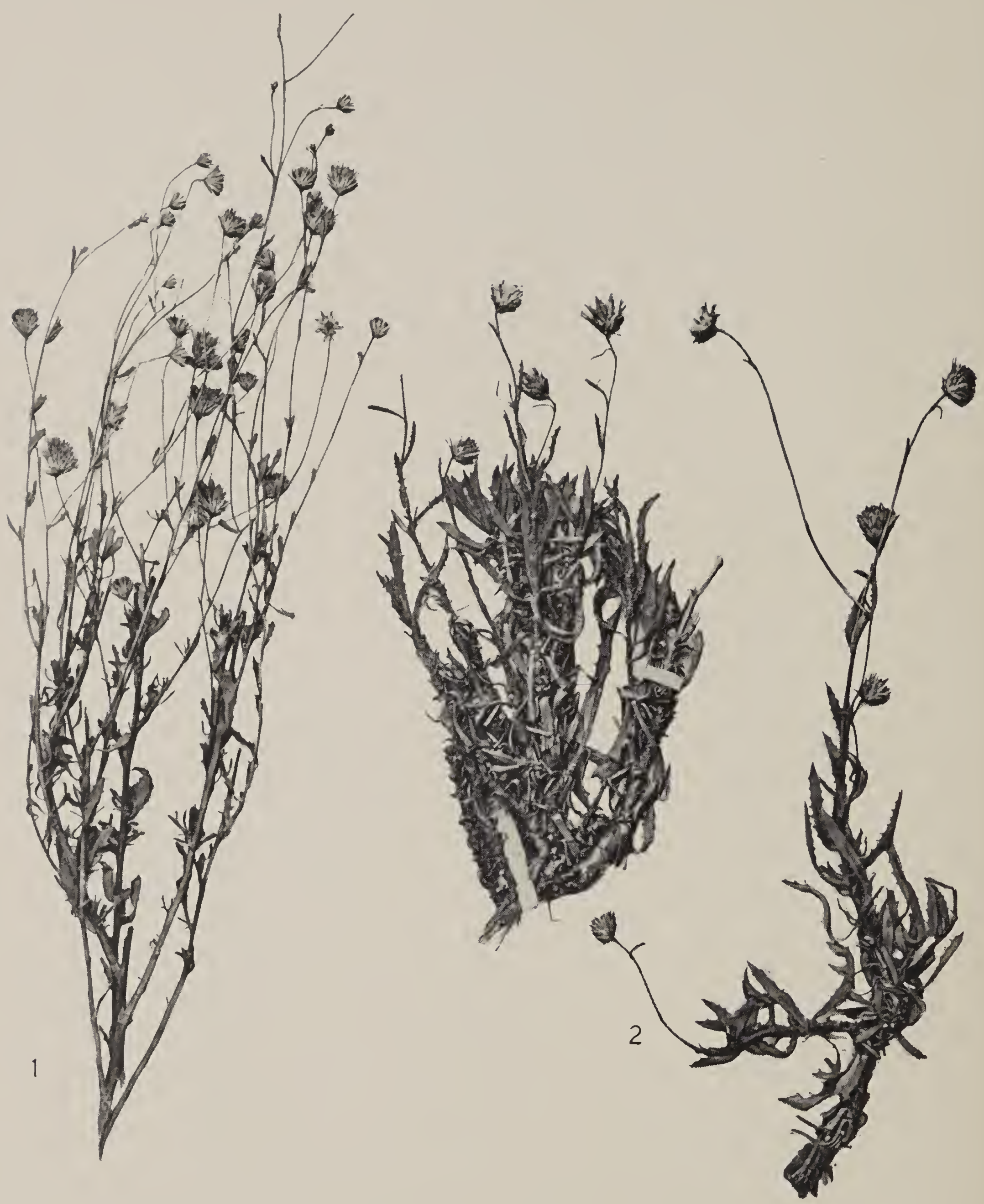

1. Haplopappus cerberoanus (Remy) Reiche; a specimen labeled "Chili Austral" and named by Remy as Pyrrocoma cerberoanus (in Herb. Mus. Paris). $\times 0.4$.

2. Haplopappus stelliger Remy; one of the two type sheets from Province Coquimbo, Chile (in Herb. Mus. Paris). $\times 0.4$. 


\section{INDEX}

Pages of principal entries of accepted names of sections and species of Haplopappus are in heavy-face type.

Abronia latifolia, 264

Acamptopappus microcephalus, 276 sphaerocephalus, 365

Adenostoma fasciculatum, 255, 270, 283 sparsifolium, 270

Aesculus californica, 218

Amellus spinulosus, 74, 76, 78

Andromachia alternifolia, 314

Antenmaria alpina, 181, 185 rosea, 147

Antirrhinum majus, 8

Aplodiscus (see Haplodiscus)

Aplopappus (see Haplopappus) 25

Aplostephium, 36

Aquilegia pubescens, 208

truncata, 183

Arctostaphylos, 283

patula, 257

Arnicella, 34

Artemisia, 176

californica, $249,255,262,268$

campestris pycnocephala, 264

frigida, 95

pattersoni, 185

spinescens, 234

tridentata, 123, 171, 204, 220, 293, 296

arbuscula, 176

Asiris, 36, 40, 288

Aster, 68, 364, 365

abatus, 365

acradenius, 234

adelberti, 340

andinus, 343

anethifolius, 312

angelandri, 94

anthylloides, 336

apargioides, 146

araucanus, 312

arbutoides, 332

armerioides, 164

atacamensis, 325

atenes, 353

aureus, 65

baylahuen, 327

berberidis, 246

berlandieri, 241

berteri, 314

bezanillanus, 350

bloomeri, 200

brachylepis, 270

brandegei, 52

bustillosianus, 322

caespitosus, 167

canbyi, 112

carthamodes, 105

cerberoanus, 355

chryseus, 338

chrysothamnus, 283

ciliatus, 85

cooperi, 276

\author{
Aster-Continued \\ coronopifolius, 236 \\ croceus, 99 \\ cuneatus, 285 \\ cuneifolius, 333 \\ densifolius, 333 \\ denticulatus, 355 \\ dieteria, 63 \\ diplopappus, 335 \\ divaricatus, 213 \\ doellianus, 325 \\ ericina, 264 \\ eryngiifolius, 365 \\ foliosus, 345 \\ gayanus, 316 \\ glabratus, 332 \\ glutinosus, 336 \\ grayanus, 125 \\ greenei, 195 \\ grindelioides, 254, 323 \\ grisebachi, 365 \\ griseus, 321 \\ gymnocephalus, 67 \\ haplopappus, 364 \\ hartwegi, 236 \\ heterophyllus, 239 \\ hirtellus, 315 \\ hookerianus, 213 \\ howelli, 221 \\ ilicifolius, 348 \\ illinitus, 318 \\ jamesi, 179 \\ lanatus, 365 \\ lanceolatus, 119 \\ laricifolius, 274 \\ lastarrianus, 327 \\ linearifolius, 158 \\ linoides, 344 \\ longipes, 316 \\ macraeanus, 354 \\ macrocephalus, 331 \\ marginalis, 324 \\ meyeni, 344 \\ minor, 211 \\ monactis, 276 \\ multicaulis, 92 \\ multifolius, 345 \\ nevini, 267 \\ nuttalli, 70 \\ ochagavianus, 326 \\ oligodontus, 336 \\ parishi, 280 \\ parvifolius, 353 \\ patagonicus, 322 \\ pectinatus, 312 \\ pedunculosus, 339 \\ philippi, 325 \\ phyllocephalus, 59 \\ pickeringi, 173 \\ pincus, 362
}


Aster-Continued pinnatifidus, 78 pityphyllus, 261 polyphyllus, 345 pristiphyllus, 351 prunelloides, 337 pulchellus, 364 pyrrocoma, 136 radicans, 336 remyanus, 324,350 rengifoanus, 347 resinotus, 295 retinervius, 352 reversus, 323 saxatilis, 351 schumanni, 342 scopiformis, 316 scrobiculatus, 334 senebierifolius, 328 serenoi, 290 setiger, 343 sonoriensis, 272 spinuliger, 362 stelliger, 355 stenophyllus, 175 stenotus, 185 stewardensis, 353 stolonifer, 50 suffruticosus, 191 tortifolius, 365 uncinatus, 316 valparaisanus, 319 venetus, 226

venosus, 335 villiger, 335 wardi, 89 whitneyi, 257

Astereae, 38

Atriplex canescens, 248, 296 confertifolia, 234 lentiformis, 234 parryi, 234 patula, 144 polycarpa, 234 truncata, 144

Baccharis assuensis, 356 fuliginea, 356 hookeriana, 348 mucronata, 347, 348 pilularis, 264 ramulosa, 365 veneta, 224,226

Bambusa, 219

Baylahuen, 327

Bigelovia, 29, 36, 272 acradenia, 233, 234 arborescens, 283 brachylepis, 270 cooperi, 276,277 coronopifolia, 236 diffusa, 272

drummondi, 241 engelmanni, 94

fuliginea, 356

furfuracea, 226

hartwegi, 236

hypoleuca, 357

lehmanni, 359
Bigelovia-Continued macronema, 206 menziesi, 226 scopulorum, 219

nelsoni, 274

oppositifolia, 364

parishi, 280

pluriflora, 239

rupestris, 285

spathulata, 285

tridentata, 225, 226

veneta, 226

decumbens, 226

sedoides, 226

wrighti, 239

hirtella, 239

Blepharodon, 33, 38, 53

Capsella bursa-pastoris, 8

Carduus drummondi, 123

Carex, 181

Cassiope mertensiana, 53

Castanea sempervirens, 257

Ceanothus cuneatus, 270,283

Celtus, 220

Centaurea, 218

Chroilema subcanescens, 321

Chromochaeta, 353

Chrysoma arborescens, 283

brachylepis, 270

cooperi, 277

cuneata, 285

spathulata, 285

diffusa, 272

ericoides, 264

fasciculata, 259

laricifolia, 275

merriami, 285

nana, 295

palmeri, 267

parishi, 280

pauciflosculosa, 364

pinifolia, 261

Chrysopsis, 27

acaulis, $165,166,167$

breweri, 257

caespitosa, 167, 169

divaricata, 213

graminifolia, 364

nivea, 365

oregana, 365

villosa, 364

Chrysothamnus, 27, 29, 265, 272, 303

bloomeri, 200

corymbosus, 277

gramineus, 219

nanus, 295

nauseosus, 296

consimilis, $114,123,144$

parryi bolanderi, 208

resinosus, 297

viscidiflorus lanceolatus, 296

Clappia, 365

Conyza punctata, 339,340

Corethrogyne cana, 244

detonsa, 244

filaginifolia, 365

Crepis capillaris, 8 glauca, 123 
Croptilon divaricatum, 213

hookerianum, 213

Croton, 218

Cystopteris fragilis, 211

Damiana, 231

Dendromecon ridumig, 283

Dieteria gracilis, 63 spinulosa, 78

Diplopappus bellidifolius, 333 canescens, 316

chamissonis, 340

chrysan themifolius, 314

coquimbensis, 314

coronopifolius, 328

cunentus, 333

diffusus, 364

divaricatus, 213

doliianus, 319

ericoides, 262, 264

filifolius, 364

foliosus, 345,347

glutinosus, 336

grindelioides, 323

ilicifolius, 347

integerrimus, 341

inuloides, 314

macrocephalus, 331

mucronatus, 348

pinnatifidus, 78,312

poeppigianus, 320

prunelloides, 337

punctatus, 319

scrobiculatus, 334

sericeus, 364

setiger, 343

spinulosus, 334

Diplostephioides, 303, 355

Diplostephium canum, 244

Distichlis, 123, 144 spicata, 144, 234

Donia ciliata, 84,85

lanceolata, 115, 119

uniflora, 148, 151

Dryas octopetala, 185

Elymus condensatus, 123, 234

Eremocarpus, 218

Ericameria, 36 , 40, 243, 258

arborescens, 283

bloomeri, 201

brachylepis, 270

cervina, 293

cooperi, 277

cuneata, 285

spathulata, 285

diffusa, 271,272

erecta, 201

ericoides, 264

fasciculata, 259

microphylla, 264

monactis, 277

nana, 295

nelsoni, 275

palmeri, 267

parishi, 280

parrasana, 160

pinifolia, 261

purpusi, 299

resinosa, 297

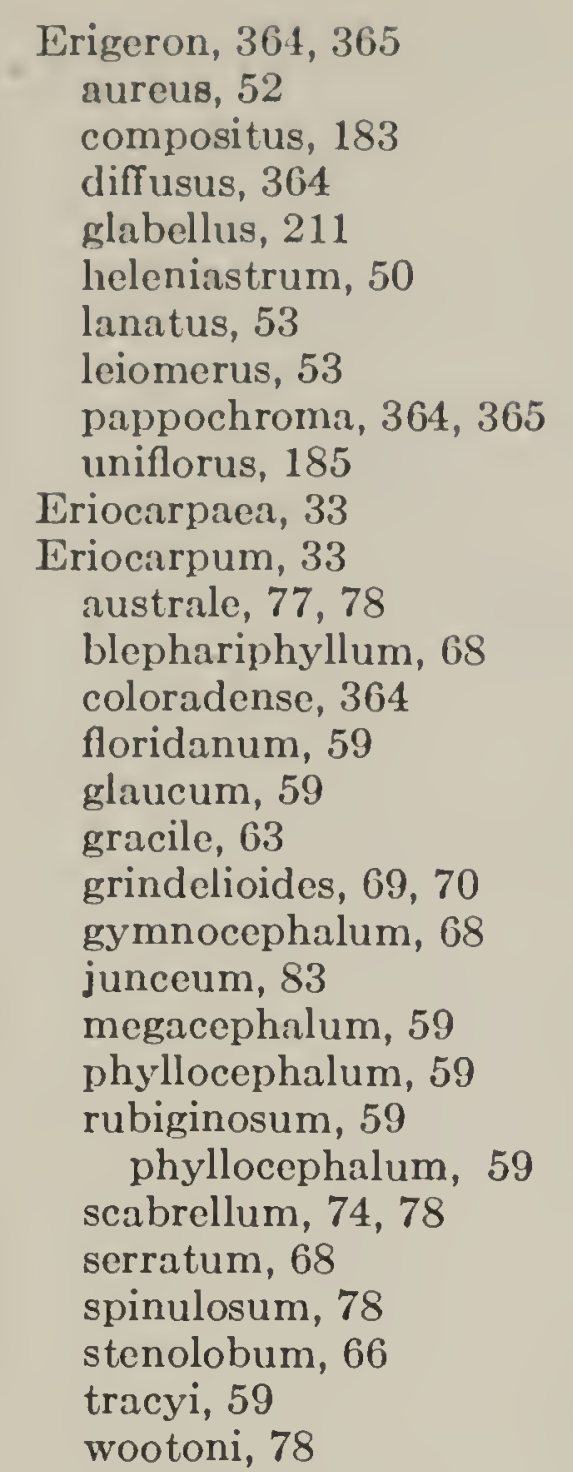

Eriodictyon californicum, 283

Eriogonum fasciculatum, 248, 249, 255, 262, 268,270

incanum, 171,208

latifolium, 264

marifolium, 208

ovalifolium, 171

wrighti, 257

Eriophyllum staechadifolium, 264

Euhaplopappus, 302, 311

Eupatorium mygindaefolium, 364

Euphorbia miser, 248, 249

Eupyrrocoma, 34

Euthamiopsis, 36

Frankenia, 144

grandiflora, 144

Franseria chamissonis, 264

Garrya elliptica, 283

Gilia pungens hookeri, 171

Grayia spinosa, 296

Grindelia, 25, 27, 38, 365

acerosa, 319,341

canescens, 319,321

glutinosa, 314

pulchella, 319

Gutierrezia sarothrae, 95

Gymnocoma, 343

Haplodiscus, 36

densifolius, 346

elatus, 319

exserens, 321

fallax, 317

graveolens, 361

humilis, 342

ischnos, 346

kingi, 346 
Haplodiscus-Continued

landbecki, 346

latifolius, 361

longiscapus, 317

pachyphyllus, 347

peteroanus, 363

polycladus, 321

sphacelatus, 351

tenuifolius, 319

vernicosus, 361

geissei, 361

zañartui, 317

Haploesthes greggi, 365

Haplopappus, 23, 24

aberrans, 185

acanthodon, 314

acaulis, 164, 208

glabratus, 166, 167, 168

typicus, 165, 167

acerosus, 341

acradenius, 232

bracteosus, 233

eremophilus, 233

typicus, 233

acuminatus, 364

alpigenus, 364

ameghinoi, 338

andersoni, 173

anethifolius, 312

angustifolius, $\mathbf{3 5 3}$

anthylloides, $\mathbf{3 3 5}$

apargioides, 144

araucanus, $\mathbf{3 1 2}$

arborescens, 281

arbutoides, $\mathbf{3 3 1}$

glabratus, 332

arenarius, 71

incisifolius, 76,78

rossi, 78

argenteus, 321

armerioides, 162, 342

assuensis, 355

aureus, 64

australis, 322

axilliflorus, 361

baccharidifolius, 317

baccharoides, 364

baylahuen, 326

bellidifolius, 361,364

bellidioides, 364

berberidis, 243, 245, 249, 269

berteri, 313,314

lanceolatus, 313,314

bezanillanus, $\mathbf{3 5 0}$

blanchetianus, 364

blerphariphyllus, 68

bloomeri, 196, 198

angustatus, 198, 201

compactus, 199

sonnei, 199, 201

typicus, 198, 201

brachylepis, 270,361

brandegei, 51

breviradiatus, 340

brickellioides, 83

bustillosianus, $\mathbf{3 2 2}$

caespitosus, 331

calendulaceus, 364

candollei, 316
H:plopappus-Continucd

canescens, 321, 364

exserens, 321

canus, 243

carthamoides, 101

cusicki, 104, 105

erythropappus, 105

maximus, 102, 103, 105

rigidus, 103, 105

subsquarrosus, 104

typicus, 103

caucanus, 359

cerberoanus, 354

cervinus, 292

chamissonis, 340

chrysan themifolius, $\mathbf{3 1 2}, 313,362$

chrysocephalus, 337

ciliatus, 84

cinerariaefolius, 364

clementis, 107

contractus, $\mathbf{1 5 5}$

cooperi, 275, 277

corniculatus, 324

coronopifolius, 328

laxus, 328

corymbosus, 339

coulteri, 78

croceus, 97, 99

genuflexus, 99

typicus, $\mathbf{9 7}, 99$

cruentus, 246

cuneatus, 284

spathulatus, 285

cuncifolius, 332, 362

decurrens, 324

densifolius, 333

denticulatus, 355

deserticolus, 246, 349

diffusus, 271, 364

diplopappus, 334, 361, 362

discoideus, 206, 226

divaricatus, 212, 216

diversifolius, 333

doellianus, 325

domeykoi, 327

donianus, 319

drummondi, 240

durus, 353

eastwoodae, 258

elatus, 318

engelmanni, 93

ericoides, 262

eriopodus, 136

eximius, 181

falcatus, 168

fallax, 317

fasciculatus, 227, 259

filifolius, 364

florifer, 364

fluehmanni, 327

foliosus, 344

foncki, 348

formosus, 314

fremonti, 86

monocephalus, 87

typicus, 87, 89

wardi, $\mathbf{8 8 ,} 89$

fruticosus, 236

fuligineus, 356 
Haplopappus-Continued glabratus, 332

glutinosus, 23, 327, 336

illinitus, 318

gooddingi, $7 \mathrm{~S}$

gossypinus, 151

gracilis, 62

gramineus, 364

graveolens, 361,363

greenei, 193, 195

mollis, 195

typicus, 194

grindelioides, 323

gummiferus, 297

gunni, 364

gymnocephalus, 66

haenkei, 364

halli, 221

hamatus, 297

hartwegi, 235

heterocomus, 324

heterophyllus, 239

heterophy'sus, 324

hirsutus, 314

hirtellus, 314, 315

hirsutus, 314

limarensis, 315

hirtus, 123, 124

lanulosus, 125

sonchifolius, 125

typicus, 124

hispidulus, 365

hookerianus, 213, 348

hoorebekia, 365

howelli, 150,151

humilis, 342

hypoleucus, 356

ilicifolius, 348 platylepis, 348

illini, 361

illinitus, 318, 361

insecticruris, 111, 112

integerrimus, $\mathbf{3 4 0}$

integrifolius, 109, 110

insecticruris, 111

liatriformis, 111

pumilus, 112

scaberulus, 111

typicus, 110

interior, 158

inuloides, 151

involucratus, 349

ischnos, 346

junceus, 81

kingi, 346

laceratus, 173

lanatus, 365

lanceolatus, 114

brachycephalus, 136

solidagineus, 118

strictus, 136

subviscosus, 117

tenuicaulis, 118, 119

typicus, 115

vaseyi, 117, 119

lanuginosus, 171, 172

andersoni, 172

typicus, 172

laricifolius, 273, 279
Haplopappus-Continued

lastarrianus, 327

latifolius, 361

ledifolius, 359

lehinanni, 358

leucan themifolius, 314

limarensis, 315

linearifolius, 156, 157

in terior, 158, 279

typicus, 156, 158

linifolius, 344, 362

litoralis, 348

longifolius, 136

longipes, 317

lucidulus, 359

lyalli, 177, 179

halli, 179

macleani, 176

macraeanus, $\mathbf{3 5 4}$

macrocephalus, $\mathbf{3 3 0}$

macronema, 171, 204

linearis, 206

typicus, 204, 206

marginalis, 323

heterophysus, 324

marginatus, 365

medicinalis, 327

megacephalus, 59

menziesi, 227

meyeni, 344

mollis, 195

monactis, 277

moyanoi, 312

mucronatus, 246, 347

multicaulis, 91

multifolius, 345

mustersi, 361

nanus, 275, 294, 295, 298

cervinus, 293

nealleyi, 365

nelsoni, 168

nevadensis, 168

niveus, 365

nuttalli, 69, 70

obovatus, 292,362

occidentalis, 214

ochagavianus, 326

orcutti, $243, \mathbf{2 4 8}$

berberidis, 248

pallidus, 335

palmeri, 265, 267

pachylepis, 267

typicus, 267, 268

paniculatus, 136, 325

stenocephalus, 136

virgatus, 137

pappochroma, 365

parishi, 280

parrasanus, 160

parryi, 208, 211

minor, 211

parvifolius, 352

patagonicus, 322, 362

paucidentatus, 336, 323

pectinatus, 311

anethifolius, 312

pedunculosus, $\mathbf{3 3 8}$

peteroanus, 335

philippi, 325 
Haplopappus-Continued phyllocephalus, 55, $5 \mathrm{~S}$ annuus, 58 genuinus, 59 megacephalus, 59 primitivus, 56 rubiginosus, 59 typicus, 58

phyllophorus, $\mathbf{3 4 5}$ pinea, 362

pinifolius, 260, 269

pinnatifidus, 343

platylepis, 348

pluriflorus, 237

poeppigianus, 320 radiatus, 342

polyphyllus, 345

prinophyllus, 350

pristiphyllus, $\mathbf{3 5 1}$

propinquus, 269

prostratus, 322

prunelloides, $\mathbf{3 3 7}$

sphaerocephalus, 337

pulchellus, 319

elongatus, 341

punctatus, 339

purpusi, 299

pygmaeus, 181, 183

racemosus, 127

brachycephalus, 134

congestus, 128, 137

duriusculus, 129

glomeratus, 132, 137

glomerellus, 137

halophilus, 136

longifolius, 130

prionophyllus, 131

sessiliflorus, 136

stenocephalus, 137

typicus, 128

virgatus, 137

radieans, 335

ramulosus, 365

reflexus, 323

reicheanus, 324

remyanus, 349

rengifoanus, 346

resinosus, 296

reticulatus, $334, \mathbf{3 5 2}$

rigidus, 325

rosmarinifolius, 339

rosulatus, 329

rotundifolius, $345, \mathbf{3 4 7}$

rubiginosus, 59

phylloeephalus, 60

rufescens, 358

rydbergi, 290

saxatilis, 351

scaposus, 331, 365

scopulorum, 218

serobiculatus, $\mathbf{3 3 3}$

sericeus, 341, 364, 365

serrulatus, 362

setiger, 342

sonoriensis, 271

soratensis, 357

sphacelatus, 351

sphaerocephalus, 365

spinulosus, $72,95,362$
Haplopappus-Continued

australis, 77

canescens, 79

cotula, 77

genuinus, 79

glaber, 79

glaberrimus, $\boldsymbol{7 7}, 79$

gooddingi, 75,79

incisifolius, 75

laevis, 78

seabrellus, 74,79

turbinellus, 79

typicus, 76

squarrosus, $243, \mathbf{2 4 9}, 251$

obtusus, 253

stenolepis, 253

typieus, 251

stellatus, 365

stelliger, 355

stenolobus, 65

stenophyllus, 174, 318

stoloniferus, 48,52

genuinus, 50

glabratus, 50

heleniastrum, 50

puberus, 50

stolpi, 320

struthionum, 362

subandinus, 316

subviscosus, 119

suffruticosus, 187, 208

tenuis, 190

typicus, 190

taeda, 363

tasmanieus, 365

tehuelehes, 362

tenuieaulis, 118, 119

tenuilobus, 66

texanus, 365

tiltilensis, 323

tortifolius, 365

tridentatus, 227

uncinatus, 315

eandollei, 316

uniflorus, 147

gossypinus, 150

howelli, 150

typieus, 148, 151

velutinus, 316

venetus, 223

furfuraceus, 226

oxyphyllus, 225

tridentatus, 225

typicus, 224

vernonioides, 224,227

vernicosus, 286, 324

vidali, 315

villaneuvae, $\mathbf{3 2 5}$

villosus, 334

virgatus, 316

watsoni, 288

whitneyi, 243, 255

zañartui, 317

Hazardia, 36, 40, 55, 243

berberidis, 246

cana, 244

cruentus, 246

detonsa, 244

obtusa, 253,254 
H:tardia-Conlinued orcutti, 249

serriata, 244

squarrosa, 254

obtusa, 254

whitneyi, 257

Heleastrum cliapmani, 365

Hemizonia congesta, 8 pungens, 144

Hesperodoria, 35, 39, 218 halli, 221

scopulorum, 219

Heterotheca lamarcki, 214

Heuchera rubescens, 183

Homocliromeae, 27

Homopappus, 34

argutus, 137

glomeratus, 134, 137

inuloides, 151

multiflorus, 119

paniculatus, 137

racemosus, $127,128,137$

uniflorus, 151

Hoorebekia, 24

acaulis, 168

caespitosa, 168

carthamoides, 105

cusicki, 105

chiloensis, 24, 365

curvata, 119

greenei mollis, 195

halli, 221

hirta, 125

integrifolia, 112

lanceolata, 119

lanuginosa, 173

lyalli, 179

racemosa, 138

stenophylla, 175

uniflora, 151

Horkelia fusca, 147

Hysterionica marginata, 365

Inula divaricata, 214

Inulopsis, 33

scaposa, 365

Isocoma, 35, 39, 40, 95, 222

acradenia, 234

arguta, 227

bracteosa, 233, 234

coronopifolia, 236

decumbens, 227

drummondi, 24

eremophila, 233, 234

fruticosa, 236

hartwegi, 236

heterophylla, 239

hirtella, 239

latifolia, 227

leucan themifolia, 227

limitanea, 239

inicrodonta, 228

oxylepis, 239

oxyphylla, 225

pedicellata, 239

pluriflora, 239

rusbyi, 241

scopulorum, 219

sedoides, 228
Isoconsa-Continued

tenuisecta, 236

tridentata, 228

veneta, 228

acradenia, 234

arguta, 228

decumbens, 228

sedoides, 228

vernonioides, 228

vermonioides, 225,228

villosa, 228

wrighti, 239

Isomeris arborea, 248

Isopappus, 35, 39, $21 \mathbf{2}$

divaricatus, 214

hookerianus, 214

Iva axillaris, 114, 123

Juncus balticus, 114, 144

parryi, 183

Juniperus, 176

utahensis, 220

Larrea divaricata, 279

Lathyrus odoratus, 8

Leiachenium, 33, 303

Leucopsis, 364, 365

Leucopsis calendulacea, 364

diffusa, 364

scaposa, 365

sericea, 364

tweediei, 364

Linosyris arborescens, 283

coronopifolia, 236

dentata, 229

drummondi, 241

heterophylla, 239

hirtella, 240

mandoni, 357

mexicana, 229

pluriflora, 238, 240

ramulosa, 365

sonoriensis, 271,272

wrighti, 240

Linum lewisi, 155

Lolium perenne, 144

Lupinus arboreus, 264

lyalli, 53

variicolor, 264

volcanicus, 53

Machaeran thera, 68 setigera latifolia, 68

Macronema, 35, 39, 187

aberrans, 186

discoideum, 204, 207

filiforme, 201

glomeratum, 201

greenei, 195

molle, 195

grindelifolium, 191

grindelioides, 191

imbricatum, 191

lineare, 206, 207

canescens, 207

molle, 195

obovatum, 292

obtusum, 207

pulvisculiferum, 195 
Macronema-Continued pygmaeum, 185 scoparium, 201 suffruticosum, 188, 190, 191 walpoleanum, 202 watsoni, 290

Neosyris, 303

fuliginea, 356

hypoleuca, 357

Noticastrum haplopappus, 364

Oenothera lamarckiana, 8

Oonopsis, 34, 38, 86

argillacea, 92

condensata, 89

engelmanni, 94

foliosa, 89

monocephala, 88,89

multicaulis, 92

wardi, 89

condensata, 89

Opuntia engelmanni, 248, 262 parryi, 262

Oreochrysum, 35, 208 parryi, 211

Osbertia, 33, 37, 48

heleniastrum, 50

glabrata, 50

scabrella, 50

stolonifera, 50

Oxyria digyna, 181, 183

Parthenium argentatum, 296

Pellaea breweri, 208

Pentstemon confertus caeruleo-purpureus, 147

Photinia arbutifolia, 255

Phyllodoce glandulifera, 53

Pinus albicaulis, 171, 183, 208

contorta, 109, 114, 171, 204, 211, 257

coulteri, 218

edulis, 293

monophylla, 220

monticola, 257

ponderosa, 203, 176, 286, 292

sabiniana, $218,283,286$

Podocoma blanchetiana, 364

Polygonum viviparum, 185

Polyphylla, 302, 246, 344

Populus tremuloides, 109

Potentilla monticola, 208

Prionopsis, 33, 84

chapmani, 365

ciliatus, 85

Prosopis, 237 juliflora, 220

Prunus emarginata, 257

Pseudotsuga taxifolia, 211

Pyrochaeta, 365

Pyrrocoma, 34, 38, 95, 303

acuminata, 155

adsurgens, 99

amplectens, 112

angustifolia, 353

apargioides, 146

arguta, 138

aurea, 338

balsamitae, 138

bezanillea, 350

brachycephala, 134, 138
Pyrrocoma-Continued

calendulacea, 108

canescens, 321

carthamoides, 102, 103, 105

cerberoana, 355

cheiranthifolia, 119

ciliolata, 138

clementis, 107, 108

congesta, 128, 138

crepidinea, 151

crocea, 100

cusicki, 105, 152

cuspidata, 119

demissa, 146

denticulata, 355

duriuscula, 129, 138

elata, 138

eriopoda, 139

erythropappa, 105

foliosa, $87,89,125,345$

genuflexa, 99, 100

glomerata, 139

gossy pina, 151, 152

grindelioides, 254

halli, 221

halophila, 136, 139

hirta, 125

hololeuca, 152

ilicifolia, 350

insecticrusis, 112

integrifolia, 112

pumila, 112

inuloides, 152

kennedyi, 119

lagopus, 120

lanceolata, 120

lanulosa, 125

lapathifolia, 112

liatriformis, 111,112

linifolia, 344

longifolia, 130, 139

longipes, 316

lyalli, 179

macraeana, 354

menziesi, 229

microdonta, 139

nuttalli, 343

paniculata, 139

virgata, 139

parvifolia, 353

pinea, 362

plantaginea, 152

pratensis, 112

prionophylla, 131, 139

pristiphylla, 351

racemosa, 139

radiata, 103, 105

reticulata, 352

rigida, 103, 105, 353

saxatilis, 351

scaberula, 111, 112

sericea, 152

sessiliflora, 136, 139

setigera, 343

solidaginea, 118, 120

sonchifolia, 125

subcaesia, 108

subsquarrosa, 104, 105

subviscosa, 117, 120 
Pyrroeoma-Continued suksdorfi, 112

tenuicaulis, 120

turbinella, 125

uniflora, 152

vaseyi, 120

villosa, $10 \mathrm{~s}$

Quercus agrifolia, 255, 270

dumosa, 270

garryana, 222

vaccinifolia, 257

wislizeni, 218

Rhamnus ealiforniea, 264 crocea, 262 ilicifolia, 268

Rhus integrifolia, 248 laurina, 268 ovata, 270

Ribes montigenum, 257

Rumex eonglomeratus, 144

Salazaria mexieana, 279

Salicornia, 155

Salix retieulata, 185

Salvia apiana, 262, 268 earnosa, 279

Sareobatus, 144, 155

vermieulatus, 114

Sibbaldia proeumbens, 181

Sideranthus, 33

aberrans, 186

annuus, 58,60

aureus, 65

australis, 79

cotula, 77,79

glaberrimus, 77, 79

gooddingi, 75,79

graeilis, 63

grindelioides, 70

junceus, 83

laevis, 78, 79

machaeranthera, 79

megaeephalus, 60

phyllocephalus, 60

pinnatifidus, 79

puberulus, 79

rubiginosus, 60

serratus, 68

spinulosus, 79

glaberrimus, 79

turbinellus, 79

viridis, 83

viscidus, 80

wootoni, 80

Sieversia turbinata, 185

Silene aeaulis, 185

Solidago, 27, 39, 211, 272

diffusa, 272

humilis nana, 185

multiradiata scopulorum, 147

occidentalis, 364

parryi, 211

minor, 211

pauciflosculosa, 364

pumila, 219

Sporobolus airoides, 114, 144

Stanficldia nealleyi, 365
Starkea pinnata, 80

Stenotopsis, 34, 39, 156

in terior, 159

linearifolia, 159

interior, 159

macleani, 177

Stenotus, 34, 39, 161

acaulis, 168

kennedyi, 168

andersoni, 172, 173

armerioides, 163, 164

borealis, 177

brandegei, 52

eaespitosus, 168

faleatus, 168

interior, 159

laceratus, 173

lanuginosus, 173

latifolius, 169, 171

linearifolius, 159

in terior, 159

lyalli, 179

macleani, 177

multicaulis, 92

pygmaeus, 183, 185

rudis, 169

seaber, 169

stenophyllus, 175

Steriphe, 302, 338

acerosa, 341

corymbosa, 339

navarri, 342

Stipa kingi, 147

Suaeda, 144, 155

depressa ereeta, 114

Thalietrum fendleri, 211

Tissa, 144

Tonestus, 34, $39, \mathbf{1 7 7}$

eximius, 182

laceratus, 173

linearis, 173

lyalli, 179

pygmaeus, 185

Townsendia florifera, 364

Trifolium nanum, 185

Triglochin, 155

Trisetum eanescens, 147 spicatum, 183

Tritieum aestivum, 8

Tsuga mertensiana, 183, 203

Tumionella, 278

monaetis, 278

Viola tricolor, 9

Vitis, 220

Wyethia mollis, 204

Xylolepis, 302, 350

Xylorrhiza, 364

Yerba de vibora, 81

Yueea brevifolia, 279

Zea mays, 8 
The Unowy hite

DIES 2 9928

UNIVERS!! HE ILINOIS 





UNIVERSITY OF ILLINOIS-URBANA

583.53H14G CO01

THE GENUS HAPLOPAPPUS\$WASHINGTON

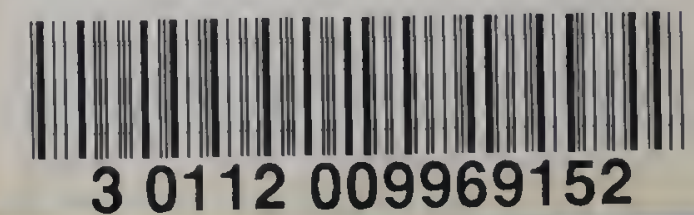

i 